
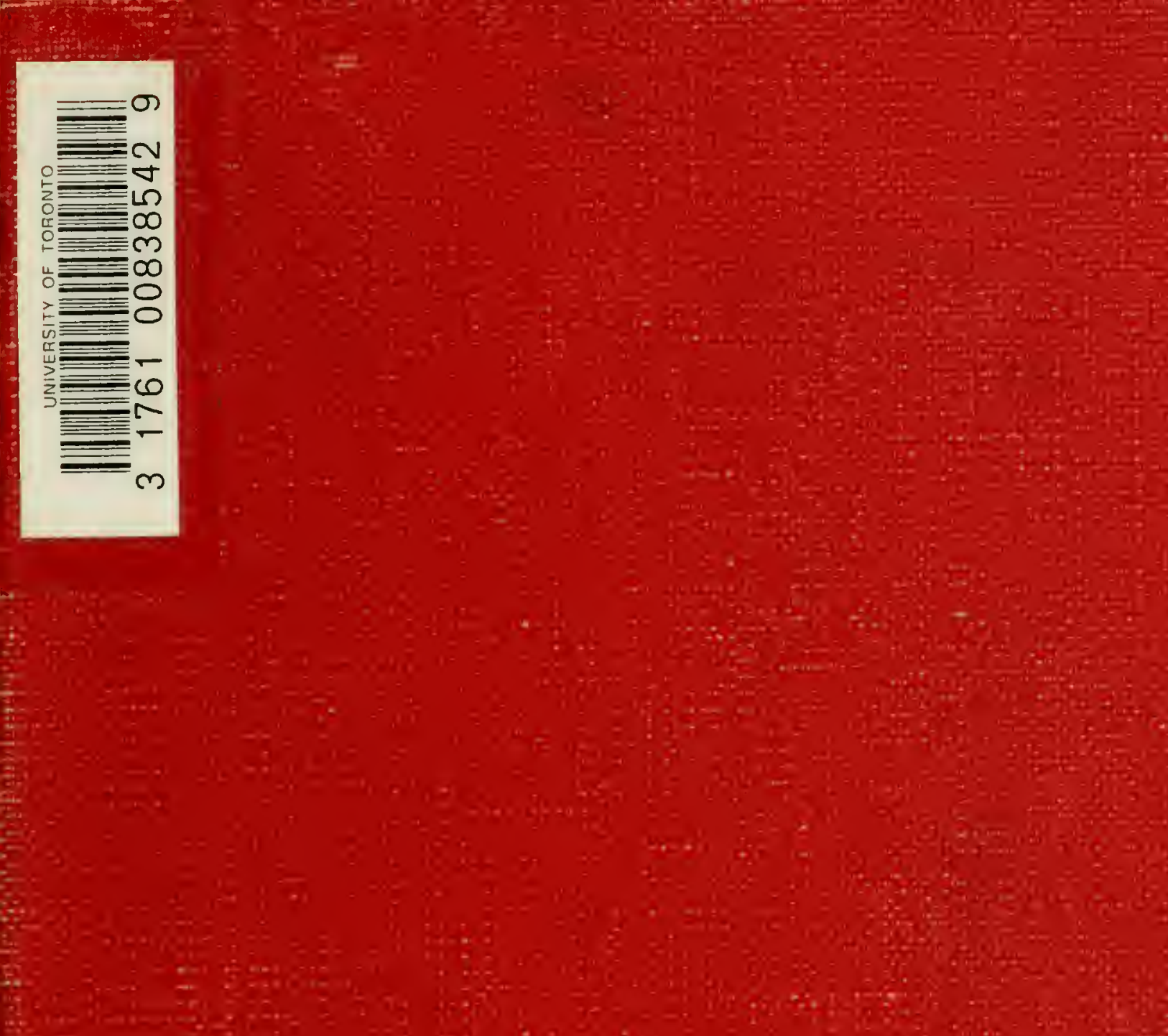

$5 \%$
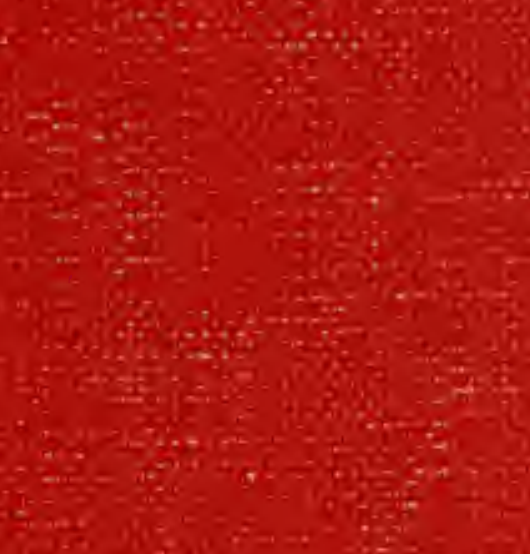

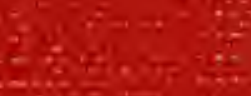
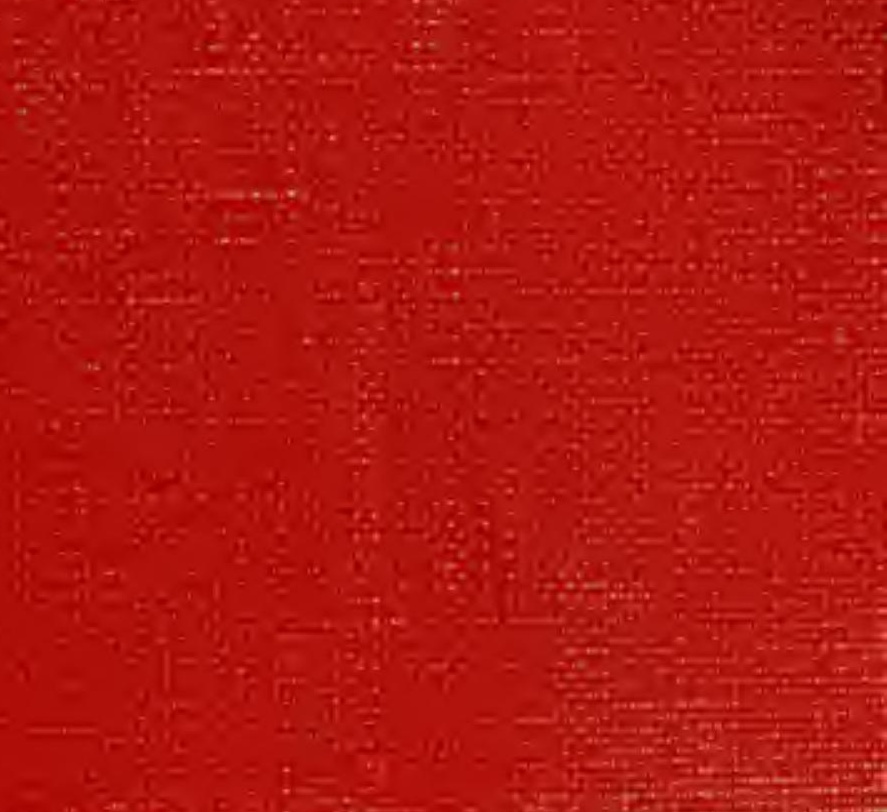

Digitized by the Internet Archive in 2008 with funding from Microsoft Corporation 



(15) 147 



\title{
THE
}

\section{ORIGIN OF THE FITTEST}

\section{ESSAYS ON EVOLUTION}

BY

E. D. COPE, A. M., PH. D. (HeidelberG)

MEABER OF THE UNITED STATES NATIONAL ACADEMY OF SCIEXCES; CORRESPONDENT OF THE ROYAL RAVARIAN ACADEMY OF SCIENCES

\author{
NEW YORK \\ D. APPLETON AND COMPANY


Copyright, 1586 ,

BY D. APPLETON AND COMPANY.

All rights reserved. 
TO MY FRIEND

PROFESSOR ALPHEUS HYAT, of BOSTON, Hass.,

WITI WHOSE STUDIES MY OWN HAVE LONG BEEN PARALLEL, AND WITI WHOSE CONCLUSIONS I HAVE LONG COINCIDED,

THIS WORK IS DEDICATED

BY

THE AUTHOR. 



\section{PREFACE.}

TuE twenty-one essays which constitute the present volume represent the reflections which have suggested themselves to the anthor while engaged in special zoölogical and paleontological studies. While the original work of the author bas been nearly confined to the vertebrata, his studies bave taken in a wider range. These have convinced him that the conclusions derived from the investigations of the vertebrata are applicable to invertebrate animals and to plants.

In reaching conclusions, the author has endeavored to avoid, as much as possible, any bias due to the influence of any opinions whatsoever on evolution and allied subjects which were already in the field. He therefore avoided, for a time, reading the works of the masters of the subject, applying to them for confirmation or criticism only after the publication of his own results. It is therefore true that the generalizations contained in these essays have been worked out by the anthor fron such material as has come under his own eyes, with little other aid. It has also followed that not a few of the conclusions he has reached were not new. On the other hand, some of the principles enunciated had not been elearly stated prior to the publication of these essays. In some cases the work accomplished has consisted in throwing well-known principles into accord with each other, as in the case of the laws of acceleration and retardation.

The earlier essays are the more hypothetical, and the later present more numerous demonstrations. The latter have resulted chiefly from the author's researches in the field of vertebrate paleontology, which have thrown the greatest possible light on the fact and method of evolution. For the history of this subject the reader is referred to the author's forthcoming "Manual of the Vertebrate Paleontology of North America"; and, for the more detailed work, to the author's publieations in the "Final Reports of the United States Geological Surreys," nnder Wheeler and Hayden, and to the "Proceedings of the American Philosophical Society of Pliladelphia."

The present essays are arranged (see table of contents) into four series, as foliows: First, on General Erolution; second, on the Structural Evidences of Evolution; third, on Mechanical Evolution; fourth, on Metaphysical Erolution. In the first series the author's earlier essays aro arranged. The general principles are here laid down or foreshadowed. The essays of the 
succeeding sections are occupied with the demonstration of these and other generalizations, so far as practicable. In each of the sections some essars will be found to be more, and others less, adapted to popular use. It is believed that the general reader can select a sufficient number of articles of minimum technicality to convey to his or her mind a sufficient idea of the views set forth. In Part I, articles first, fourth, and sixth are of this character. In Part II, the first, second, aud third essays are the least technical. In Part III, the first article is the most popular, although the others are essential to an understanding of the doctrine of mechanical evolution. In Part IV, all are sufticiently popular for the reader who lias some knowledge of mental science.

A historical synopsis of the essays may be now given. The attempt is made to point out the aim of each, with an indication of what may have been new in its contents. They are taken up in the order of date of publication:

II. The Origrn of Genera. From the "Proceedings of the Philadelphia Academy of Natural Sciences" for October, 1868, and published separately by the author early in 1869 . In this essay the following doctrines were taught:

First, that development of new characters has been accomplished by an acceleration or retardation in the growth of the parts changed. This was demonstrated by reference to a class of facts, some of which were new, which gave ground for the establishment of the new doctrine.

Second, that of exact parallelism between the adult of one indiridual or set of individuals, and a transitional stage of one or more other individuals. This doctrine is distinct from that of inexact parallelism which had already been stated by von Bacr. And that this law expresses the origin of genera and higher groups, because-

Third, they can only be distinguished by single characters when all their representatives come to be known.

Fourth, that genera and various other gronps have descended, not from a single generalized genus, etc., of the same group, but from corresponding genera of one or more other gronps. This was called the doctrine of homologous groups.

Fifth, the doctrine that these homologous groups belong to different geological periods, and,

Sixth, to different geographical areas, which, therefore, in some instances, are,

Seventh, related to each other in a successional way like the epochs of geological time.

Of these doctrines it may be observed that the first and second are now the common property of evolutionists, and are recognized everywhere as matter of fact. The names which I selected to express them have, however, only come into partial use. The author believes that, although the doctrine was vaguely sliadowed ont in the minds of students prior to the publication of this essay, it had not previously been clearly expressed, nor been reduced 
to a demonstration. Of the truth of the doctrine the author is more than ever convinced, and he believes that paleontological discovery has demonstrated it in many instances, and that other demonstrations will follow. The fourth proposition (that of homologous groups) is now held as a hypothesis explaining the phylogeny of various groups of animals. For the descent of one homologous group from another, the term polyphyletic has been coined. It remains to be seen whether the doctrine is of nniversal application or not. That homologous groups belong to different geological horizons, as stated under the fifth head, has been frequently demonstrated since the publication of the essay. That the sixth proposition is true in a certain number of cases is well known, and it follows that the seventh proposition is also true in those cases. The latter hypothesis, which was originally advanced by Prof. Agassiz, is, however, only partially true, and the advance of paleontological study has not demonstrated that it has had a very wide application in geological time.

A proposition which was made prominent in this essay was, that the prevalence of non-adaptive characters, in animals, proves the inadequacy of hypotheses which ascribe the survival of types to their superior adaptation to their environment. Numerous facts of this kind undoubtedly indicate little or no activity of a selective agency in nature, and do point to the existence of an especial developmental force acting by a direct influence on growth. The action of this force is the acceleration and retardation appealed to in this paper. The force itself was not distinguished until the publication of the essay entitled "The Method of Creation" (No. V), where it was named growth-force, or bathmism. The energetic action of this force accounts for the origin of characters, whether adaptive or non-adaptive, the former differing from the latter in an intelligent direction, which adapts them to the environment. The numerous adaptive characters of animals had by that time engaged the attention of the author, and he found that they are even more numerous than the non-adaptive. Some of the latter were accounted for on the theory of the "complementary location of growth-force."

IV. The Hrpotnesis of Erolotion, Prisioal and Metaphisioal. "Lippincott's Magazine," Pliladelphia, 1870; reprinted by Charles C. Chatfield \& Co. New Haven, $18 \% 0$.

This essay embraces a popular exposition of the principles maintained in the essay entitled the "Origin of Genera," with some conclusions derived from the general facts of anthropology. To this were added some facts in the evolution of human physiognomy and hmman character, which had not been previously thrown into harmony with the laws already set forth. Unfortunately, the author attempted to correlate these again with the theories of some theologians, and, in some instances, without success. A few paragraphs have been stricken from this part of the essay, and others are allowed to remain as illustrations of far-reaching hypotheses resting on little information.

V. Tine Metion of Creation of Organio Types. From the "Proceedings of the American Philosophical Society," December, 1871 ; repub- 
lished by MeCalla \& Stavely the same year. Read before the American Association for the Advancement of Science, at Detroit, August 27, 1871. Receired the Walker prize of the Boston Society of Natural History.

In this essay were added to the preceding, the following hypotheses:

1. The law of repetitive addition, in which the structures of animals were shown to have originated from simple repetitions of identical elements.

2. The existence of an especial force which exhibits itself in the grow th of organic beings, which was called growth-force, or bathmism.

3. That derelopment consists in the location of this energy at certain parts of the organism.

4. That this location was accomplished by use or effort, modifying and being modified by the environment; or the doctrine of kinetogenesis.

5. That the location of this energy at one point canses its abstraction flom other points, producing "complementary diminution" of force at the latter.

6. That the location of this energy, so as to produce the progressive change called evolution, is dne to an influence ealled "grade influence."

7. That inheritance is a transmission of this form of energy, which builds in precise accord with the sources from which it is derived.

8. That this "grade influence" is an expression of the intelligence of the animal, which adapts the possessor to the environment by an "intelligent selection."

9. An attempt to account for the origin of "mimetic analogy" by "maternal impressions."

On these propositions, the following comments may be made: First, the law of repetitive addition is much like the law of rhy thm previously proposed by Herbert Spencer.* Second, the force of growth, or bathmism, had already been called constructive force by Carpenter, who, however, did not treat of its evolutionary or "grade" characteristics. That such force exists there can be no doubt at the present time, but it may be that its varied aspects should each be considered a separate species of force (i. e., energy). Third, the relations of the energetic and static conditions of this force were considered, but were not sufiiciently followed out to be clear. It is hoped that greater clearness has been attained by the omission of a few paragraphs and the insertion of an explanatory foot-note.

Fourth, that the location of this energy is due to the influence of use and effort. The doctrine of the development of parts of living beings by use, and their loss by disuse, is well known to have been put forth by Lamarck in 1809, who devotes one of the longest chapters (No. VII) of his "Philosophio Zoölogique" to its discussion. He did not, however, include the element of effort, prior to the appearance of any rudiment of an organ, in his hypothesis, which was proposed, so far as I know, for the first time in the present essay. The doctrine of use and disuse has been sustained 
by Spencer in his "Principles of Biology" as respects the effect of motion on structure in general,* and in the particular case of the origin of vertebræ.t Fifth, the complementary derelopment of parts had also been pointed out by Herbert Spencer.f

Serenth, the explanation of inheritance by the transmission of the type of growth-force possessed by one generation to another. This doctrine was subsequently announced by Haeckel, under the name of perigenesis, \# and is the only good hypothesis yet proposed for the explanation of this phenomenon. Eighth, the theor'y of "intelligent selection," or the agency of the intelligence of a living being in directing its movements, and thercfore its growth, although a plain and necessary consequence of the "law of use and effort," had not been, so far as I am aware, announced prior to the publication of this paper. This important theory at once opened the way for an investigation of the general relations of mind to evolution, which incolved the question of the origin and development of mind itself. These questions were more fully discussed in the papers of Part IV, on "Metaphysical Evolntion." Ninth, the origin of mimetic analogy. The explanation offered is almost neccssary, if the doctrine of the influence of effort on structural growth be true.

I. Evolution And its Consequences. From the "Penn Monthly Marazine," Philadelplia, for May, July, and August, 1872.

This is a popular exposition, with elaboration, of the doctrines contained in the preceding essays. The evolution of mind is more fully stated, the hypothesis adopted being that proposed by Spencer in his "Principles of Psychology," published in 1855.

VII. The Homologies and Origiv of the Trpes of Molar Teeti of tire Mammalia Educabilia. From the "Journal of the Academy of Natural Sciences," Philadelphia, March 30, 1874.

The object of this paper was to show that the various more or less complex types of molar teeth displayed by the Ungulate Mammalia are leferable to modifications of a primitive quaditubercular type, from which they were supposed to have been descended. The histories and homologies of the carnivorous dentition were not included in this paper. In order to complete the subject, I hare inserted brief notes of the conclusions I have since attained in this field: first, as to the type of inferior sectorial teeth, in 1875 ; and, second, as to the superior molars, in 1883.

At the end of the paper a similar comparison between the feet of the same type of mammals is made, and general conclusions reached in the following language: "I trust that I have made it sufficiently obvious that the primitive genera of this division of mammals [Mammalia Educabilia $=$ Unguiculata and Ungulata sensu latâ] must have been bunodonts with pentadactyl plantigrade feet."

\footnotetext{
* Vol. ii, p. $167 . \quad+$ Vol. ii, p. 195. † "Principles of Biology." \# See Ryder, "American Naturalist," January, 1879.
} 
The nearest approaches to a similar antieipation on the part of other naturalists, which I have been able to find, refer to the number of toes only, and are of restricted applieation. Thus Kowalevsky remarks ("Monographie der Gattung Anthracotherium, Palaeontographica," xxii, p. 1452) : "So we cun assume a tetradactyl foot as our point of departure, alchough it can not hare the least effect on the result in case tlie original ungulate foot should have been pentadactyl. If I have set out with a tetradactyl foot it is simply because I wish to adhere so far as possible to facts." This was written Angust, 1873, but how soon thereafter it was printed I do not know. I did not meet witli it until'at least a year after the publication of my paper of Mareh, 1S74, cited. Secondly, Marsh, in writing on the genealogy of the horses ("American Journal of Scienee and Arts," March, 1874, p. 257), says: "A still older ancestor [of the horse], possibly in the Cretaceous, doubtless had fire toes on each foot, the typical number in mammals." My paper was published during the same month as the above; but I communicated the substance of the generalization in questiou to the Philadelphia Aeademy the day it was read, November 18, 1873, which was published in the "Proceedings of the Society," January 13, 1874, p. 2.

XVIII. Consciousness in Eroudrion. From the "Penn Monthly Magazine," Philadelphia, July, 1875.

In this paper the doctrine of intelligent selection is analyzed, and the problem redueed to its essential-the relations of consciousness to matter. The doetrine of the origin of reflex and automatic acts from conscious states, or archaesthetism, is liere first proposed. From the characters of protoplasm the inference is derived that that substance is not necessarily the only one capable of supporting conscionsness. The author is not aware of any previous attempt to render these propositions probable.

VIII. The Relation of Man to the Tertiary Mamalia. From the "Penn Monthly Magazine," December, 1875. Read before the American Association for the Adrancement of Science, at Detroit.

The fact that the hard tissues, and probably. the digestive system, of man, are constructed on the type of the Mammalia of the early Eocene period is here pointed ont for the first time.

III. Tine Theors of Erolution. Remarks made before the Academy of Natural Sciences of Philadelphia, February 22, 1876, and published in the "Proceedings of the Society," 1876, p. 15.

These remarks exhibit the correspondence between the evolutionary systems of IIaeckel and of the writer, and combine them into a symmetrical whole.

XXI. The Origix of the Will. From the "Penn Monthly Magazine," Philadelphia, June, 1877.

In this paper the attempt is made to render the existence of freedom of will probable by a proeess of argument, and also to demonstrate its existence by another kind of argument. As is well known, there are two opposed doctrines respecting this important question. One of these, which has by far the largel number of adherents, is that the human mind embraces 
anong its powers a freedom of will, or spontaneity in action. The other view is, that there is no such power, but that the actions are merely the necessary result of the strongest pressure of the strongest inducement or motive. The doctrine of erolution is known to lend support to the latter doctrine. In the present paper the atiempt is made to prove that free will is a new power which supervenes on the process of evolution. This is done by assuming the existence of a class of acts for which the term altruistic is retained, which, undoubtedly, would require freedom for their performance. The only question here is, whether there be any such class of acts as are defined under the above name in this essay. If there be no such class of acts, the demonstration based on it falls to the ground; and the author is not at present sure whether there be such a class of acts or not.

The argument by which freedom of will is rendered probable is not open to any serious objection, and rests on the necessity for action which sometimes arises in cases where there is no experience or knowledge to serve as a determining motive or power. These cases are supposed to incolve moral questions. The doctrine is then intermediate betreen the tro opposing ones which have long divided the world of thought.* It permits of the derelopment of a free will in previously automatic beings, as a phenomenon superposed on mental erolution. The argument demonstrates nothing more than that freedom is possible; a conclusion which is, however, important, since it shows that the position of the determinists is not impregnable.

XiI. The Relation of Animal Motion to Aximal Erolution. From "The American Naturalist," January, 1878. Read before the American Association for the Advancement of Science, at Nashrille, August, 1877.

The effects of the actions of animals on their structure are considered, as in previous papers, and especial attention is paid to the influence of animals in the changes they produce in their environment.

XIV. The Orighn of the Speoralized Teeth of tie Carsirora. From "The American Naturalist," March, 1879.

The mechanical reasons for the changes in the dentition of carnivorous mammals during geologic time are pointed out for the first time.

VI. A Pieriew of the Modern Doctrine of Erolution. From "The American Naturalist," March and April, 1880. A lecture delivered before the California Academy of Sciences, October 27, 1879. It is a general synopsis of riews presented in preceding papers.

XV. On the Origin of the Foot-Structrte of the Uxgulates. From "The American Naturalist," April, 1881.

This essay embraces an explanation of the cause of the diminution of the number of digits in the diplarthrons ungulate mammals; of the reasons why some are even- and some odd-toed; and of the origin of some of the

* This view is adopted by President Noah Porter in one of his latest metaphysical rorks.

+ A synopsis of the relations of animals to their environment is giren by Sipencer, "Principles of Biology," vol. i, p. 466. 
articulations of the tarsus. These explanations, so far as based on paleontological grounds, were new at the time.

XVI. The Effeot of Impaot and Stiatis on the Feet of M.immalia. From "The Ameriean Naturalist," July, 1881.

The origin of the structures of all the articulations of the limbs of all the Mammalia are explained as the effects of impacts and strains. The demonstration is based largely on paleontological evidence, and is new.

XIX. On Arouansthetism. From "The American Naturalist," June, 1882.

This doctrine is discussed and illustrated on the basis laid down in the essay "Consciousness in Evolution," and a classification of theories of creation is presented.

IX: Tie Developmental Significanoe of Human Physiognomy. From "The American Naturalist," June, 1883.

In this paper suggestions presented in $\Lambda$ rt. IV, entitled "The Hypothesis of Evolution, Physical and Metaphysical," are developed, and the physical significance of the form-characters of men in general are considered. Nothing except reference to a few leading points of the subject had been published prior to this paper, so far as the author has been able to discover. In connection with a paper" on the "Evolutionary Significance of IHuman Character," a foundation was laid for a scientific physiognomy.

X. Thie Etidenoe for Erolution in the History of the Extinot Nanimalia. A lecture delivered before the American Association for the Advancement of Science, at Minneapolis, August, 1883.

In this paper are collected the evidences of descent displayed by the Mammalia (and in one instance by the Batrachia), as derived from the paleontological researches of the author. These had been in some points foreshadowed in the author's memoir on the homologies and origin of the structure of the molar teeth in the Mammalia Educabilia in 1874, which were here shown to have been realized by subsequent discovery, and a number of other evidences added. Restatements of the laws of kinetogenesis, and of the origin of morals, were made.

XVil. The Evolutionary Significanoe of Human Character. From the "American Naturalist," September, 1883.

The characters of the adult mind are compared with those of the child, and with those of the lower animals, and the direction of their evolution pointed ont. Most of the propositions contained in this paper were new at the time of its publication.

XiII. Tine Trituberodlar Trpe of Molar Teeth in time Mamalia. From the proceedings of the Ameriean Philosophical Society, 1883, page $324 ; *$ published in adrance in the "Paleontological Bulletin," No. 37, January 2, 1884.

The origin of the ungulate molar tooth had already been traced to a quadritubereular type in paper No. VII (March and January, 1874). The 
present paper shows that this type in the upper jaw is a derivative of a tritubercular type, while that of the lower jaw is a derivative of a quinquetubercular type, or a tritubercular type with a heel, which may support two adritional tubercles. The tritubercular type was again traced to the simple cone. This generalization was new at the time of publication.

X.. Catagenesis. Vice-presidential address delivered before the biological seciion of the American Association for the Adrancement of Science, Philadelphia, September 4, 1884.

The hypothesis of catagenesis which is put forth in this paper teaches that primitive energy was and is conscious, and that all uneonscious forms of energy, whether "vital" or non-vital, have been derived from it by a process of retrograde metamorphosis. The first stage of this retrogression is the loss of consciousness, or cryptopnoy. Evidence for this kind of metamorphosis is derived from every-day experience, and from the designed character of automatic acts. That a form of energy is conscious is inferred from the nature of designed conscious acts of animals. The anthor had not met with any scientific statement of this theory prior to the preparation of this lecture.

XI. The Evolution of the Vertebrata, Progressive and RetroGRessire. From the "American Naturalist," February, March, and April, 1885 .

This paper sets forth the results of paleontological investigation of the Vertebrata, in a series of phylogenies. These are, first, the phylogeny of the classes; then the special phylogenies of their contents or of the orders. Here are introduced the newly-discovered relations of the Antiarcha and the Ichthyotomi to the fish-like vertebrates, and of the theromorphous reptiles to the Mammalia. Also, the ancestral relation of the Theromorpha to most other reptiles, and of the Condylarthra to the placental Mammalia, and to man. Many of the other results set forth in this essay are derived from the paleontological researches of the author. Some of them, especially the lemurine (condylarthrous) ancestry of the placental Nammalia, had been anticipated on theoretical grounds by Haeckel in his "History of Creation" ("Schöpfungsgeschichte"). Haeckel was very general in his proposition, and did not anticipate the details of the demonstration. My investigations enabled me to produce these, which bring out in a striking manner the sagacity of Prof. Haecke]. I considel further the question of degeneracy, and the significance of. the phylogeny with reference to this subject is pointed out.

In conclusion, it may bo said that the principal object $w$ lich the author set before him, in the studies here recorded, has been the discorery of the laws of variation, or of the "Origin of the Fittest." These essays express the light which he has been able to obtain on this difficult question up to the present time. The results conld be better and nore briefly presented in a systematic form, but tho authol reserves this for a future occasion. 



\section{O N TENTS.}

\section{PART I.-GENERAL EVOLUTION.}

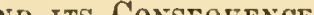

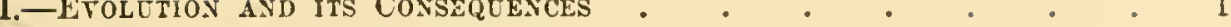

II.-The Origin of Genera . . . . . • • . . 41

III.-The Theory of Erolction . . . . . . . . 124

IV.-The Hypothesis of Erolttion, Phrsical and Metaphysical • • 128

V.-The Method of Creation of Organic Foms . . . . . 178

VI.-Reriew of tue Modery Doctrine of Evolution . . . . 215

PART II.-STRUCTURAL EVIDENCE OF EVOLUTION.

VII.-The Hovologies and Origin of the Trpes of Molar Teeth of the

Mamalia Edvcabilia • . • . . . . . . 241

ViII.-The Relation of Man to the Tertiart Majmalid • • . 268

IX.-The Derelopuental Significance of IIcman Pitsiognomy • . 281

X.-The Evidence for Eroletion in the History of the Extinct

MAMMALA . . . . . . . . . . . 294

XI.-The Erolution of the Vertebrata, Progressive and Retrogres-

SIVE $\cdot \quad \cdot \quad \cdot \quad \cdot \quad \cdot \quad \cdot \quad \cdot \quad \cdot \quad \cdot 314$

\section{PART II.-MECHANICAL EVOLUTION.}

XII.-The Regation of Animal Motion to Animal Erolotion • • 350

XIII.-ON the Tritubercelate Tooth in the Mammalia . . . . 359

XiV.-The Origin of tile Spechalized Teetil of the Carnivora . . 363

XV.-The Origin of the Foot Strccteres of the Uxgelates • . 368

XVI.-The Effect of Impacts and Strains on the Feet of Mamalata • 373 


\section{PART IV.-METAPHYSICAL EVOLUTION.}

XViI.-The Evolutionary Significance of Heyan Character a r 378

XVIII.COnsciousness in Etolution . . . . . : . 390

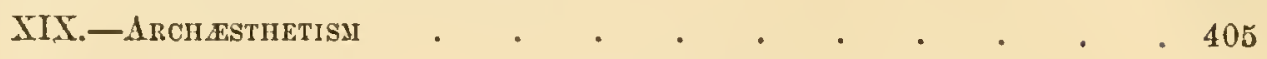

XX.-Catagenesis . . . . . . . . . . . 422

XXI.-The Origix of the Will . . . . . . . . . 437 


\section{LIST OF ILLUSTRA'TIONS.}

\section{Plates.}

PLATE

I. Figures and Diagrams of the Cirenlatory Centers of Vertebrata. Copied from Gegenbaur and His, mostly enlarged . . . . .

II and II $a$. Figures of Lizards of the families Iguanidx and $A$ gamidx

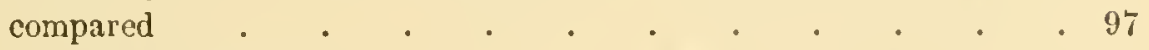

III and III $a$. Mimetic analogy in the colors and patterns in snakes of different genera and species . . . . . . . . . 105

IV and V. Series of Crania of Different Families of Tailless Batrachia showing similar stages of development. Original . . . 220, 221 Explanation . . . . . . . . . . 222

VI. Succession of Modifieations of Feet of Diplarthrous Ungulata. Original 271

VII. Succession of Dental Forms, mostly of Ungulata. From Gaudry, Wortman, and Cope . . . . . . . . . . . . 275

VIII. Uintatherium rormutum Cope, restored, one twenty-seventh natural size.

From Cope, Marsh, and Osborn . . . . . . . 27

IX. Anaptomorphus and Homo; Cranium, Brain, and Tecth. Original, except Figs. 8 and 9 from Allen . . . . . . . . . 279

X. Esequibo Indians. From photograplss by Endlich . . . . . 286

XI. The Wrestler. From the Vatican . . . . . . 289

XII. Venus of the Capitol . . . . . . . . . . . 292

XIII. Phenacodus primcous Cope, Skeleten as found in matrix, one serenth natural size. Original . . . . . . . . . . . 30n

XIV. Brains of Extinet Mammalia. Original, exeept Fig. 2 from Marslı . 308

XV. Diclonius mirabilis, Skull Profile. Original . . . . . . 335

XVI. Diclonius mirabilis, Skull from below, one half the mandible remored. 339

XVII. Phenacodies vortmani, Skeleton as found in Matrix, two ninths natural size. Original

XVIII. Mycenodon horridus Leidy, Skull one half natural size. From Leidy . 364

sis.

$$
\text { WOOD-CUTS. }
$$

1. Diagram illustrating acceleration and retardation . . . . 10

2. Diagram illustrating relations of genera of batrachia anura . . . 80

3 to 6. Diagrams illustrating development of genera of batrachia anura . S1

7. Same as Fig. 1 . . . . . . . . 176 
FIG.

8. Sternum and adjacent parts of Scaphiopus holbrooki

9. Sternum of Tadpole of Rana tcmporaria . . . . . . . . 217

10. Sternum of adult Rana tcmpararia . . . . . . . . . . 217

11. Metacarpus, carpus, and distal extremity of radius of Poëbrothcrium vilsoni . 219

12. The same, less radius, with first phalanges of Procamelus occidentalis $\quad .219$

13. Skull of Protolatis transmontanus . . . . . . . . . . . . . . . . . . . . . .

14. Skull of Procamelus occidcntalis. . . . . . . . . . . . 223

15. Tooth of Globicephalus . . . . . . . . . . . . . . . . . . . . . .

16. Tooth of Jaculus hudsonicus . . . . . . . . . . . . 243

17. Tooth of Lcptochcerus spcetabilis. From Leidy . . . . . . . 243

18. Tooth of Rhinocerus, milk superior molar . . . . . . . . 24t

19. Tooth of Achcenodon insolens . . . . . . . . . . . . . . . . . . . . . . . . .

20. Tooth of Hippopotanus amphitizs. From Curier . . . . . . . 254

21. Tooth of Hyopotamus velaunus. From Blainville . . . . . . 254

2). Tooth of Hyopotamus amcricanus. From Leidy . . . . . . 254

23. Tooth of Procumelus robustus. From Leidy . . . . . . 254

24. Tooth of Merychyus major. From Leidy . . . . . . . . 255

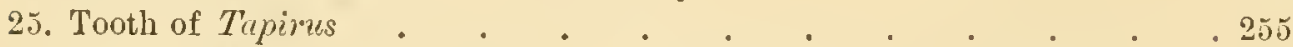

26. Tooth of Mustodon angustidens. From Cuvier . . . . . . . 256

27. Tooth of Mastodon americanus. From Cuvier . . . . . . . 256

28. Tooth of Dinotherium. From Curier . . . . . . . 256

29. Tooth of Elephas indicus. From Curier . . . . . . . . 256

30. Tooth of Microsyops elcgans. From Leidy . . . . . . . 257

31. Tooth of Hyopsodus paulus. From Leidy . . . . . . . . . 257

32. Tooth of Palcosyops levidens. From Leidy . . . . . . . . . . . . . . . .

33. Tootl of Anchippodus riparius. Fron Leidy . . . . . . . 257

34. Tooth of Palcosyops vallidens. From Leidy . . . . . . . 257

35. Tooth of Palcothcrium. From Curier . . . . . . . 258

36. Tooth of Hipposyus. From Leidy . . . . . . . . . 258

37. Tooth of Hipposyus more worn. From Leidy . . . . . . . 258

38. Tooth of Hypohippus. From Leidy . . . . . . . . . 258

39. Tooth of Equus, superior molar. From Leidy . • . . . . 259

40. Tooth of Eques, inferior molar. From Leidy : . . . . . 259

41. Tooth of Buthmadon radians . . . . . . . . . . 260

42. Tooth of Uintatherium robustum, superior molar. From Leidy . . . 260

43. Tooth of Uintatherium robustum, inferior molar. From Leidy . . . 260

44. Periptychus rhabdodon, part of posterior foot . . . . . . 268

45. Coryphodon elcphantopus, right fore foot, one third natural size. . $\quad 269$

46. Coryphodon clcphantopus, right posterior foot . . . . . . 269

47. Phenacodus primceves, right anterior foot, one third natural size, . . 270

48. Phenacodus primovess, left posterior foot, one third natural size . $\quad .270$

49. Homo sapiens, left anterior foot (hand), one third natural size . . . 272

50. Homo sapions, left posterior foot, one third natural size . . . . . 272

51. Phcnacodus primaves Cope, slull, one third uatural size, from below . 273

52. Simia satyrus, section of skull of adult . . . . . . . . . 283

52a. Simia satyrus, section of skull of young . . . . . . . . . 283

53. IIomo sapiens, infant at term . . . . . . . . . 284 
FIG.

54. Homo scpiens, portrait of girl at five years . . . . . . . 285

55. Homo sapiens, portrait of same at seventeen years . . . . . . 285

56. Homo sapiens, portrait of Luehatze negro woman . . . . . . 287

57. Homo sapiens, portrait of Luehatze negro woman . . . . . . . 287

58. Homo sapiens, portrait of Satanta, chief of the Kiowa Indians of Forth

America . . . . . . . . . . . . 288

59. An Australian native . . . . . . . . . . . . . . 291

60. Eryops megacephalus, a batrachian of the Permian epoch of Texas ; vertebral

column . . . . . . . . . . . 304

61. Sleere of coat, showing folds . . . . . . . . . . . . 305

62. Bothriolepis canadcnsis, from above . . . . . . . . . . 323

63. Chclyosoma maclovianum, a tunieate from Point Barrow, Alaska, from above 523

64. Stypolophus utitice, skull and dentition, displaying the tritubereular type of

molars . . . . . . . . . . . . 360

65. Deltathcrium fundaminis, skull, profile . . . . . . . . 362

66. Oxycena lupina, jaws and teeth . . . . . . . . . . 365

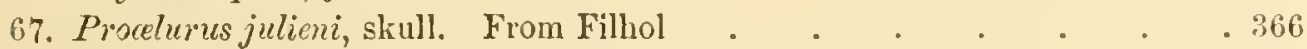

68. Dinictis cyclops, skull . . . . . . . . . . . . . . . . . 366

69. Smilodon ncogreus, skull . . . . . . . . . . . . . . . . . . . . . . . . . . . .

70. Coryphodon elephantopus, hind foot above . . . . . . . . . . . 369

71. Aphelops megalodus, hind tarsus and metatarsus, from front and abore . 369

72. Protohippus sejunctus, posterior foot, front . . . . . . . 370

73. Poëbrotherium labiatum, posterior foot, front . . . . . . . 370

74. Poëbrotherium vilsoni, carpus, metacarpus, and end of radius, from front . 371

75. Amblyctonus sinosus, a creodont; distal end of tibia . . . . . . 375

76. Oxycena morsitans, a creodont; distal end of tibia . . . . . . . . 375

77. Archcelurus debilis, an extinet eat; distal end of tibia, with astragalus . 375

75. Nimravus gomphodus, a eat; femur . . . . . . . . . 375

79. Procamclus occidcntalis, part of fore foot . . . . . . . . . . . . . . . . . . . . .

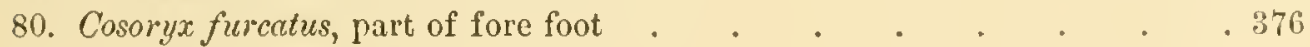

81. Poëbrotherium vilsoni, part of fore foot . . . . . . . . 376 



\section{PART I. \\ GENERAL EVOLUTION.}

\section{I. \\ EVOLUTION AND ITS CONSEQUENCES.}

THe broad theory of evolution includes the theories of development of the solar system and its members, as expressed by the nebular hypothesis ; the theory of development of life by moleeular movements consequent upon certain combinations of non-living matter; and, lastly, the theory of development of the speeies of animals and plants by descent, the later from the earlier, with aceompanying change of form and character. It attempts nothing less than a history of the process of creation of the miverse, so far as we can behold it; and is, therefore, an attempt to formulate the plans and thouglats of the Author of that miverse. Hence, it is not surprising that it excites the interest of the best of men, especially as it is one of the results of the efforts of a class of these, crowning many centuries of labor and thought.

The object of the present essay is to discuss familiarly the latter of these theories of evolution, viz., that respecting the species of animals and plants. As all are aware, this mode of aceounting for the creation of organized beings has attained espeeial prominence at the present time, and possesses more of interest to most readers becanse of its explanation of our own origin. Morcover, it rests on more indubitable evidence than the two other theories. The constitution and arrangement of the members of the solar system point to their origin by derivation from primal masses of vaporous matter through the niutual operation of the ordinary laws of attraction and motion. The positioning is preeisely as it shonld be had sueh process taken place, but the process itself, that is, the change from type to type of celestial body, has not been observed. 
The case is far diferent with the theory as regards organized or living beings. Not only are the mutual relations of animals and plants to each other such as should have resulted from a descent or development, but the changes from type to type have been actually observed, and in sufficient number to place the hypothesis on the basis of ascertained fact, as referring to a certain range of objects-say, in the case of the animal lingdom, to individuals distinguished by structural characters within the range of each of the three to six great primary divisions or "branches."

There are two totally distinct propositions involved in this question, which are confounded by the general public, and not unfrequently by students and writers on it. These are, first, the evidence which seems to prove that this evolution has taken place; secondly, the evidence as to the nature of the laws of its progress. A want of constant distinction between these views of the case has greatly obscured it and injured the evidence on one side or the other.

The evidence in faror of evolntion is abundant, and is cited in fragments by various contemporary writers, foremost among whom, both in time and abundance of writings, comes Charles Darwin.

Much less has been done in explanation of the laws of erolution. Darwin and his immediate followers have brought ont the law of "natural selection"; Spencer has endeavored to express them in terms of force; while Hyatt, Cope, Packard, and others have advanced the law of "acceleration and retardation."

In earlier days, when information was distributed slowly and books were few, it was long before any new truth or doctrine reached the majority of people, still less was adopted by the ruling classes. But the modern theory of evolution has been spread everywhere with unexampled rapidity, thanks to our means of printing and transportation. It has met with remarkably rapid acceptince by those best qualified to judge of its merits, riz., the zoölogists and botanists, while probably a majority of the public, in this region at least, profess to rejeet it. This inconsisteney is due to two principal causes. In the first place, Darwin's demonstration contained in the "Origin of Species" extends little further than as stated in the title of his work. He proves little more than that species of the same genus or other restricted groups have had a common origin ; and, further, his theory of natural selection is to the plainest understanding incomplete as an ex- 
planation of their "origin," as its author indeed freely allows. Besides, the unscientific world is particularly unreasonable on one point. Little knowing the slow steps and laborious effort by which any general truth is reached, they find in incompleteness ground of condemuation of the whole. Seience is glad if she can prove that the earth stands on an elephant, and gladder if she can demonstrate that the elephant stands on a turtle; but, if she can not show the support of the turtle, she is not discouraged, but labors patiently, trusting that the future of discovery will justify the experience of the past.

If, then, some of the people find Mr. Darwin's argument incomplete, or in some points weak, it may be answered, so do the student classes, who, nevertheless, beliere it. This is largely because Darwin's facts and thoughts repeat a rast multiplieity of experiences of every student, which are of as much significance as those cited by him, and which only required a courageous officer to marshal them into line, a mighty host, conquering and to eonquer. These will slowly find their way into print, some in one country and some in another.

\section{THE FACT OF EVOLGTION.}

As to the truth of the theory, the proof has been stated in more than one form. The first and simplest, and essentially the central argument of Darwin, is as follows:

In every family or larger group of animals and plants there exists one or more genera in which the species present an aggregation of specific intensity of form; that is, that species become more and more closely related, and finally varieties of single species have to be admitted for the sake of obtaining a systematic definition or "diagnosis," which will apply to all the individuals. These rarieties are frequently as well marked as the nearly-related species, so far as amount of difference is concerned, the distinetion between the two eases being that in the varieties there is a gradation from one to the other ; in the species, none. Nevertheless, between some of the varieties transitions may be of rare occurrence, and in the case of the "species" an intermediate individual or two may occasionally be found. 'Thus it is that differences, called varietal and speeific, are distinguished by degree only, and not in kind, and are, therefore, the results of the operation of uniform laws. Yet, aceording to the old theory, the varieties have a common origin, and the species an independent one! 
To find examplas of what is asserted, it is only necessary to refer to the diaguestic tables and keys of the best and most honest zoölogists and botanists. It is true that these diagnoses are dry reading to the non-professional, yet they embrace nearly all that is of value in this part of biological science, and must be mastered in some department before the student is in possession of the means of forming an opinion. The neglect to do this explains why it is that, after all that has been written and said about protean species, etc., the subject should be so little understood.

It is true that in but few of these cases have the varieties been seen to be bred from common parents, a circumstance entirely owing to the difficulties of observation. The reasoning derived from the relations of differences appears to be conclusive as to their common origin, muless we are prepared to adopt the opposite view, that the varieties have originated separately. As these avowedly grade into individual variations, we must at onee be led to believe that individnals have been ereated independently-a manifest absurdity.

But variations in the same brood have been found among wild animals; for example, both the red and gray varieties of the little horned owl (Scops asio) have been taken from the same nest.

As further examples of gradation between species and variety, found in nature, I only have to select those genera most numerous in species, and best studied. Among birds, Corvus, Empidonax, Buteo, Falco, ete. Reptiles, Eutaenia, Anolis, Lycodon, Naja, Caudisona, Elaps, Oxyhrropus, ete. Batrachia, Rana, Hyla, Chorophilus, Borborocoetes, Amblystoma, Spelerpes, etc. Fishes, Ptychostomus, Plecostomus, Amiurus, Salmo, Perca, and many other's.

In all these groups of species, or "genera," it is impossible in some cases to deternine what is variety and what species. This is notoriously the case with the salmon and tront (Salmo), for one of the greatest opponents of close division of species, Dr. Günther, of London, thought himself necessitated, a very few years ago, to name and deseribe lualf a dozen new species of tront from the lakes of the British Islands, and, from being a stanch supporter of the old view of distinct creations, was completely converted to evolutionism.

Such is one of the views which has forced conviction on the minds of thoroughly honest men who were not only desirous of knowing the truth, but were in many cases brought orer from a 
position of strong opposition. But the earnest objector says, you have not after all shown me any real transitions from species to species; until that is done your development is but a supposition.

The all-sufficient answer to this statement is to be found in the imperfection of our system of classification. Thus, if we first assume, with the anti-developmentalist, that varieties have a common parentage, and species distinct ones, when intermediate forms connecting so-called species are discovered, we must confess ourselves in error, and admit that the forms supposed to hare had a different origin really had a common one. Such intermediate forms really establish the connection between species, but the question is begged at once by asserting unity of species, and, therefore, of origin, so soon as the intermediate form is found; for, as before observed, it is not degree, but constancy of distinction, which establishes the species of the zoölogical systems. Transitions between species are constantly discovered in existing animals; when numerous in individuals, the more diverse forms are regarded as "aberrant"; when few, the extremes become "varieties," and it is only necessary to destroy the annectant forms altogether to leare two or more species. As the whole of a variable species generally has wide geographical range, the varieties coinciding with sub-areas, the submergeuce, or other change in the intervening surface, would destroy connecting forms, and naturally produce the isolated species.

Formerly naturalists sometimes did this in their studies. A zoölogist known to fame once pointed out to me some troublesome specimens which set his attempts at definition of certain species at defiance. "These," said he, "are the kind that I throw ont of the window." Naturalists having abandoned throwing puzzling forms out of the window, the result of more honest study is a belief in evolution by nine tenths of them.

But, says the inquirer again, your rariations and transitions are but a drop in the ocean of well-distinguished speeies, classes, ete. The permanent distinetion of species is matter of erery-day observation; your examples of changes are few and far between, and utterly insufficient for your purpose.

It is true that the eases of transition, intermediate forms, or diversity in the brood, observed and eited by naturalists in proof of evolution, are few compared with the number of well-defined, isolated species, genera, etc., known; though far more numerous than the book-student of natural history is apt to discover. But 
althongh the origin of most species by descent has not been observed, every one knows the worthlessness of argument based on a negative. Unless these cases exhibit opposing evidence of a positive eharacter, they are absolutely silent witnesses.

He who eites them against evolution commits the error of the native of the Green Isle who testified at a murder trial. "Althongh the prosecuting attorney bronght three witnesses to swear positively that they saw the murder committed, I conld produce thirty who swore they did not see it done!"

By the indnetive process of reasoning we transfer the monnown to the known, for it is the key of knowledge. It rests upon the invariability of Nature's operations under identical circumstances, and for its application mereiy demands that analysis and comparison shall fix that the nature of that of which something is unknown is identical with that of which the same thing is known. We then with certainty refer that which is known as an attribute of that object of which the same quality had been previously unknown. The following form exhibits its application to the question of evolution. As preliminary facts it may be assumed that:

1. Many species are composed of identical elemental parts which present minor differences.

2. Some of these differences have been seen to originate spontaneously from parents which did not possess them, or, what is the same thing, are known to exist in individuals whose parentage is identical with others which do not possess them.

3. The gradation of differences of the same elemental parts is one of degree only, and not of kind.

4. Induction.-Therefore all such differences have originated by a modification in growth, or have made their appearance without transmission in descent.

\section{THE MANNER OF EVOLUTION.}

In disenssing this pomt, new evidence in faror of development must be produced, and some statements of the history of the opinion made.

The laws which are expressed by all that we find of structure in animals are fonr, viz. :

1. Homology.-'This means that animals are composed of corresponding parts; that the variations of an original and fixed number of elements constitute their only differences. A part 
large in one animal may be small in another, or vice versa; or complex in one and simple in another. The analysis of animals with skeletons or vertebrati has yielded several hundred original elements, out of which the 28,000 included species are constructed. Different this from the inorganic world, which can only claim about sixty-two elemental substances. The study of homologies is thus an extended one, and is far from complete at the present day.

2. Successional Relation.-This expresses the fact that species naturally arrange themselves into series in consequence of a mathematical order of excess and defieiency in some feature or featmes. Thus speeies with three toes naturally intervene between those with one and four toes. So with the number of chambers of the heart, of segments of the body, the skeleton, etc. There are greater series and lesser series, and mistakes are easily made by taking the one for the other.

3. Parallelism. - This states that while all animals in their embryonic and later growth pass throngh a number of stages and conditions, some traverse more and others traverse fewer stages; and that, as the stages are nearly the same for both, those which accomplish less resemble or are parallel with the young of those which accomplish more. This is the broad statement, and is qualified by the details.

4. Teleology. - This is the law of adaptation so much dwelt upon by the old writers, and admired in its exhibitions by men generally. It includes the many cases of fitness of a structure for its special use, and expresses broadly the general adaptations of an animal to its home and habits.

Of comrse, these laws must be all laws of evolution, if evolution be true. And such they are; but this is far from being perceived by some students, for some of them were in abeyance or neglect prior to the stimulus to thought caused by the appearance of the "Origin of Species."

Forty or fifty years ago Germany had been flooded with the writings of the "physiophilosophs." Oken and Goethe had obtained glimpses of the wonderful "unity in variety" expressed by the laws of homology. The latter saw vertebræ in the segments of the skull, and leares in the floral organs of plants. He had found the magic wand, and many were the harmonious visions that delighted the laborious toilers among old bones and dusty skins; the patient harnspices saw omens in the intestines of birds 
and snakes, and he whose hours were spent over his lens ceased to be a mere wondermonger. But fashion is fashion, and always ends in absurdity and stagnation. The physiophilosophs became extravagant, and mistook superficial appearances for realities. They did not dream how misleading some of the resemblances between different elements, for example, of the skeleton may be, and for once German students did not analyze exhaustively. Cuvier laughed at these seekers for beauty, and confounded the true and the untrue in one condemnation. But the best men labored forward ; errors began to be exposed, and soon a reaction set in. Another extreme followed, and the school of Müller, at Berlin, denied the meaning of these resemblances and ceased to see anything but differences. Minnte and thorough investigation flourished in their hands, and the modern school of German anatomists has seen no superiors. So the theory of evolution found Berlin. The disfavor in which physiophilosophy was held sccured to evolntion a cold welcome, and it has been for Jena and other universities to give it its true impetus in Germany.

So it has been with the law of parallelism. Some of the physiophilosophs declared it, stating that the inferior animals were merely the repressed conditions of the higher. This view was taught by some men in high position in France. Their statements were, however, too broad and uncritical. The father of embryology, von Baer, of Koenigsberg, declared there was "Keine Rede" of such theory, and Lereboullet stated "that it is founded on false and deceptive appearances." Even Professor Agassiz in our day has asserted that no embryonic animal is ever the same as the adult of another, though he also once informed the writer that the embryology of two nearly related species had never been studied and compared. This was subsequently done by Professor Hyatt, of Salem, for the nautilus and ammonite division of mollusks, and at about the same time by the writer, for many species of our native frogs and salamanders, and the result has been a complete clearing up of the confusion about parallelism, and the clear establishment of the law.

The results attained are these: The smaller the number of structural characters which separate the two species when adult, the more nearly will the less complete of the series be identical with an incomplete stage of the higher species. As we compare species which are more and more different, the more necessarily must we confine the assertion of parallelism to single parts of the 
animals, and less to the whole animal. When we reach species as far removed as man and a shark, which are separated by the extent of the series of vertebrated animals, we can only say that the infant man is identical in its numerous origins of the arteries from the heart, and in the eartilaginons skeletal tissue, with the class of sharks, and in but few other respects. But the importance of this consideration must be seen from the fact that it is on single characters of this kind that the divisions of the zoölogist depend. Hence we can say truly that one order is identical with an incomplete stage of another order, though the species of the one may never at the present time bear the same relation in their entirety to the species of the other. Still more frequently can we say that such a genus is the same in character as a stage passed by the next higher genus; but when we can say this of species, then their distinction is almost gone. It will then depend on the opinion of the naturalist as to whether the repressed characters are permanent or not. Parallelism is then reduced to this definition : that each separate character of every kind, which we find in a species, represents a more or less complete stage of the fullest growth of which the character appears to be capable. In proportion as those characters in one species are contrasted with those of another by reason of their number, by so much must we confine onr comparison to the characters alone, and the divisions they represent; but when the contrast is reduced by reason of the fewness of differing characters, so much the more truly can we say that the one species is really a suppressed or incomplete form of the other. The denial of this principle by the authorities eited has been in consequence of this relation having been assigned to orders and classes, when the statement should have been confined to single characters; and divisions characterized by them. There seems, however, to have been a want of exercise of the classifying quality or power of "abstraction" of the mind on the part of the objectors. This faculty seems to be by no means so common as one would expeet, judging from the systematic ideas of many.

To explain by a few examples selected at random : First, of species characters, I may eite the fact that all deer are spotted when young, and that some of the speeies of eastern and southern Asia retilin the spotted coloration throughout life. All salamanders are uniform, often olive during a larval stage ; some species, and some individuals of other species, retain the color in maturity. To take a genus character : all the deer in the second year develop 
their first horn, which is umbranched and small, or a "spike." A genus of deer inhabiting South America never develops anything else. 'To take a character of higher grade : the exogenous plants usually present net-reined leaves, but the first pair, or those of the plumule, are of much simpler structure, being often parallelveined; for example, the cucumbers and squashes. Now, the endogens nsually produce nothing else than parallel-veined leaves, and no case is known where a plant bearing this type of leaf exhibits the net-reined type as its earliest growth.

But what do these facts mean? As in growth the genus characters usually appear last, I will suppose a case where one genus represents truly, or is identical with, the incomplete stage of another one.

In $A$ we have four species whose growth attains a giren point, a certain number of stages having been passed prior to its termination, or maturity. In $B$ we have anA other series of fonr (the number a matter of no importance), which, during the period of growth, can not be distin-

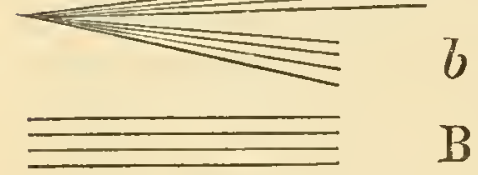

FIG. 1.

6 guished by any common, i. e., generic B character, from the individuals of group $A$, but whose growth has only attained to a point short of that reached by those of group $A$ at maturity. Here we have a parallelism, but no true evidence of descent. But if we now find a set of individuals belonging to one species (or, still better, the individuals of a single brood), and therefore held to have had a common origin or parentage, which present differences among themselves of the character in question, we have gaimed a point. We know in this ease that the individuals, a, have attained to the completeness of character presented by group $A$, while others, $b$, of the same parentage have only attained to the structure of those of group $B$. It is perfectly obvious that the individuals of the first part of the family have grown further, and, therefore, in one sense faster, than those of group $b$. If the parents were like the individuals of the more completely grown, then the offspring which did not attain that completeness may be said to have been retarded in their development. If, on the other hand, the parents were like those less fully grown, then the offspring which have added something have been accelerated in their development. I elaim that a consicleration of the uniformity of nature's processes, or inductive 
reasoning, requires me to believe that the groups of species, that is, groups $A$ and $B$, are also derived from common parents, and the more advanced have been accelerated or the less advanced retarded, as the case may have been with regard to the parents.

This is not an imaginary case, but a true representation of many cases which hare come under notice. I can not repeat them here, but refer to the original memoirs, where they may be found.*

This is a simple statement of the law of "acceleration and retardation" of some American naturalists, which probably expresses better than any other the "manner of evolution," the proposition with which we started.

Hyatt thus defines it as seen in a group of ammonites which he studied: "The young of higher species are thus constantly accelerating their development, and redncing to a more and more embryonic condition the stages of growth corresponding to the adult periods of preceding or lower species." $\nmid$

This form of demonstration of erolution is of far wider application than that which I first bronght forward. ‡ In the latter ease the induction may be limited to a certain range of variation, but the present law is as extensive as the organic world; that is, the "positioning" essential to it is found everywhere, from the lowest to the highest, and in characters from the least to the greatest in import.

Let an application be made to the origin of the human species. It is scarcely necessary to point out at the start the fact, universally admitted by anatomists, that man and monkeys belong to the same order of Mammalia, and differ in those minor characters, generally used to define a "family" in zoölogy.

Now, these differences are as follows: In man we have the large head with prominent forehead and short jaws; short canine teeth without interruption behind (above) ; short arms, and thumb

* See "Origin of Genera, and Method of Creation," Naturalists' Agency, Salem, Massachusetts; or McCalla \& Starely, 237 Doek Street, Pliladelphia.

+ "On the Parallelism between Stages in the Individual and those in the Group of the Tetrabranchiata." "Boston Society of Natural History," 4to, 1866, p. 203.

$\ddagger$ It is quite misunderstood by Darwin, as will be sufficiently evident from the following quotation from the last edition of his "Origin of Species," 1872, p. 149: "There is another possible mode of transition, namely, through the accelcration or letardation of the period of reproduction. This las lately been insisted on by Prof. Cope and others in the United States." This has only been dwelt on as accounting for a very minor grade of differenees seen in race and sex. 
of hind foot not opposable. In monkeys we have the reverse of all these characters. But what do we see in young monkeys? A head and brain as large relatively to the body as in man ; a facial angle quite as large as in many men, with jaws not more prominent than in some races; the arms not longer than in the long-armed races of men, that is, a little beyond half way along the femur. These observations are made on a half-grown Cebus apella, from Brazil, a member of a group more remote from men than are the old World apes, yet with an umusually large facial angle. At this age of the individual the distinctive charneters are therefore those of homo, with the exception of the opposable thumb of the hind foot, and the longer canine tooth; nevertheless, the canine tooth is shorter in the young than in the adult.

Now, in the light of various cases observed, where members of the same species or brood are found at adult age to differ in the number of immature characters they possess, we may conclnde that man originated in the following way: that is, by a delay or retardation in growth of the body and fore limbs as compared with the head; retardation of the jaws as compared with the brain case, and retardation in the protrnsion of the canine teeth. The precise process as regards the hinder thumb remains obseure, but it is probably a very simple matter. The proportions of the young Cebus apella enable it to walk on the hind limbs with great facility, and it does so much more frequently than an adult $C$. capucinus with which it is confined.*

The "retardation" in the growth of the jaws still progresses. Some of our dentists have observed that the last (3d) molar teeth (wisdom teeth) are in natives of the United States very liable to imperfect growth or snppression, and to a degree entirely unknown among savage or even many civilized races. The same suppression has been observed in the outer pair of superior incisors. This is not only owing to a reduction in the size of the arches of the jaws, but to successively prolonged delaty in the appearance of the teeth. In the same way men, and the man-like apes, lave fewer teeth than the lower monkeys, and these again fewer than the ordinary Mammalia, and this reduction has proceeded in relation to an enlargement of the upper part of the head and of the brain.

The cause of development may be next considered, and under

* The same relations of man to the anthropoid apes have been dwelt upon by Prof. C. Vogt. 
this head may be discussed the natural selection of Wallace and Darwin and other propositions of similar import.

"Retardation" continued terminates in extinction. Examples of this result are common; among the best known are those of the atrophy of the organs of sight in animals inhabiting eaves. It is asserted that the young of both the blind crawfish (Orconectes pellucidus) and the lesser blind fish (Typhlichthys subterraneus) of the Mammoth Cave possess eyes. If these statements be accurate, we have here an example of what is known to occur elsewhere, for instance, in the whalebone whales. In a fœtal stage these animals possess rudimental teeth like those of many other Cetacea when adult, which are subsequently absorbed. So also with the fotal ox ; the upper incisor teeth appear in a rudimental condition, but are very early removed. The disappearance of the eyes is regarded by Dr. Packard, with reason, as evidence of the descent of the blind forms from those with visual organs. I wonld suggest that the process of reduction illustrates the law of "retardation" accompanied by another phenomenon. Where characters which appear latest in embryonic history are lost, we have simple retardation, that is, the animal in successive generations fails to grow up to the highest point of completion, falling farther and farther back, thus presenting an increasingly slower growth in the special direction in question. Where, as in the presence of eyes, we have a character early assumed in embryonic life, retardation presents a somewhat different pluase. Each successive generation, it is true, fails to come up to the completeness of its predecossor at maturity, and thus exhibits "retardation," but this process of reduction of rate of growth is followed by its termination in the part long before growth has ceased in other organs. This is an exaggeration of retardation, and means the carly termination of the process of force-conversion, which has been preriously diminishing steadily in activity.

Thus the eyes of the Orconectes probably exhibited for a time at maturity the incomplete character now found in the young, a retarded growth continuing to adult age, before the termination of growth was withdrawn by degrees to earlier stages. With this early termination of growth came the phase of atrophy, the incomplete organ being remored and its materials transferred to other parts through the greater activity of "growth-force." Thus, for the reduction of organs, we have "retardation"; but for their extinction, "retardation and atrophy." 


\section{ON THE CAUSES OF EVOLUTION.}

\section{Inductive Reasoning.}

In the present investigation we are endeavoring to discover new principles, not to apply old ones. 'The work is similar to that which occupied Newton in his investigation of the law of attraction or gravitation. The process by which we arrive at general truths rests on the consideration of a sufficient number of observed facts, and the determined qualities which are common to all we regard as a law. This process requires for its proper condnct a careful analysis and discrimination of the nature of the objects considered; otherwise fallacy will result. As exact analysis is not always observed by the arerage mind, this inductive reasoning is not always successfully employed by it, nor understcod when presented by others. In the deductive process it is more at home. With an ascertained principle giren, as something like a staff for the mind to lean on, its application is not so difficult; but to such a mind induction presents an appearance of uncertainty and eien of confusion, and these will certainly exist until order is evoked by the first step-classification. The theory of evolution has thus been charged with confusion, as though it asserted that which overtinew the order of nature. But the confusion only exists in the mind of such critics. The order of the creation is one of the foundation facts, and thus enters the inductive argument as one of its elements. That conclusion which is consistent with this order can not be regarded as its enemy.

\section{On Natural Selection.}

In endeavoring to assign a cause for the existence of the peculiar structures which define the divisions among animals, Messrs. Wallace and Darwin have proposed the now well-known law of natural selection. This states, that, inasmuch as slight variations appear continnally in all species, it is evident that some will be more beneficial to the animal than others, in its exertions to supply itself with food, protect itself from enemies, the weather, etc. It then asserts that those whose peculiarities are beneficial will excel those less favored, in the successful use of their powers, and hence will live better, grow better, and increase more rapidly. That by the force of numbers, if not by direct conflict, they will ultimately supersede the weaker and destroy or drive them away. 
Then, as there are many fields of action and possibilities of obtaining support in the world, that the weaker will first be driven to adopt such of these as their peculiarities may adapt them for, or not exclude them from. 'Thus all the positions in the world's economy are filled and the surplus destroyed. This is styled by Spencer the "survival of the fittest"; an expression both comprehensive and exact.

This doctrine is no doubt a true one, and has regulated the preservation of the variations of species, and assigned them their locations in the economy of nature. It was natmral that this great law should have been brought out by such men as Darwin and Wallace, who are by nature much more of observers of life in the field, or out-door physiologists, than they are (or were) anatomists and embryologists. Their writings in their chosen field of the mutual relations of living beings in their search and struggle for means of existence are admirable, and almost unique, especially some of those of Darwin.

It is to be observed, however, that they both (especially Darwin) start with the variations observed. This is assumed at the outset, and necessarily so, for "selection" requires alternatives, and these are the product of variation. Great obscurity lias arisen from the supposition that natural selection can originate anything, and the obscurity has not been lessened by the assertion often made that these variations are dne to inheritance! What is inheritance but repetition of characters possessed by some (no matter what) ancestor; and if so, where did that ancestor obtain the peculiarity? The origin of variation is thus only thrown upon an earlier period.

Another reason why natural selection fails to account for the structures of many organic beings is the fact that in expressing "the survival of the fittest" it requires that the structures preserved should be especially useful to their possessors. Now, perhaps half of all the peculiarities of the parts of animals (and probably of plants) are of no use to their possessors, or not more useful to them than many other existing structures would have been. It fails to account for many characters which express the relations of homology and parallelism, and is almost confined in its exhibitions to features which express teleology. This objection has been insisted on by Kölliker, the writer, and by Mirart; and now IIuxley, while defending Darwinism proper against the lastnamed anthor, says that "what the hypothesis of evolution wants is a good theory of variation." 
Plainly enough, then, nothing ever originated by natural selection, and as the present essay relates to the origin of types, little space can be given to its discussion; for natural selection, important though it be, is but half the question, and indeed the lesser half. It is to the great causative forces as are the gutters and channels which conduct the water in comparison with the pump and the man who pumps it.

\section{On Teleology.}

Two classes of structures have been alluded to : those which are useful to an animal, and those which are not useful; or the adaptive and non-adaptive. Nothing is better known than that animals are well adapted to their situations in the world, and for their needs as to supplying themselves with food, etc. Some part of every species is so constructed as to enable it to live under conditions where most other kinds of animals would perish. Thus the sea-rangers, among birds, as the great albatross, etc., possess long and pointed wings; while those that live in thickets or under cover have short, round ones, as grouse, woodcock, etc. Even our sparrows-those that love the bushes and swamps, as the song-sparrow (Melospiza melodia) -have short, rounded wings, while those that haunt trees have them sharper and pointed, as the chipping and tree sparrow (Spizella socialis, pusilla, ete.). Water-frogs have their feet webbed; land-frogs have smill or no webs; while tree-toads possess sucker-like expansions of the ends of the toes, which secrete a glutinous fluid, by which they adhere to the trunks and leares of trees. Finally, frogs that burrow have one or more of the bones of the base of the hind foot (tarsus) modified into a projecting blade, like that of a shovel; and, as they squat down, they literally sit into the ground, and are soon out of sight in the hole which they dig with these busy trowels.

Cave insects have long and delicate antennæ and limbs, exceeding those of their out-door relations by much. Moreover, their usual lack of eyes is a clear case of the reverse of adaptation, i. e., the absence of an organ where not needed.

Less attention has been directed to the non-adaptive characters, yet they are as numerous as the adaptive. I do not include under this head useless organs or parts only, but also those which are useful, but whose peculiarities do not relate to that use as advantageous to it.

Notable examples of this kind are to be found in the characters 
which distinguish all of the higher groups of animals and of plants among themselves. It is easier to ask than to answer what advantages the mammalian skeleton possesses over the reptilian that it should have superseded it. What end was served by aborting the coracöid bone, which in reptiles supports the shoulder-joint from behind, answering to the ischium of the pelvis? I do not know how to answer this question on a teleological basis, although it involves one of the principal characters of the class of reptiles. What mechanical end was gained by withdrawing the rib-bones of two cranial segments into the cavity of the ear, to become the hammer, anvil, and stirup of the organ of hearing?* Was it to perfect the auditory faculty? Scarcely; for birds possess as refined and as musical an ear as any mammals, and appear to be superior to them in discriminating power, yet in them the hammer is the basal element of the lower jaw, and the anvil supports it, being entirely outside the cranial walls. See again one ground of distinction between reptiles and batrachians. The base of the brain-ease in the former consists of an axis of bony segments developer in the primordial cartilage, while in the batrachian it is a single bony plate, formed by deposit in the membrane which originally bounded this cartilage. Who can assign any advantage of the one type above the other which ean be looked upon as in any way related to the external needs of the animals of those classes?

Another example may be found in the ankle-joints of reptiles, birds, and mammals. In the first two the hinge is between the first and second series of tarsal bones; in the mammals, between the bones of the lower leg and the first row of tarsal bones. Something besides the superior mechanical advantages of the latter has given it predominance over the former.

To turn to the nautilus and ammonite types of Mollusca, we observe beantiful illustrations of all the laws already stated. As is well known, these shells have their tubular eavity divided by transverse partitions. In the nantilus these unite with the outer wall by a plain angle, but in various genera wlich lead toward the ammonites this margin becomes complicated. This results from an excessive growth of the peripheral part of the partition or septum, so that in order to confine it to the same space of contact it must be folded. This plication takes place in a symmetrical manner. 'The folded edge in Aturia forms a tongne-like loop on each

* The homolories here expressed have been rendered improbable by late investigation. The argument is, however, not affected. 
side, on the outer surface. In Goniatites a fold is added on the back. In successive genera other main folds are added, the last appearing nearest the center of the coil. These then become complicated by subordinate undulations which in the more complex forms become the axes of a double row of new lobes and folds, the whole presenting symmetrical lobate outlines of much complexity and beanty.

But another series of changes accompanies those of the septa, and are entirely independent of them. These relate to the various degrees of winding of the shell. The early form with simple septa (Orthoceras) was straight, but others which succeeded began to turn their shell-making round an axis, thus commeneing a partial coil. In some the coil was very open; in others it began close, and then ceased, the shell finishing straight. Others after such a course began to wind again, while some made a single turm near the middle. 'The most remote from the starting-point ( $\mathrm{Am}$ monites, sp.) made a tight and complete flat coil, while some, whose septa remained simple, did the same (Nautilus).

The direct uses of these various forms of septum and coil are simply inexplicable, and that one of them was any "fitter" to "survive" than another, by virtue of its usefulness, is for me more than doubtful.

I am tempted to continue this theme, for it might be prolonged indefinitely by any one familiar with the details of anatomical structure, but I will only repeat that the illustrations would be drawn chiefly from the characters of the classes, orders, families, and other higher groups.

It is not difficnlt to believe, in the case of the useful structures first cited, that the law of natural selection has had much, probably everything, to do with the preservation of the animals possessing them in the various localities to which they are adapted. But that it has had opportunity to direct the lines of progress in the second series is not likely. That it had nothing to do with the origin of either, is certain.

\section{On Growtle-Force.}

Every change by complication of structure is by addition; every simplification is by subtraction. Every addition is a matter of growth, which is carried on by a process of nutrition. The inquiry respecting the origin of new forms centers itself at once on the history of growth and the influences affecting it. 
If, as I suppose, these additions, either adaptive or non-adaptire, be produced by an acceleration * of growth, it is evident that the same immediate cause of that increase must be potent in both cases. That one of the "forces" is concerned in growth as well as in all the active animal and regetable processes, is obvious to those who have carefully observed it. The fact that growth, like work, requires food for its progress and continuance, is reason enough for suspecting the existence of a force, and in some cases the relation between this force and other known forces may be measured.

Prof. Henry pointed out these facts many years ago, and illustrated them by observations on the growth of the potato and of the egg. The starch of the former, a complex "organic" chemical compound, weighs much more than the young shoot of cellulose, etc., into which it is conrerted by the process of growth, so that a portion of the substance of the tuber has eridently escaped in some other direction. This was found to be carbonic-acid gas and water, derived from the slow combustion of the starch, which, in thus "running down" from the complex organic state, to the more simple inorganic compounds, erolres an amount of force precisely equal in amount to the chemical force (chemism) requisite to bind together the elements in the new and complex substance cellulose. $\nmid$

It is well known that substances differ in their capacities for giving out different kinds of force. This, of course, means their capacity for converting one kind of force into another. Thus, if glass be rubbed with silk, the motion is conrerted into electricity, while, if it be rubbed by the hand, heat is the principal result. In some cases chemical force, set free by decomposition, is converted into light; in others, heat; in others, to electricity, oftener to several at once. But one substance, so far as known, posscsses the power of converting this chemical force or heat into growth-activity, and that is the material out of which the living parts of animals and plants are composed. This is a protein, a compound of carbon, oxygen, and nitrogen, in the order of relative quantity, with a smaller proportion of hydrogen, the whole being often associated with still smaller quantities of sulphur

* For the definition of this term sec first article, in May number of "Penn Yonthly." (Antea, p. 11.)

$\dagger$ "Agricultural Report of Patent Office," 1857. 
and phosphorus. In its mechanical aspect, as the material out of which structures and tissues are made, it is called protoplasm.

This substance exhibits two different phenomena of forceenergy, viz., motion and growth. Motion is exhibited by contraction and expansion, but which is the active state and which the passive state is matter of question. Some physiologists regard "contractility" as the energetic state. Radcliffe believes that extension is the energetic condition, and contraction a rebound or discharge of the extending force. He finds dead protoplasm to be a dielectric, and believes that in life each muscular fibrilla acts like a Leyden jar. It has been demonstrated that the outer layer of the sheath of a muscular fibrilla is positively electrified in life, while the cut extremities are negative, and it is shown by Radcliffe that the inner side of the sheath becomes negatively electrified by induction. The attraction of the opposite electricities on opposite sides of the sheath compresses and elongates it, thus, according to his theory, producing muscular extension. The nervous cells and tubes he believes to act in the same way; the difference being that the walls and sheaths are in a state which prevents compression and extension. The phenomena of muscular extension and nerrous tension he believes to be terminated by a discharge of the force, such as takes place in electrical fishes, but in much smaller quantity. Thus motive force resides as a form of electricity in protoplasm, and in highly organized animals is specialized into neurism.

As to growth-force, all its exhibitions may be reduced to celldivision, cell-nutrition, and cell-origin. Cell-division exhibits two prominent varieties. In both the cell nucleus first divides; in the ordinary mode, the cell-wall contracts at opposite points, forming approaching plications, which, when they meet, divide the cell. In the other mode or proliferation, the divisions of the nuclei approach the cell-walls, which bulge opposite to them, forming diverticula, which isolate themselves by opposing contractions at the base, which meet as before. The nature of the force thus displayed is as yet only speculative, and its demonstration will result largely from observation on cell-origin from homogeneous protoplasm. Radcliffe snggests an ingenious theory. He supposes that the protoplasm acquires an external layer differentiated from the internal mass by exposure to and contact with external substances, and that the electricity generated in the interior is distributed on the under surface of this stratum. That 
this induces opposite electricity on the external surface, which, as in the muscular cell, causes compression, and therefore extension of the stratum. This extends itself beyond its contents, which may be attenuated, filling the space, or contracting, forms the nucleus.

This view will not, however, account for nucleus and celldivision, which are the subsequent and principal exhibitions of growth-force. Perhaps the following suggestions may throw some light on it. Should a polar tendency appear in the nucleus, were the protoplasm of the proper viscidity, the poles being of like electric name, would tend to separate by repulsion, thus forming the hour-glass shape so well known, and afterward division. This nucleus division would inevitably be followed by division of the cell-wall, if its inner face were electrified in opposition to the nucleus. For the wall being attracted toward it equally all round, the separation of the two nuclei would be followed by an incurvature of the walls opposite the interval between the nuclei, in order that each should maintain a position equidistant from its center. Further divergence would result in the completion of the cell-wall of each, apart from the other. This process would be supported by nutrition of the cell, which procecds by the passage through the cell-wall to the nuclens, of additional protoplasm from the blood. Of course, the prime question is as to whether polarity can appear in the nucleus. 'That growth is first polar appears probable on consideration of the globular and discoidal forms of the lower animals, and that this principle lies at the basis of the growth of the higher is rendered equally probable by the phenomena of symmetry of different kinds, as bilateral, anteroposterior, etc. The electricity supplied to the outer sheaths of muscular fibrillæ is, according to Dubois Reymond, positive. That covering the surface of the nucleus must be thought to be positive also, if it be effected in opposition to the inner wall of the cell-wall, which is known to be negative by experiment. But in that case it wonld be difficult to perceive why it should not fill the cell by attraction to the wall. If, on the other hand, it be a generator of negative electricity, it would retain its integrity and induce a temporary change in the wall. The transmission of protoplasm through the cell-wall to the nucleus would produce an accumulation of electricity to be discharged in extension, or a disturbance of equilibrimm, to be followed by polarity and division; but the conditions under which 
these results would appear are, of course, unknown. The mechanical arrangement and condition of the parts would have much to do with it.

We are, however, here in the areana of life, and the forms of law which rise before the mental vision are but as the statues of Memnon that greet the toiler on the river of mysteries; they loom upon its banks in twilight, and the when, the how, and the wherefore remain unanswered. But the river of Africa is yielding. her secrets, and, thongh the life that she nourishes may be the last she will give up, it is no less surely promised to the patient inquirer.

A great advance toward an explanation of the operation of this growth-force was made in the demonstration of the fact that its highest exhibitions are confined to the multiplication of cells by division of pre-existent ones, by contraction of their nuclej and walls in lines which finally meet.

'The construetion of additional parts consists solely of this cellgrowth, but the character of the result is, of course, dependent on the position at which this addition takes place. It may be at the terminus of a limb to add another toe, or on the wall of an artery to add a valve. It may be in the brin to add a band of fibers, or on the edge of a musele to extend its width.

That tissues are made of cells of original or altered shape, separate or confluent (flown together) is well known. 'That the arrangement of tissues into organs is due to the direction of this multiplication is also true. Thus a gland is a collection of follicles, each of which is a bagging of a plane tissue. This bagging is an exaggerated convexity, which is occasioned mechanically by excess of cell-growth at one spot on a uniform surface. Solid parts are all formed, in the first instance, of simple segments. These are parts produced in a straight rod by excessive elongation or growth; the process being as before, the division of cells and distribution of homogeneous protein between them. All this is derived from the study of homologies combined with embryology, and the result is wonderful, and simplifies at once our ideas of the action of the glowth-force. It is mainly a repetition of cell-division, the result as to strueture being entirely dependent on the influenees which locate its activity and regulate its amount.

Now, its amomt will depend on the eapacity of the existing organism to eonvert heat, ete., into it; and the form, as to tissue, etc., in which it appears, depends no doubt on the complexity of the machines or organs of which the organism is composed. In 
the case of the higher organisms we have muscle, converting the results of nutrition into muscle ; skin and nails making more skin, etc.; brain making more brain ; bone making more bone.

The prime question is the cause of the location of growthforce. Experiments on this point are greatly needed, and in their absence it will be necessary to take a wide survey of facts.

A given animal organism can only convert a given amount of force, and that capacity must remain uniform so long as the machine or structure remains the same. If, however, an addition to its work is developed in one quarter, a subtraction from some other region must take place if the whole amount remain the same. When, then, a useful organ is added, subtraction from some less important locality must result, and, as a consequence, the latter must become still less prominent in the general economy. Hence, the development of the useful class of organs already cited must always be accompanied by a corresponding disappearance of useless ones. 'This would be by reduction or retardation. But, in the case of the complex folds of the margins of the septa in the ammonite, useless parts are added by acceleration. Here a gradual increase in the amount of growth-force must be believed in.

The representation of simple growth-force, i. e., the result of bathmism, not specially located, is seen in general addition to size. In domestication careful feeding, associated with protection against all exhausting exposnre or exertion, tends to this increase of size. 'This is well known to be the case in $\operatorname{logs}$ and cattle and animals of quiet and easy life. The reverse conditions, as poor food, exposure, and disproportionate exertion, reduce the size ; witness the Maryland breed of cattle, and the semi-wild hogs of the Southern States. This matter is, however, nicely balanced with the production of motion, for if the latter be excessive, or the supply of material for consumption be insufficient, growth-force must be evolved in less amount.

It will be necessary here to state that the supply for the conversion of all the forces of the body is derived from the nutriment as circulated in the blood.

But the condition of plethora of growth-force is also the one highly favorable for the appearance of rariations of structure, or the location of growth-force in new places. Domesticated animals are notorious for this variation, while the still more numerous examples of "protean" species in nature are always predominant forms, abundant in individuals and widely spread. For example, 
the wolf, the red fox, the red-tailed hawk, the garter-snake, the tiger, salamander, etc.

That the variability depends on a peculiar condition of the animals themselves, and not on domestication, excepting in so far as it produces these conditions, is plain, not only from the above facts, but from those observed in domestication. It is well known that while pigeons, fowls, cattle, dogs, etc., are variable, or " protc:in," the peafowl (Pavo) has maintained its specific characters with great accuracy during a period of domestication as long as that of the other species named. The same may be said of the guinea (Numida) and the turkey (Meleagris). These facts show that domestication is only a remote canse of variability.

\section{On the Location of Growth-Frorce.}

With the fact of increase of general growth-force before us, have we any others which can guide us in fixing on a cause for its special location? It is plain that the useful additions which have constituted certain genera, families, orders, etc., what they are, must have been produced as a consequence of the existence of a need for them; or, on the other hand, being ereated first, they must have songht for use, and found it. But what are the relative chances of truth for these two propositions? In the second case, admitting evolution as proved (see Part I), we perceive that an almost infinite chance exists against any usual amount of variation, as observed, producing a structure which shall be fit to survive in consequence of its superior adaptation to external circumstances. It would be incredible that a blind or undirected variation should not fail in a vast majority of instances to produce a single case of the beautiful adaptation to means and ends which we see so abundantly around us. The amount of attempt, failure, and consequent destruction, would be preposteronsly large, and in no wise consistent with the facts of teleology as we behold them.

What of the opposite view? We have in its support the wellknown facts of [determination of nutritive fluid during use of parts, ]not only for supplying fuel for the motions of use, but also for growth-force and material for the increase in bulk of the part used. Who has not remarked the large size of the hands of the laborer, and of the nails of the working-woman? Who can not remember some of the conntless examples of certain modifications of form being associated with special exeellenee of use of the parts 
in different races of the same species of individuals of common parentage, showing that they must have grown with the history of those races? Who does not know the short, wide jaws of the bull-dog, with their oblique teeth, produced by the expansion of the zygomata to accommodate the huge temporal muscles so necessary for maintaining a firm hold of its enemy. Then the long and full nose of the hound, and its more extended turbinate boneshow closely is this connected with its developed scent; while the light muscular forms of the greyhound are undoubtedly necessary to its well-known speed. If it be said that these variations have not resulted in a single change of structure worthy of note by a systematist, we can point to the Japanese dog, where the excessive reduction of the jaws anteriorly has resulted in a total loss of some of the premolars and molars. The loss of molar and incisor teeth from shortening of the jaws, in the human species, has been already noted. The number of such instances is very great, but, as space to enumerate them fails, it is only necessary to add that they are characters of high importance in a systematic sense. Their importance will be more readily conceded in remembering the proposition, already stated, that species are simply isolated varieties, and of similar origin.

Confirmatory of this view are the facts already cited with reference to the relation of motive to growth-force. The force involved in both being seen to be similar, perhaps identical, the former represents its energetic state as discharge and motion, the other energetic without discharge, in the growth of cells. And whatever determines this force to a given part of the body must then probably result in both of its exhibitions, dependent on the kind of cells which receive it. As above remarked, the conditions which determine the result are nnknown, except that the two kinds of muscular cells are the only ones in which elongation is strongly marked.

Another reason for believing in use as a eause of structural change is the manner in which the same useful structures have evidently appeared on totally distinct stems, as an evident adaptation to the same circumstances in which the different types have been equally placed. Thus the birds of prey possess the hooked, often toothed, beak, appropriate for tearing and destroying anjmals. Their stock is the sime as that of the cuckoos and parrots, and even of the pigeons. The butcher-birds are of the division of songsters, not widely removed from the thrushes, and far enough 
from the raptores, yet the same hook and dentate bill reappears in them, as adapted to flesh-eating habits.

Among the reptiles, which were no doubt originally land animals, and derived from batrachians, we liave a large number adapted to swimming in the ocean, and these not all of the same stock. Thus the Plesiosauri are crocodilian in relationship, while the Pythonomorpha of America were of the same that produced the snake and lizard. Again, the same modification appears in the Cetaceans, or whale, etc., among mammals which are primarily a terrestrial division.

It is a nice point of phylogeny (or the science of genealogy) to ascertain whether adaptive or strictly "bathmic" (or embryonic grade) characters came first in a time in a given group. Among frogs we have four divisions. One has an embryonic mouth and embryonic breast-bones; another, embryonic mouth and complete breast-bones; the third, embryonic breast-bone but complete mouth; and the fourth, with both complete. The first is the lowest and probably the oldest in time; agreeably to this supposition, it is distributed over the whole eurth. The second is East Indian and African; the third and most extensive is Australian and American; while the fourth is confined to the old World and North America. The second, third, and fourth divisions possess corresponding series of genera of different structure adapted to different modes of life. Some have shovels for burrowing, some webs for swimming, and some palettes for adhering to branches and leaves of trees. If these characters were first fixed, then those with the more perfect breast-bone and mouth are descendants of those with the less perfect; if, on the other hand, the conditions of mouth and breast-bone were first fixed, then each division thus defined in its special region was modified into the subdivisions, each adapted to a special mode of life. I have called these parallel divisions "homologous groups," and probably the origin of the embryonic modifications has sometimes come first, and sometimes the adaptive structures have preceded. Nevertheless, the lowest or most embryonic division will often have developed its own adaptive divisions, and each of these will agree in producing descendants which have advanced in the embryonic scale, and so produce homologous groups.

For these and other reasons it is concluded that the useful characters, defining natural divisions of animals, have been produced by the special "location of growth-force" by use. Useless 
ones have been produced by location of growth-foree without the influence of use, or by its subtraction, due to a disturbance of equilibrium, consequent on the special location elsewhere.

But we go back to the origin of the question in investigating the action of growth-force undisturbed by the interferenee of locating influences. This is only to be ascertained by an examination of lower organisms in comnection with the higher. A point that first strikes the stident of higher animals is, that after he has proved the law of homology to be true, as regards different animals when compared, he further finds that the parts of the same animal are also homologous, that is, right hand and left, front and behind, bottom and top are also construeted on the same plan, so as to be reduced to the same elemental parts. This is described under the names of "anteroposterior" and "bilateral symmetry," etc.* These laws apply to all parts of the organism, and, though there appear to be exceptions, these are traceable to a common symmetrical type, the change wrought being one form of specialization. It is not surprising then that the lower we deseend in the scale of life the less marked is the departure from the entirely symmetrical disposition of parts as regards the common center. This is beantifully seen in the Radiata, ete., where the jelly-fish, the star-fish, and the sea-urehin are familiar examples.

But these are complex compared with forms below them. The minute Polycystina construct shells of beautiful sculpture or tracery; but, though they present many forms, they may be all referied as modifications, to the symmetrically-marked disk. Of cellular animals, Trichodiscus represents a discoidal aggregate, and Actinophrys a globular mass of cells. Monas and its allies consist of one or several cells in globular form.

Lastly, in the first appearance of life in the most complex animal we hare first a cell, which, then "segmenting," divides itself so as to become a globular mass of identieal cells, arranged about the center.

From the cellular animal upward the operation of addition of parts is then one of repetition, and that centrifugally in the case of bodies which are developed in all planes, or peripherally in those which are in one plane.

Thus the complication of the edges of the septa of the ammonites is aceonted for. First, the growing animal was supplied

* See Prof. B. Wilder, in Procecd. Boston Socicty Nat. Ilist. 
with an excess of growth-force. The type of the preceding generation being strictly adhered to according to the laws of inheritance, the only opportunity for its exhibition was necessarily after the inherited parts were completed by acceleration. The results could only, therefore, be exhibited on the edges of the new septa and free margin of the onter wall. As the older growths mechanically restrained the new septa from mere extension, folding or plication must have resulted from the crowding of additional surface into the small space. This folding would take the form of simple branching, and then "repetition" of the process by a refolding of the outlines of the first fold. The edge would thus have the digitate or pinnately branched appearance it is known to present.

Another case of folding is that of the brains of the higher mammals, including man. This was occasioned by excess of growth-force distributed to the circumference (from an inherited central region), exceeding in amount that of the space (skull) in which it was inclosed. Folding was necessary for its accommodation in the contracted space. This is a highly useful modification. Another case like that of the ammonite above cited, whose use is not so readily determined, but which illnstrates excess of growthforce on some other account, is that of cotyledonary leaves in some plants. In these cases the growth of the leaf is accelerated, requiring plication for its accommodation.

We therefore have the two laws regulating the "location of growth-force" irrespective of nse, viz.: 1, the centripetal or polar tendency; 2 , the peripheral tendency; both more or less determined by the inherited central or first grown parts.

There is, however, another element which in animals disturbs the symmetrical direction of growth-force besides use, and which precedes use, i. e., effort. Use presupposes a part to use, and a simple part is sufficient for its influence, so that it be usable; but the first beginnings of few structures are usable. As Mivart has objected to natural selection, that the first rudiments of organs could never be sufficiently important to an animal to give it a preference in the strnggle for existence, so it might be urged against the theory of use that rudiments are generally useless, and could not lave been originated by use.

The effect of use is, however, twofold. The contact with objects used has some effect in stimulating nutrition, as well as the exertion of the muscles necessary to nse. But determination of 
nutritive fluid is well known to be under the influence of nerveforce. How imagination stimulates secretion is seen in the familiar example of the flow of saliva in anticipation of food; a very different example is the phenomenon of blushing under emotional stimulus. Nevertheless, it is not evident that growth can result with any such facility in a fully grown animal. It is thought that the effort becomes incorporated into the metaphysical aequisitions of the parent, and is inherited with other metaphysical qualities by the young, which during the period of growth is much more susceptible to modifying influences and is likely to exhibit struetural change in consequence. Certain it is that acceleration ceases with growth, and, as the young of animals are not in complete relation with the surrounding world, the influences controlling it must be inherited. This consideration renders it doubly probable that the results of effort on the part of the parent appear in change of structure in the offspring.

Of course, immense numbers of cases of continued effort can be produced by the objector, in which no structural modification has resulted. There are various reasons why a modification should not take place. In the first place, the exertion of use must be great, habitual, and long-continued; in the next place, abundant food must be at hand; finally, growth-foree must be to spare in the growing young, either from some less necessary part or by excess. Now, cases are probably not rare where none can be spared from another part withont injuring the efficiency or viability of the animal; hence, all such changed individuals would perish through some form of natural selection or disease.

Domesticated animals can be pointed out where effort and use have long been put forth in the service of man without changing structure. But such effort is not to be compared for a moment with that put forth by animals in a wild state, in seeking food or protection from enemies. - The protection furnished by man, and consequent release from the struggle for existence, has reduced the chances for such variations greatly. Nevertheless, variations profitable to man have resulted; witness the race-horse and carter.

In cases where one side of the body is used in excess of the other, unsymmetrical development would be counteracted by the law of polar or centrifugal growth, all that might be acquired by the one side being inherited by both. Even this original symmetry has, however, been overcome in some types, is in the flounders (in the jaws and teeth as used parts). 'This part of 
the subject is purely hypothetical, however probable, but the aspect of the discussion will be materially brightened to the reader, if he have previonsly adopted, with the anthor, the principle that evolution has been the mode of origin of the present life-forms of the earth.

Reverting now to those beings which are either in part or entirely destitnte of the power of determining these movements, as plants, various causes present themselves as modifiers of the polar or centripetal activity of growth-force. In the case of a plant, the medium in which it grows modifies the result; for example, the downward growing axis or root differs much from the npward aërial portion or stem. Aquatic plants, supported beneath or on the surface of the water, lack the strong stems and braces necessary to air-growing plants; while of the latter, those with weak stems develop tendrils and other supports. In these cases physical laws have been the gnides of growth-force. In the case of bright colors, which we know to be impossible in vegetation without sunlight, the influence is chemical.

The first physical law is, that growth-force, uninfluenced by inherited pecnliarity, ${ }^{*}$ any stronger influence locating a nutritive fluid, must develop extent in the direction of least resistance, and density on the side of greatest resistance, when not too great. The illustration of this statement would be that a globular mass of cells brought to the point of junction of two media, as water and earth or air and eartl, elongates in the direction of the medium presenting the least resistance, i. e., air. Thus a longitudinal development would originate from a centrifugal, and a repetition of the same process would produce branches. The reason why repetition should appear along the sides instead of as continned prolongation of the axis, arises probably from the difficulty of conreying fluid nutritive material far from the base as a source of supply, and the occurrence of various mechanical obstacles easy to be conceived. In low plants, where nutrition is absorbed by all parts of the axis, which branch, as the subterranean parts of fungi (mycelium), difference of local supply wonld produce an effect. In higher plants, where fluid nutriment is only introduced at one point (the root), and conveyed by special layers of cells or tubes, the difficulty of maintaining supply at a distance from its source would encourage lateral repetition or branching. $\dagger$

* This is supposed to be due to atomic peculiarity of eell-substance.

$\uparrow$ The great power exerted in a giren direction by growth-force due to gradual 


\section{On the Origin of Intelligence.}

Leaving this part of the subject, we approach one of higher interest, viz, the effects of the metaphysical or mental acquirements of animals on their exertions in effort and use. 'The growth of the mind in animals has, no donbt, followed the same laws obeyed by that of man: the difference being that the lower forms have remained permanently fixed in stages early passed by the lord of living beings. The foundation qualities from which all the phenomena of intellect may be derived are, the powers of retentiveness (memory) and of perceptions of resemblance and difference. These traits are well known to be possessed by many animals, and perhaps in some degree by all. Their possession will be modified by the power of exercising attention, which, in its turn, will depend on the sensitiveness of the animal to impressions-in other words, the ease with which consciousness may be aroused.

The origin of the disposition to take food will be the rudiment of all that appears as will in higher animals, and which, though supposed to guide, is the creature of so many stimuli. This origin is supposed by metaphysicians to be the result of education of the "spontaneous activity" of animals by their pleasures and pains.

The brain of man and of other animals is an organ which receives and retains pictures and impressions, both painful and pleasurable. The retention of these pictures is not a state of conseionsness, but they may be brought into the consciousness according to the law of "contiguity," or association. That is, that the recurrence in the actnal of some object or event, which was perceived on a former oceasion, at or near the same time as another object or event not again repeated in the actual, will bring the latter before the consciousness. So, also, the revival of one such picture will bring within the mental vision others impressed on the mind at or near the same time as the first. These events may have been in the reality either painful or pleasurable. On the recurrence of eircumstances which on a former oeeasion resulted in pain, the resuscitation of the mental picture, then impressed on

acquisition and inheritance is illustrated by the plantain, Plantago major. Although without axis, it has been observed by James C. Cresson, in the Philadelphia Park, and Alfred Cope, on his drive, to force itself through a solid bed of hard vulcanite pavement, several inches in thickness. 
the memory, produces an anticipation of the pain, and the animal at once flies from the source of danger. So, also, with pleasurable objects, the resultant action being the reverse, or an attraction to the object. In both cases a previous experience of the relation between the object and the sensation of pleasure or pain must have been had.

There is, in addition, the power of determining differences and likenesses, by which contiguities or associations are originated in the mind, of a character different from that resulting from the relations of times of receipt of the impression. Snch contiguities recall pictures to the consciousness in consequence of their resemblances in essential qualities.

On these two bases, together with the perceptive faculties, rest the complex phenomena of the animal and human minds. They are probably physiological functions of brain tissue, for the following reasons, among others :

1. Impressions are conveyed by physical means to the brain. The brain can only receive a given number at a time withont exhaustion, and is prepared to receive more after being nourished. Impressions long forgotten are revived in certain states of disease. Impressibility and memory are most marked during growth, and diminish with age.

2. If impressions are physically produced and preserved in the brain, those made at or near the same time would remain close together in the brain, and this material proximity would be the "contiguity" aceording to which they would come before the consciousness.

3. Classification or appreciation of resemblances takes place unconsciously in the mind (by "unconscious cerebration"). Resemblances not seen at the time of impression suddenly flash into the consciousness on a subsequent revival of it. The "contiguity" to like things thus established may be more or less lasting in the mind than the contiguity of circumstances under which the impression was made.

4. As "contiguity" in time is believed to be revived by contiguity in location of impressions in the "perceptive" part of the brain, so "contiguity" of resemblance may be believed to depend on contiguity of location in the "reflective" part of the brain.

The retention of the contiguities of time and of resemblance constitute the basis of education of an animal, and its intelligence 
will be in proportion to the number and complexity of these acquisitions.

The lowest exhibitions of contiguity, or association in time, do not require a nervous system for their display. The Protozoa, which are without nerrous system, exhibit its results in their determinate seizure of some small objects as food and rejection of other's. The sea anemones (Actinia) display some preferences as to the substances to which they attach themselves. All power of taking food implies the retention of the impression of pleasure on first accidentally coming in contact with it. This power is then present in protoplasmic beings of the simplest type.

All the movements of animals have been sliown to depend on a direction of this motive force, consequent on a necessity for avoiding pain and obtaining pleasure. It may be regarded, moreover, as a truth that heightened vitality or energetic conversion of force is always a state of pleasure, while depressed vitality is generally the cause (as well as a consequence) of pain. Hence the pleasurable nature of taking food, and the early education of an animal in the distinction between objects nutritive and non-nutritive.

It is well known, however, that food may be taken, and many or all other functions and acts be performed automatically, or in a state of unconsciousness. This is as much the ease with the highest powers of thought (as in unconscious cerebration) as with the humblest acts which satisfy bodily wants. The question then arises whether these acts may not arise in a state of unconscionsness. So far as our own self-knowledge goes, we would reply in the negative. All intellectual functions are produced by edncation, and education involves consciousness at every step. Other habitual and antomatic acts were originated consciously, but the contiguity of parts of the act becoming impressed on the brain, future repetitions of it are reflex or uneonscious. We have seen that the development of the habits of animals is in strict obedience to the preference for pleasure and avoidance of pain. Pleasures and pains of course express sensations which involve consciousness. It then appears to me that, in the lowest animal, consciousness must be present at the time of origin of every habit, but that it may have been soon lost in each case, and the habit become automatic.

If this position be true, every subsequent addition to or change of habits must have been accompanied by a resuscitation of con- 
sciousness. But how is consciousness aroused in the cases which we can investigate-that is, in our own species? In the common case of sleep, a mere sound is sufficient to cause its return. In syncope and other forms of loss of conscionsness, a sudden shock, as of cold water thrown on the face, will often restore it. In ordinary states, compulsion or pressure will produce a more intense degree of consciousness. Indeed, in many per'sons consciousness varies greatly under different influences; thus a dreamy state naturally follows a lack of nutrition of the brain, as during a fast, but the mind is readily aroused from it by a strong or sudden impression made on the senses or by an effort of will. It is, hence, to be believed that in animals whose acts may be largely automatic consciousness is aroused by exceptional sights, sounds, hunger, and other sensible impressions, the more readily in proportion to the development of the sensory ganglia of the brain. In the lowest animals, consciousness will be aroused with much greater difficulty, and life must be in part a blank, and in part a dream, at rare intervals illumined by gleams of consciousness produced under the influence of strong external stimulns. At these times of awakening we must believe that new movements are instituted, which will become habitual in proportion to the extent to which they are repeated.

From what is known of reflex actions, it is evident that movements may become habitual, and hence automatic, wherever cellular or gray nerve-substance exists. Thus, movements instigated by the spinal nerves derive their automatism from the spinal medulla. This axis no doubt derived the original nerve-force from the brain, but repetition of the act under the original stimulus confers the antomatic power on the spinal cord or ganglionic center as certainly as on the brain. This must of necessity follow the complication of nervous structures by addition to the original center. Thus are explained the antomatic movements of the frog's or centipede's legs in the well-known experiments, when separated from the brain or principal nervous center.

Greater difficulties are experienced in accounting for the origin of the automatic movements of plants. It is evident, however, that many of these, perhaps all, are not due to the energy of motive-force, but are phenomena of growth-force alone. Motion is produced by the change of direction imparted to growth-force by the influence of heat, light, contact, etc. This will largely follow as a consequence of the longer persistence of growth in plants 
than in animals. In some of the rery lowest plonts morement would seem to be similar to that seen in the lowest animals. 'The origin of intelligence is then to be found in the first traces of consciousness. But inquiry will go further in the search for truth. One school of physiologists believes conscionsness to be due to certain molecular changes of nerve (i. e., brain) substance. No doubt. these are essential to conscionsness; jet it is, at lcast, utterly inconceivable that any molecular condition should be capable of recognizing either pleasure or pain. Here we find the first appearance of the "feelings," that part of the human mind which deserves to be called, par excellence, "the soul," and which is the "locator" of all the forces which go to build up the tissues, organs, and parts of the body; and hence the organic type of the intelleet and even of the will. For if we find growth-foree to be a correlative of physical foree, and subject to motive-force for its "location," so, while we find that motive-force is in like manner but another equivalent of ordinary force, we find it also subordinate to this principle which "locates" it.

\section{\%. On Intelligent Selection.}

We will now retrace our steps along the line of causes and effects, and see, if possible, the nature and results of "intelligent selection."

Protoplasm, homogencous or cellular, discharges a force called "motive-force," or neurism, which it converts from surrounding forces by virtue of its molecular (chemical) or atomic constitution. Its spontaneous exhibitions as movements bring it into contact with surrounding objects, when, if sufficiently sensitire to impressions, consciousness of a pleasurable or painful character is aroused. Then in proportion to its sensitiveness, and the strength of the impression, the protoplasm retains the latter in an unconscious way, and, on the subsequent recurrence of the object to the consciousness, the pleasurable or painful attribute is also revired by the law of "contiguity." The "vital principle" interfering restrains the motive-force from exereise toward it, if it be painful, or releases it for motion toward it, if it be pleasurable. This quality of the vital principle is a power of ehoice, and, in so far as consciously exercised, is will. * Nothing is better known than that acts originated consciously may, by repetition,

* For further development of this subject see Part IV of this book. 
come to be exercised unconsciously, or as habits. The form these habits take, will depend on the opportunities and conditions offered, for instance, in the matter of food, by the surrounding order of things. Motive-force is, of course, only another name for effort and use; the former being a putting forth by means of conducting material or organs, without exccutive apparatus; the latter always requiring organs or parts by which to execute.

If, as previously assumed, effort and use locate growth-force, cellular structure will appear in the directions indicated by the activity of motive-force. It is converted by protoplasm from heat and ehemism, or one only of these. That it does not require differentiated "motive-force" as a source, is proved by the growth of plants, which have no motion proper.

Growth-force, by its "repetitive" action," creates organs. These at first will be extremely simple, but, as machines, at once increase the power of the animal to produce motive-force by conversion, whether the machine be a digestive apparatus for the appropriation of the material, or a mechanical one for the exercise of the force, the former necessarily preceding the latter in time.

With the increased power of assimilation (digestion) comes a larger amonnt of material for increased exhibition of growth-force, a part being burned or otherwise converted into the force, and a part remaining as the material from which the cells are constructed. In the latter part of the growth-period a cousiderable portion is usually consumed for motive-force.

In the history of the material environment, various changes of condition succeeded each other. Changes of level took place; waters were purified by precipitation of chemical compounds; fresh waters were established; the atmosphere deprived of various gases; new mineral, and especially vegetable, products took their appropriate places. All these offer a vast variety of food-supply and opportunity for the pleasurable discharge of motire-force, and, under the laws pointed out, efforts of animals were directed in rarious lines, as the conditions presented themselves. Thus executive organs were produced of varied character. Some acquired limbs and others wings for transportation from place to place. What a vast addition to their impressions must have been acquired by the first animals which could thus leave the place of their birth! How many new "contiguities" were established, and how

* See "Method of Creation," on the Law of Repetition. 
many new habits originated! Look again at the acquisition of teeth. From a soft uniform diet the animal no doubt gradually lcarned to appropriate hard substances, and what a world of experience and consequent habit must have been at once placed in its way!

These acquisitions are of coulse mental, and include both kinds of contiguity, viz., that of succession in time, and that of association through resemblance. Animals choose between objects chiefly in accordance with the first mode, but arc not lacking in the second quality. As an example of the latter, classification according to color is exhibited by some birds, which choose brightly colored objects and reject dull oncs-the Australian bower-bird, for instance.

As is well known to metaphysicians, these acquisitions lead to "predication" and "forcthought." Thus a hound becomes acquainted with the habit of a buck or rabbit in doubling, or in following a giren circuit. The recurrence of the chase recalls the habit in consequence of contiguity of the impression of the former pursuit of the animal and the course it took. The hound then supposes or "predicates" that the deer will repeat the course. We know that some do so from the fact that they have been observed to cut off the curves in the animal's track, or to station themselres at the point where the deer, for instance, will pass. In the second act forethought is also involved. The hound sacrifices the lesser pleasure of the chase for the greater one of securing the prey. In forethought, experience having taught which circumstance results in greater and which in less pleasure, action is restrained in the presence of the second for the sake of procuring the first. Thus in ants, immcdiate pleasure suggests a life of labor enough for present wants, and case for the remaining time; but the greater pleasure of existence during some time of scarcity has induced some of them to lay up a store, which has dereloped into the complcte protection against winter they display in cold climates.

In the cascs cited it is perfectly crident that the hound would never have learned to predicate had he not had limbs to bring him in contact (by pursuit) with the habits of the buck. Nor would the ant have learned to provide if it had not been furnished with the jaws necessary to the excaration of chambers and the carrying of food. And neither would have performed these mentil acts had they not possessed nervous centers capable of sensation, reten- 
tion, and classification. But the development of these qualities depended on the possession of the executive organs.

Thus intelligence of various degrees has resulted-first, from possession of executive organs; secondly, establishment of contiguities by their use; thirdly, from classifications based on contiguities.

There are two notable examples of the great advance in mental accomplishment inaugurated by the acquisition of an executive organ. The first is the acquisition of the hand by the monkey. Any one who has compared their manners with those of the species of unguiculate (clawed) animals-as, for example, the dogmust be struck by the immense advantage possessed by the former. To begin with, it renders the monkey an expert climber and catcher of moving objects. Then he greatly increases his habits of observation by the facility with which he brings objects before his eyes. The minuteness of his criticism is aided by his power of manipulating with his fingers. He learns the results of throwing. A cantious monkey, set on a strange animal or person, does not rush at them to bite like the dog, but takes the more refined method of throwing sticks and stones. In obtaining objects, if they be out of reach, a monkey uses a stick to draw them in with. In a Cebus capucinus, in my possession, a leather strap was preferred, and was thrown with great dexterity, and the object always secured by drawing it nearer in loops of the strap. If the strap were sometimes thrown out of reach, the mcnkey would use a stick or poker in order to obtain it again. All this would have been quite impossible withont a hand. This facility has not been lost on the intelligence of the monkeys. Their curiosity is proverbial, and no animal can compare with them as successful thicves; moving in bands, with watchers stationed, and taking pains to store their booty in their cheek-pouches while they have opportunity, and not wasting time in eating exclusively.

Another instance is that of man. Here the acquisition consisted of vocal organs capable of speech. Any means of communicating and recording thoughts had the stupendous consequence of rendering the acquisitions of one man or class of men the common property of all. Another consequence, equally important, is the preservation of successive races of men from the necessity of passing through the experiences of those that preceded them, and the enabling them to commence their intellectual life nearly where the other's left off. So great would necessarily 
De the location of activity in the brain, that its stages of growth would be the principal changes of structure to be witnessed in human history, together with those which should result from loss of growth-force in other regions by abstraction.

To return to the material aspect of the case. The discrimination between pleasure and pain locates motive-force, which is derived from without. Motion or use locates growth-force, also derived from withont, and thus produces organs ont of material derived from without. These organs diversify the directions of motion. From new movements arise new pleasures and pains, and motion is again "located" in its exhibitions in some particular directions, and restrained in others. These directions depend on external circumstances at the first. The determination of motion to certain lines locates growth-force in those lines, and new parts are prodnced, which are further executive organs and types of structure. We now repeat the circuit. New executire organs introdnce new contignities, the number depending on the general complication of the animal in connection with that of the organ, and new pleasures and pains result. The pleasures again determine activity, and, under the circumstances already mentioned, growth-force is again located.

In these facts lies the explanation of the principle of direction or location of executive structures abont the head, termed by Prof. Dana "cephalization." The increasing demands of intelligence locate growth-force round its organ, the brain, etc., while such location reacts by furnishing means of increased activity of mind.

These conjunctions of growth with executive capacity, constitute a class of "expression points"; points attained without leaps, and abandoned without abruptness, but constituting great steps of progress, pregnant with future results.

The part played by "intelligent selection" remains to be considered. I have heretofore spoken only of variation of types, and not dwelt on their persistence. 'This is a most important consideration, for most men see a great deal more of the latter than the former. Species present their characters intact for long periods, and many structural peculiarities hare had great ringe in time.

I recur to the origin of the "location of growth-forcc," i. e., the direction of motive-force. This is located by the appreciation of pleasure and pain. Now, every one knows that different ani- 
mals of the same species vary exceedingly in their sensitiveness to exterior influences; that is, they differ in the degree in which the same object affects their consciousness. That which excites one is unnoticed by another; what fills one with alarm scarcely rouses the attention of another. It is well known also that differences in the power of retention are to be found in the same species of animals. The variations in persistence of memory arc very great. While, therefore, one individual of a species will acquire a store of "contignities," another of the same will possess but few. In other words, the degree with which objects are impresed on the consciousness, and the degree with which they are returned to the consciousness, vary greatly in the same species. Here we have the basis for the origin of totally different unconscions habits and reflex actions, and consequent divergenees in the "location of growth-force."

Those in which these impressibilities are most highly developed will accumnlate mental acquisitions most rapidly; in other words, they will be the most intelligent of their species. While others follow the old routine of once acquired and then inherited habits, those in whom conseiousness most frequently reeognizes events will originate new acts and new habits.

Intelligence is a conservative principle, and always will direct effort and use into lines which will be beneficial to its possessor. Here we have the source of the fittest-i. e., addition of parts by increase and location of growth-force, directed by the influence of various kinds of compulsion in the lower, and intelligent option among higher animals.

Thus, intelligent ehoice, taking advantage of the successive evolution of physical conditions, may be regarded as the originator of the fittest, while natural selection is the tribunal to which all the results of accelerated growth are submitted. This preserves or destroys them, and determines the new joints of departure on which accelerated growth shall build.

If the above positions be true, we have here also the theory of the development of intelligence and of other metaphysical traits. In accordance with it, each trait appropriates from the material world the means of perpetuating its exhibitions by constructing its instruments. These react by furnishing increased means of exercise of these qualities, which have thus grown to their full expression in man. 
II.

\section{ON THE ORIGIN OF GENERA.}

Introduction. - The present fragmentary essay is a portion of what other occupation has prevented the anthor from completing. It does not, therefore, amount to a eomplete demonstration of the points in question, but it is hoped that it may aid some in a classification of facts with a reference to their signification. When all the vast array of facts in possession of the many more learned than the writer are so arranged, a demonstration of the origin of species may be looked for somewhere in the direction here attempted to be followed.

Conelnsions of any kind will seareely be reached, either by anatomists who neglect specific and generie characters, or, secondly, by systematists who in like manner neglect internal structure. Such will never perceive the system of nature.*

ANALYSIS OF THE SCBJECT.

I. Relations of allied genera.

First : in adult age.

Second : in relation to their development.

$\alpha$. On exact parallelism.

$\beta$. On inexact or remote parallelism.

$\gamma$. On parallelism in higher groups.

$\delta$. On the extent of parallelisms.

II. Of retardation and acceleration in generic eharacters.

First: metamorphoses in adult age.

a. The developmental relations of generic and specific characters.

* It might seem ineredible that either class should systematize with confitence, yet a justly estecined author writes even at the present dap, "Iowerer, there is scareely a systematist of the present day who does not pay more or less attention to anatomical charaeters, in establishing the ligher groups!" (The italics are our own.) As though a system were of any value which is not based on the whole struct$w e$, and as though lower groups were only visible in extemal characters; in a word, as though external (muco-dermal, dental, ete.) charaeter's were not "anatomical"! 


\section{$\beta$. Probable cases of transition.}

$\gamma$. Ascertained cases of transition.

Second : earlier metamorphoses.

$\delta$. The origin of inexact parallelisms.

III. Relations of higher groups.

a. Of homologous groups.

$\beta$. Of heterology.

$\gamma$. Of mimetic analogy.

IV. Of natural selection.

a. As affecting class and ordinal characters.

$\beta$. As affecting family characters.

$\gamma$. As affecting generic characters.

$\delta$. As affecting specific characters.

є. On metaphysical species.

$V$. Of cpochal relations.

The laws which have regulated the successive creation of organic beings will be found to be of two kinds, as it appears to the writer. The first, that which has impelled matter to produce numberless nltimate types from common origins; second, that which expresses the mode or manner in which this first law has executed its course, from its commencement to its determined end, in the many cases before us.

That a descent, with modifications, has progressed from the beginning of the creation, is exceedingly probable. The best enumerations of facts and arguments in its favor are those of Darwin, as given in his various important works, "The Origin of Species," etc. There are, however, some views respecting the laws of development on which he does not dwell, and which it is proposed here to point ont.

In the first place, it is an undoubted fact that the origin of genera is a more distinct subject from the origin of species than has been supposed.

A descent with modification involves continuous series of organic types through one or many geologic ages, and the co-existence of such parts of such various series at one time as the law of mutual adaptation may permit.

These series, as now found, are of two kinds: the uninterrupted line of specific, and the same uninterrupted line of generic characters. 'These are independent of each other, and have not, it appears to the writer, been developed pari passu. As a general 
law, it is proposed to render highly probable that the same specific form has existed through a succession of genera, and perhaps in different epochs of geologic time.

With regard to the first law of development, as abore proposed, no one has found means of discorering it, and perhaps no one erer will. It would answer such questions as this: What necessary coincidence of forces has resulted in the terminus of the series of fishes in the perches as its most specialized extreme; or, of the Batrachia, in the fresh-water frogs as its ultimum; or, of the thrushes, among birds, as their highest extreme: in a word, what necessity resulted in man as the crown of the mammalian series, instead of some other organic type? Our only answer and law for these questions must be, the will of the Creator.

The second law, of modes and meaus, has been represented to be that of natural selection, by Darwin. This is, in brief, that a disposition to a general variation on the part of species has been met by the greater or less adaptation of the results of such variation to the varying necessities of their respective situations. That the result of such conflict has been the extinction of those types that are not adapted to their immediate or changed conditions, and the preservation of those that are.

In determining those characters of plants and animals which constitute them what they are, we hare, among others of higher import, those which constitute them species and those which constitute them genera. What we propose is: that, of the latter, comparatively very few in the whole range of animals and plants are adaptations to external needs or forces, and of the former a large proportion are of the same kind. How, then, could they owe their existence to a process regulated by adaptation?

Darwin is aware of these facts to some degree, but, as alleady said, he does not dwell on them. Where he does, he does not attempt to account for them on the principle of natural selection.

There are, it appears to us, two laws of means and modes of development: I. The law of acceleration and retardation. II. The law of natural selection.

It is my purpose to show that these propositions are distinct. and not one a part of the other : in brief, that, while natural selection operates by the "preservation of the fittest," retardation and aceeleration act without any reference to "fitness" at all; that, instead of being controlled by fitness, it is the controller of fitness. Perhaps all the characteristics supposed to mark generalized groups 
from genera up (excepting, perhaps, families) have been evolved moler the first mode, combined with some intervention of the second, and that specific characters or species have been evolved by a combination of a lesser degree of the tirst with a greater degree of the second mode.

I propose to bring forward some facts and propositions in the present essay illustrative of the first mode.

\section{ON THE RELATIONS OF NEARLY ALLIED GENERA.}

First. The writer's views of the relations of genera have already been given at the close of an "Essay on the Cyprinoid Fishes of Pennsylvania." It is easy enongh to define isolated genera which have few immediate affines; but among extensive series of related forms the case is different. One primeiple, however, pervades the conception and practice of all zoölogists and botanists, which few take pains to analyze or explain. It is simply that they observe a successional relation of gronps, by which they pass from one type of structure to one or several other types, and the presence or absence of the steps in this succession they regard as definitions of the genera.

It is true that the reader will often find introdnced into cliagnoses of genera characters which indieate nothing of this sort. It is often necessary, indeed, to introdnce characters which are not peculiar to the genus characterized, for the sake of distingnishing it from similar ones of other series, but this only in an imperfect state of the record. Moreover, the ability of the writer to distinguish genera being thus tested, he too often fails by introducing family and specific characters, or by indnlging in an unnecessary redundancy. In general, it may be said that adjacent genera of the same series differ from each other by but a single character; and, generally, that the more remote differ by characters as numerons as the stages of their remove.

It is precisely as, among the inorganic elements, we pass from the electro-negative, non-oxidizing extreme of the halogens, with fluorine as the extreme, to the electro-positive, violently oxidizing extreme of the alkaline metals, whose extreme is potassium, by steps whose relative position is measured or determined first by these tests; and as these steps have each their included, series of

* "Trans. Amer. Philos. Soc.," 1866, from "Proc. Acad. Nat. Sci.," Phil., 1859, p. 332 . 
bodies, characterized by their successive relations on the lorer level of a subordinate range of characters. 'This principle is distinctly admitted by many zoölogists, * those who deny it generally failing to perceive it because they attempt to gange a major scale by characters which are really the test of one or all of the subordinate or included scales. It holds true of most of the gromps of organic beings; thus the class is a scale of orders, the order of tribes. I will not now say that the tribe is a scale of families, as the case is here much modified; but what is chicfly to be considcred in this essay is, that the family is composed of one or several scales of genera.

Second. Now, the more nearly allied genera are, the more surely will these generic steps be found to fall into the direct line of the steps of the development of the highest, or that with the longest scale, the former being truly identical with the latter in generic character's. Less allied genera will offer an inexact or incomplete imitation of such identity-some additional character being present to disturb it. Such genus belongs to another series, characterized by the disturbing feature, whose members, however, bear to each other the relation claimed above ior such.

The relation of genera, which are simply steps in one and the same line of development, may be called exact paralletism, while that of those where one or more characters intervene in the maturity of either the lower or higher genus, to destroy identity, may be called incomplete parallelism.

The latter relation has been dwelt on by von Baer, Agassiz, and other writers, but none have accepted the existence of exact parallelism, or seen its important relation to the origin of genera.

Third. That the lowest or most generalized terms or genera of a number of allied series will stand to each other in a relation of exact parallelism. 'That is, if we trace each series of a number, up to its lowest or most generalized genus, the latter together will form a series, similar in kind to each of the sub-series; i. e., each genus will be identical with the undeveloped conditions of that which progresses the farthest, in respect, of conrse, to the characters which define it as a series.

Those characters of the skeleton which we are accustomed to call embryonic are only so because they relate to the develop-

* Prof. Bronn, in his "Classen ". Orinungen des Thierreiches," has everywhere a chapter on "Die aufsteigende Reihe" ("the ascending scale"). 
mental succession witnessed in animals at the present time. Characters not so called now were probably as much so at one period now passed. Hence embryonic characters of the bony system do not, as I have often had occasion to observe, characterize the types of the highest rank, but only subordinate divisions of them. Thus the elasmobranchs are probably repressed forms of groups of a really higher grade than the bony fishes, or teleostei, which may be known to us. In their early presence in the geologic series we have evidence of the first beginning of a higher type.

In the same manner it has been discorered that the molecular aggregation of the elementary substances does not characterize their highest or most distinct series, but rather the substances themselves within the group or family to which they belong. The gaseons, liquid, and solid molecnlar conditions, being characters distinguishing otherwise allied substances in the same way morphologically (we can not say yet developmentally), as the cartilaginous, osseons, and exostosed or dermosseous characters distinguish otherwise nearly allied genera.

The "family" group embraces one or many of such series. If we trace the series in several families to their simplest or most generalized terms or genera, and compare them, we will not find the relation to be one of exact parallelism in the series of the "order," so far as our present knowledge extends, but, in a developmental sense, one of divergence from the commencement.

If we could know the simplest known terms or family characters of a number of groups of families, or "order's," we wonld probably find them to represent a series of exact parallelism, though to find such simplest terms we must go far into past periods, since the higher the group the more extensive the range of its character, and the less likely to be found ummixed with additions and extensions, in modern times.

Finally, the series of classes is in the relation of the essential characters of the same, as expressed in their now extinet, most generalized and simple representatives, also one of "exact parallelism."

\section{a. Examples of Exact Parallelism.*}

1. As an example we may take the genus Trachycephalus (Batrachia anura). Nearly allied to it is the genus Osteo- 
cephalus, which differs in the normal exostosis of the cranium not inrolving the derm, as in the former. Close to this is Scytopis, where the fully ossified cranium is not covered by an exostosis. Next below Scytopis is Hyla, where the upper surface of the cranium is not ossified at all, but is a membranous roof over a great fontanelle. Still more imperfect is Hylella,* which differs from Hyla in the absence of romerine teeth. Now, the genus Trachycephalus, after losing its tail and branchiæ, possesses all the characters possessed by the genera Hylella and Hyla, either at or just before the mature state of the latter, as the ethmoid bone is not always ossified in advance of the parietals. It soon, howerer, becomes a Scytopis, next an Osteocephalus, and finally a Trachycephalus. It belongs successively to these genera, for an exhaustive anatomical examination has failed to reveal any characters by which, during these stages, it could be distinguished from these genera.

Now, it would be a false comparison to say that the young of Trachycephalus was identical with the genus Agalychnis, which in truth it resembles, because that genus is furnished with one other character-the presence of a vertical pupil-and belongs to another series in consequence, which is represented as jet, with our present imperfect knowledge-or perhaps imperfect faunaby three genera only.

2. The lowest type of the near allies of our common freshwater frogs is the genus Ranula, where the prefrontal bones are narrow strips on each side the ethmoid cartilage; the ethmoid cartilage itself entirely unossified above, and the romerine teeth very few and on a small elevation. There are two species, $R$. affinis and R.palmipes. $\dagger$ The other species hare the etlimoid cartilage ossified abore, at least beneath the extremities of the frontoparietals.

'Those of the latter most like Ranula possess the same type of narrow prefrontals, separated by a broad area of cartilaginous ethmoid, and fasciculi of teeth. Of this type is Rana delalandii, and probably $R$. porosissima, Steind., of the South Ethiopian region. Other species of the same type extend their vomerine patches into lines; such are $R$. mascariensis, $R$. fasciata, $R$. oxyrhynchus, R. grayi, and other South African species.

* I refer to H. carnca $m$, not having Reinhardt and Lütken's type of this genus.

$\uparrow$ These species are now beliered to be identical, but three others have been dis. covered (1856). 
The prefrontals are subtriangular, and approach each other more or less in the numerous species of North America and of the Regio Palæarctica, while generally the vomerine teeth are in fascicles or very short serjes. In the Ethiopian Rana fuscigula the prefrontals unite on the median line, roofing over the ethmoid cartilage and reducing it, while the vomerine teeth are in very short lines.

In the species of the Palæotropical region, Rana tigrina, $R$. vittigera, $R$. cyanophlyctis, $R$. grunniens, $R$. hexadactyla, $R$. corrugata, $R$. ehrenbergii, $R$. gracilis, and the Ethiopian $R$. occipitalis, the prefrontals not only unite solidly (the suture remaining on the median line), but extend and closely fit to the frontoparietals. The vomerine patches have lengthened ont into series.

Now, the young of the latter type of Rana (I take as an example the $R$. tigrina, one of the most abundant and largest of Indian frogs) presents the subtriangular prefrontals neither in contact with each other or with the frontoparietals, and the vomerine series is much reduced; in fact, it belongs in all respects to the Palæarctic group. I have not examined younger specimens, but have no doubt they are like those of the Palæarctic; which are, in their young stage, precisely of the type of the Ethiopian Rana, with fasciculate teeth like the young of those of the same region with teeth in series, since the prefrontals are still more reduced, becoming linear. Finally, the first stage of the Nearctic Rana, after losing the larval tail, is the genus Ranula, having linear prefrontals, minute vomerine teeth, and the ethmoid ring cartilaginons above.

These points of structme are of generic quality, but I have not regarded any group as sufficiently defined to be so regarded, except Ranula, as the adults of some species appear not to be constant in possessing them. Thins a very large Rana catesbeyana sometimes exhibits prefrontals in contact on the median line, while it is difficult to say whether $R$. areolate of North America is of the Nearctic type so much as of the Athiopian. Nevertheless, the groups are generally quite geographically restricted.

3. A similar relation exists between the genera Hyperolius, Staurois, and Heteroglossa in respect to the prefrontal bones and the separation of the outer metatarsi, and--

4. Between Ixalus, Rhacophorus, and Polypedates also, in reference to vomerine teeth, bifurcation of last phalange, and dermoössification of the craninm. 
5. When the larvæ of certain salamander's (Spelerpes) possess branchix, they also lack one digit of the hind foot, also the maxillary, nasal, and prefrontal bones, and exhibit a broald continuous palatopterygoid arch, in close contact with the parasphenoid. The proötic is separated from the exoccipital by a mombranous space, and the exoccipitals themselves are not yet mited abore the foramen magnum. There is at the same time a scrics of splenial teeth. Both ceratohyals are confluent, the posterior is present, and there are but three supcrior hyoid arches. After they lose the branchix, the hinder foot, which has four toes only for a time, gradually adds another at first rudimental digit, in the Mexican species; in most North American species the fifth digit appears at an early larval stage. Five digits are finally present in all Spelcrpes.

We have thus four combinations of the above characters, at different periods of the life history of certain (but not of all) of the species of Spelerpes. There exist four permanent series of species or genera, equivalent to these stages. The well-known "perennibranchiate" Necturus is nearly identical with the first, Batrachoseps with the second, the half-toed Spelerpes with the third, and the typical Spelerpes is the last.

In one character of generic value only do I find that Necturus differs from the early larval Spelerpes. It closes the premaxillary fontanelle with which it commences, by an approximation of the premaxillary spines, but not by a sutural union, as takes place in Amblystoma. It thus, in this one point, advances a stage beyond the condition to which Spelerpes attains, though it may be a question whether such a closure without union should not be classcd among the specific characters by which $N$. maculatus differs from the young of the various Spelerpes, as they do from each other. Characters of the latter kind are the following: in $N$. maculatus the frontals are more deeply emarginate behind; it has little or no ala on the inferior keel of the candill vertebræ, which is prominent in Spelerpes larvæ.

It may be that the parallelism in the case of Spelerpes is inexact by one character, and that a strictly derelopmental one; or it may be regarded otherwise. *

6. It is well known that the Cervida of the Old World derel-

* Necturus differs from these larve by another and more important character, viz., the presenee of the 03 interealare. 
op a basal snag of the antler (see Cuvier, "Ossem. Fossiles"; (Gray, "Catal. Brit. Mus.") at the third year" a majority of those of the New World (genera Cariacus, Subulo) never develop it except in "abnormal" cases in the most vigorous maturity of the most northern Cariacus (C. virginianus); while the South American Subulo retains to adult age the simple horn of the second year of Cervus.

Among the higher Cervidæ, Rusa and Axis never assume characters beyond an equivalent of the fourth year of Cervus. In Dama the characters are on the other hand assumed more rapidly than in Cervus, its third year corresponding to the fourth of the latter, and the development in after years of a broad plate of bone, with points, being substituted for the addition of the corresponding snags, thus commencing another series.

Returning to the American deer, we have Blastocerus, whose antlers are identical with those of the fourth year of Cariacus.

Now, individuals of the genus Cerrus of the second year do not belong to Subulo, because they have not as yet their mature dentition. Rusa, however, is identical with those Cervi whose dentition is complete before they gain the antlers of the fifth year. When the first trace of a snag appears on one beam of Cariacus virginianus, the dentition inchdes the full number, but there remain $\frac{1}{3}$ milk molars much worn and ready to be shed. Perhaps the snag is dereloped before these are displaced. If so, the Cariacus is never a Subulo, but there can be little doubt that the young Blastocerus belongs to that genus before its adnlt characters appear.

\%. Leidy states * that certain Perissodactyl remains, containing a foot of a horse, contained the teeth of a genus, Protohippus, which has the permanent teeth of Equns, and the deciduous dentition of Anchitherium. He observes: "The deciduous and permanent dentitions of both these genera are alike; therefore the new genus is in early life an Anchitherinm, and later in life a true horse." This is therefore a case of exact parallelism, always providing that the Protohippus has not added to its immature equine characters others in other parts of the body, which invalidate the identity. In the latter case it will still be an interesting exanple of the "inexact parallelism." $†$

* "Proceed. Acad. Nat. Sci.," 1858, p. 7.

$\uparrow$ This is not a proper example of parallelism if, as some zoölogists believe, the 
8. It is well known that the Cephalopoda form a number of series of remarkable regularity, the advance being, in the first place, in the complication of the folds of the external margins of the septa, and, in the second place, in the degree of involution of one or both extremities of the shell to the spiral; third, in the position of the siphon.

Alpheus Hyatt, in an important essay on this subject, * points out that the less complex forms are in many cases identieal with the undereloped conditions of the more complex. He says: "There is a direct conneetion between the position of a shell, in the completed cycle of the life of this order, and its own development. Those shells occupying the extremes of the cycle" (in time), "the polar forms, being more embryonic than the intermediate forms. $f$ The first epoch of the order is especially the era of rounded, and, in the majority of the species, of unornamented shells with simple septa; the second is the era of ornamentation, and the septa are steadily complicating; in the third the complication of the septa, the ornamentation, and the number of species, about twice that of any other epoch, all combine to make it the zenith of development in the order; the fourth is distinguishable from all the preceding as the era of retrogression in the form, and partially in the septa.

"The four periods of the individual are similarly arranged, and have comparable characteristics. As has been previously stated, the first is rounded and smooth, with simple septa; the second tuberculated, and the septa more complieated; the third was the only one in which the septa, form, and ornamentation simultaneousty attained the climax of individual complication;

deciduous or temporary dentition is not a remnant of the primitire dentition, but is a later product of mammalian evolution. If it be a case of parallelism, it is inexact, because the genus Protohippus was discovered by the writer to have three toes, while Equus has but one.

* "Jicmoirs Boston Soc. Nat. IIist.," 1866, p. 193.

† He adds here: "Although in regard to geological sequence and structural po sition one of the extremes must be of higher geologieal rank." The "highest" extreme will be of higher geologieal rank, according to the complexity of structure and length of developmental seale, whether it come at the mildle or end of the history of the elass in time. If, as has been the ease, so fir as known, a decline has termi. nated the history of a class, its later forms are zoölogieally lorem than its older ones. Henee the adjectire high is only appropriate to tyjes of the latter lind, when used as synonymous with extreme. 
the fourth, wi:en amounting to anything more important than the loss of a few ornaments, was marked by a retrogression of the whorl to a more tabular aspect, and by the partial degradation of the septa."

I will here quote an entirely antagonistic statement of Bronn's, " as follows: "In the development of lamellibranchiate mollusks it is not possible to estimate the successional changes of one genus by those of another, though nearly related; so diverse are the most significant relations in the manner of progress among nearest allies. 'Therefore, embryologic indications are throughout useless in classification, and it is necessary to keep carefully separate the statements of observations on development of a given species, and not transfer such facts to the history of another species for the purpose of completing it. We can not even range these histories in conformity with family groups." For us this statement, though no doubt largely true, is an indication of imperfection-first, of knowledge of true affinities of recent, but especially of extinct adults, and, second, of imperfection of knowledge of development. The position appears to be based on negative evidence, while the opposing can and does stand on nothing but positive.

\section{B. Examples of the Inexact Parallelism.}

1. The genera of the batrachian family Seaphiopodidæ form a series of steps differing a little more than as repressions or permanent primary conditions in the development of the highest. $\uparrow$ Thus two of the genera, which are North American, maintain their tubæ enstachii and tympanum through life, while three European lose them at an early period. $f$ The three European genera also advance beyond the larval character of the American in the ossification of the basis of the xiphisternum into a broad style. Thus we have two series established, which differ only in the two characters named. Each shows its developmental steps in a similar manner, the European series extending further ; thus :

* "Classen 1. Ordnungen des Thierreiehs," iii, p. 445.

+ See "Journal Aeademy," Philadelphia, 1866, on Areifera.

$\$$ Aceording to Bruch and Tseluudi, in Pelobates. I have found traces of the eustachian diverticula, in a tailed Pelobates fuseus, whose body measured 1 in. 4 lin., from Mus. Peabody Institute, Salem, Mass. 


\section{European.}

1. Temporal fossa over arched.

Cultripes.

Temporal roof not ossified.

2. Fronto-parietal bones ossified, involving derm.

\section{Pelobates.}

3. Fronto-parietals ossified, äistinct from derm.

$$
\text { * }
$$

$*$

(Unknown.)

4. Fronto-parietals not ossified, distinct from derm.

Didocus.
In this case Didocus can not be said to be identical as a genus

North American.

米

$*$

Scaphiopus.

*

$*$ with an undeveloped stage of Cultripes, since, while the cranium of the latter is in the condition of Didocus, it bears a long tail, and the limbs are but little developed. Nor is Didlocus identical with the undereloped condition of Pelobates, since both cranium and limbs of the latter are developed before the tail is absorbed. Nor is Pelobates identical with the undeveloped condition of $\mathrm{Cul}$ tripes, since, while the cranium of the latter is that of the former, the limbs and tail are still larval. The same relations exist between the other members of the family. The genus Scaphiopus is not an undeveloped form of Pelobates as to its anditory organs, for, when the latter is identical with the former in this respect, it bears otherwise entirely larval characters. Nor is Spen an arrested Scaphiopus, the relation being here precisely that between Didocus and Pelobates. Spea approaches more closely an arrested Didocus in all respects, but that when the latter possesses the auditory appirratus * of the former, it is a larva in limbs and tail, and that it loses this apparatus before reaching the other characters of Spea. The relations of these genera, as compared with those of the Trachycephalus, Cystignathidr, and Bufo series, may be represented as follows: the lines represent the developmental scale of each.

This is an example of the simplest case of incxact parallelism. as distinguished from the exact parallelism or identity. As the fauna of the present period is but a fragment, so the simple incx-

* The posscssion of cavum tympani and tuba Eustachii in the meleveloped condition of this genus is only assumed from its close relation to Pelubates. 
Relations between the terms of the different series, Heterology or Remote Parallelism.
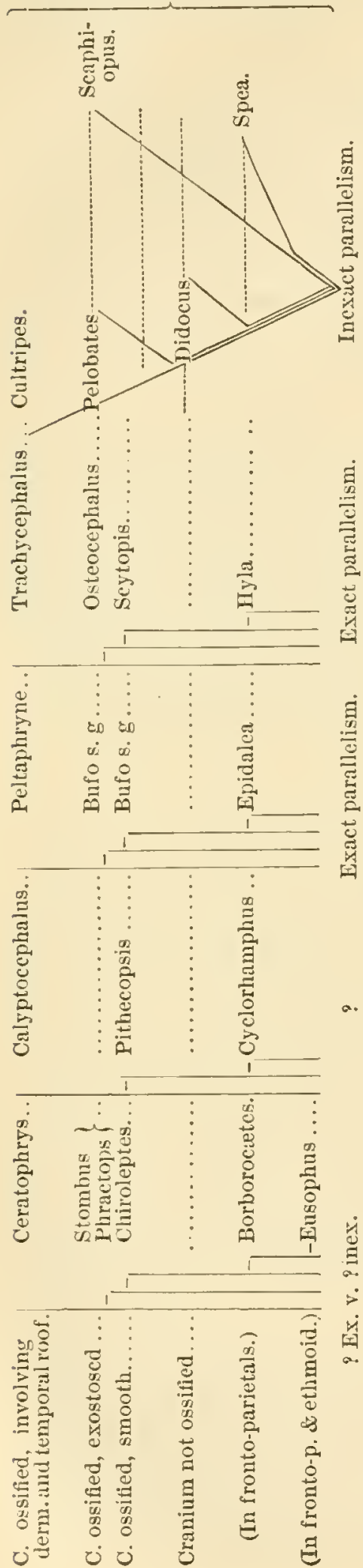

act is a more frequeut relation than the exact, while the more complex inexact relation is still more common. The greater the inexactitude, the more frequently do such parallels occur till we have those of the most remote character, as, for instance, the parallelism between the different stages of the development of the mammal, in the structure of the heart and origins of the aorta, and the existing classes of vertebrates. The relation of these facts to the origin of genera will be noted hereafter.

It will be borne in mind that in the Scaphiopodida the generic types are identical for a long portion of their developmental history. (See figures on plate iv for the representation of these facts.)

2. In both Perissodactylous and Artiodactylous Mammalia, certain types develop their family character of canines at the earliest appearance of dentition, other's not till a comparatively late period of life (Equus), and the extreme individuals never produce them.

3. Among cetaceans the genus Orca maintains a powerful and permanent series of teeth, which is an important generic eharacter. In Belnga the series is shed in old age, in Globiocephalus, or the Caing whales, they are shed at middle age, while in the Balænidæ, of which the absence of teeth is an essential character, these organs are developed and absorbed during foetal life (Eschricht). Thongh the condition of the teeth is not of systematic value in the two named intermediate genera, it is the important feature in the history of progress to such value. 
4. Among the tortoises, the Testudinidre rapidly extend the ribs into a carapace, which fits closely the marginal bones, while equally early in life the elements of the sternum unite together. This is also the case with most Emydidæ; among whose genera, however, we find the trimsitional seale. In Dermatemys and Batagur the carapace is rery late in attaining its complete ossification, while the plastron is early finished. In Chelydra, on the other hand, while the carapace is eren more slowly developed, the plastron is nerer free from its larral fontanelles. In the marine turtles neither plastron nor carapace is ever completed, while in the Trionychidx the marginal bones are also entirely undereloped.

In order that this last illustration be a true one for the theory in question, as applied to the families, these developmental characters should be the true distinctice features of these families respectively. This, as is well known, they are not. The Cheloniidæ are characterized by the form of their anterior limbs, which is in an adaptive strueture, while the Testudinidx similarly are distinguished by an extreme opposite modification of foot-structure, adapted to an extreme difference of habit. Here there is an example of the co-working of both liws. Nevertheless, we only claim at present to show the developmental relation of genera of the same family and the same series. This we see among the Emydidie.

5. In the important character of the scutellation of the tarsi among the Passerine birds, the "boot" appear's early in life in the highest Oscines, later in the lower, and does not appear at all in the majority. In respect to the still more important feature of the long posterior plates which appear very early in most Oscines, in the Myiadestes type * they appear late, the squamæ remaining long, while the Clamatores nerer develop the plates, not advaucing beyond the infantile squamous stage.

6. It has been shown by Falconer that the genera of great Proboscidians form a remarkably regular and graded series, distinguished by their dentition. These are Dinotherimm Kanp, 'Trilophodon Falc., Mastodon Cuv., Pentalophodon Fale., Stegodon Falc., Loxodon F. Cnv., and Elephas Linn. In the first there are but two cross crests on the third molars, and a pair of permanent mandibular tusks; in the seeond, three cross erests

* Baird, "Review of Birds of North America." 
and mandibular tusks permanent in some males; in the third, four cross crests and the mandibular tusks variable; in the fourth, five cross crests on the third molar; tusks unknown. In Stegodon the mandibular tusks cease to appear, the crests of the third molar become more numerous, and embrace between them, in the bottoms of the valleys, a strong deposit of cementum. In Loxodon the erests have the whole interspaces filled with cementum, while the same thing holds in Elephas, with a greatly increased number of cross crests, which become vertical laminæ. The laminar character has become apparent from its rudimental condition in Stegodon.

Now, these are stages of development, thongh not in a continuous, single line. The shedding of the inferior tusks takes place earlier and earlier in the genera from Dinotherium, till they never appear in Stegodon. The molar teeth, it is well known, present, as they succeed each other from back to front, a regularly increasing number of transverse crests in the same species. Thus, in Tritophodon ohioticus the first molar presents but two, while the last presents six. The last molars of other genera present a very much increased number. What is it, then, but that the increased number of erests in the third molar, definitive of these genera, is an acceleration of growth; the fourth in Trilophodon is structurally third in Mastodon, and the fourth of Mastodon being third in Pentalophodon; the fourth of Pentalophodon becoming third in Stegodon, and so to the end? This is confirmed from the proved fact of the disappearance of the premolars. They are fewer in Trilophodon than in Dinotherium, and are soon shed; they are also early shed in Mastodon and Stegodon (insignis Falc. Caut.), and are not known to exist in the succeeding types; the acceleration of succession of teeth has caused them to be entirely omitted. The young tooth of Elephas, moreover, is represented by a series of independent parallel laminæ at first, which, when they unite, form a series of erests similar to the type of the genus Mastodon and others of the beginning of the scries. The deposit of cementum takes place later, till the valleys are entirely filled up. Thus the relations of this part of the tooth-structure in the series are also those of the successional growth of those of Elephas, the extreme of the series.

It would be only necessary to show that two distinct conditions, in any of these respects, occurred among the different indi- 
viduals of the same species of any of these genera, to render a hypothesis of evolntion a demonstrated fact.*

It must be here observed that great size indicates little or nothing as to zoölogical rank. The greatest species are often not far removed in affinity from the least; thus there can be but little dombt that elephants are not far removed from the rodents, and the rhinoceros is near the cony. Indeed, in the same genus the most extraordinary diversity prevails, for we have a rery small elephant of Malta, and in the Miocene of Maryland a fin-back whale not so large as the new-born young of the fin-backs now living. Hence the objection to the developmental hypothesis, based on the great size of the primal Selachians and Ganoids, has but little weight.

7. Rathke has shown that the arteria ophthalmica of the higher Ophidians is originally a branch of the arteria cerebralis anterior, and that it later forms a connection with the arteria facialis. 'This connection increases in strength, while the other diminishes, until finally its supply of blood is derived from the facialis instead of the cerebralis.

Rathke has also shown that the cerebral origin of this artery is continued throngh life in the three lowest suborders of the serpents, the Scolecophidia, Catodonta, and Tortricina; also in the next suceeeding group, the Peropoda.

8. In most serpents the left lung is nerer developed; in such the pulmonary artery, instead of being totally wanting, remains as a posterior aorta bow, comnected with the aorta by a dnctus botalli; serpents without left lung being therefore identieal in this respect with the embryonic type of those in which that lung exists.

9. Dr. Lespes states that the optic region of the brain of blind cave Coleoptera, examined by him is similar in strueture to that in the blind larve of Coleoptera, whose imagos possess visual organs.

10. $\nmid$ 'Those Saurians (Uromastix, etc.), in which the premaxillary region is produced into a uniform cutting edge, are furnished during early stages with a series of premaxillary teeth, which become gradually fused and confluent with the alreolar margin. IIenee other Acrodonts are equivalent, in this respect,

* This variability has since been shown to exist in species of the M. anguestidens type (1886).

f See under section on Aeceleration and Retardation. 
to the young of Uromastix, etc. The same thing occurs among the Scaroid and Labroid fishes. In this most natural family we find the majority of generic forms provided with a normal complete dentition; in others (Chaerops, Xiphochilus, Psendodax, etc.) the lateral teeth are gradually and normally replaced by a more or less cutting edge of the mandible; and finally, in the Scarina and Odacina, the entire mass of teeth and jaws are coalesced, forming a beak with sharp cutting edges, the single teeth being still visible in the true Scarns, while they have entirely disappeared in adult Pseudoscarus and Odax. * Thus, in dentition, the adilt Scarus is identical with not fully developed Odax; Chaerops, with the teeth less confluent, equals a still younger stage of Odax, while those with distinct teeth are the same in this point as the embryos of the highest-Odax, etc. I venture to predict that here will be found a long series of exact parallelism, in which the different genera, resting exclnsively on these dental characters, will be found to be identical generically with the various stages of the successively most adranced.

11. Prof. Agassiz states that the absence of rentral fins is characteristic of an embryonic condition of the Cyprinodont fishes. The genns Orestias does not progress beyond this stage in this one point. Probably the genus will be found which will only differ from Orestias in the presence of ventral fins. If so, Orestias will be identical with an imperfect stage of that genus, if, as will probably be the case, the fins appear in the latter, after other structures are fully completed.

\section{$\gamma \gamma$. Parallelism in Higher Groups.}

It is not to be anticipated that the series of genera exhibiting exact parallelism can embrace many such terms, since comparatively few stages in the developmental condition of the same part, in the highest, would bring us back to a larval condition, which, as far as we yet know, has no exact parallel among existing genera. But it is to be believed that the lowest terms of a number of the most nearly allied of such series do of themselves form another series of exact parallelisms.

Thus exact parallelism between existing genera of mammals ceases, with all characters which are larval or foetal, only prior to

* Günther on Hatteria, "Philosophical Transactions," 1867, ii. I had already notieed the peculiar development in Uromastix, but not published it. 
the assumption of the arnlt dentition, since among the higher Mammalia at least we know of no genus which, however similar to undeveloped stages of the higher, never loses the milk dentition. It is nevertheless an important fact that among smooth-brained mammals, or many of them, but one tooth of the second series appears; and inasmuch as smooth-brained forms of the higher orders have become extinct, it is not too much to anticipate that a type of permanent milk dentition will be found among the extinct forms of the same high orders.

As an example of exact parallelisms in series of series, I select the following :

1. In the batrachian family Cystignathide there are six groups or sets of genera. In the highest of these we have an ossified cranium and xiphisternum-i. e., in the Cystignathi ; in the Pleurodemæ the cranium is not ossified, thus representing the Cystignathi while incomplete; in the Criniæ the xiphisternum is cartilaginous, as well as the fronto-parietal region, being an equivalent of a still lower stage of the Cystignathi. From this simplest type we can find a rising series by a different combination of characters; thus the Ceratophydes add an osseous cranium to the ineomplete xiphisternum, while two succeeding groups diverge from each other at the start, the Pseudes loosening the outer metatarsus in their development to maturity, while the Hylodes add by degrees a cross-limb to the last phalange. The Ceratophrydes and Crinix are stages in the development of these; but neither one of them is a step in the development of the other. They are measured by adaptive characters purely.

2. The whole suborder of the Anurous Batrachia, to which the above family belongs, the Areifera, differs from the suborace Raniformia by a charaeter which distinguishes a primary stage of growth of the latter from its fully dereloped form. 'That is, the Raniformia present, at one period of their development, a pair of parallel or over-Iapping curved cartilages, connecting the procorilcoid and coricoid bones, which subsequently unite and become a single, slender median, scarcely visible rod, while the bones named expand and meet. The first condition is the permanent and sole systematic character of the Arcifera.*

Objection. - It may be objected, by those who have observed

* This may be readily understood by comparing my monograph of the Arciferi, "Jour. Ae. Nat. Sci.," Phil., 1866, with Duges's work, or Gegenbaur and Parker's memoir on the Shoulder-Girdle. 
some of these developmental relations, that they are exhibited by certain single structures only, and not by whole organisms. These objectors must not forget that the distinetions of those groups, which alone we have in one geological period in a relation of near affinity, exists in single characters only; and that it is therefore infinitely probable that the higher groups, when we come to know their representatives with the same completeness, will prove to be separated by single characters of difference also.

3 . The following table (pages 63 to 73 ) is introduced to illustrate the relations of groups higher than the preceding. This is largely measured by the circulatory system, not only as to the class relations, but also as regards orders. In its less central portions it is, however, definitive of families at times.* (See also Plate I.)

If the reader will compare the history of the development of vertebrates of any class or order, as those of Teleosts and the lizard by Lereboullet, of the snake and tortoise by Rathke and $\Lambda$ gassiz, and of the bird and mammal by von Baer, he will find the most complete examples of the incxact parallclism of the lower types with the embryonic stages of the higher. A few points are selected as examples, from the histories included in a fow of the columns of the table, and given at its end.

Similar parallels may be found to exist in the most beautiful manner between the adult anatomy and structure of the urogenital apparatus within each class of the series taken separately, as indicating ordinal relationship. This department is, however, omitted for the present.

As an example of the homologies cierivable from the cirenlatory system, and of the use of the following table, I give the following relations between the types of the origins of the aorta. $t$

The single ventricle of Teleostei is no doubt homologons with that of Lepidostens, and that of Lepidosiren. 'The arteria vesicce

* This sketch is not nearly complete; but is published in hopes of its being useful to students. It is compiled from the works of Meckel, Rathke, Barkow, Müller, Iyrtl, Brücke, Stannius, and others, in connection with numerous dissections.

† Prof. Agassiz ("Contrib. Nat. Mist. U. S.," i, p. 295) states that the ventricle of the Testudinata "is not any more identical with the one ventricle of fishes than with the two ventricles of warm-blooded vertebrata; for in fishes we find only one vessel, the aorta, arising from it, while in turtles both the corta and arteria pulmonalis start together from it." We think this statement, which, if true, is destructive to the asserted homologies of the circulatory system, ean not be substantiated, for the reasons above given. 
PLATE I.
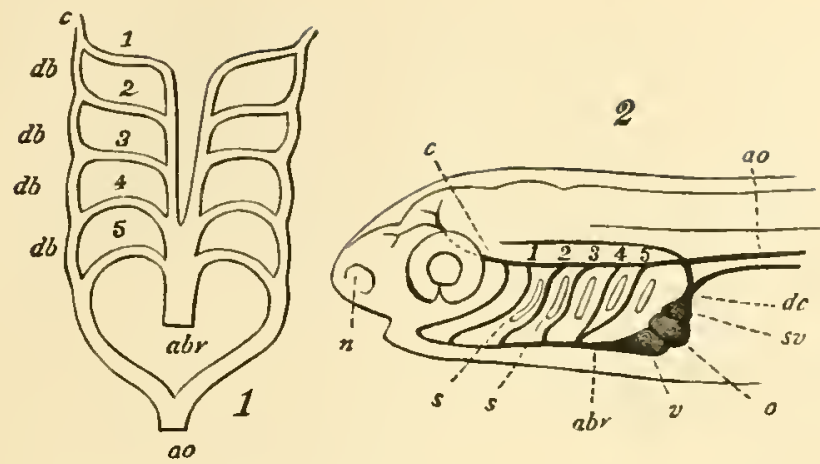
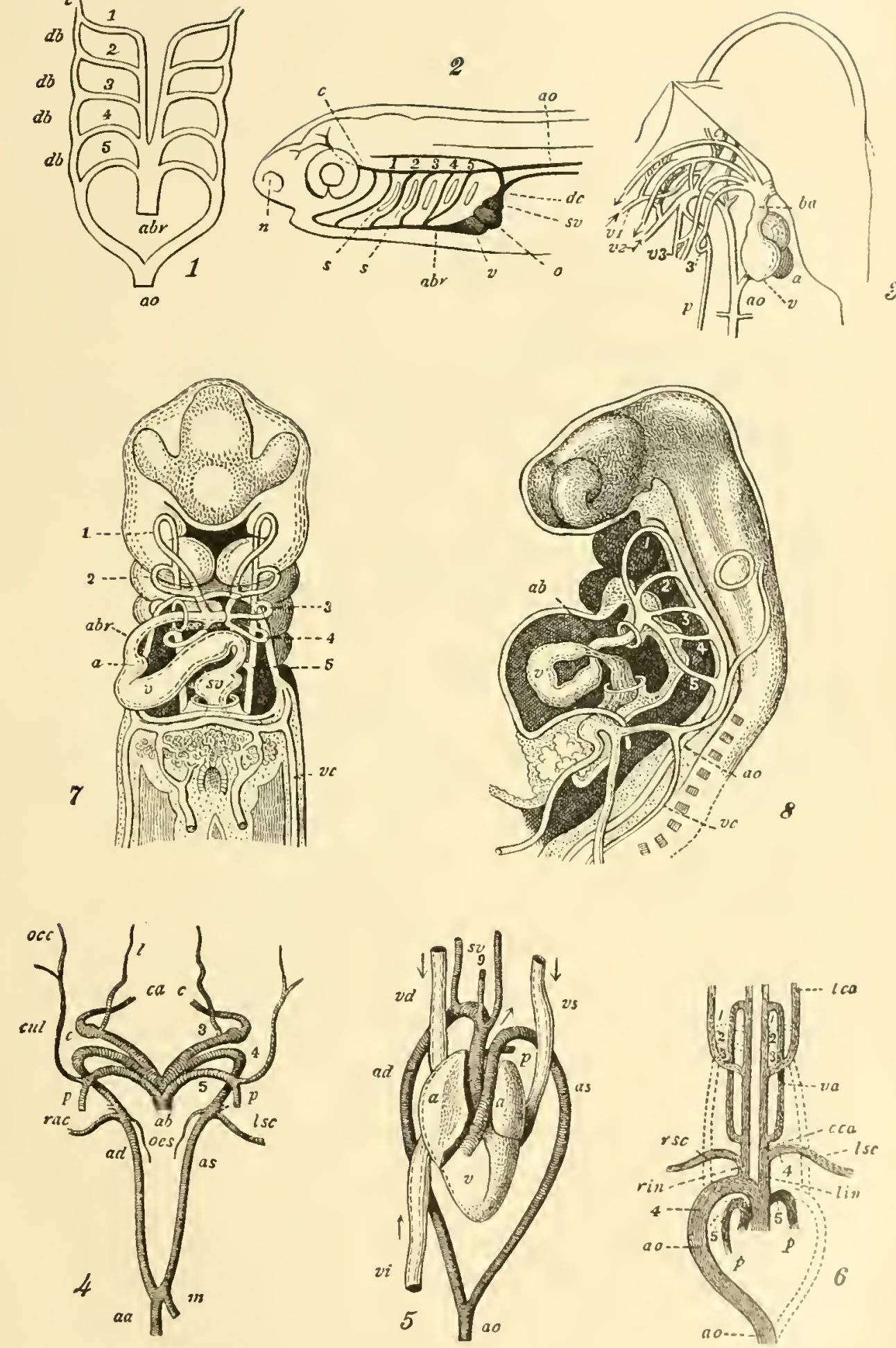

Central Circulatory Systear.

FIGs. 1, 2, fish. F1gs. 3, 4, batrachian. Fra. 5, reptile. F11. (6, bird.

Figs. $\imath$, 8, human fietus. 


\section{PLATE I.}

Figures and Diagrams of the cirenlatory centers of Vertebrata. Copied from Gegenbaur and His, mostly enlarged.

Fig. 1. Diagram of the arterial arelses of a Fish (species not given).

Fig. 2. Head of an embryonic Teleostean, with the rudiments of the vascular system (diagrammatic).

Fig. 3. Heart and arterial trunks of a larva of a Salamander.

FiG. 4. Arterial system of the Frogr.

Fig. 5 Heart and arteries of an Ophidian (Boa).

Fig. 6. Diagram of the arterial system of the adult Fowl.

Fig. 7. Central circulatory system of Man; foetus of the second month; front view.

FIG. 8. Same as Fig. 7, left side.

$v$, ventricle of heart.

$r$, auriele of heart.

$s v$, sinus venosus of heart.

$b a$, buibus arteriosus of heart.

$a b$, aorta branchialis.

$1,2,3,4,5$, arteria branchiales.

$v 1,2,3$, venæ branchiales.

ao, aorta.

$a d$, aorta dextra (right).

$a s$, aorta sinistra (left).

$P$, arteria pulmonalis.

$d b$, ductus botalli.

$c \alpha$, arteria carotis.

cca, common carotid.
Rsc, lsc, right and left subclavian arteries.

Rin, lin, riglit and left innominatearteries. cut, arteria cuticularis.

$o c c$, arteria oceipitalis.

$v c$, vena cardinalis.

$v d$, right vena cava.

$v s$, left vena cava.

vi, inferior (posterior) vena cara.

«'s, œsophageal artery.

$m$, mesenteric artery.

$s$, spiracular or bramchial fissure.

$n$, nostril.

de, ductus cuvieri.

l, lingual artery. 
natatoriae, which is the homologue of the A. putmonatis of airbreathers, issues in Lepidostens from the last vena branchicatis, thus receiving aërated blood from the gills. In Lepidosiren it issues from the point of junction of two gill-less and two gill-bealing vence branchiales, thus receiving mixed blue and red blood, or blue blood altogether, when the branchiæ are not in functional activity. In Protens it issues from the last vena branchialis, where it receives the ductus botalli of the preceding vein, which, when the gill is inactive, becomes a gill-less aortil-bow, which brings it only carbonized blood, which it readily aërates in the swimbladder, now become a lung. The ventricle is homologons with the preceding. In salamanders, where the substitution of the accessory gill arches by the ductus botalli, converts the arteria and vence branchiales into "aorta-bows," the A. pulmonalis is given off from the posterior bow, and receires henceforth mixed blood. In the Anura the origin is the same, but nearer the heart. In Cæciliidæ it approaches the heart so far as to issue from the extremity of the bulbus arteriosus, which is now divided by an incomplete septum, one half conreying blood to the aortc-roots, and the other to the A. putmonalis. This septum was already preceded by a longitudinal ralve with free margin in the Anura! As if to meet the coming event, a trace of ventricular septum appears at the apex within. There can now be no question of the homology of the rentricles of the gar, and of the Cæcilia. But we have next the true Reptilia. The bulbus arteriosus is split externally, as it already was internally, but it is first represented in most tortoises by an adherent portion, one half being the now, to this point, independent arteria pulmonalis and the other the nearly split aorta-roots. There can, I think, be little question of the exactitude of the homology throughout.

It is no less certain that the salamander * fulfills in its derelopment the different stages to its permanent one, and is identical in each stage, in respect to this point, with the orders it represents at the time. This is true even of the long period during which it bears the long branchial appendages and contained arteries and veins which are not found in fishes; it is then like the Protepterus, which has hyoid renous arches and appendages of those arches at the same time. The tortoise $\nmid$ and Tropidonotus $\ddagger$ are also identical in their successive stages with the types already 
enumerated, the external or appendicular branchial vessels being omitted, as belonging to the special serial development of the line of air-breathing Anallantoidans. The division of the bulbus arteriosus into three instead of two may indicate a case of incxact parallelism; but, on the other hand, it may be that the pulmonary partition is completed a little before the aorta-root partition, thus passing through the batrachian permanent type. For explanations of inexactitude see under Part II. No doubi the batrachian type of bulbus arteriosus is passed by many serpents less extreme and specialized than the Tropidonotus.

The aortic and pulmonary divisions of the bulbus in the Cæcilia are not laterally placed, but one is dorsal and the other ventral, the one passing a little spirally to the right of the other. So the pulmonary division of the bulbus turns over to the right in the Anura. When the septum of the true reptiles appear, it rises on the anterior wall of the ventricle till it is seen, in Eunectes, to meet the partition between the arteria pulmonalis and aorta-roots, and we have at once the right and left ventricles of the bird and mammal structurally and functionally. Thus are the two ventricles of man the same as the one ventricle of the fish, merely divided by a septum.*

In the fissure of the aortic bulbus, in the reptiles, a spiral turn is again given, and in Testudo the one aorta-root issues behind the other. In the crocodile the turn is still greater, and the right aorta-root issues to the left of the left root, and vice versa. In the birds we have lost the left root, and parallelism ceases with this change. In the Manmalia the right root turns to the left, so that in the comparison of these classes the rule of von Baer above quoted is true; no mammal at present known is identical in a fœtal stage with any fully grown bird, but with a fœtus of the same, up to a certain point. But for both classes the parallelism of those below them holds true.

But it is with the exact parallelism or identity of genera that we have to do in the present essay. 'That being established, the inexact parallelism between the modern representatives of higher gromps follows by a process of reduction.

* Agrssiz, l. c., denies the homology of the ventricles of the turtle and mammal; but it appears to me erroneously. IIe says: "The fact that the great blood-ressels (aorta and art. pulmonalis) start together from the carum venosum seems to prove that the two carities in the heart of turtles, which are by no means rery marked, do not correspond to the two rentricles in Mammalia and birds." 
ON THE ORIGIN OF GENERA.

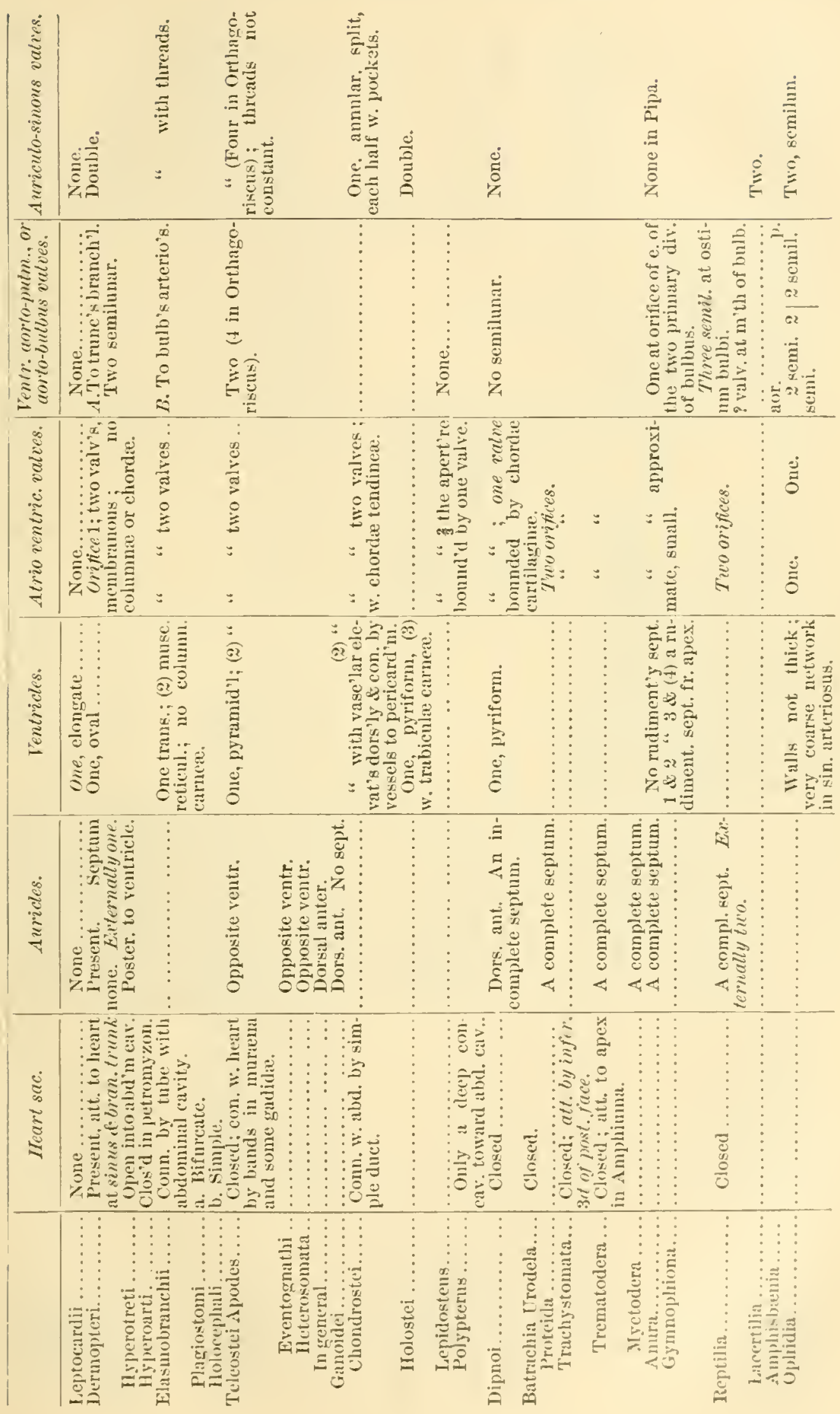




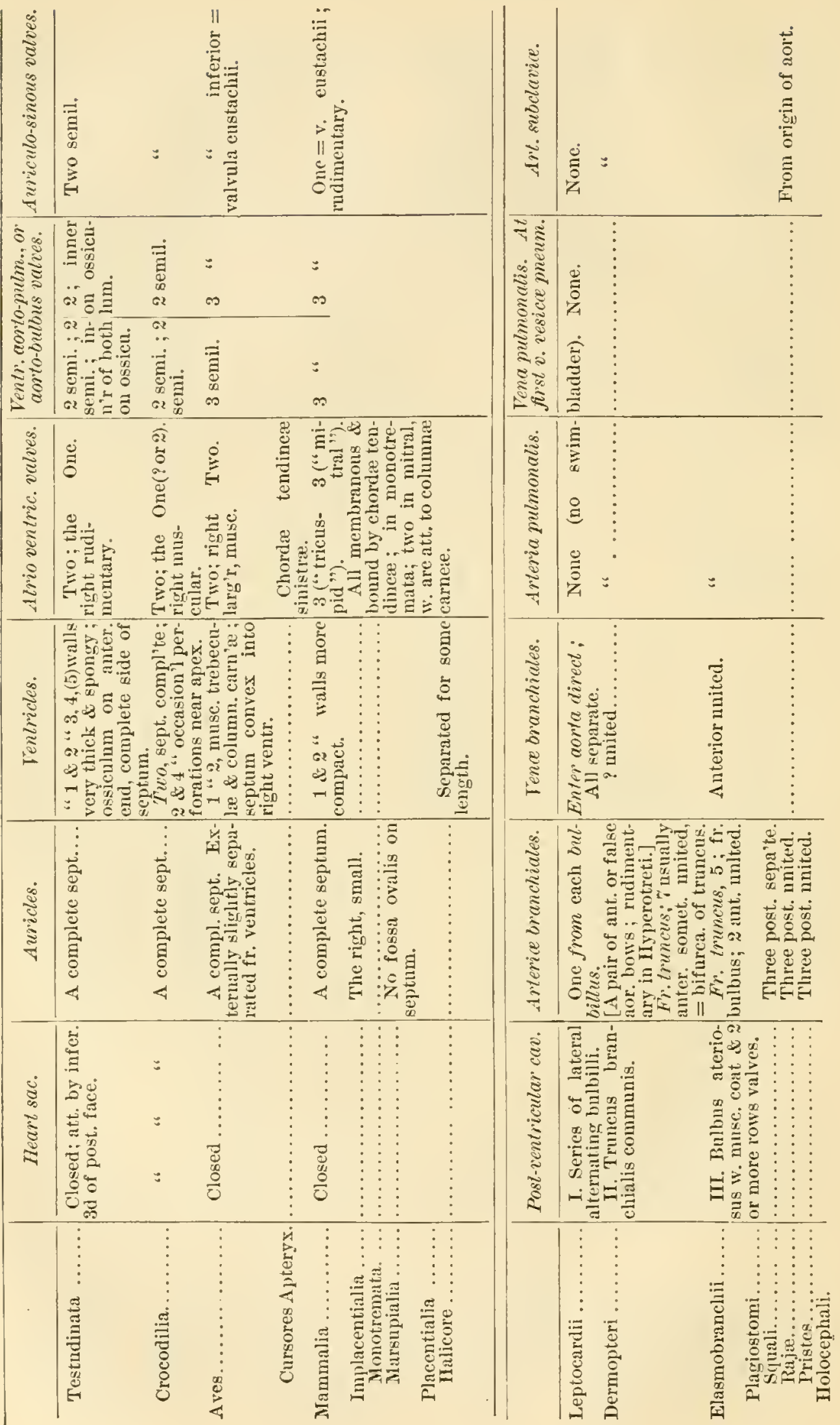




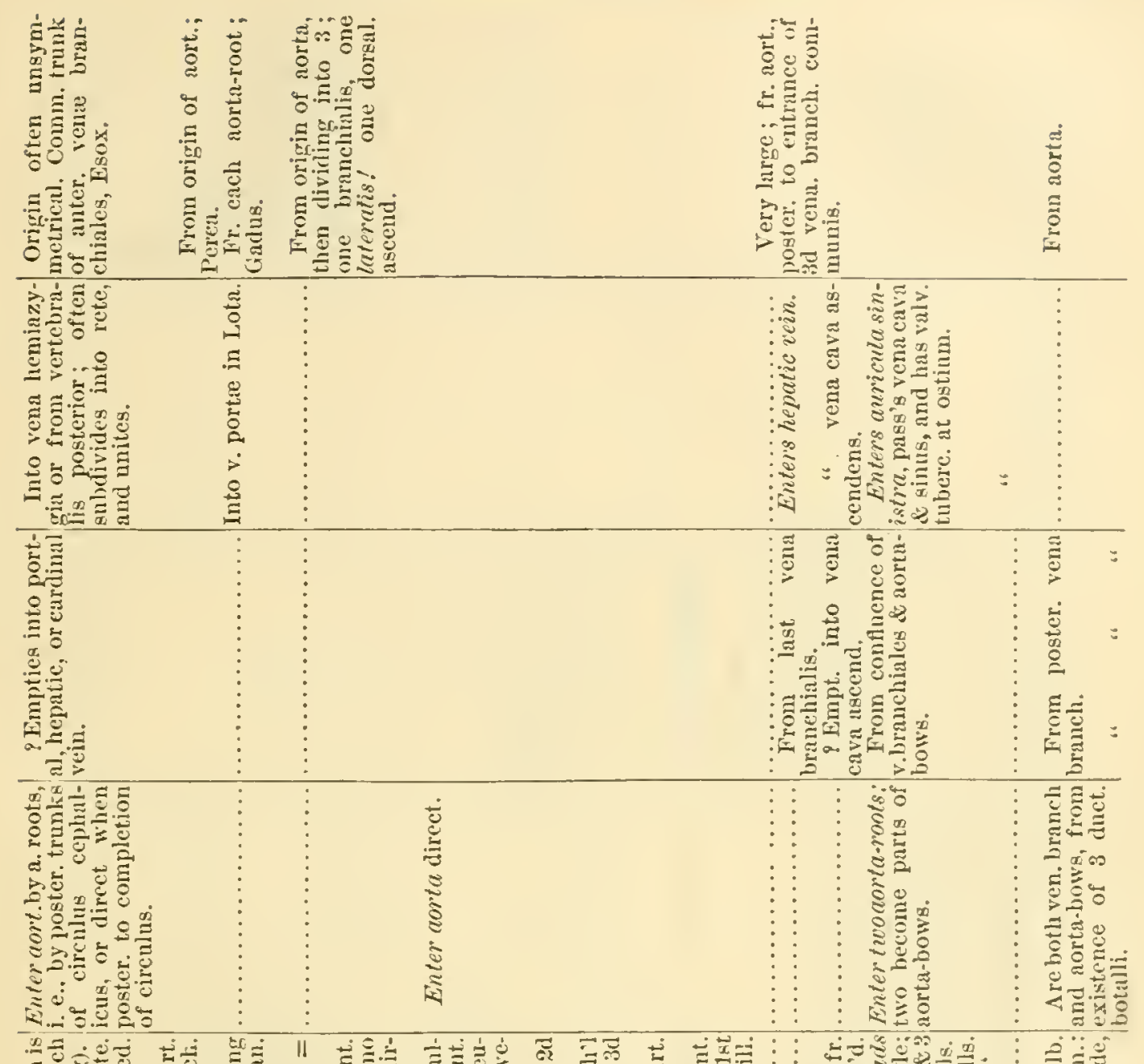

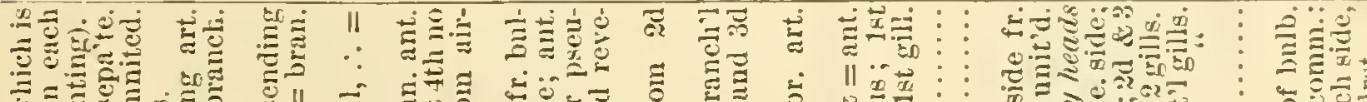

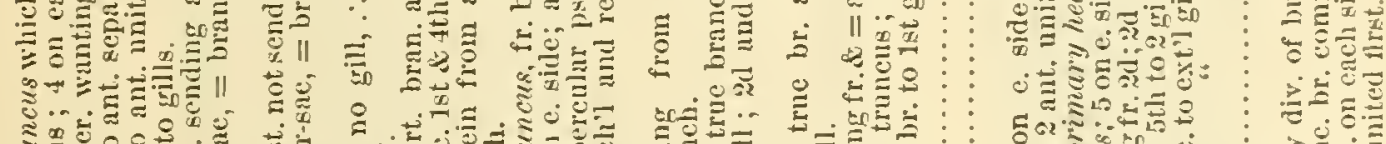

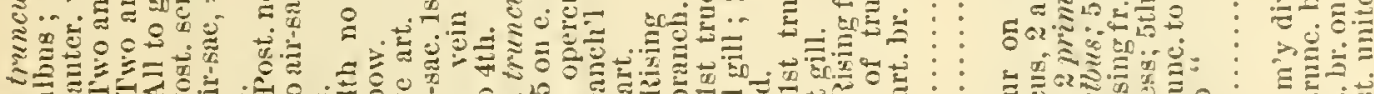

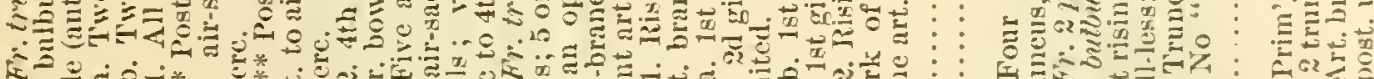

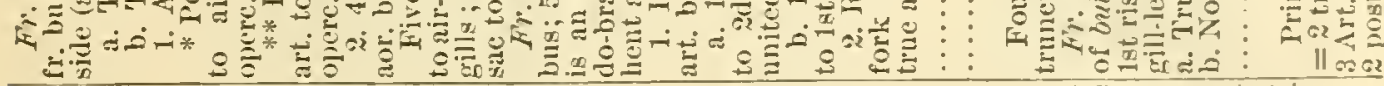

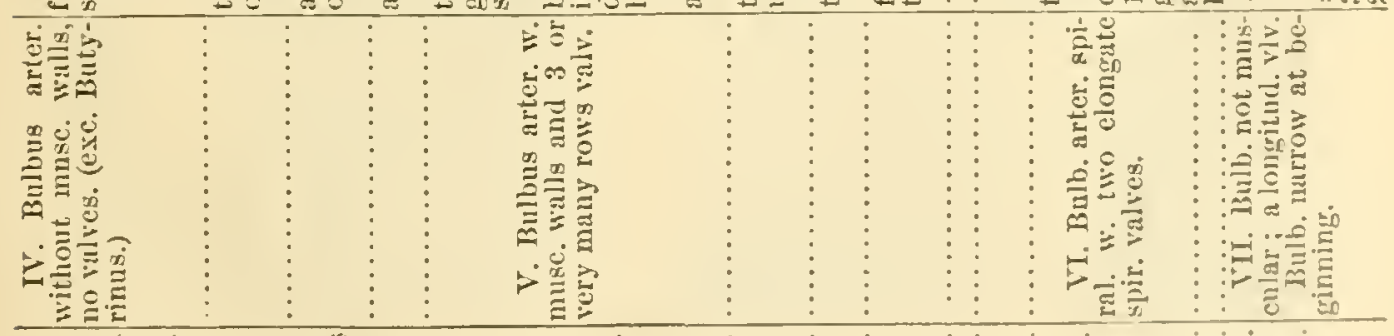

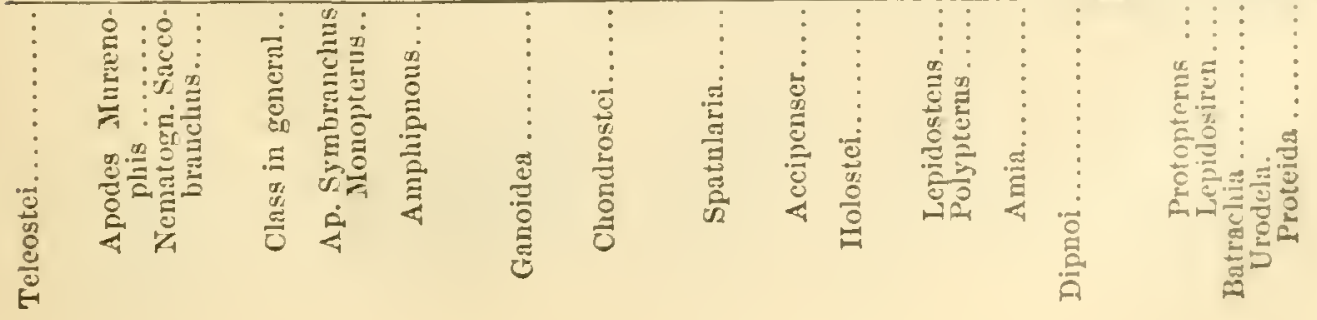




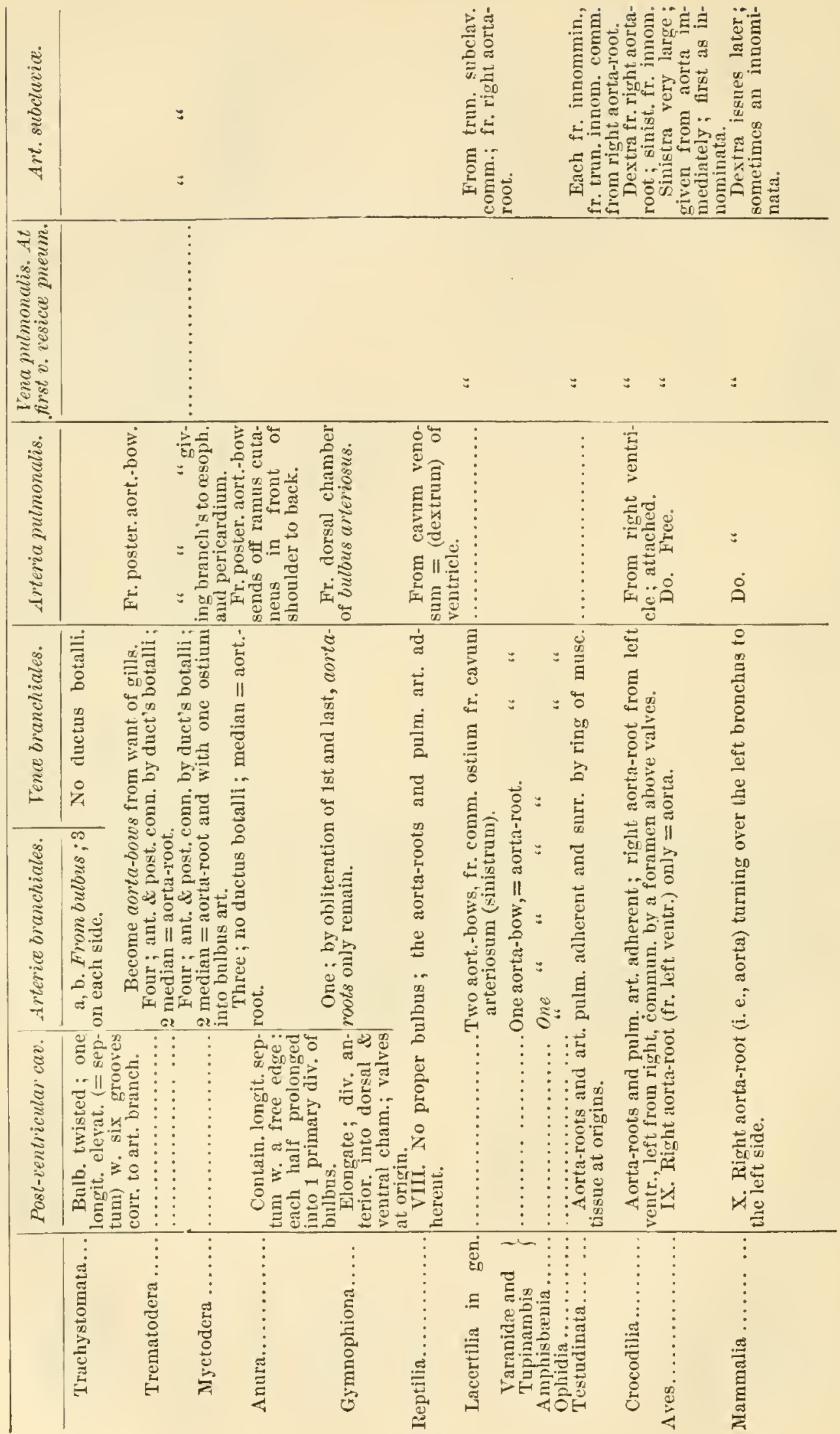




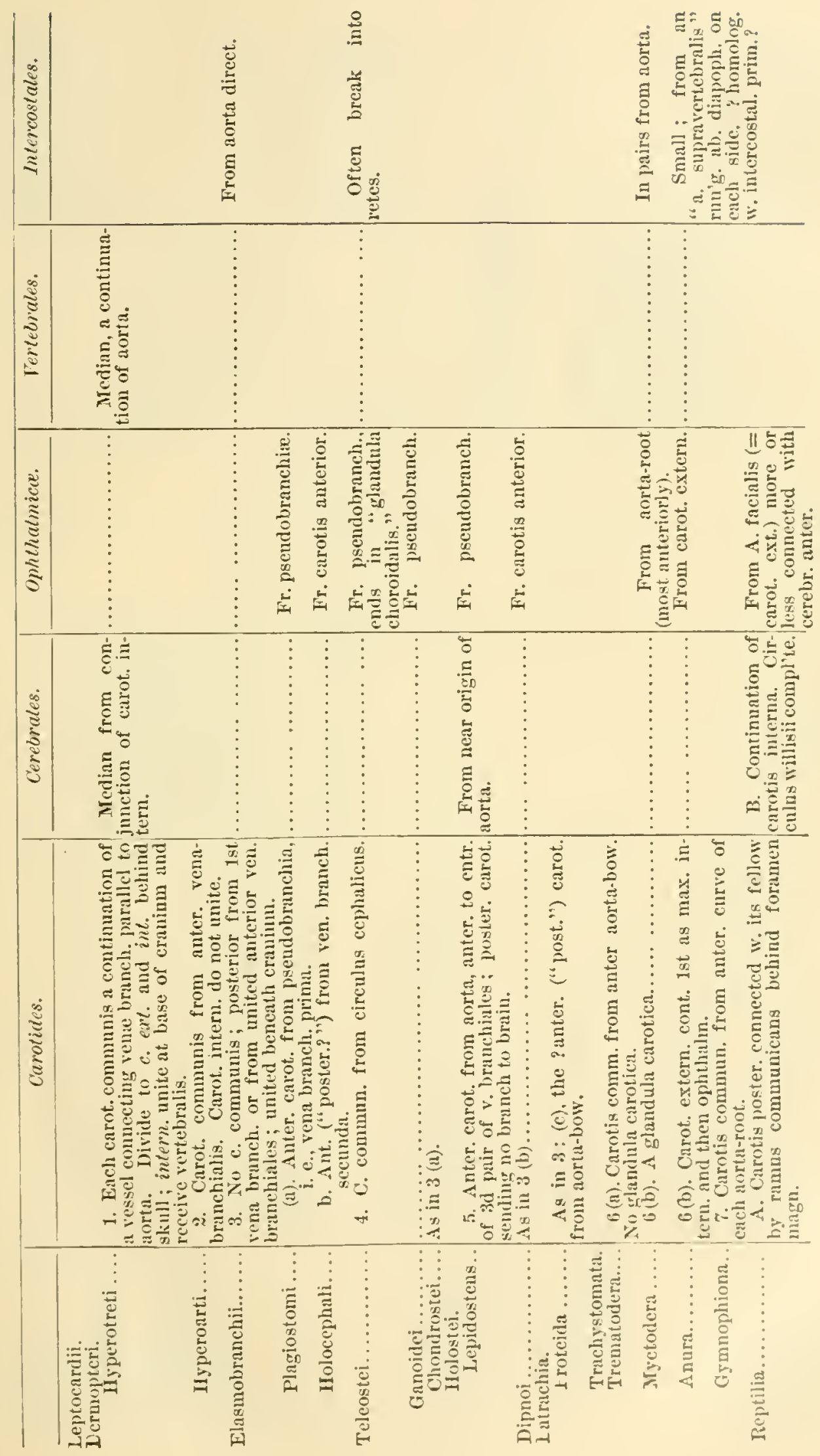




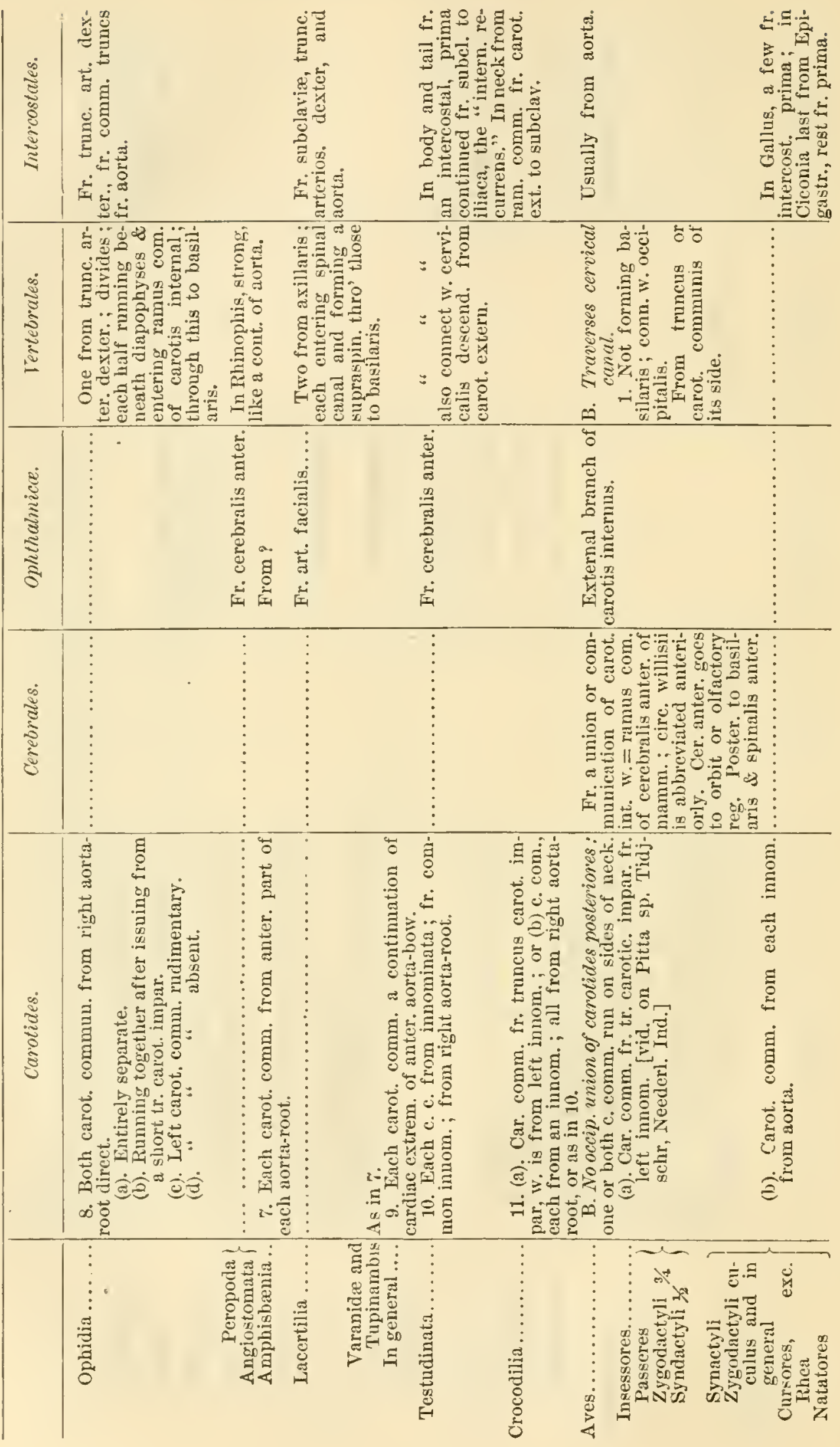




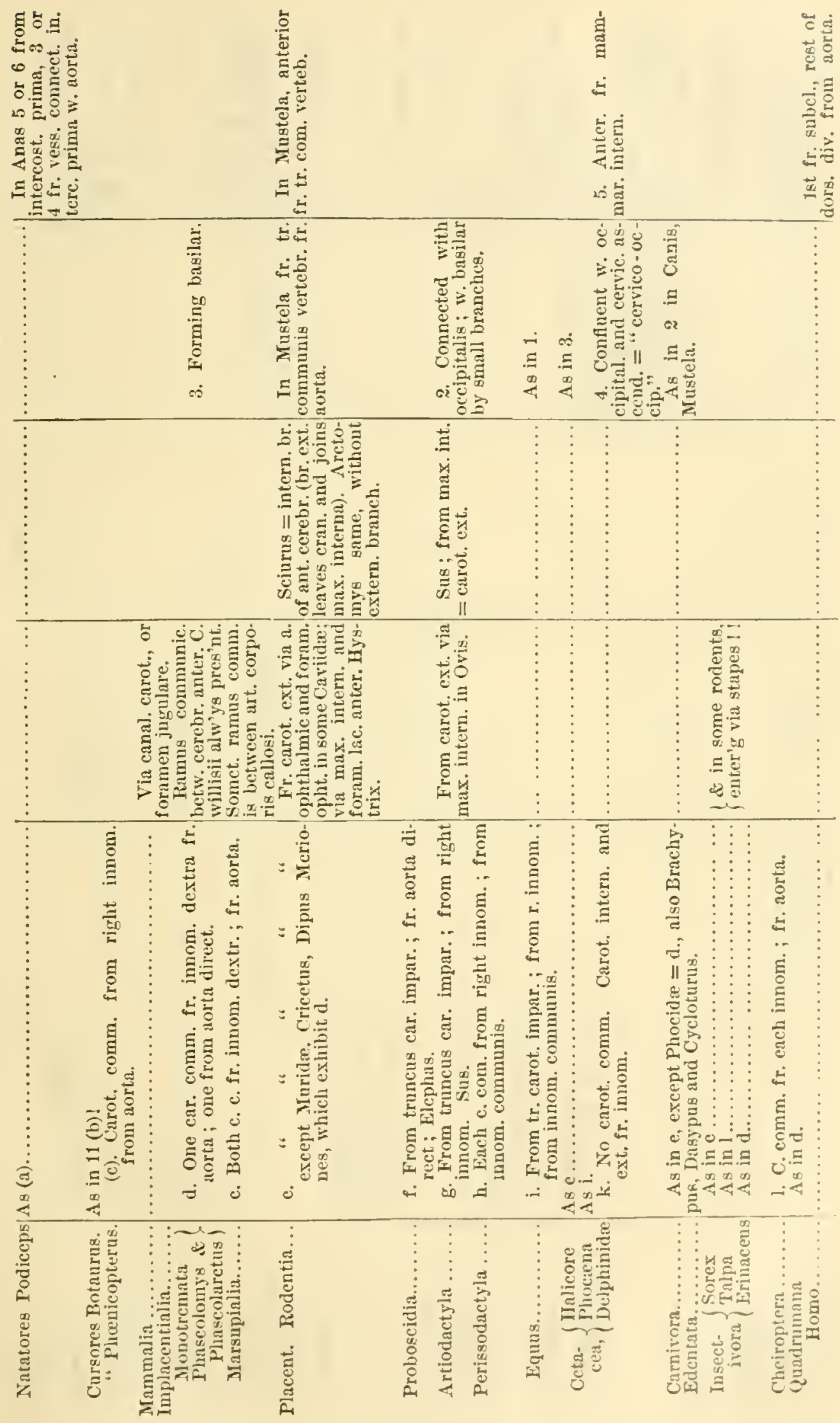




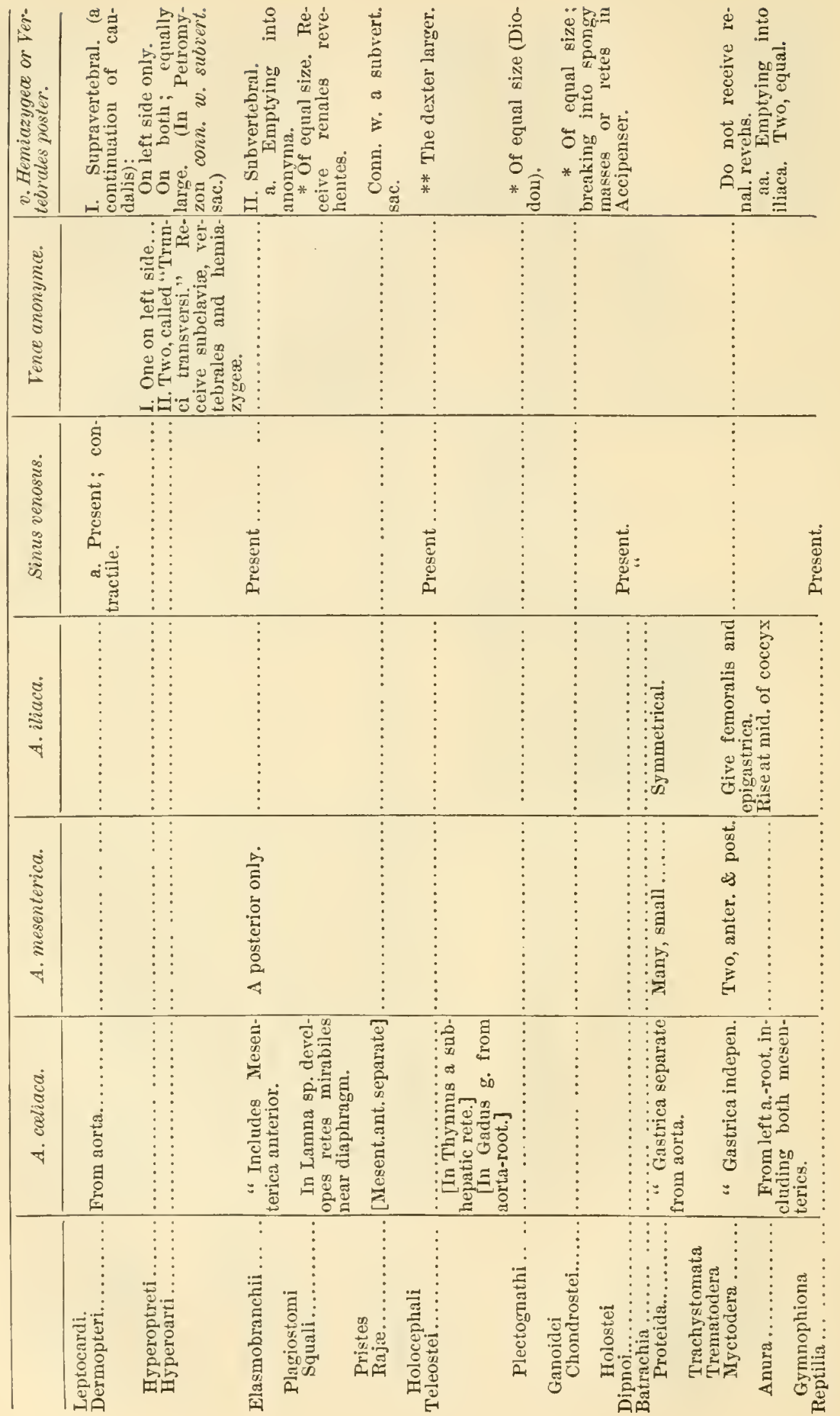




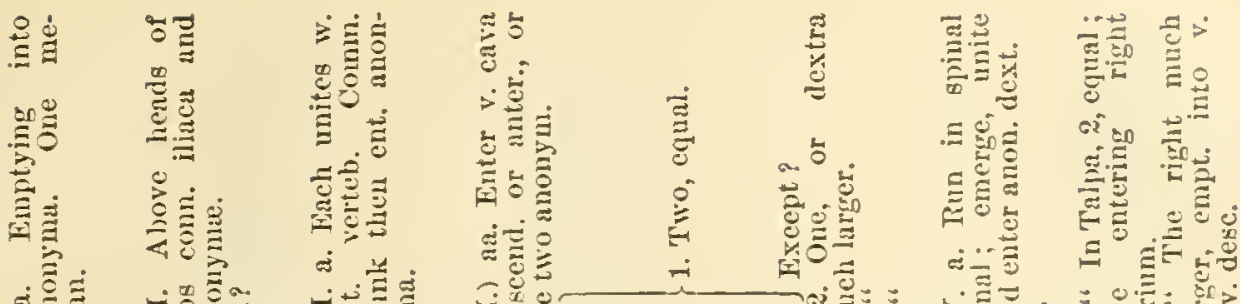

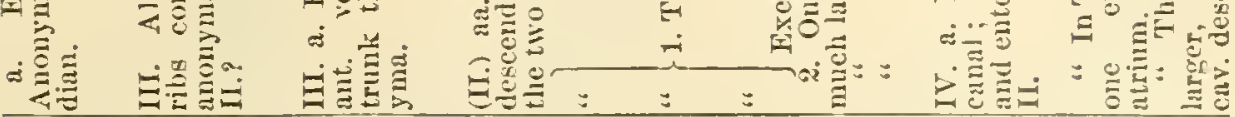

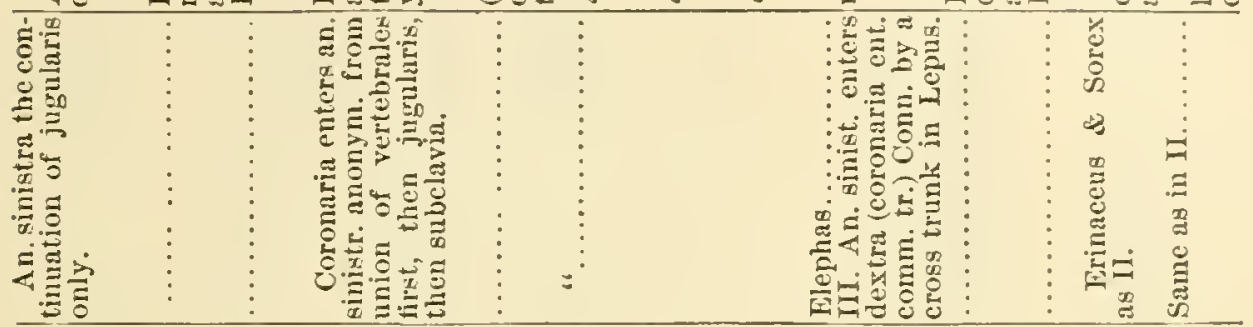
ذ̇ : $=\quad$ 苟

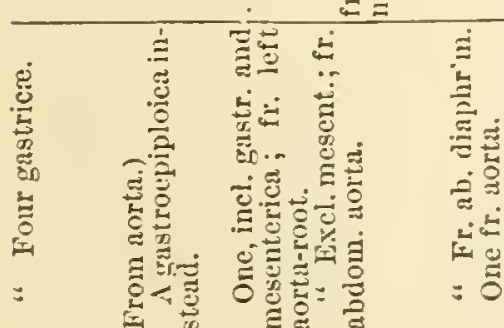
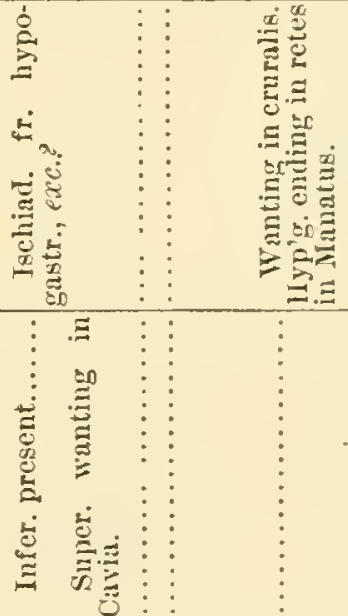

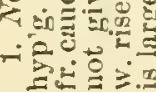

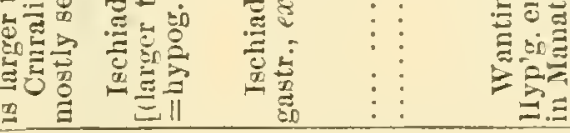

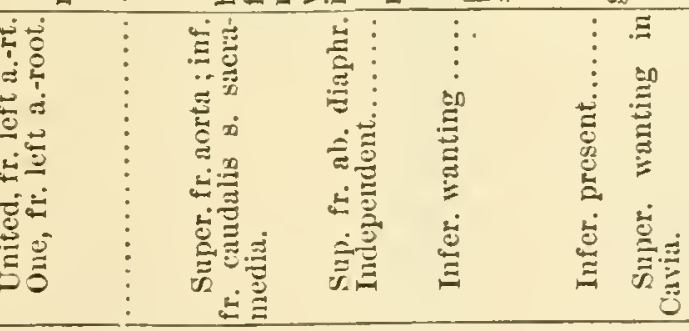




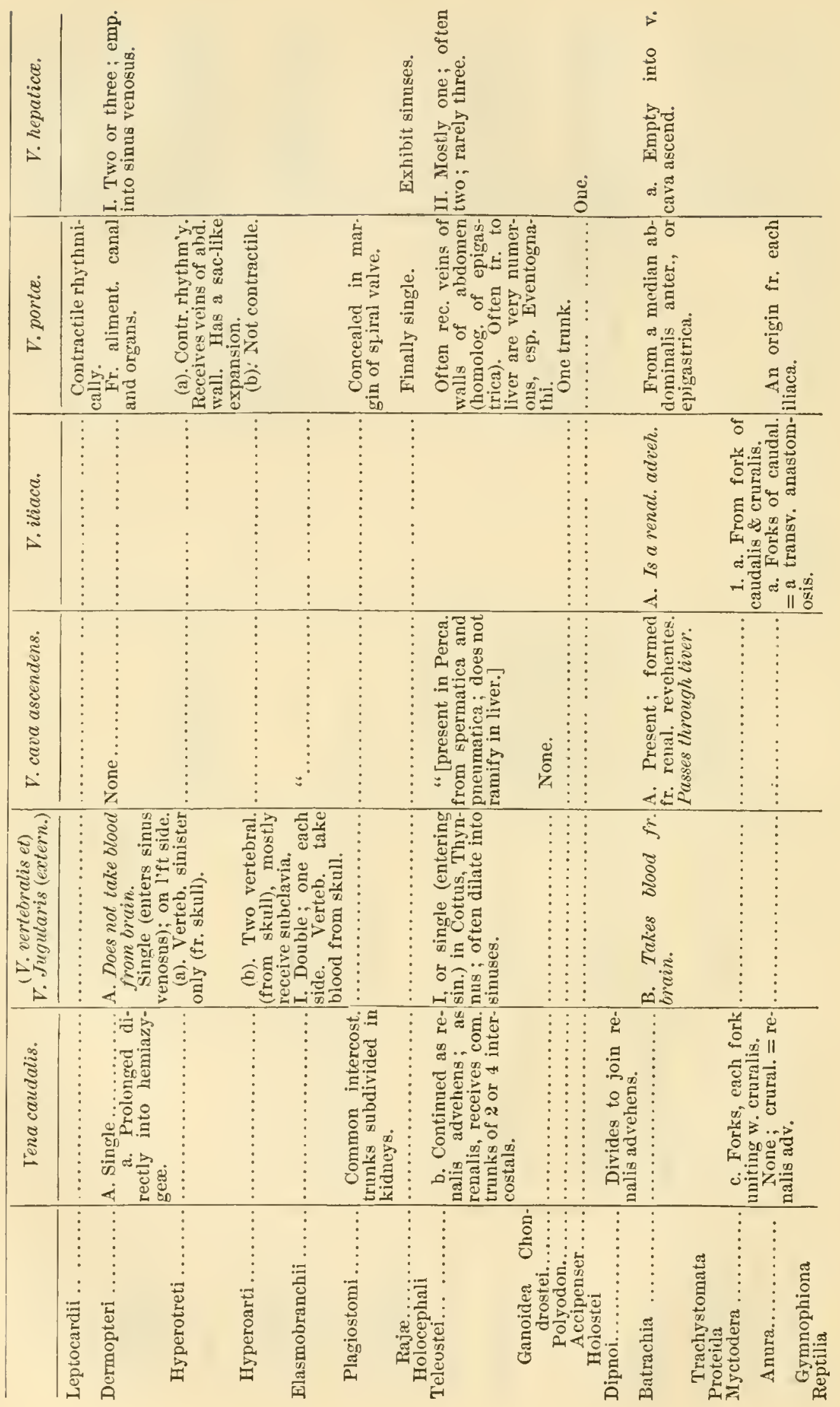




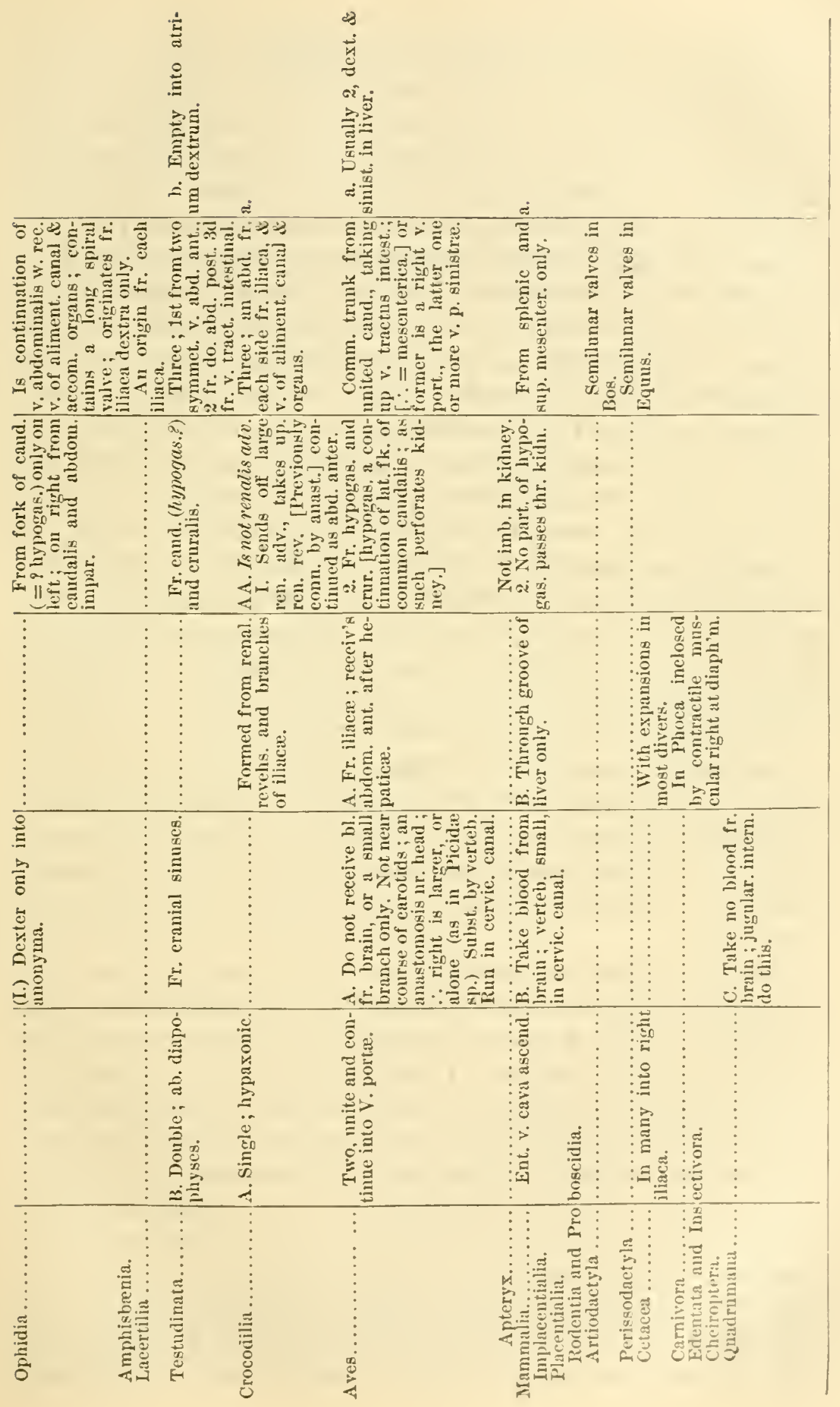




\section{ס. The Extent of Parallelism.}

Prof. de Serres and others have stated it as their belief that the lower "branches" of the animal kingdom are identical with the undeveloped forms of the higher; i. e., that the mollusk and articulate are not merely parallel with, but the same as the lower conditions of, the vertebrate. The works of various embryologists, as von Baer and Lereboullet, have shown this statement to be erroneous, "and founded on false and deceptive appearances." The embryos of the four great branches of the animal kingdom appear to be distinct in essential characters from their first appearance. But Lereboullet, who, in his prize essay, has compared with care the development of the trout, pike, and perch of the Teleosts, with that of a Lacerta among reptiles, has failed to point out characters by which the embryos of the two vertebrate classes essentially differ, for a considerable period. It is true that, as each and all of the species belong to widely different generic series, parallelism is of the kind to be called inexact or remote. But enough is known of embryology and paleontology to render it extremely probable that the historic predecessors, of the types whose embryology Lereboullet studied, formed a series of parallels of the kind termed in this essay exact.

Lereboullet states that a certain difference exists between the eggs of the fishes and those of the Lacerta. This is for us merely stating that the parents of the embryos differ, a fact which no one will contest. The same may be said of the elevated or depressed character of the surface of the vitellus on which the embryo reposes.

Secondly, after the appearance of the embryo the Lacerta is furnished with the amnios and allantois; the Teleost not. This is certainly neither a generic, ordinal, nor class character of the adult, for it is but temporary ; therefore, in generic, ordinal, and class characters the embryos of the Teleost and Reptile are still identical. It is a physiological character, and not morphological, and therefore far the less likely to be a permanent one, even in embryos, under changed circumstances. The female of one of the species of Trachycephalus inverts the skin of the back at one season of the year to receive her eggs, beeause she can not lay them in the water; the other species of the genus do not. The next genus in direct morphological line possesses a single speeies whose female does the same for the same reason; but the rela- 
tions of these species and genera are zoölogically the same as though this modification did not oceur. Many such instances will occur to many naturalists. It is not pretended that they are as important as the presence of the allantois; but they constitute a character, no doubt, similar in kind, and entirely at the service of the needs of the great system of morphological succession. The same may be said of the vascular area of the Reptile.

Lereboullet concludes his summary of the differences between the Teleost and Reptile, up to the period of completion of the heart, by saying, "It is easy to perceive that all these differences, however important they may appear, are constituted by the accessory organs of the embryo, and do not modify the development of the latter, which progresses in reality exactly as in the fishes." He says the same previously, as to the relation of the sime to the bird and mammal.

We have, then, in the embryos of the lower vertebrates at a certain time in the history of each, an "exact parallelism" or identity with the embryonic condition of the type which progresses to the next legree beyond it, and of all the other types which progress successively to more distant extremes.

We have, however, so far, every reason to suppose that the embryos of the other branches of animals never present an exact parallelism with those of the Vertebrata.*

The embryo of the fish and that of the reptile and mammal may be said to be generically, if not specifically, identical up to the point where preparation for the aerrial respiration of the latter appears. They each take different lines at this point. The fish diverges from the course of the reptile, and proceeds to a different goal; the shark does the same, but proceeds a shorter distance; while the Dermopter scarcely leares the point of departure. No donbt, there have been types which never left this point and whose plan of circulatory system is identical with that of the embryo reptile and mammal. Such a type was only generically. different from the reptile or mammal which had only taken the succeeding step, provided other structures were not superadded.

By comparing the development of types of different classes in

* At about the time this was written the important papers of Haecliel on his admirable Gastræa theory were published, but had not reached the author. Ineckel shows the approximate identity of all the types of embryonic developuent. (Note, 1886.) 
certain features which are only ordinal or generic in meaning, very erroneous conclusions may be reached by the inexact student as to the want of parallelism of classes to each other. Thus Rathke says of the development of the eye of the snake Tropidonotus, at a certain period, that it is far in advance of that of the mammal at the same stage. Here, says the objector, is a case where their parallelisms do not coincide; the mammal is really similar to a younger stage of the reptile.

But, in fact, the size of the eye is but a generic or family character; if the development of the lemur had been compared with the snake, the mammal would have been found to be in advance; of the mole, much farther behind. If the suake selected were the purblind Atractaspis, almost any mammal would have been in advance; if, on the other hand, the great-eyed Dipsas, but few Mammalia would have been parallel to it.

In a word, to find exact parallelism it is necessary to examine the closest allies.

It is also of first importance to distinguish between the existence of generic or ligher characters, and their condition under various cireumstances of individual life. If a fotal or larval character be conserved through the adult life of a type, it will be of course adapted to the functions of mature age. Thus the undeveloped character of the horns of the genus of deer, Rusa, are not accompanied with the marks of individual youth of the corresponding stage of Cervus; its individuals are fully grown and functionally perfect. The species of Hyla are not small and incapable of self-preservation and reproduction, as is the corresponding stage of Trachycephalus; they are functionally developed. The student need not be surprised, then, if, when identity or exact parallelism is asserted, he finds some differences dependent on age and adaptation, for if he be an anatomist he need not be informed that a morphological relation constitutes types what they are, not a physiological.

\section{OF RETARDATION AND ACCELERATION IN GENERIC CHAR- ACTERS.}

First. Of adult metamorphosis:

The question has necessarily arisen, Hare these remarkable relations between genera resulted from an arrangement of distinct generations according to a permanent seale of harmony, or have the same genctic series of individuals been made to assume the 
different positions at the same or different periods of the earth's lisistory.*

Prof. Marcel de Serres proposed the theory of repressions of development to account for the existence of the lower groups of animals as now existing, an error easily exposed, as has been done by Lereboullet in his various important embryological writings. But little observation is sufficient to prove that a mammal is not a shark where it has fire gill-arches or aorta-bows, nor a batrachian where it has three, or a reptile where it has the two aorta-roots. This has been already sufficiently pointed out by von Baer, who says there is "keine Rede" of such a theory as was afterward proposed by de Serres. Thus are true the rules propounded by

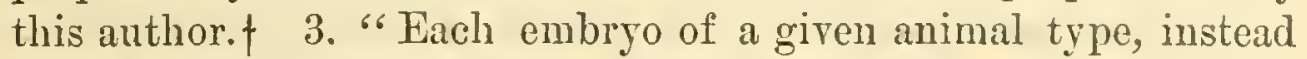
of passing through the other given animal found, diverges still more from it." 4. "In the basis, therefore, the embryo of a higher animal type is never identical with an inferior type, but with the embryo only of the latter."

I think that I have already made some progress in proving that the near or true generic relationship is one of absolute developmental repression or adrance. Paleontology shows that families and orders, as now existing, were preceded in time by groups which are synthetic or comprehensire, combining the common characters of modern generic series. This process of synthesis must, it is obvious, if continued, result in the near approximation of the single representatives of the now numerous and diverse gromps. There is every reason to believe that a bachward view through time will show this to hare prevailed throughont the

* Some naturalists seem to imagine that the demonstration of the existence of intermediate types is only necessary to establish a developmental hypothosis. Thus Dr. Dohrn ("Ann. Magaz. N. Hist.," 1868), writing of his discovery of that most interesting genus, Eugereon, which combines characters of Neuroptera with those of Hemiptera, does not hesitate to say that it proves the truth of Darwin's theory. Now, it appears to me that a denonstration of the existence of a regularly graduated sucession of types, from the monad to man, would be only the minor of a syllowism without its major, in evidence for development, so long as the proof of transition of one step into another is wanting; and the idea that such a discovery could establish a developmental theory is entirely unfounded. Indeed, the reasoning in which some indulge-if we dare so call the spurious article-based on this premise alone, is unworthy of science. The successional relation of types, though a most important element in our argument, has been long known to many who give no sanction to the idea of development.

† "Entwickelungageschichte," p. 224. 
Vertebrata and other branches, as we already can in part prove. And I have no doubt that the synthetic types, which represent modern orders, have existed in a generic relationship subordinate to the plan of the synthetic class, and that the latter have existed as genera only, of the type of the great branch. This is not ideal. We only have to look to our extinet ganoids, Arehegosaurs, Labyrinthodonts, Compsognathus, Archæopteryx, Ornithorhynchus, etc., to realize these facts.

The first genera then formed a scale of which the members were identical with the undeveloped stages of the highest, and each to each according to their position.

Such a series of antitypic groups having been thus established, our present knowledge will only permit us to suppose that the resulting and now existing kingdoms and classes of animals and plants were conceived by the Creitor according to a plan of his own, according to his pleasure. That directions or lines of development toward these ends were ordained, and certain laws applied for their realization. That these laws are the before-mentioned law of RETARDATION AND ACCELERATION ; and law of NATURAL SELECTION.

The first consists in a continual crowding backward of the successive steps of individual derelopment, so that the period of reproduction, while occurring periodically with the change of the year, falls later and later in the life history of the species, conferring upon its offspring features in advance of those possessed by its predecessors, in the line already laid down partly by a prior suppression on a higher platform, and partly, as above supposed, by the special creative plan. This progressive crowding back of stages is not, however, supposed to have progressed regularly. On the contrary, in the development of all animals there are wellknown periods when the most important transitions are accomplished in an incredibly short space of time (as the passage of man through the stages of the aorta-bows, and the production of limbs in Batrachia anura); while other transitions oceupy long periods, and apparently little progress is made.

The rapid change is called metamorphosis; the intervening stages may be called larval or pupal. The most familiar examples are those which come latest in life, and hence are most easily observed, as in the insects and frogs. When, during the substationary period, the species reproduces, a constancy of type is the result; when the metamorphosis only appears at the period of reproduction, a protean type is the result; when the metamorphosis is crowd- 
ed back to an earlier period of life, then we have another persistent type, but a new genus of a higher grade than its predecessor.

In reviewing many examples everywhere coming under the eye of the naturalist, it is easy to perceire what would constitute a plastic and what a conserved condition of generic, or even of specific form.

As one or more periods in the life of every species is characterized by a greater rapidity of development (or metamorphosis) than the remainder, so in proportion to the approximation of such a period to the epoch of maturity or reproduction, is the offspring liable to rariation. During the periods corresponding to those between the rapid metamorphoses the characters of the genus would be preserved unaltered, though the period of change would be ever approaching.

Hence the transformation of genera may have been rapid and abrupt, and the intervening periods of persistency very long; for it is ever true that the macrocosm is a parallel or repetition of the microcosm in matter and mind. As the derelopment of the individual, so the development of the genus. We may add : so the derelopment of the whole of organized beings.

These metamorphoses may be fitly compared to those in the molecular constitution of matter. 'The force of colnesion between the atoms of a vapor steadily increases with descending temperature, and in a regular ratio, till a given point is reached, when a sudden metamorphosis to a denser or liquid condition takes place. Nor have we reason to believe, with regard to many substances, that there is any parallel relation between the temperature and the molecular constitution before or after the metamorplosis takes place. So, the temperature continuing to descend, the molecular character of the liquid remains unchanged until, the vis conservatrix suddenly giving way at the ordained point, a soild is the result. 'Thus, while the change is really progressing, the external features remain unchanged at other than those points, which may be called expression-points.

Now, the expression-point of a new generic type is reached when its appearance in the adult falls so far prior to the period of reproduction as to transmit it to the offspring and to their descendants, until another expression-point of progress be reached.

Thus a developmental succession does not so obliterite the lines drawn around Nature's types as to render our system ineffectual as an expression of them. 
The successional acceleration or retardation in metamorphosis may be best illustrated in certain tailless batrachians, by the following tables. 'These are taken, it will be remembered, from the Bufonidæ and Hylidæ as examples of "exact parallelism"; three are now added from the Ranidæ and Discoglossidæ. The case of "inexact parallelism" is that of the Scaphiopodidæ.

Whether they are cases of acceleration or retardation can only be determined by reference to the paleontology of the respective groups, or a careful comparison of times of metamorphosis. In the case of the Discoglossidx I suspect it to be retardation, as the highest genus is extinct. The others I shall arrange with them for temporary convenience. Were I dealing with a group of Ganoids, I should imagine the process to be retardation, as this group is going out of existence. On the other hand, were they higher Oscine birds, we might imagine the case to be reversed.

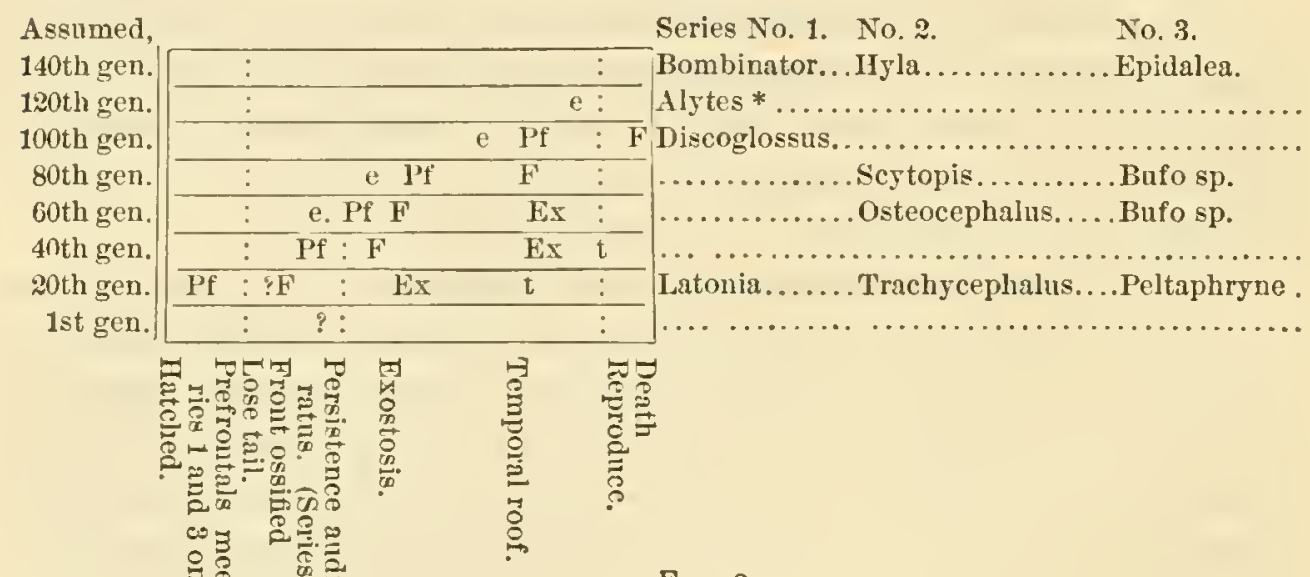

Fra. 3.

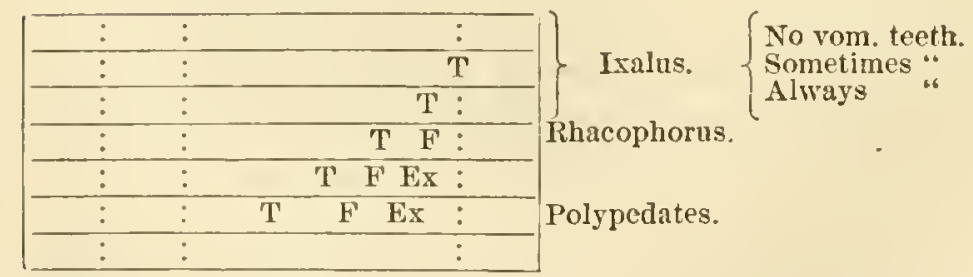

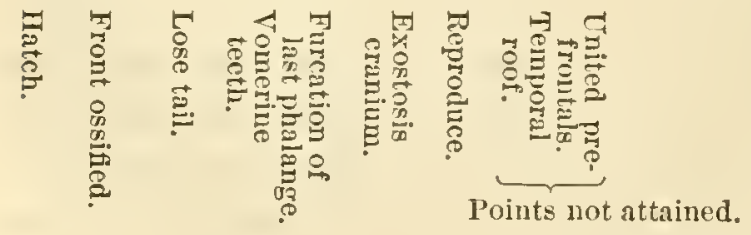

F10. 4.

* A parotoid gland of small size is added here, bitt is not generic as compared with Bombinator, as the latter has collections of crypts on the same region and over the body. 

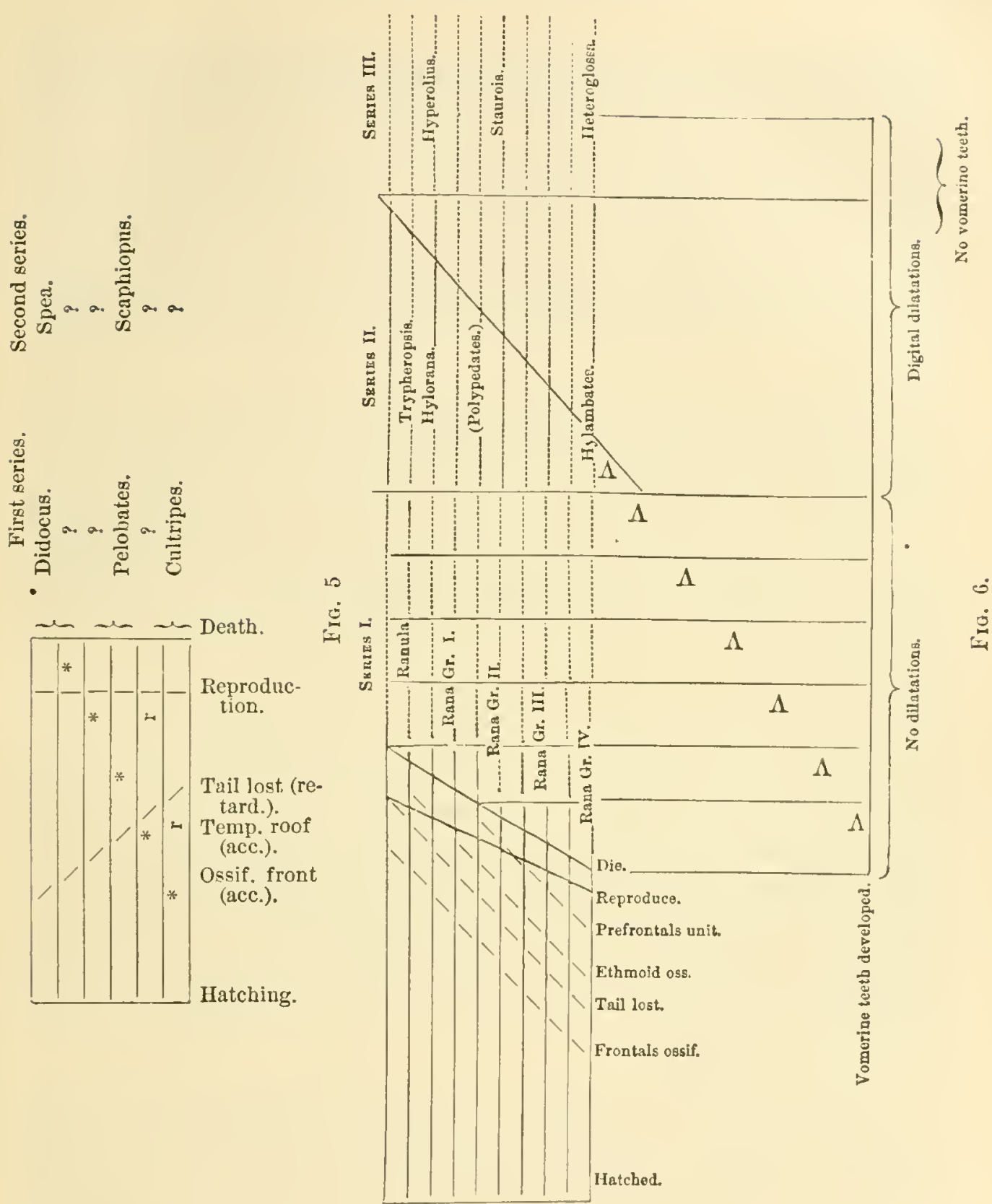

In the preceding diagrams each horizontal column represents the life history of the individuals of each genus. The line of dots, stars, etc., represents the same developmental stage of each, as it appears earlier or later in the life of the individuals. The point of crossing the breeding period is that at which the character is rendered permanent. When the change falls on this period the character is not generic, as in Ixilus, Fig. 4. The period of losing the tail, like that of breeding, is represented as ocenrring at nearly the sime time in the history of every genus, as it is gener- 
ally seasonal. Yet this is not always so, and, like the other character's, has most likely had its period of shifting. Compare difference of time of development, for instance, of the frontal and prefrontal bones in Figs. 3 and 6 . 'The comparison of the adult stages of the less developed genera, at the tops of the columns, with the larval conditions of those more fully developed, may be traced in the absence of characters which appear in the latter. I have convinced myself of the acenracy of the above relations by the examination of many skeletons and wet preparations of adults and larvæ.

The diagrams* are representations of mature, and not ideal sketches. It is to be noted as remarkable that the advance thronghont so many direrse groups is in the same direction, viz., to complete or excessive ossification of the cranium; and this identity of progress might be readily shown by adding other char: acters, were it not that the tables wonld become too complex for convenience.

Has any such transition from genus to genus ever been secn to accur?

It must of course take place during the life of the individuals of a species, and probably at different times during the lives of different individuals, dependent on their relative vigor. In our view, ordinary metamorphosis is such a change, and we have stated its bearing in this form, that " every character distinguishing suborders, families, and genera is to be found among the individuals of some species, living or extinct, to mark new varieties or stages of growth."

\section{a. The Developmental Relation of Generic to Specific Characters.}

For the relation of the law of retardation and acceleration to specific characters we will look to development again. While the

* Notes on the diagrams: Fig. 4. Polypedates is here restricted to P. maculatus and $P$. quadrilineatus. The other species are referred to Rlacophorus, which has not hitherto rested on any proper basis; the asserted character-the palmation of the hands - being one quite graduated from species to species among Iyla. Chiromantis, Peters, is referred to the same, as its character is not strongly marked and is visible in other species. For similar reasons Leptornantis is referred to Ixalus.

Fig. 6. In each of series ii and iii, two series are mingled for the sake of comparing the structures of the prefontal bones. Thus Heteroglossa, Staurois, Hylorani and Trypheropsis are one series, and Hyperolius and Hylambates members of another. 
young of Trachycephalus are successively different genera, they preserve most of their specific characters so as not to be mistaken. Agassiz says of the development of the North American turtles, * "I do not know a turtle which does not exhibit marked specific peculiarities long before its generic characters are fully developed." The same thing can be said of the characters of our salamanders, whose specific marks appear before their generic or eren family characters. I suspect that this will be found to be a unirersal law.

It also follows, if a developmental process, as proposed, has existed, that at times the change of generic type has taken place more rapidly than that of specific, $\dagger$ and that one and the same species (if origin be the definition) has, in the natural succession, existed in more than one genus.

Apart from any question of origin, so soon as a species should assume a new generic character it ceases, of course, to be specifically the same as other individuals which have not assumed it. If supposed distinctness of origin be, however, a test of specific difference, we shall then have to contend with the paradox of the same species belonging to two different genera at one and the same time.

It follows, therefore, in our interpretation of nature, that groups defined by coloration alone are not to be regarded as genera, as is done by some ornithologists and entomologists. They are simply groups of species in which distinctive generic characters had not appeared up to the period of reproduction. Inasmuch as in development certain specific characters appear first, among them part or all of the coloration pattern, it is obvious that the latter do not belong to the generic category. The employment of such characters, then, in this sense, is only to commence reversing the terms generic and specific, and to inangurate the process of regarding each species as type of a separate genus.

\section{Of Probable Cases of Transition.}

Thus the transition between the toothed and edentulous conditions in Cetacea takes place in the ordinary growth of the inclividuals of the genus Globiocephalus, and the transition between

* Contrib. "N. Hist. United States," i, p. 391. Fote.

+ Sec "Procecdings Acalemy," Philadelphia, 1867, p. 86, where I observe that generic characters are probably less inherent than specific. 
the ossified and non-ossified types of Chelonia occurs during the life of the individuals of the genus Dermatemys.

But, in attempting to demonstrate this proposition, we must bring forward facts of another kind. The anti-developmentalists are accustomed to put such changes aside, as part of the necessary history of established types; hence we will not appeal to such.

1. The frog Ranula affinis, of South America, was described by Peter's as probably a climatal variety of European Rana temporaria. In this he is supported by the fact that the specific characters do not differ more than would characterize it as a local variety, were it an inhabitant of Enrope. But I have found that it differs generically in the non-ossification of the ethmoid bone, as has been confirmed by Steindachner, and represents an embryonic condition of the same bone in Rana. It is in fact an undeveloped Rana. That this is a true genus is confirmed by many specimens, by additional species, and by the fact that the allied genus Trypheropsis, embracing three species in the same region, differs in the same way from the otherwise identical genus of the Old World, Hylorana.

2. The South African Saurians, Chamcesaura anguina and Mancus macrolepis, are very closely allied in specific characters in all respects, though distinct. They have one important ground of generic distinction: the latter has one pair of limbs less thin the former. They are rudimental in Chamæsaura, and the disappearance in Mancus is but another step in the same direction. The difference in specific characters is of much less degree.

3. In the genus Celestus there are numerous species, which range from a slender suake-like form with weak limbs, to stonter, strong-limbed forms with a more saurian build. Among these the Haytian $C$. phoxinus is well distinguished by form and coloration. An allied genus from the same region is Panolopus, which in specific characters approaches the $C$. phoxinus very closely, much more so than any Celestus (one species possibly excepted). But in generic characters it is distinguished by the loss of all its toes and the non-separation of nine plates on the end of the muzzle. The genus Diploglossus, on the other hand, occupying a superior place on account of the division of the fronto-nasal into three, is, in specific characters (of $D$. monotropis) much closer to the stont Celesti than the species of the latter genus are among themselves.

4. The Gronias nigrilabris is a Silurid, which in specific char- 
acters more nearly resembles the Amiurus lynx, than the latter does the A. albidus and many other species of the genus. The A. lynx is found in the same streams. The important generic character, the absence of eyes, is, however, its constant feature (in three specimens known to naturalists, others to fishermen).

5. The Cinclidium maximum, a large tree-toad of Brazil, resembles in all its characters the Centrotelma geographicum. The specific differences between them amount to almost nothing, but both sexes of the former grow larger and are furnished with a generic peculiarity in the addition of some phalanges to the thumb.

6. The Oporornis agilis, Baird, a North American bird of the Tanager family, resembles very closely, in form, color, and habits, the adjacent species of the adjacent genus Geothlypis. While its specific characters are thus very close to Geothlypis tephrocotis, it differs in the generic feature of a longer wing. By this it is associated, and properly so, with another species $O$. formosus, which has the general color and habits of species of Myiodioctes (M. canadensis), the next related genus.

\%. The following fact I give on the authority of Prof. Leidy, who will publish it in his fortheoming work on the extinct Mammalia of Nebraska, ete.

Three species of Oreodon occur in the Miocene strata; they are a larger, a medium, and a small sized species. In the Pliocene beds above them they are represented by three species of Merychyus, which are in all respects known, identical specifically with the three preceding. Each one may thus be said to be more nearly allied to the species of the other genus than to its fellow of the same genus, in specific characters. But each, on the other hand, differs from each in generic characters. The teeth of Merychyus are more prismatic, have longer crowns and shorter roots, approaching the sheep, as Oreodon does the deer.**

* This phenomenon sugrgests an explanation on the seore of adaptation, which the other eases do not. The existence during the later period of a tourher material of diet would increase the rapidity of wearing of the erown of the tooth, and require a longer crown and greater rapidity of protrusion. This necessitates a diminution of the basal shoulder and shortening of the roots, producing the prismatic form aforesaid. The deer browse on forest foliage, which is more tender, while the Cavicornia graze the grasses, which contain, as is known, a greater amount of silex; hence the more rapid attrition of the tooth.

This may have been the case with the two extinet irenera; the different periods 
8. The Coreopsis discoidea $T$. and $G$., var. anomata, Gray, is, according to Mr. Aubrey Smith, much more nearly allied to Bidens frondosa than to other species of its own genus, and the latter is nearer to it than to other species of Bidens. It differs chiefly, if not altogether, in the generic character : the barbs of the achenia are directed upward; those of the Bidens downward.

From these and many other such instances it may be derived : That the nearest species of adjacent genera are more nearly allied in specific charactcrs than the most diverse species of the same genus.

9. While Taxodium distichum and Glyptostrobus europceu, conifers of North America and of Eastern Asia, respectively, are readily distinguished by generic peculiarities of their cones, in specific characters they appear to be identical. *

Confirmatory of this proposition is the statement of Parker : $\uparrow$ "In tracing out the almost infinite varieties of the modifications of any one specific type of shelled Rhizopod, my friend Prof. Rupert Jones and I found that like varietics of distinct specics are much nearer in shape and appearance than untike varieties of the same essential species." (It is not unlikely that species should here be read genus and varicty species, though the latter may not fulfill the requirements in regard to distinctiveness observed among higher animals. In types like the Rhizopod, forms of this grade may not be really differentiated. Their enormous geographical range would suggest this, if nothing else.)

Objection.-A class of objectors to the preceding explanation of the relations in question will ascribe them to hybridization. They have already done so to considerable extent among the Teleosts (see the writings of von Siebold, Steindachner, and Gïnther). 'Tlat hybrids exist in nature will be denied by none, but that they are usual or abundant is not a probable condition of a creation regulated by such order as ours is. The tendency to modify in given lines of generic series, if admitted, will account for many of the cases regarded as hybrids by the above authors, for it is to be remarked in many cases how the generic characters

during which they lived may have seen a change from forest to prairie. (It is not intended to suggest that the species of the two genera are necessarily of the same or any given number.)

* See Meehan, "Proc. Amer. Ass. Adv. Sci.," 1868. Newberry, "Ann. Lyc.," N. Y., 1868 .

† "Transac. Zoöl. Soc.," London, 1864, p. 151. 
are strikingly affected, and are chiefly used in guessing at the parentage. This is among Cyprinidæ so much the case that there is scarcely an example of a hybrid between two species of the same genus brought forward, but often between speeies of different genera.

\section{$\gamma$. Ascertained Cases of Transition.}

This naturally suggests that, in accordance with the theory of acceleration and retardation, a transition can take place in the life history of species. Have we any means of proving this suspicion?

1. The genus Ameiva (Saurians of South America) has been composed of species of moderate size furnished with acutely tricuspid teeth. 'Teius, on the other hand, embraces very large species with the molars obtusely rounded and of the grinding type. These genera are generally held to be well founded at preseut. I find, however, that in Ameiva pleii, which is the largest species of the genus, in adults the greater part of the maxillary and mandibular teeth lose their cusps, become rounded, then obtuse, and finally like those of 'Teius. While young, they are true Ameive. Strangely enongh the A. pleii, from Porto Rico, acquires but three such obtuse teeth when of the size of the other (St. Croix) forms. In youth the teeth of all are as in other Ameive. Here is a case of transition from one genus to another in the same species.

2. In the importaut characters of the possession of branchiæ, of maxillary bones, and of ossified vertebræ, the tailed Batrachia presents a series of a rising scale, measured by their successively earlier assumption. Thus Salamandra atra* produces living young, which have already lost the branchix; S. maculosa living young with branchiæ; Plethodon $\nmid$ produces young from eggs which bear branchiæ but a short time, and do not use them funetionally; Desmoganthus nigra uses them during a very short aquatic life; $D$. fusce and other Salamanders maintain them longer; while Spelerpes preserves them till full length is nearly reached. Finally, species of Amblystoma reproduce while carrying branchiæ, thus transmitting this feature to theil young as an adult character. And it is a rery significant fact that Spelerpes, which bears branchiæ longest, next to Amblystomi, is associated

* See Schreiber"s "Isis," 1833, p. 527; Koeliker, "Zcitschr. f. wissensch. Zoülogie," ix, p. 464.

+ Baird, "Iconographic Encyclopadia"; Wyman, Cope. 
in the same zoölogical region with a genus (Necturus) which differs from its four-toed form (Batrachoseps*) in nothing more than the possession of the osseous and branchial characters of its larva, in a permanent and reproducing condition. 'That this is a genus, to be one day converted into Batrachoseps by an acceleration of its metamorphosis, or that has been derived from it by the reverse process, I am much inclined to believe. $\dagger$ In support of this I quote the following examination into the time of change of the species of Amblystoma from my essay on that genus :

"The great difference between the different speeies, and between individual species in this respect, may be illustrated by the following comparison between the size of the animals at the time of losing the branchia, so far as known, and that to which they ultimately attain.

SPECres.
A. jeffersonianum,
A. punctatum,
A. conspersum,
A. opacum,
A. texense,
A. microstomum,
A. talpoideum,
A. paroticum,
A. tigrinum,

A. mavortium,

A. mexicanum,
Size at LOSS OF BRANCHil.

\begin{tabular}{|c|c|}
\hline \\
\hline & \\
\hline \\
\hline & $\begin{array}{l}\text { Lines. } \\
5 \cdot 75 \\
10\end{array}$ \\
\hline 1 & $10 \cdot 5$ \\
\hline 2 & 2 \\
\hline 2 & 1 \\
\hline 2 & $3 \cdot 5$ \\
\hline \multicolumn{2}{|c|}{3 (perhaps too large). } \\
\hline 3 & 75 (not smallest) \\
\hline $\int 3$ & 7 to \\
\hline$\{6$ & 7 \\
\hline $\int 3$ & $9 \cdot 5$ to \\
\hline$\{8$ & 0 \\
\hline
\end{tabular}

AVERAGE FULL SIZE.

In

2

3

8
6

$6 \cdot 1$

?

4

3

$7 \cdot 2$

8 to 10

89

Lines.

6

$7 \cdot 5$

$9 \cdot 5$

$9 \cdot 5$

$2 \cdot 5$

8

The last species, though not uneommon in collections, is not known to pass through its metamorphoses in its native country, but reprodnces as a larva, and is therefore type of the genns Siredon of Wagler, Cuvier, Owen, and others. The larva of A. movortium in like manner reproduces, but their offspring have in the Jardin des Plantes and at Yale College undergone an early metamorphosis. ${ }^{*}$

* See Cope, "Jour. Ac. Nat. Sci.," Phila., 1866.

+ Necturus differs from all true Salamanders in the possession of the os interealare of the skull; the parallelism is therefore inexact. (Note, 1856.)

‡ "Proceed. Academy," Phila., 1867.

\# Through the kinduess of Prof. Duméril I have received both larvæ and adult of the species here noted, and observed by him. The larva is, as he states, Siralon lichenoides of Baird, while the adult is his Amblystoma mavortium, not $A$. tigrinum ( $=$ luridum), as also supposed by Duméril. (Note, 1886. I now believe these forms to belong to one species.) 
Here is a case where all the species but two change their generic characters; one changes them or not, according to circumstances, and one does not change them at all. What are the probabilities respecting the change in the first set of species?

As we know from the experiments of Hogg, Dumeril, and others that metamorphosis is greatly hastened or delayed by the conditions of temperature and light, what would not be the effect on such a protean species of a change of topographical situation, such as the eleration or depression of the land? And I hare no hesitation in saying that if the peculiarities of series of indiridnals of $A$. tigrinum and $A$. mavortium, in the respects above enumerater, were permanent, they would characterize those series as species, as completely as any that zoölogists are accustomed to recognize. For the evidences on this head, see the discussions of those species in my monograph.

The experiments of Hogg, abore alluded to, are as follows, as giren by him in the "Annals and Magazine of Natural History."

He placed a number of impregnated ora of frogs in ressels arranged at regular distances from the light, in a care. The lessening degrees of light were of course accompanied by a corresponding but much less rapid decline in temperature. 'The resulting effects on the metamorphosis may be tabulated as follows:

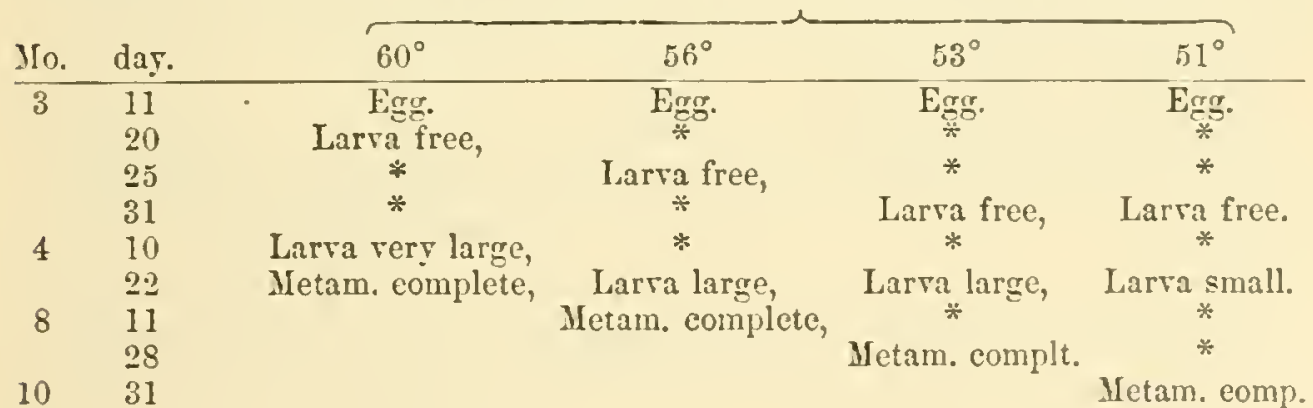

3. The reproduction of some species of insects before they complete their metamorphosis is a well-known fact, and it is particularly to the point that, in many of them, some indiriduals do attain to their full derelopment, while the many do not. Westwood says, "Two British species of this family (the Reduriidx), Prostemma guttula and Coranus subapterus, are interesting on account of their being generally found in an undereloped state, the latter being either entirely apterous or with the fore-mings rudimental, although occasionally met with having the fore-nings

* Uhler informs me that Imyot's asserted color characters are not reliable. 
completely developed." "I think," says Spinola, "that the presence of wings and their development depends on the climate"; and, in speaking of Oncocephalus griseus, he says, "The influence of the northern climate appears to have arrested the development of the organs of flight. It will be seen that I have referred elsewhere that I have noticed that it is especially in hot seasons that certain species acquire wings, while the circumstance noticed respecting the ordinary oceurrence of winged specimens of Microcolia in the West Indies is confirmatory of the same opinion."

4. It is now known that certain Orthoptera do not get through their metamorphosis in time for the period of reproduction, and hence never, or in rare instances only, develop more than a short distance beyond the pupa state.

5. My friend P. R. Uhler tells me of an example among Hemiptera of the genus Velia. The speeies V. rivulorum, Fab., and $V$. currens, *f Europe, are only distinguished by the developmental feature of the presenee of wings in one, and their absence in the other. Another species of the tropieal region of the West Indies, Halobates americanus, Uhler, is furnished with wings, while its individnals, which oecur abundantly in North America, have been generally supposed to lack them. Individuals, however, no doubt occur whose development is so far accelerated as to permit them to aequire wings before the period of reprodnetion, since one such has been found by Uhler.

These wing characters are in many cases generic, it appears to the writer; and the fact that they differ, withont corresponding specific differences, is important evidence as to the origin of the genera.

6. The females of the Lepidopterous genus Thyridopteryx never develop beyond the pupa state, according to the same anthority, before reproduction; they are reproducing pupx, so far as the external characters concerned in metamorphosis go. In other words, the latter have been retarded, while the reproductive system and others have progressed. Now, generic characters are seen in the first, not in the last. The influence of the males is sufficient to prevent more than a part of the offspring from being retarded in the same manner.

I have selected a few of this class of facts which have come before my mind during the present writing, as drawn mainly from 
my own experience. How many more of the same purport could be found by seareh through the great literature of science, or in the field of nature, may be readily imagined. I have no doubt that the field of entomology especially will furnish a great number of eridences of the theory of acceleration and retardation, especially among the insects with active pupæ.

Finally, having already stated the law according to which these processes naturally take place, I quote the following significant language of Hyatt in the abore quoted essay on the Cephalopoda, as approaching nearer to the "law of acceleration and retardation" than anything I have found written. He says:

"In other words, there is an increasing concentration of the adult characteristies of lower species, in the young of higher species, and a consequent displacement of other embryonic features, which had themselves, also, previonsly belonged to the adult periods of still lower forms."

The preceding propositions have been formulated as follows, a few additions being now made :

I. That genera form series indicated by successional differences of structural character, so that one extreme of snch series is rery different from the other, by the regular addition or subtraction of characters, step by step.*

II. 'That one extreme of such series is a more generalized type, nearly approaching in characters the corresponding extreme of other series.

III. 'That the other extreme of such series is excessively modified and specialized, and so diverging from all other forms as to admit of no type of form beyond it. $\dagger$

IV. That the peculiarities presented by such extremes are cither only in part or not at all of the nature of adaptations to the external life of the type. $f$

V. That rudimental organs are undeveloped or degraded conditions of the respective characters developed or obliterated in the extreme of the series.

VI. That the differences between genera of the same natural scries are only in the single modifications of those characters which characterize the extreme of that series.

* St. IIilaire, Owen, Agrassiz, Duméril.

† Dana on "Cephalization"; Leconte.

† Owen on "Cetacea," "Trans. Zoöl. Soc." London, 1S66, p. 44. Lccoute on "Carabida," "Trans. Amer. Philos. Soc.," 1853, p. 364. 
VII. That the relations of the genera of a primary series are those of the different steps in the development of the individuals of the extreme genus $a b$ ovo (von Baer, Agassiz) (with sometimes the addition of special adaptive features?).

VIII. That the presence, rudimental condition, or absence of a given generic character can be accounted for on the hypothesis of a greater rapidity of development in the individuals of the species of the extreme type, such stimulus being more and more vigorous in the individuals of the types as we advance toward the same, or by a reversed impulse of development, where the extreme is characterized by absence or "mutilation" of characters.

IX. And that, as the character of the genus at the period of reproduction of its species is that which is perpetuated;

$X$. So the character of the genus has been first inferior, then protean, and then advanced, as the metamorphosis has been by a retrograde movement in time, posterior to, at, or anterior to the period of reproduction.

XI. That it therefore results that there is one primary structural type involved in such a series of species, which is made to present, at any given period in its geologic history, that appearance of succession of genera ordained by Creative Power.

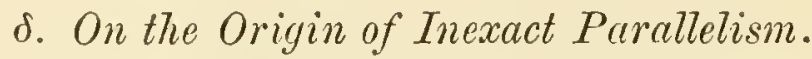

The hypothesis can only be demonstrated in case of exact parallelism. If proved in these, it readily accounts for the cases of inexact parallelism, which are of course in any single period vastly in the majority. First take the case of simple inexact parallel$i s m$. A series of individuals of the genus Didocns undergo the metamorphosis of the cranial structure earlier and earlier in life, commencing by completing the ossification of the membrane of the fronto-parietal region in full age, until at last it becomes completed as early as the period of reproduction. Heretofore the adult offspring have appeared during a long period, invariably characterized by the larval cranium; but like now producing like, this development springs into new power, and the offspring ossify the cranial bones far earlier than their immediate predecessors; in a word, the genus Pelobates has been created! At this state of progress Didocus is an undeveloped Pelobates.

Let us, however, suppose the "acceleration" of development of the cranial bones still to progress. The character appears now soon after the ordinary metamorphosis has been passed, and now 
a little before. The identity of Didocus with the undereloped Pelobates is thereupon lost!

So may have been the relations between Pelobates and Cn]tripes. Pelobates was probably once identical with the undere]oped Cultripes; but the same acceleration has concentrated the characters more rapidly than the other larval stages, learing Pelobates behind.

This I coneeive to be the explanation of this relation: when the parallelism is inexact by two steps, as in Spea to Didocus, by the obliterated ear and ossified xiphisternum. The continued concentration of characters has been carried to earlier stages till the identity exists in the adult state of neither one, but at a period of lirval life of both, shortly preceding the adnit period of the lower. The relations between the Amblystomidie and Plethodontida, which I have elsewhere * pointed out, have probably had their origin in this way.

If we attempt to prove the identity of the modern Mammalian fœtal circulation with that of the modern adult fish, we may find nearly an exact parallel in this respect, as it is the basis of class distinction; but in other respects the identity will not exist, rendering the parallel inexact or remote. The structure of the origins of the aorta is at one time identical with that of the shark, with one exception : in the former but four aorta-bows appear together ; in the latter fire. In the former the first disappears as the fifth comes into being. This is simply a continuation of acceleration. The first generalized representative of the Mammalia lost the first aorta-bow toward the latter part of its growth, and became the next genus in advance of the selachian. 'The fact that these bows do not appear exactly simultaneously, but rather successively, renders it necessary that in a regularly shortening period of possession of transitory characters, one siich, as the existence of the first aorta-root, should ranish before the appearance of a permanent, the fifth, in the more specialized types, where acceleration reaches its maximum. This is indicated by the fact that in the Batrachia, where the acceleration has not attained so high a degree, the first and fifth aorta-bows co-exist for some time, though the first and second disappear before maturity.

So also with the splitting of the bulbus arteriosus. As in the Batrachia, the pulmonary ductus communis only is to be sepra- 
rated; the remaining bulbus is divided by a long valve or incomplete septum, tracing the division of the aorta-roots. In the serpent (Rathke) this division is so accelerated as to appear at nearly the same time as the septrm of the pulmonary duct. In the mammal, on the other hand, while the division of the aorta-root takes place as soon as in the last, the pulmonary septum is accelerated so as to appear long before the first named. Hence, in the septa in the serpent, the singular anomaly seems to present of the mammal passing through the Batrachian stage, while the serpent, a nearer relative, does not.* If, howerer, we take the less typical serpent, we will find the aortic septum to appear a little later, thus giving the Batrachian type, and if we reverse the order of time, so that the succession becomes one of retardations, we will find the same known ratio will bring us to an identity under all circumstances.

This, then, is the explanation of the divergence and want of "exact parallelism," which is observed in comparing the develop. mental histories of all types not most closely allied. It has not, according to our theory, always been a divergence, but was at a prior epoch in each case a relation of "cxact parallelism," the lower type a repressed higher; the former identical with one of the stages of the latter. But the process which has produced this relation, continned, has of necessity destroyed it, so that the exact parallelism has always been a temporary relation, and one shifting over the face of the system.

\section{OF HIGHER GROUPS.}

First. Comparison of the contemporary.

Having now admitted a developmental succession of genera, and, second, that this has progressed more rapidly at certain times in the earth's bistory than any modification of specific forms, the hypothesis already broached naturally comes up : Has such transformation of types, goneric or higher, taken place in any degree simultancously, throughout a great number of species? An affirmative answer to such a proposition is absolutely necessary to its acceptance as expressing the phenomena exhibited by geological succession of types. Let us try to answer the question put in a closer form. Have the same speeies been transferred from one

* This is the way indeed in which it is stated by Rathle, "Entwickelungsgeschichte der Natter," p. 164. 
geologic epoch to another by a change of generic form; and has not the genus been transferred from one epoch to another inder change of ordinal type, and as a consequence the same species?

As a reply I propose to render the affirmative of the first of these questions lighly probable.

Paleontology only will be able to answer this question conclusively, though, as we have abundant eridence that the relations of species to genera and other higher groups were the same then as now, we may look to the present status as furnishing important evidence on the subject. We are turned at once to the probable history of development in the separate zoölogical areas of the earth's surface. The question may be asked, Are the present zoological regions on an equal plane as to the geologic relations of their faunæ, or are they related as the different subdivisions of a geologic period in time?

I have on a former occasion asserted that the latter of these propositions was true.*

\section{a. Of Homologous Groups.}

Naturally following the admission of a derelopmental succession of organic beings is the question of its relation to the different surfaces of land and water on the earth. The following considerations bear on this subject.

Among the higher groups of animals can be detected series "homologous" on the same principle as the alcohols (? compound radicals) and their derivatives; and the component types of each can be, and have been in many instances, shown to be "heterologous," as are the cthers, mercaptans, aldehydes, acids, etc. Among Mammalia two partly homologous series have been pointed out, Implacentialia and Placentialia; possibly such are the types Altrices and Prrecoces among Ares; of a lesser grade in this class are the parallel series of Pullastræ and Gallinæ, of Clamatores and Oscines. Among tortoises I have alluded to the Plenrodira as compared with the remainder of the order, already parallelized by Wagler; and, of lesser grades, the series among Lacertilia of Acrodonta and Ignania, parallelized by Duméril and Bibron, and of Teidx and Lacertidæ, compared by Wiegmann. I have discorered a full parallelism between the Raniform and Areiferous Anura. It is carried out between the Characini and a group of remaining Physostomous Fishes, perhaps not yet well defined; it

*On "Arciferous Anura," "Journ. Ac. Nat. Sci.," 1866, p. 108. 
is exhibited between the orders Diptera and Hymenoptera among insects. None of these comparisons can be allowed, of comrse, without the most searehing anatomical and embryological analysis.

This heterology is what Swainson and others called "analogy" as distinguished from affinity. It generally relates genera of diiferent zoölogical regions. Mimetic analogy, on the contrary, relates genera of the same region; it is a superficial imitation which has occurred to eritical biologists, and is of much interest, though as yet but little investigated. It has as yet been observed in external characters only, but occurs in internal also; it has been accounted for in the first case by the supposed immunity from enemies arising from resemblance to well-defended types. No such explanation will, however, answer in the latter case. I believe such coineidences express merely the developmental type common to many heterologons series of a given zoölogical "region" ; this will be alluded to a few pages later.

We naturally inquire, Is there anything in the food, the regetation, or the temperature to account for this apparent diversity in the different regions? Are there not carnivora, herbivora, seed-eaters, insectivores, and tree-climbers, where game and grass, seeds and insects and forests grow the world over? We answer undoubtedly there are, and these adaptations to food and climate are indeed as nothing in the general plan of creation, for every type of every age has performed these functions successively.

\section{Of Heterology.*}

This relation will be exhibited by a few examples from groups known to the writer, commencing with the Batrachia anura.

External metatarsal frec.

RANIFORMES.

Aquatic.

Metatars. shovel.

External metatarsal attached.

Metatars. shovel.
Rana.

Hoplobatrachus.
Pyxicephalus.
ARCIFERI.

Pseudis.

Mixophyes.

Feet webbed.

Tomopterna.

* Some of the cases below eited as heterology I believe to be truly of this character; but some others are probably not such, but are merely series of genera presenting similar structural peculiarities as consequences of the operation of identical laws. I would place under this head, and withdraw from the homologous class, the families of Laccrtilia Leptoglossa, Diploglossa, and Typhlophthalmi, those of the Old and New World Quadrumana and those of Cephalopoda. These distilict modes of origin of corresponding forms have been recently termed, by Lancaster, homogeny in the ease of homologous groups, and homoplassy when the initative types are on distinet lines. (Ed. 1886.) 


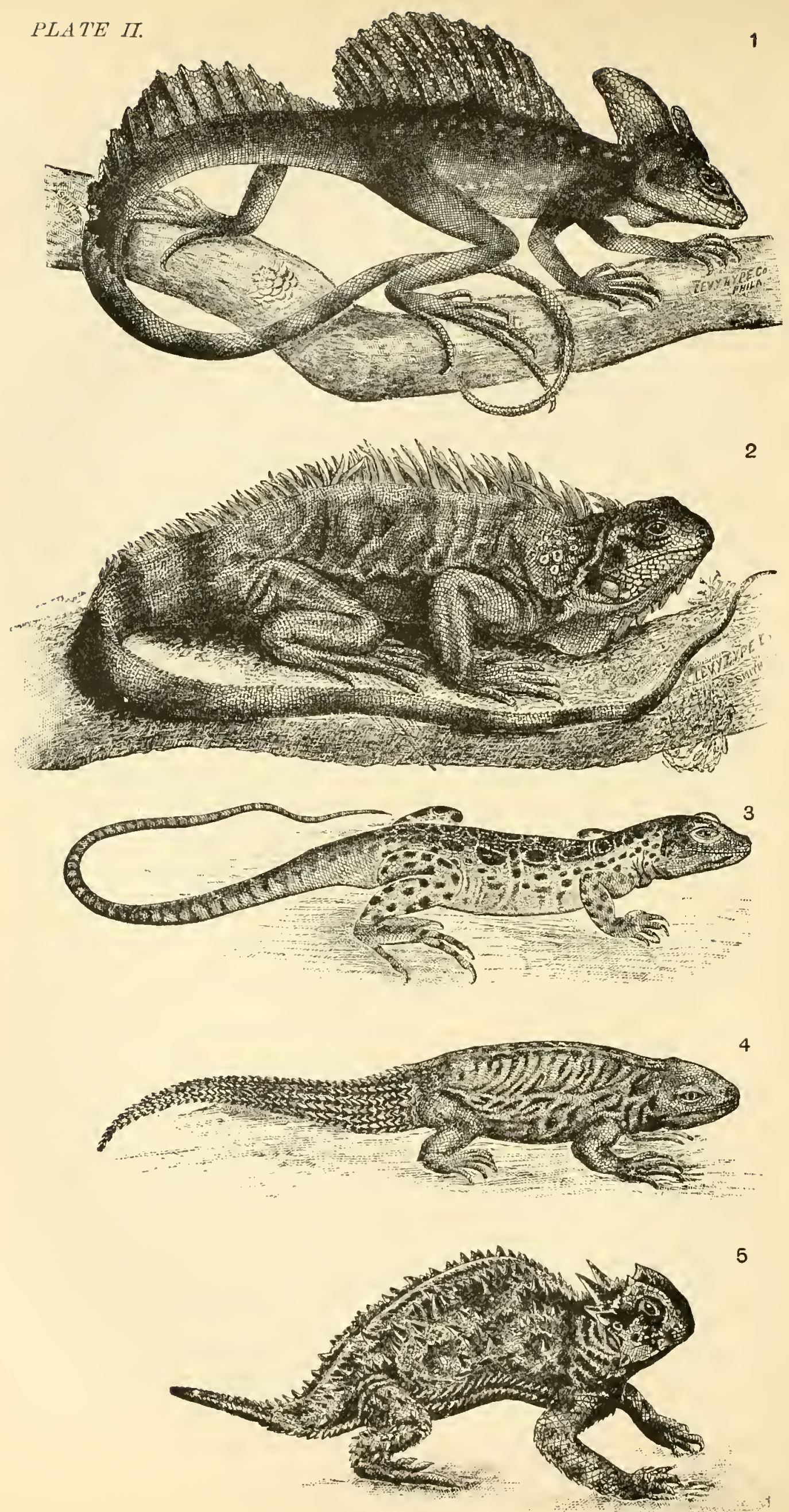



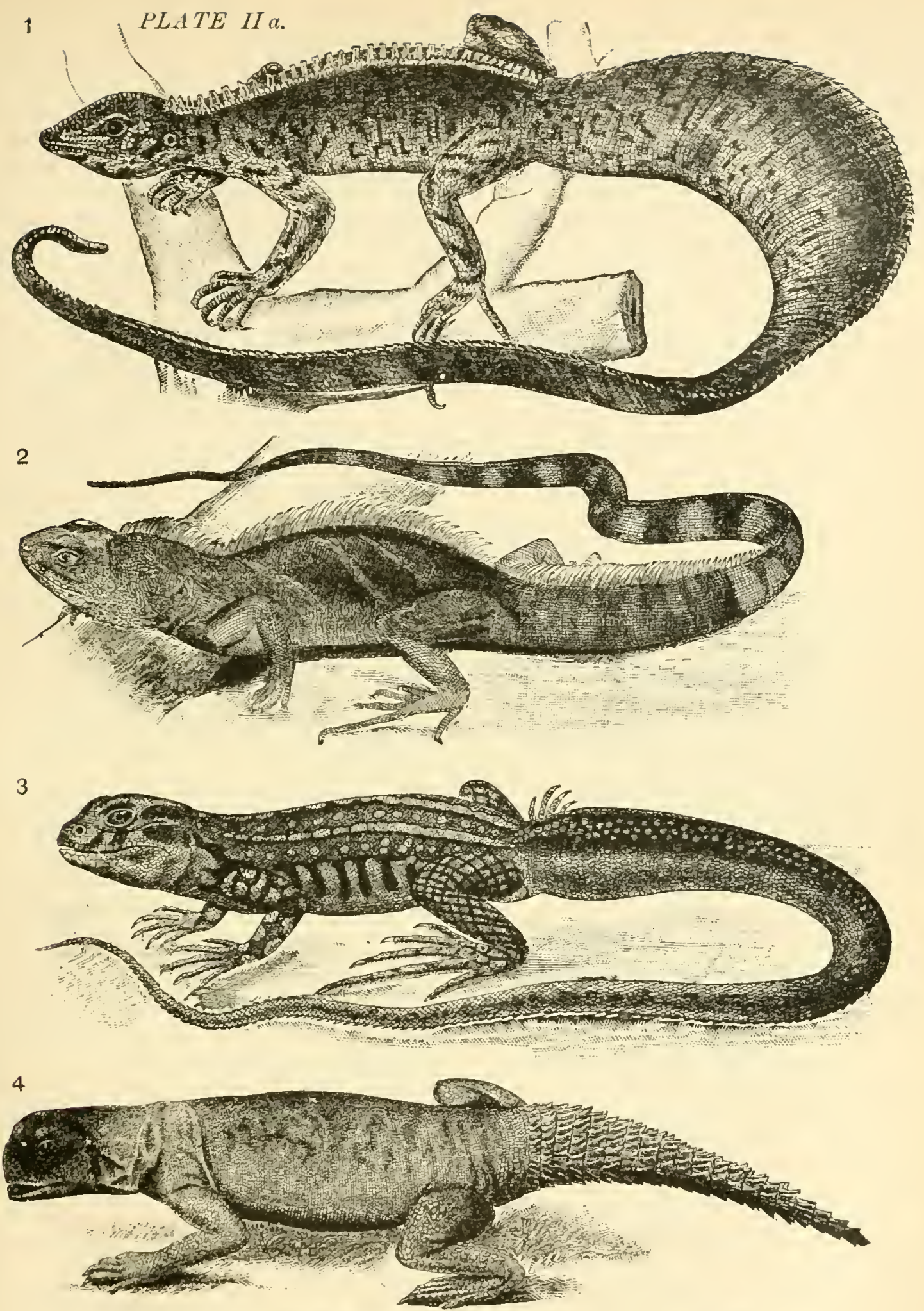

5

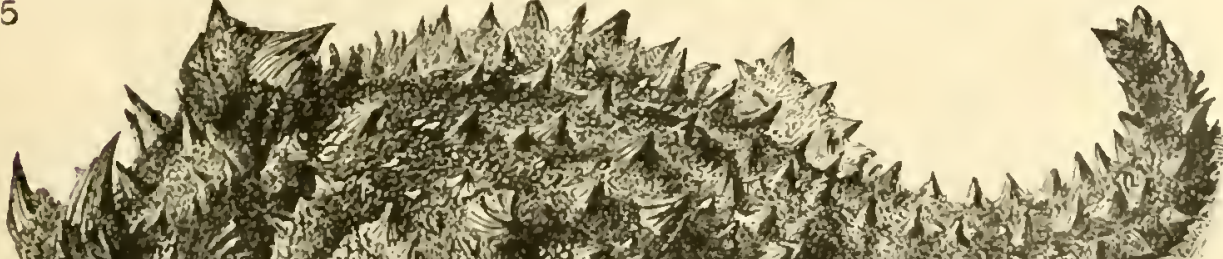

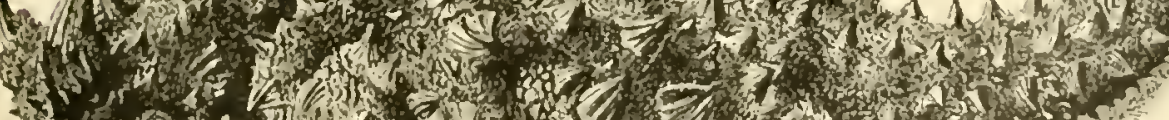

(1)

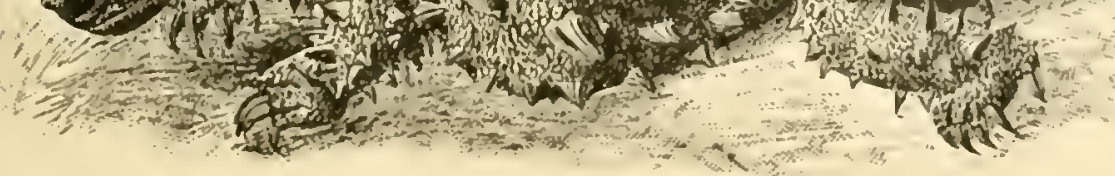




\section{PLATE II.}

Figures of Lizards of the family Ignanida to be compared with a homologous series of Agamidre represented in Plate II $a$. The speeies are:

Fig. 1. Basiíiscus plumifrons Cope, Costa Riea. From Cope.

Fig. 2. Iguana tuberculate Linn., South America. From the "Standard Natural History."

FIr. 3. Crotaphytus wistizeni B. G., Sonoran Region of North America. From Baird.

Fic. 4. Phymaturus palluma Grav., Chili. From Bell.

Fıg. 5. Phrynosoma cornutum Harl, Texas. From "Standard Natural History."

\section{PLATE II $\alpha$.}

Figures of Lizards of the family Agamide which form a homologous series with the Iguanidx represented on Plate II.

Fig. 1. Lophura amboinensis Schloss., Amboina. From Wagler.

Fig. 2. Physignathus mentagcr Günther, Siam. From Günther.

Fig. 3. Liolepis bellii Gray, China. From Duméril and Bibron.

Fig. 4. Uromastix spiuipes Cuv., Arabia. From Guérin.

Fi(. 5. Moloch hovridus Gray, Australia. From "Standard Natural History." 
RANIFORMES,

Arboreal ; rom. teeth. Leptopelis. " no " " Hyperolius.

Subarboreal.

Terrestrial. "s spurred,
Hylambates.

Feet not webbed.

Cassina.

Hemimantis.
ArCifERi.

Hrla.

Hylella.

Nototrema.

Cystignathus.

Gomphobates.

Comparing the genera in a general physiological sense, we may parallelize further.

Aquatic, with digital dilatations.

Heteroglossa.

Acris.

$\left.\begin{array}{c}\text { Arboreal ; cranium hy- } \\ \text { perostosed. }\end{array}\right\}$ Polypedates.

" cranium free. Rhacophorus.

Trachycephalus.

$\{$ Hyla.

$\{$ Agalychnis.

The same kind of parallels exists between the primary groups of the Testudinata, as follows:

Criptodira.

Pleurodira.

Five complete pairs of bones aeross the plastron.

Pleurosternidæ.

Sternothæridæ.

Four pairs of bones across plastron; not more than two phalanges on all toes.

Three phalanges on most digits;

Testudinida.

Pelomedusidæ.

Zygomatic arch; no parieto-mastoid.

Emydida.

Temporal fossa orer-roofed by parietal. Mrerochelys.

No zygoma; a parieto-mastoid areh. *

Podocnemididæ.

Podocnemis.

Hydraspididæ.

If we compare the peculiarities of generic structure merely with reference to their adaptation to the animals' habits, we will see the following :

Feet reduced for terrestrial progress.

Cryptonira.

Pleurodira.

Testudinidæ.

Feet normal.

Anterior lobe of sternum morable.

Cistudo.

Cinosternum.

Pelomedusidx.

Anterior lobe fixed.

Neck very elongate.

Neck shorter; aquatic.

Trionychida.

Sternothærus.

Temporal fossa npen.

Temporal fossa over-roofed.

Emydidæ in gen. Mydraspididre.

Cheloniidæ.

Podocnemis.

The parallels between the genera of the American Iguanidx and the Old World Agamide are similarly quite close. They are shown on Plates II and II a. 
Abdominal ribs.

IGUANIDE.

Polychirus.

No abdominal ribs.

Ribs greatly prolonged into a lateral wing.

Ribs not prolonged.

Arboreal types, generally compressed.

A dorsal and caudal fin supported by bony rays.

No vertebral fin.

Basiliscus (no fem. pores). Lophura (pores).

No femoral pores.

Form slender, scales in equal series.

Form elongate; cyebrows elevated, tail compressed.

Form stouter, seales less regular.

Low crested; small hyoid disk.

High crested; large hyoid disk.

Tail with spinous whorls.

\section{Terrestrial types of fiattened form. \\ Cyclura.}

Calotes.
Bronchocela.

Gonyocephalus.

Hypsibates.

Femoral pores.

Brachylophus.

Iguana.

Draco.

AGAMIDE.

$$
\text { * * }
$$

Læmanctus.

Ophryoëssa.

Tiaris.

Diporophora.

$\underset{*}{\text { Plysignathus. }}$.

Tail with whorls of spiny scales.

Femoral pores.

Tail long, simple; scales small.

Tail simple, scales large.

Hoplocercus.

Crotaphytus.

Sceloporus.
Uromastix.

$\underset{*}{\text { Liolepis. }}$

No femoral pores; preanal pores.

Tail with whorls of spines.

Tail simple, not elongate, ear open.

Proctotretus.

Stellio.

Agama.

Neither femoral nor anal pores.

Much flattened, tail short, scales irregular.

Ear exposed.

Ear concealed.
Phrynosoma.

(Doliosaurus, s. g.)
Moloeh.

I Phrynocephalus.

(Megalochilus.

A similar parallel may be drawn between the American Teidæ, and the Old World Lacertidæ, and in fact between all the families of the Lacertilia Leptoglossa. I have added to these for comparison two families of the Typhlophthalmi. Each family embraces one or more series, and these exhibit a renarkable similarity in the relative development of the limbs and digits; among the higher groups the parallelisms lie in the arrangement-as greater or less separation-of the head shields. The Scincida are cosmopolite; the Gymnophthalmidæ, which have the eyelids of their fotus, are Australian ; the Sepsidæ, either larval or senile in head shields, are mostly Ethiopian. 


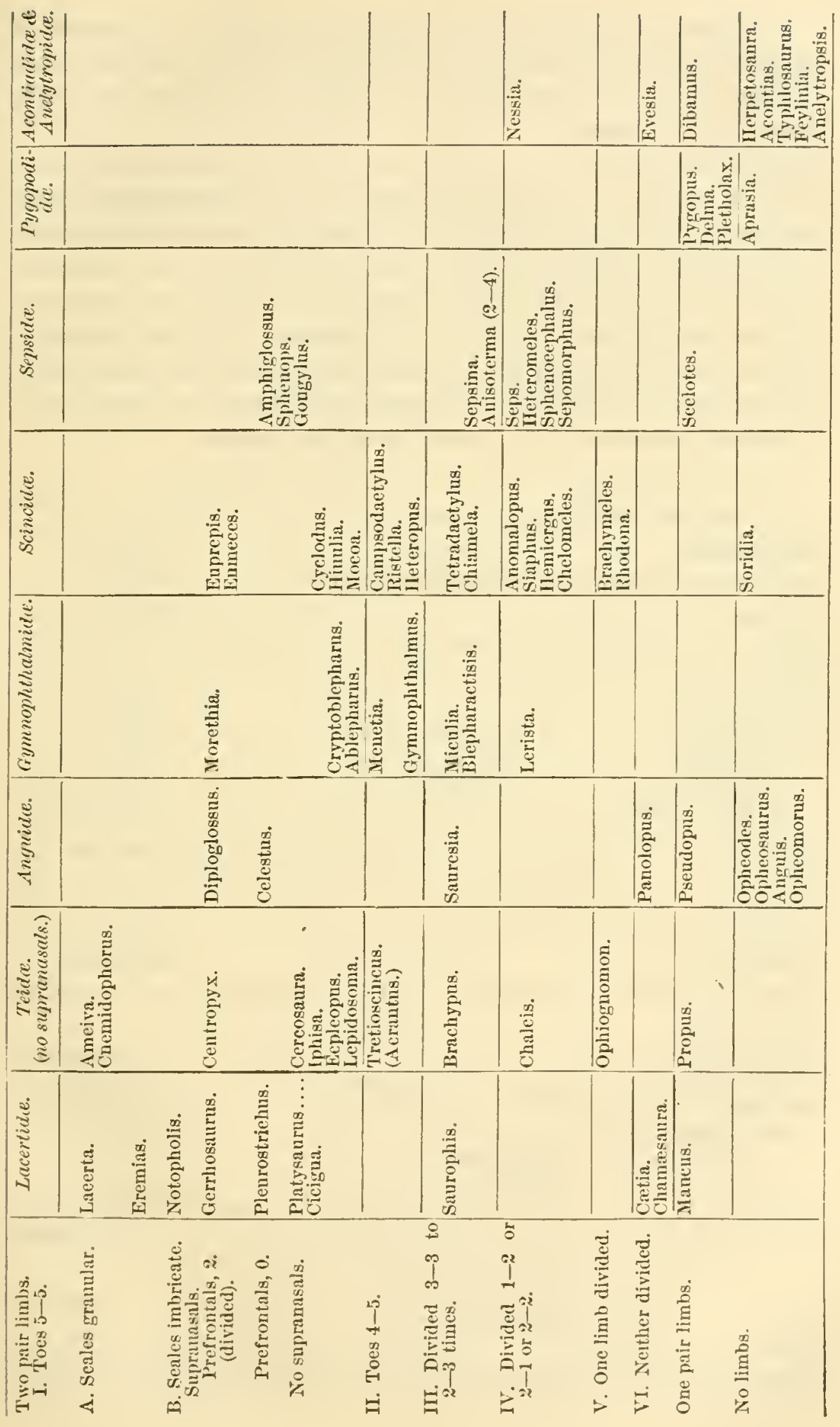


The first comparison of these groups was made by Wiegmann (Herpetologia Mexicana), who employed, however, only the Scincidæ and Lacertidæ, and conld not include the many types made known since his day.

From the class Aves I have selected only the homologous series of the Clanatorial and Oscine Passeres. Naturalists more fully acquainted with the genera conld probably increase the examples of heterology largely. Each group furnishes us with carnivorous, insectivorous, and frugivorous forms; each with walkers, climbers, and sedentary genera ; each with butcher-birds, thrushes, warblers (not in song!), wrens, and fly-catchers. Each and all of these types are teleologically necessary to any country complete in the wealth of nature, and to each geological period.

Clamatores.

Oscines.

I. Tree-climbers, with long hind toe and tail feathers stiffened and acute. Dendrocolaptidie.

Certhiidos.

II. Terrestrial in part, with the tertials as loug as the primary quills. Gcobatide.

Motacillidop.

III. Tree-perchers with hooked bill, graduating from powerful to medium and slender.

Formicariide

Thamnoptilus.

Formicarius.

Formicivora.

Rhamphoccemes.
Bill strongest, hooked.

" moderate.

" weak.

" slender (wrens).
Turdido.

Lanius.

Turdus.

Sylvia.

Troglodytes.

IV. Fly-catchers with flat bill and weak legs; wait for their prey and take it on the wing.

\section{Tyranuide.}

Druscicapa et aff.

V. Flat-billed berry and fruit caters.

\section{Cotingidce.}

Bombycillida.

From the Mammalia the well-known series of the Marsupialia and Placentialia may be chosen.

Placentialia.

Marstialia.

I. Toes unguiculate, in normal number; sectorial tecth; i. e., one or more molars with one or no internal tubereles; canines strong:

Carnivor"a.

I. Digitigrade.

Sarcophaga.

Toes $5-4$.

Amphicyon.

True molars $\frac{3}{3}$ (upper incisors more numerous in some).

II. Plantigrade; molars tubercular.

Thylacinus. a. Posterior molars $\frac{4}{4}$.

aa. Posterior molars $\frac{2}{2}$.

Ursidæ.

II. Toes unguiculate; molars with more than one row of pointed tubercles; canines weak or none; incisors large. 
Inscctivora.

a. Tubereular molars $\frac{4}{4}$, toes $4-5$. Tail naked.

Gymnura.

Cladobates.
Entomophaga.

Didelphys.

Myoictis

IV. Molars with transverse crests, no canines; tusk-like incisors; pairs of limbs of similar proportions.

Proboscidia.

Diprotodontidee.

Two inferior incisors; molars with two eross-crests; size huge.

$*$ *

a. Two rudimental lateral incisors above.

Dinotherium. ax. ? One pair of incisors only above; a trunk.

Diprotodon.

V. No canines; two pairs of cutting incisors.

Rodentia. a. Three true molars.

$*$

*

Rhizophaga.

The parallels are in this case very imperfect in details, and but few worthy of the name can be made. They are, however, illustrative of a remote heterology, sufficiently remarkable to have claimed the notice of naturalists for many years.* I also have little doubt but that future paleontological discoveries will increase the number of parallels, $\uparrow$ and bring to light truly heterologous generic terms of the Marsupial series. Predictions of this kind have been on many occasions fulfilled (e. g., some of D'Orbigny's among the Cephalopoda), and I look with confidence to the ultimate demonstration of that heterology here which has been already seen in the Batrachia and Reptilia.

The homologous groups of the Catarrhine and Platyrrhine Quadrumana are measured as follows:

Tailless.

Tail short.

Long tail.

Thumb developed.

Thumb rudimental.

Thumb none.
Catarrhini.

Andropithecus.

Simia.

Hrlobates.

Crnocephalus.

Miacacus.

Cercopithecus.

Semnopitheeus.

Colobus.
Platyrrhini.

*

*

*

Brachyurus.

Lagothrix.

Mycetes.

Brachyteles.

Atcles.

* We owe very many observations on the Marsupials to Owen.

t The extinct carnirorous family of the Nimraride which forms a homologous series with the cats (Felidx) was discovered by the writer some years after this was written. (Ld. 1886.) 
I append two homologous series, represented by the Nautilea and the Ammonites of the Tetrabranchiate Cephalopoda, which are distinguished, the first by the simple septa and the siphon central or marginal ventral ; and the second by the complex and folded septa and siphon central or marginal dorsal. The parallelisms have been noted by Barrande, Bromn, and many conchologists, who can furnish a much more full table than the following, from the most recent sources:

NAUTILI.

Ammonites.

A. The shell straight, unwound.

Orthoceras.

B. The shell more or less curved or wound.

Baculites.

a. Simply curved.

Cyrtoceras,

Phragmoceras, $\}$

Toxoceras.

$a \alpha$. A more or less straight portion, folded on the remainder.

$\beta$. Folded portion in close contact with remainder.

Ascoceras.

$\beta \beta$. Folded portions not in contact.

Ptychoceras.

?

$a \alpha a$. One extremity spirally wound, the volutions not in contact.

$\beta$. Extremity of the shell prolonged beyond the wound portion.

Lituites.

$\beta \beta$. Extremity not prolonged in a line.

Ancyloceras.

$\gamma$ The spiral flat.

Gyroceras.

Trochocerus.

$\gamma \gamma$. The spiral elevated (heliciform).

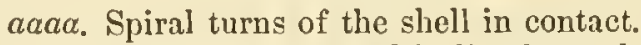

$\beta$. Evtremity prolonged in line beyond the spiral.

$\beta \beta$. Extremity not prolonged beyond spiral.

Crioceras.

Turrilites.

*

Nautilus.

Scaphites.

Ammonites.

We may now consider the question of the origin of these higher groups. In the first place, we must lay down the proposition that the characters which constitute groups "higher" in the comparison of rank (we do not of course mean higher in the same line, as we say higher genus in a family, or higher order in a class) are such solely from their being more comprehensive, or present throughout a greater range of species.

What is true, therefore, in respect to characters of genera, is likely to be true in respect to characters of higher groups, such as we have been considering in the preceding pages. Believing, then, that a new genus bas been established by the transition of a number of species of a preceding genus in order, without necessary loss of specific characters, I think the same process may have established the suborders and orders in question. That is, that a large number of genera have near the same time, in past or pres- 
ent geological history, pussed into another suborder or order by the assumption or loss of the character or characters of that to or from which they were transferred, and that without necessary loss of their generic characters.

I will cite a probable case of this kind, the facts of which I hare already adduced.

It has been shown above that the genera of six of the families of the Batrachia anura form series characterized by the successive stages of ossification of the skull, terminating in a dermoössified condition, with over-roofed temporal fossæ. That in nearly all the other families similar relations between genera exist, but are nowhere carried so far. The character attained by all the first series is now only generic; but should all the genera of each of the six families assume this character in time, as is necessary in accordance with a derelopment hypothesis, it would at once possess a new and higher importance, and would become ordinal or otherwise superior. It would define a series homologous with all those types which had not attained it. This character of the over-roofing of the temporal fossæ has actually attained a family significance among the Testudinata-e. g., as defining the marine turtles; and similar characters are found by Owen to characterize the Labyrinthodontian order of Batrachia."

Agassiz has pointed out a similar and more extended case, in the Heterocercal and Homocercal ganoids. Had we not so many of the closest approximations between members of these groups, they would stand in the systems as two great homologous series, with their contained heterologous genera. As it is, these heterologous terms or genera are evidently so nearly allied that Agassiz, in the "Poissons Fossiles," has thonght it best to arrange the latter together, thus instituting a system transverse, as it were, to the other. This may be necessary, since Kölliker points out transitional forms, and perhaps certain types may have begun to abandon the heterocercal form near the period of reproduction, producing offspring somewhat protean in character, preparatory to an earlier appearance and consequent permanence of the lomocercal type. This is to be derived from the history of the metamorphosis of Amblystoma.

In the same manner the development of the convolutions of the brain does not define groups of the highest rank, since it pro-

* The roof here alluded to by Owen ineludes some tro distinct bones not known in the arch of the Anura, and therefore different. 
gresses chiefly during the later periods of embryonic life, and is therefore a "developmental character." Owen has endeavored to distinguish the primary divisions of Mammalia by the character of these convolutions, whereas they really define only the subgroups of the orders. For we have Lissencephalous (smoothbrained) monkeys-certain lemurs-and smooth-brained Ruminants-i. e., the extinct Brachyodon and Anoplotherium, according to Lartet and Gratiolet. The lowest types of the existing smooth-brained Mammalia, including especially those with no or rudimental corpus callosum, the Marsupials, are also distinguished by the non-development of the deciduous teeth * (excepting one premolar). If now, through some topographical change, the whole series of Mammalia between the smooth-brained and convolute-brained were lost to us, as by the elevation of a region, and the absence of favorable localities or borlies of water for the preservation of their remains, we would have to study two homologous groups, with the heterologons terms of each corresponding with each other, as do now the genera of the Clamatores and Oscines of the Arcifera and Raniformia, etc.

In the same way the characters defining Implacental Mammalia will be found transitional in some type, and this great series, homologons with the Placentals, will have to be placed in closer connection, in its genera, with the series of the latter, with genera of the same, perhaps, now extinet.

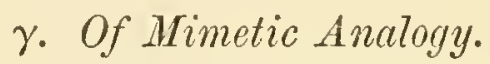

It has been often remarked that the animals of the Equatorial Ethiopian region were very generally of smoky and black colors. This is remarkibly the case, and the peculiarity of the genus Homo in this respect is shared by birds, reptiles, and fishes in a considerable degree. This can not be traced to the effect of torrid climate, for the same latitudes in India and the Malaysian Archipelago, and in South America, do not produce such colors.

The similarity in color of desert types has also been remarked. The gray sand-hue so well adapted for concealment is miversal, with few variations, in the reptiles of the Tartar and Arabian

* This I have alluded to as the non-development of the permanent series; the homology of the dental system of Marsupials appears, however, to be with the latter and not with the milk series. See "Flower," "Trans. Roy. Soc.," 1867. (Wortman now denies the correctness of Flower's view, and demonstrates that the milk series is primitive. Sce "Encyclopædia of Dentistry," 1886. Ed. 1886.) 



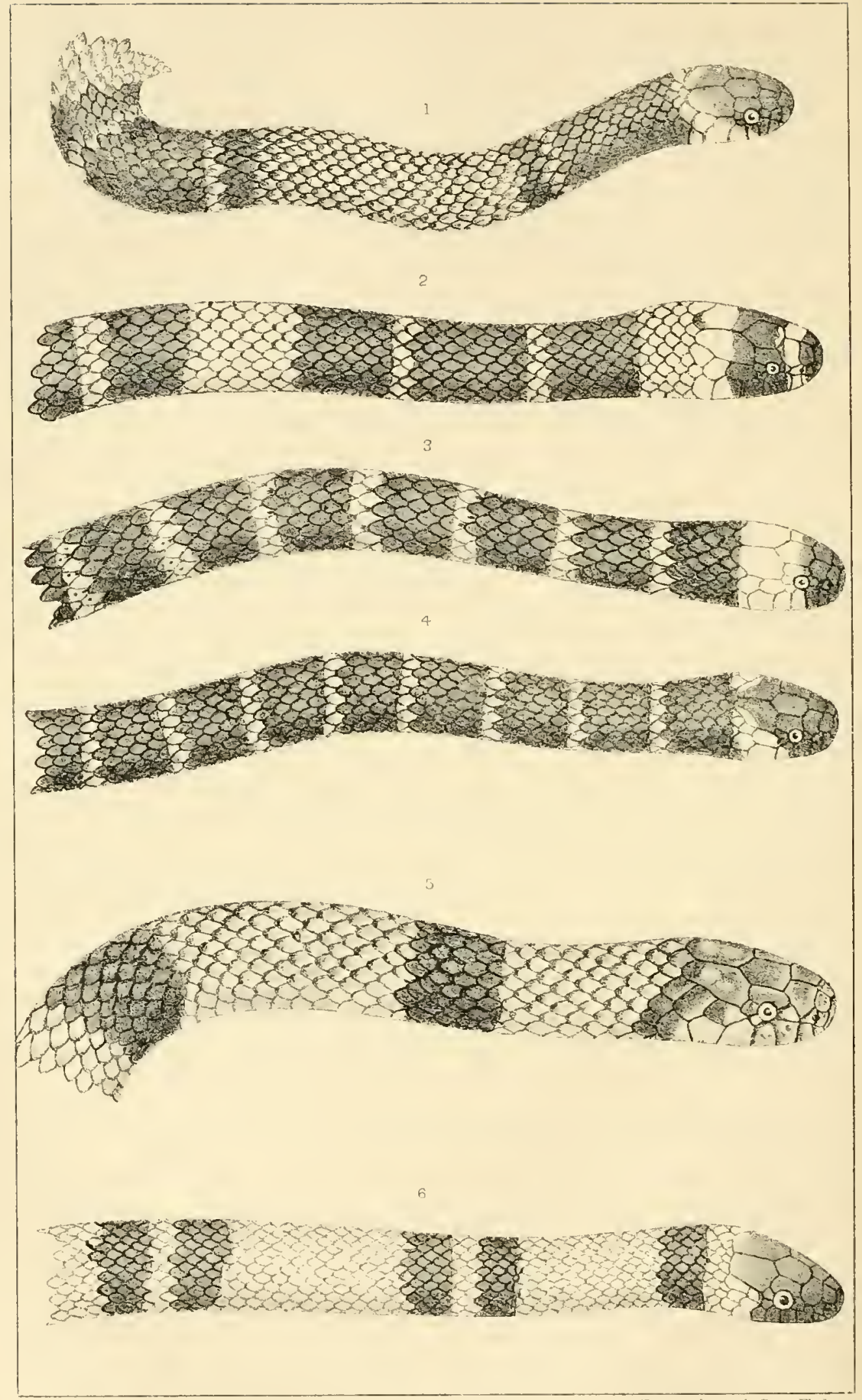






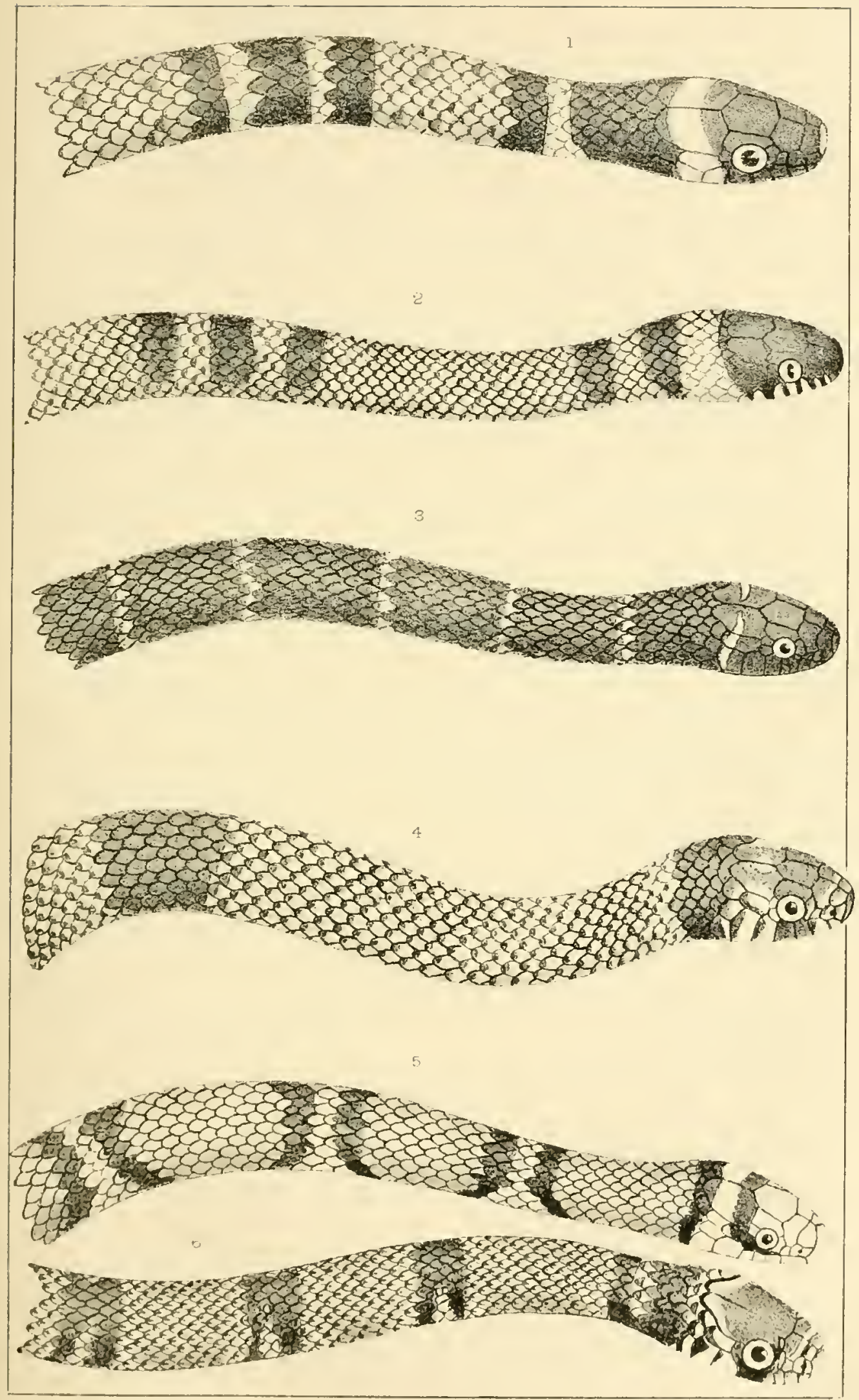




\section{PLATE III.}

Fır. 1. Elaps dumerili Jan; New Granada.

Fig. 2. Elops lcmmiseatus I.: Brazil.

Fia. 8. Elaps somipartitus D. and B; New Granadia.

Fig. 4. Elaps psyche Daurl.; Brazil.

Frg. 5. Elaps corallinus Linn.; Brazil, Central America.

IIt. 6. Opliboles doliatus Linn.; Southern United States to Central America.
PLATE III $\alpha$.

Fig. 1. Plioereus clapoides Cope; Mes. ico.

FIG. 2. (xymolopus trigcminus J). and B. ; Brazil.

Frg. 3. Pliocereres curyzonus Cope; New Granada.

F1c. 4. Erytherolamprus csculapii L. ; Brazil.

Fig. 5. Cemophore coscince Blum.; Southern United States.

Fic. 6. Erythrolemprus venustissimus Nenw. ; Brazil, Centr'l America.

The species placed opposite to each other present similar patterns of coloration. Figs. 3 and 4, Plate III, eorrespond with Jig. 3 , Plate III $q$, ank I"ig. 6, Plate III, with Figs. 5 and 6 , Plate $I I a$. The speeies inhabit the same regions, more or less exactly, excepting the two Figs. 1. The Elaps dumerili would have been better replaced by a variety of the Eleys fulvius of Mexico, which has the red spaces black bordered; but a gool colored plate was not aceessible at the time the drawing was made. All the figures are copied from Jan's "Iconographic Générale des Opliiaiens "; and the colors of such as I have not at liand for reference (Elaps dumerili,

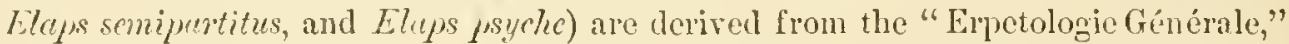
anu from Jan's "Prodrome." The species of Elaps are poisonous; the other's are liamless. 
deserts, the great Sahara and the sands of Arizona and California. There is also a tendency to produce spiny forms in such places; witness the Stellios and Uromastix and Cerastes of the Sahara, the Phrynosomas and horned rattlesnake of Southwestern America. The regetation of every order, we are also informed, is in these situations extremely liable to produce spines and thorns.

The serpents of the Neotropical region furnish remarkable illustrations of mimetic analogy. All the species of the genera Elaps, Pliocercus, Erythrolamprus, and many of those of Oxyrrhopus, Ophibolus and Rhabdosoma are ornamented with black and yellow rings on a crimson ground. The species of all these genera are harmless, except in the case of Elaps, which is renomous. We may give for this genus, as the most raried, the following range of variation in coloration :

Pairs of black rings; $\quad$ Single black rings, far apart. Single black rings, very close.

Elaps corrallinus.
nigrocinetus. c
Pliocercus equalis. c
Oxyrrhopus?

Oxyrrhopus?
Erythrolamprus albostola. Scolecophis zonatus. a

Erythrolamprus renustissimus. a

Ophibolus polyzonus. a

Xenodon bicinctus. $\mathrm{b}$

Single black rings with faint Black rings in threes. latcrals.

Elaps fulvius.

elegans. a

Pliocercus elapoides. a

Procinura amula. a
Elaps mipartitus. d

Pliocereus euryzonus. d tus. b

Elaps lemniscatus. b

Oxyrrhopus trigeminus. b Pliocercus elapoides var. a

Leptognathus anthracops. a
Single black rings about equal to intcrvals.

Elaps.

Pliocereus dimidiatus. a

Catostoma semidoliatum. a

Oxyrrhopus sebæ. d

Ophibolus pyrrhomelas. h

Chionactis occipitale. b

Sonora semiannulata. $\mathrm{h}$

Contia isozona. h

Chilomeniseus ephippicus. h

Species a, from Mexico and Central America. (Two species are now added, 1886.)

$\begin{array}{cccl}\text { " } & \text { b, " } & \text { Brazil, Venezuela. } \\ \text { " } & \text { d, " } & \text { Central America. } \\ \text { " } & \text { h, } & \text { " } & \text { Arizona side of Andes. Sonora. }\end{array}$

Many of the species in the same column are exceedingly similar, and some have little (perhaps nothing) to distinguish them but generic characters. The most similar are almost always from the same sub-region.* These facts are illustrated in Plates III and III a.

* Similar parallels exist betwcen the Mexiean species of Rhadinaca, Conophis, and Erythrolamprus ( $=$ Coniophanes). (Note, 1886.) 
Similar analogies have been pointed out by Bates among the Lepidoptera of Brazil, and by Wallace among those of Borneo and Celebes, etc. I call attention to these authors here without copying them, as they will repay perusal in the originals.

A case of analogy which may belong to this class is that of the three genera Chelys among tortoises; Pipa among frogs, and Aspredo among Siluroid fishes, species of which inhabit at the same time the rivers of Guiana. The crania of these genera are similarly excessively flattened and furnished with dermal appendages, and their eyes are very minute. 'The singular similarity need only be mentioned to those familiar with these genera, to be reeognized.

The bearing of the mimetic analogy, on the question of transition of types in the developmental hypothesis, is its demonstration of the independence of generic and speeific charaeters of each other, which may suggest the possibility of the former being modified withont affecting the latter.

These facts might have been introduced under Section II $a$, but they illustrate the general laws of the present section.

\section{OF NATURAL SELECTION.}

\section{a. As affecting Class and Ordinal Characters.}

The second law which may be supposed to have governed a descent with modification, in the production of existing genera, is the foree which the environment exercises in permitting or forbidding the existence or persistence of new forms. The forms which survive are supposed to have done so by virtue of their superior adaptation to their enviromment. This is the "natural selection " of Darwin.

That this law is subordinate to the one first propounded must, I think, be evident to any one who studies the assumed results of the workings of both, as seen in the characters of genera. It is sufficiently well known that the essential features of a majority of genera are not adaptive in their natures, and that those of many others are so slightly so, as to offer little ground for the supposition that this necessity has preserved them.

Both laws must be subordinate to that unknown force which determines the direction of the great series. If a series of suppressions of the nervous and circulatory systems of beings of common birth produced the "synthetie" predecessors of the classes of Vertebrata, the direction toward which the highest advanced, 
or its ultimate type, can be only ascribed as yet to the divine fiat. So far as we can see, there is no reason or law to produce a preference for this direction above any other direction.

If from these fixed bases descendants have attained to successive stations on the same line of progress, in subordinate features of the nerrous and circulatory systems, constituting the "synthetic" predecessors of the orders in each class, the type finally reached seems to rest on no other basis than the pleasure of the Almighty.

\section{As affecting Family Characters.}

If from the single species generalizing a modern order we attempt to deduce synthetic predecessors of existing families, we find some difficulty, if we attempt to see in these stages a uniform succession of progress. A suppression of some features, and advance in others, in one and the same individual up to the period of reproduction, would produce offispring divergent from the start, and represent the relationship of families as we find them.

\section{\%. As affecting Generic Characters.}

If the extremes of our series of genera were characterized by structures particularly adapting them above all others to some contemporary necessity of existence, this second law, or Darwin's, might be regarded as primary. But the writer's experience of comparative anatomy has led him to believe that this is not the case, as expressed in Proposition IV, page 91.

This riew had not been overlooked by Darwin, who, however, treats of it very briefly, and appears to attach it to the theory of adaptations, or modifications for a physiological purpose. He says, "Origin of Species," page 388 (Amer. edit., 1860) : "We may extend this riew to whole families, or even classes. The fore-limbs, which served as legs in the parent species, may become, by a long course of modification, adapted in one descendant to act as hands, in another as paddles, in another as wings; and on the above two principles-namely, of each successive modification supervening at a rather later age, and being inherited at a correspondingly late age-the fore-limbs in the embryos of the several descendants of the parent species will still resemble each other closely, for they will not have been modified. But in each individnal new species the embryonic fore-limbs will differ greatly from the fore-limbs in the mature animal; the limbs in the latter have undergone much modification at a rather late period of life, 
and having thus been converted into hands, paddles, or wings." He then inclines to assign this change to the uecessity of external circumstance. But such modification must be the same in kind as others, which the same hypothesis must explain, and of which the same author remarks (page 382) : "We can not, for instance, suppose that in the embryos of the Vertebrata the peculiar looplike course of the arteries near the branchial slits are related to similar conditions in the young mammal, which is nourished in the womb of its mother, in the egg of the bird which is hatched in a nest, and in the spawn of a frog under watel. We have no more reason to believe in such a relation than we have to bclicve that the same bones in the hand of a man, wing of a bat, and fin of a porpoise, are related to similar conditions of life. No one will suppose that the stripes on the whelp of the lion, or the spots on the young blackbird, are of any use to these animals, or related to the conditions to which they are exposed."

The law of natural selection, however, has no donbt been a very important ageney in the production of organic types in different periods of the world's history ; but the part it has played in the determination of generie features would appear to have been very small.

In its first effect-that of producing a structure adapted for a particular purpose-it would seem to have acted differently to produce the same results, and hence not to have produced any of the more extended groups, as families, where hundreds of species are identical in a single feature. Witness the differences in diverse types of the tree-frogs, each type adapting its possessor to an aboreal life :

I. Claw-like, with globular base.............. HүLID.E.

Leptopelis.

II. Simple, obtuse-depressed at tip............. RANIDE. I $a c$ and III $a$.

III. With a terminal transverse limb................. Ranide, Hylarana et aff. Calluela.

Brachymerus.

Hylodes.

IV. Bifureate ...................... Batrachyla.

Dendrobates.

Polypcdates.

Rhacophoins.

The short foot of the Testudinidx, where one row of phalanges is omitted, has been already alluded to. 'The gradual reduction of this set of bones, accompanying general modification of form in the increased convexity of dorsal region, as we leave the more aquatic and progress toward the terrestrial tortoises, would 
seem to be intimately connected with difference of habit. The increased convexity of carapace is an increased defense from falling objects-a danger to which land tortoises are far more subject than the aquatic. Another protection, not needed by water tortoises so much as by terrestrial, is the faculty of closing one or both free lobes of the plastron, as seen in the Cistudo, Sternothærus, etc., or of portions of the carapace, as in Pixys, Cinixys, etc. This might really have been produced by excessive tension on the sternal and pelvic muscles while young, and while the sutures were not fully interlocked. This, continued for a long time, might have produced the result. Yet it is not easy to see what protection the aquatic Kinosterna need in this respect, above the Emydes of the same conntries. The backs of these genera are also as convex as are many of the terrestrial genera or Testudinidæ.

I can not better express my views than by quoting the following from the pen of the late Dr. Falconer. It is extracted from one of his essays on the Elephantida : *

"Each instance, however different from another, can be shown to be a term of some series of continued fractions. When this is coupled with the geometrical law governing the evolution of form, so manifest in shells of the Mollusca, it is difficnlt to believe that there is not in nature a deeper-seated and imnate principle, to the operation of which natural selection is merely an adjunct.

"The whole range of the Mammalia, fossil and recent, can not furnish a species which has had a wider geographical distribution, and at the same time passed through a longer term of time, and through more extreme changes of climatal conditions than the mammoth.

"If species are so unstable and so susceptible of mutation throngh such influences, why does that extinct form stand ont so signally a monument of stability? By his admirable researches and earnest writings, Darwin has, heyond all his contemporaries, given an impulse to the philosophical investigation of the most backward and obscure branch of the biological sciences of the day; he has laid the foundation of a great edifice; bnt he need not be surprised if, in the progress of ereetion, the superstructure is altered by his successors, like the Dnomo of Milan, from the Roman to a different style of architecture.

* See writings of Hugh Falconer, vol. ii (ed. by Murchison). 
"The inferences which I draw from these facts are not opposed to one of the leading propositions of Darwin's theory.

"With him I have no faith in the opinion that the mammoth and other extinct elephants made their appearance suddenly, after the type in which their fossil remains are presented to us. The most rational view seems to be, that they are in some shape the modified descendants of earlier progenitors. But if the asserted facts be correct, they seem clearly to indicate that the older elephants of Europe, such as E. meridionalis and $E$. antiquus, were not the stocks from which the later species, E. primigenius and $E$. africanus sprung, and that we must look elsewhere for their origin. The nearest affinity, and that a very close one, of the European E. meridionalis, is with the Miocene E. (Loxod.) planifrons of India, and of $E$. primigenius with the existing Indian species.

" Another reflection is equally strong in my mind, that the [theories of the origin of] species by 'natural selection,' or' a process of variation from external influences, are inadequate to account for the phenomona. The law of Phyllotaxis, which governs the evolution of leaves around the axis of a plant, is nearly as constant in its manifestation as any of the physical laws connected with the material world."

\section{ס. As affecting Specific Characters.}

As I have hitherto attempted to prove that the higher grade of groups, or, in other words, the higher grade of characters, could not have had their origin throngh natural selection alone, thongh admitting it as a conserving or restricting principle, I now come to ground where natural selection must be allowed full sway. The "origin of species" is not the object of this essay, as a greater has gone before me, and has done a great deal toward showing that a selective power, dependent on adaptation and teleological relation, has favored or repressed, or even called into existence, the varied peculiarities that characterize species and races. I will therefore only refer to his well-known works on the "Origin of Species" and the "Modifications of Animals under Domestication."

I may add that it is within the range of possibility that that grade or kind of characters found to define the family group may be more or less the result of natural selection.

Acceleration and retardation are also far from excluded from 
the probable causes of specific characters. The species of many genera do exhibit a proportion of characters which are the successive stages of that one which progresses farthest, as the species of Amblystoma in the position of their teeth, nostrils, form of tail, and coloration; of Hyla in form of romerine teeth, etc. But the majority of specific characters are of divergent origin-are "morphic" as distinguished from developmental.

\section{ع. On Metaphysical Species.}

One of the arguments employed against the developmental hypothesis, in any form, is that that inherent "potentiality," which camses that like shall always produce like, is a metaphysical being, which can not be transformed, and which holds the structure which it vivifies as a material expression or stamp of itself, and which therefore can not be changed.

One expression of this inherent metaphysical specific individuality, if the term may be allowed, has been said to be the peculiar traits of the intelligence of species, their motions, voices, and instincts. But intelligence of all animals is susceptible of impressions, the lower the intelligence the less susceptible, and the more antomatic. But, as we rise in the scale of animal being, this impressibility and capacity for education is undeniably cxhibited by the dog, horse, and all the well-known domesticated companions of man. There can, in view of the capacities of Ares and Mammalia in these respects, be little doubt that all animals are educated by the "logic of events," that their intelligence, impressed by changed circumstances, can accommodate itself more or less to them, and that there is nothing in this part of their being opposed to the principle of "descent with modification."

There is another difficulty in the way of accepting metaphysical peculiarity or progenitiveness as isolating species. It is marked often strongly in races or varieties, which no one pretends to have had distinct origin. Here like produces like continually, though not persistently, but sufficiently to show that it resides in varicties of common origin. The isolation of allied species in fact depends, I believe, solely on the supremacy of the automatic over the intelligent spirit. When the intelligent rises above the bounds of nature, or the automatic, the mixture or separation of allied species depends merely on circumstances of necessity, determined by that intelligence.

But the metaphysical "potentiality" loses all basis, if the law 
of acceleration and retardation be true, for in accordance with it, at certain times, like does not produce like.

\section{OF EPOCHAL RELATIONS, OR THOSE MEASURING GEOLOGIC} TIME.

If it can be shown that groups having the developmental relation above insisted on are contemporaries, and if it can be shown that this relation is identical in kind with that which we regard as measuring the successions of geologic time, we will be led to doubt the existence of any very great interruptions in the course of this succession throughout geologic time. And if we can show that famme so related are more or less characteristic of distinct portions of the earth's surface, at the present time, we will be led to anticipate that contemporaneous faunæ in different regions, during geologic periods also, bore such a relation. If this proposition be true, we are led to the further conclusion, which is at variance with received canons, that identity of faumæ proves successional relation in time, instead of synchronism. * 'That this will ultimately be demonstrated appears highly probable to the writer, though, as yet, the eridence is but fragmentary.

If the relations expressed nnder the terms homology and heterology, taken together with the observations on metamorphosis, render it probable that a number of genera have reached their $e x$ pression-points, or periods of metamorphosis, at near the same time in geologic history, an important point has been gained. If we can render it probable that a change in any organic character has been nearly simultaneous throughout a large extent of specific forms, the change becomes, on the latter account alone, of higher than generic value, but characteristic of such groups as Marsupialia, Clamatores, Acrodonta, Areifera, Heterocerca, and the like.

We have here, also, an important element in the estimation of the value of apparent interruptions in the geological history of the life of the globe. These interruptions, it is true, are greater than any such theory as the present can bridge over; yet such a theory, if true, lessens their importance. They are in any case well accounted for on the theory of the existence of periods of elevation, during which the life of a given region is necessarily almost entirely lost to us, through lack of means of preservation of their remains.

\footnotetext{
* This view has been insistod on by Huxley.
} 
We may also compare such extended metamorphoses with those of cosmical matter, such as when, in the conrse of ages, a primeral rapor has in a short time eollapsed to the liquid form, or as when the vast of liquid in turn has shrunk to its solid condition; both alike for ages approaching their change, yet stationary in external relations till the moment of transition has arrived.

'The following are the zoölogical relations of the groups already referred to :

The most generalized group of fishes of the Regio Neotropica is that of Characins. Its type, in respect to fin-structure, which is eommon to all the Malacopterygians, is that of an undereloped stage of the Acanthopterygians, the adipose fin being an undeveloped cartilaginous fin, and the cartilaginous fin an undeveloped spinous fin.* It may be said to be the highest among Malacopterygians, if we look to the complete oviducts, opereula, jaws, etc., $\nmid$ but it is the lowest as removed farthest from the extreme of Malacopterygian peenliarities, as being most generalized or embracing representatives of all the rest, and approaching nearest the types of the past-the Ganoids. For example, Butyrinus and Vastres may be compared with Amia. The family is distributed chiefly in the Southern Ilemisphere.

The genus Orestias, which Agassiz says is characterized by a feature which exists in the immature state of all other Cyprinodonts-the absence of rentral fins-is only found in the Neotropieal region.

Of the renomons serpents, the inferior gromp, the Proteroglypha, belong to the Southern Ifemisphere, and the Australian and Neotropical regions almost exclusively embrace by far the greater proportion. Australia contains none other.

The Iguanian lizards are lower than the Acrodont, exhibiting a larral type of detention, and one characteristic of all lower Sanria and Batrachia. The only aerodont type of Ophiosaura (Trogonophis) is Old World.

The New World Teidx have not the extent of ossified temporal roof that their representatives, the old World Lacertidx, have. So the chiefly Neotropical Anguide have the tongne part-

* Kner, "Ueber den Bau der Flossen."

t This is the correct riew, for this family and the Siluroids are the most specialized of the Malacopterygian fishes. (1886.) 
ly of papillose type of their Old World representatives, the Zonuridæ, and partly the smooth or scaly type of the cosmopoite Scincidæ, which are inferior to them.

The snake-like forms of the families of the Lacertilia Leptoglossa greatly predominate in the Sonthern Hemisphere; also those with undeveloped palpebræ.

The Neotropical type of Testudinata is quite coincident with the family Characinidæ in relations. It is, like it, largely distributed over the Sonthern Hemisphere, and like it may be regarded, in respect to its pelvic peeuliarities, as higher than the remaining types, but in its generalized character and relationship to the past periods may be called lower.

The Neotropical type of Batrachia anura, that is, the Arcifera, is lower in developmental characters than the opposed series, the Raniformia; such of the latter as are found in its limits partake in some way of larval incompleteness. The Arcifera are chiefly distributed elsewhere in Anstralia, where no Raniformia exist.* Those genera of Old World Raniformia of the lowest or toothless group, which display the least development of the cranial bones, as Brachymerns and Breviceps, are of the Southern HemisphereSouth African.

The Pullastrine birds are a generalized group, inferior to the group opposed to them-the Gallinæ. Their typical forms, like the last, are distributed to the Neotropical and Australian regions: the outliers (pigeons) are not so numerously distributed in the other regions.

The Struthions birds, the most synthetic of the class, belong exclusively to the Sonthern Hemisphere; as is well known, they chiefly abound in Australia and its adjacent islands, with an abundant outlying type-the Tinamus-in Sonth America.

The penguins, which only of all birds display the metatarsus nearly divided, inhabit the Antarctic regions and Cape Horn.

* The Eucnomis bicolor, Gray, would appear to be an exception, were its generic and subordinate affinities truly represented by its name. I have examined the type specimen through the kindness of Dr. Günther, and can state that it is not an Ixalus (=Eucnemis), and does not even belong to the Raniformia, but is an Areifer of the family IIylida. If it be not a young Calamita or Hyla, it will be a Hylella near the H. camea type. (Boulenger, in 1882, determined it to be a IIylella. Ed. 1886.)

Günther states that Hylorane crythraea has been found at the extreme northern point-Cape York-of Australia. If so, the ease is parallel to the occurrences of the Raniform Ranula in northern South America. 
The Clamatorial type of the Passeres exhibit larval characters in the non-development of the singing apparatus, and the scaled or nearly naked tarso-metatarsus. These are chicfly South American.

Of Mammalia, the placentals withont enamel on their teeth, which, in this respect, never reach the full development of the class, whose dentition is also monophyodont, i. e., the Edentata, inhabit only the Sonthern Hemisphere, and almost altogether the Neotropical region. The implacental Mammalia, also (except in one tooth) monophyodont, which approach birds and reptiles in so many respects, are confined to the Southern Hemisphere, and chiefly, as all know, to Australia.

Of the Quadrumana, the Platyrrhine group is known to be inferior to the Catarrhines: the former presents an entirely embryonic condition of the os tympanicum, which is passed by the latter in early age; * it contains also the only clawed genus of the true monkeys. It is confined to the Neotropical realm. 'To Madagascar, also of the Southern Hemisphere, and nearest in many ways to the Neotropieal, pertain the lowest families of the Quadrumana, the Lemuridx and Chiromyidæ; the former presenting brains without convolutions, and approaching in many ways the Insectivora ; the last imitating, at least, a Rodent.

There are also other reasons for the inferiority of South America. Its deer, which are few, include those which never prodnce more than the "dague," or the first horn of the northern Cervus, and also those which never get beyond the fourth step in the development of the lower group of $R$. Nearctica.

'The Loricariidæ, of Sonth America, I am informed by Prof. Agassiz, possess the fotal pupil of the vertebrate type.

If we glance at Coleoptera we find the great predominance of the groups with undeveloped tarsus, the three- and four-jointed Trimera and 'Tetramera, and of the lower' group with undeveloped sterumm, the Rynchophora, in the Neotropical region.

Among Lepidoptera it is known that the most gigantic of the species of the Neotropical region are Noctuidre (Erebus, etc.), and that in that region this low type of the order reaches its greatest development. The largest forms of the Regio Nearctica, as well as Palrearctica, are representatives of the higher type of the Satur-

* See Dr. II. Allen, "Proceed. A. N. S.," Phila., 1867.

† Leconte, American Association, 1867. 
niidæe (Atticus, Telea, etc.), while the largest and most powerful of this order in the Palæotropical (Indian) region are the Papilionid forms of Ornithoptera, etc., the generally admitted crown and head of all. Of course other types, both higher and lower, are largely developed in each and all of these regions, and the significance of the above facts is perhaps only to be seen when taken in connection with a large number of others pointing in the same direction.

Two or three comparisons of different faumæ may be brought forward finally. First, returning to the birds, a survey of some of the differences between the birds of Panama, Pennsylvania, and Palestine may be made.*

Tristram noticed three hundred and twenty-two species of birds within the range of the ancient territory of Palestine. Of these two hundred and thirty were land and ninety-two water birds, i. e., Natatores and the wading Cursores. Of the two hundred and thirty, seventy-nine are common to the British Islands, and thirty-six of them are found in China, but a small proportion extending their range to both these extremes. Of the water birds, which are always more widely distributed, fifty-five of the ninetytwo are British and fifty-seven Chinese. Twenty-seven appear to be confined to Palestine, and to the immediately adjacent country; the largest of these is a crow.

Taking the two hundred and thirty land birds at a glance, we find the utter absence of so many of the well-known forms that enliven our grounds and forests. The absence of Tanagridx (imcluding Sylvicolidæ) and Icteridx, changes the aspect of the bird-fanna at once. What have we here, then, of nine-quilled Oscines to enliven the meadows like onr swarms of blackbirds, or' fill the tree-tops and thickets with flutter like onr wood-warblers? Nothing; for the twenty-four species of finches, Fringillidæ, will but balance our own, though the genera are all different but four, and they the most weakly represented by species. We must look to the higher series, the ten-quilled song-birds, for the missing rank and file. While a much larger extent of the Eastern United States possesses fifty species of these types, the little Palestine has already furnished a list of one hundred and twenty-eight.

First, of the crows, which verge nearest Icteridie by the star'lings, we have thirteen species against five in our district of the

* From the "American Naturalist," 1868, by the author. 
United States, and not less than seven of the type genus Corvus, to our one common and two rare. Of these two are of the larger species, the ravens. If we turn to the cheerful larks, we find the proportion again the same; fifteen speeies for Palestine and one for the whole United States. One congener of our species oecurs there ; the other genera eall to mind the African deserts and Russian steppes. Motacillidx, again, ten to one against our fauna. We have two Tanagridx to imitate them, besides the one true relative. In swallows we are about equal, and in the forest-haunting Paridre -titmice and wrens-we exceed a little; but the comparison of Sylviidæ and 'Turdidx is most striking. These highest of the bird series, especially made to gladden man's haunts with song, exeeed in number all the other ten-quilled Oseines together inhabiting Palestine, amounting to seventy-five species. In our corresponding region of the United States nineteen species is the quantum. It is true no mocking-bird or wood-robin is known away from our shores, but Palestine has the nightingale, the black-cap, and the true warblers or sylrias, which, while they glean from shrub and tree their smallest inseet enemies, as do our equally numerous small Tauagride, have much londer and sweeter roices.

Our solitary bluebird represents the long-winged 'Turdidæ; in the Holy Land there are twenty species corresponding, thongh none are of our genus. There are, indeed, but three genera of these two families common to both countries. One of these, Lanius, the butcher-bird, oceurs here in one species, in Palestine in six.

Turning now to a lower series, we look in rain for Clamatorial perchers; that series which gives us the fieree king-bird and querulous perwee, and which peoples South America with thrush and warbler, and slirike and tree-creeper.

In taking a hasty glance over the lower groups, where the carotid arteries begin to be double, as the Syudactyli, we find Palestine too far from the tropies to present us with much array; but in the related zygodactyles our forest-crowned continent must elaim great pre-eminence. It has but a solitary Pieus, while we have eight in the immediate neighborhood of lat. $40^{\circ}$, in our Eastern States.

I will close with the birds of prey. Four swamp-hawks, eleven speeies of faleons, four kites, and eight natire eagles, form a list unequaled in the annals of nobility by any land. 'There are together thirty-one speeies of Falconidx, and of Vultures four. The 
eagles appear to be all common, among them the most magnificent birds of prey, the imperial and golden species of these creatures.

'To the ornithologist, acquainted with the fauna of North America, it will thus be readily pereeived that, in eomparison, the ornis just examined, possesses more numerous representatives of the higher groups of the birds, and amoug lower groups possesses chiefly those of superior grade, or lacks them altogether. Let us, however, compare it with that of Central Ameriea, where varied surface and temperature offer eren greater opportmnity for variety, within quite as restricted an area.

The bird famma has been found by Messis. Sclater and Salvin to embrace about three hundred and eighty-fire species, which is sixty-three more than were mentioned to occur in Palestine, which is open on three sides to the great continent. Eighty of three liundred and forty-eight land birds are characteristic of Central Ameriea; and those which find their kin limited to the Isthmus and adjoining regions of New Grenada and Equador amount to about seventy-five more. Twenty-seren is the number not known to extend beyond the boundaries of Palestine; as to the Middle States of our Union, not one speeies has been shown to be restrieted within snch narrow limits.

A single species ocenrs in Europe; this is the fish-hawk, an animal which combines the cosmopolite habit of the sea-bird with the powerful flight of the bird of prey. This is also the only speeies eommon to the Panama and Palestine catalogues.

The birds of prey are numerous-twenty-nine speeies. Among these there is no true eagle or falcon, and of the nineteen genera but four belong to the fauna of the Holy Land. There is but one species to represent the great grouse family, but, instead, three families of their South American imitators, the Pullastræ, instead of the one-that of the Pigeons-slimly represented in Palestine, and in North America as well.

Coming to the eloser test of superiority, the Passeres-those delieate creatures, apparently so dependent on those laws which govern inerease and provision, and so affected by the changes that man works in the face of Nature-what do we find? We count one hundred and six distinct species. There are none in Palestine. Of songsters, the Oscines, ninety-six species, await man's conquest of the wildermess, to increase in numbers and to display their gifts, while Palestine rejoices in a whole army of them. But the contrast is more remarkable if we analyze these forms. Of the 
Isthmian Oscines, serenteen only hold the first rank, by virtue of their additional, the tenth primary quill, while this featnre marks one hundred and twenty-eight species of Palestine. As we rapidly follow the line to the point where its extreme is manifested, in the family of the Thrushes or 'Turdidx, Panama is left but two solitary pioneers of these songsters of the North, while serenty-fire species represent the family in Palestine.

'The comparison between different faumæ exhibits an apparent gradation in some other groups equally curious. Thus, the true Cyprinidx in the Palæarctic region reach a great development, and produce the highest number of teeth on their pharyngeal jaws known, as well as attains the greatest bulk and importance. The number of these teeth is usually seven to five in the inner row; only two or three genera exhibit only four on both. In the Nearetic region the number of teeth is almost always 4-4, more rarely $4-5$, and very seldom as high as $5-5$. The species of the family are excessively numerous, but are, with scarcely any exception, of small size and weak organism. 'These statements apply to those of the eastern district of the region between the Rocky Monntains and the Atlantic. Similar types ocenr in the northern region of the Neotropical-Mexico, but in no great numbers. Farther sonth the family disappears, its place being supplied by the generalized family of Characinidæ.

I have already alluded to the great rariety of the highest or pentamerous carnivorons beetles in the Palaarctic region. They are extremely abundant in the Nearctic, while the intermediate territory, the Sonoran and Mexican sub-districts, are the headquarters of the next lower form, the Tenebrionida, which have the tarsal joints 4-5. These give place in the Neotropical to the multitudes of the still lower series-those with the joints $4-4$ and 3-3-Tetramera and Trimera.

The preceding comparisons indicate that an inherent difference between the types of a continent exists at the present time, though the difference is subordinated to a universal distribution of the higher gronps throughout the earth. Has this state of things existed for any long period, or is it a result of different progress in the same group since the human period? 'This brings us necessarily to a consideration of the truths of paleontology, especially of the last periods, which have been already urged by Darwin. Thus the present fauna of Australia was preceded in the Post-Pliocene and Pliocene by forms possessing similar peculiarities, and 
belonging to the same classes. That is by herbivorous and carnivorous marsupials and monotremes, and by Varanid Sauria, all of greater size than their predecessors.

The same fact is well known of the Neotropical region, its present peculiar Edentata having been preceded by giants of the same type in the Post-Pliocene and Pliocene.

In the Nearetic region peculiar existing genera, as Procyon, Alees, Castor, Bos, Sciurus, Aretomys, Lepus, Oribos, Sorex, Mephitis, Felis, Ursus, Menopoma, Aspidonectes, Crotalus, are represented by Post-Pliocene fossils.

The same occurs in the later Palæaretic formations, where Cervus, Bos, Canis, Mustelidæ, Insectivora, Vipera, Alytes, Triton, etc., are allied predecessor's of existing types. In the Palæotropical area a wonderful development of Elephas and Gavialis preceded the same types of the present.

Prior to these faunæ another state of things has, however, existed. North America has witnessed a withdrawal of a Neotropical famna, and the Palaarctic the retreat of an Ethiopian type. During the Post-Pliocene in North America, Neotropical genera were to Nearctic as 12 to 29, as the record now stands. In the Pliocene beds of Pikermi (Greece) antelopes, giraffes, rhinoceros, hippopotamus, huge manis, * monkeys, monitors, and other genera and species of African relationship are the prevailing forms.

Still earlier, a strong mingling of Nearctic, and more of Neotropical types, abounded in the Palæaretic. The genera Chelydra, Andrias, Podoenemis, $\uparrow$ Platemys, Caviiform, Psammoryetid and Hesperomys-like Rodentia, Opossums, and Raccoon-like Carnivora.

We have, then, three important terms from which to derive a theory of the creation: 1 , the existing six faunæ bear in many of their parts developmental relations to one another; 2 , they were preceded immediately by faunæ similar to them in each case, but more remotely by faunæ like that now next lower.

On the whole, there can be no doubt of the truth of the generalization: That the Southern Hemisphere is a geologic stage behind the Northern Hemisphere in progress, on account (1) of its perfection in types extinct in the Northern, and (2) inferiority in modern types prevalent in the Northern.

In order, however, to demonstrate this point more fully, let us

* Ancylotherium, Macrotherium.

† P. bowerbankii (Platcmys, Owen). P. lavis (Emys, Owen). 
examine to what extent the higher types exist in the Southern, and lower or ancient in the Northern.

The Percoid fishes and their allies have Anstralian and South American representatives in their fresh waters, but they are as mere ontliers of the great mass in the Northern Hemisphere. 'The higher type of venomous serpents (Solenoglypha) occur in both the Ethiopian and Neotropical regions, but they preponderate in the Northern Hemisphere. The higher group of the Saurians (the Acrodonta) abounds in the Ethiopian and Australian regions; they are as abundant in the Indian and Palrarctic regions of the Northern Hemisphere. In the Southern, also, by Uromastix and the Rynchocephalia, they approach nearest the ancient types of the Dicynodontia and the Crocodilia. Lacertidæ, and not Teidæ, occur in the Ethiopian; but they are but a proportion of the whole, which chiefly exists in the Nearctic.

Raniform, and not Arciferous Anura, populate Sonth Africa; they, however, form but a small proportion compared with the great series of the Nearctic, Palæarctic, and Palæotropical regions. It is, however, superior in Anmra to the Nearctic, taken by itself.

Rasorial birds, and not Pullastræ, are the food species of Sonth Africa; but they do not compare in abundance or size with those of the three regions just mentioned.

Moreorer, but few Clamatores exist in either Australia or Ethiopia. 'The Oscine types are abundant; nerertheless, they can not be compared in relative abundance with those of the northern regions. It must also be remembered that the migratory capabilities of birds render them less expressive of the true nature of any famna.

The higher family of the Quadrumana, the Simiidæ, replaces in Africa the Cebidæ of the Neotropical ; they are, however, most abundant in the Palæotropical region, in the other hemisphere.

There are two ancient or inferior types of the Northern Hemisphere: First, its fishes, the Sturgeons of the Nearctic and Palæarctic, and the Gars of the Nearetic.* 'The latter only lave representatives in the Sonthern Hemisphere, Polypterus and Calamoichthys in Africa, and so may be said to be equally distributed; but the former are confined to the north. We do not know, however, whether they are of a modern or an ancient type, nor do we

* Subsequent investigations have proved that Polypterus and Calamoichthys are of much more ancient type than gars and sturgeons. (Ed. 1856.) 
know of extinct sturgeons in the Sonthern Hemisphere. Indeed, the Ganoid series is not well defined or known as yet. If, as Agassiz states, the Siluroids pertain to it, it is cosmopolitan, though least represented in the Palæarctic.

Second, the Tailed or Urodele Batrachia. This order, entirely characteristic of the Northern Hemisphere, is a group which combines characters of Anura with those of the ancient forms, and possesses in its Nearetic types many of low development. The Gymnophidia of the Sonthern Hemisphere can not be considered inferior to them. In the possession of this group the Northern Hemisphere presents its first element of inferiority.

The preceding comparisons indicate also the relations of the regions proper to each other. It is obvious enough that the Ethiopian is much superior to the two others of the Sonthern Hemisphere. As to the Australian and Neotropical, the former must still be regarded as probably the most ancient, though possessing at the same time a much stronger admixture of northern forms. I have already presented the relations, with the inferior forms of each, thus: *

R. Australis.-Inferior in possessing Monotrematous and Marsupial Mammalia, Pullastriform and Struthious Birds, Serpentiform Plenrodont Lacertilia, Arciferons Batrachia, Plenrodire Tortoises, its Elapid venomous snakes, and the whole Flora, according to Unger.

R. Neotropica.-Marsupial and Edentate Mammalia, Inferior Rodentia and Quadrumana, Plemrodire Tortoises, Plenrodont Lacertilia, Arciferous Batrachia, Clamatorial and Pullastriform Birds, Characin and Erythrinid Malacopterigii.

\section{Conclusions.}

The following may be looked upon as conclusions which have been indicated in the preceding pages:

I. Species have developed from pre-existent species by an inherent tendency to variation, and have been preserved in given directions and repressed in others by the operation of the law of natural selection (Darwin).

II. Genera have been produced by a system of retardation or acceleration in the development of individuals; the former on pre-established, the latter on preconceived lines of direction. Or, 
in other words, that while nature's series hare been projected in accordance with the law of acceleration and retardation, they hare been limited, modified, and terminated by the law of natural selection, which may itself have operated in part by the same law.

III. The processes of development of specific and generic character's hare not proceeded pari passu, transitions of the one kind not being synchronous with transitions of the other; and that, therefore, species may be transferred from one genus to another without losing their specific characters, and genera from order to order without losing their generic characters.

IV. And as the heterologons terms of the peculiar homologons gromps present an "inexact parallelism" with each other; and as types related by inexact parallelism are each among themselves exact parallels in separate scries, whose earliest members present "exact parallelisms" with each other, it follows-

$V$. That the heterologons terms or genera in the later series are modified descendants of those of the earlier series; in other words, that certain groups higher than genera are produced from others of similar high valne by "descent with modification."

VI. 'That the result of such successional metamorphoses will be expressed in geologic history by more or less abrupt transitions or expression-points, rather than by miformly gradual successions.

Of course, under the conclusion stated in Proposition II, the genus Homo has been dercloped by the modification of some preexistent genus. All his triits which are merely functional hare, as a consequence, been prodneed during the process. Those traits which are not functional, but spiritual, are of course amenable to a different class of laws, which belong to the province of religion. 
III.

\section{ON THE THEORY OF EVOLUTION.}

Ат a meeting of the Philadelphia Academy of Natural Sciences, held February 22, 1876, Prof. Cope gave a history of the progress of the doctrine of evolution of animal and vegetabie types. While Darwin has been its prominent advocate within the last few years, it was first presented to the scientific world, in a rational form, by Lamarck, of Paris, at the commencement of the present century. Owing to the adverse influence of Cuvier, the doctrine remained dormant for half a century, and Darwin resuscitated it, making important additions at the same time. Thus Lamarek found the rariations of species to be the primary evidence of evolution by descent. Darwin enunciated the law of "matural selection" as a result of the struggle for existence, in accordince with which "the fittest" only survive. This law, now generally accepted, is Darwin's principal contribution to the doctrine. It, however, has a secondary position in relation to the origin of variation, which Lamarck saw, but did not account for, and which Darwin has to assume in order to have materials from which a "natmral selection" can be made.

The relations exhibited by fully grown animals and plants with transitional or embryonic stages of other animals and plants, had attracted the attention of anatomists at the time of Lamarck. Some naturalists deduced from this now universally observed phenomenon that the lower types of animals were merely repressed conditions of the higher, or, in other words, were embryonic stages become permanent. But the resemblances do not usually extend to the entire organism, and the parallels are so incomplete that this view of the matter was clearly defective, and did not constitute an explanation. Some embryologists, as Lereboullet and Agassiz, asserted that no argument for a doctrine of descent could be drawn from such facts.

The speaker, not adopting either view, made a full investiga- 
tion into the later embryonic stages, chiefly of the skeleton of the Batrachia, in 1865, and Prof. Hyatt, of Salem, Mass., at the same time made similar studies in the development of the Ammonites and Nautili. The results as bearing on the doctrine of erolution were published in 1869 (in "The Origin of Genera"). It was there pointed out that the most nearly related forms of animals do present a relation of repression and adrance, or of permanent embryonic and adult type, leaving no doubt that the one is descended from the other. 'This relation was termed exact parallelism. It was also shown that, if the embryonic form were the parent, the adranced descendant was produced by an increased rate of growth, which phenomenon was ealled acceleration; but that if the embryonic type were the offspring, then its failure to attain to the condition of the parent is due to the superrention of a slower rate of growth; to this phenomenon the term retardation was applied. It was then shown that the inexact parallelism was the result of unequal acceleration or retardation; that is, acceleration affecting one organ or part more than another, thus disturbing the combination of characters which is necessary for the state of exact parallelism between the perfect stage of one animal and the transitional state of another. Moreorer, acceleration implies constant addition to the parts of an animal, while retardation implies continual subtraction from its characters, or atrophy. Ife had also shown ("Method of Creation," 1871) that the additions either appeared as excet repetitions of pre-existent parts, or as modified repetitions, the former resulting in simple, the latter in more complex organisms.

Prof. Haeckel, of Jena, has added the keystone to the doctrine of erolntion in his gastræa theory. Prior to this generalization it had been impossible to determine the true relation existing between the four types of embryouic growth, or, to speak otherwise, than that they are inherently distinct from each other. But Hackel has happily determined the existence of identical stages of growth in all of the types of eggs, the last of which is the gastrula; and beyond which the identity ceases. Not that the four types of gastrula are without difference, but this difference may be aceounted for, on plain prineiples. In $18 \% 4$, Haeckel, in his "Anthropogenie," recognizes the importance of the irregularity of time of appearance of the different characters of animals, during the period of growth, as affecting their permanent strueture. While maintaining the view that the low forms represent 
the transitional stages of the higher, he proceeds to account for the want of exact correspondence exhibited by them at the present time, by reference to this principle. He believes that the relation of parent and descendant has been eoneealed and changed by subsequent modifications of the order of appearanee of eharacters in growth. To the original, simple descent he applies the term palingenesis; to the modified and later growth, conogenesis. The causes of the change from palingenesis to coungenesis he regards as three, viz, aeceleration, retardation, and heterotopy.

It is elear that the two types of growth distinguished by Prof. Haeckel are those which had been pointed out by Prof. Cope in "The Origin of Genera," as producing the relations of "exact" and "inexact parallelism"; and that his explanation of the origin of the latter relation by acceleration or retardation is the same as that of the latter essay. The importance which he attaches to the subject was a souree of gratifieation to the speaker, as it was a similar impression that led to the publication of "The Origin of Genera" in 1869.

It remains to observe that the phenomena of exact parallelism or palingenesis are quite as neeessarily accounted for on the principle of acceleration or retardation as are those of inexact parallelism or cœnogenesis. Were all parts of the organism accelerated or retarded at a like rate, the relation of exact parallelism wonld never be disturbed; while the inexactitude of the parallelism will depend on the number of variations in the rate of growth of different organs of the individual, with additions introduced from time to time. Hence it may be laid down that synchronous acceleration or retardation produces exact parallelism, and heterochronous acceleration or retardation produces inexact parallelism.

In conclusion, it may be added that accleration of the segmentation of the protoplasma or animal portion of the primordial egg, or retardation of segmentation of the dentoplasma or regetative half of the egg, or both, or the same relation between the growth of the circumference and center of the egg, has given rise to the four types which the segmentation now presents.

An analysis of the laws of evolution may be tabulated as follows : 


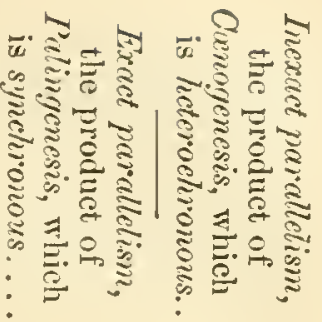

acceleration, which procceds by

retardation,

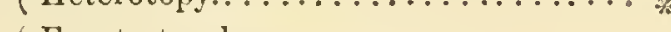
which proceds by

* So called by Prof. Hyatt. 


\title{
IV. \\ ON THE HYPOTHESIS OF EVOLUTION :
}

\author{
PHYSICAL AND METAPHYSICAL.
}

"Man shall not live by bread alone, but by every word that proceedeth out of the mouth of God shall man live."

THERE is apparently considerable repugnance in the minds of many excellent people to the acceptance, or even consideration, of the hypothesis of development, or that of the gradual creation by descent, with modifications from the simplest beginnings, of the different forms of the organic world. This objection probably results from two considerations: first, that the human species is certainly involved, and man's descent from an ape asserted; and, secondly, that the scheme in general seems to conflict with that presented by the Mosaic acconnt of the Creation, which is regarded as communicated to its anthor by an infallible inspiration.

As the truth of the hypothesis is held to be infinitely probable by a majority of the exponents of the natural sciences at the present day, and is held as absolntely demonstrated by another portion, it behooves those interested to restrain their condemnation, and on the other hand to examine its evidences, and look any consequent necessary modification of om metaphysical or theological views squarely in the face.

The following pages state a few of the former ; if they suggest some of the latter, it is hoped that they may be such as any logical mind would deduce from the premises. That they will coincide with the spirit of the most advanced. Christianity, I have no doubt; and that they will add an appeal through the reason to that direct influence of the Divine Spirit which shonld control the motives of hmman action, seems an muaroidable conchnsion.

\section{PHYSICAL EVOLUTION.}

It is well known that a species is nsually represented by a great number of individuals, distinguished from all other similar associ- 
ations by more or less numerous points of structure, color, size, etc., and by habits and instincts also, to a certain extent; that the individuals of such associations reproduce their like, and can not be produced by individuals of associations or species which present differences of structure, color, etc., as defined by naturalists; that the individuals of any snch series or species are incapable of reprodncing with those of any other species, with some exceptions; and that in the latter cases the offspring are usually entirely infertile.

The hypothesis of Cuvier assumes that each species was created by divine power as we now find it at some definite point of geologie time. The paleontologist holding this view sees, in accordance therewith, a succession of creations and destructions marking the history of life on our planet from its commencement.

The development hypothesis states that all existing species have been derived from species of pre-existent geologieal periods, as offspring or by direct descent; that there have been no total destructions of life in past time, but only a transfer of it from place to place, owing to changes of circumstance; that the types of structure become simpler and more similar to each other as we trace them from later to earlier periods; and that finally we reach the simplest forms consistent with one or several original parent types of the great divisions into which living beings naturally fall.

It is evident, therefore, that the hypothesis does not inelude change of species by hybridization, nor allow the descent of living species from any other living species: both these propositions are errors of misapprehension or misrepresentation.

In order to understand the history of creation of a complex being, it is necessary to analyze it and ascertain of what it consists. In anilyzing the construction of an animal or plant we readily arrange its characters into those which it possesses in common with other animals or plants, and those in which it resembles none other: the latter are its individual character's, constituting its individuality. Next, we find a large body of characters, generally of a rery obvious kind, which it possesses in common with a generally large number of individuals, which, taken collectively, all men are aceustomed to call a species; these charaeters we consequently name specific. Thirdly, we find characters, generally in parts of the body which are of importance in the activities of the animal, or which lie in near relation to its mechanical construction in details, which are shared by a still larger 
number of individuals than those which were similar in specific characters. In other words, it is common to a large number of species. This kind of character we call generic, and the grouping it indicates is a genns.

Farther analysis brings to light characters of organism which are common to a still greater number of individuals; this we call a family character. Those which are common to still more numerous individuals are the ordinal: they are usually found in parts of the structure which have the closest connection with the whole life-history of the being. Finally, the individuals composing many orders will be found identical in some important character of the systems by which ordinary life is maintained, as in the nervous and cirenlatory : the divisions thus outlined are called classes.

By this process of analysis we reach in our animal or plant those peculiarities which are common to the whole animal or regetable kingdom, and then we have exhausted the structure so completely that we have nothing remaining to take into account beyond the cell-structure or homogeneous protoplasm by which we know that it is organic, and not a mineral.

The history of the origin of a type, as species, genus, order, etc., is simply the history of the origin of the structure or structures which define those gromps respectively. It is nothing more nor less than this, whether a man or an insect be the object of investigation.

EVIDENOES OF DERIVATION.

\section{a. Of Specific Characters.}

The evidences of derivation of species from species, within the limits of the genus, are abundant and conclusive. In the first place, the rule which naturalists observe in defining species is a clear consequence of such a state of things. It is not amount and degree of difference that determine the definition of species from species, but it is the permanency of the characters in all cases and under all circumstances. Many species of the systems include varieties and extremes of form, etc., which, were they at all times distinct, and not connected by intermediate forms, would be estimated as species by the same and other writers, as can be easily seen by reference to their works.

Thus, species are either "restricted" or "protean," the latter 
embricing many, the former few variations; and the varieties included by the protean species are often as different from each other in their typical forms as are the "restricted" species. As an example, the species Homo sapiens (man) will suffice. His primary varieties are as distinct as the species of many well-known genera, but can not be defined, owing to the existence of innumerable intermediate forms between them.

As to the common origin of such "varicties" of the protean species, naturalists never had any doubt; yet when it comes to the restricted "species," the anti-derelopmentalist denies it in toto. Thus the varieties of most of the domesticated animals are some of them known-others held with great probability to have had a common origin. Varieties of plumage in fowls and canaries are of every-day occurrence, and are produced under our eyes. 'The cart-horse and racer, the Shetland pony and the Norman, are without doubt derived from the same parentage. The varieties of pigeons and ducks are of the same kind, but not every one is aware of the extent and amount of such variations. The varicties in many characters seen in hogs and cattle, especially when examples from distant countries are compared, are very striking, and are confessedly equal in degree to those found to define species in a state of nature: here, however, they are not definitive.

It is easy to see that all that is necessary to produce in the mind of the anti-developmentalist the illusion of distinct origin by creation of many of these forms would be to destroy a number of the intermediate conditions of specific form and structure, and thus to leave remaining definable groups of individuals, and therefore "species."

That such destructions and extinctions have been going no ever since the existence of life on the globe is well known. That it should affect intermediate forms, such as bind together the types of a protean species as well as restricted species, is equally certain. That its result has been to produce definable species can not be denied, especially in consideration of the following ficts: Protean species nearly always have a wide geographical distribution. They exist under more varied eircumstances than do individuals of a more restricted species. The subordinate variations of the protean species are generally, like the restricted species, confined to distinct subdivisions of the geographical area which the whole occupies. As in geological time changes of level have separated areas once continuous by bodies of water or high mount- 
ain-ranges, so have vast numbers of individuals oceupying such areas been destroyed. Important alterations of temperature, or great changes in abundance or character of vegetable life over given areas, would prodnce the same result.

This part of the subject might be prolonged, were it necessary, but it has been ably discussed by Darwin. The rationale of the "origin of species," as stated by him, may be examined a few pages farther on.

\section{B. Of the Characters of Higher Groups.}

a. Relations of Structures. - The evidences of derivative origin of the struetures defining the groups called genera, and all those of higher grade, are of a very different character from those discussed in relation to specific characters; they are more difficult of observation and explanation.

First : It wonld appear to be supposed by many that the creation of organic types was an irregular and capricious process, varionsly pursued by its Author as regards time and place, and withont definite final aim ; and this notwithstanding the wonderful evidences we possess, in the facts of astronomy, chemistry, sound, etc., of his adhesion to harmonions and symmetrical sequences in his modes and plans.

Such regularity of plan is found to exist in the relations of the great divisions of the animal and vegetable kingdoms as at present existing on the earth. Thus, with animals we have a great class of species which consists of nothing more than masses or cells of protoplasmic matter, without distinet organs; or the Protozoa. We have then the Colenterata (example, corals), where the organism is composed of many cells arranged in distinct parts, but where a single very simple system of organs, forming the only internal cavity of the body, does the work of the many systems of the more complex animals. Next, the Echinodermata (such as star-fish) present us with a body containing distinct systems of organs inclosed in a viseeral cavity, including a rudimental nervous system in the form of a ring. In the Mollnses to this condition is added further complication, including extensions of the nerrous system from the ring is a stirting-point, and a special organ for a heart. In the Articulates (crabs, insects) we have like complications, and a long distinct nerrous axis on the lower surface of the body. The last branch or division of animals is considered to be higher, beeause all the systems of life 
organs are most complex or specialized. The nerrous ring is almost obliterated by a great enlargement of its usual ganglia, thus become a brain, which is succeeded by a long axis on the upper side of the body. This and other points define the Vertebrata.

Plans of structure, independent of the simplicity or perfection of the special arrangement or structure of organs, also define these great groups. Thus the Protozoa present a spiral, the Colenterata a radiate, the Echinodermata a bilateral radiate plan. The Articulates are a series of external rings, each in one or more respects repeating the others. The Molluses are a sac, while a ring above a ring, joined together by a solid center-piece, represents the plan of each of the many segments of the Vertebrates which give the members of that branch their form.

These bulwarks of distinction of animal types are entered into here simply because they are the most inviolable and radical of those with which we have to deal, and to gire the anti-derelopmentalist the best foothold for his position. I will only allude to the relations of their points of approach as these are affected by considerations afterward introduced.

The Vertebrates approach the Molluses closely at the lowest extreme of the former and higher of the latter. The lamprey eels of the one possess several characters in common with the cuttle-fish or squids of the latter. The amphioxus is called the lowest Vertebrate, and, though it is nothing else, the definition of the division must be altered to receive it ; it has no brain !

The lowest forms of the Molluses and Articnlates are scarcely distinguishable from each other, so far as adhesion to the "plan" is concerned, and some of the latter division are very near certain Echinodermata. As we approach the boundary-lines of the two lowest divisions, the approaches become equally close.

More instructive is the evidence of the relation of the subordinate classes of any one of these divisions. The conditions of those organs or parts which define classes exhibit a regular relation, commencing with simplicity and ending with complication; first associated with weak exhibitions of the highest functions of the nervous system -at the last displaying the most exalted traits found in the series.

For example: In the classes of Vertebrates we find the lowest nervous system presents great simplicity-the brain can not be recognized; next (in lampreys), the end of the nerrons axis is 
subdivided, but scarcely according to the complex type that follows. In fishes the cerebellum and cerebral hemispheres are minute, and the intermediate or optic lobes very large: in the reptiles the cerebral hemispheres exceed the optic lobes, while the cerebellum is smaller. In birds the cerebellum becomes complex and the cerebrum greatly increases. In mammals the cerebellum increases in complexity or number of parts, the optic lobes diminish, while the cerebral hemispheres become wonderfully complex and enlarged, bringing us to the highest development, in man.

The history of the circulatory system in the Vertebrates is the same. First, a heart with one chamber, then one with two divisions: three divisions belong to a large series, and the highest possess fonr. The origins of the great artery of the body, the aorta, are first five on each side : they lose one in the succeeding class in the ascending scale, and one in each succeeding class or order, till the Mammalia, including man, present us, with but one on one side.

From an infinitude of such considerations as the above, we derive the certainty that the general arrangement of the various groups of the organic world is in scales, the subordinate within the more comprehensive divisions. The identification of all the parts in snch a complexity of organism as the highest animals present is a matter requiring much care and attention, and constitutes the study of homologies. Its pursuit has resulted in the demonstration that every individual of every species of a given branch of the animal kingdom is composed of elements common to all, and that the differences which are so radical in the higher gronps are but the modifications of the same elemental parts, representing completeness or incompleteness, obliteration or subdivision. Of the former character are rudimental organs, of which almost every species possesses an example in some part of its structure.

But we have other and still more satisfactory evidence of the meaning of these relations. By the study of embryology we can prove most indubitably that the simple and less complex are inferior to the more complex. Selecting the Vertebrates again as an example, the highest form of mammal-e.g., man-presents in his earliest stages of embryonic growth a skeleton of cartilage, like that of the lamprey; he also possesses five origins of the aorta and five slits on the neck: both which characters belong to 
the lamprey and the shark. If the whole number of these parts does not co-exist in the embryonic man, we find in embryos of lower forms, more nearly related to the lamprey, that they ado. Later in the life of the mammal but four aortic origins are found, which arrangement, with the heart now divided into two chambers, from a beginning as a simple tube, is characteristic of the class of Vertebrates next in order-the bony fishes. The optic lobes of the human brain hare also at this time a great predominance in size-a character above stated to be that of the same class. With adrancing derelopment the infant mammal follows the scale already pointed out. Three chambers of the heart and three aortic origins follow, presenting the condition permanent in the Batrachia; and two origins, with enlarged cerebral hemispheres of the brain, resemble the reptilian condition. Four heart-chambers, and one aortic-root on each side, with slight derelopment of the cerebellum, follow, all characters defining the crocodiles, and immediately precede the special conditions defining the mammals. These are, the single aorta-root from one side, and the full development of the cerebellum; later comes that of the cerebrum also in its higher mammalian and human traits.

Thus we see the order already pointed out to be true, and to be an ascending one. This is the more erident as each type or class passes through the conditions of those below it, as did the mammal; each scale being shorter as its highest terminus is lower. Thus the crocodile passes through the stage of the lamprey, the fish, the batrachian, and the reptile proper.

b. In Time.-We have thus a scale of relations of existing forms of animals and plants of a remarkable kind, and snch as to stimulate greatly our inquiries as to its significance. When we turn to the remains of the past creation, preserved to us in the deposits continued thronghout geologic time, we are not disappointed, for great light is at once thrown upon the subject.

We find, in brief, that the lowest division of the animal kingdom appeared first, and long before any type of a higher character was created. The Protozoön, Eozoön, is the earliest of animals in geologic time, and represents the lowest type of animal life now existing. We learn also that the highest branch appeared last. No remains of Vertebrates have been found below the lower Deronion period, or not until the Echinoderms and 
Molluses had reached a great pre-eminence. It is difficult to be sure whether the Protozoa had a greater numerical extent in the earliest periods than now, but there can be no doubt that the Colenterata (corals) and Echinoderns (crinoids) greatly exceeded their present bounds in Paleozoic time, so that those at present existing are but a feeble remnant. If we examine the subdivisions known as classes, evidence of the nature of the succession of creation is still more conclusice. The most polyp-like of the Molluses (Brachiopoda) constituted the great mass of its representatives during Paleozoic time. Among Vertebrates the fishes appear first, and had their greatest development in size and numbers during the earliest periods of the existence of the division. Batrachia were much the largest and most important of land animals during the Carboniferous period, while the higher Vertebrates were unknown. The later Mesozoic periods saw the reign of reptiles, whose position in structural derelopment has been already stated. Finally, the most perfect, the mammal, came upon the scene, and in his humblest representatives. In Tertiary times Mammalia supplanted the reptiles entirely.

Thus the struetural relations, the embryonic characters, and the successive appearance in time of animals coincide. The same is very probably true of plants.

That the existing state of the geological record of organic types should be regarded as anything but a fragment is, from our standpoint, quite preposterous. And, more, it may be assumed with safety that when completed it will furnish ns with a series of regular successions, with but slight and regular interruptions, if any, from the species which represented the simplest beginnings of life at the dawn of creation, to those which have displayed complication and power in later or in the present periods.

For the labors of the paleontologist are daily bringing to light structures intermediate between those never before so connected, and thus creating lines of succession where before were only interruptions. Many such instances might be adduced: two might be selected as examples from American paleontology ; * i. e., the

* Prof. Huxley, in the last anniversary lecture before the Geological Society of London, recalls his opinion, enunciated in 1862 , that "the positively-ascertained truths of Paleontology" negative "the doctrines of progressive modification, which suppose that modification to have taken place by a necessary progress from more to less embiyonic forms, from more to less generalized types, witlin the limits of the 
near approach to birds made by the reptiles Lrlaps and Megadactylus, and the combination of characters of the old genera Ichthyosaurus and Plesiosaurus in the Polycotylus of Kansas.

We had no more reason to look for intermediate or connecting forms between such types as these than between any others of similar degree of remove from each other with which we are ac-

period represented by the fossiliferous roeks; that it shows no eridence of such modification; and, as to the nature of that modification, it jields no evidence whatsoever that the earlier members of any long-continued group were more generalized in structure than the later ones."

Respecting this position, he says: "Thus far I have endearored to expand and enforce by fresh arguments, but not to modify in any important respect, the ideas submitted to you on a former occasion. But when I come to the propositions respecting progressive modification, it appears to me, with the help of the new light which has broken from various quarters, that there is much ground fol softening the somewhat Brutus-like severity with which I have dealt with a doctrine for the truth of which I should have been glad enough to be able to find a good foundation in 1862. So fur indeed as the Invertebrata and the lower Vertebrata are concerned, the facts and the conclusions which are to be drawn from them appear to me to remain what they were. For anjthing that as yet appears to the contrary, the earliest known Marsupials may lave been as highly organized as their living congeners; the Permian lizards show no signs of inferiority to those of the present day; the labyrinthodonts can not be placed below the living salamander and triton; the Devonian ganoids are closely related to polypterus and lepidosiren."

To this it may be replied: 1 . The seale of progression of the Vertebrata is measured by the condition of the circulatory system, and in some measure by the nerrous, and not by the osscous: tested by this scale, there has been successional complication of structure among Vertebrata in time. 2. The question with the evolutionist is, not what types have persisted to the present day, but the order in which ț̣pes appeared in time. 3. The Marsupials, Permian saurians, labyrinthodonts, and Devonian ganoids are remarkably generalized groups, and predecessors of tynes widely separated in the present period. 4. Prof. Huxley adduces many such examples among the mammalian subdivisions in the remaining portion of his lecture. 5. Two alternatives are yet open in the explanation of the process of evolution: since generalized types, which combine the eharacters of higher and lower grouns of later periods, must thus be superior to the lower, the lower must (first) be descended from such a generalized form by degradation; or (second) not descended from it at all, but from some lower contemporaneons type by advance; the higher only of the two being derived from the first-mentioned. The last I suspect to be a true explanation, as it is in accordance with the homologous groups. This law will shorten the demancls of paleontologists for time, since, instead of deriving all Reptilia, Batrachia, ete., from common origrins, it points to the derivation of higher Reptilia of a higher order from higher Reptilia of a lower order, lower Reptilia of the first from lower Reptilia of the second ; finally, the several groups of the lowest or most generalized order of Reptilia from a parallel series of the elass below, or Batraehia. 
quainted. And inasmuch as almost all groups, as genera, orders, etc., which are held to be distinet, but adjacent, present certain points of approximation to each other, the almost daily discovery of intermediate forms gives us confidence to believe that the pointings in other cases will also be realized.

\section{$\gamma$. Of Transitions.}

The preceding statements were necessary to the comprehension of the supposed mode of metamorphosis or development of the varions types of living beings, or, in other words, of the single structural features which define then.

As it is evident that the groups of highest rank have had their origin in remote ages, cases of transition from one to the other by change of character can not be witnessed at the present day. We therefore look to the most nearly related divisions, or those of the lowest riuk, for eridence of such change.

It is necessary to premise that embryology teaches that all the species of a given branch of the animal kingdom (e. g., Vertebrate, Molluse, etc.) are quite identical in structural character at their first appearance on the germinal layer of the yolk of the parent egg. It shows that the character of the respective groups of high rank appear first, then those of less grade, and last of all those structures which distinguish them as genera. But among the earliest characters which appear are those of the species, and some of those of the individual.

We find the characters of different genera to bear the same relition to each other that we have already seen in the case of those definitive of orders, etc. In a natural assemblage of relited genera we discover that some are defined by characters found only in the embryonic stages of others, while a second will present a permanent condition of its definitive part, which marks a more advanced stage of that highest. In this manner many stages of the highest genus appear to be represented by permanent genera in all natural gromps. Generally, however, this resmblance does not involve an entire identity, there being some other immaturities found in the highest genus at the time it presents the character preserved in permaneney by the lower, which the lower loses. Thus (to use a very gross illustration) a frog at one stage of growth has four legs and a tail; the salamander always preserves four legs and a tail, thus resembling the young frog. The latter is, however, not a salamander at that time, because, among other 
things, the skeleton is represented by cartilage only, and the salamander's is ossified. 'This relation is therefore an imitation only, and is called inexact paralletism.

As we compare nearer and nearer relations-i. e., the genera which present fewest points of difference-we find the differences between undeveloped stages of the higher and permanent conditions of the lower to grow fewer and fewer, until we find numerous instances where the lower genus is exactly the same as the undeveloped stage of the higher. This relation is ealled that of exact paralletism.

It must now be remembered that the permanence of a character is what gives it its value in defining genus, order, etc., in the eyes of the systematist. So long as the condition is permanent no transition can be seen; there is therefore no derelopment. If the condition is transitional, it defines nothing, and nothing is dereloped; at least, so says the anti-developmentalist. It is the old story of the settler and the Indian: "Will yon take owl and I take turkey, or I take turkey and you owl ?"

If we find a relation of cxact parallelism to exist between two sets of species in the condition of a certain organ, and the difference so expressed is the only one which distinguishes them as sets from each other-if that condition is always the same in each set -we call them two genera: if in any species the condition is variable at maturity, or sometimes the undeveloped condition of the part is persistent and sometimes transitory, the sets characterized by this difference must be united by the systematist, and the whole is called a single genus.

We know numerous cases where different individuals of the same species present this relation of exact parallelism to each other; and, as we ascribe common origin to the individuals of a species, we are assured that the condition of the inferior individnal is, in this case, simply one of repressed growth, or a failure to fulfill the course accomplished by the highest. Thus, certain species of the salamandrine genus Amblystoma undergo a metamorphosis involving several parts of the osseous and circulatory systems, etc., while half grown; others delay it till fully grown; one or two species remain indifferently unchanged or changed, and breed in either condition, while another species breeds mohanged, and lias never been known to complete a metamolphosis.

'The nature of the relation of exact paralletism is thus explained to be that of checked or advanced growth of individuals having a 
common origin. 'The relation of inexact parallelism is readily explained as follows: With a case of exact parallelism in the mind, let the repression producing the character of form $B$ parallelize the latter with a stage of form A in which a second part is not. quite mature : we will have a slight want of correspondence between the two. Form $B$ will be immature in but one point, the incompleteness of A higher being seen in two points. If we suppose the immaturity to consist in a repression at a still earlier point in the history of the ligher, the latter will be undeveloped in other points also : thus, the spike-horned deer of South Ameriea have the horn of the second year of the North American genus. They would be generically identical with that stage of the latter, were it not that these still possess their milk dentition at two years of age. In the same way the nature of the parallelisms seen in higher groups, as orders, etc., may be accounted for.

The theory of homologous groups furnishes important evidence in favor of derivation. Many orders of animals (probably all, when we come to know them) are divisible in to two or more sections, which I have called homologous. 'These are series of genera or families, which differ from each other by some marked character, but whose contained genera or families differ from each other in the same points of detail, and in fact correspond exactly. So striking is this correspondence that were it not for the general and common character separating the homologous series, they would be regarded as the same, each to each. Now, it is remarkable that, where studied, the difference common to all the terms of two homologous groups is found to be one of inexact parallelism, which has been shown above to be evidence of deseent. Homologous groups always occupy different geographical areas on the earth's surface, and their relation is precisely that which holds between successive groups of life in the periods of geologic time.*

In a word, we learn from this source that distinct geologic epochs co-exist at the same time on the earth. I have been forced to this conclusion $\nmid$ by a study of the structure of terrestrial life, and it has been remarkably confirmed by the results of reeent deep-sea dredgings made by the United States Coast Survey in the Gulf Stream, and by the British naturatists in the North Atlantic. These have brought to light types of Tertiary life, and of eren

* The extinct family of the Nimravide, whieh is homologous with the existing family of Felide, has been discovered since this was written. (Ed. 1886.)

† "Origin of Genera," pp. 70, 77, 79. 
the still more ancient Cretaceous periods, living at the present day. * That this discovery invalidates in any wise the conclusions of geology respecting lapse of time is an unwarranted assumption that some are forward to make. If it changes the views of some respecting the parallelism or co-existence of faunæ in different regions of the earth, it is only the anti-developmentalists whose position must be changed.

For, if we find distinct geologic fanne, or epochs defined by faunæ, eo-existing during the present period, and fading or merging into one another as they do at their geographical boundaries, it is proof positive that the geologic epochs and periods of past ages had in like manner no trenchant boundaries, but also passed the one into the other. The assumption that the apparent interruptions are the result of transfer of life rather than destruction, or of want of opportunities of preservation, is no doubt the true one.

\section{S. Rationale of Development.}

a. In Characters of Higher Groups. - It is evident in the case of the species in which there is an irregularity in the time of completion of metamorphosis, that some individuals traverse a longer developmental line than those which remain more or less incomplete. As both accomplish growth in the same length of time, it is obvious that it proceeds with greater rapidity in one sense in that which accomplishes most; its growth is said to be accelerated. 'This phenomenon is especially common among insects, where the females of perfect males are sometimes larvæ or nearly so, or pupæ, or lack wings or some character of final development. Quite as frequently, some males assume characters in advance of others, sometimes in connection with a peculiar geographical range.

In cases of exact parallelism we reasonably suppose the cause to be the same, since the conditions are identical, as has been shown; that is, the higher conditions have been produced by a crowding back of the earlier characters and an acceleration of growth, so that a given succession in order of advance has extended over a longer range of growth than its predecessor in the same allotted time. That allotted time is the period before maturity and reproduction, and it is evident that as fast as modifications or characters should be assumed sufficiently in adrance of that period, so certainly would they be conferred upon the offspring by

* Most of the deep-sea forms are, however, degenerate forms of existing orders. (Ed. 1886.) 
reproduction. The acceleration in the assumption of a character, progressing more rapidly than the same in another character, must soon prodnce, in a type whose stages were once the exact parallel of a permanent lower form, the condition of inexact parallelism. As all the more comprehensive groups present this relation to each other, we are compelled to believe that acceleration has been the principle of their successive evolution during the long ages of geologic time.

Each type has, however, its day of supremacy and perfection of organism, and a retrogression in these respects has succeeded. 'This has no cloubt followed a law the reverse of acceleration, which has been called retardation. By the increasing slowness of the growth of the individnals of a genus, and later and later assumption of the characters of the latter, they would be successively lost.

To what power shall we ascribe this acceleration, by which the first beginnings of structure have accumulated to themselves through the long geologic ages complication and power, till from the germ that was scarcely born into a sand-lance, a human being climbed the complete scale, and stood easily the chief of the whole?

In the cases of species, where some individuals develop farther than others, we say the former possess more growth-force, or "vigor," than the latter. We may therefore say that higher types of structure possess more "vigor" than the lower. This, however, we do not know to be true, nor can we readily find means to demonstrate it.

The food which is taken by an adult animal is either assimilated, to be consumed in immediate activity of some kind, or stored for futmre use, and the excess is rejected from the body. We have no reason to suppose that the same kind of material could be made to subserve the production of force by any other means than that furnished by a living animal organism. 'The material from which this organism is constructed is derived first from the parent, and afterward from the food, etc., assimilated by the individual itself so long as growth continues. As it is the activity of assimilation directed to a special end during this latter period which we suppose to be increased in accelerated development, the acceleration is evidently not brought about by increased facilities for obtaining the means of life which the same individual possesses as an adult. That it is not in consequence of such increased faeilities possessed by its parents over those of the type preceding it 
seems equally improbable when we consider that the characters in which the parent's advance has appeared are rarely of a nature to increase those facilities.

'The nearest approach to an explanation that can be offered appears to be somewhat in the following direction :

There is every reason to believe that the character of the atmosphere has gradually changed during geologic time, and that various constituents of the mixture have been successively removed from it, and been stored in the solid material of the earth's crust in a state of combination. Geological chemistry has shown that the cooling of the earth has been accompanied by the precipitation of many substances only gaseous at high temperatures. Hydrochloric and sulphuric acids have been transferred to mineral deposits or aqueous solutions. The remoral of carbonicacid gas and the vapor of water has been a process of much slower progress, and after the expiration of all the ages a proportion of both yet remains. Evidence of the abundance of the former in the earliest periods is seen in the vast deposits of limestone rock; later, in the prodigious quantities of shells which have been elaborated from the same in solution. Proof of its abundance in the atmosphere in later periods is seen in the extensive deposits of coal of the Carboniferous, Triassic, and Jurassic periods. If the most luxuriant regetation of the present day takes but fifty tons of carbon from the atmosphere in a century, per acre, thus producing a layer over that extent of less than a third of an inch in thickness, what amount of carbon must be abstracted in order to produce strata of thirty-five feet in depth? No doubt it occupied a long period, but the atmosphere, thus deprived of a large proportion of carbonic aeid, wonld in subsequent periods undoubtedly possess an improved capacity for the support of animal life.

The successively higher degree of oxidization of the blood in the organs designed for that function, whether performing it in water or air, would certainly accelerate the performances of all the rital functions, and among others that of growth. Thus it may be that acceleration can be accounted for, and the process of the development of the orders and sundry lesser groups of the Vertebrate kingdom indicated; for, as alleady pointed ont, the definitions of such are radically placed in the different structures of the organs which aërate the blood and distribute it to its various destinations.

But the great question, What determined the direction of this 
acceleration? remains unanswered. One can not understand why more highly oxidized blood should hasten the growth of partition of the ventricle of the heart in the serpent, the more perfectly to separate the aërated from the impure fluid; nor can we see why a more perfectly constructed circulatory system, sending purer blood to the brain, should direct accelerated growth to the cerebellum or cerebral hemispheres in the crocodile:

b. In Characters of the Specific Kind.-Some of the characters usually placed in the specific category have been shown to be the same in kind as those of higher categories. The majority are, however, of a different kind, and have been discussed several pages back.

The eause of the origin of these characters is shrouded in as much mystery as that of those which have oceupied the pages immediately preceding. As in that ease, we have to assume, as Darwin has done, a tendency in Nature to their production. This is what he terms "the principle of variation." Against an unlimited variation the great law of heredity or atavism has ever been opposed, as a conservator and multiplier of type. This prineiple is exemplified in the fact that like prodnees like-that children are like their parents, frequently even in minutia. It may be compared to habit in metaphysical matters, or to that singular love of time or rhythm seen in man and lower animals, in both of which the tendeney is to repeat in continual cycles a motion or state of the mind or sense.

Further, only a proportion of the lines of variation is supposed to have been perpetuated, and the extinction of intermediate forms, as already stated, has left isolated groups or species.

The effective cause of these extinctions is stated by Darwin to have been a "natural selection"-a proposition which distinguishes his theory from other development hypotheses, and which is stated in brief by the expression, "the survival of the fittest." Its meaning is this: that those characters appearing as results of this spontaneous variation which are little adapted to the conflict for subsistence, with the nature of the supply, or with rivals in its pursuit, dwindle and are sooner or later extirpated; while those which are adapted to their surroundings, and favored in the struggle for means of life and increase, predominate, and ultimately beeome the centers of new variation. "I am convineed," salys Darwin, "that natural selection has been the main, but not exelusive, means of modification." 
That it has been to a large extent the means of preservation of those structures known as specific, must, I think, be admitted. They are related to their peculiar surroundings very closely, and are therefore more likely to exist under their influence. Thus, if a giren genus extends its range over a continent, it is usually found to be represented by peculiar species-one in a maritime dirision, another in the desert, others in the forest, in the swamp or the elevated areas of the region. The wonderful interdependence shown by Darwin to exist between inseets and plants in the fertilization of the latter, or between animals and their foodplants, would almost induce one to believe that it were the true expression of the whole law of development.

But the following are serious objections to its universal application :

First: The elaracters of the higher groups, from genera up, are rarely of a character to fit their possessors especially for surrounding cireumstances; that is, the differences which separate genus from genus, order from order, etc., in the ascending scale of each, do not seem to present a superior adaptation to surrounding cirenmstances in the higher genus to that seen in the lower genus, etc. Hence, superior adaptation could scarcely hare caused their selection above other forms not existing. Or, in other words, the very differences in structure which indicate snecessional relation, or which measure the steps of progress, seem to be equally well fitted for their surroundings.

Second : The higher groups, as orders, classes, etc., have been in each geologie period alike distributed orer the whole earth, under all the varied cireumstances offered by climate and food. Their eharacters do not seem to have been modified in reference to these. Species, and often genera, are, on the other hand, eminently restricted according to climate, and consequently regetable and animal food.

The law of development which we seek is indeed not that which preserves the higher forms and rejects the lower after their creation, but that which explains why higher forms were ereated at all. Why in the results of a ereation we see any relation of higher and lower, and not rather a world of distinct types, each perfectly adapted to its situation, but none properly higher than another in an ascending scale, is the primary question. Given the principle of advance, then natural selection las no doubt modificd the details; but in the successire adrances we can 
scarcely believe such a principle to be influential. We look rather upon a progress as the result of the expenditure of some force fore-arranged for that end.

It may become, then, a question whether in eharacters of high grade the habit or use is not rather the result of the acquisition of the structure than the structure the result of the encouragement offered to its assumed beginnings by use, or by liberal nutrition derived from the increasingly superior advantages it offers.

\section{$\epsilon$. The Physical Origin of Man.}

If the hypothesis here maintained be true, man is the descendant of some pre-existent generie type, the which, if it were now living, we would probably call an ape.

Man and the chimpanzee were in Linnæus's system only two species of the same genus, but a truer anatomy places them in separate genera and distinct families. There is no doubt, however, that Cuvier went much too far when he proposed to consider Homo as the representative of an order distinct from the Quadrumana, under the name of Bimana. The structural differences will not bear any such interpretation, and have not the same value as those distinguishing the orders of Mammalia; as, for instance, between Carnivora and bats, or the cloren-footed animals and the rodents, or rodents and edentates. The differences between man and the ehimpanzee are, as Huxley well puts it, much less than those between the chimpanzee and lower Quadrumana, as lemurs, etc. In fact, man is the type of a family, Hominidie, of the order Quadrumana, as indicated by the characters of the dentition, extremities, brain, ete. The reader who may have any doubts on this score may read the dissections of Geoffroy St. Hilaire, made in 1856, before the issue of Darwin's "Origin of Species." He informs us that the brain of man is nearer in structure to that of the orang than the orang's is to that of the South Ameriean howler, and that the orang and howler are more nearly related in this regard than are the howler and the marmoset.

The modifieations presented by man have, then, resulted from an acceleration in development in some respects, and retardation perhaps in others. But until the combination now characteristic of the genus Homo was attained, the being could not properly be called man.

And here it must be observed that as an organic type is char- 
acterized by the co-existence of a number of peculiarities which have been developed independently of each other, its distinctive features and striking functions are not exhibited until that coexistence is attained which is necessary for these ends.

Hence, the characters of the human genus were probably developed suceessively ; but few of the indications of human superiority appeared until the combination was aecomplished. Let the opposable thumb be first perfeeted, but of what nse wonld it be in human affairs without a mind to direet? And of what use a mind without speech to unlock it? And speech could not be possible though all the muscles of the larynx but one were developed, or but a slight abnormal convexity in one pair of cartilages remained.

It would be an objection of little weight eould it be truly urged that there have as yet no remains of ape-like men been discorered, for we have frequently been called upon in the course of paleontological discovery to bridge greater gaps than this, and greater remain, which we expeet to fill. But we have ape-like characters exhibited by more than one race of men yet existing.

But the remains of that being which is supposed to have been the progenitor of man may lave been discovered a short time since in the care of Naulette, Belgium, with the bones of the extinct rhinoceros and elephant.

We all admit the existence of higher and lower races, the latter being those which we now find to present greater or less approximations to the apes. The peculiar structural characters that belong to the negro in his most typical form are of that kind, however great may be the distance of his remove therefrom. The flattening of the nose and prolongation of the jaws constitute snch a resemblance; so are the deficiency of the calf of the leg, and the obliquity of the pelvis, which approaches more the horizontal position than it does in the Caucasian. The investigations made at Washington during the war with reference to the physical eharacteristies of the soldiers show that the arms of the negro are from one to two inches longer than those of the whites: another approximation to the ape. In fact, this race is a species of the genus Homo, as distinet in character from the Caucasian as those we are accustomed to recognize in other departments of the animal kingdom; but he is not distinct by isolation, since intermediate forms between him and the other speeies can be abundantly found. 
And here let it be particularly observed that two of the most prominent character's of the negro are those of immature stages of the Indo-Enropean race in its characteristic types. The deficient calf is the character of infants at a very early stage; but, what is more important, the flattened bridge of the nose and shortened nasal cartilages are universally immature conditions of the same parts in the Indo-European. Any one may convince himself of that by examining the physioguomies of infants. In some racese. g., the Slavic-this undeveloped character persists later than in some others. 'The Greek nose, with its elevated bridge, coincides not only with asthetic beauty, but with developmental perfection.

This is, howerer", only "inexact parallelism," as the characters of the Irair, etc., can not be explained on this principle among cxisting races. 'The embryonic characters mentioned are probably a remnant of those characteristic of the primordial race or species.

But the man of Naulette, if he be not a monstrosity, is a still more distinct and ape-like species. The chin, that marked character of other species of men, is totally wanting, and the dentition is quite approximate to the man-like apes, and different from that of modern men. The form is very massive, as in apes. That he was not abnormal is rendered probable by approximate characters seen in a jaw from the cave of Puy-sur-Aube, and less marked in the lowest rices of Australia and New Caledonia.

As to the single or multiple origin of man, science as yet furnishes no answer. It is very probable that, in many cases, the species of one genus have descended from corresponding species of another by change of generic characters only. It is a remarkable fact that the orang possesses the peculiarly developed malar bones and the copper color characteristic of the Mongolian inhabitants of the regions in which this animal is found, while the gorilla exhibits the prognathic jaws and black hue of the African races near whom he dwells. This kind of geographical imitation is very common in the animal kingdom.

\section{IT. METAPHYSICAL EVOLCTION.}

It is infinitely improbable that a being endowed with such capacities for gradual progress, as man has exhibited, should have been full-fledged in accomplishments at the moment when he could first claim lis high title, and abandon that of his simian ancestors. We are, therefore, required to admit the growth of human intelligence from a primitive state of inactivity and abso- 
lute ignorance; including the development of one important mode of its expression-speech; as well as that of the moral qualities, and of man's social system - the form in which his icleas of morality are first displayed.

The expression "evolution of morality" need not offend, for the question in regard to the laws of this evolution is the really important part of the discussion, and it is to the opposing riews on this point that the most serious interest attaches.

\section{a. Development of Intelligence.}

If the brain is the organ of mind, we may be surprised to find that the brain of the intelligent man scarcely differs in structure from that of the ape. Whence, then, the difference of power? Though no one will now deny that many of the Mammalia are cupable of reasoning upon observed facts, yet how greatly the results of this capacity differ in number and importance from those achieved by human intelligence! Like water at the temperatures of $50^{\circ}$ and $53^{\circ}$, where we perceive no difference in essential character, so between the brains of the lower and higher monkeys no difference of function or of intelligence is perceptible. But what a difference do the two degrees of temperature from $33^{\circ}$ to $31^{\circ}$ produce in water! In like manner the difference between the brain of the higher ape and that of man is accompanied by a difference in function and power, on which man's earthly destiny depends. In development, as with the water, so with the higher. ape; some Rubicon has been crossed, some floodgate has been opened, which marks one of Nature's great transitions, such as have been called "expression-points" of progress.

What point of progress in such a history would account for this accession of the powers of the human intelligence? It has been answered, with considerable confidence-the power of speech. Let us picture man without speech. Each gencration would learn nothing from its predecessors. Whatever originality or observation might yield to a man would die with him. Each intellectual lifo would begin where every other life began, and would end at a point only differing with its original capacity. Concert of action, by which man's power over the material world is maintained, would not exceed, if it equaled, that which is seen among the bees; and the material results of his labors would not extend beyond securing the means of life and the employment of the simplest modes of defense and attack. 
The first men, therefore, are looked upon by the developmentalists as extremely embryonic in all that characterizes humanity, and they appeal to the facts of history in support of this view. If they do not derive much assistance from written history, evidence is found in the more enduring relies of human handiwork.

'The opposing view is, that the races which present or have presented this condition of inferiority or savagery have reached it by a process of degradation from a higher state-as some believe, through moral delinquency. This position may be true in certain cases, which represent perhaps a condition of senility, but in general we believe that savagery was the condition of the first man, which has in some races continued to the present day.

\section{B. Evidence from Archceology.}

As the objeet of the present essay is not to examine fully into the evidences for the theories of evolntion here stated, but rather to give a sketch of such theories and their connection, a few facts only will be noticed.

Improvement in the Use of Materials.-As is well known, the remains of human handiwork of the earliest periods consist of nothing but rude implements of stone and bone, usefnl only in proenring food and preparing it for use. Even when enterprise extended beyond the ordinary rontine, it was restrained by the want of proper instruments. Knives and other cutting implements of flint still attest the skill of the early races of men from Java to the Cape of Good Hope, from Egypt to Ireland, and through North and South America. Hatchets, spear-heads and ornaments of serpentine, granite, silex, clay slates, and all other suitable rock materials, are found to have been used by the first men, to the exclusion of metals, in most of the regions of the earth.

Later, the probably accidental discovery of the superiority of some of the metals resulted in the substitution of them for stone as a material for entting implements, Copper-the only metal which, while malleable, is hard enough to bear an imperfeet edge -was used by suceeeding races in the old World and the New. Implements of this material are found scattered over extensive regions. So desirable, however, did the hardening of the material appear for the improvement of the cutting edge, that combinations with other metals were sought for and discovered. The alloy with 
tin, forming bronze and brass, was discovered and used in Europe, while that with silver appears to have been most readily produced in America, and was consequently used by the Peruvians and other nations.

The discovery of the modes of reducing iron ores placed in the hands of man the best material for bringing to a shape convenient for his needs the raw material of the world. All improvements in this direction made since that time have been in the quality of iron itself, and not through the introduction of any new metal.

The prevalent phenomena of any given period are those which give it its character, and by which we distinguish it. But this fact does not exchde the co-existence of other phenomena belonging to prior or subsequent stages. Thus during the many stages of human progress there have been men more or less in advance of the general body, and their characteristics have given a peculiar stamp to the later and higher condition of the whole. It furnishes no objection to this view that we find, as might have been anticipated, the stone, bronze, and iron periods overlapping one another, or men of an inferior culture supplanting in some cases a superior people. A case of this kind is seen in North America, where the existing "Indians," stone-men, have sneceeded the mound-builders, copper-men. The suceessional relation of discoveries is all that it is necessary to prove, and this seems to be established.

The period at which the use of metallie implements was introduced is unknown, but Whitney says that the language of the Aryans, the ancestors of all the modern Indo-Europeans, indieates an aequaintance with such implements, though it is not certain whether those of iron are to be included. The dispersion of the danghter races, the Hindoos, the Pelasgi, Tentons, Celts, etc., could not, it is thought, have taken place later than 3000 B. c.a date seven hundred years prior to that assigned by the old chronology to the Deluge. Those races co-existed with the Egyptian and Chinese nations, already eivilized, and as distinet from each other in feature as they are now.

Improvement in Architecture.-The earliest periods, then, were characterized by the utmost simplieity of invention and construetion. Later, the efforts for defense from enemies and for architectural display, which have always employed so much time and power, begin to be made. 'The megalithic period lias left traces 
over much of the earth. The great masses of stone piled on each other in the simplest form in Southern India; and the circles of stones planted on end in England at Stonehenge and Abury, and in Peru at Sillustani, are relies of that period. More complex are the great Himyaritic walls of Arabia, the works of the ancestors of the Phœnicians in Asia Minor, and the titanie workmanship of the Pelasgi in Greece and Italy. In the iron age we find granitie hills shaped or excavated into temples; as, for example, everywhere in Sonthern India. Near Madura the circumference of an acropolis-like hill is cut into a series of statues in high relicf, of sixty feet in elevation. Easter Island, composed of two volcanic cones, one thousand miles from the west coast of South America, in the bosom of the Pacific, possesses several colossi cut from the intrusive basalt, some in high relief on the face of the rock, others in detached blocks removed by human art from their original positions and brought nearer the sea-shore.

Finally, at a more advanced stage, the more ornate and complex structures of Central Ameriea, of Cambodia, Nineveh and Egypt, represent the period of greatest display of architeetural expenditure. The same amount of human force has perhaps never been expended in this direction sinee, though higher conceptions of beauty have been developed in architecture with increasing intellectuality.

Man has passed through the block-and-brick building period of his boyhood, and should rise to higher conceptions of what is the true disposition of power for " him who builds for aye," and learn that "spectacle" is often the unwilling friend of progress.

No traces of metallic implements have ever been found in the salt-mines of Armenia, the turquoise-quarries in Arabia, the cities of Central America, or the excavations for mica in North Carolina, while the direct evidence points to the eonclusion that in those places flint was exclusively used.

The simplest oecupations, as requiring the least exereise of mind, are the pursuit of the chase and the tending of flocks and herds. Aceordingly, we find our first parents engaged in these occupations. Cain, we are told, was, in addition, a tiller of the ground. Agriculture in its simplest forms requires but little more intelligenee than the pursuits just mentioned, though no employment is eapable of higher development. If we look at the savage nations at present oceupying nearly half the land surface of the earth, we shall find many examples of the former indus- 
trial condition of our race preserved to the present day. Many of them had no knowledge of the use of metals until they obtained it from civilized men who visited them, while their pursuits were and are those of the chase, tending domestic animals, and rudimental agriculture.

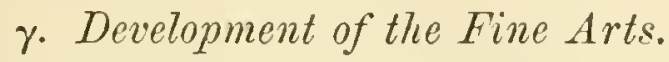

If we look at representation by drawing or senlpture, we find that the efforts of the earliest races of which we have any knowledge were quite similar to those which the untaught hand of infaney traces on its slate or the savage depicts on the rocky faces of hills. The circle or triangle for the head and body, and straight lines for the limbs, have been preserred as the first attempts of the men of the stone period, as they are to this day the sole representations of the human form which the North American Indian places on his buffalo robe or mountain precipice. The stiff, barely outlined form of the deer, the turtle, ete., are literally those of the infancy of civilized man.

The first attempts at sculpture were marred by the influence of modism. Thus the idols of Coban and Palenque, with human faces of some merit, are orerloaded with absurd ornament, and deformed into frightful asymmetry, in compliance with the demand of some imperious mode. In later days we hare the stiff, conventionalized figures of the palaces of Nineveh and the temples of Egypt, where the representation of form has somewhat improved, but is too often distorted by false fashion or imitation of some unnatural standard, real or artistic. This is distinguished as the day of archaic sculpture, which disappeared with the Etrusean nation. So the drawings of the child, when he abandons the simple lines, are stiff and awkward, and but a stage nearer true representation; and how often does he repeat some peculiarity or absurdity of lis own!

The introduction of the action and pose of life into senlpture was not known before the early days of Greece, and it was there that the art was brought to perfection. When art rose from its medixval slumber, much the same suecession of development may be discorered. First, the stiff figures, with straightened limbs and eylindric drapery, found in the old Northern churehes--then the forms of life that now adorn the porticoes and palaces of the cities of Germany. 


\section{d. Rationale of the Development of Intelligence.}

The history of material development shows that the transition from stage to stage of development, experienced by the most perfect forms of animals and plants in their growth from the primordial cell, is similar to the succession of created beings which the geological epochs produced. It also shows that the slow assumption of main characters in the line of succession in early geological periods produced the condition of inferiority, while an increased rapidity of growth in later days has resulted in an attainment of superiority. It is not to be supposed that in "acceleration" the period of growth is shortened; on the contrary, it continues the same. Of two beings whose characters are assumed at the same rate of succession, that with the quickest or shortest growth is necessarily inferior. "Acceleration" means a gradual increase of the rate of assumption of successive characters in the same period of time. A fixed rate of assumption of characters, with gradual increase in the length of the period of growth, would produce the same result-viz., a longer developmental scale and the attainment of an advanced position. The first is in part the relation of sexes of a species; the last of genera, and of other types of creation. If from an observed relation of many facts we derive a law, we are permitted, when we see in another class of facts similar relations, to suspect that a similar law has operated, differing only in its objects. We find a marked resemblance between the facts of structural progress in matter and the phenomena of intellectual and spiritual progress.

If the facts entering into the categories enumerated in the preceding section bear us ont, we conclude that in the beginning of human history the progress of the indiridual man was very slow, and that but little was attained to ; that, through the profitable direction of hmman energy, means were discovered from time to time by which the process of individual development in all metaphysical qualities has been accelerated; and that up to the present time the consequent advance of the whole race has been at an increasing rate of progress. This is in accordance with the general prineiple, that high development in intellectual things is accomplished by rapidity in traversing the preliminary stages of inferiority common to all, while low development signifies slnggishness in that progress, and a corresponding retention of inferiority. 
How much meaning may we not see, from this standpoint, in the history of the intelligence of our little ones! First they crawl, they walk on all-fours; when they first assume the erect position they are generally speechless, and utter only inarticulate sounds. When they run about, stones and dirt, the objects that first meet the eye, are the delight of their awakening powers; but these are all cast aside when the boy obtains his first jackknife. Soon, however, reading and writing open a new world to him; and, finally, as a mature man he seizes the forces of Nature, and steam and electricity do his bidding in the active pursuit of power for still better and higher ends.

So with the history of the species: first, the quadrumane; then the speaking man, whose humble industry was, however, confined to the objects that came first to hand, this being the "stone age" of pre-historic time. When the use of metals was discovered, the range of industries expanded wonderfully, and the "iron age" saw many striking efforts of human power. With the introduction of letters it became possible to record events and experiences, and the spread of knowledge was thereby greatly increased, and the delays and mistakes of ignorance correspondingly diminished in the fields of the world's activity.

From the first we see in history a slow advance as knowledge gained by the accumulation of tradition and by improvements in habit based on experience; but how slow was this advance while the use of the metals was still unknown! The iron age brought with it not only new conveniences, but increased means of future progress; and here we have an acceleration in the rate of advance. With the introduction of letters this rate was increased manifold, and in the application of steam we have a change equal in utility to any that has preceded it, and adding to the possibilities of future adrance in many directions. By it power, knowledge, and means of happiness were to be distributed among the many.

The uses to which human intelligence has successively applied the materials furnished by Nature have been-first, subsistence and defense; second, the accumulation of power in the shape of a representative of that labor which the use of matter involves-in other words, the accumulation of wealth. The possession of this power involves new possibilities, for opportunity is offered for the special pursuits of knowledge and the assistance of the weak or undeveloped part of mankind in its struggles.

Thus, while the first mon possessed the power of speech, and 
conld advance a little in knowledge through the accumulation of the experiences of their predecessors, they possessed no nieans of aceumulating the power of labor, no control over the aetivity of numbers-in other words, no wealth.

But the aceumulation of knowledge finally brought this advance about. The extraction and utilization of the metals, especially iron, formed the most important step, since labor was thus facilitated and its productiveness increased in an incaleulable degree. We have little evidence of the existence of a medium of exchange during the first or stone period, and no doubt barter was the only form of trade. Before the use of metals, shells and other objects were used; remains of money of baked clay have been found in Mexico. Finally, though in still ancient times, the possession of wealth in money gradually became possible and more common, and from that day to this avenues for reaching this stage in social progress have ever been opening.

But wealth merely indicates a stage of progress, since it is but a comparative term. All men could not become rich, for in that case all would be equally poor. But labor has a still higher goal ; for, thirdly, as capital, it constructs and employs machinery, which does the work of many hands, and thus eheapens produets, which is equivalent in effect to an acenmulation of wealth to the consumer. And this increase of power may be used for the intellectual and spiritual advance of men, or, otherwise, at the will of t?e men thus favored. Machinery places man in the position of a creator, operating on Nature through an increased number of "secondary causes."

Development of intelligence is seen, then, in the following directions: First, in the knowledge of facts, inchuding science; second, in langnage; and, as conseqnences of these, the aceumulation of power by development-first, of means of subsistence ; and, second, of mechanieal invention; and, third, in the apprehension of beauty.

Thus, we have two terms to start with in estimating the beginning of human development in knowledge and power : first, the primary capacities of the human mind itself ; second, a material world, whose infinitely varied components are so arranged as to yield results to the energies of that mind. For example, the transition-points of vaporization and liquefiction are so placed as to be within the reach of man's agents; their weights are so fixed ats to accord with the muscular or other forces which he is able to 
exert; and other living organizations are subject to his convenience and rule, and not, as in previous geological periods, entirely beyond his control. These two terms being given, it is maintained that the present situation of the most civilized men has been attained through the operation of a law of mutual action and reaction-a law whose results, seen at the present time, have depended on the acceleration or retardation of its rate of action; which rate has been regulated, according to the degree in which a third great term, viz., the law of moral or (what is the same thing) true religious derelopment, has been combined in the plan. What it is necessary to establish in order to prove the above hypothesis is-

I. That in each of the particulars above enumerated the derelopment of the human species is similar to that of the individual from infancy to maturity.

II. That from a condition of subserviency to the laws of matter, man's intelligence enables him, by an accumulation of power, to become in a sense independent of those laws, and to pursue a course of intellectual and spiritual progress.

III. That failure to accomplish a moral or spiritual development will again reduce him to a subserviency to the laws of matter.

This brings us to the subject of moral development. And here I may be allowed to suggest that the weight of the eridence is opposed to the philosophy, "falsely so called," of necessitarianism, which asserts that the first two terms alone were sufficient to work out man's salvation in this world and the next; and, on the other hand, to that anti-philosophy which asserts that all things in human progress, intellectual and moral, are regulated by immediate divine interposition instead of through instrumentalities. Hence, the subject divides itself at once into two great departments-viz., that of the development of mind or intelligence, and that of the development of morality.

That these laws are distinct there can be no doubt, since in the individual man one of them may produce results without the aid of the other. Yet it can be shown that each is the most invaluable aid and stimulant to the other, and most favorable to the rapid advance of the mind in either direction.

\section{SPIIITUAL OR MORAL IEVELOPMENT.}

In examining this subject, we first inquire (Section $a$ ) whether there is any connection between physical and moral or religions 
development; then $(\beta)$, what indications of moral development may be derived from history. Finally $(\gamma)$, a correlation of the results of these inquiries, with the nature of the religious development in the individual, is attempted. Of course in so stupendous an inquiry but a few leading points can be presented here.

If it be true that the period of human existence on the earth has seen a gradually increasing predominance of higher motives over lower ones among the mass of mankind, and if any parts of our metaphysical being have been derived by inheritance from pre-existent beings, we are ineited to the inquiry whether any of the moral qualities are included among the latter; and whether there be any resemblance between moral and intellectual development.

Thus, if there have been a physical derivation from a preexistent genus, and an embryonic condition of those physical characters which distinguish Homo-if there has been also an embryonic or infantile stage in intellectual qualities-we are led to inquire whether the development of the individual in moral nature will furnish us with a standard of estimation of the successive conditions or present relations of the human species in this aspect also.

\section{a. Relations of Physical and Moral Nature.}

Although, cceteris paribus, men are much alike in the deeper qualities of their nature, there is a range of variation which is best understood by a consideration of the extremes of such variation as seen in men of different latitudes, and women and children.

(a) In Children.-Youth is distinguished by a peculiarity, which no doubt depends upon an immature condition of the nervous center concerned, which might be called nervous impressibility. It is exhibited in a greater tendency to tearfulness, in timidity, less mental endurance, a greater facility in acquiring knowledge, and more ready susceptibility to the influence of sights, sounds, and sensations. In both sexes the emotional nature predominates over the intelligence and judgment. In those years the character is said to be in embryo, and theologians, in using the phrase, "reaching years of religious understanding," mean that in earty years the religious capacities undergo development coincidentally with those of the body.

(b) In Women.-If we examine the metaphysical characteris- 
tics of women, we observe two classes of traits-namely, those which are also found in men, and those which are absent or but weakly developed in men. Those of the first class are very similar in essential nature to those which men exhibit at an early stage of derelopment. This may be in some way related to the fact that physical maturity occurs earlier in women.

The gentler sex is characterized by a greater impressibility, often seen in the influence exercised by a stronger character, as well as by music, color, or spectacle generally; warmth of emotion, submission to its influence rather than that of logic; timidity and irregularity of action in the outer world. All these qualities belong to the male sex, as a general rule, at some period of life, though different individuals lose them at very various periods. Ruggedness and stermmess may rarely be developed in infancy, yet at some still prior time they eertainly do not exist in any.

Probably most men can recollect some early period of their lives when the emotional nature predominated-a time when emotion at the sight of suffering was more easily stirred than in maturer years. I do not now allude to the benerolence inspired, kept alive, or developed by the influence of the Christian religion on the heart, but rather to that which belongs to the natural man. Perhips all men ean recall a period of youth when they were hero-worshipers-when they felt the need of a stronger arm, and lored to look up to the powerful friend who could sympathize with and aid them. This is the "woman stage" of character: in a large number of cases it is early passed; in some it lasts longer ; while in a very few men it persists through life. Severe discipline and labor are unfarorable to its persistence. Luxury preserves its bad qualities without its good, while Christianity preserres its good elements without its bad.

It is not designed to say that woman in her emotional nature does not differ from the undeveloped man. On the contrary, though she does not differ in kind, she differs greatly in degree, for her qualities grow with her growth, and exeeed in power many fold those exhibited by her companion at the original point of departure. Hence, since it might be said that man is the undereloped woman, a word of explanation will be useful. Embryonic types abound in the fields of nature, but they are not therefore immature in the usual sense. Maintaining the lower essential quality, they yet exhibit the usual results of growth in individual 
characters; that is, increase of strength, powers of support and protection, size and beauty. In order to maintain that the masculine character coincides with that of the undeveloped woman, it would be necessary to show that the latter during her infiney possesses the male characters predominating - that is, unimpressibility, judgment, physical courage, and the like.

If we look at the second class of female characters-namely, those which are imperfectly developed or absent in men, and in respect to which man may be called undeveloped woman-we note three prominent points: facility in language, tact or finesse, and the love of children. The first two appear to me to be altogether developed results of "impressibility," already considered as an indication of immaturity. Imagination is also a quality of impressibility, and, associated with finesse, is apt to degenerate into duplicity and untruthfulness-a peculiarity more natural to women than men.

The third quality is different. It generally appears at a very early period of life. Who does not know how soon the little girl selects the doll, and the boy the toy-horse or machine? Here man truly never gets beyond undeveloped woman. Nevertheless, "impressibility" seems to have a great deal to do with this quality also.

Thus the metaphysical relation of the sexes would appear to be one of inexact parallelism, as defined in Section I. That the physical relation is a remote one of the same kind, several characters scem to point out. The case of the vocal organs will suffice. Their structure is identical in both sexes in early youth, and both produce nearly similar sounds. They remain in this condition in the woman, while they undergo a metamorphosis and change both in structure and vocal power in the man. In the same way, in many of the lower creation, the females possess a majority of embryonic features, thongh not invariably. A common example is to be found in the plumage of birds, where the females and young males are often undistinguishable.* But there are a few points in

* Meehan states that the upper limbs and strong laterals in Conifera and other trees produce female flowers and eones, and the lower and more interior branches the male flowers. Ile calls the former condition one of greater "vigor," and the latter one of "weakness," and argues that the vigorous condition of growth produces females, and the weaker males. What he points out, however, is in harnony with the position here maintained-namely, that the female eharacters include more of those which are embryonic in the males than the male characters include of those 
the physical structure of man also in which the male condition is the immature one. In regard to structure, the point at which the relation between the sexes is that of exact paralletism, or where the mature condition of the one sex accords with the undeveloped condition of the other, is when reproduction is no longer accomplished by budding or gemmation, but requires distinct organs. Metaphysically, this relation is to be found where distinct individuality of the sexes first appears; that is, where we pass from the hermaphrodite to the bisexual condition.

But let us put the whole interpretation on this partial undevelopment of woman.

The types or conditions of organic life which have been the most prominent in the world's history-the Ganoids of the first, the Dinosaurs of the second, and the Mammoths of the third period-have generally died with their day. The line of succession has not been from them. The law of anatomy and paleontology is, that we must seek the point of departure of the type which is to predominate in the future, at lower stages on the line, in less decided forms, or in what, in scientific parlance, are called generalized types. In the same way, though the adults of the tailless apes are in a physical sense more highly dereloped than their young, yet the latter far more closely resemble the human species in their large facial angle and shortened jaws.

How much significance, then, is added to the law uttered by Christ!- "Except ye become as little children, ye can not enter" the kingdom of hearen." Submission of will, loving trust, confiding faith-these belong to the child: how strange they appear to the executing, commanding, reasoning man! Are they so strange to the woman? We all know the answer. Womran is nearer to the point of departure of that development which outlives time and peoples hearen; and if man would find it, he must retrace his steps, regain something he lost in youth, and join to

which are embryonic in the female: the female flowers are the product of the younger and more growing portions of the tree-that is, those last produced (the upper limbs and new branches)-while the male flowers are produced by the older or more mature portions-that is, lower limbs or more axial recions. Further, we are not accustomed to regard the condition of rapid growth as that of great vigor in animals, but rather ascribe that quality to maturity, after such growth has ceased.

Meehan's observations coincile with those of Thury and others on the origin of sexes in animals and plants, which it appears to me admit of a similar explanation. 
the powers and energies of his character the submission, love and faitly which the new birth alone can give.

I Thus the summing up of the metaphysical qualities of woman would be thus expressed: In the emotional world, man's superior ; in the moral world, his equal; in the laboring world, his inferior.

There are, however, vast differences in women in respect to the number of masculine traits they may have assumed before being determined into their own special development. Woman also, under the influence of necessity, in later years of life, may add more or less to those qualities in her which are fully dereloped in the man.

The relation of these facts to the principles stated as the two opposing laws of development is, it appears to me, to be explained thus : First, that woman's most inherent peculiarities are not the result of the external circumstances with which she has been placed in contact, as the conflict theory would indicate. Such circumstances are said to be her involuntary subserviency to the physically more powerful man, and the effect of a compulsory mode of life in preventing her from attaining a position of equality in the activities of the world. Second, that they are the result of the different distributions of qualities as already indicated by the harmonic theory of development ; that is, of the unequal possession of features which belong to different periods in the developmental succession of the highest. There is then another beautiful harmony which will erer remain, let the development of each sex be extended as far as it may.

(c) In Men.--If we look at the male sex, we shall find various exceptional approximations to the female in mental constitution. Further, there can be little doubt that in the Indo-European race maturity in some respects appears earlier in tropical than in northern regions; and though subject to many exceptions, this is sufficiently general to be looked upon as a rule. Accordingly, we find in that race-at least in the warmer regions of Europe and America-a larger proportion of certain qualities which are more universal in women; as greater activity of the emotional nature when compared with the judgment; an impressibility of the nervous center, which, ceteris paribus, appreciates quickly the harmonies of sound, form, and color; answers most quickly to the friendly greeting or the hostile menace; is more careless of consequences in the material expression of generosity or hatred, and more indifferent to truth under the influence of personal relations. 
The morements of the body and expressions of the countenanee answer ts the temperament. More of grace and elegance in the bearing marks the Greek, the Italian, and the Creole, than the German, the Englishman, or the Green Mountain man. More of vivacity and fire, for better or for worse, is displajed in the countenanee.

Perhaps the more northern type left all that behind in its youth. The rugged, angular eharaeter which appreeiates force better than harmony, the strong intellect which delights in forethought and caleulation, the less impressibility, reaching stolidity in the unedneated, are its well-known traits. If there be in such a eharacter less generosity and but little chivalry, there is persisteney and unwavering fidelity, not readily obseured by the lightning of passion or the surmises of an active imagination.

All these peculiarities appear to result, first, from different degrees of quickness and depth in appreciating impressions from without; and, second, from differing degrees of attention to the intelligent judgment in consequent aetion. (I leave eonscience out, as not belonging to the category of inherited qualities.)

The above observations have been eonfined to the Indo-Enropean race. It may be objected to the theory that savagery means immaturity in the senses above deseribed, as dependent largely on "impressibility," while savages in general display the least "impressibility," as that word is generally understood. "This ean not be asserter of the Africans, who, so far as we know them, possess this peeuliarity in a high degree. Moreover, it must be remembered that the state of indifference which preedes that of impressibility in the individual may charaeterize many savages; while their varied peeuliarities may be largely accounted for by recolleeting that many combinations of different species of emotion and kinds of intelligence go to make up the complete result in each case.

(d) Conclusions. - Three types of religion may be selected from the developmental conditions of man : first, an absence of sensibility (early infaney) ; seeond, an emotional stage more productive of faith than of works ; thirdly, an intellectual type, more favorable to works than faith. Though in regard to responsibility these states may be equal, there is absolutely no gain to laboring humanity from the first type, and a serious loss in actual results from the second, taken alone, as compared with the third.

These, then, are the physical velicles of religion-if the phrase 
may be allowed-which give character and tone to the deeper spiritual life, as the color of the transparent ressel is communicated to the light which radiates from within.

But if evolution bas taken place, there is evidently a provision for the progress from the lower to the higher states, either in the education of circumstances ("conflict") or in the power of an interior spiritual influence ("harmony"), or both.

\section{B. Evidence derived from History.}

We trace the development of Morality in-first, the family, or social order; second, the civil order, or government.

Whatever may have been the extent of moral ignorance before the Deluge, it does not appear that the earth was yet prepared for the permanent habitation of the human race. All nations preserve traditions of the drowning of the early peoples by floods, such as have occurred frequently during geologic time. At the close of each period of dry land, a period of submergence has set in, and the depression of the level of the earth, and consequent overflow by the sea, has caused the death and subsequent preservation of the remains of the fanma and flora living upon it, while the elevation of the same has produced that intermption in the process of deposit in the same region which marks the intervals between geologic periods. Changes in these respects do not occur to any very material extent at the present time in the regions inhabited by the most highly developed portions of the human race; and as the last which occurred seems to have been expressly designed for the preparation of the earth's surface for the occupation of organized human society, it may be doubted whether many such changes are to be looked for in the future. 'The last great flooding was that which stratified the drift materials of the north, and carried the finer portions far over the south, determining the minor topography of the surface and supplying it with soils.

The existence of floods which drowned many races of men may be considered as established. 'The men destroyed by the one recorded by Moses are described by him as exceedingly wicked, so that "the earth was filled with riolence." In his eyes the Flood was designed for their extermination.

That their condition was evil must be fully believed if they were condemned by the executive of the Jewish law. This law, it will be remembered, permitted polygamy, slavery, revenge, aggressive war. The Jews were expected to rob their neighbors, the 
Egyptians, of jewels, and they were allowed "an eye for an eye and a tooth for a tooth." They were expected to butcher other nations, with their women and children, their flocks and their herds. If we look at the lives of men recorded in the Old Testament as examples of distinguished excellence, we find that their standard, howerer superior to that of the people around them, would ill accord with the morality of the present day. They were all polygamists, slaveholders, and warriors. Abraham treated Hagar and Ishmael with inhumanity. Jacob, with his mother's aid, deceived Isaac, and received thereby a blessing which extended to the whole Jewish nation. David, a man whom Paul tells us the Lord found to be after his own heart, slew the messenger who bronght tidings of the death of Saml, and committed other acts which would stain the reputation of a Christian beyond redemption. It is scarcely necessary to turn to other nations if this be true of the chosen men of a chosen people. History, indeed, presents us with no people prior to, or contemporary with, the Jews who were not morally their inferiors. *

If we turn to more modern periods, an examination of the morality of Greece and Rome reveals a curious intermixture of lower and higher moral conditions. While each of these natious prodnced excellent moralists, the influence of their teachings was not sufficient to elevate the masses abore what would now be regarded as a very low standard. The popularity of those scenes of cruelty, the gladiatorial shows and the combats with wild beasts, sufficiently attests this. The Roman virtue of patriotism, while productive of many noble deeds, is in itself far from being a disinterested one, but partakes rather of the nature of partisanship and selfishness. If the Greeks were supcrior to the Romans in humanity, they were apparently their inferiors in the social virtues, and were much below the standard of Christian nations in both respects.

Ancient history points to a state of chronic war, in which the social relations were in confusion, and the development of the useful arts was almost impossible. Savage races, which continue to this day in a similar moral condition, are, we may easily believe, most unhappy. 'They are generally divided into tribes, which are mutually hostile, or friendly only with the view of injuring some other tribe. Might is their law, and robbery, rapine,

* The evidenee on this point being very imperfect, judgment may be properly suspended. (Ed. 1886.) 
and murder express their mutual relations. This is the history of the lowest grade of barbarism, and the history of primeval man so far as it has come down to us in sacred and profane records. Man as a species first appears in history as a sinful being. Then a race maintaining a contest with the prevailing corruption and exhibiting a higher moral idea is presented to us in Jewish history. Finally, early Christian society exhibits a greatly superior condition of things. In it polygamy scarcely existed, and slavery and war were condemned. But progress did not end here, for our Lord said, "I have yet many things to say unto you, but ye can not bear them now. Howbeit, when he, the spirit of truth, is come, he will gnide you into all truth."

The progress revealed to us by history is truly great, and if a similar difference existed between the first of the human species and the first of whose condition we have information, we can conceive how low the origin must hare been. History begins with a considerable progress in eivilization, and from this we must infer a long preceding period of human existence, such as a gradual evolution would require.

\section{$\gamma$. Rationale of Moral Development.}

I. Of the Species. -Let us now look at the moral condition of the infant man of the present time. We know his small accountability, his trust, his innocence. We know that he is free from the law that when he "would do good, evil is present with him," for good and evil are alike mknown. We know that until growth has progressed to a certain degree he fully deserves the praise pronounced by our Saviour, that "of such is the kingdom of heaven." Growth, however, generally sees a change. We know that the buddings of evil appear but too soon; the lapse of a few months sees exhibitions of anger, disobedience, malice, falsehood, and their attendants-the fruit of a corruption within not manifested before.

In early youth it may be said that moral susceptibility is often in inverse ratio to physical vigor. But with growth the more physically vigorous are often sooner tanght the lessons of life, for their energy brings them into earlier confliet with the antagonisms and contradictions of the world. Here is a beautiful example of the benevolent prineiple of compensation.

1. Innocence and the Fall. - If physical evolution be a reality, we have reason to believe that the infantile stage of human mor- 
als, as well as of human intellect, was much prolonged in the history of our first parents. This constitutes the period of human purity, when we are told by Moses that the first pair dwelt in Eden. But the growth to maturity saw the development of all the qualities inherited from the irresponsible denizen of the forest. Man inherits from his predecessors in the creation the buddings of reason-he inherits passions, propensities, and appetites. His corruption is that of his animal progenitors, and his sin is the low and bestial instinct of the brute creation. Thus only is the origin of sin made clear-a problem which the pride of man wonld have explained in any other way had it been possible.

But how startling the exhibition of evil by this new being as compared with the scenes of the countless ages already past! Then the right of the strongest was God's law, and rapine and destruction were the history of life. But into man had been "breathed the breath of life," and he had "become a living soul." The law" of right, the Divine Spirit, was planted within him, and the laws of the beast were in antagonism to that law. The natmal derelopment of his inherited qualities necessarily brought him into collision with that higher standard planted within him, and that war was commenced which shall never cease "till he hath put all things under his feet." The first act of man's disobedience constituted the Fall, and with it would come the first intellectual "knowledge of good and of evil"-an apprehension up to that time derived exclusirely from the divinity within, or conscience."

2. Free Agency.-Heretofore development had been that of physical types, but the Lord had rested on the serenth day, for man closed the line of the physical creation. Now a new development was to begin-the development of mind, of morality, and of grace.

On the previous days of Creation all had progressed in accordance with ineritable law apart from its objects. Now, two lines

* In our present translation of Genesis, the Fall is ascribed to the influence of Satan assuming the form of the serpent, and this animal was cursed in consequence, and compelled to assume a prone position. This rendering may well be revised, since serpents, jrone like others, cxisted in both America and Europe during the Eocene epoch, five times as great a period before Adam as has elapsed since his day. Clark states, witl great probability, that "serpent" should he translated monkey or ape-a conclusion, it will be observed, exactly coinciding with our inductions on the basis of evolution. The instigation to cril by an ape mercly states inheritance in anothel form. Ilis curse, then, refers to the retention of the horizontal position retained by all other quadrumana, as we find it at the present day. 
of development were at the disposal of this being, between which his free will was to choose. Did he choose the courses dictated by the spirit of the brute, he was to be subject to the old law of the brute creation-the right of the strongest and spiritual death. Did he choose the guidance of the Divine Guest in his heart, he became subject to the laws which are to guide-1, the human species to an ultimate perfection, so far as consistent with this world; and, 2 , the individual man to a higher life, where a new existence awaits him as a spiritual being, freed from the laws of terrestrial matter.

The charge brought against the theory of development, that it implies a necessary progress of man to all perfection withont his co-operation-or necessitarianism, as it is called-is unfounded.

The free will of man remains the source alike of his progress and his relapse. But the choice once made, the laws of spiritual development are apparently as inevitable as those of matter. Thus men whose religious capacities are increased by attention to the Divine Monitor within are in the advance of progress-progress coinciding with that which in material things is called the harmonic. On the other hand, those whose motives are of the lower origin fall under the working of the law of conflict.

The lesson derivable from the preceding considerations would seem to be "necessitarian" as respects the whole human race, considered by itself; and I believe it is to be truly so interpreted. That is, the Creator of all things has set agencies at work which will slowly develop a perfect hnmanity out of his lower creation, and nothing can thwart the process or alter the result. "My word shall not return unto me void, but it shall aceomplish that which I please, and it shall prosper in the thing whereto I sent it." This is our great encouragement, our noblest hope-second only to that which looks to a blessed inheritance in another world. It is this thonght that should inspire the farmer, who, as he toils, wonders, "Why all this labor? The Good Father conld hare made me like the lilies, who, though they toil not, neither spin, are yet clothed in glory ; and why should I, a nobler being, be subject to the dust and the sweat of labor?" This thought should enlighten every artisan of the thonsands that people the factories and guide their whirling machinery in our modern cities. Every revolution of a wheel is moving the car of progress, and the timed stroke of the crank and the rhythmic throw of the shuttle are but the music the spheres have sung since time began. A new significance then 
appears in the prayer of Darid: "Let the beauty of the Lord our God be upon us, and establish thou the work of our hands upon us: the work of our hands, O Lord, establish thou it." But, beware of the catastrophe, for "He will sit as a refiner"; "The wheat shall be gathered into barns, but the chaff shall be burned with unquenehable fire." If this be true, let us look for--

3. The Extinction of Evil.-How is necessitarianism to be reconeiled with free will? It appears to me, thus: When a being whose safety depends on the perfection of a system of laws abandons the system by which he lives, he becomes smbject to that lower grade of laws which govern lower intelligenees. Man, falling from the laws of right, comes under the dominion of the laws of brute force; as said our Sariour, "Salt is good, but if the salt have lost his savor, it is thenceforth good for nothing but to be cast forth and trodden under foot of men."

In estimating the practical results to man of the actions prompted by the lower portion of our nature, it is only necessary to carry out to its full derelopment each of those animal qualities which may in certain states of society be restrained by the social system. In human history those qualities have repeatedly had this development, and the battle of progress is fought to decide whether they shall overthrow the system that restrains them, or be orerthrown by it.

Entire obedience to the lower instincts of our uature insures destruction to the weaker, and generally to the stronger also. A most marked ease of this kind is secn where the dereloped rices of civilization are introduced among a sarage people-as, for example, the North American Indians. These seem in consequence to be hastening to extinction.

But a system or a circuit of existence has been allotted to the civil assoeiations of the animal speeies man, independently of his moral derelopment. It may be briefly stated thus: Races begin as poor offshoots or emigrants from a parent stock. The law of labor develops their powers, and increases their wealth and numbers. These will be diminished by their various vices; but, on the whole, in proportion as the intellectual and cconomical clements prevail, wealth will inerease - that is, they aecumulate power. When this has been accomplished, and before activity has slackened its speed, the nation has reached the enlminating point, and then it enters upon the period of declinc. The restraints imposed by cconomy and active occupation being removed, 
the beastly traits find in accumulated power only increased means of gratification, and industry and prosperity sink together. Power is squandered, little is accmmulated, and the nation goes down to its extinction amid scenes of internal strife and vice. Its cycle is soon fulfilled, and other nations, fresh from seenes of labor, assanlt it, absorb its fragments, and it dies. This has been the world's history, and it remains to be secn whether the virtues of the nations now existing will be sufficient to save them from a like fate.

Thns the history of the animal man in nations is wonderfully like that of the type or families of the animal and regetable kingdoms during geologic ages. They rise, they increase, and reach a period of multiplication and power. The force allotted to them becoming exhansted, they diminish and sink and die.

II. Of the Individual. - In discussing physieal development, we are as yet compelled to restrict ourselves to the evidenee of its existence and some laws observed in the opcration of its cansative force. What that force is, or what are its primary laws, we know not.

So, in the progress of moral development, we endeavor to prove its existence and the mode of its operation, bnt why that mode shonld exist, rather than some other mode, we can not explain.

'The moral progress of the species depends, of course, on the moral progress of the individnals embraced in it. Religion is the sum of those influences which determine the motives of men's actions into harmony with the divine perfection and the divine will.

Obedience to these influences constitutes the practice of religion, while the statement of the growth and operation of these influences constitutes the theory of religion, or doctrine.

The Divine Spirit planted in man shows him that which is in harmony with the Divine Mind, and it remains for his free will to conform to it or reject it. 'This harmony is man's highest ideal of happiness, and in seeking it, as well as in desiring to flee from dissonance or pain, he but obeys the disposition common to all conscious beings. If, hewever, he attempts to conform to it, he will find the law of evil present, and frequently obtaining the mastery. If now he be in any degrce observing, he will find that the laws of morality and right are the only ones by which human society exists in a condition superior to that of the lower animals, and in which the capacities of man for happiness can approach a 
state of satisfaction. He may be then said to be "awakened" to the importance of religion. If he carry on the struggle to attain to the high goal presented to his spiritual vision, he will be deeply grieved and humbled at his failures; then he is said to be "convicted." Under these eireumstances the necessity of a deliverance becomes clear, and is willingly accepted in the only way in which it has pleased the Author of all to present it, which has been epitomized by Paul as "the washing of regeneration and renewal of the Holy Spirit through Jesus Christ." Thus a life of advanced and ever-advancing moral excellence becomes possible, and the man makes nearer approaches to the "image of God."

Thus is opened a new era in spiritual development, which we are led to believe leads to an ultimate condition in which the nature inherited from our origin is entirely overcome, and an existence of moral perfection entered on. Thus, in the book of Mark the simile occurs: "First the blade, then the ear, after that the full corn in the ear" ; and Solomon says that the development of righteousness "shines more and more unto the perfect day."

\section{ס. Summary.}

If it be true that general development in morality proceeds in spite of the original predominance of evil in the world, through the self-destructive nature of the latter, it is only necessary to examine the reasons why the excellence of the good may have been subject also to progress, and how the remainder of the race may have been influeneed thereby.

The development of morality is then probably to be understood in the following sense: Since the Divine Spirit, as the prime force in human progress, can not in itself be supposed to have been in any way under the influence of natural laws, its capacities were no doubt as eternal and unerring in the first man as in the last. Bnt the facts and probabilities discussed above point to development of religious sensibility, or capacity to appreciate moral good, or to receive impressions from the source of good.

The evidence of this is supposed to be seen in-first, improvement in man's views of his duty to his neighbor ; and, second, the substitution of spiritual for symbolic religions: in other words, improvement in the capacity for receiving spiritnal impressions.

What the primary cause of this supposed development of religious sensibility may have been, is a question we reverently leave untouched. 'That it is intimately comnected in some way with, 
and in part dependent on, the evolution of the intelligence, appears very probable ; for this evolution is seen-first, in a better understanding of the consequences of action, and of good and of evil in many things; and, second, in the production of means for the spread of the special instrumentalities of good. The following may be enumerated as such instrumentalities:

1. Furnishing literary means of record and distribution of the truths of religion, morality, and science.

2. Creating and increasing modes of transportation of teachers and literary means of disseminating truth.

3. Facilitating the migration and the spread of nations holding the lighest position in the scale of morality.

4. The increase of wealth, which multiplies the extent of the preceding means.

And now, let no man attempt to set bounds to this development. Let no man say even that morality accomplished is all that is required of mankind, since that is not necessarily the evidence of a spiritual development. If a man possess the capacity for progress beyond the condition in which he finds himself, in refusing to enter upon it he declines to conform to the divine law. For "from those to whom little is given, little is required, but from those to whom much is given, much shall be required." 


\section{V.}

\section{THE METHOD OF CREATION OF ORGANIC FORMS.}

Chapter I-On the Law of Aogeleration and Retardation.-Nature of law of Natural Selection. Two kinds of eridence. Illustration. Examples from Cervidæ, Helicidæ, insects and men.

Chapter II-The Law of Repetitive Addition.--Segment and cellrepetition. Illustration from limbs and vertebral colmmn. A, On segment addition; definitions. On repetition in bilateral and antero-posterior symmetry; in structure of compound teeth; in segments of Articulata; limbs of Reptilia; brain of lanprey. B, On cell-repetition: simple segment a repetition of cells; simple diverticulum the same. The cell theory; the nucleated cell. C, Synthesis of repetition. From unicellular to multicellular animals; simple repetition to compound repetition; Actinia, Lepidosiren, Ichthyosaurus, Plesiosaurus, Tonia ; the heart; mammalian teeth. D, On growth-force; relation to other forees; definition. E, Direction of repetition, its location, centrifugal and longitudinal; movements longitudinal. Inheritance; its relation to growth-force.

Chapter III-The Law of Use and Effort.-Points to be investigated. A, On the location of growth-force. Relation of effort to use. Rudimental characters. Examples of growth under influence of physical laws; Examples of colors under influence of light. Use and disuse of gills. Rattlesnake; horned animals. Teeth of ruminants. B, Change in amount of growth-force. Local increase of growth-force. Convoluted structures; brain, teeth, cotyledons. Absolute loss of growthforce. Teeth and toes of Ruminants; incisors of Rodents.

Chapter IV-On Grade Influence.-A, On the nature of Grade Influence or Bathmism. Definitions. In plants; in animals. Increase in time of Bathmism and growth-force. Vital forces and vital influences. Thonght-force. Origin of Bathmism in time. B, Physiologieal origin of Bathmism. Function of nervous system in forceconversion. Automatic and habitual movements. Effect on nervous system.

Culapter V-Intellifent Seiforion.-Development of intelligenco. Stimuli to use. Compulsion, Choice; Bees, Food, Rattlesnake; Change of color; Mimetic analogy ; Examples. Development of character.

IN the present state of biological science, essays like the present can only be tentative in so far as they treat of the laws of ero- 
lution. Nevertheless the present time is pre-eminently one of generalization in this field, and properly so. Facts hare been accumulating for a long period, and are now sufficiently numerons to yield important results, under proper classification and induction. Darwin led the way in this work, and the development hypothesis is regarded as demonstrated by most biologists. 'The discussion of the laws of its progress inrolves a multitude of subordinate hypotheses. In the following essay, these are arranged under five prominent heads, viz.: 1. The law of Acceleration and Retardation; 2. The law of Repetitive Addition; 3. The law of Use and Effort; 4. 'The law of Grade Influence; 5. The law of Intelligent Selection. Of these, the first and second are regarded by the anthor as demonstrated, the third and fourth as only rednced to a partial denonstration, while the fifth is a conseqrence of the third, and stands or falls with it.

The discussion of this subject divides itself into two parts, viz. : a consideration of the proof that evolution of organic types or descent with modification has taken place; and, secondly, the investigation of the laws in accordance with which this development has progressed. As the latter involves the use of the evidence included in the former, I will not devote a special chapter to the proof for evolution.

The influences and forces which have operated to produce the type structures of the animal kingdom lave been plainly of two kinds: 1. Originative; 2. Directive. The prime importance of the former is obvious; that the latter is only secondary in the order of time or succession is evident from the fact that it controls the preservation or destruction of the results or creations of the first, and thus furnishes the bases of the exhibitions of the originative forces in the production of the successive generations of living beings.

Wallace and Darwin have propounded as the eause of modification in descent their law of natural selection. This law has been epitomized by Spencer as the "survival of the fittest." This neat expression no doubt covers the case, but it leaves the origin of the fittest entirely untonched. Darwin assumes a "tendency to variation" in nature, and it is plainly necessary to do this, in order that materials for the exercise of a selection shonld exist. Darwin and Wallace's law is, then, only restrictive, directive, conservative, or destructive of something already created. I propose then to seck for the originative laws by which these sub- 
jeets are furnished-in other words, for the canses of the origin of the fittest.

It has seemed to the anthor so clear from the first as to require no demonstration, that natural selection includes no actively progressive principle whatever ; that it must first wait for the development of variation, and then, after securing the survival of the best, wait again for the best to project its own variations for selection. In the question as to whether the latter are any better or worse than the characters of the parent, natural seleetion in no wise concerns itself.

\section{ON THE LAW OF ACCELERATION AND RETARDATION.}

There are two modes of demonstration of erolntion, both depending on direct observation. One of these has been snccessfully presented by Darwin. He has observed the origin of varieties in animals and plants, either in the domesticated or wild states, and has shown, what had been known to many, the lack of distinction in the grades of difference which separate varieties and species. But he has also pointed out that species (snch, so far, as distinetness goes) have been derived from other species among domesticated anımals, and he infers by induction that other species, whose origin has not been observed, have also descended from common parents. So far. I believe his indnetion to be justified; but when from this basis evolution of divisions defined by important structural characters, as genera, orders, classes, ete., is inferred, I believe that we do not know enongh of the uniformity of Nature's processes in the premises to enable us to regard this kind of proof as conchusive.

I therefore appeal to another mode of proving it, and one which eovers the case of all the more really structural features of animals and plants.

It is well known that in both kingdoms, in a general way, the young stages of the more perfect types are represented or imitated with more or less exactitude by the adults of inferior ones. But a true identity of these adults with the varions stages of the higher has, comparatively, rarely been observed. Let snch a case be supposed.

In $A$ we have four species whose growth attains a given point, a eertain number of stages having been passed prior to its termination or maturity. In $B$ we have another series of four (the number a matter of no importance), which, during the period 
of growth, can not be distinguished by any common, i. e., generic character, from the individuals of grouj) $A$, but whose growth lias only attained to a point short of that reached by those of gromp $A$ at maturity. Here we have a parallelism, but no true evidence of descent. But if we now find a set of individuals belonging to one species, or, still better, the individuals of a single brood, and therefore held to have had a common origin or parentage, which present differences among themselves of the character in question, we have gained a point.

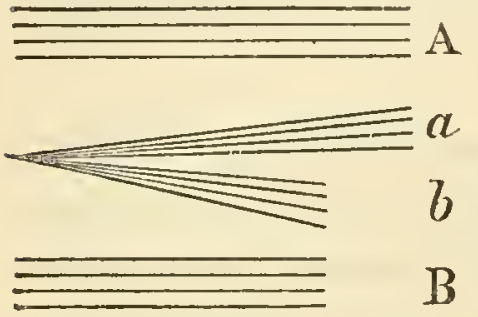

FIG. 7 .

We know in this case that the individuals, $a$, have attained to the completeness of character presented by group $A$, while others, $b$, of the same parentige have only attained to the structure of those of group $B$. It is perfectly obvious that the individuals of the first part of the family have grown further, and, therefore, in one sense faster, than those of gromp $b$. If the parents were like the individuals of the more completely grown, then the offspring which did not attain that completeness may be said to have been retarded in their devclopment. If, on the other hand, the parents were like those less fully grown, then the offspring which have added something have been accelerated in their development.

I claim that a consideration of the uniformity of Nature's processes, or inductive reasoning, requires me (however it may affect the minds of others) to believe that the groups of species, whose individuals I have never found to vary, but which differ in the same point as those in which I have observed the above variations, are also derived from common parents, and the more advanced have been accelerated or the less advanced retarded, as the case may have been with regard to the parents.

This is not an imaginary case, but a true representation of many which have come under obserration. The developmental resemblances mentioned are miversal in the animal, and probably in the vegetable kingdoms, approaching the exactitude above depicted in proportion to the near structural similarity of the species considered.

Example 1.-It is well known that the Cervide of the Old World develop a basal snag of the antler (see Cuvier, "Ossemens Fossiles," and Gray, "Cat. British Musenm") at the third year ; a majority of those of the New World (genera Subulo, Cariacus) 
never develop it except in abnormal cases in the most vigorous maturity of the most northern Cariacus ( $C$. virginianus), while the South American Subulo retains to adult age the simple horn or spike of the second year of all Cervide.

Among the higher Cervidce, Rusa and Axis never assume characters beyond an equivalent of the fourth year of Cervus. In Dama the characters are, on the other hand, assumed more rapidly than in Ccrvus, its third year corresponding to the fourth of the latter, and the development in after year's of a broad plate of bone, with points being substituted for the addition of the corresponding snags, thus commencing another series which terminates in the great fossil elk, Megacer'us.

Returning to the American deer, we have Blastocerus, whose antlers are identical with the fourth year of Cariacus. Corresponding with the Dama-Megacerus type of the Old World, we have the moose (Alces) developing the same palmate horn on the basis of Cariacus (i. e., without eye-snag).

Example 2.-I select the following series, embracing the majority of the genera of the North American Helicidx."

1. Turns of spire very few; wide umbilicus; shell thin, with thin lips.. Binneya.

2. Turns few, but more; rest as above.................. Vitrina.

3. Turns still more numerous; rest as above................. Iyalina.

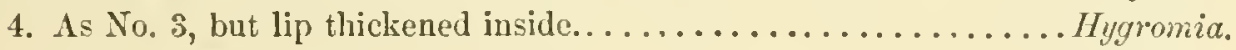

5. Coiled; unbilicus closed; lip thickened inside and out. . Tachea and Pomatia.

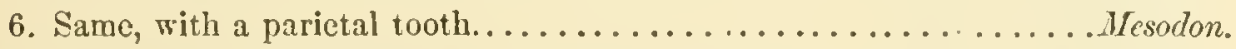

7. Same, with parietal and two interior lip teeth............ Isognomostoma. * * Recommencing at No. 4. All with open umbilicus.

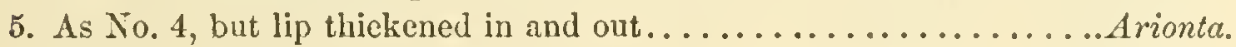

6. Sime as No. 5 , but with parietal tooth................. Polymita.

7. Same, with both parietal and lip teeth............... Triodopsis.

The successional relation of these genera may be represented in such a diagram as this:

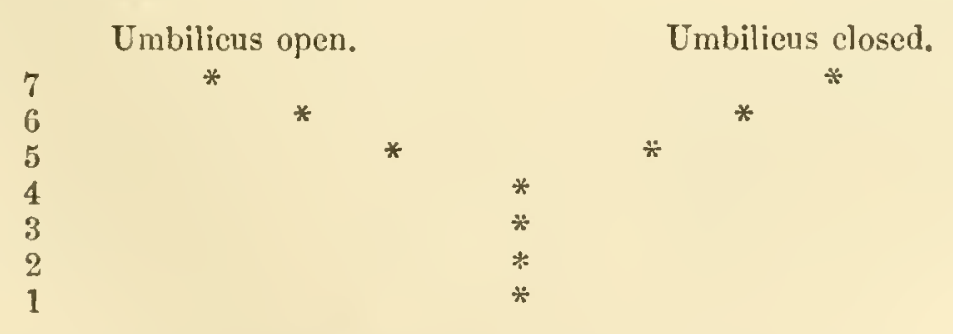

* See Tryon, "Terrestrial Mollusea of the United States." Probably other (e. g., dental) characters distinguish some of these genera, but the above furuishes the history of one set of characters. 
In the history of the growth of the genera Isognomostoma and Triodopsis, the extreme forms of the two scries, it is well known that at first the coils of the shell are extremely few, as in Binneya; and that, like it, it is very thin and with a delicately thin edge; that the turns increase successively in number, as in Vitrina and Hyalina; and that, finally, the lip thickens, as in Hygromia. Then the umbilicus may close, as in Tachea, or (in Triodopsis) remain open, as in Arionta. In either case a tooth is soon added on the body-whorl (Polymita, Mesodon), and, finally, the full maturity of the shell is seen in the added teeth of the inside of the lip-margin. How many of the stages of the genera Triodopsis and Mesodon are identical with the genera of the series which represent them, I leave to more thorough conchologists, but that some now exhibit and all have once presented illustrations of the relation of exact parallelism, I can not doubt.

Example 1.-An abundant race of the American deer, Cariacus virginianus, exists in the Adirondack region of New York, in which the development of the antlers never progresses beyond the spike stage of the second year. Therefore, some individuals of this species belong to Cariacus and some to Subulo.*

Example 2.-A large part of the individuals of the common snail, Mesodon albolabris, never develop the tooth of the bodywhorl, characteristic of the genus whose definition has to be modified to retain them.

Example 3.-Many individuals of Triodopsis tridentata from eastern North Carolina occir withont the lip-teeth, claracteristic of the genus Triodopsis. Hence these specimens, thongh of common origin with others of the species, must be referred to another genis.

Example 4.-Structural characters are known in many, if not all, species which are said to be "inconstant," being present or absent indifferently, thus being useless for definition. They may be rudimental when present or considerably developed. The presence or absence of wings in some species of insects may be cited; also the presence of generic characters in the male sex of many Coleoptera and their absence in the females. The characters of

* Since the above was written the facts as stated hare been denied. But the author has seen specimens of Cariacus virginianus and $C$. macrotis in which the horns had assumed the characters of the genus Alees, throwing these individuals into that genus. Sce "American Naturalist," 1883-'84. (E.d. 1886.) 
males, females, workers and soldiers in bees and ants may be added. All these facts belong to the same eategory as those cited among deer and mollusks, and have a similar explanation.

Example 5. - It does not seem to be the law in "retardation" that parallelisms exhibited by the series in its rise to its highest point of development should retrace the steps by which it attained it, and that "exact parallelisms" should be exhibited in a reversed order. Parallelisms, it is true, are exhibited; but so far as I have observed always "inexact," often in a high degree. A marked case of retardation occurs in the dental development of a number of persons who have come under my observation in the neighborhood of Philadelphia. It is not very uncommon to find persons in whom the third molars in both jaws are incomplete as to number, one, two, three, or all, being deficient. It is still more common for them to be incompletely covered by the enamel layer, and to become in consequence so worthless as to require early removal. I am acquainted with two families in which the absence of the exterior upper incisor on each side is common. In one of these the second and third generation have inherited it from the mother's side, and it now characterizes many of the children. The significance of this modification will be best understood by cxamining the dental structures of the Quadrumana in general. Commeneing with the highest family and its abnormal dentition, we have:

\section{Incisors. Canines. Premolars. Molars.}

\begin{tabular}{|c|c|c|c|c|}
\hline Hominida I Abnormal. & $\frac{1}{2}$ & $\stackrel{1}{1}$ & $\frac{2}{2}$ & $\frac{2}{3}-\frac{2}{2}$ \\
\hline Homenide, ,. T Normal. & $\frac{2}{2}$ & $\stackrel{l}{1}$ & $\frac{2}{2}$ & $\frac{3}{3}$ \\
\hline Simiidce............. & $\frac{2}{2}$ & $\frac{1}{1}$ & $\frac{2}{2}$ & $\frac{3}{3}$ \\
\hline Cebida.............. & $\frac{2}{2}$ & $\frac{1}{1}$ & $\frac{3}{3}$ & $\frac{3}{3}$ \\
\hline Lemuridle ............ & $\frac{2}{3}$ & $\frac{1}{1}$ & $\frac{3}{3}-\frac{2}{3}$ & $\frac{3}{3}$ \\
\hline Mammalia, Normal..... & $\frac{3}{3}$ & $t$ & $\frac{4}{4}$ & $\frac{3}{3}$ \\
\hline
\end{tabular}

In this table we see a decline in the number of teeth of the higher groups. 'Thus, the premolars are one less than the normal number in the whole order, and they lose one in each jaw in the old World apes, and man. The molars maintain the nolmal number throughout, but the third in both jaws is in the Simiide reduced by the loss of a fifth or odd tuberele, thus becoming fourlobed. In the upper jaw, this is first lost in the Semmopitheeus; in the lower, in the next highest genus Cercopithecus. In Homo its appearunce is "retarded," the interval between that event and the protrusion of the sccond molar-six to ten years-being relatively greater than in any genus of Quadrumana. Its ahsence is 
then the result of eontinued retardation, not of a new and adaptive suppression, and is of direet systematic zoölogical value.

In the incisors a reduetion is also plainly visible, as we pass from the most completely furnished mammals to the genus Homo. One from the upper jaw is first lost, then, in the Cebida, one from the lower also. The number remains the same through the Simiidce and normal Hominick, but, in the abnormal cases cited, the process of reduetion is continned and another incisor from each side disappears. That this also is truly "retardation" is evident from the fact, that the exterior incisor is the last developed, being delayed in ordinary growth a year later than those of the inner pair. The same retardation is seen in the quadrumane Cheiromys (the ayeaye), and the whole order Rodentia. In the latter, the rare presence of the reduced second incisors, as in Lepus, shows a less degree of this modification. 'This retardation is also of systematie importance, and, should either of the charaeter's described be constant in any of the species of the genus Homo, would at once entitle it to new generie rank. The very frequent absence of the posterior molars (wisdom teeth) has been reeently found to characterize a race in India. Should this peenliarity prove constant, this race would with propriety be referred to as a new genus of Hominida, as we have many eases of very similar speeies being referred to different genera. It is altogether probable that such will, at some future time, be the condition of some race or raees of men. *

I am now disposed to regard the above as the method of production, not only of generie but of all other, including speeific charaeters. It would appear that, by excessive acceleration or retardation, some of the characters of a series may be skipped; but observations are not conclusive on this point, since very close examination is necessary for the appreciation of very transitory embryonic conditions.

\section{ON THE LAW OF REPETITIVE ADDITION.}

'The origin of new structures, which distinguish one generation from those which have preceded it, I have stated to take place under the law of acceleration. As growth (creation) of parts usually ceases with maturity, it is entirely plain that the process of acceleration is limited to the period of infancy and youth in all animals. It is also plain that the question of growth is one of

* The preceding section is merely an abbreviation, with new illustrations, of the propositions brought forward in the writer's "Origin of Genera," 1868, where a considerable extension of the subjeet will be found. 
nutrition, or of the construction of organs and tissues out of protoplasm.

The construction of the animal types may be referred to two kinds of inerease-the addition of identieal segments and the addition of identical cells. The first is probajly to be referred to the last, but the laws which give rise to it ean not now be explained. Certain it is that scgmentation is not only produeed by addition of identical parts, but also by subdivision of a homogeneous part. In reducing the vertebrate or most complex animal to its simplest expression, we find that all its specialized parts are but modifications of the segment, either simply or as sub-segments of compound but identical segments. Gegeubaur has pointed out that the most complex limb with hand or foot is constructed, first, of a single longitudinal series of identical segments, from each of which a similar segment diverges, the whole forming parallel scries, not only in the oblique transverse, but generally in the longitudinal sense. Thus, the limb of the Lepidosiren represents the simple type, that of the Ichthyosaurus a modification. In the latter, the first segment only (femur or humerus) is specialized, the other pieces being undistinguishable. In the Plesiosamrian paddle the separate parts are distinguished, the ulna and radins well marked, the carpal pieces hexagonal, the phalanges defined, etc.

As regards the whole skeleton, the same position may be safely assumed. Though Huxley may reject Owen's theory of the rertebrate character of the segments of the brain-case, because they are so very different from the segments in other parts of the column, the question rests entirely on the definition of a rertebra. If a vertebra be a segment of the skeleton, of course the brain-case is composed of vertebræ; if not, then the eranimm may be said to be formed of "selerotomes," or some other name may be used. Certain it is, however, that the parts of the segments of the cranium may be now more or less eompletely parallelized or homologized with cach other, and that, as we descend the seale of rertebrated animals, the resemblanee of these segments to rertebræ increases, and the constituent segments of each become more similar. In the types, as Amphioxus, cte., where the greatest rescmblance is seen, segmentation of either is ineomplete, for they retain the original non-osseous basis. Other animals which present eavitics or parts of a solid support are still more casily reduced to a simple basis of segments, arranged either longitudinally (rorm) or centrifugally (star-fish, etc.). 


\section{DEFINITIONS.}

a. The succession of construction of parts of a complex, was originally a succession of identical repetitions; and grade influence merely determined the number and location of such repetitions.

$\beta$. Acceleration signifies addition to the number of those repetitions during the period preceding maturity, as compared with the preceding generation, and retardation siguifies a reduction of the numbers of such repetitions during the same time.

$\gamma$. The successive additions now characterizing the growth of the highest animals are not exact repetitions of segments at this time, because of influences brought to bear on cell-nutrition during long periods. The nature of these influences is made the subject of another section.

In the endeavor to prove these positions, I will produce evidenee, first, that some simpler animals grow according to the principle of modified repetitive addition, and that traces of it are to be observed in the most complex; second, that every addition to structure which has resulted in the complexity of the higher animals was originally a repetition of a pre-existent structure.

Detailed explanations of the law of repetitive addition are attempted in the following pages, under two heads-segment-repetition, and cell-repetition.

\section{A. On Segment-Repetition.}

This is everywhere seen in the construction of animals and plants. Double bilateral symmetry may serve as one example of repetition in growth.

a. Bilateral symmetry. Anatomists have little diffienlty in determining the bilateral symmetry in most animals-that is, the homologies of the parts on opposite sides of the median line. It might be almost asserted that it was a necessity of organization ; but, when we observe the growth of many plants, we are undeceived. And though bilateral symmetry in the Coelenterata and many Articulata is perfect, yet in ligher animals it is more or less departed from. In the Vertebrata the Amphioxus is almost completely bilaterally symmetrical. In the fishes, the digestive system is the only one which does not conform to it; while in the birds the reproductive system is atrophied on one side. In the serpents the respiratory and part of the circulatory are similarly 
modified; and in the Mammalia the digestive and cireulatory systems have both beeome unsymmetrieal ; and the crauium, even, in the Cetaeea.

If evolution be true, the unsymmetrieal forms have descended from the symmetrieal, and the asymmetry being thus not inherited, is the result of laws which have interfered with the original tendeney to bilateral repetition.

Many eases of bilaterally symmetrieal discases have been enumerated by physiologists, and I will seleet as an example one which has eome under my observation. They were those of two boys who had had that disease involving the muco-dermal system called varieella, while the erowns of the suecessional ineisor teeth were still inclosed in the mueons eapsules of the alveolar walls. The deposit of phosphate of lime forming their surfaces was interrupted by the disease of the tissuc, and the result was a surface pitted, or sculptured intaglio fashion. The sculpture of the two ineisors of the right side was precisely imitated by those of the left in reversed order, even in minute details, which were numerons, thus prodneing a result not displeasing to the cye. 'This has been observed on two distinct oeeasions some years apart.

Another interesting example of bilaterally symmetrical disease is recorded in a paper" on "A Case of Universal Hyperostosis, etc.," by Drs. Mears, Keen, Allen, and Pepper. " They deseribe the skeleton of a boy of fourteen which displayed an extraordinarily exostosed condition, the bones themselves remaining in the condition known as osteoporosis. 'They deseribe the uniform repetition of the abnormal growths of one side on the other in the following language (p. 22) :

"Comparing the two sides externally, not only is there no differenee in the extent and character of the disease, but there is the most remarkable symmetry of the eorresponding diseased bones, which may be traced even into details. The disease begins and ends on both sides at eorresponding points, it changes in character from simple porosity to the growth of osteophytes at eorresponding points; if, on one side, the posterior part of the bone is most diseased, the sime is true of the other sicle; if the osteophyte growth is continuous or interrupted on one bone (fibula, Fig. 1S), it is so on the opposite one; if one is unusually diseased at a tendinous or aponeurotie insertion, so is its mate; if a groore ol a ralriation in

* Sec "Proceed. Amer. Philos. Soc.," 1870, p. 19. 
color exist on the one side, the same will be found on the other side; even of single marked spiculæ of bone the same may be said, so that a description of one side will answer for both, minute differences being noted as they occur."

b. Anteroposterior symmetry.

That this is an absolnte law of creation will be less readily admitted than in the case of donble bilateral symmetry, since the exceptions appear to be so miversal. Nevertheless, I believe it to be as much a part of the law of repetitive nutrition as the other. 'The anteroposterior homologies even of the human skeleton have been largely demonstrated, bat, as usnal, we must appeal to the lower forms for a clear view of it. In the rudimental skeletal axis we find such symmetry almost perfect in the Amphioxus, but in no other vertebrate. In limbs we have it clearly indicated in the Reptilian order Ichthyopterygia, and in the Piscine order Dipnoi, where the anterior and posterior are scarcely or not at all distinguishable. In the scapular and pelvic arches we find it also approximated in the first-named orders.

In the nervous system it also exists approximately in the $\mathrm{Am}$ phioxus. It is not seen in any vertebrate, and in but few other animals, in the digestive system, but it appears to exist in some lower Articulata in both the respiratory and cirenlatory systems.

$c$. As illustrations of exact repetition involving large portions of the organism the higher Polyps may be eited, which differ from the lower chiefly by the addition of similar septa and similar tentacles. Examples of repetition of nearly the whole organism may be found in many Entozoa, as Trenia, where the cephalic segment only differs from the others, the remainder or proglottides being alike. The most entire repetition of structure is seen in Vibrio, where the segments are all alike, there being none representing a head.

d. As an example in special detilils of structure, the pelvic arch of Ichthyoscurus, when first created, was a repetition of the scapnlar, and the hind limb, of the fore limb. The segments of the limbs of the Dipnoi are mere repetitions, the later created of the earlier. The special parts of the pes and manus of Ichthyosaurus are simply repetitive efforts of growth-force joined with a diminishing amonnt. The addition of a digit, often distinguishing one genus of Salamander's or Saurians from another, is evidence of a similar repetitive effort. The low mammal Ornithorhynchus possesses but a single tooth in each jaw ; the simple teeth of armadil- 
los and cetaceans, increasing as they have done from a simpler commencement, present examples of repetitive acceleration of growth-force.

$e$. Complication of a single element of repetition is accomplished apparently by a double repetition. 'This is best understood by the consideration of the transition from simple to complex teeth. In the cetaceans this occurs in the Squalodonts; the cylindric incisors are followed by flattened ones, then by others grooved on the fang, and then by two-rooted, but never double-crowned teeth. This is the result of anteroposterior repetitive acceleration of the simple cylindric dental type of the ordinary toothed cetacean.

Another mode of dental complication is by lateral repetition. Thus, the heel of the sectorial tooth of a Carnivore is supported by a fang alongside of the usual posterior support of a premolar, and is the result of a repetitive effort of growth-force in a transverse direction. Nore complex teeth, as the tubercular molars, merely exhibit an additional lateral repetition, and sometimes additional longitudinal ones. As is well known, the four tubereles of the human molar commence as similar separate knobs on the dental papilla.

The above are cited as examples to explain the meaning of the proposition. When fuller demonstration is desired, a greater uumber might be given.

\section{B. On Cell-Repetition.}

That each additional act of creation in growth was originally identical with one which preceded it, and therefore an exact repetition in its character and results, is proved by the following considerations.

It has been already determined by the study of homologies that all organs and parts of an organism can be referred to an original simple archetype.

The question then remains as to whether the first element, or lowest term, of a given organized part is essentially a new strueture, or whether it be a repetition of some previously existing one. It may be asserted that the simplest expressions which shall cover all organs are the solid segment, and the hollow sack, and tube. For example, we have already noted that the ultimate element of the limb is the first segment of the single ray of Lepidosiren. Is this short eartilaginous eylinder (which probably represents the fore limb of some undiscorered member of the Dipnoi) a result of 
the repetition of a pre-existent structural element? This is no doubt the case, for, as will be shown beyond, cartilage, though the least cellular of all the tissues, is formed originally by cell repetition or division. Again, the ultimate lobules of the most complex gland are but repetitions of the diverticula of the simply branched, and each of the latter repetitions of the simple cul-de-sac, which has its origin in a convexity of an originally plane surface. This convexity is again the result of repetition of cells or cell-division, whereby their number is increased and the surface rendered convex.

We are thus, in both the solid segment and hollow sack, brought down to cell-repetition. Thus it is with organs, as with entire animals, in which, following the line of simplification, we reach at last forms composed of cells only (Actinophrys, e. g.) and then the unicellular (Amøba).

If this be the origin of organs, the question whether repetitive growth has constructed tissnes remains for consideration.

In growth, each segment-and this term includes the parts of a complex whole or parts always undivided (as the jaw of a whale or the sac-body of a mollusk) -is constructed, as is well known, by cell-division. In the growing fœtus the first cell divides its nucleus and then its whole ontline, and this process, repeated millions of times, produces, according to the cell theory, all the tissnes of the animal organism or their bases, from first to last. That the ultimate or histological elements of all organs are prodnced originally by repetitive growth of simple nucleated cells, with varions modifications of exactitnde of repetition in the more complex, is tanght by the cell theory. The formation of some of the tissues is as follows :

First Change.-Formation of simple nucleated cells from homogeneous protoplasm or the eytoblastema.

Second. -Formation of new cells by division of nucleus and body of the old.

Third.-Formation of tissues by multiplication of cells with or withont addition of intercellular eytoblastema.

$A$. In connective tissne, by slight alteration of cells and addition of cytoblastema.

$B$. In blood, by addition of fluid cytoblastema (fibrin) to free cells (lymph-corpuscles), which in higher animals (vertebrates) develop into blood-corpuseles by loss of membrane, and by cell-development of nucleus. 
C. In muscles, by simple confluence of cells end to end, and mingling of contents (Kölliker).

$D$. Of cartilage, by formation of cells in cytoblast which break up, their contents being added to eytoblast; this oecurring several times, the result being an extensive cytoblast with few and small cells (Vogt). The process is here an attempt at development with only partial suceess, the result being a tissue of small vitality.

Even in repair-nutrition, recourse is had to the nueleated cell. For Cohnheim first showed that if the cornea of a frog's eye be scarified, repair is immediately set on foot by the transportation thither of white or lymph or nucleated corpuscles from the neighboring lymph-heart. This he ascertained by introducing aniline dye into the latter. Repeated experiments have shown that this is the history in great part of the construetion of new tissues in the adult man.

Now, it is well known that the circulating fluid of the foetus contains for a period only these nucleated cells as corpuscles, and that the lower vertebrates have a greater proportion of these corpuscles than the higher, whence probably the greater faeility for repair or reconstruction of lost limbs or parts enjoyed by them. The invertebrates possess only nucleated blood-corpuscles.

\section{Synthesis of Repetition.}

That growth-foree is capable of exhibiting great complexity of movement with inerease in amount, will now be shown. That this quality of complieation is one of its distinguishing features will appear plain.

The simplest forms of life, as stated by Haeckel, are simply homogeneous drops of protoplasm (Protamceba). These only grow by ordinary accretion, and display a form of self division or reproduction which is the simplest possible-i. e., the biseetion of the mass by eontraction at opposite points.

The next grade of animal type is represented by the nucleated cell. This is simple in Amoba, complex in Actinophrys, ete. With snch forms as the latter, cell-growth begins, and its development is accomplished, by cell-division. This is simple repetition of ultimate parts. In the growth of all higher types we have nothing more than this, but following a law of complex repetition. 'Thus in the growth of the parts of an archetypal vertebral column or an archetypal limb, we have the repetition of cell-growth till the first segment is formed, when it ceases at that point, and re- 
peats the process again, forming another segment like the first; repetition within repetition. So with the construction of muscular tissue; first, the nucleated cell repeated in a series, whose adjacent walls disappear, and whose cell-contents flow together, thus forming a fibrilla; then a repetition of the same process, forming a second fibrilla; and so on to the completion of thonsands of them in fasciculi.

Let us then trace the series of repetitions and cluplicated and still more complex repetitions, seen in following up animal forms from their archetypes.

In the simplest repetition of cell-growth in a longitudinal direction we have Vibrio; in the centrifugal, Actinophrys. The former may be represented by a line of simple dots, thus: Fig. 1.

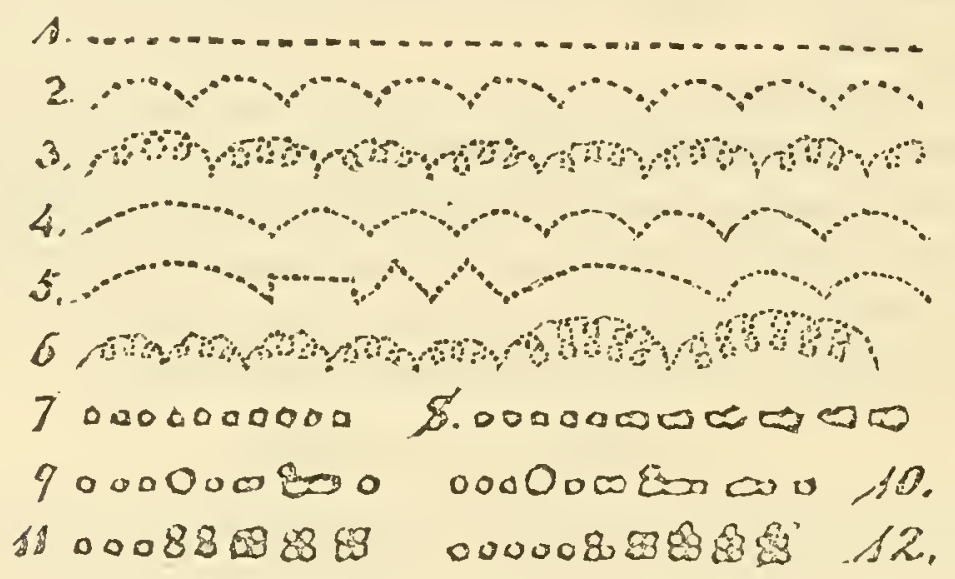

In a complex repetition we rarely have the same degree of complication in each repeated part. We have it centrifugally almost perfect in a Colenterate (Actinia), and linearly in some of the lower vermes. An archetype of the latter kind might be represented thus: Fig. 2. In a more complex form, as of the proglottides of Trenia, thus: Fig. 3. The same might represent an archetypal vertebrate.

If now we attempt to express the complication of an organ by modified repetition of once identical parts, the liistory of extremities will serve us. Thus the limb of Lepidosiren, which is composed of identical segments, may be thus represented: Fig. 2. Each longitudinal segment of the limb of Ichthyosaurus may be similarly represented with a modifieation, in size only, of the proximal or litmerus; thus: Fig. 4. But in Plesiosaurus an important series of changes of shape (but not in complexity) appears, which maly be represented thus: Fig. 5; the first being 
humerus, second ulna, third and fourth carpals (tarsals), the last phalanges, which are first specialized in this genus.

By far the most usual modification is, however, complication by duplicated and triplicated and still more highly multiplied repetition in some segments of the archetype, and its omission in other segments. Thus in the Trenia, the cephalie segments are much modified, and the nature of the repetition might be thus expressed : Fig. 6 ; the simpler segments representing the body segment, the two complex representing those of the head. In each, it will be observed, the complication is represented by loops of similar form, and each loop of dots which represent the cells in the first linear (Fig. 1) arraugement.

A somewhat similar figure might represent the nature of the complication in the Myriapod. In the insect the additional complications of the thoracie segments would alter the diagram near the middle.

In the rertebrate eranium a somewhat similar diagram might be used, except that the modification of the segments or vertebræ, as compared with the segments of the vertebral column, is not by repetition with modification of the parts of each segment, but rather by modification of the forms of the parts of the segments. The basieranial segments thus compare with the dorsal vertebra as the segments of the limb of Plesioscurus do with those of Ichthyosaurus.

The above considerations have referenee to repetition of parts in a linear direction. Centrifugal repetition is seen in the ardition of chambers to the heart, by the subdivision in the earliest stages into auricle and ventricle in the linear direction, considered in connection with the enrlier division of each in the transverse direction by the growth of partitions. This molle of repetitive addition is not readily represented by diagram.

A good example of repetitive addition, in both linear and transverse direction, may be fornd in the suceessive complication of tooth structure seen in Mammalia. In the dolphin, the dental scries may be represented thus: Fig. $\%$; in the squalodon thus: Fig. 8 ; in the cat: Fig. 9 ; in the dog: Fig. 10 ; in man : Fig. 11 ; in some Insectivora : Fig. 12.

The eircles represented here are each a simple ensp.

In conclusion, the direetions of repetitive growth may be tabulated as follows: The types to the left represent the original ; to the right, the derivative : 


$$
\text { Centrifugal. }\left\{\begin{array}{l}
\begin{array}{c}
\text { Longitudinal antero-pos- } \\
\text { terior and bilateral. }
\end{array} \\
\text { Centrifugal. }\left\{\begin{array} { l } 
{ \text { More bilaterally } } \\
{ \text { symmetrical. } }
\end{array} \left\{\begin{array} { l } 
{ \text { Only bilateral. } } \\
{ \text { Ifore antero-pos- } \begin{array} { l } 
{ \text { Only antero. } } \\
{ \text { teriorly. } }
\end{array} }
\end{array} \left\{\begin{array}{l}
\text { In plane. } \\
\text { In globe. }
\end{array}\right.\right.\right.
\end{array}\right.
$$

\section{On Growth-Force.}

From such examples as those that precede, but more especially from the last, it seems neeessary to believe that there resides in organized matter, and in its most nnmodified representative, the nucleated cell, an affection which displays itself in repetition. 'This phenomenon reduced to its lowest terms, may mean cell-division only, but the proof is only clear in cases of growth proper. This affection displays itself in very slow or more rapid repetitions -cell-division in growth occurring rapidly, while its recurrences at rutting seasons in the development of horns, feathers, etc., are separated by long intervals of time. In acceleration these repetitions oceur with increased rapidity, i. e., in the adding of more strnetures during the same growth periods, while in low types its repetitions are few and therefore slow.

What is the relation of cell-division to the forces of nature, and to which of them as a cause is it to be referred, if to any? The animal organism transfers solar heat and the chemism of the food (protoplasm) to correlated amounts of heat, motion, electricity, light (phosphorescence), and nerre force. But cell-division is an affection of protoplasm distinct from any of these ; although addition to homogeneons lumps or parts of protoplasm (as in that lowest animal, Protamaba of Hrekel) should prove to be an exhibition of mere molecular force, or attraction, cell-division is certainly something distinct. It looks like an exhibition of another force, which may be called growth-force. It is correlated to the other forces, for its exhibitions cease unless the protoplasm exhibiting it be fed.

Professor Henry pointed ont many years ago that this must be the case, basing his belief on the observed phenomena of growth in the potato, and in the egg. The starch of the potato weighs mnch more than the young shoot of cellulose, etc., into which it has been converted by growth-activity, so that a portion of the substance of the tuber has evidently escaped in some other direction. This 
is shown to be carbonic acid gas and water, derived from the slow combustion of the starch, which in thus running down from the complex organic state to the more simple inorganic compounds, erolves an amount of force precisely equal in amount to the chemical force (or chemism) requisite to bind together the elements in the more complex substance.*

Carpenter ilso states that in his opinion the growth of the Fungi is produced by a force liberated by the retrograde metamorphosis of their food, which is of an organic character (i. e., humus). This metamorphosis consists, as in the tuber, in the production of carbonic acid gas and water, and a force equivalent to the chemism which had bound them in the former complex union. $f$ But in higher forms of vegetable life, and in growth that follows germination, the plant must appropriate carbon from the carbonic acid of the atmosphere. The decomposition of the binary compound (which sets free its oxygen) liberates the chemical force which had previously maintained the compound (or an equivalent force), which Henry regards as furnishing the growth-force, which produces the plant. Carpenter derires but a portion of the force in this way, obtaining the greater part from the heat of the sun. To this source also he looks for the heat necessary to the construction of coldblooded animals ; while in warm-blooded animals, the retrograde metamorphosis or running down of the material (protoplasm) of the food furmishes a requisite amount of heat.

Growth-force we may then regard as potential in organized tissue, and as energetic during growth. $\downarrow$ Our present knowledge

* "Agricultural Report of the Patent Office," 1857.

$\nmid$ "Correlation of Physical and Vital Forees," 1864 ("Quarterly Jour. of Science ").

$\ddagger$ Bathmism or growth-force must be static or potential in each unit or plastid (cell) of a liring organism, the type differing with each organic species. When it is in excess in a giren locality it becomes energetic, and builds tissue in various forms. $\Lambda$ portion of this energy is, in this process, developed as molar motion of nutritive material, and is accompanied in the completed structure by the ordinary cohesive energy, by which the newly-built material maintains its attachment as a whole and in its parts. If living tissue be construeted, a portion of the excess remains as the statie energy of the plastids or cells of the new part, as it dicl of the old. The spermatozoil is highly cndowed with static bathnism, and communieates it to the female ovum. The mingling of the two elements in the presenee of nutritious material presents an cxeess, and form-building results. Its activity will regulate subserquent new growth, by giving the motion of nutritive material its proper direetion. When the tissuc dies, this energy must leave belind a dynanic equivalent, but what this may be is as yet a nystery. (Ld. 1886.) 
only permits us to believe that other force is only converted into it under the influence of pre-existent life, but of the real cause of this conversion we are as ignorant as in the case of the physical forces.

In the animal organism, different tissues display different degrees of "vitality." "The most vital display cell-organization and its derivative forms, while the least so, approach nearer to homogeneity. As organized tissue is the machine for converting vital forces, we may believe that less growth-force is potential as such in cartilage than in muscle, for it is formed by a retrograde process, by which cells once formed are mostly lost, and the contents form the intercellular, nearly structureless mass characteristic of this tissue. Growth-force must be here liberated in some other form, perhaps the mere cohesire force of the former or "dead" intercellnlar substance.

The higher vitality we may believe to result from the greater perfection of the more complex machine as a force converter, as compared with the inefficiency of the more simple.

\section{E. On the Direction of Repetition.}

It has been already pointed ont that growth-force exhibits itself in cell or segment repetition. The forms in which it thus displays itself may be briefly considered. The approximate canse is treated of in the next chapter; but enough may be shown here to indicate that duplication and complex duplication is the law of growth-force, and that therefore this process must always follow an increase in amount in any given locality.

The size of a part is then dependent on the amount of cell-division or growth-force, which has given it origin, and the number and shape of segments is due to the same canse. The whole question, then, of the creation of animal and regetable types is reduced to one of the amount and location of growth-force.

Repetition is of two kinds, centrifugal and Tongitudinal. As an example of the former, the genus Actinophrys has been cited, where the animal is composed of cells arranged equidistally around a common center. 'The arrangement in this type may be discoidal or globular, providing no definite axis be discoverable. As an example of longitudinal repetition, Vibrio, and numerous cellular plants may be cited, where the arrangement is in a single line.

In by far the greater number of animals these kinds of repeti- 
tive structure co-exist. The longitudinal is, however, predominant in the Vertebrata, Mollusca, and Articulata, while the centrifugal is greatly developed in the Coelenterata and Ratliata. In none but the simplest forms are either of these modes to be found alone.

The centrifugal repetition, or addition, more nearly rescmbles the mode of aggregation of atoms in inorganic or crystalline bodies, and hence may be regarded as the inferior manifestation. It implies that growth-force in this case conforms to a law of polarity in exhibiting itself at equal distances from a centerwhich is allied to ordinary molecnlar force, and independent of the localizing influences of which higher organisms seem capable. In centrifugal animals, then, the latter evidently plays an inferior part. In Cœlenterates and Radiates, howerer, the body possesses a short longitudinal axis, in some (Asterias) very short, in others (Holothuria) more elongate. The amount of complication of centrifugal growth greatly exceeds the complication in a longitudinal direction in all of these animals except the Holothuricla.

It is now important to observe that great numbers of centrifugal animals are sedentary or sessile; while the longitudinal are ragrant, moring from place to place. Many of the centrifugal animals which wander, do not do so in the direction of their axis, but sideways (Medusce). It is also proper to notice that not only the morements of the muscles but also the direction taken by the food is in the long axis. It is therefore to be concluded that in longitudinal animals growth-force has assumed a more truly animal type, and that this tendency has predominated over the polar or molecular tendency.

In most longitudinal animals, howerer, certain lateral portions, limbs, etc., extend on each side of the axis; and were the space marked by their cxtremities, and the extremities of the axis, filled, we would have the outline of a centrifugal animal.

Before discussing the influenees which have increased and located growth-force, it will be necessary to point out the mode in which these infuences must necessarily hare effected growth. Acceleration is only possible during the period of growth in animals, and during that time most of them are removed from the influence of physical or biological canses, either through their hidden lives or incapacity for the energetic performance of life functions. 'These influences must, then, have operated on the 
parents, and become energetic in the growing foetus of the next generation. However little we may understand this mysterions process, it is nevertheless a fact. Says Murphy, "There is no act which may not become habitual, and there is no habit that may not be inherited." Materialized, this may be rendered-there is no act which does not direct growth-force, and therefore there is no determination of growth-force which may not become habitual; there is, then, no habitual determination of growth-foree which may not be inherited; and, of course, in a growing fœtus becomes at once energetic in the production of new structure in the direction inherited, which is aceeleration.

But if the forces converted into growth-force are derived from without the animal organism, whence and what the agency by which the acceleration or retardation of the latter is inherited from the parent? A few suggestions only on this head can be made in the fourth section.

\section{THE LAW OF USE AND EFFORT.}

Up to this point we have followed paths more or less distinctly traced in the field of nature. The positions taken appear to me either to have been demonstrated or to have a great baknce of probability in their favor. In the closing part of this paper I shall indnlge in more of hypothesis than heretofore.

Since repetitive addition only produces identical results in archetypes, and each effort produces results more and more unlike its predecessor as strueture becomes specialized, it becomes important to examine into the influences which have originally modified the repetitive efforts snccessively, producing strnctures more or less different in detail in the sceond generation from those of the parents, in acceleration, or the reverse, in retardation.

Going further back, the question arises, why a simple exhibition of repetition (e. g., cell-division) should be converted into a complex or duplicated repetition" (e. g., jointed ray). This, it has already been stated, is one consequence of increased amount of the growth-force.

We then seek explanation of the main question, as to what determines the location of this additional or new growth-force. (Div. A.)

Lastly, why the total amount of this force should change in a given individual or part of an individual. (Div. B.) 


\section{A. On the Location of Growth-Force.}

What are the infuences locating growth-force? The only efficient ones with which we are acquainted, are, first, physical and chemical canses ; second, use ; and I would add a third, viz.: effort. I leave the first, as not especially prominent in the economy of type-growth among animals, and confine myself to the two following. The effects of use are well known. We can not nse a muscle without increasing its bulk; we ean not long use the teeth in mastication without inducing a renewed deposit of dentine within the pulp-cavity to meet the encroachments of attrition. The hands of the laborer are always larger than those of men of other pursuits. Pathology furnishes us with a host of hypertrophies, exostoses, ete., produced by excessive use, or neeessity for increased means of performing excessive work. The tendency, then, induced by nse in the parent, is to add segments or cells to the organ used. Use thus determines the locality of new repetitions of parts already existing, and determines an increase of growth-force at the same time, by the increase of food always accompanying increase of work done, in erery animal.

But supposing there be no part or organ to nse. Such must have been the condition of every animal prior to the appearance of an additional digit or limb or other useful element. It appears to me that the canse of the determination of growth-force is not merely the irritation of the part or organ used by contact with the objects of its use. This wonld seem to be the remote cause of the deposit of dentine in the nsed tooth; in the thickening epidermis of the hand of the laborer; in the wandering of the lymph-cells to the scarified cornea of the frog in Cohnheim's experiment. You can not rub the sclerotica of the eye withont producing an expansion of the capillary arteries and corresponding inerease in the amount of nutritive fluid. But the case may be different in the muscles and other organs (as the pigment cells of reptiles and fishes) which are under the control of the volition of the animal. Here, and in many other instances which might be cited, it can not be asserted that the nutrition of use is not nnder the direct control of the will through the mediation of nerve force. 'Therefore I am disposed to believe that growthforce maly be, through the motive force of the animal, as readily determined to a locality where an executive organ does not exist, as to the first segment or eell of snch an organ already com- 
menced, and that therefore effort is, in the order of time, the first factor in acceleration.

Addition and subtraction of growth-force, in accordance with the modes pointed ont below, account for the existence of many characters which are not adaptive in their nature.

Acceleration under the influence of effort accounts for the existence of rudiments of organs in process of development, while rudiments of organs in process of extinction are results of retardation, occasioned by absolute or complementary loss of growth-force. Many other characters will follow, at a distance, the modification resulting from the operation of these laws.

Examples of the Influence of Physical Causes. - This is nowhere better seen than in the case of coloration, which requires the light of the sun for its production. The most striking examples of this are seen in the colorless surface of animals inhabiting the recesses of caves, as the blind craw-fish and the Amblyopsis, ete. If evolution be true, these have descended from more highly colored progenitors. The flat fishes, also (Pleuronecticlce), as is known, swim on one side in adult age, but many of them are hatched symmetrical fishes, or nearly so, one eye rotating from one side to the other by a twisting of the cranial bones. It is thus probable that they have descended from symmetrical fishes, which were similarly colored on both sides. Now the lower side is colorless, the upper retaining often brilliant hues. The influenee of sunlight is thus as distinctly discoverable among animals as among plants, where it has been generally accepted as a principle of vegetable physiology. *

Examples of the Effects of Effort and Use.-a. The Respiratory and Circulatory System of Vertebrates. - It is well known that the succession of classes of Vertebrates is measured first by their adaptation to aerration in water, and then by their successive departures from this type in connection with the faculty of breathing air. The same succession of structure is traversed by the embryos of the vertebrates, the number of stages passed being measured by the final status of the adult. This transition takes place in the Batrachia later in development than in any other class. Now, it is well known that the transition or metamorphosis may be delayed

* In this and similar cases, carc must be taken not to misunderstand the writer by supposing him to mean that in each generation separately the peculiar coloration is the result of changed exposure to light. The evolutionist will understand that the effect of such influenee increases with sueceding generations by the addition to in. herited character of the effect of immediate external cause. 
or encouraged by suppression of use of the branchial and encouragement of use of the pulmonary organs, or the reverse.

The aquatic respiration of tadpoles may be indefinitely prolonged by preventing their access to the surface, and it is known that in nature the size or age of the larva at time of metamorphosis may vary much in the same species. If perennibranchiates (Siren, e. g.) are deprived of their branchiæ, they will aërate blood by the lungs exclusively, and there is no reason to doubt that by use of these, and disuse of the branchiæ, aërial respiration might become the habit of the animal. It is also easy to perceive that geologic changes wonld bring about a necessity for precisely this change of babit. This occurred in the period of the coal measures, where large fresh-water areas were desiceated, and it was precisely at this period that many air-breathing Batrachians originated and had a great development.

$\beta$. The rattle of the Rattlesnake. - Nearly all the larger harmless snakes which live on the ground have a habit of throwing the end of the tail into violent vibrations when alarmed or excited, with the view of alarming a supposed enemy. Among Coronelline snakes, Ophibolus triangulus possesses it; among the water snakes, Tropidonotus sipedon. In the typical Colubrine group the black suake, Bascanium constrictor, is an example; Pityoptis sayi also shakes the tail violently. The copperhead (Ancistrodon contortrix) and the moccasin (A. piscivorus) (fide Günther) have the habit in a marked degree. Among the rattlesnakes it is a means of both warning and defense, in connection with the rattle which they carry.

In the structure of the end of the tail of harmless snakes, we see a trace of the first button of the rattle in a horny cap that covers the terminal vertebræ. In the venomous genera, it is conspicnous in Lachesis especially, reaching a considerable length and having a lateral groove. In the plate-headed rattlesnakes (Crotalus) this corneous cap is inflated into a button with lateral groove, and in some of them possesses only one or two buttons or joints. In the perfected rattlesnakes (Candisona) not only are the segments numerous and inflated, but a number of the terminal caudal vertebre are greatly enlarged vertically, and co-ossified into a mass.* This is important from the fact that the rattlesnakes are the most spe-

* See good figures of this structure in "Zeitsehı. f. wissensel. Zoologric," viii, Tab. 12. 
cialized of all snakes, standing at the head of the order, and as such, on the principle of acceleration, present the greatest amount of grade-nutrition.

Now it appears to me that the constant habit of violent vibration in a part tends to determine an increased amount of nutritive fluid to it, in other words to localize growth-nutrition, and when this has attained complex repetition or grade-nutrition, to result in new grade-structure. (The segments of the rattle being nearly all alike, it is a case of simple repetition.) This view appears to be as reasonable as that generally entertained with regard to the canse of spavin in the horse's leg. Here, owing to excessive use, exostoses appear on the bones surrounding the tibio-tarsal articulation. As to the reason of the structure in question not appearing in forms lower in the scale than the rattlesnake, it is explained below, if the law of accumulation of grade-nutrition be true. (See Sec. B.) This is, that repetition (or acceleration) is only possible where the animal has an excess of growth-force at its disposal, or can abstract it from some portion which is unused or useless.

$\gamma$. On horns. - The possession of horns on the posterior part of the cranium, as defenses against enemies, is a character found in many distinet types of animals. (Herbirora have no (dental) weapons and need horns.) It is seen in the Batrachia Stegocephala in the extinct genus Ceraterpeton; among Anura it is approached by Triprion and Hemiphractus. Among Reptilia it is well marked in Phrynosoma, a Lacertilian genus. In Mammalia the Artiodactyla Ruminantia are the horned animals of the order. We have opportunities of observing the habits of these representatives of the Frogs, the Lizards, and the Mammals.

In the first case, any one who has kept ordinary toads and tree-toads in confinement, is aware that when attacked and unable to escape, they defend themselves by presenting the top of the head forward and using it as a shield. Now I have already pointed ont* that in both toads, tree-toads, and frogs there are natural series of genera, measured by the degree of assification of the superior eranial walls, the longest being that of the Hylidw, which embraces six terms, viz.: Hylella, Hyla, Scytopis, Osteoceptalus, Trachycephalus, and Triprion. The two last have the head thoroughly shielded, and Hemiphractus has projecting angles which appear in some South American forms, described by M. 
Espada, to be developed into short horms. That this excessive ossification is associated with the habit of protecting the whole body with the front seems likely.

In the case of Phrynosomu we know that precisely the same habit is associated with the presence of the sharp horns; and that some genera without horns possess it also. Phrynosoma is an exceptionally shggish genus in a family of most active forms, and must necessarily resort to this mode of defense more than they.

In the case of Ruminants, we also know that defense is accomplished by throwing the head down with the horns thrown forward. But this is not confined to this group. That generalized suborder, the Artiodactyla Omnivora, represented by the hog, which were no doubt the genetic predecessors of the Ruminants in time, also throw the head down in defense in the same way, having thus a manner totally distinct from that seen in the Carnivora. The latter show their teeth and often eronch preparatory to a leap.

These cases present so constant an association between habit and use that, admitting evolution, we are compelled to believe that the structure has given rise to the habit or the habit to the structure. In the former case we have to suppose, with the anthor of "Natural Selection," that among the many spontaneous variations rudimental horns occasionally appeared, and that their possessors, being thus favored in the struggle for existence, were preserved and multiplied; while those not favored dwindled, and were ultimately nearly all extirpated or starved. The question of origin is here left to chance, and Alfred Bemnett has made a mathematical estimate of the chances of any particular profitable variation occurring among the great number of possibilities of the case. This has shown the chince to be so excessively small as to amount in most cases to a great improbability.

If we turn to the probabilities of such structure laving arisen through the selection of that mode of defense by the animal, we find them greatly increased. The position occupied by the horns, in all the animals described, is that which is at once brought into contact with an enemy in conflict, and as sport among animals is a gentle imitation of conflict, the part would be constantly excited in sport as well. With an excess of growth-nntrition, our knowledge of the eflects of friction on the epidermis, and of excessive ligamentous strain and inflammation on bone (e. g., spavin in horses), as well as of abnormal exostoses in general, would warrant 
us in the belief that the use of the angles of the parts in question in these animals would result in a normal exostosis, of a simple kind in the frogs, or as horn cores in the Ruminantia.* As to the sheathing of the cores in the Bovidce, and nakedness in the Cervidee, it is in eurious relation to their habitat and to their habits. The epidermis and derm would of course share in the effects of friction. In the Bovidæ which dwell in treeless plains, or feed on the grasses in great part, the development of these coverings of the horn cores into a horny sheath wonld naturally meet with no interruption. In the case of the deer, which mostly live in forests or browse on trees, constant contact with the latter would prevent the healthy growth of the dermal covering, and it would be liable to injury or constant excoriation by the animals themselves on the branches of trees, ete. This we know to be the present habit of the deer as regards the dermal covering of the horns. $\dagger$ I have elsewhere pointed ont the similar connection between the dental structure and habitat among the oxen and the deer. The former, eating the harder grasses, are provided against the consequent rapid attrition of the tooth by a prismatic form, which allows of more prolonged growth and more rapid protrusion. The deer, in accordance with their foliage-eating habits, do not wear the erown of the tooth with such rapidity. Long-continned protrusion is not so necessary, hence the teeth are more distinctly rooted and have a prominence or shoulder, distinguishing the body of the crown.

\section{B. Change in Amount of Growth-Force.}

1. Absolute increase of Growth-Force.-As every type has had its period of greatest development in numbers, size, and complication of structure, the present law indicates as an explanation, a culmination of the process of conversion of growth-force from its energetic to its potential state in tissne. The canse is primarily the increased exercise of effort and use, which, while effecting a conversion, increases the capacity of the organs by which further conversion is effected.

* The now well-known fact that all cranial ossification was primitively dermal, is confirmatory of the ilea that its appearance was due to moderate friction of the skin on resistant bodics. (Ed. 1886.)

+ Palæontological studies go far to show that the origin of the shedding of the deer's horn was due to the loss of their dermal covering, and that this was caused by violent use. (1886.) 
2. Local increase of Growth-Force.-Examples of a local increase of this kind are probably to be seen in convoluted organs; as the convolutious of the brain in higher Mammalia ; the convolutions of the tooth-dentine of the Labyrinthodont Batrachia; the same phenomenon in the cotyledons or plumule of some seeds. In these cases the superficial arcin of the parts is excessively developer, and the inclosing organs not being proportionately cnlarged, a convolution necessary follows. In the first case, the skull; in the second, the alveolus; in the third case, the seed-envelope, restrain the expanse of the contained part, which wouid otherwise follow increase of growth-force.

3. Absolute lose of Growth-Force.-This will follow defective nutrition, prodnced by inability of the animal to obtain heat and food requisite to that end. This is supposed to be due, according to the view hereafter proposed, primarily to deficiency of intelligence, in failing to adapt habits to changed physical circumstances, and secondarily to the unfarorable influence of such changed circumstances. The extinction of highly specialized types, which has closed so many lines of animal types, will be accounted for by their less degree of plasticity and want of capacity for change under such changed circumstances. Such changes consist of modified topography and temperature, with irruptions of many new forms of life by migration. The less dereloped forms wonld be most likely to experience modification of stmeture under a new order of things, and paleontology teaches that the predecessors of the characteristic types of one period were of the less specialized forms of that period which went before.

Thus is explained the fact that, in following ont the line of succession of animal forms, we hare constantly to retrace our steps from specialized extremes (as osseous fishes, tailless Batrachia, song birds, ete.) to more generalized or simple forms, in order to advance beyond.

4. The complementary diminution of growth-nutrition follows the excess of the same in a new locality or organ, of necessity, if the whole amount of which an animal is capable be, as I believe, fixed. In this way are explained the cases of retardation of character seen in most higher types. 'The discovery of truly complementary parts is a matter of nice observation and experiment. Perhaps the following eases may be correctly explained.

A complementary loss of growth-foree maly be seen in absence of superior incisor teeth and digits in ruminating Mammalia, where 
excessive force is evidently expended in the development of horns, and complication of stomach and digestive organs. The excess devoted to the latter region may aceount for the lack of teeth at its anterior orifice, the month; otherwise, there appears to be no reason why the ruminating animals should not have the superior ineisors as well developed as in the odd-toed (Perissodactyl) Ungulates, many of which graze and browse. The loss to the osseous system in the subtraction of digits may be made up in the development of horns and horn-cores, the horn sheath being perhaps the complement of the lost hoofs. It is not proposed to assert that similar parts or organs are necessarily and in all groups complementary to each other. The horse has the bones of the feet still further reduced than the ox, and is nevertheless without horns. The expenditure of the complementary growth-foree may be sought elsewhere in this animal. The lateral digits of the Equiclo are successively retarded in their growth, their reduction being marked in Hippotherium, the last of the three-toed horses; it is accompanied by an almost coincident acceleration in the growth-nutrition of the middle toe, which thus appears to be complementary to them.

The superior incisors of the Artiodactyla disappear coincidentally with the appearance of horns, which always exist in the toothless division of the order, exeept in some very small antelopes (Cephalophus, ete.) where the whole amount of growth-force is small. Possibly the superior incisors and horns are complementary here. The retardation in development of the teeth in the higher apes and men, as compared with the lower apes, is coincident with the inerease of number of brain eonvolutions. That this is not necessarily coincident with reduction of teeth in other groups is plainly proved by the rodents and Chiromys, where the loss of many teeth is complementary to the great size of the incisors of the middle pair. But in man there is no eomplementary increase of other teeth, and the reduction is no doubt due to contraction of the jaws, which is eomplementary to increase in other parts of the cranium, in both apes and men.

I am confident that the origin and loss of many struetures may be accounted for in this way, and the correlation of parts to each other be measured aceurately.

Objection.-The first one which arises is that which the anthor of the "Vestiges of Creation" made against Lamarek's theory of a similar kind, i. e., that by assuming that effort, use, and physical 
causes hare originated modifications of structure, we gire the adaptive prineiple too much to do. I have made the same objection to the theory of natural selection. It is true that an application to a purpose is involved in the present theory of the "location of growth-force"; but in point of fact, a large number of nonadaptive churacters are accounted for by it. These are the rudimentil and transitional ones which mark the successive steps preliminary to the completion of an adaptive structure; second, those produced by deficiency of growth-force in less favored regions of the body ; and third and fourth, phenomena consequent on general deficiency and excess of growth-force.

And it may be said in conclusion that if the thrce principles, or if use especially, should be found to be inadequate to the scrvice here demanded of them, it may be at least said that they, or the last named, constitute the only controllers of growth-force to any degree at all with which we are acquainted.

\section{IT. ON GRADE-INFLCENCE.}

The object of the present section is the attempt to discuss how the influence of effort and use on the parent is placed in a position to be inherited by the offspring.

\section{A. Of the Nature of Grade-Influence.}

In the first place, it is necessary to note the definition and chalacter of grade-influence.

$a$. Growth-force uninfluenced by grade-influence simply adds tissue either $(a)$ in enlarging size, or $(b)$ in replacing waste. It does this by repeating the cell, by division, in localities which have already assumed their specific form. 'This form of growth-force may persist throughout life, but with diminished energy in age.

$\beta$. Grade-influence directs growth-force in building up the tissucs into organs, and constructs the parts of the body snccessirely to completion, the result expressing the type or grade of the animal or plant. Its energy terminates with maturity, except in cases of periodical reprodnction of scxual ornaments of the male (birds, deer), where it continues throughout life, appearing at regular intervals.

But it has occurred in acceleration that instead of a simple repetition of the nltimate histological clement of an organism, in adding to its amount, it adds a completely organized part of the struct- 
ure, as a tube, a phalange, a digit, a limb or an arch; an ocellus or a tooth. For instance, in the genus Amblystoma, one section possesses four plualanges on the longest digit; another section exhibits but three. In the species $A$. mavortium, some individuals have the small number of phalanges, but the majority possess the larger number. As all are of common parentage, a whole phalange has been lost or added. The explanation of this pheromenon is essential to the comprehension of the origin of type structures.

* In plants, growth-nutrition continues thronghont life, but in the higher plants it is more active during the earlier year's in perennial species, addition to size becoming less and less marked with inereasing age. Grade-nutrition also persists thronghout life, but is chiefly active dnring a short period only of every yeur, or during flowering and fuiting. Not only in the production of the reproductive organs, but also in the yearly additions to other typical parts of the plant, grade-nutrition is aetive.

** In animals, growth-nutrition is more active in the early stuges of life, but is continued thronghout in the lower divisions; in the highest, it is also continued throughout life, but there is a greater contrast between its results during youth, when nearly the whole size is attained, and during age, where the additions are mueh less.

Grade-nutrition is, on the other hand, entirely confined to infancy and youth, except in those low animals which produce their reprodnetive organs periodically (some Entozoa, etc.), where it may be said to be in nearly the same condition as in plants.

$\gamma$. While the amount of simple growth-force, represented in adult living animals, has varied very irregularly throughout the animal kingdom, there being large and small in every division, it would seem to have accumulated, on the whole, with the rising scale of animal types. 'Thus the lower or Protozoa are the smallest; Radiates are next in size; Molluscs and Articulates reach nearly the same maximum, which exceeds that of the Radiates, and falls far below that of the Vertebrates. Among the last the Mammalia have attiined as large if not larger size than any of the other orders (e. g., Cetace $a$ ). This is, however, not necessary to the history of evolution.

That an increased amount of grade growth-force has been constantly rendered potential during the advance of time is clear, if the preceding inferences be true. It is also evident that some individuals have aceumulated it more rapidly than others, if all 
alike originated from the simplest forms known to us. Multitndes have remained in the carliest stages (Protozoa) of the whole series, or of their own special series (Lingula), forming "persistent types"; or taken directions which rendered them incapable of expansion beyond a certain point without exhaustion or death; for example, complicated types, as Ammonitide. 'The quadrumanous animal, which was the progenitor of man, may thus be believed to have acquired a higher capacity of this accumulation than his contemporaries.

Assuming the nucleated cell to be the nltimate element of organic tissue, there are two types of life in which grade-influence has not appeared, viz.: unicellular animals and plants, and living forms composed of homogeneous protoplasm. In the latter neither grade-influence nor animal growth-force is potential; in the former, simple growth-force only. It is therefore apparent that gradeinflnence has been developed in the organism itself; perhaps this may have been in the plant, through the moditied influence of external physical causes; in the animal, if onr inductions as to use and effort be true, under the influence of the activities of the parent, which determined a structural change either in itself or in its offspring. The possibilities of this origin are considered in the next section.

$\delta$. The Location of Growth-Force proceeds under the direction of what Prof. Henry calls "Vital Influence." With this anthor I discard the nse of the term "Vital Force," what was originally understood by that term being a complex of distinct idcas. The Vital forces are (nerve-force) Neurism, (growth-force) Bathmism, and (thought-force) Phrenism.* All these are supposed to be correlated to the Physical Forces, but are under direction and control of the Vital principle which locates their action, etc., just as molecular or atomic constitution determines the locality and charicter of the physical forces. The laws of the vital principle and of atomic constitution also determine the nature of the conversion of one force into another. Now, since physical and vital forces are correlated and convertible, the close relationship of the two controlling principles becomes obvious and suggestive of their identity.

* The objection of President Barnard to thought being an exhibition of a force, is that "thought can not he measured." This objection does not take into consicleration the two-fold nature of thought. The amount of thought can most assuredly be measured, the quality of the thought can not. 
Dr. Carpenter, in describing the correlation of physical and vital forces, defines the difference of organic species to be similar to that prevailing between different chemical bodies (the latter depending on different molecular and atomic constitution), which leads them "to behave differently" from each other under similar cirenmstances. 'This may be more fully expressed by saying that different species possess different capacities for the location of the conversion of the physical forces into growth-force. A "descent with modifications" contemplated by a process of evolntion, signifies a progressive change in this capacity. Acceleration means an increase in this capacity; retardation a diminution of it. Grade-infuence means the inflnence which produces this change of capacity.

\section{B. The Origin of Grade-Influence.}

Living protoplasm can convert heat and nutriment into growth-force without the ageney of the nervous system. This is proved by the nutrition of the Protozon and Coclenterata, and from experiments on the muscles of frogs, etc. In the latter case, as is well known, the nerre may be divided, and the musele retain its size if a current of electricity be passed through it, thus sustaining the nutrition. As the presence and structure of the nervous system is in relation to the specialization of animal structure in other respects, it is rery probable that the nervous system is in higher animals the agent of the location of growth-force. In the lowest it is not affected by any such means. As the nervons system is the instrument of the metaphysical peculiarities of the animal (emotions, choice, ete.), we may conclude that, in the lower animals, location of growth-force is influenced by necessity withont choice; in the higher by necessity with choice.

The impulses derived from the nervons system, it is known, may be reflex or antomatic in answer to stimuli from withont. They may become so, also, after having been originated conscious. ly or by effort of will. In the case of habits, frequent exereise of choice has so impressed the nervous system as to result in its repetition of effort, often in opposition to changed choice.

The influence of effort in muscular action, through the nerrous system, appears to be, first, to enable it to convert heat to nerveforce, and, then, to conduct nerve-force to the involuntary muscles, or those controlling cirenlation, where it is converted into motion, which thus controls nutrition through eireulation. The 
nervous system, like others, develops in capacity with use, hence probably nerve-tissue converts heat * into nerve-force as muscular tissue converts heat into motion. In other words, by repctition, the capacity of the nervous system for this conversion of heat is known to increase. As the amount of heat converted is in proportion to the amount of appropriate nerve-tissue (see above), it is evident that use and effort increase the amount of nerve-tissue.

'The phenomena of thought render the same modification of structure probable. Effort in the direction of thought is supposed to convert heat into thought-force. Inasmuch as the more intelligent animals possess the highest development of cerebral hemispheres, it is highly probable that brain substance converts heat into growth-force also, which produces tissue of its own kind precisely as muscle does.

As different parts of the nervous centers subserve different purposes, the development of these parts must proceed approximately under the influence of spccial kinds of effort and nse. Where, as in the adult, heat is converted into growth-force in the tissucs to a very limited extent, if the above principles be true, the conversion of heat by the nervous system into nerve growthforce and tissuc is, on the other hand, not terminated.

Capacity for effccting conversion of force is regarded, as above pointed out, as dependent on molecular constitution. Hence we conclude that change in that capacity on the part of the nervons system involves a molccular change in its constitution.

Now, we know physical and metaphysical peculiarities of parents to be inherited by offspring; hence, no doubt, the nerrous structure determinative of growth-force is inherited. This will then control the localities of special conversion of heat, etc. (from the mother), into growth-force, in accordance with the structure of the parent, and the more decidedly, as its own increase progresses.

The result will be acceleration, or construction of tissues and organs in excess of those of the parent, if the effort or use devoted to a nerve or organ be represented in the nerve-center of the parent by a greater amount of force-converting tissuc than is

* The supposition that this and other forms of vital energy are derived from metamorphosis of heat, was in accordanec with views held at the time this essay wns written (1871). The much more probable hypothesis is that such energy is derived from retrograde metamorphosis of nutritive material. (Ed. 1886.) 
necessary when inherited in the foetus for the construction (by conversion) of tissues and organs like those of the parent.

That this is a partial explamation of inheritance, is rendered probable from the fact that the types of structure presented by the nervous centers express the grade of the animals possessing them far more nearly than those of any other organ or set of organs. If the brain, like other organs, derelops by intelligent use, it can not be doubted that this relation of its development to grade is not accidental, but that grade-structure * is an expression of its capacities, physical and mental.

\section{ON INTELLIGENT SELECTION.}

As neither use nor effort can be ascribed to plants, and as we know that their life history is much more dependent on their surroundings than is that of animals, we naturally look to the physieal and chemical causes as having a prime influence in the origination of their type-structures. Withont greater familiarity with the subject, I will not attempt to say how far the various degrees of growth-force possessed by parent plants, located under the influence of meteorie and other surroundings, and preserved, destroyed or restricted by natural selection, may account for the characters of their suceessors of the present period. But other agencies similar to use, that is, automatic movements, may be also introduced as an element in the argument. The movements of tendrils seeking for support may be here considered, and, as Dr. Asa Gray has pointed ont, hare consequences similar to those of use in animals. When the tendril seizes a support, growth-force is located at the point of contact, for the tendril increases considerably in thickness.

Among animals of the lowest grade, movement must be quite similar to those of plants, or antomatic from the start, and not even at the beginning under the influence of will. Evidence of will is, however, soon seen in the determinate morements of many of the Protozoa in the seizing of food. With will necessarily appears a power of choice, however limited in its lowest exhibitions, by the lack of suggestive metaphysical qualities, or the fewness of alternatives of action presented by surrounding circumstances, to animals of low and simple organism. We ean, however, believe

* Grade growth-foree is not regarded here or elsewhere as a simple form of energy, but as a class of energies, which are the resultants of the interference of mind (i. c., consciousness) with simple growtl-foree. (Ld. 1886.) 
that the presence of greater or less number of external facilities for action characterize different situations on the earth's surface, as well as that greater and less metaphysical capacity for perceiving and taking advantage of them must exist in different individuals of every species of animal, however low, which possesses consciousness and will. 'These qualities must, of course, influence effort and use to the advantage of the animal, or the reverse.

Effort and use have very various immediate stimuli to their exertion.

Use of a part by an animal is either compulsory or optional. In either case, the use may be followed by an increase of nutrition under the influence of reflex action or of airect rolition.

A compulsory use would naturally occur in new situations which take place apart from the control of the animal, where no alternatives are presented. Such a case would arise in a submergence of land where land-animals might be imprisoned on an island or in swamps surrounded by water, and compelled to assume a more or less aquatic life. Another case, which has also probably often occurred, would be when the enemies of a species should so increase as to compel a large number of the latter to combat who had previously escaped it.

In these cases, the structure produced would be necessarily adaptive. But the effect would sometimes be to destroy or injure the animals (retard them) thus brought into new situations and compelled to an additional struggle for existence, as has, no doubt, been the case in geologic history.

Direct compulsion would also exist where alternatives shonld be presented by nature, but of which the animal would not be sufficiently intelligent to take advantage.

Most situations in the struggle for existence afford alternatives, and the most intelligent individuals of a species will take advantage of those most beneficial. Nevertheless, it is scarcely conceivable that any change or increase of eflort, or use, conld take place apart from compulsion derived from the relation of external circumstanees, as a more or less remote cause.

Preservation, with modifications, wonld most probably ensue when change of stimulus should oecur gradually, thongl change of structure might occur abruptly, under the law of cxpression points. * 
Choice is influence not only by intelligence, but by the imagination and by the emotions.

Intelligence is a conservative principle, and always will direct effort and use into lines which will be beneficial to its possessor. Here we have the source of the fittest-i. e., addition of parts by increase and location of growth-force, directed by the will-the will being under the influence of various kinds of compulsion in the lower, and intelligent option among higher animals.

Thus, intelligent choice, taking advantage of the successive evolution of physical conditions, may be regarded as the originator of the fittest, while natural selection is the tribunal to which all the results of accelerated growth are submitted. This preserves or destroys them, and determines the new points of departure on which accelerated growth shall build.

'The influences locating growth-force may be tabulated as follows :

DIVISION. INFLUENCE.

Plants. Physical and ? + ? ?

Plants with mechanical movements; animals with indeterminate movements.

Animals with determinate move ments or will,* but no intelligence.

Animals with will and less intel-
ligenee.

Animals with ? more intelligence. I
“

$$
+ \text { use }
$$

“

"

+ effort under
compulsion.

เ$$
\text { ، }
$$

+ choice.

66

66

" $"$ "

+ intelligent choice.

As examples of intelligent selection, the modified organisms of the varieties of bees and ants must be regarded as striking cases. Had all in the hive or hill been modified alike, all soldiers, nenters, ete., the origin of the structures might hare been thonght to be compulsory; but varied and adapted as the different forms are to the wants of a community, the influence of intelligence is too obvious to be denied.

The selection of food offers an opportunity for the exercise of

* Will must be here regarded as the answer to stimulus, without any element of freedom. See Article XX, on the "Origin of the Will." (Ed. 1886.) 
intelligence, and the adoption of means for obtaining it still greater ones. It is here that intelligent selection proves its supremacy as a guide of use, and consequently of structure, to all the other agencies here proposed. The preference for regetable or for animal food determined by the choice of individual animals among the omnivores, which were, no doubt, according to the paleontological record, the predecessors of our herbivores, and perhaps of carnivores also, must have determined their course of life and thus all their parts, into these totally distinct directions. The choice of food under ground, on the ground, or in the trees would necessarily direct the uses of organs in the appropriate directions respectively.

In the selection of means of defense a minor range of choice is presented. The choice must be limited to the highest eapabilities of the animal, since in defense, these will, as a general thing, be put forth. 'This will, however, not be necessarily the case, but will depend in some measure on the intelligence of the animal, as we readily observe in the case of domesticated species.

In the case of the rattlesnake, already cited, the habit of rapid vibration of the tail appears to me to be the result of choice, and not of compulsion. For the cobra of India, for the same purpose, expands the anterior ribs, forming a hood, which is a very different habit.* Here are two alternatives, from which choice might be made, and violent hissing is a third, which the species of the colubrine genns Pityophis have adopted to some purpose. As to the benefit of the rattle, it no doubt protects the animal from all foes other than man; but is rather a disadvantage as regards the latter, being by a beautiful turn of events a protection to the higher animal.

On the principle of natural sclection it might be supposed that the harmless snakes which imitate the Crotalus for the sake of defense were preserved; but if the above explanation of the origin of the habit in the latter be true, the second explanation is not valid. (Since in time the harmless snakes preeded the rattlesnakes. Ed. 1886.)

The power of metachrosis, or of changing the color at will, by the expansion under nerre-influence of special pigment eells, exists in most Reptilia, Batrachia, and fishes. It is then easy to believe that free choice should, under certain circumstances, so habitually

* The North American Heterodons possess a similar habit. (Ed. 1886.) 
avoid one or another color as to result finally in a loss of the power to produce it.

'Thus, it appears to be a fact that not only are species of fishes which dwell in the mud of darker hues than those that inhabit clear water, but that individuals of the same species differ in a similar manner in relation to their habitats ; those that live in impure or muddy waters having darker tints than those of clear streams.

Land animals present equally abundant and remarkable imitations of the objects or substances on which they live. This is well known in insects and spiders, which look like sticks or leaves, or the flowers on which they feed. It is seen in reptiles, which in very many cases can roluntarily assume the hue of leaf, stone, or bark, or have constantly the gray color of their native desert sands.

These cases are largely selective or optional in their origin, for thongh metachrosis is also induced by some external stimulus, as an enemy or a food animal, yet other means of escaping the one and procuring the other are generally open.

These facts pave the way for a consideration of the phenomenon of mimetic analogy, which, though well known to naturalists, may be illustrated by the following new facts:

On the plains of Kansas there is a species of Mutilla whose abdomen and thorax are colored ochraceous, or brown-yellow, above. A spider of the genus Salticus is equally abundant, and is almost precisely similar in the color of the npper surfaces, so much so as to deceive any but a most careful observer. The Mutille being a well-armed insect, and a severe stinger, there can be no doubt that the Salticus derives considerable immunity from enemies from its resemblance.

On the same plains, the Crotalus confluentus, or prairic rattlesnake, abounds. It is an olive gray, with a series of transverse brown dorsal sprots, and two rows of smaller lateral ones. The head exhibits a number of brown and white bands. The prairie Heterodon (II. nasicus) possesses not only the same tints but the same pattern of coloration, and at a short distance can not be distinguished from it.

In consequence, as one may justly say, this species is, with the rattlesnake, the most common serpent of the plains, as it shares, no doubt, in the protection which the armatnre of the Caudisona gives its possessor. This is in accordance with the riews of Wallace and Bates. 
A curious case occurred to me in four species of fishes, which I took in a small tributary of the Yadkin River, in Roane County, N. C. Among several others, there were varieties of the widely distributed species Chaenobryttus viridis, Hypsilepis analostanus, and Ptychostomus pidiensis (each representing a different family), which differ from the typical form of each in the same manner, viz.: in having the back and upper part of the sides with longitudinal black lines, produced by a line along the middle of each scale. This peculiarity I have not observed in these species from any other locality. Until I had examined them I thought them new species.

The only other species presenting such marking in the Yadkin River is the large perch, the Roccus lineatus. According to the theory of natural selection a resemblance to this well-armed species might be of advantage to the much weaker species in question; yet the same species co-exist in other rivers withont presenting the same mimicry.

It is difficult not to urge the importance of the causes already regarded as efficient in the origination of structure in the present branch of the subject also. We are especially disposed to call in use and effort here, after noticing how much more distinctly change of color is under the control of the animal, than change of shape. It must, howerer, be borne in mind that similar resemblances exist among plants; though, as Professor Dyer shows, a large majority of these cases occur in species of different floral regions. Thus in this case, as in those of structure already cited, we appeal first to physical laws in the lowest beings, but with the increasing interference of use, effort, and intelligence, as we rise in the scale. 'Thus it is that, in the Vertebrates generally, the mimetic resemblances are found in species of the same region, where only an intelligent or emotional agency conld be illustrated. If among animals as low as butterflies the influence of intelligence be denied, that of admiration for the beauty, or fear of the armature, of the predominant species imitated, would appear to be sufficient to account for the result. Admiration and fear are possessed by animals of very low organization, and, with the instincts of hunger and reproduction, constitute the most intense metaphysical conditions of which they are capable. But our knowledge of this branch of the subject is less than it ought to be, for animals possess many mental attributes for which they get little eredit.

It appears to be impossible to account for the highest ilhstri- 
tions of mimetic analogy in any other way, the supposition of Wallace that such forms must be spontaneonsly produced, and then preserved by natural selection, being no explanation. It has been shown by Bennett that the chances of such modification arising out of the many possibilities are exceedingly small.

If the above positions be true, we have here also the theory of the development of intelligence and of other metaphysical traits. In accordance with it, each trait appropriates from the material world the means of perpetuating its exhibitions by constructing its instruments. These react by furnishing increased means of exercise of these qualities, which have thus grown to their full expression in man. 


\section{VI.}

\section{A REVIEW OF THE MODERN DOCTRINE OF EVO- LU'TION.*}

THE doctrine of evolution of organie types is sometimes appropriately ealled the doctrine of derivation, and its supporters, derivatists. This is becanse it teaches the derivation of species, genera, and other divisions, from pre-existent ones, by a process of modification in ordinary descent by reproduction. The opposite or creativist doctrine teaches that these forms were created as we see them to-day, or nearly so ; and that the natural divisions and species of organic beings have never been capable of change, the one into the other.

\section{THE EVIDENCE FOR EVOLUTION.}

The reasons which induce me to accept the derivatist doctrine, and to reject the creational, fall under the two heads of probabilities and eonclusive evidence. The probabilities are cumnlative in their pointings, and strengthen that part of the evidence which is, to my mind, eonclusive. The reasons why derivation is probable are the snccessional relation of increment or decrement of strueture, observed in :

1. Systematic relation (taxonomy); 2. Embryonic growth (embryology) ; 3. In geologic time (paleontology); 4 . And in the coincidence in the snceessions seen in Nos. 1, 2, and 3.

The fact that it is necessary to arrange animals in an order corresponding with the phases of their embryonic history is remarkable; but the further fact, shown by paleontology, that the sume snccession marked the ages of past time, at once brings erolution within the limits of strong probability. Nevertheless, all this might have been a mere system, withont transitions between its

* Abstract of a lecture delivered before the Califormia Acadeny of Scienees, Oet. 27,1879 . 
members; organic types might lave been created unchangeable, but presenting the mutual relations in question. But if transitions among these members can be shown to take place, then indeed the phenomena mentioned received a sufficient explanation. They are seen to be the necessary relations of the parts of a shifting scene of progression and retrogression ; they express combinations of structure, which, though often long enduring, are, nevertheless, not perpetual, but gire way to other combinations to be in their turn dissolved. Now, if there is anything well known in nature, it is that there are divisions of various ranks in the vegetable and animal kingdoms, whose contents present variations of structure which are confessedly additions to or subtractions from the eharacters of ancestors, which have appeared during ordinary descent. The protean species, genera, etc., are well known to biologists, and every naturalist who admits varieties, sub-species, sub-genera, ete., admits derivation so far as they are concerned. The facts of variation, including "sporting," ete., are notorious, not only among domesticated, but also in wild animals and plants. 'The facts have led some persons to suggest that species have been prodneed by evolution from a single specifie center, but that the genus and other comprehensive divisions are mnehangeable. But I think I have shown, in a paper entitled "The Origin of Genera," * that the struetural charaeters which define genera, and even higher divisions, are snbjects of variation to as great an extent as are the less profound specific eharacters; and, moreorer, that the evidence of derivation which they present is singularly elear and conehnsive. The ehanges of both genus and speeies character are always of the nature of additions to or subtractions from those of one generation displayed by their descendants. As such, they form the elosing chapters of the embryonic or growth-history of the modified generation.

In order to explain more fnlly the application of the above statements, I introduce a few examples seleeted from the subjects of my studies. Their number might be indefinitely extended. I first cite the genera of the tailless Batrachia Anura (frogs, toads, ete.), whose relations are very simple and elear, and show the parallelism between adult structure and embryonic succession. See above, 1 and 2 .

The greater number of Batrachia Anura fall into two divis-

*Philadelphia, 1869. " Proceedings Academy Natural Sciences, 1868." 
ions, which differ only in the structure of the lower portion of their scapular arch, or shoulder-girdle. In the one the opposite halves are capable of movements which contract or expand the capacity of the thorax; in the other the opposite halves abut against each other so as to be incapable of movement, thus prescrving the size of the thoracic cavity. But during the early stages, the frogs of this division have the movable shoulder-girdle which characterizes those of the other division, the consolidation constituting a modification superadded in attaining maturity. Furthermore, young Anure are toothless, and one section of the species with cmbryonic shoulder-girdle never acquire teeth. So here we have a group which is imperfect in two points instead of one. This is the tribe Bufoniformia; the tribe with teeth and embryonic shouldel-girdle is called the Arciferu, and that which is advanced in both these respects is the Raniformia. Now the frogs of each of these divisions present nearly similar scales of development of another part of the skeleton, viz., the bones of the top of the skull. We find some in which one of these bones (ethmoid) is represented by cartilage only, and the frontoparietals and nasals are represented by only a narrow strip of bone each. In the next type the ethmoid is ossified; in the next, we hare the frontoparictal completely ossified, and the nisals range from narrow strips to complete roofs; in the fourth station on the

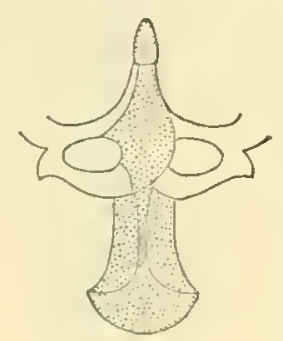

FIG. 8.

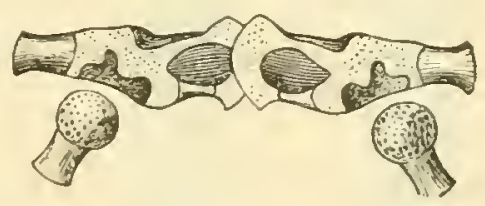

FlG. 9.

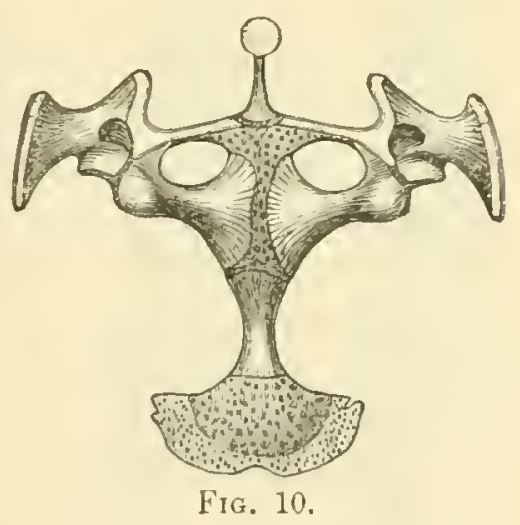

Siroulder-Girdles of "Axura."

Fig. 8, of the Areiferous type (Scaphiopus holbrooki). Fig. 9, Runa temporaria, tadpole with budding linbs. Fin. 10, do. adult. Figs. 9 and 10 fiom Parker. line, these bones are rough, with a hyperostosis of their surfaces; and in the next set of species this ossification fills the skin, which is thus no longer separable from the erinial bones; in the sixth form the ossification is extended so as to roof in the temporal muscles and inclose the orbits behind, while in the rare seventh 
and last stage, the tympanum is also inclosed behind by bone. Now all of these types are not found in all of the families of the Anura, but the greater number of them are. Six principal families, four of which belong to the Arcifera, are named in the diagram below, and three or fonr others might have been added. I do not give the names of the genera which are defined as above described, referring to the explanation of the ents for them, but indicate them by the numbers attached in the plate, which correspond to those of the definitions above given. A zero mark signifies the absence or non-diseovery of a generic type.

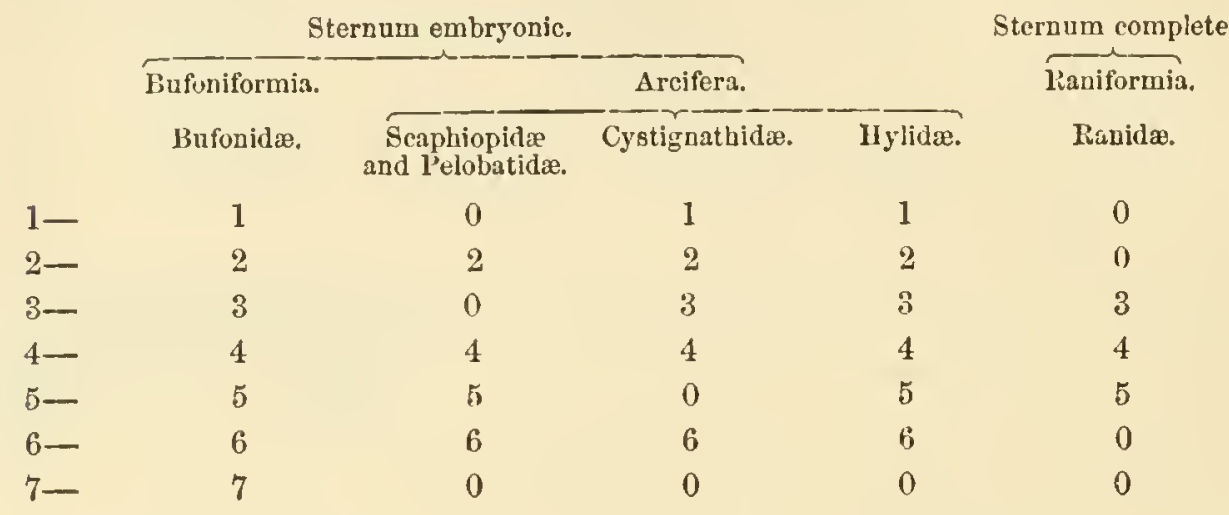

It is evident, from what has preeeded, that a perfecting of the shonlder-girdle in any of the species of the Bufoniform and Alciferons columns would place it in the series of Raniformia. An accession of teeth in a species of the division Bufoniformia wonld make it one of the Arcifera; while a small amount of change in the ossification of the bones of the skull would transfer a species from one to another of the generic stations represented by the numbers of the columns from one to seven.

There are few groups where this law of parallelism is so readily observed among contemporary types as the Batrachia, but it is none the less universal. The kind of parallelism usually observed is that in which there is only a partial resemblance between adults of certain animals and the young of others. This has been termed "inexact parallelism," and the relation is presented by forms not very nearly phylogenetically related. The more remote the phylogenetic lines of two types, the more "inexact" will their parallelism be. It was once a question whether any parallelism can be traced between the members of the five or six primary divisions of animals, and in my essay on the "Origin of Genera," I was compelled to state that there was then "no evidence of the community 
of origin of these divisions." Since that time, Haeckel has published his "Gastræa Theory." 'This is a grand generalization from the facts of embryology, which shows the community in type of the early stages of all animals, and the similarity of the phases which they present during a part of their larval life. The exeeptions to this law which have been observed will probably be explained, as have been those which have been urged against the law of homologies in anatomy.

The paleontology of the Batrachia anura is largely $u n k n o w n$, so we must look elsewhere for proof of the truth of the fourth proposition, viz., that the suecessional relition in embryology corresponds with that shown by paleontology to have existed in geologic time.

For this purpose I select one of the most complete series known to paleontology; that of the camels or Cametidce, wliose remains are found abundantly in various parts of our country. The suceession of the known genera is seen in the strueture of the bones of the feet, and of the superior incisor and premolar teeth. The metatarsal and metacarpal bones are or are not co-ossified into a cannon bone; the first and second superior incisor teetl are present, rudimental or wanting, and the premolarsnumber from four to one. The relations which these conditions bear

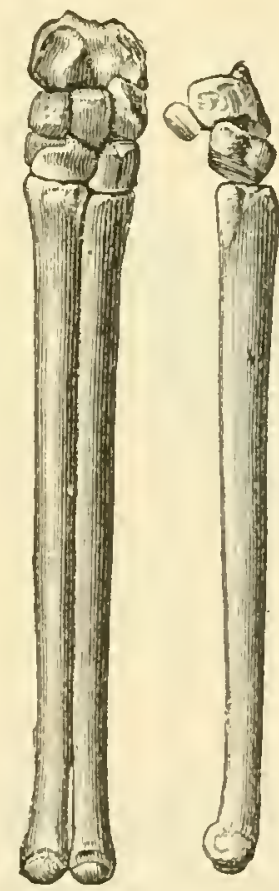

Fı。. 11.

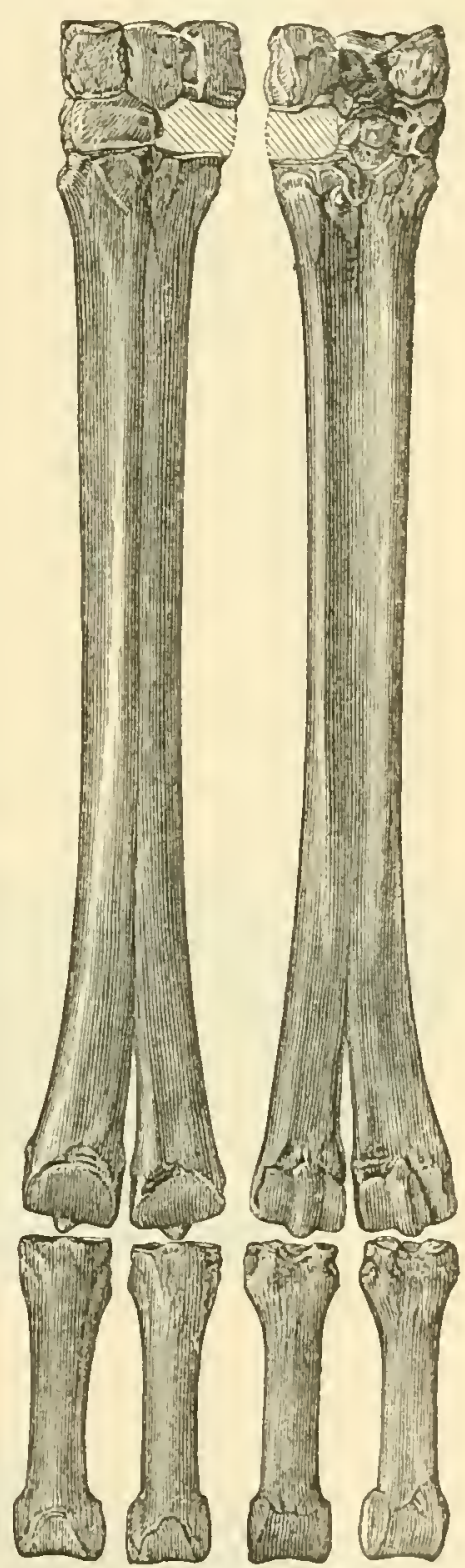

Fio. 12.

Fı. 11.-Pöbrotherium vilsoni carpus and metaearpus with end of radius, three fiths natural size. Original; from White River Miocene of Colorado.

Fis. 12.-Carpus and metacarpus of I3ocamelus occidentalis, about two fifths natural size. Original; from report of G. M. Wheeler, U. S. Expl. Surv. W. of 100tl Mer., vol. iv, jt. ii. From New Mexico. 


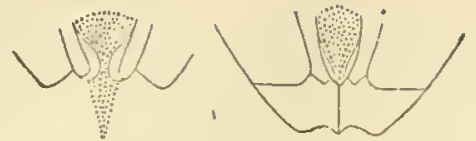

Fic. 1.

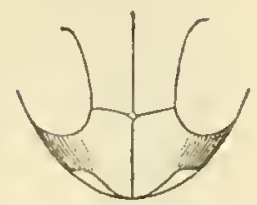

FiG. $3^{3}$.

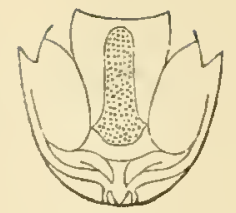

FIG. 2.

FIG, 3, wanting.

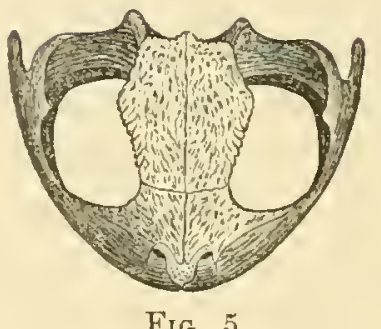

FIG. 5 .

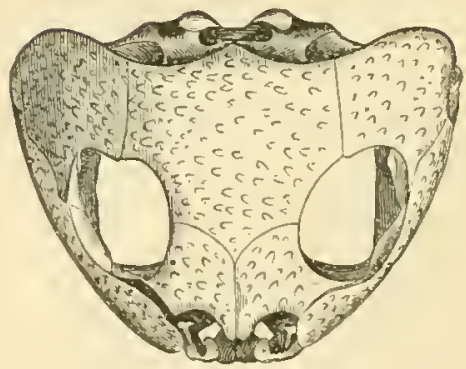

FIG. 6.

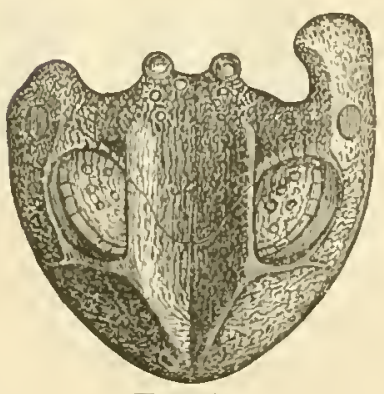

FIG. 7.

BUFONIDAE.
FIG. 7, wanting.

SCAPHIOPIDAE AND PELOBATIDAE. 
PLATE V.

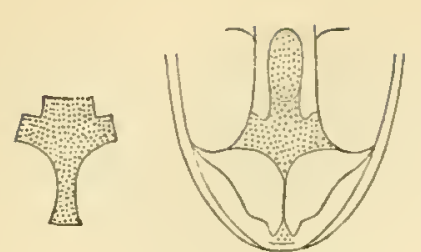

FIG. 1.

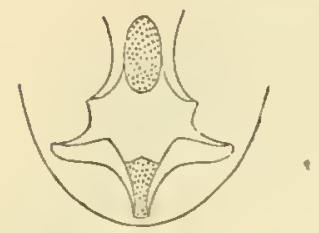

FIG. 2.

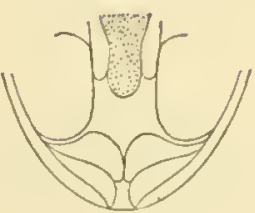

FIG. 21.

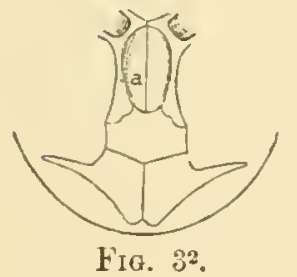

Fig. $3^{2}$.

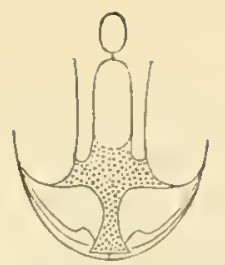

Fig. 1.

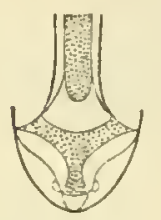

FIG. 2.

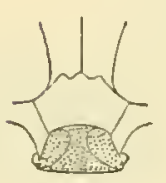

FIG. 3.

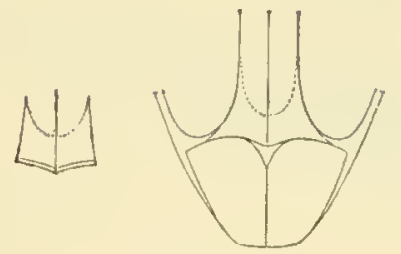

EIG. ${ }^{3}$.
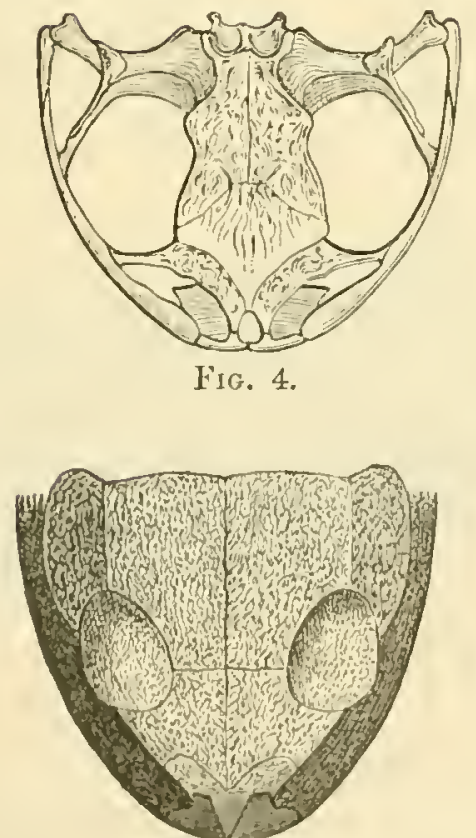

Fia. 6.

CYSTIGNATHIDAE.

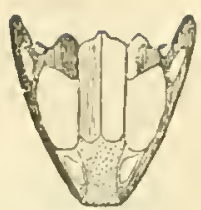

FIG. 3 .

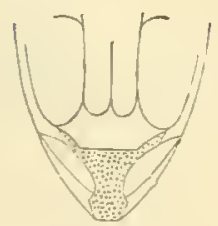

F19. 3.

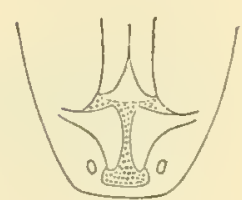

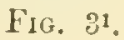

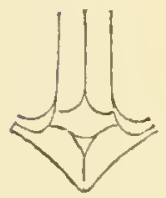

FIG. 32.
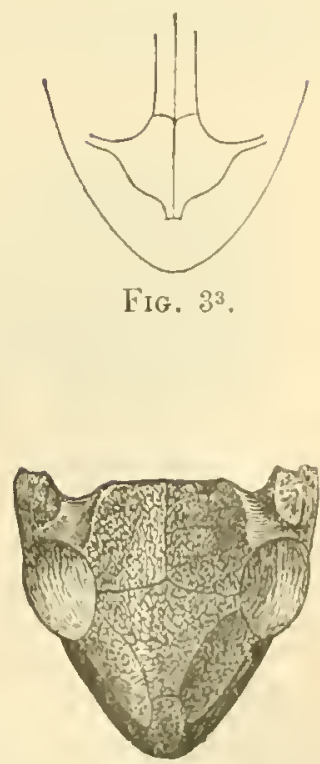

Fig. 5.

RANIDAE. 


\section{EXPLANATION OF CUTS OF CRANIA OF ANURA.}

The numbers in each colnmn correspond with the types of ossifieation mentioned in the text, and are the same as those in the table of families given in the same eonnection. The power numbers attached to Fig. 3, represent the degree of ossification of the nasal bones, except the ${ }^{-1}$, which signifies unossified ethmoid. Most of the cuts are original.

BCFONIDA.-Fig. 2, anterior part of skull of Chelydobatraches gould Giay, from Australia. Fig. 3, do. of Schismaderma carcns Smith, S. Africa. Fig. 6, top of head of Peltaphryne peltaccphala D. and B., Cuba. Fig. 7, top of head of Otaspis cmpusa Cope, Cuba.

Sachilopide and Pelobatide.-Fig. 2, diagram of top of eranium of Didocus calcaratzes Micahelles, Spain. Fig. 5, skull of Scaphiopus holbrooki Harl., United States. Fig. 6, skull of Cultripcs provincialis, from France, after Dugès.

Irylde.-Fig. 1, Thoropa miliaris Spix., Brazil. Fig. 2, Hypsiboas donmerci D. and B., Surinam. Fig. $2^{1}, H_{y} / p s i b o a s$ punctutus Schn., Brazil. Fig. $3^{2}$, Scytopis venulosus Dandin, Brazil. Fig. 6, Trachyccphalus geographicus D. and B., Brazil, after Stcindachner.

Crstignatnide.-Fig. 1, Eusophus ncbulosus Gir., Chili. Fig. 2, Borboroccetes tasmanicnsis Gtlır., Tasmania. Fig. 3, Elosia nasus Licht., Brazil. Fig. $3^{3}, H y$ lodes oxyrhynchus D. and B., IV. Indies. Fig. 4, Grypiscus umbrimus Cope, Brazil. Fig. 6, Calyptocephalus gayi D. and B., Chili.

Ranide.-Fig. 3-1.-Ranula chrysoprasina Cope, Costa Rica. Fig. 3, Rana oxyrhyncha Sund., S. Africa. Fig. $3^{1}$, Rana clamata Daud., N. America. Fig. $3^{2}$, Rana agilis Thomas. Fig. $3^{3}$, Rana hexudactyla Less., India. Fig. 4, Polypedates quadrilineatus D. and B., Ceylon.

to geologic time are displayed in the following table, commencing with the lowest horizon:

No cannon bone:

Cannon bone present.

Incisor tectl present. Incisors one and two wanting.

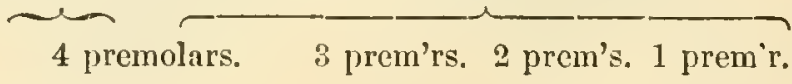

Lower Miocene. $\quad\{$ Poëbrotherium.

Upper Miocene. $\left\{\begin{array}{c}\text { Protolabis. } \\ \text { Procamelus. } \\ \text { Pliauchenia. }\end{array}\right.$

Pliocene and Recent. \{

Camclus.

Aucheria.

This table shows that geological time has witnessed, in the history of the Camelidice, the consolidation of the bones of the feet and a great reduction in the numbers of the incisor and premolar teeth. The embryonic history of these parts is as follows: In the. 
foetal state all the Ruminantia (to which the camels belong) have the cannon bones divided as in Poëbrotherium; they exhibit also incisor teeth, as in that genus and Protolabis. Very young recent

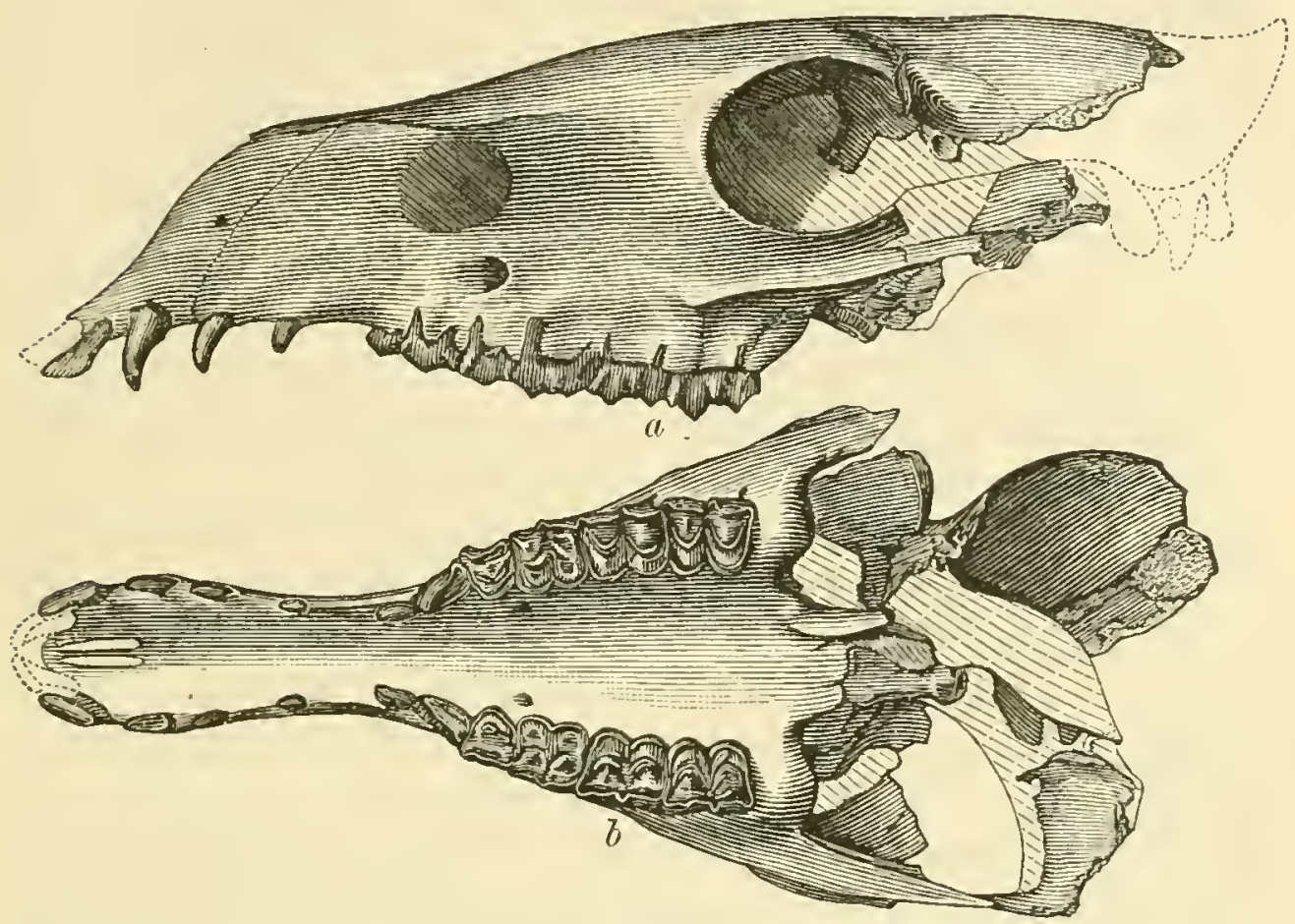

Fig. 13.-Protolabis transmontanus Cope, skull. $a$, in profile; $b$, from below, one third (linear) natural size. Original; from vol. iv, Report U. S. Geol. Surv., under F. V. Hayden. Ticholeptus bed of Oregon.

camels have the additional premolar of Pliauchenia. They shed this tooth at an early period, but very rarely a camel is found in which the tooth persists. The anterior' premolar of the normal

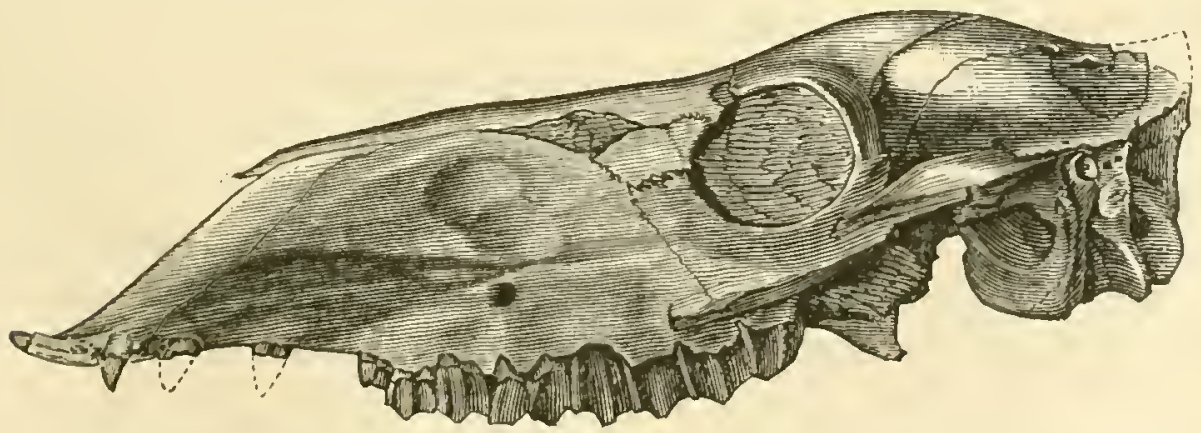

Fig. 14.-Procamelus occidentalis Leidy, profile of skull, about two serenths natural size. Original; from report of Capt. G. M. Wheeler, U. S. Geol. Geog. Surv. W. of 100th Mer. Vol. iv, pt. ii. From Loup Fork bed of New Mexico.

Camelus is in like manner found in the young lamal (Auchenice), but is shed long before the animal attains maturity. I may add that in some species of Procumelus caducous scales of enamel 
and dentine in shallow carities represent the incisive dentition of Protolabis.

It remains to show that characters of the kind above mentioned are sometimes inconstant; that they may or may not al)pear in individuals of a species. Under such circumstances it is evident that their origin does not imply any break in the line of descent.

First, as to a family character. It is well known that the deer differ from the giraffes in the presence of a burr or ring of osseons excrescences surrounding the base of the horn. Now, in the extinct tertiary genus Cosoryx there are three species which possess or lack this burr indifferently. Why some individuals should, and others should not possess it, is not known.*

Second, as to a generic character. The genus Canis (dog) is defined by the presence of two tubereular molars in the inferior series. The allied genus Thous possesses three such teeth, while Icticyon has but one. Now examples of Canis familiaris (domestic dog) with but one tubercular molar are not rare, while an individual with three is occasionally found.

To take another case. The normal dentition of Homo (man) is, on each side, incisors, 2 ; canine, 1 ; premolars, 2 ; molars, 3. It is very common to find in the higher races, individuals who have molars only two in one or both jaws; and the absence of the external incisors of the upper jaw is almost as frequently met with. Here we have two new generic variations in one and the same species.

In specific characters variations are most familiar. 'Thus, the young of deer are generally spotted, and the adults are nearly uniform in coloration. Some deer (as the Axis) retain the spotted coloration thronghout life, while an occasional spotted individual of unicolor species is a violation of specific character by a failure to develop. The larræ of some salamanders are of uniform coloration, and the adults spotted. The unicolor adults of the same species, not mocommonly met with, present examples of the same kind of variation.

Any biologist can select hundreds of similar cases from his special department of study.

* The explanation I hare offered is that the horn was stripped of its integuments to the position of the burr by the animals in fighting. The condition of the specimens renders this hypothesis probable. See "Report U. S. Expl. Surv. W. 100th Ner.," Capt. G. M. Wheeler, vol. iv, pt. ii. 


\section{THE LAWS OF EVOLUTION.}

Haring reviewed the reasons why the doctrine of evolution should be receired as truth, I desire to give attention to the laws which may be made out by reference to its phenomena. Progress in this direction is difficult, owing to the natural impediments in the way of studying the history of the growth of living beings. We will, howerer, commence by examining more fully the phenomena with which we have to deal.

It is well understood that the world of animal life is a nicely adjusted equilibrium, maintained between each individual and its environment. This environment exerts forces both purely physical, and those exercised by other animals. Animals antagonize each other in procuring food, whether that food consist of vegetation or of other animals, but in the latter case the conflict is more severe. A similar competition exists among male animals in the matter of reproduction. These exhibitions of energy constitute the struggle for existence, which is the daily business of the living world. It is well understood that in this struggle the individuals best provided with means of self-preservation necessarily survive, while the weak in resources must disappear from the scene. Hence those which survive must display some especial fitness for existence under the circumstances of their environment, whatever they may be. So the "survival of the fittest" is believed to be a law of evolution, and the process by which it is bronght about has been termed "natural selection." The works of Darwin and others have satisfied biologists that this is a vera causa.

Before the excellence of a machine can be tested, it must exist, and before man or nature selects the best, there must be at least two to choose from as alternatives. Furthermore, it is cxceedingly improbable that the nicely adapted machinery of animals should have come into existence withont the operation of causes leading directly to that end. The doctrines of "selection" and "survival" plainly do not reach the kernel of evolution, which is, as I have long since pointed out, the question of "the origin of the fittest." "The omission of this problem from the discussion of erolution, is to leare Hamlet ont of the play to which he has given the name. The law by which structures originate is one thing; those by which they are restricted, directed, or destroyed, is another thing.

'There are two kinds of evolution, progressive and retrogres- 
sive ; or, to use expressions more free from objection, by addition of parts, and by subtraction of parts. It is further evident that that animal which adds something to its structure which its parents did not possess, has grown more than they; while that which does not attain to all the characteristics of its ancestors has grown less than they. To express the change in the growth-history which constitutes the beginning of evolution, I have employed the terms "acceleration and retardation." Generally these expressions are literally exact, i. c., there is an increased rate of growth in evolution by addition, and a decreased rate in evolution by subtraction; but this is not always the case, for some divisions of animals have increased the length of their growth-period without reference to evolution in structure. The terms express the phenomena figuratively, where not exact in the sense of time, and I believe they are sufficiently clear. The origin of the fittest is then a result of either acceleration or retardation. It is easy to perceive that a character which makes its appearance in a parent before or near to the breeding scason is likely to be transmitted to its descendants; so also a character which is lost near this time is likely to be wanting from the offspring. The causes of acceleration and retardation may next claim attention.

It is well known that the decomposition of the nutritive fluids within living animals gives rise, in the appropriate tissues, to exhibitions of different kinds of forces. These are, motion in all classes; heat in some only; in a still smaller number, electricity and light; in all, at certain times, growth-force or bathmism ; in many, phrenism or mental or thought-force. These are all derived from equivalent amounts of chemical force which are liberated by the dissolution of protoplasm. This organic substance, consisting of CHON, undergoes retrograde metamorphosis, being resolved into the simpler $\mathrm{CO}_{2}, \mathrm{HO}$, etc., and necessarily liberates force.in the process. None of the functions of animal life can be maintained without supplies of protoplasm. We have here to do with bathmism. It consists of the movement of material to, and its deposition in, certain definite portions of the growing egg, or foetus, as the case may be. It is different in its morements in every species, and its direction is probably the resultant of a number of opposing strains. In the simplest animals its polar equilibrium is little disturbed, for these creatures consist of nearly globular masses of cells. As we ascend the scale a greater and more marked interference becomes apparent; radiated animals 
display energy in a number of radiating lines rather than in the spaces between them; and in longitudinal animals, a longitudinal axis exceeds all others in extent and importance. In the highest animals its results are much more erident at one extremity of the axis (head) than at the other, and the diverging lines are reduced to four (the limbs). In each species the morements of this force are uniform and habitual, and it is evident that the habit is so deeply seated that only a very strong dynamic interference can modify or dirert it. The interfering forces are probably all those transmissible through living tissue, and especially molar force. Thus every species has its own specific kind of bathmic force.

The characters of living beings are either adaptire or nonadaptive; they are either machines especially fitted to meet the peculiarities of their environment, or they are not. Among the latter may be ranged rudimental structures and also many others of no sufficient use. They are all due either to exeess or defect of growth-force; they are either consequences of a remoral of nutritive material to other portions of the body; or they are due to an excess of such material which renders an organ or part useless throngh disproportionate size. Of the former class may be cited the absence of the tail in some monkeys and birds; also of the teeth in some Cetaceans; of the latter kind are the enormous tusks of the mammoth and the recurved superior canines of the babyrussa. The change of destination of this material has been probably due to the construction of adaptice machines whose perfection from time to time has required the use of larger and larger proportions of force and material.

In considering the origin of adaptive structures, two alternative propositions are presented to us. Did the occasion for its use follow the appearance of the structure, or did the need for the structure precede its appearance? The following answer to the question has always been the most intelligible to me. Animals and plants are dependent for existence on their enriromment. It is an every-day experience that changes in environment occur without any preparation for them on the part of living things. If the ehanges are rery great, death is the result. It is erident that the influence of environment is brought to benr on life as it is, or has been, and that speeial adaptations to it on their part must follow, not precede, changes of climate, topography, popnlation, etc. We have another important consideration to add to this one, riz., the well-known influence of use, i. e., motion, on nutrition. Ex- 
ercise of an organ determines nutritive material to it, and the nervous or other influence which does this, equally determines nutritive material to localities in the body to which an effort to move is directed, whether an executive organ exist there or not. The habit of effort or use determining the nutritive habit must be inherited, and result in the growing young, in additional structure. Change of strueture, denied to the adult on account of its fixity, will be realized in the growing or plastic condition of fotal or infant life. The two considerations here brought forward lead me to think that the canse of acceleration, in many adaptive structures, is environment alone, or environment producing movements, which in turn modify structure. The character of the stimulus in the successive grades of life may be expressed by the following table, passing from the lowest to the lighest:

1. Passive or motionless beings:

by climate and food only.

2. Movable beings :

by climate, food and motion.

By motion either :

$a$, unconscious, or *

aa, conscious, which is,

$b$, reflex, or

67 , directed by desire without ratiocination, or

bbb, by desire directed by reason.

The only general rules as to the direct influence of motion on structure which can be laid down at present are two, viz., That density of tissue is in direct ratio to pressure, up to a certain point; $\nmid$ and that excess of growth-force, in a limited space, produces complications of the surfaces stimulated. These and other laws, yet unknown, have probably led the changes expressed by evolution, while many others have followed the disturbance of equilibrium which they have produced.

I here allude incidentally to the question of transmission or inheritance. It has been maintained above that the bathmic force of each species is different from that of all other species. This force is characteristic of some unit of organization of living be-

* Morements coming under this head are often called reflex.

+ See "Penn. Monthly," 1872; this work Art. I.

$\ddagger$ "Method of Creation," Philacelphia, 1871. 
ings; and this probably consists of several molecules. This unit has been termed, by Haeckel, the plastidule. The transmission of the bathmic force of one generation to another would be effected by the transmission of one or more living plastidnles; and this is probably precisely what is accomplished in reproduction. The Dynamic Theory of reproduction I proposed in $18 \% 1, *$ and it has been since adopted by Haeckel under the name of perigenesis. I compared the transmission of bathmic force to that of the phenomenon of combustion, which is a force conversion transmitted from substance to substance by contact. 'The recent observations of Hertwig, Bütschli and others, confirm this view. 'The theory of pangenesis, devised to explain the phenomenon of reproduction, is to my mind quite inadequate.

\section{METAPHYSICS OF EVOLUTION.}

I enter here upon a wide field, over which I can only skim on an occasion like the present. The subject has been already introduced by reference to consciousness as modifying morement; of course, then, if movement modify structure, the latter is in fnenced by conscionsness. The word conscionsuess was then, and is now, used in its simplest sense, viz.: as synonymous with plyssical sensibility. Its lowest and most usual exhibition is the sense of touch; the special senses, taste, sight, etc., are higher forms, while thoughts and desires are organized products of the same raw material. Conscionsness can not be denied to many of the inferior animals; indeed, if we grant it to any, we must admit that it is displayed at times by even the lowest Protozoön. That these humble ereatures should possess it, is apparently quite as probable as that the very similar bioplasts of the brain of man should be its seat.

Consciousuess alone is not a sufficient basis for the development of mind. For this, one more element is necessary, and that is, memory. Impressions made by the environment are registered, and soon cease to be present in conscionsness. Under the influence of association the impressions return to consciousness. Associations are those of place, of the order of time, and of similarity or difference in varions qualities, as size, color, or any other physical features. Experiences of these qualities are to all conscions beings either painful, indifferent, or pleasurable. When associa- 
tion requires, events, objects, or characteristics, are returned to consciousness in the order in which they cohere most firmly in the mind, which may or may not be that in which they entered it. The liking for or dislike to the object, are equivalent to an attraction to or repulsion from it. Thus experience is begotten: as its material increases, new combinations are formed, new relations observed, and in the highest types of mind, laws are discovered. No one can deny memory to animals; it is the medium of their education by man, and has been as well the means of their education by nature. Impressions cause a re-arrangement of certain elements of structure which give the form to consciousness when it arises again. It is also probable that these arrangements are not the same as those which represent classifications and conclusions, but that nevertheless the arrangement or organization of these is determined by the simpler arrangements cumsed by perceptive stimuli. Experience produces these combinations in the bioplastic aggregations of all animals, be they in the form of ganglia, brains, or less specialized forms. Nowhere in the human orgunism are the effects of effort and use so strikingly witnessed as in the increase of brain power ; and familiarity with the edneation of the lower animals shows that this is the ease with them also, though in a lesser degree than in man.

If, then, we grant the propositions, first, that effort and nse modify structure; and second, that effort and use are determined by mind in direct ratio to its development, we are led to the conclusion that evolution is an outgrowth of mind, and that mind is the parent of the forms of living nature. This is, however, to reverse a very usual evolutionary hypothesis, viz.: that mind is the product and highest development of the universe of matter and force. The contradiction is, however, not so absolute as at first appears. By mind, as the anthor of the organic world, I mean only the two elements, conscionsness and memory. But it is the view of some thinkers that consciousness is a product; that it is not only a correlative of force, but a kind of force. To the latter theory I can not subscribe; when it becomes possible to metamorphose music into potatoes, mathernatics into mountains, and natmal history into brown paper, then we can identify conscionsness with force. The nature of consciousness is such as to distinguish it from all other thinkable things, and it must be ranged with matter and force as the third element of the universe. 
It is true that unconsciousness does not imply absence of life as generally understood. A majority of the processes of life are performed unconscionsly by living creatures; mind itself being no exception to this rule. There is another class of acts whose performance produces sensation, but consciousness is not concerned in them as an immediate cause. Therefore, it is a common cndearor to associate reflex and unconscions acts with the molecular morements of inorganic and non-living substances. But the one great difficulty in making this identification has never been surmounted. This is the different nature of the morements in the two cases. In non-living matter they are simply polar, nothing more. In liring beings they display design. Perhaps I use the word "design" in a new sense, but the expression is nevertheless appropriate. What I mean is, that the morements of living things have direct reference to conscionsness, to the satisfiction of pleisures, and to the avoidance of pains. The molecular morements within animals of the simplest class are the digestion of food and the elaboration of the materials of reproduction. The molar movements of the simplest animals are to enable them to cscape the pains of hunger and celibacy. Moreover there is reason why the morements of living beings display design. We all know the nature of habits; how they are performed unconscionsly, and as antomatically as digestion itself. But did any one ever know of a habit in an animal, whose origin he conld trace, which has been formed in unconsciousness? According to our knowledge, habits are always the result of stimuli which are conscionsly felt, and which cause by repetition or through reminiscence a repetition of the resulting movement. After a sufficient number of repetitions such an act becomes a habit, i. e., is performed antomatically, or withont the intervention of effort, and frequently withont consciousness. It thus becomes a part of the character of the individual or species. This common phenomenon is expliained by the hypothesis that an organization of the centers controlling action is cansed by the efforts of the animal under the stimulus, and that finally a machine is constructed which determines the nature of the force expended, without further mental exertion of the individual. Such a process is education, and the result is an addition to the stock of faculties already on hand. Thus is explained the vist number of antomatic and unconscions activities displayed by animals; to the same source, I believe, the common reflex acts may be traced; it 
even appears to me probable that the organic functions in general have had the same origin.* While these latter have mostly long since passed beyond the control of the mind, portions of the urogenital functions still linger within the confines of its jurisdiction. Thus have conscionsness and mind endowed living nature with useful functions; and this, which may be ealled the Theory of Endowment, accounts for the element of design which is so puzzling when seen in unconscious and reflex acts.

As it has been maintained above, that strueture is the effect of the control over matter exercised by mind, it is erident that the evolution of mind must be directly followed by corresponding development of organism. The science of paleontology substantiates this theory in a wonderful manner. But the animal mind being gencrally oceupied with simple functions, its expressions in structure are usnally nothing more than the progressive creation of improved instruments for obtaining food, resisting climate, escaping enemies, and reprodueing their kind. The strnggles of animals liave been seen on this platform, and mind has only been necessary to aid in accomplishing the ends above mentioned. Wonderfully effective machines for grinding, eutting, scizing, and digging; for running, swimming; and flying have been produced. 'The development of mind proper must appenr in the size and structure of the brain; and though the history of the latter in past ages must always remain, in large part, hidden from us, it is known that in the former respect there has been great progress made in rarious lines of animals. Now the line which has carried brain to its present development in man, the Quadrumana, has been deficient in special mechanical excellencies of the kind enumerated above. Perhaps primitive inferiority in these many respects has kept the Quadrumana under greater mental tension, and compelled them to exercise caution in their acts, and give that opportunity to thought which was less demanded in the case of other animals. Furthermore, if they are less specialized in their mechanism than most other Mammalia, they are less restricted by it to peculiar modes of life. They are more versatile, and more capable of the adoption of new habits as a consequence. And here we have a glimpse of a most important principle in evolution, which is the keynote to its method; this is what I have called the The Doctrine of the Unspecialized.

* "Consciousness in Erolution." "Penn Monthly," 1875. 
Paleontology shows that the succession of living types has not been in a single straight line. It has been in many divergent lines, and a large number of them have not continued to the present time. The history of life has been well compared to a tree with divergent branches, many of which do not reach the elcration of the summit. Furthermore, in the many cases in which we can trace the lower lines to the present period, it is evident that in their present condition they could not have given rise to the higher forms. Each line, in fact, has developed to an extreme of specialization of structure, which it wonld seem is incapable of modification in any direction very divergent from that which it has already taken. Much less have such specialized types been able to survive the environment for which they were designed; with important changes in that respect they have perished. A fow examples will serre to illustrate my meaning. The direction of development has been from fishes, through Batrachia and reptiles, to birds and mammals. But we can not derive any living type from the osseons fishes of the present or past ages (Teleostomi): to find the origin of Batrachia, we must pass below these to more generalized and older forms, the Dipnoi, a class whose position in the system was for years a controverted point. We can not obtain Mammalia from any of the existing types of reptiles, but we must go back to the Permian period, and trace their ontlines in the Theromorpha of that day. In spite of the prophetic resemblance of these remarkable animals, they are inferior to later Reptilia in the structure of their vertebral column, and display resemblance to some of their immature stages, as well as to those of the Mammatia. Among mammals we can not derive monkeys from Carnivora or Ungulata, nor the latter from each other, but can only trace their close approximation in the Bunotherian types of the Lower Eocene. So with the great divisions of Ungulata; Proboscidians, Hyrax, and the even- and odd-toed orders must all be traced to the unspecialized Amblypodc, with small brains and five-toed plantigrade feet, as their ancestors. * It is easy to perceive that the generalization and plasticity of all these forms has furnished the ground of their ancestral relation.

We are now in a position to comprehend more clearly the general nature of crolution. The doctrine of the unspecialized

* See the origin of types of Mammalia cducabilia, " Journal Academy," Philadelphia, 1874. 
teaches that the perfection prodnced by each snccessive age has not been the source or parent of future perfection. The types which have displayed the most specialized mechanism have either passed away, or, undergoing no change, have witnessed the progress and ultimate supremacy of those which were once their inferiors. This is largely true of animals which have attained great bulk. Like those with perfected weapons, they have ever been superior to the attacks of other animals in their day, and doubtless led, so long as food abonnded, lives of luxurious indolence. With change or diminution of food, such huge beasts would be the first to sncenmb, and it is a fact that no type of land animals has maintained great size through many geologic changes. It is true that all of the lines of ancestry of the existing higher Mammalia, as the subdivisions of the Carnivora, Ungulata, and Quadrumana, which we know in detail, commenced with types of small size and correspondingly little muscular power.

Some important conclusions may be derived from what has preceded. It seems that evolution has witnessed a continual rnnning down of types to their great specialization or extinction. That many types have arisen in weak and small beginnings, but that the conflict with more powerful forms has developed some qualities in which they sooner or later excelled, and which formed the basis of their future superiority and persistence. That while this has probably been the true cause of the origin of the many admirable mechanical adaptations displayed by animals, it is preeminently true of the development of mind. That the reason why progress has reached its limit in the lines of greatest specialization, has probably been the removal of the occasion of its original canse, i. e., active exercise in the struggle for existence. This explanation is suggested by the remarkable degradation which is witnessed in animals whose mode of life relieves them from the necessity of working for a livelihood, e. g., the parasites and sessile animals whose young are free. Some of these creatures, on assuming their parasitic life, lose the semblance of even the order to which their young belong. The primary stages of various plants move actively through the water like the lowest forms of auimals, and their sessile adult condition must be looked upon as a degeneration. It is well known that the endeavor to relegate the lowest forms of life to the two kingloms of animal and vegetable, has been generally abandoned. 'The great vegetable kingdom probably exhibits a life degraded from more animal-like be- 
ginnings. Animal irritability and mobility have been lost, and their own consciousness must be entirely eliminated from the question of the origin of the many later and specialized types of plants. But I renture here the hypothesis that the consciousness of plant-using animals, as insects, has played a most important part in modifying the structure of the organs of fructification in the regetable kingdom.* Certain it is that insects hare been effective agents in the preservation of certain forms of plants. I would snggest whether the mutilations and strains they hare for long periods inflicted on the flowering organs, may not, as in some similar cases in the animal kingdom, have originated peculiarities of structure.

Erolntion of living types is then a succession of elerations of platforms on which succeeding ones hare built. The history of one horizon of life is, that its own completion but prepares the way of a higher one, furnishing the latter with conditions of a still further derelopment. Thus the regetable kingdom died, so to speak, that the animal kingdom might live; haring descended fron an animal stage to subserve the function of food for animals. The successive types of animals have first stimulated the development of the most susceptible to the conflict of the struggle for existence, and afterward furnished them with food. Donbtless, in the occupation of the world's fields, the easiest and nearest at hand hare been first occupied, and successively those which were more difficult. The digging animals are generally those which first abandoned the open field to more courageous or stronger rivals ; and they remain to this day generally of low type compared with others of their classes (e. g., Monotremata, Rodentia, Insectivora). All occupations hare been filled before that one which requires the greatest expenditure of energy, i. e., mentil activity. But all other modes of life have fallen short of this one in giving the supremacy orer nature.

Automatism then represents a condition of "lipsed intelligence" and diminished life. The unconscions automatism of animals is a condition of still greater lapse. On the contrary, sensibility is the condition of development, and the susceptibility and impressibility which is the extreme reverse of automatism is the especial character of youth. Here the "doctrinc of the unspecialized" finds justification again.

* This opinion has also been expressed by IIermann Müller. 
What the future has in store for us in the history of inorganic force and its results we can not now foresee, but I call attention in this connection to the important part played by life in the distribution of minerals. It has long been known that the carbon of the earth's crust was once in a living state, and it is admitted that the limestone once circulated in the fluids of animals. We have recently been compelled to believe that siliceous rocks are composed of the consolidated shells of minute plants, which they have elaborated from the water of the ocean. Silver and gold are segregated and deposited by seaweeds. The principal rock material, whose relation to life lias not been ascertained, is alumina. How far the processes which now cliaracterize dead matter were once related to life is a problem for the future.

\section{THE MORALS OF EVOLUTION.}

The doctrines of the struggle for existenee and survival of the fit in human life have a two-fold application. The relative proportions in which these applications are made will depend on the moral development of him who makes them. Moral density and intellectual stupidity (often nearly allied) will see in these two laws only the struggle for material power, and the survival of the strongest. They will hardly urge in these days, as they would infallibly have done had they lived a few centuries ago, that the strongest means the hardest hitter, or the most successful assassin, but they will probably believe that this pre-eminent position belongs to the most wealthy. From a purely dynamical standpoint this position is correct, yet it might be a useful question for such advocates to consider why it is that physical oppression and assassination should be less suceessful avenues to power than they once were.

There are two reasons why man does not grant the first place in his esteem to physical force. The first principles of morals are acquired in the struggle for existence. The idea of meum and tuum was speedily developed so soon as men associated together; and the habit of justice has doubtless been formed by the insistence of every man on his own rights, and by the power of combinations of men to control those who may from superior strength or other canse seek to violate the rights of property. Thus law originated, and from the earliest history of the race to the present day it has educated the barbarous and semi-barbarous to civilization. It is then easy to perceive that man gives the highest place 
in his affections to the most just; but there is yet another reason why this should be the case.

The reproductive instinet in the lower animals has developed into social affections, and these form a part of the character of the higher animals and, in an especial degree, of man. The sentiments of sympathy and benevolence are probably outgrowths of the same. While the rational faculties are coneerned in the knowledge of right, these sentiments are a souree of the love of right. This disposition is trusted by men as leading to the practice of right, in eases where the power to enforce it is not immediately present. The struggle for existence then among men ranges all the way from a rivalry of physieal force to a rivalry for the possession of human esteem and affection. The robber and assassin of the lowest human races are represented by the slanderer and defamer in the higher. The ultimate prosperity of the just, asserted and foretold by prophets and poets, is but a forecast of the doctrine of the survival of the fittest. The unjust are soouer or later eliminated by men from their society, either by death, seclusion, or ostracism.

But the organized moral qualities can not normally transcend in power, as motives of human action, those which secure man's physical preservation. Lines of men in whom the sympathetic and generous qualities predominate over the self-preservative, must inevitably become extinct. Evolution ean produce no higher development of the race (whaterer may sometimes appear in individuals) than an equivaleney in these two classes of forees. Beyond this the organization of the social faeulties of the brain must always be repressed in the race, so that we ean only expect to attain an equilibrinm between them and the more purely selfish ones, as the very highest result of mnassisted evolution. In this position the judgment is suspended between the opposing elasses of motives; and it must ever remain doubtful in general as to whether resulting action will be just and right, or the reverse. I exclude from this question those generous acts which do not appear to the actor to confliet with self-interest. These may be termed sympathetic acts, and are quite distinet from the altruistic. * The sympathetic actions are seen at times in most animals. The altruistic acts, on the other hand, are those that express what is usually called "moral principles." Such acts may often coineide 
with the interest of the actor, but so long as they do not appear to him to do so, they are altruistic. It is part of the doctrine of evolution that habits will ultimately disappear on the removal of their stimulating canse. The moral nature originated, and has been maintained, throngh the pressure of the fear of consequences. The removal of this pressure, through the aequisition of power, would then ultimately result in the diminution or loss of the moral nature, through disuse. The abuses of power are well known. This appears to be all that evolution can do for us in the production of the moral nature. So it would appear that no organized faculty of self-sufficient altruistic justice can be derived by the proeess of mental evolution. The result is rather a continned struggle between justice and injustiee. It is, then, evident that any power which shall cause the permanent predominance of the just over the selfish faculties must be derived from without.

After we omit from customary religion, cosmogony, which belongs to science, and theogony, which belongs to the imagination, we have left an art which has for its object the development and sustentation of good works or morals among men. If the teachers and professors of this art produce the results in this direction at which they aim, their great utility must be conceded by all. Their method has the advantage over that of the law, in being of the character of inducements supplied before action, instead of pains and penalties inflieted after aetion. They strive to originate good conduct, rather than to punish bad conduct. They are working ou the side of the originative foree in development, rather than the destruetive; the "origin of the fittest," rather than the "survival of the fittest." Whether man possesses the spontaneous power called "free will" or" not, the work of supplying inducements for good conduct is most nseful to society. But religion, as generally understood, pre-supposes free will; and the definition of the word responsibility implies its existence. The question as to the presence of such a faculty is an interesting one, and will now be briefly considered.

The well-known doctrine of necessity leaves no place for free will. All acts are the consequences of motives, and are the ontcome of a balaneing of interests. The heaviest side of the account determines action. Our physical necessities supply the motives for most of our activities; onr pursuit of food and clothing is of necessity, and no condition is free from it. Erolution supports and explains this doetrine, as can readily be perceived. It de- 
rives our instincts from an ancestry whose daily occupation has been their gratification. But it has been shown above that this derelopment does not supply the motives of an independent morality.*

The direction of action under stimulus is determined by intelligence, which is, as has been above maintained, the product of experience. Intelligence is organized or classified knowledge, and directs the activities set on foot by the likes and dislikes, that is, the affections. When there is knowledge, there is no necessity for spontaneous action or free will, since action is determined by the organization of the mind. Even if the mind is conscious of insufficient knowledge, an inducement to seek knowledge is supplied, and according to the result of investigation will be the direction of knowledge.

But we are here bronght to face the case where knowledge can not be or is not obtained. This is the condition of the two questions of the practice of morals, and the nature of the future life. The evolution of mind consists of a continual adrance from the known into the mnknown, and a transfer of the unknown to the known. So long as there is any inducement to progress of this kind, and nature responds to inquiry, development will go on. Although it is true that it is only among men, and but few men at that, that the pursnit of knowledge is an occupation, most men add to their stock incidentally as they pursue other arocations. The knowledge of right and the indncements to its practice are learned in their every-day intercourse, so far as it can be acquired. But knowledge in these directions soon attains its limit, and accordingly, derelopment dependent on knowledge must ceise. If any further progress in practical morals is to be made, some new force must intervene at this point.

Here is the opportunity for the appearance of will or spontancity; here it is at least needed. I am willing to believe that it may appear at this point, and that so long as wo have to face the unknown in moral progress, so long it will remain. As a force it must be equivalent of other forces, but as a form of conscionsness it is a new element of mind. As represented in new molecnlar organization, it may always continue, even after much of the unknown may lave been conquered, and a stationary period may have ensned. Such an accession to character would be a fitting

* "On the Origin of the Will." "Penn Monthly," 1 sร7. 
crown of evolution, and a justification of this labor of the ages. If a true factor in human development, it might be compared, in the ereation of character, to the apical bud of a growing tree. As the part pre-eminently living, it leads the growth of the trunk and branches. They all follow of neeessity the path it has marked ont. Under its lead they are successively formed, become fixed, and finally decay. 


\section{PART II. \\ THE STRUCTURAL EVIDENCE OF EVOLUTION.}

VII.

\section{ON THE HOMOLOGIES AND ORIGIN OF THE TYPES OF MOLAR TEE'TH OF THE MAMMALIA EDUCA- BILIA.}

\section{THE TYPES OF MAMMALIAN MOLARS.}

IT has been already stated * that the transition from simple to complex teeth is accomplished by repetition of the type of the former in different directions. "In the cetaceans this oceurs in the Squalodonts; the cylindric incisors are followed by flattened ones, then by others grooved in the fang, and then by two-rooted, but never by double-crowned teeth. This is the result of anteroposterior repetitive acceleration of the simple cylindric dental type of the ordinary toothed cetacean. Another mode of dental complication is by lateral repetition. Thus the internal heel of the superior sectorial tooth of a carnivore is supported by a fang alongside of the usual posterior support of a premolar, and is the result of a repetitive effort of growth-foree in a transverse direction. More complex teeth, as the tubereular molars, merely exhibit an additional lateral repetition, and sometimes additional longitudinal ones. As is well known, the four tubereles of the human molar commence as similar separated knobs on the [primitive] dental papilla."

Accordingly, the simple tuberele may be regarded as the least specialized form of tooth. It may be low and obtuse, as in the Chiromys, or the wallus; more elevated and conic, as in the dol-

* "Method of Creation," p. 10. Philadelphia, 1871. 
phins; or truncate, as in sloths and some rodents. The form is complicated in two wass, viz., either by the folding of the sides, as in Glyptodon and many rodents, as Arvicola, Castor, Lepus, etc. ; or by the development of tubercles on the erown, as in Mus, Dicotyles, Homo, etc. Upon this basis are constructed the more complex types of teeth exhibited by the varions families of Ungulata and some Rodentia, as has been pointed out in the following language: "The genus Uintatherium* has been shown to be a Proboscidian, which combines some important features of the Perissodactyla with those of its own order. . . . The number of such characters was shown to be somewhat increased in Bathmodon, which therefore stands still nearer to the common point of departure of the two orders. This point is to be found in types still nearer the clawed orders (Unguiculata) in the number of their digits $(4,5)$, and in which the transverse and longitudinal crests of the molar teeth are broken up into tubercles more or less connected, either type of dentition [i. e., Proboscidian or Perissodactyle] being derived according as such tubercles are expanded in the transverse or longitudinal directions." $\dagger$

As is well known, the erowns of the superior molar teeth of the higher Mammatia are supported on three roots, two of which are external, and the third internal. The corresponding inferior molars are supported on two roots, and are therefore, in so far, less complex. But these two roots usually support four tubercles, two to each, while the roots of the superior molars support directly but one each. Hence, as Prof. Harrison Allen remarks, the crown of the inferior molar is more complex than that of the superior. $t$

In tracing the degrees of complication of the crowns of the superior molars of Mammatia from the simple cone of the Cetaccan, the first step is seen in the Squatodon and teeth of similar character. In these there are two roots, antero-posteriorly related. In the Squalodont Portheodon gervaisii (Squalodon Auct.) the third root is present. In Mammalia with but three tubercles in the crown, e. g., Carnivora, the inner root has much the form of one of the external ones. In many of those with four tubercles of the crown, e. g., Quadrumana, the form of the internal root is

* Eobasileus in the original. (Ed. 1886.)

† "On the Primitive Types of Mammalia Edueabilia," published by E. D. Cope, May 6, 1873. "Proceedings of the American Philosophical Society," 1873, p. 224.

‡"Dental Cosmos," Deeember, 1874. 
not modified; but in the Lophodont types it is materially altered. In Hyracodon, Rhinocerus, Anchitherium, Oreodon, Cervus, and others, it is flattened, with the long diameter anteroposterior, and is grooved on the inner face, so as to assume the form, as it does the function, of two roots conjoined. In the temporary dentition of Sus, Merychyus, ete., the inner root is divided, so that the superior molar has four distinet roots.

The proper homologizing of the varions forms of dental structure of the Ungulates with each other, and with the primitive types of tubereular teeth, is entirely essential to their intelligent classification, and therefore comprehension of their mode of origin. In order to lay a foundation for this work, I define the four types as follows, giving the subdivisions of the first two in brief, and diseussing those of the third and fourth more fully afterward:

Division I. Haplodont type; the crown undirided or simple.

a. Crown low, obtuse; Cetacea (Beluga), Carnivora (Rosmarus).

b. Crown elevated, acute; Cetacea (Delphinus); eanine teeth in general.

c. Crown truncate; Edentata (Bradypus); Rodentia (Geomys, Dipodomys).

Division II. Ptychodont type; the crown folded on the sides; the folds frequently erossing the crown.

a. Sides only folded; Rodentia

(Arvicola Castor); Edentata (Glyptodon).

b. Summit of crown also folded;

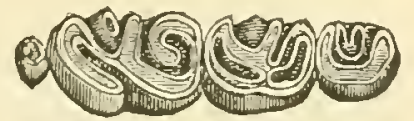

Rodentia (Lepus, Chinchilla).

Division III. Bunodont type; crown supporting tubereles.

a. 'Tubereles few, opposite; Ungrelate, Achcenodon, Dicotyles, Elotherium; Carnivora, Procyon; Rodentia, Heliscomys.

b. 'Tubereles few, alteruate; IIyopsoclus.

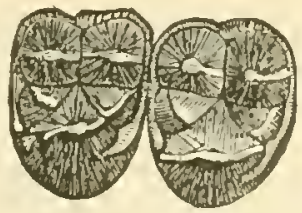

FIG. 17.-Leptochorus.

c. Tubereles numerous, irregular; Mastodon, Phacochcerus.

Division IV. Lophodont type; the summit of the erowns thrown into folds of transverse or longitudinal direction. Higher Ungulates. 
This division embraces the many types observed in the Ungulates, some Rodents, and possibly Carnivora. Inasmuch as the teeth of the maxillary and dentary (mandibular) bones do not always conform to the same type (e. g., Symborodon, Equus), it will be necessary to consider them separately. Besides the differ-

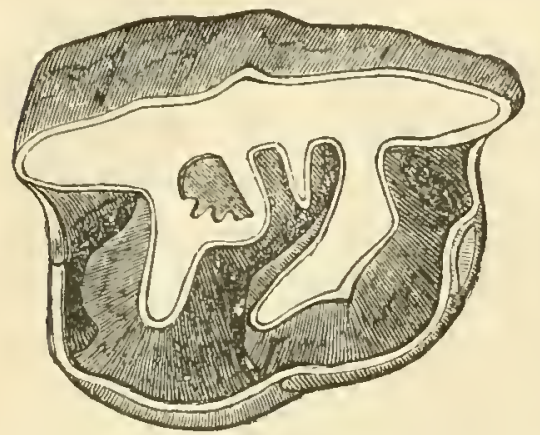

Fro. 18.-Rhinocerus (temporary). ence in type, they differ in their relative development in width in the more specialized forms; thus, in Homo, Mus, Mastodon, and such genera, the molars of both jaws are identical ; in Palcootherium, Eobasileus, Tapirus, etc., and most Carnivora, the superior are the wider, the inferior narrower, appropriately to the greater slenderness of the mandibular bone. 'The latter, or' anisognathous type, may then be regarded as the more specialized. The Bunodonts, except some Carnivora, are all of the former or isognathous type; among Lophodonts the few Rodents, the Dinotheriide, and Elephas are isognathous, while all of the other Proboscitlia, the Perissodactyla, and Ruminantia are anisognathons. Examples may be selected as follows :

Isoginathous; Bunodonts : Homo, Dicotyles, Sus, Mastodon, Elotherium; Lophodonts: Dinotheriidce, Elephas; Rodentia, Sciuritce.

Anisognathous ; Bunodonts : Macacus, Lemuroiden, Procyon; Lophodonts: Anoplotherium, Hyopotamus, Oreodon, Ruminantia, Perissodactyla, Bathmodon, Uintatherium.

\section{THE SUBORDINATE TYPES OF BUNODONTS.}

\section{The Maxillary Teeth.*}

It is apparent that the type of superior molar tooth which predominated during the Puereo epoch was triangnlar or tritubercular ; that is, with two external and one internal tubercles. $\nmid$ Thus, of sixty-seven species of placental Mammalia of which the superior molars are known, all but four have three tubercles of the crown,

* This division is inserted from the "Proceedings of the Ameriean Philosophical Society," for Deeember, 1883, for the sake of supplying an omission in the original memoir. (Ed. 1886.)

† See "American Naturalist," April, 1883, p. 407. 
and of the remaining sixty-fire, all are triangular, excepting those of three species of Periptychus, and three of Conoryetes, which hare a small supplementary lobe on each side of the nedian principal inner tubercle.

This fact is important as indicating the mode of derelopment of the rarious types of superior molar teeth, on which we have not heretofore had clear light. In the first place, this type of molar exists to-day only in the insectivorous and carnirorons Marsupialia ; in the Creodonta, and the tubercular molars of such Carnivora as possess them (excepting the plantigrades). In the Ungulates its persistence is to be found in the molars of the Coryphodontidæ of the Wasatch, and Dinocerata of the Bridger Eocenes. In later epochs it is occasionally seen only in the last superior molar.

It is also evident that the quadritubercular molar is derived from the tritubercular by the addition of a lobe of the inner part of a cingulum of the posterior base of the crown. Transitional states are seen in some of the Periptychidæ (Anisonchus), and in the sectorials of the Procyonidæ.

\section{The Mandibular Teeth.}

The tritubercular or triangular superior molar is associated with a corresponding form of the anterior part of the inferior molar. This kind of inferior molar I have called the tubercular sectorial, and is very variable as to the degree of development of the sectorial cutting edge. The anterior triangle is formed by the connection by angle or crest, of the median and anterior internal crests with the anterior external. Its primitive form is seen in Didelphys, Pelycodus, Pantolambda and the Amblypoda generally ; in Centetes and Talpa; and in its sectorial form, in Stypolophus and Oxyæna, etc.

The * tubercular molar of some Viverride, and among the extinct forms especially the Didymictis protenus, Cope, present a similar structure to that just described. This furnishes a ready explanation of the tooth immediately in advance, which is the primitive form of sectorial tooth characteristic of primitire Carnivora. 'The three anterior tubercles are largely developed, stand-

* The remainder of this seetion (2) is taken from the writer's "Srmopsis of the Vertebrata of the Eocene of New Mexieo," p. 800. Publication of the U. S. G. G. Survey, W. 100th Jeridian, 1875. (Ed. 1856.) 
ing at opposite angles of a triangular space; the onter and anterior cusps are the most elevated, and the ridge which connects them is now a eutting blade. The posterior portion of the tooth does not share in this elevation, and its two tubercles are in some genera obsolete, and in others replaced by an elevation of one margin, which leans obliquely toward the middle of the crown. In Mesonyx this is represented by a median longitudinal crest. If the two tubereles of the posterior part of this tooth (which may be termed a tubercular sectorial) are elevated and acnte, we have the molar of many recent and extinct Insectivora; if the same portion (now called a heel) is much reduced, we have the type of Oxycena and Stypolophus. In the Canida the three anterior tubercles are much less elevated than in the genera above named; the external is much the larger, and the anterior removed farther forward so as to give the blade a greater antero-posterior extent. The heel is large and without prominent tubercles. In the Mustelide the inner of the two median cusps is often reduced to a rudiment, or is entirely wanting, and the heel is large. The lower sectorial of the Hycenidce has no inner tubercle, and the heel is much rednced. In some of the saber-toothed tigers the heel remains as a mere rudiment, while in the true cats it has entirely disappeared, and the carnassial tooth remains perfected by subtraction of parts, as a blade connecting two subequal cusps. The Hycenodontidee, as is known, possess three carnassial teeth without inner tubereles. The history of this form is as yet uncertain, as it was evidently not derived from contemporary forms of the Eocene with tuberenlar sectorials.

The development of the inferior carnassial dentition has thus been accomplished by the subtraction of the inner and posterior cusps, so that of the original four of the quinquetuberculate molar but a single one, i. e., the anterior external, remains.

\section{THE SUBORDINATE TYPES OF LOPHODONTS.}

\section{The Maxillary Teeth.}

In the essay already quoted * the following remarks (page \%) explain the relation between the Bunodont genera and several of the Lophodont types of superior molar teeth: "In the superior

* "Primitive Types of Mammalia Educabilia," May, 1873, and Hayden's "Report on Geological Survey of Montana, Wyoming, etc.," 1873, p. 646. 
molar series the flattening of the outer tubercles may proceed so far as to produce, on wearing, a confluence of the [resulting] crescentoid surfaces. . . I In both Palceosyops and Hyrcachyus these tubercles of the uper molars are confluent into two Vs (more or less open when unworn). In the former the inner tubereles retain their primitive conic tubercular form, but in Palcotherium, Rhinocerus, Lophiodon, Hyrachyus, and Tapirus they elongate transversely so as to meet the corresponding onter tubercles (now crests) forming the familiar cross-crests of those genera. If alternate, the oblique crests of Palcotherium; if opposite, the cross-crests of Tapirus. If, on the other hand, the inner tubercles flatten like the outer, we have, on wearing, the quadricrescentoid [Selenodont] type of the Ruminantia and Anoplotherium. In the Quadrumanous families, including man, the primitive quadrituberculate type of molars is preserved."

Four types of Lophodont dentition are included in the above discussion, and three others may be added. They belong to two series, viz., those in which the crests represent the modification of opposite tubercles, and those where the tubercular elements of the crown are alternate. These series may be called the Amobodont (alternate), and Antiodont (opposite), and the component types are :

Antiodonts.-Selenodont (Ruminants); Tapirodont (Tapir, Rhinocerus) ; Trichechodont (Manati, Elephant).

Amciodonts.-Palceotheriodont (Palieotherium, etc.) ; Symborodont (Palrosyops Symborodon, etc.) ; Bathmodont (Bathmodon, etc.) ; Loxolophodont (Uintatherium, etc.).

These types are defined as follows:

\section{Antiodonts.}

Selenodonts. - The tubereles separate or united at their angles, much elevated, narrow crescentic in section, separated by decp valleys.

To this group belong the molars of the Ruminants, the Tragutide, the Oreodontide, and Merycopotamida; of Perissodactyles the Equiclie.

Tapirodont.s. - The onter tubercles longitudinally compressed, suberescentic in section; the inner transversely compressed, continued as transverse ridges to the end or middle of the corresponding exterior erests.

Rhinocerus, Tapirus, Hyrachyus, Lophiodon, and Hyrax rep. 
resent this type; the last molar of Lophiodon appears to be Amobodont.

Trichechodonts. - Tubercles confluent in to two or more transverse crests.

The Dinotherium represents this form, so does Elephas, Trichecus (the manati), and a number of the larger Marsupiatia.

\section{2. Амeвodonts.}

Palcotherioctonts. - External tubereles longitudinal, suberescentic in section; the inner united with them by transverse oblique crests.

Palceotherium and Anchitherium present this type, which only differs from the Tapirodont in the alternation of the opposing tubereles.

Symboroctonts. - External tubereles longitudinally compressed and subcrescentic in section; the inner independent and unaltered, i. e., conic.

To this group are to be referred the types of Palcesyops, Menodus, and Symborodon. 'They, of all Lophodonts, approach nearest to the Bunodonts.

Bathmodonts. - The posterior pair of tubercles approximated and connected, together compressed and subcrescentoid in section ; the anterior onter conneeted with the anterior inner by an oblique crest forming a $V$ with the preeeding.

Bathmodon and Metalophodon. - The homologies of the orests are diffieult to make ont; the suberescentic erest of the seeond molar may include ouly the posterior onter tubercle, and thus be entirely homologous with the posterior erescent of Palæosyops. In support of this view we have the structure of the premolars, where it beeomes the only external crescent, while the anterior transverse crest turns round on its inner side, supporting the imner anterior tubercle of the tooth. [Note to this edition: The latter view is the eorrect one, as the posterior inner tuberele is wanting.]

Coxolophodonts-Anterior inner tuberele conneeted with the two external by oblique crests; the posterior inner tuberele rudimental or wanting.

Uintatherium and probably Tillotherium represent this group, both being like those of the last, extinct genera from the Eocene of Wyoming. 


\section{The Mandibular Tceth.}

The types of structure are less numerous than those of the maxillary teeth, since I am only acquainted with six. Still more distinctly than those of the upper jaw do they represent the types of opposite or alternating tubercles, or the antiodont and amœbodont. The essential principles of modification are the same as in the maxillaries, and they correspond with them as to genera, as follows :

Inferior.

Selenodont.

Hyracodont.

'Trichecodont.
Axtionost.

\author{
Superior. \\ Selenodont. \\ Tapirodont pt. \\ \{ Tapirodont pt. \\ \{richecodont.
}

Amøbonont.

Symborodont.

Hippodont.

Loxolophodont. $\left\{\begin{array}{l}\text { Palæotheriodont. } \\ \text { Symborodont. }\end{array}\right.$ Selenodont pt. $\{$ Bathmodont. \{ Loxolophodont.

The characteristics of these groups are as follows:

A. Axtiodonts.

Selenodonts.-Constructed, typically, like the upper molars. Ruminantia.

Hyracodonts.-External tubercles compressed longitudinally and crescentic in section, continuous by a cross-crest with the corresponding tubercle of the inner side.

'The animals which possess this type of teeth are the Rhinocerus, Hyracodon, and the Hyrax; it is nearly approached by some of the Hyrachyi. It corresponds in structure with the true tapirodont arrangement of the maxillary teeth ; but many of the Tapirodonts have the Trichecodont type of mandibular tceth.

Trichecodonts. -Definition the same as for the maxillary tecth.

Tapirus, Lophiodon, Hyruchyus, Dinotherium, Elephes, Trichecus (the manati), and the Kangaroos and their extinct allies belong here.

B. Amarodonts.

Hippodonts.-In the horses the maxillary molars are constructed on an opposite crested basis, while the mandibulars repre- 
sent an alternate crested type. 'This is not constituted as in the next form, by a union of altermating tubercles, but as in the Selenodonts by the special development of each crest into a crescent extended antero-posteriorly. As alternating, the inner crescents stand at the apices of the outer, and are connected with them. In Anchitherium the inner are so reduced as to constitute a condition intermediate between the Hippodont and Symborodont types.

Symborodonts. - The alternating tubereles connecting by oblique ridges which form together two $V_{s}$.

'To this type is to be referred a great number of Perissodactyles, e.g., Anchitherium, Patwotherium, Palcosyops, Menodus, Symborodon, Anchippodus.

Loxolophodonts. - Alternate cusps connected by two cross ridges from the outside forward and one from the inside forward; from which result an oblique posterior cross ridge, and a $V$ opening inward.

Here are Eobasiteus and Bathmodon; the last molar of the latter having the anterior ridge of the $\mathrm{V}$ quite low.

\section{Comparison of the Opposing Series.}

In review, the abore types of molar dentition may be classified as follows, with reference to the amount or complication of the modification of the tubercular type. The orders of Ungulata with which they correspond, are also given.

a. Both inner and outer tubercles erescentoid.

Selenodonts.

$$
\left\{\begin{array}{l}
\text { Ruminantia. } \\
\text { (Anoplotherium, Oreodon, Hyopotamus). } \\
\text { Perissodactyla (Equides). }
\end{array}\right.
$$

$\beta$. External tubercles only crescentoid; the inmer transverse or tubercular.

$\left.\begin{array}{l}\text { Tapirodonts. } \\ \text { Palæotheriodonts. } \\ \text { Symborodonts. }\end{array}\right\} \quad$ Perissodactyla in gen.

$\gamma$. Neither kind of tubercles crescentoid, but united in pairs. Trichecodonts. Proboscitia.

It may be added that the groups arranged under $\gamma$ are the only ones in which the types of crests of the superior and inferior molars are fundamentally simple and alike. Thus in the gromp $\alpha$, tubereles of both upper and lower series are modified independently to prodnce the type ; in group $\beta$, the tubercles of the upper series are modified independently of each other, while those of the 
inferior series unite, in order to prodnce the result; in division $\gamma$ the tubercles of both jaws unite entirely across the crown, without any distinction between those of the outer and inner sides. 'Thus the molar type of dentition of the Proboscidians is the most generalized among the Lophodonts, resembling in this respect the type of construction of the feet.

\section{THE ORIGIN OF THE MODERN TYPES OF BLNODONT AND}

LOPHODONT DENTITION.

The four types of molar dentition, the Haplodont, Ptychodont, Bunodont, and Lophodont, are by no means sharply defined, but pass into each other by insensible gradations at many points. The addition of cusps to the simple cone has been accomplished by the appearance of folds at the base of the erown, which have increased in size so as to resemble the primitive cusp to which they are attached. As already pointed ont, the first additional eusp in the transverse direction appears on the inner side of the first, or anterior cusp. The last one was apparently the inner posterior. I first consider the carnassial molars.

\section{The Carnassial Bunodonts.}

In tracing the appearance of the different types of superior sectorial in time, the following faets are patent: In the Eocene genera Mesonyx, Amblyctonus, Oxycena, Stypolophus, * etc., the inner tuberele is much more largely developed than in any $\in \mathbf{x}-$ jsting Carnivora, with the exception of some of the Viverrida. In all, the sectorial crowns are less efficient as shear-like cutters than in Canidae, Mustelider, Hycenidee, and Felidee, on account of the shortness of the posterior blade and the slight compression of the anterior cone. On the other hand, in all of them the number of teeth presenting the curnassial or three-tubercled type is greater than in existing genera, the posterior upper molars in the latter being either narrowly tubereular or wanting. The genus Hycenodon, while agreeing with the others in this respeet, differs from them in the great reduetion of the inner cusp, which is obsolete eren in the representative of the true carmassial tooth, althongh the inner root remains in all. Hence this type of dentition might be regarded as the most specialized of those of the Carnivora,

\footnotetext{
* In the original, the synonym Prototomus is used here.
} 
but for the fact of the imperfection of the shear blades in all except the last. This is seen in the large and prominent anterior cusp and very short posterior blade.

In all recent and most Miocene Carnivora, the sectorials are reduced to one in each jaw, the exception in the latter period being the genus Hycenodon, which did not continne later. The posterior carnassials of the Eocene forms disappear, and in the most specialized recent families Hycenides, Mustelidex, and $\mathrm{Fe}_{e}$ lidce have scarcely any representatives. The shortening of the series appears in the premolars as well, nntil we have the formula of the Felida, P. m. 2; M. 2.

In the inferior dentition the same process may be observed in the successional modifications of the entire series. The Eocene forms of carnivora frequently display more numerous sectorial teeth (such as they are) than any of the existing families. The important change, which is clearly indicated, is the progressive extinction of the genera with numerons sectorial teeth, accompanying the increasing specialization of the sectorial tooth in the genera which remain. In other words, the numerous types of digitigrade carnivora which have survived are those developing but one sectorial tooth (whose earliest representative is Didymictis). The increased perfection of the sectorial tooth has been associated with a reduction in the nnmber of other molars, first, posterior, then anterior to it, which reduction has been accompanied by an increased relative size of the sectorial. By this process concentration of the carnassial function has been gained, and increased robustness of the jaws, by progressive shortening. The slender form of the rami of the Eocene genera and Hycenodon are much less efficient in functional nse than the stont jaws of existing Mustelidee, Hycenidce, and Felidce.

\section{The Lophodonts.}

'Transitions between the Bunodonts and Lophodonts are very. obvious, so much so as to lead to the belief that the several subdivisions of the Lophodonts represent modifications of corresponding types of Bunodonts, and that the two are partially "homologons gromps." Both present corresponding Amœbodont and Antiodont types; as an example of the former kind of Bunodont, the mandibular molars of the genus Hyopsodus may be eited; of the latter kind, the same of the genus Achcenodon, both the earliest, or Eocene genera. It remains to indicate the intermediate 
forms, if any there be, which give color to the supposition that the various divisions of Lophodonts have descended from Bunodont predecessors. Here, then, I mention a fact of prime importance, i. e., that in America, at least, no Selenodonts are known from formations of older age than Miocene; while the greatest development of Bunodonts is in the beds of the next older epoch, the Eocene.

The speeial forms of Lophodonts may be separately considered as follows:

First, as to the opposite and alternate types, or the Antiodont and Amobodont. They pass into each other by many intermediate conditions among the Bunodonts, as in Notharctus, Limnotherium, ete., of the Wyoming Eocene. There is reason, also, to believe that this has been the ease with some of the Lophodonts after they had left the bunodont stage behind. Thus Equus is an antiodont as to its upper molars, but has been probably derived from Palceotheriodont ancestors, which are amœbodont; this is rendered especially probable by the fact that the mandibular teeth are of the amobodont division (hippodont). It is also highly probable that the antiodont genus Tapirus, though so near to Palceotherium, was derived from an antiodont Bunodont. Hence, while the discrimination between opposite and alternate types is in some cases most radieal, in others its importance is bnt slight.

I. Antiodonts: Bunodont type Achanodon (Fig. 19).

1. Selenodont type approximated by the bunodont Hippopotamus, where the tubercles are compressed, thus: the intervening

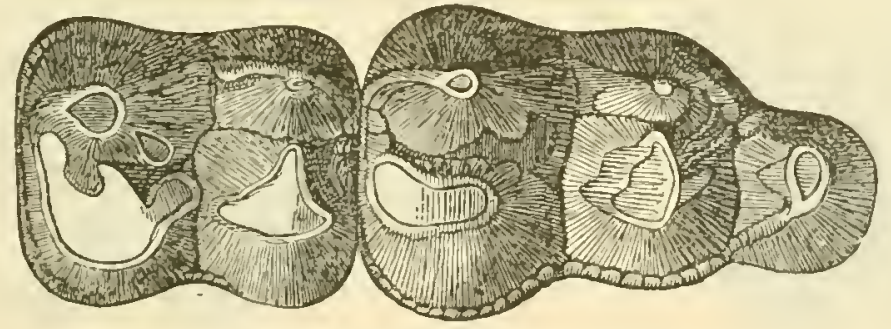

FIG. 19.-Achanodon insolens.

valleys are deepened, and the eusps wear readily into separate erescents. Another intermediate form is seen in the genus $A n$ thracotherium, where the tubereles of the numdibular teeth are compressed, while they remain conic (Fig. 21) ; selenodont forms of Omnivora present us with near approaches to these Bunodont genera. Thus in IIyopotamus and Anoplotherium, the crowns, 
when unworn, present four principal tubercles, which are openly $V$-shaped in section, and which are separated by open valleys.

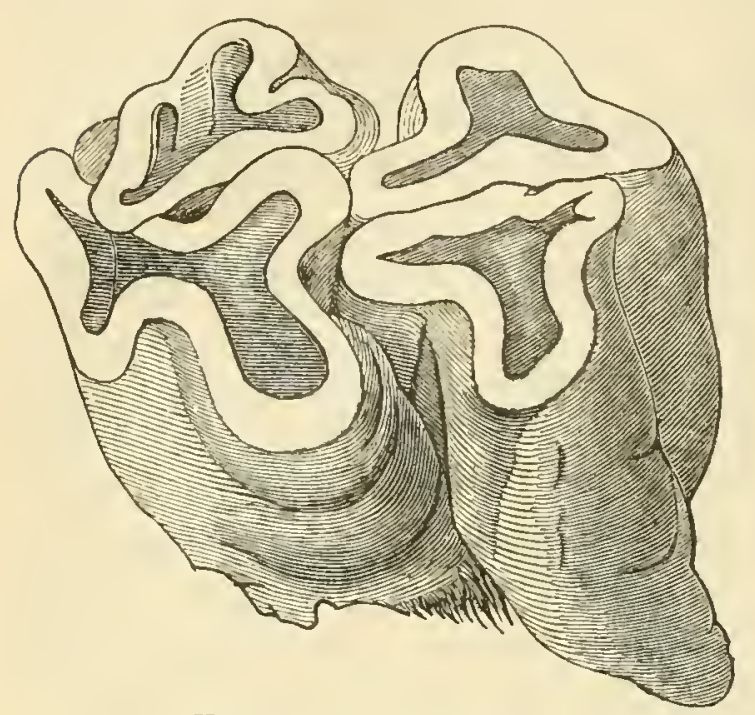

FIG. 20.-Hippopotamus.

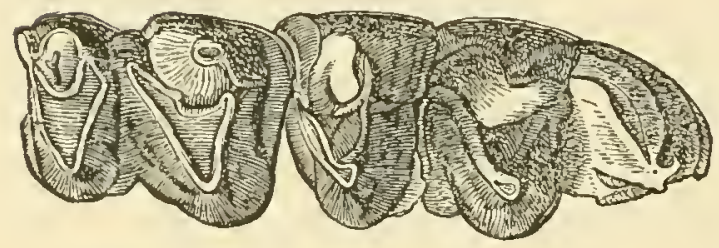

Fig. 21.-IIyopotamus velaunus. The latter are deeper than those of the truly Bunodont genera, but much shallower than those of the typical Selenodonts. In Oreodon the valleys are somewhat deepened and the crescents elevated, while in the deer the same infolding is carried still further. In the Cavicornia the type reaches its fullest expression in the loss of the shoulder at the base of the crown, the great elongation of the latter, and correspondingly deep infolding of the terminal valleys.

Professor Lartet* states that the most aneient deer have very short-crowned molars, and the depressions on the surface are so shallow that the bottom is always visible, while in the Cervidae of the more recent Tertiary periods, and

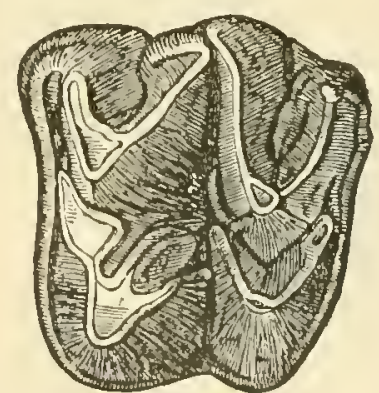

Fig. 22.-Hyopotamus americanus. especially the Plistocene and living species, these same carities are so deep that what-

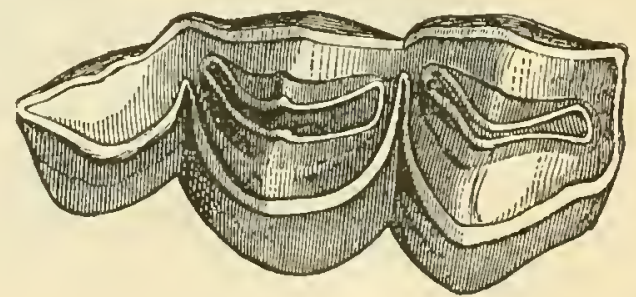

Fic. 23.-Procamelus robustus.

ever be the state of attrition, the bottom can not be seen. This, he says, is a perfectly reliable rnle for distinguishing the ancient from the more modern forms of deer, and can be applied to other animals as well as the Cervidx. 
The writer neirly contemporaneously * recalled the observations of Leidy that the tecth of the Oreodont "Merychyus are more prismatic, have larger crowns and shorter roots, approaching the sheep, as Oreodon does the deer." Now Oreodon is Miocene, and Merychyus Pliocene. It was then observed: "This phenomenon suggests an explanation on the score of adaptation which the other cuses do not. The existence during the later period of a [hard]er material of diet would increase the rapidity of wearing of the crown of the tooth, and require a longer crown and greater rapidity of protrusion. This necessitates a diminution of the

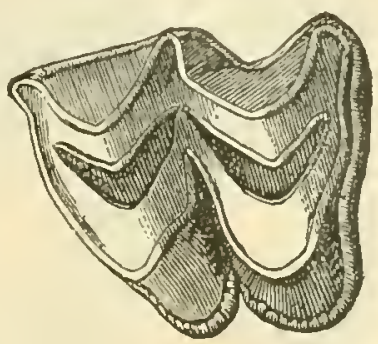

FIG. 24.-Merychyus major. basal shoulder and shortening of the roots, producing the prismatic form aforesaid."

These observations render it highly probable that the selenodont molar is produced by a modification of the antiodont bunodont molar. Also, that the manner of the change has been by constant acceleration of growth of the folds of the tooth upward and perhaps downward in its long axis; and an acceleration in the lengthening of the crown.

2. Tapirodonts. - This form is so nearly similar to the Palieotheriodont that any series amectant between the latter and the Bunodonts will render very probable such a connection for the Tapirodonts also. Indeed, it is clear that the same evidence will

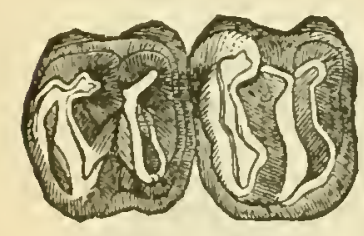

F19. 25.-Tapirus. be sufficient in both cases, since the premolars and last molar of Lophiodon are amœbodont, like Palceotherium. In point of fact, however, the tubercles of the molars of Achcenodon are partly united in transverse pairs, while there are intermediate tubercles connecting the opposite cones in some molars of Elotherium. These structures foreshadow this group as well as the Trichechodont.

3. Trichecodonts. - The Mastodons and Elephants form a most complete series between this form and the Bunodonts, als has been pointed out by Falconer. In this series, the transierse rows or pairs of tubercles, as well as the erests, may be few or many. Thus

* "Proceedings of the Academy of Natural Sciences of Philadelplia," 1868, p. 274, "Origin of Genera," p. 44. 
in Elotherium, Halitherium, and Trichechus they are few; in Trachytherium and Dinotherium more numerous; in Mastodon,

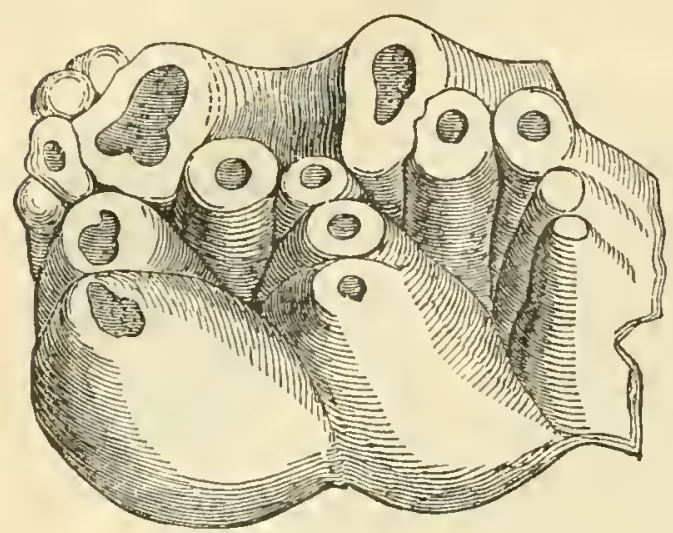

FIG. 26.-Mastodon angustidens. Stegodon, and Elephas, most numerons. The tubercles are united into serrated crosscrests in Halitherium, the extinct sea-cow; in Trachytherium, another fossil ally of the Manati, the tubercles are not mited. The succession from Mastodon to Elephas may be represented by the aecompanying figures: Fig. 26 (from Curier) is a molar of $M$. angustidens, where, beside the principal tubercles, numerous lesser ones appear. Fig. 2\% represents Mastodon olioticus, in which

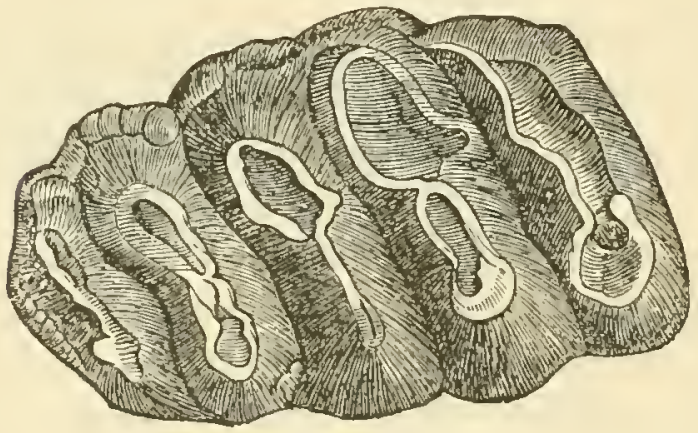

Frg. 27.-Mastodon ohioticus.

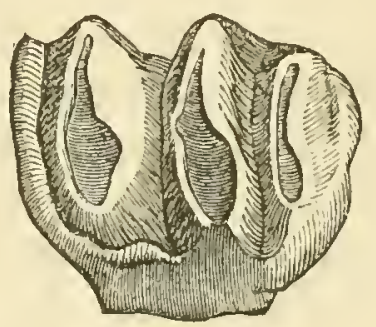

FIG. 28.-Dinotherium giganteum.

the opposite tubercles are nearly united into transverse crests. In Dinotherium (Fig. 28) and Elephas (Fig. 29) the union is complete. The relation of these genera has been described as one of "inexact parallelism"; a condition supposed by the writer to depend on modification in descent under the law of acceleration. The language used is : * "The young tooth of Elephas, moreover, is represented by a series of independent parallel

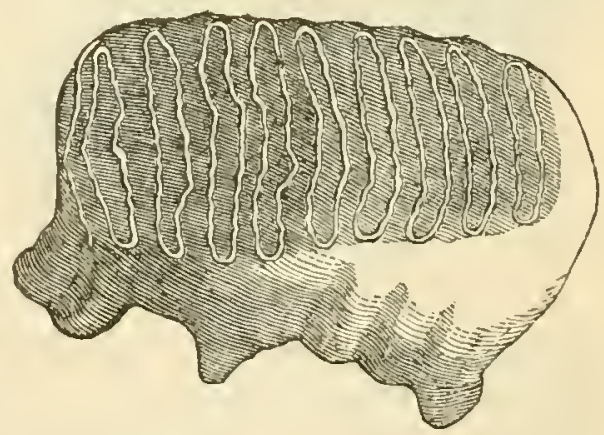

Fig. 29.-Elephas indicus. lamina at first, which, when they unite, form a series of crests 
sinilar to the type [i. e., pattern] of the genus Mastodon [Stego$d o n$ ] and others of the beginning of the series. The deposit of cementum takes place later, till the valleys are entirely filled up. Thus the relations of this part of the tooth structure in the series are also those of the successional growth of Elephas or the extreme of the series."

The transition from the

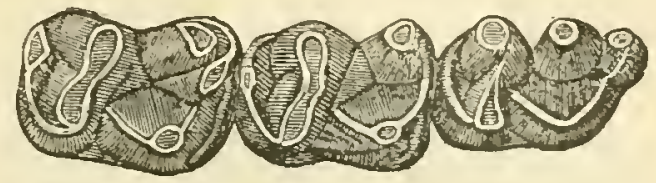

FIG. 30.-Microsyops elegans. bunodont type to the lophodont in the mandibular dentition is seen in the Eocene genera Microsyops and Limnotherium, where the opposite cones are connected by a low cross-crest.

\section{U. Amerononts; Bunodont type Hyopsodus.*}

4. Symborodonts. - In Hyopsodus the exterior cones are already somewhat excavated on the inner side, so that a section of each is somewhat triangular. It is obvious that but little more compression and curvature are required to produce the type of Palcosyops,

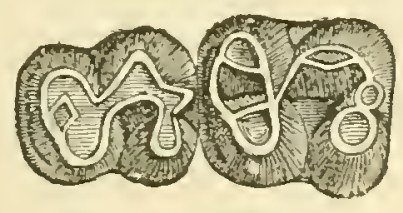

Fia. 31.-Hyopsodus.

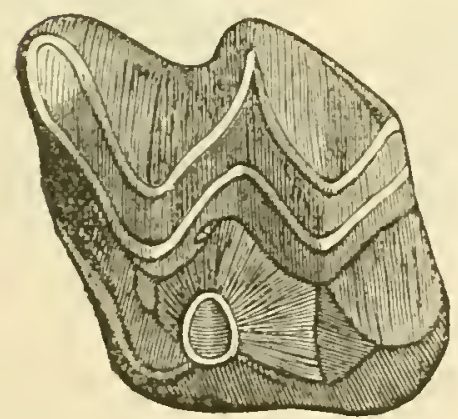

Fio. 32.-Palcosyops lavidens.

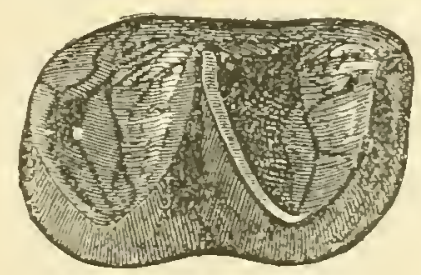

Fig. 33.-Anchippodus.

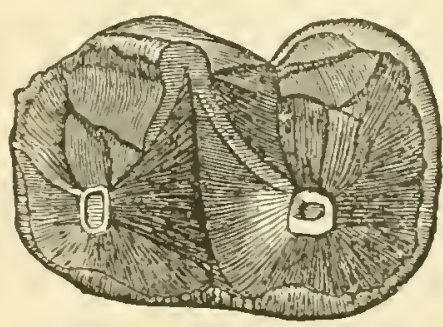

Fig. 34.-Palcosyops.

etc. (Fig. 32). The angles of the outer cones in Hyopsodus are also slightly produced as low ridges to the bases of the alternating tubercles of the opposite side : the elevation of these ridges is only

* I originally ("On the Primitive Types of Mammalia Edueabilia," p. 9; "Mayden's Geolog. Surrey Terr.," 1872, 1873, p. 648) selected Pliolophus (Oligolomus Cope) for this position, but as it has a considerable dinstema, it is better exchanged for Hyopsodus, where the dental series is uninterrupted. 
necessary to produce the two vis of the mandibular dentition of Palcotherium, Palcosyops (Fig. 34), Symborodon, Anchippodus (Fig. 33), and all their allies (Fig. 35, Palceotherium).

5. Palceotheriodont type.-Immediately following the form of the Palcesyops molar we have that of Hipposyns, where inter-

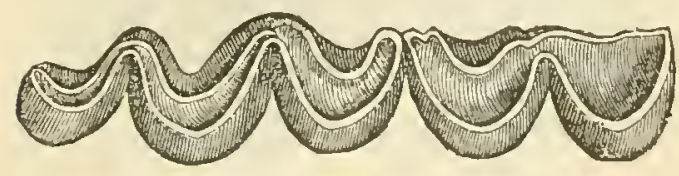

irg. 35.-Palaotherium.

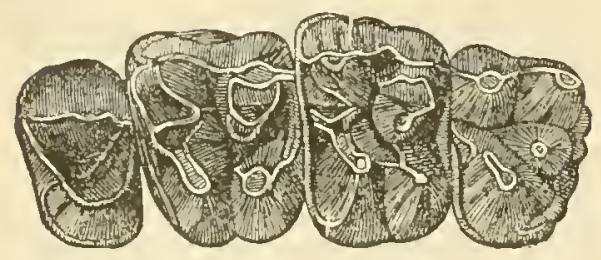

Fia. 36.-IIipposyus. mediate tubercles stand between the inner subconic and the exterior longitudinal crescentoid tubercles. They are compressed so as to be transverse, and only need more complete connection with the adjacent tubercles to give the oblique transverse ridges of Anchitherium, Palcotherium, and Hyracodon, Rhinocerus, etc. Hipposyus was originally compared with Anchitherium by Dr. Leidy, and the writer in ignorance of his language remarked : " An interesting annectant form is seen in Lambdotherium procyoninum, where the two intermediate tubercles which separate the inner cones from the outer $V_{s}$ in Limnohyms are so developed as to constitute parts of an incomplete pair of transverse ridges which disappear in front of the bases of the onter Vs. They represent the oblique crests of Palceotherium and Anchitherium, and thus the genus Lambdotherium furnishes a station on the line from Palce-

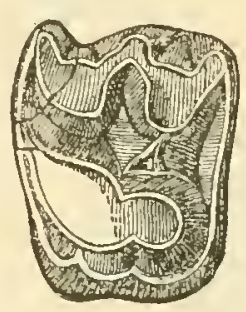

FIG. 37.-Hipposyus.

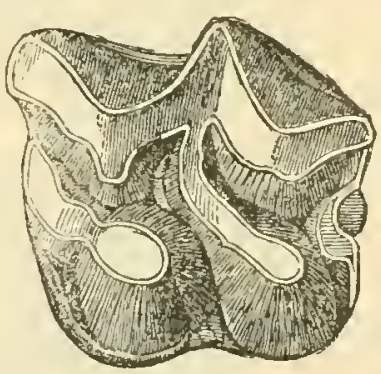

FIG. 38.-Hypohippus. osyops to the horses." Contemporaneously and quite independently Prof. Marsh expressed similar views $\$$ as to its affinities.

A greater longitudinal extent of these ridges or longitudinal expansion of the tubercles in the molars in both jaws, the oblique connections being still retained, gives the type of Equns (Fig. 39). The elevation of the tubercles and deepening of the valleys gives

* IIayden's "Gcol. Surv. Montana," etc., 1873, p. 647.

$\nmid$ This species was in the original erroneously called Orofippus procyoninus. (Ed. 1886.)

‡"Amer. Journ. Sci. A:ts," 1873, p. 407. 
us the Selenodont type of superior molars again in this genus; while the lower molars only differ from that type in having the crescents alternate instead of opposite, forming the Hippodont pattern (Fig. 40). There can be little doubt that the line of the horses comes through Hipposyus * from the Bunodonts, rather than through Palceotherium, as has been suggested by some writers.

6. Bathmodont type.-I know of no genus which by its intermediate structure connects this type of molar with the Amœbodont form of Bunodonts. $\nmid$ Such will doubtless be discovered, for it is impossible that the upper molar of Bathmodon could have been produced by the modifieation of any known Palæotheriodont, the type which it most nearly resembles. The structure of the feet of the animal forbids any such supposition. Such intermediate types would

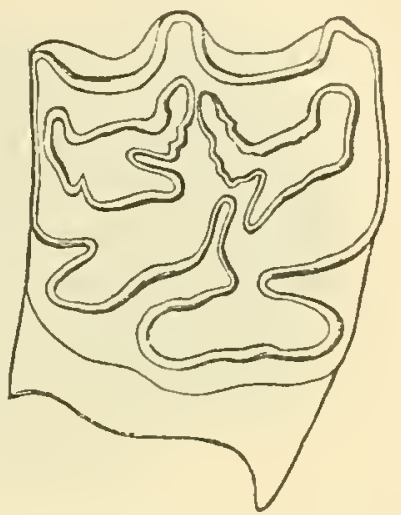

Fıg. 39.--Superior molar of Equus.

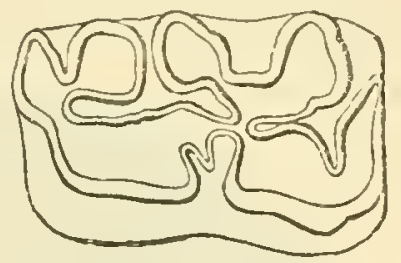

Fia. 40.-Inferior molar of Equus. aus. That this was probably the history of this curious type is rendered probable by the form of the mandibular teeth, which exhibit two of the intermediatc stages above anticipated. Thus the last inferior molar exhibits two obliquely transverse crests of subequal length, with rudimental oblique or diagonal ridges eonnecting them. In the median lower molars one of the latter is developed, giving a $\mathrm{V}$, as in Palceotherium, but the postcrior one is undeveloped, leaving only the original oblique eross-erest. $t$

7. The Loxolophodonts. - Like the preceding group I know of no type eonneeting this form with the Bunodont, but anticipate the discovery of a type with a rudimental posterior $V$ on the

* I have since shown that Iyracolhcrium and Pliolophes, which have very similar dentition, are the types which oceupy this position. (Ed. 1S86.)

+ Such has sinee been discovered in the genus Pantolambda (Cope). (Ed. 1886).

$\ddagger$ See "Proceed. Amer. Philosophical Society," Sept., 1872, "On the Dentition of Mclalophorlon." 
upper molars,* which shall conneet it with the W-shaped type proposed above as the probable predecessor of Bathmodon. Or, a pair of oblique parallel crests with rudimental diagonals like the posterior lower molars of Bathmodon may intervene between this form and the Bunodont. This is, however, not probable in view

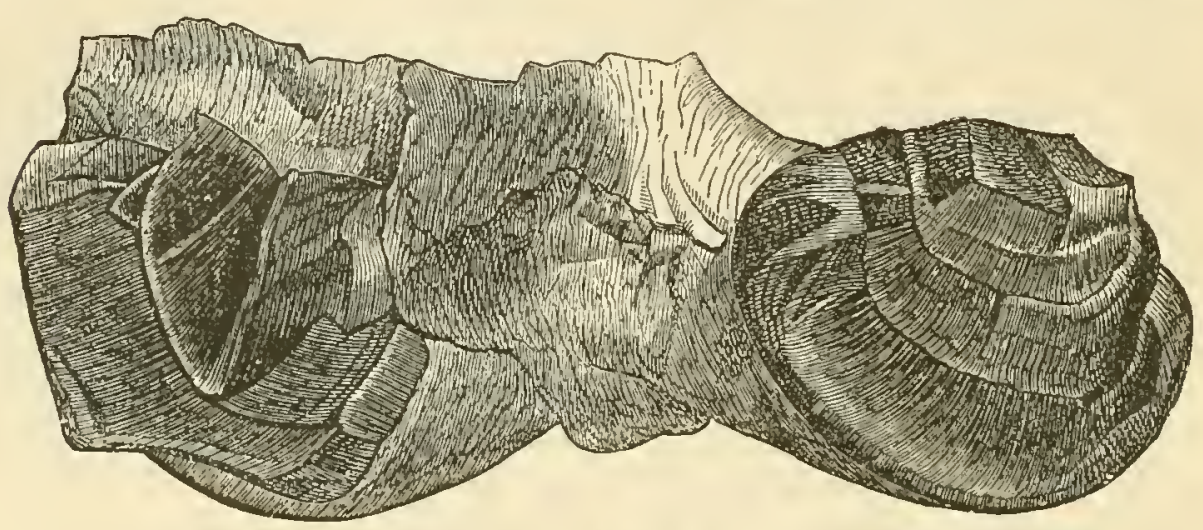

Fig. 41.-Bathmodon.

of the diagonal crest of the upper molars (Fig. 42, Uintatherium robustum), and especially if the parallel with the type of the lower molars is kept up. These are like those of Bathmodon, ex-
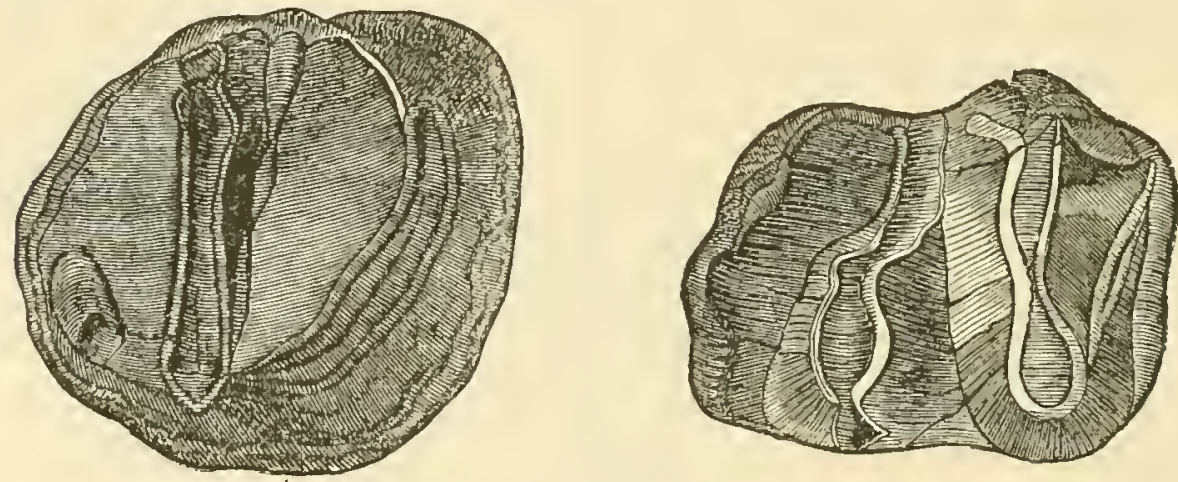

FIGs. 42 and 43. - Vintatherium robustum.

cept that the type of the middle molars of the latter is continued to the posterior end of the series in Uintatherium (Fig. 43); that is, the last molar of the latter consists of a $V$ and an oblique erosscrest.

V. RELATIONS OF THE TYPES OF DENTITION TO TYPES OF FOOT STRUCTURE.

I hope that I have succeeded in showing that the Bunodont and Lophodont types of dentition form two homologous series,

* This has since been discovered in Pantolambda (Cope). (Ed. 1886.) 
similar to those already indicated among Batrachia, Anura, Cephalopoda, etc.* That this relation inaicates descent of the corresponding terms of the one series from those of the other has also been rendered highly probable. This conclusion has also been previously stated as a theorem, $\nmid$ as follows: " $\mathrm{V}$ * The heterologons terms or genera in the later series are modified descendants of those of the earlier series"; in other words, that certain groups higher than genera are produced from others of a similar high value by "descent with modification."

As already pointed out, the Bunod ont primary gencra belong to the older geologic epoch of the Eocene, while most of the derivative ones belong to later periods. Some were contemporary with the primary forms, but doubtless have descended from pre-existent members of the same type as yet unknown to us. The genus Achcenodon, Cope, is especially generalized in three respects : (1) the simplicity of the construction of its molars; (2) the same simplicity of the premolars, which are without inner or posterior lobes; (3) the absence of all diastemata and consequent continuity of the dental series. Hence it may be regarded as more primitive than Palcoochorus, Choromorus, Dicotyles, or Elotherium, in all which there are marked diastemata. The two series may then be arranged as follows: with the understanding that in some cases names of genera used represent rather family groups, in which the special generic lines have not jet been made out. $\neq$

The following table has been already published in its essential features in the "Report on Geological Survey of the 'Territories," 1873, p. 648. \#

It remains now to ascertain whether the genealogical or taxonomic relations expressed by the tecth coincide with those derived from the other diagnostic regions of the body. First of these must be selected, as of chief importance, the limbs and feet.

* See "Origin of Genera," p. 53.

+ Loc. cit. p. 79 .

$\ddagger$ Since the following table was published it has become probable that Achenodon is an unguiculate and a flesh-cater. It has also been discorered that the genus Phenacodus possesses the characters which give it the place as the ancestor of all the lines in the table. (Fd. 1886.)

\# It was previously published in a separate form in "On the Primitive Types of Mammalia Educabilia," May 6, 1S73. An error oceurs in this edition in the reversal by a lapsus calami of the positions of the types Omnivora and Anoplotherium. It is also important to note, that in the "Report G. S.," p. 545 , where it is stated that "during the Eocene they (the orders) were in process of differentiation," ete., Mammalia Educabilia and not Lissencephala, are referred to. 


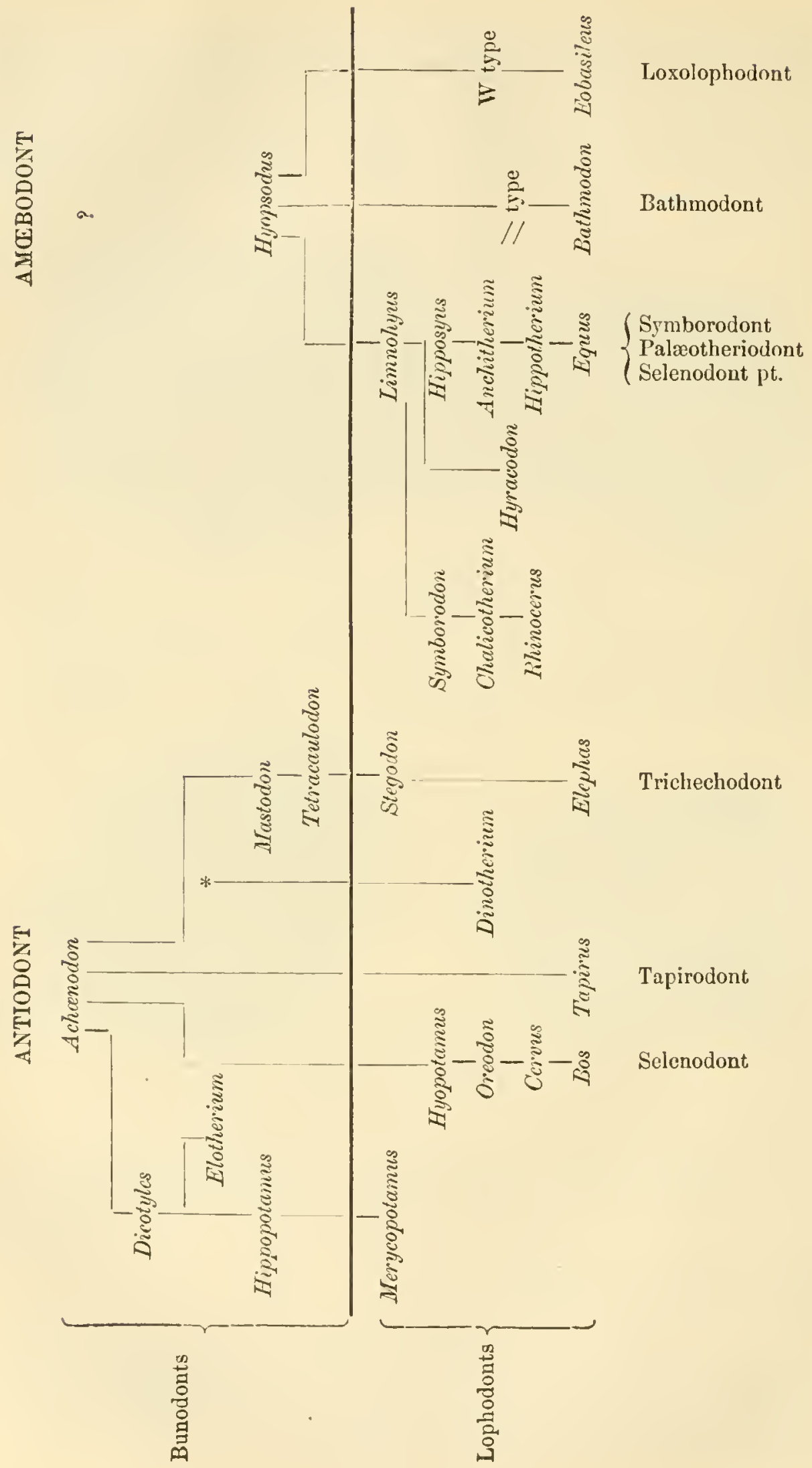


We may look on the Artiodactyla-even-toed or cloven-footed mammals-as one of the most homogeneous groups in the elass, not only in respect to the structure of the extremities, bnt also in that of the cranium, vertebræ, etc. But here we have both Bunodont and Selenodont types of molars. The Perissodactyla, as defined by the feet, axis, palate, ete., present us with the Symborodont, Palcotheriodont, Tapirodont, and Sclenodont types of dentition in the superior series, and the Hippodont, Hyracodont, $P a-$ locotheriodont, and Trichechodont types in the mandibular teeth. The pentadactyle, plantigrade type, for which I have used the name Proboscidia, presents us with the Trichechodont, Bathmodont, and Loxolophodont types of molar structure. Among Sirenians, as defined by the marked peculiarities of the entire skeleton, we have the great differences in dentition presented by Halicore and Trichecus, the former being Haplodont, the other Trichechodont. Finally, the Marsupial group is unquestionably well defined, and here Phascolomys is Ptychodont; Didelphys, Bunodont; Petaurus between Bunodont and Setenodont, and the Kangaroos and their gigantic extinct allies the Diprotodontide, Trichechodont.

It is thus evident that the molar types are everywhere subordinated to those which we call ordinal; therefore in the case of the placental mammals, and especially those with complex folding of the cerebral hemispheres, to the types of construction of the feet. As to the modifications presented by the canine and incisor teeth, these exist within a still more narrow range of variation; for instance, in the allied genera Equus, Rhinaster, and Symborodon; Sus and Phacochorus ; Bathmodon and Unitatherium, and others.

It is thus probable that modifications in the three points of strneture considered were introduced in the following order:

First, Of the feet.

Second, of molar type.*

Third, of the relations of canines and incisors.

With regard to the signifieance of the tnree types of feet, Proboscidian, Perissodactyle, and Artiodactyle, it has been already remarked: "It is to be observed that the lines of Ungulata,

* In the case of the Marsupialic the relation of the dental and extremital types may be reversed. T'hus we have pentadactyle plantigrade forms (Opossums) and (nearly) dilactyle digritigrade forms (Macropus) in the same order. Also Halmaturus and Dimmodon, hoth Triehcehodonts, differ in the type of fcet, as do the carnivorous Didelphys and Thylacinus, both Bunodonts. 
Quadrumana, and Carnivora originate in plantigrade types, a state of things quite predominant among the lower series or Lissencephata (smooth brains). It is universal in Edentata and very usual in Rodentia and Insectivora. The lower forms of Marsupialia and all of the Monotremes present it. In the Marsupials, Rodents, Ungulates, and Carnivores, we have series whose highest expression is in the most highly digitigrade genera." * To this it may be added that the lower terrestrial vertebrates are plantigrade, with some exceptions. Thus in some Anurous Batrachia there is a partial digitigradism; the only digitigrade Reptilia are some Dinosauria, especially such carnivorous forms as Laclaps; all birds are digitigrade. The digitigrade modification evidently has reference to speed in running, or projectile force in leaping.

The connecting points between the different types of footstructure among the Mammalia Educabilia are as obvious as in the case of the types of molar structure. Examples may be adduced as follows:

Carnivora.-In all of the genera of the Eocene Carnivora which I have had the opportunity of examining, excepting Mesonyx, namely, Amblyctonus, Oxycena, Prototomus, Didymictis, the tibioastragalar articulation is of a primitive character. The astragalus is flat, and the applied surfaces are nearly a plane, and without the pulley-shaped character seen in existing Carnivora; as dogs, cats, and in a less degree in the bears and in other Mammalia with specialized extremities, as Perissodactyla, Artiodactyla, etc. The simplicity of structure resembles, on the other hand, that found in the opossum and various Insectivora, Rodentia, and Quadrumana, and in the Proboscidia, most of which have the generalized type of feet. The structure indicates that the carnivorous genera named were plantigrade-a conclusion which is in conformity with the belief already expressed that the Mammalia of the Eocene exhibit much less marked ordinal distinction than do those of the Miocene or the recent periods. It is, indeed, questionable whether some of the genera here included in the Carnivora are not gigantic Insectivore, since the tibio-tarsal articulation in many, the separation of the scaphoid and lunar bones in Mesonyx, the form of the molars, and the absence of incisor teeth in some, are all characteristic of the latter rather than the former order.

Artiodactyla. - Approximations to the Perissodactyla are to be

* "Mammalia Educabilia," p. 8; Hayden's “Geological Survey," 1873, p. 647. 
seen in Hippopotamus in the increase in development of the lateral or first and fourth digits, thus equaling the number in the fore-foot of Tapirus and Menodus, though preserving the equality of the two median digits. But an inequality of these digits appears in the genera Anoplotherium and Ccenotherium, as has been stated * in the following language: "In Anoplotherium secundarium the digit $i i$ is developed in each foot, though not nearly so long as $i i i$, which is nearly symmetrical in itself. There is an approach to the sime structure in the manus of Ccenotherium." The only approximation to the Proboscidian type is to be seen in the shortening of the metapodial bones in Hippopotamus, a point of very inconsiderable value.

Perissodactyla. - Approximation to the preceding order is made in the anterior foot of Menodus, in which, according to Marsh, there are four toes of nearly equal size. $\nmid$ Approximation to the Proboscidia $t$ is seen in Symborodon, where the cuboid facet of the astragalus is rather larger than in Rhinoceros, and developed much as in Bathmodon; the small third trochanter of the femur is also much like that in Bathmodon. The osseous horncores may be compared with those on the front of Loxolophodon. The knee was probably free from the integument of the abdomen, as in Proboscidians. In all other respects there is no approximation to this order.

Proboscidia. - The approximations to other orders in the structure of the feet are only to be seen in the Eocene genera Bathmodon and Eobasileus. The latter, or its ally Uintatherium, presents, according to Marsh, but four toes on the hind foot; the anterior lias five. In the former point we have a resemblance to Hippopotamus, but one of little significance, in view of the radical differences between the two in the form of the astragalus, calcaneum, and cuboid bones. The former is essentially Proboscidian in all respects, with the addition of a cuboid facet alongside of and bchind the navicular, as in Symborodon; thus constituting a Perissodactyle character, but leaning to the forms of that order which betray probably the elosest, though slight, approach to the omnirorous division of the Artiodactyla. Thus, while the Uintatherida present the Proboscidian type of feet and molar dentition.

* Iuxley, "Anatomy of the Vertebrated Animals," p. 321.

† "American Journal of Science and Arts," 1873, p. 4 S6.

\pm This should be Amblypoda, not scparated from the Proboscidia at the time this was written. (Ed. 1886.) 
if they present any ordinal characters resembling those of the Artiodactyla, they are equally shared by certain extinct Perissodactyla.

From the hints above furnished, we may regard the succession of modifications of foot-structure to be nearly as follows :

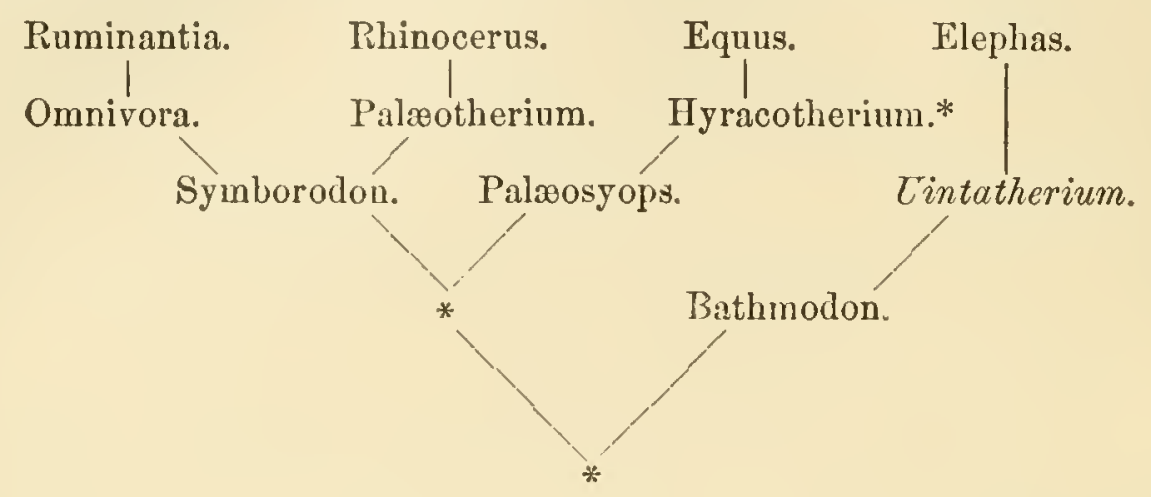

VI. THE ANCESTRAL TYPE OF MAMMALIA EDUCABILIA.

I trust that I have made it sufficiently obvious that the primitive generi of this division of mammals must have been Bunodonts with pentadactyle plantigrade feet. It therefore follows that Elephas was not the descendant of Eobasileus nor Bathmodon in a direct line, but from some common ancestor with tuberenlar teeth, through Mastodon. We may anticipate the discovery of such a genus, and believe that it will not be widely removed from the Eocene Hyopsodus, or perhaps Achconodon. 'This will, then, be the primitive ungulate.

But it will be more than this ; it can not be far removed from the primitive carnivore and the primitive quadrumane. The Carnivora are all modified bunodonts, and the lower forms (Ursus Procyon, e. g.) are pentadactyle and plantigrade. As to the Quadrumana, man himself is a pentadactyle plantigrade bunodont. This view has been already expressed, as follows: "The type of Tomitherium, already described, evidently stands between lemurine monkeys and such sinall allies of Palceotheriidee with conic tubereular teeth (Oligotomus, Orotherium, $\uparrow$ etc.), and which abound in the Eocenes of Wyoming. . . The dentition of the two types is, indeed, but little different in the Quadrumanous and

* This was ealled flipposyus in the original essay - a name which really applies to a different type. (Ed. 18s6.)

† Both these are names for Pliolophus, a elose allay of Hyracotherium. (Ed. 1886.) 
Ungulate types respectively, being a continuous series of I. 1 or 2 ; C. 1 ; P. m. $3-4$; M. 3 ; the canines but moderately developed." * Snch a hypothetical type might be expressed by the name Bunotheriidce, with the expectation that it will present subordinate variations in premolar, canine, and incisor teeth. The premolars might be expected to differ in the degree of development of the internal lobes, the canine in its proportions, and the incisors in their number.

In respect to the limbs proper, neither the Quadrumana nor Carnivora attain to the specialization seen in the Artiodactyla and Perissodactyla, for the ulna and fibula are never atrophied nor co-ossified with the radius and tibia, but are always distinct and free; the only modification of structure in these points being the slight one involved in developing the rotary capacity seen in the higher monkeys.

Thus the human series preserves in its feet, limbs, and dentition, more of the characteristics of the primitive Bunotherium than any other line of descent of the Mammalia Educubilia. It even exhibits a retrogression, in the transition from the anisognathous Tomitherium to the genus Homo, where the teeth in the two jaws are exactly alike, as well as in the resumption of the continuity of the dental series after the diastema had prevailed among the higher monkeys. In one respect it has steadily advanced, viz., in the number of convolutions and extent of the cerebral hemispheres and relative size of the brain as a whole.

Note (Ed. 1886). - As remarked in a previous note, the discorery of the general characters of the genus Phenacodus in 1881, more than six years after the publication of this paper, demonstrated the truth of the hypothesis here proposed, viz.: that the ancestor of the Mammalia Educabilia was a pentadactyle plantigrade buno. dont. The numerous genera and species allied to Phenacodus have been placed in a suborder Condylarthra. See "American Naturalist," 18\$4, 790, for an illustrated article on this group.

* IIaydden's "Geological Survey of Montana," ete., 1872, p. 645. 


\section{VIII.}

\section{THE RELATION OF MAN TO THE TERTIARY . MAMMALIA.*}

Is order to prove the affirmative of a doctrine of evolution by descent of the existing types of living beings, two propositions

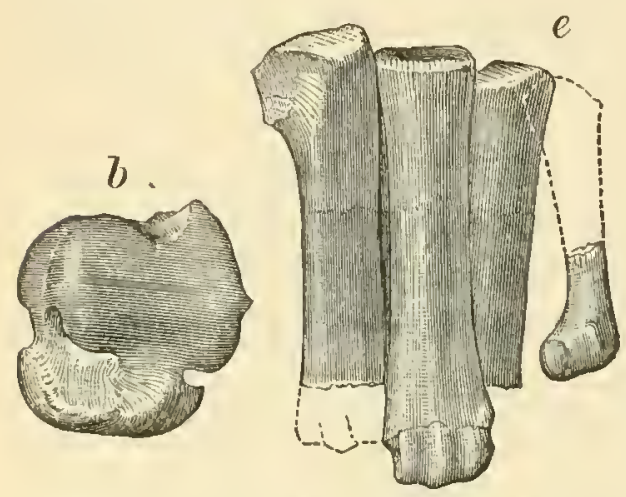

F1a. 44.-Periptychus rhabdadon, part of posterior foot, two thirds natural size; $b$, astragalus from above, showing flat face; $e$, metatarsals, the first lost, showing plantigrade foot. Original; from Puereo Epoch of New Mexico. must be established. The first, that a relation of orderly succession of structure exists, which corresponds with a suceession in time. Second, that the terms (species, genus, etc.) of this succession actnally display transitions or connection by intermediate forms, whether observed to arise in descent, or to be of such varietal character as to admit of no other explanation of their origin than that of deseent.

In the field of paleontology it is quite possible to demonstrate the first of these propositions, while the proof of the seeond is necessarily restricted to the observation of variations and the discovery of connecting forms which destroy the supposed definitions of species, genera, etc. The conditions are more favorable for the investigation of animals of the higher types than of those of the lower. Their late origin insures to us the opportunity of discovery of their ancestry far more eertainly than in the case of the lower, whose beginnings are Jost in the remote past, and belong to periods whose deposits have undergone physical ehanges, or have been entirely removed and redeposited elsewhere, thus insuring the destruction of the fossil remains onee contained in them. The series of the tertiary Mammalia is becoming more eomplete through the

* Read before the American Association for the Advancement of Science, at Detroit, 1875 , under another title. 
recent explorations in the West, and the results are embraced in the fortheoming quarto reports of the Hayden and Whecler U.S. Geological, etc., surveys of the Territories. An abstract of some of these is given in the present essay.

The primary forms of the Mammalia repose in great measure on the structure of the feet. Those of the teeth are also very significant, but present a greater number of variations among animals otherwise nearly related. The

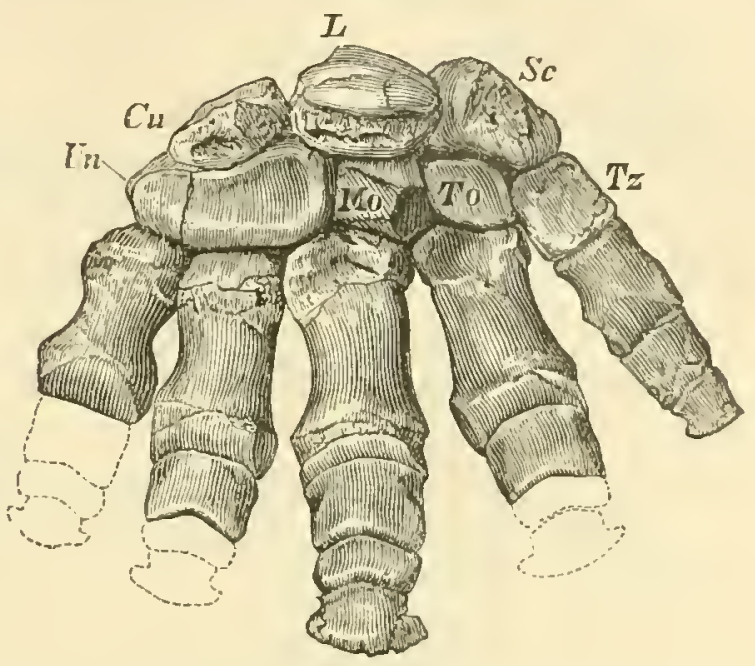

Fic. 45.-Coryphodon elephantopus, anterior foot from above, one third natural size. From Lower Eocene of New Mexico. The euneiform (Cu) is injured. (Original.) osteology of the feet of recent land manmals falls into several categories. These may be

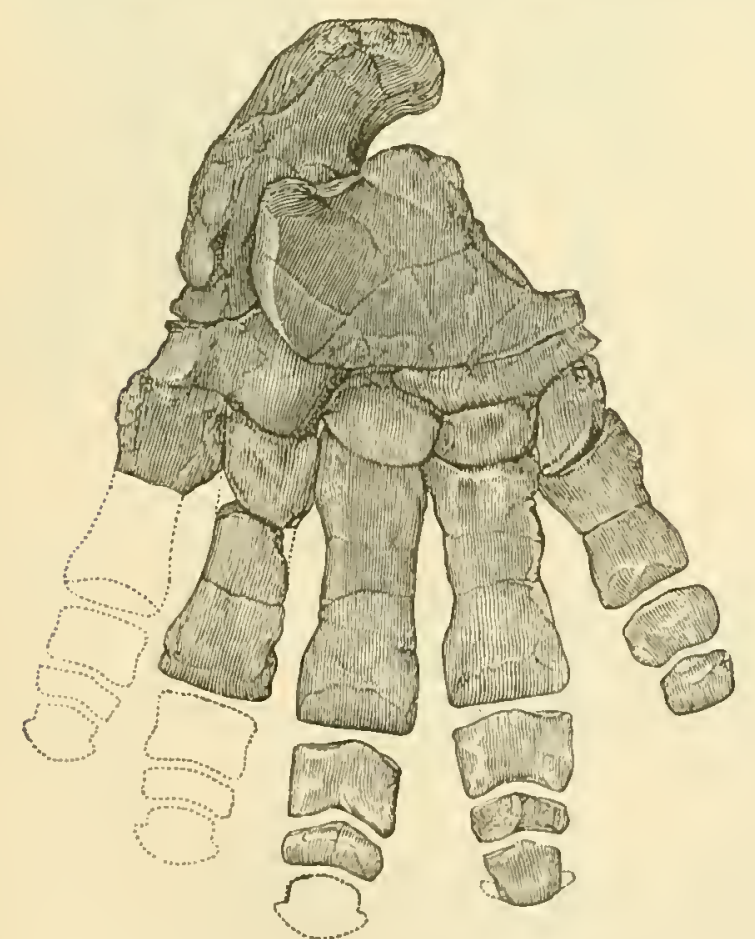

F10. 46.-Posterior foot of Coryphodon elephantopus. From Lower Eocene of Now Mexieo. (Original.) called the plantigrade, many-toed type ; the carnivorous type; the liorse type, and the ruminant (e. g., ox) type. The lower vertebrates, as salamanders, lizards, etc., display the simplest form of feet, having usually five toes, with numerous separate bones of the palm and the sole, which they apply to the ground in progression. The manytoed or multidigitate type of mammalian foot most nearly resembles this condition, but differs in the points of difference which are common to all Mammalia. In the hind foot a succession of forms leads from this general- 
ized type to the extreme specializations observed in the horse and the ox.

The modifications are as follows: The hind foot is composed of two rows of tarsal bones, of which the second is followed by the long metatarsal bones, from which the bones of the toes originate. The seeond segment of the hind leg is composed of two bones, tibia and fibula, which in the salamander, ete., have a subequal union with the foot. In some multidigitates, as the genus Coryphodon, both these bones articulate with the two bones of the first row of the tarsus, and one (fibula) is the smaller of the two. In many higher forms they articulate with but one of these tarsal bones, viz., the astragalus, with which they form a perfect hinge joint; the other tarsal bone of the first row is the calcaneum or heel-bone. In Coryphodon the astragalus and the applied leg-bone (tibia) are nearly flat, offering an extremely imperfeet hinge for the foot, and the heel-bone (calcaneum) is exceedingly short. The animal plainly walked on the entire sole of the foot, and must have had an awkward gait, from the slight power of flexing the ankle-joint. From

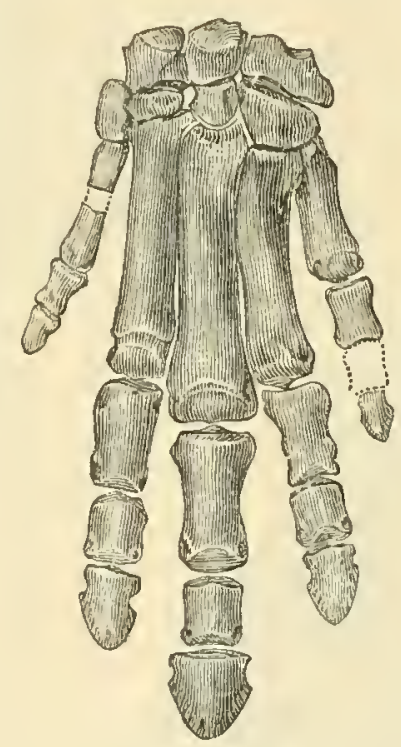

Fig. 47.-Left anterior fout of Phenacodus primavus, 1/3 nat. size. (Orig.)

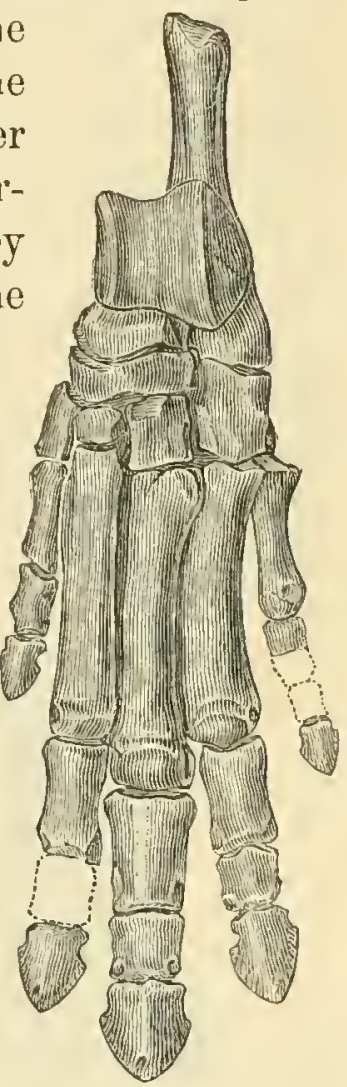

Fig. 48.-Left posterior foot of Phenacodus primavus, $1 / 8$ nat. size. (Orig.) this point to the horse on one side, and to the ox on the other, we have a line of succession of intermediate forms. And before describing them, I may state that the Coryphodon is one of the oldest known Mammalia, its remains having been found in the Lower Eocene Tertiary of New Mexico and Wyoming, while the ox and horse are extremely modern animals, their advent on the earth having preeeded that of man by but one geological period.

The most perfect ankle-joint is that of the ruminating animals. The astragalus presents a deeply grooved segment of a pulley; an angutated pulley, face downward to the rest of the foot, and a 
PLATE VI.

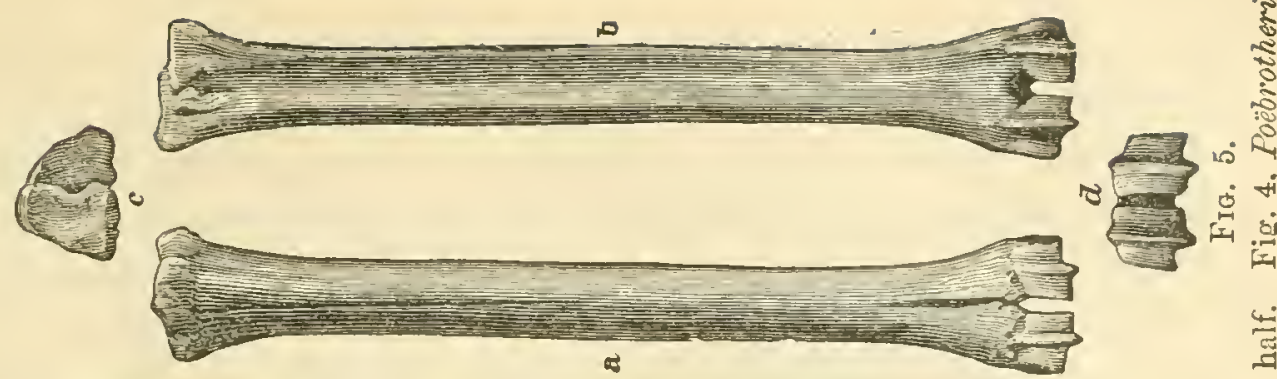

(1)

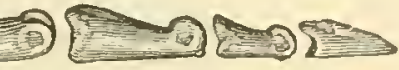

$\stackrel{8}{8}$

$+\lim ^{\circ}$

$\dot{0}$

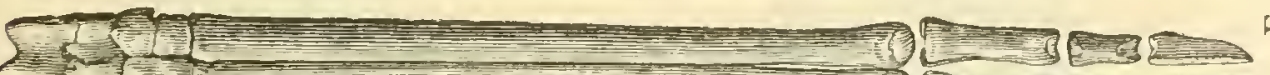

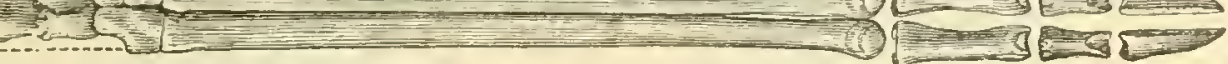
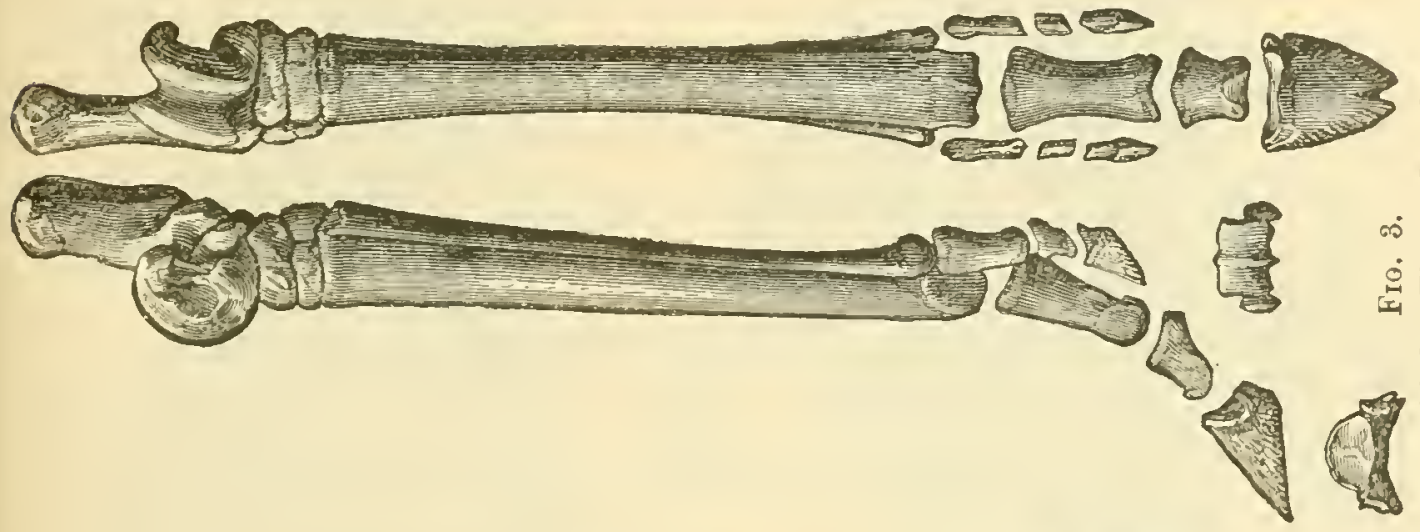

का की

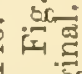

$\dot{8} \cdot \overrightarrow{2}$

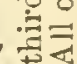

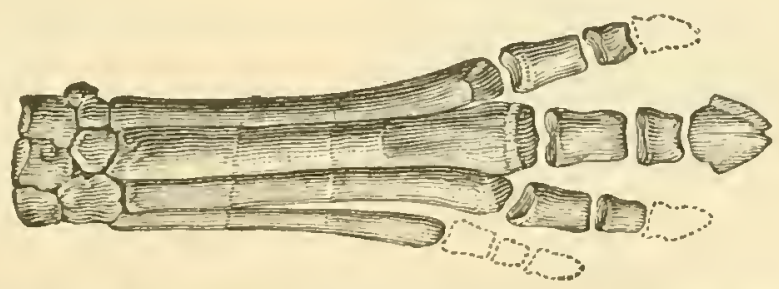

हi

은

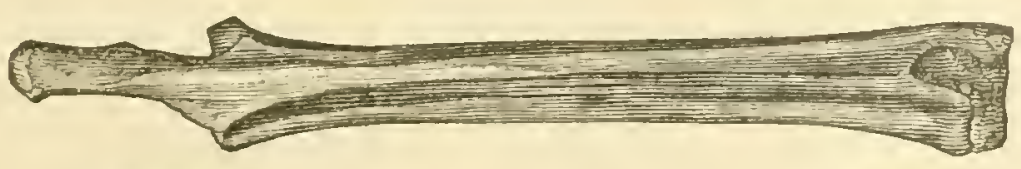

$-\therefore 8$

을

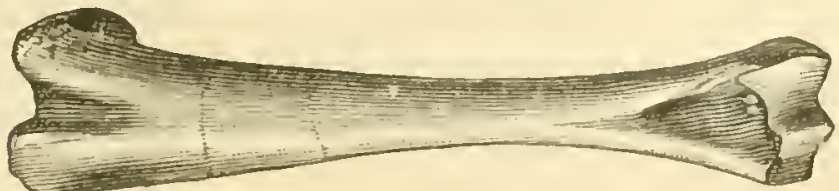


smooth convexity to the hollow of the applied heel-bone behind. No such astragalus has ever been found in the Lower Eocene formations of America ; animals bearing it in a less perfect stage appear in the next higher period, the Miocene; but it is not until the Pliocene and modern times that they abound. In the Hippopotamus foot, we have an example of the less perfect astragalus of this type of animals. The pulley surfaces are flatter and less deeply grooved.

In the horse, the upper surface of the astragalus forms as perfect

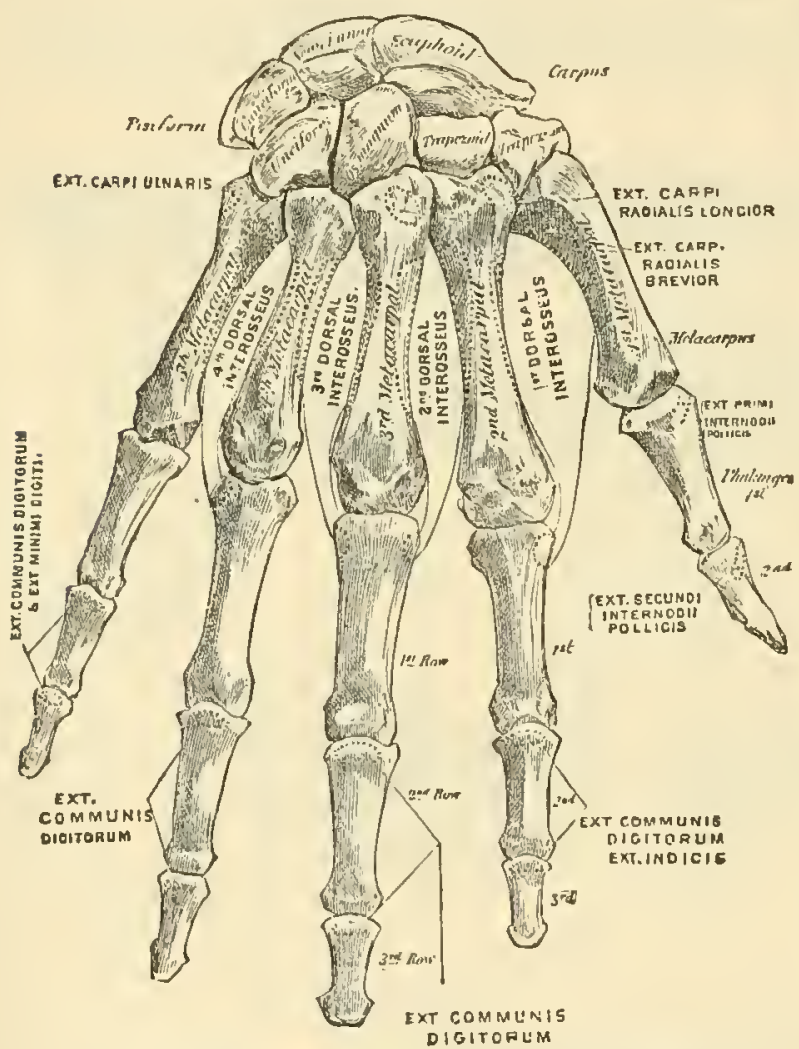

Fig. 49.-Anterior foot of Homo sapiens from above, one third natural size. From Allen's Anatomy.

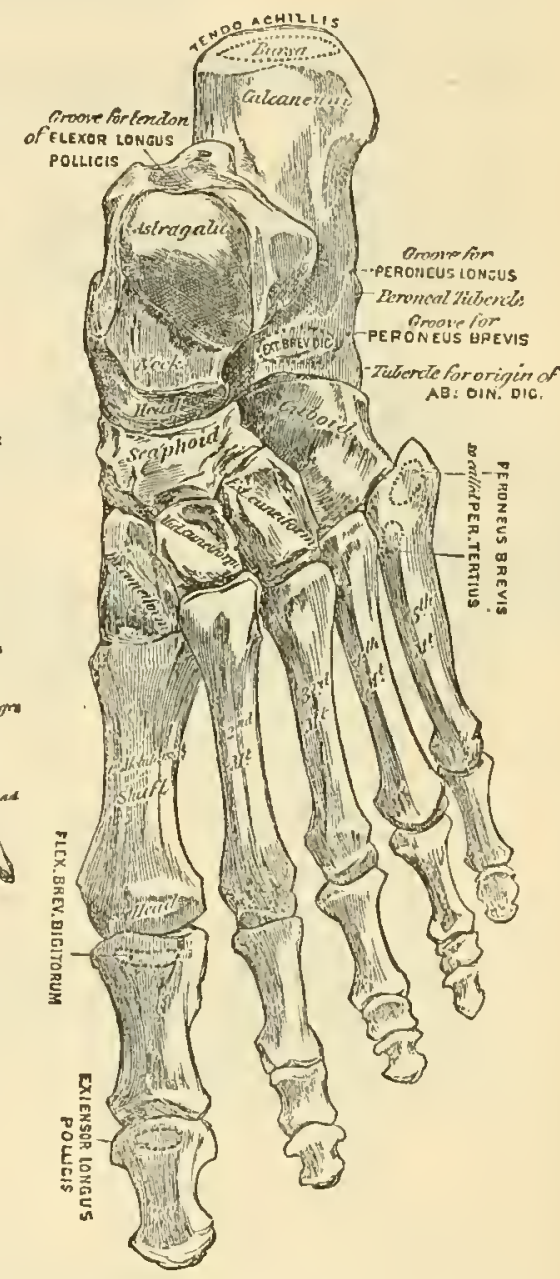

Fia. 50.-Posterior foot of do. from above, one third natural size. From Allen's Anatomy.

a joint as in ruminants, but the lower and hinder faces present the flattened surfaces which belong to the many-toed Mammalia. The lower face especially is mainly occupied by one large facet, instead of the two-faced pulley of the ruminants. In the rhinoceros a later facet is more distinct, while in the Miocene Menodus the second facet is larger, resembling, except in the still convex tibial articulation, the structure of that of the primitive Coryphodon. 
In the heel-bone we have a snccession from the short and flat form of Coryphodon to the long and slender one of the horse and ruminants; the increase in length being associated with the elongation of the bones of the toes, and the assumption of the digitigrade type from the plantigrade. The mammals of the Lower Eocene * exhibit a greater percentage of types that walk on the entire sole of the foot, while the succeeding periods exhibit an increasing number of those that walk on the toes, while the hoofed animals and Carnivora of recent times, nearly all have the heel high in the air, the principal exceptions being the elephant and the bear families.

A most noticeable succession is seen in the diminution of the number of toes. In the series leading to the horse, the ox, and the hyæna and cat, this reduction proceeds by the loss of a toe from the one side or the other, until in the ruminants but two are left, and in the horse but one. 'The series extending from the primitive Eocene types with five digits, to the existing reduced forms, is most complete, although a few of the New Mexican Eocene genera themselves probably exhibit but four

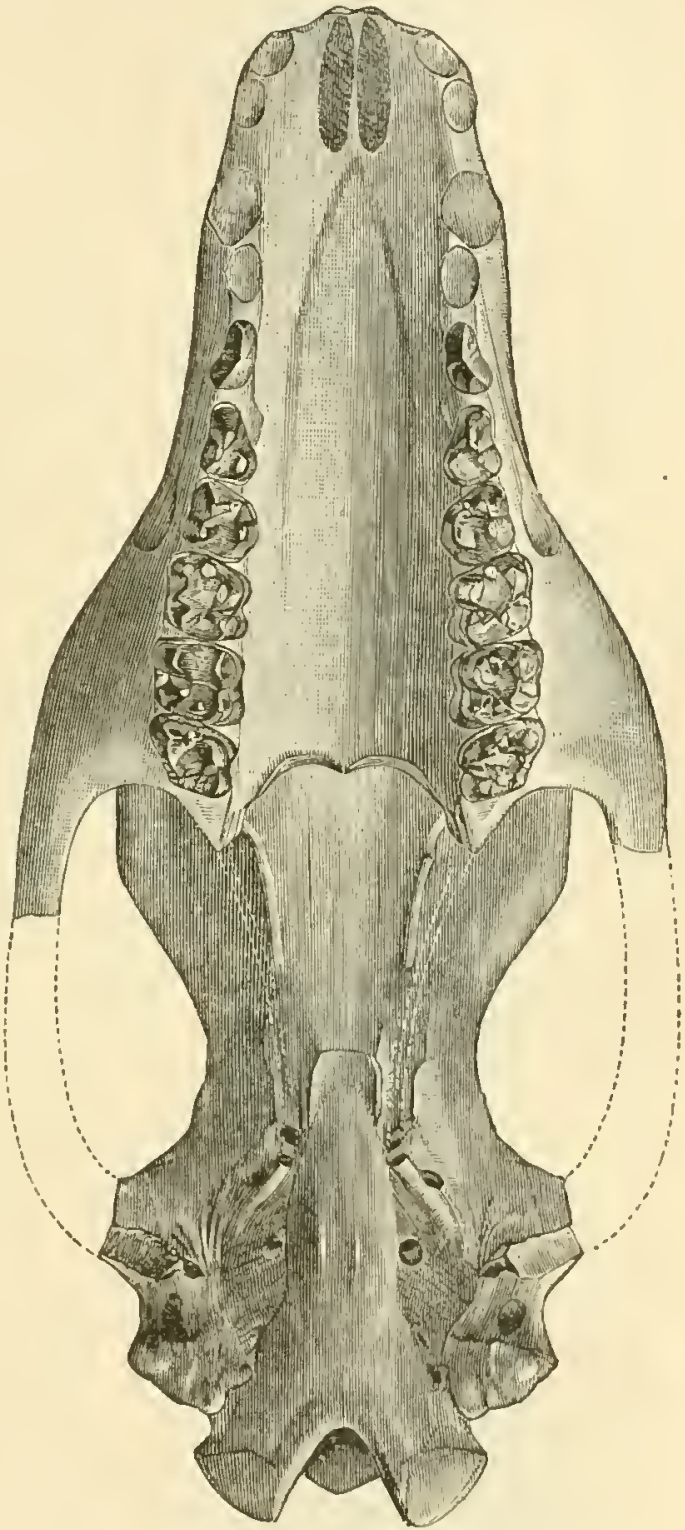

Fio. 51.-Phenacodus primcevus skull, one third natural size, from below, showing quadritubereular true molars. From specimen figured on plate. digits on one or both pairs of feet. The presence of the rudiments

* All the Mammalia of the Puereo fauna (which was unknown at the time this leeture was delivered) are plantigracie. (Ed. 1886.) 
of the lost lateral digits is constantly observed, and when these disappear it is to be finally replaced by the rudiments of the adjoining toes in process of similar reduction. The bones of the second row of the tarsus which are in connection with the toes are not reduced so rapidly as the toes themselves; hence, the bones of the toes, in order to maintain the fit of the parts, increase in width, and consequently in strength. As is well known, in the horse the single toe is as stout as several united toes of lower forms, and the two toes of the ruminants hare their basal segments (metatarsals) united into a stout solid mass, the cannonbone. At the same time several of the small bones of the second tarsal row become coössified, so that we have, in the ruminants and horse, the greatest consolidation of structure, connected in the former with the most elegant mechanism. It is scarcely necessary to add that, in the varions cases of coössification and consolidation described, the fœtus displays the original elements separated.

In the fore limb the same successional reduction in the number of toes may be traced as I have described in the hind foot; but, as the bones of the palm differ from those of the sole, the snccessional modification of these is also characteristic. The bones of the second row of the carpus are four in number, but as the toes are reduced, in the lines of the hoofed animals, the inner (trapezium) is soon dropped, and the second (trapezoides) becomes united with the third (magnum). In the carnivorous order, the trapezoides is always separate, but the inner pair of bones of the first row (scaphoid and the lunar) become consolidated into a single mass, although their original distinctness is easily determined by examination of the foetus.

The two bones of the leg which articulate with the foot and hand, exhibit a suceession of changes of relation in progress toward the more specialized types. In the Coryphodon and Uintatherium of the Eocene, each of these bones has considerable share in the articulation; but as we rise in the series, the surface of attachment of the lesser bones, the fibula in the foot, and the ulna in the hand, becomes sncessively smaller, until in the ruminants the fibula is almost obliterated, its distal end remaining as a small tuberosity coössified to the side of the end of the tibia. In the same manner the articular end of the nlna in the fore leg is successively reduced, until this bone also becomes a thin strip coössified to the lower side of the radius, with no distinct termination, 


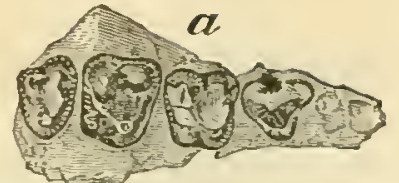

Fio. 1.

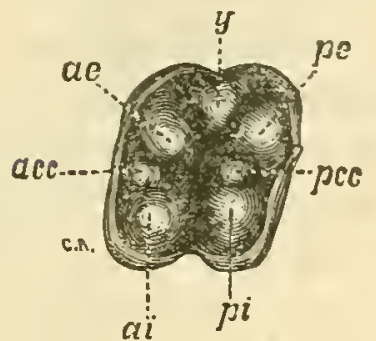

FIG. 3.

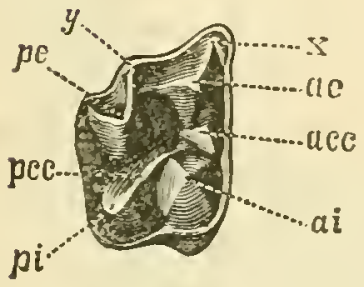

Fra. 5.

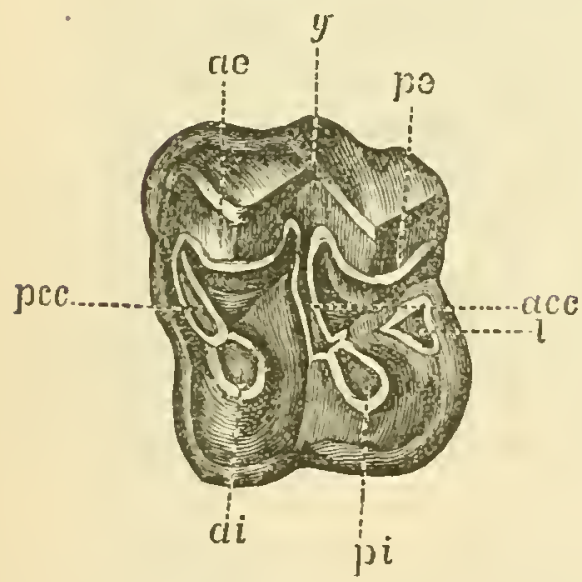

FIG. 7.

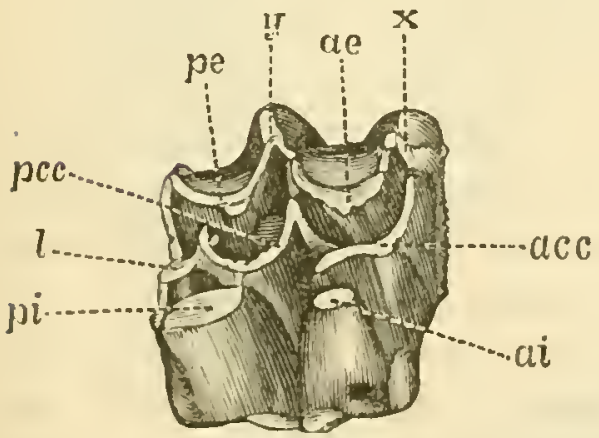

Fro. 9.

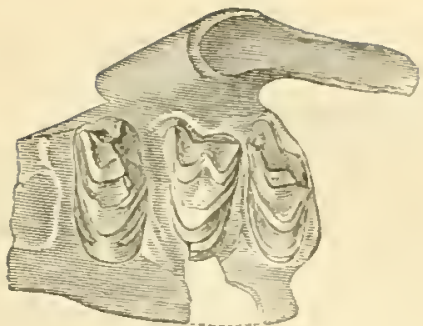

Fig. 2.

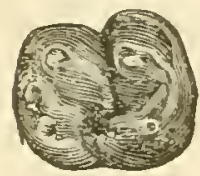

FIG. 4.

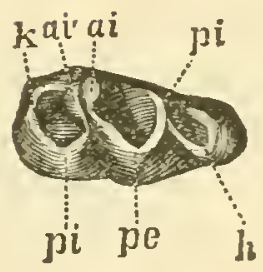

Fro. 6.

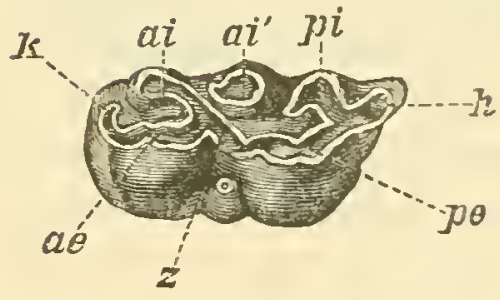

Frg. 8.

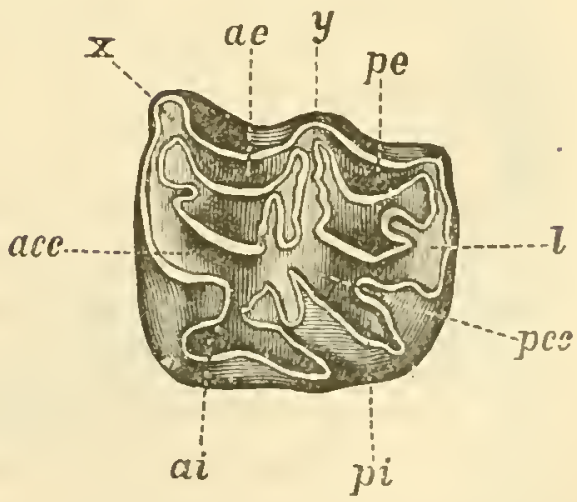

Fia. 10

Fig. 1, Minclaenus corrugatus, superior molars. Fig. 2, Pantolambdn linthmodon, superior true molars. Fig. 3, Phenacodus primavus, superior molar. Fig. 4. do, interior molar. Fitr. 5, Lambdotherium popoagicum, superior molar. Fig. 6, do, inferior molar. Fig. 7, Anchitherium aurelianense, superior molar. Fig. 8, Hippotherium gracile, inferior molar. Fig. 9, superior molar young crown of a Hippotherium. Fig. 10, superior molar of Equus. Figs. 1, 2, 5, 6, from Cope; 3,4, from Wortman; the others trom Graudry. 
in both the horse and the ox. In the fœtus these bones are well distinguished.

The dentition tells as clearly as possible the same story. Here, again, as I have pointed out in a paper on the "Homologies and Origin of the Types of Dentition of the Mammalia Educabilia," the most specialized forms of dental structure are presented by the horse, the ox, and the tiger. But they are all modifications of a single type of tooth, viz., an oval crown supporting four tubercles on the summit, in the lower jaw, and three or four in the upper jaw. In the lower eutting molar of the cat but one of these tubercles remains, forming with another in front of it a double shear blade, whose development may be traced from its earliest beginnings in the genera of the Eocene. In the odd-toed forms (tapir, rhinoceros, ete.) the tubercles become conneeted transversely, forming cross-erests, and the outer ones are generally flattened on the outer side. In the horse the tubereles have a very complex form, and the spaces between them filled by a peculiar substance, the cementum. In the ruminants the tubercles come to have a crescent-shaped seetion and are drawn out to an enormous length, forming a prismatic tooth : here, also, the intervening deep valleys are filled with cementum. In the third serics, that of the elephant, the original tubercles (permanently separate in the mastodons) are connected into cross-crests, which are drawn out to a great length, and as in the other scries are supported by a deposit of hard cementum in the intervening valleys. The transitions between these and the primitive four-tubereled molar are numerous and direct.

There is not now opportunity to eonsider the question of transition from type to type by descent, further than to indicate by a few examples the manner in which it has evidently oecurred. This has been by unequal growth of parts during fotal life, according to the laws of acceleration and retardation. The union of the two basal bones of toes into a single one (the "cannonbone") in the ruminants, is accomplished by the more and more rapid completion of the process of ossification in the growth of those bones; the eonfluence of the various carpal and tarsal bones in various orders has the same history. In many genera it has been observed that the milk dentition has resemblances to other and older dentitions, which entirely disappear in the permanent teeth. This is the case with Coryphodon and Equus; while it may be observed in the kitten, whose sectorial milk-tooth has the 


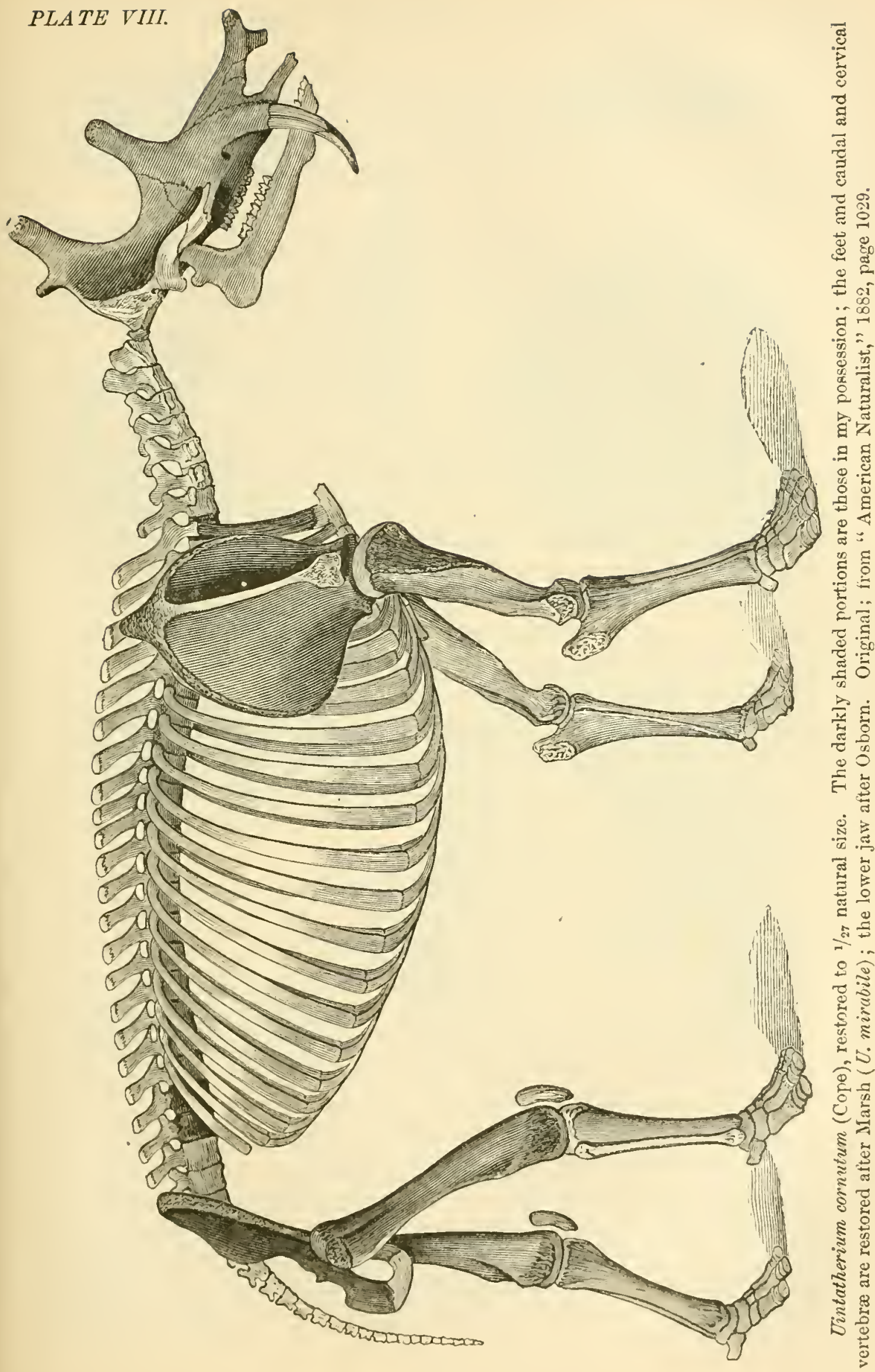


heel belonging to all the lower and primitive Carnivora which is wanting from the sectorial of the adult cat. Moreover, in complex teeth, the different stages of wear represent primitive conditions of the same animal, elsewhere preserved to us in extinct adult genera and species.

Forms which violate the definitions of the orders above given are also well known. 'Thus Mesonyx, with the skull and dentition of a carnivore, has the separate scaphoid and lunar bones and flat claws or hoofs of an ungulate. Calamodon has the molars of an ungulate, the incisors of a rodent, and claws resembling somewhat those of a carnivore. Uintatherium lias feet partly like an elephant, and teeth of a tapir.

I have referred the Mammalia with five and four toes, the full number of distinct tarsal and carpal bones, which form interlocking series, and in which the tread is plantigrade, to a new order called the Amblypoda. 'These represent the primitive type of the higher Mammalia with convoluted brains, ete., but present much variation in the constitution of the teeth. From the latter have come off not only the three hoofed-orders represented by the elephant, the horse, and the ox, but the origin of the Carnivora and Quadrumana is searcely distinguishable from it, if at all; while there is little doubt that the natatory Sirenian order was derived from it by a process of degradation, chiefly of the extremities, in connection with the assumption of an aquatic life. The manatee, of which a fine example may now be seen in our zoölogical gardens, represents this division.

The relation of man to this history is highly interesting. Thus in all general points his limbs are those of the primitive type so common in the Eocene. He is plantigrade, has five toes, separate carpals and tarsals; short heel, rather flat astragalus, and neither hoofs nor elaws, but something between the two. The bones of the forearm and leg are not so unequal as in the higher types, and remain entirely distinet from each other, and the ankle-joint is not so perfect as in many of them. In his teeth his character is thoronghly primitive. He possesses, in fact, the original quadrituberenlate molar with but little modification. His structural superiority consists solely in the complexity and size of his brain. The forms of the quadrumanous order, while agreeing with each other in most respects, display the greatest range of brain structure, and show that while they have made but little progress sinee the Eocene in perfection of organization of the skeleton, they 

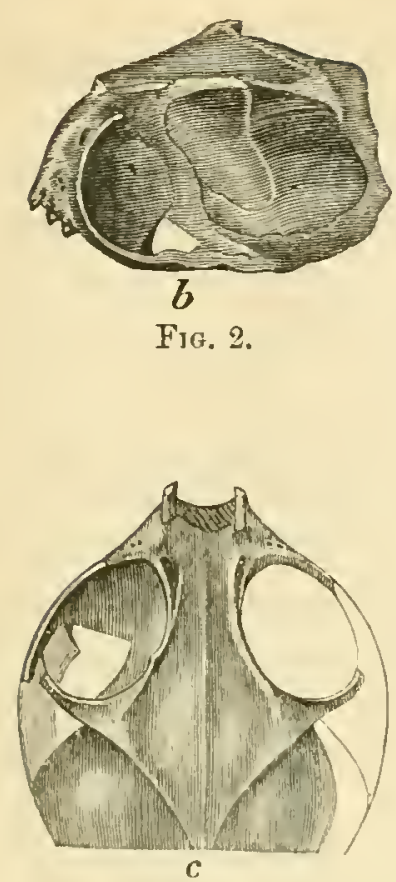

FiG. 3.

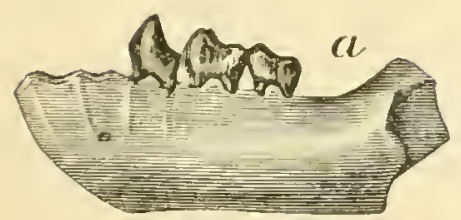

Fia. 5 .

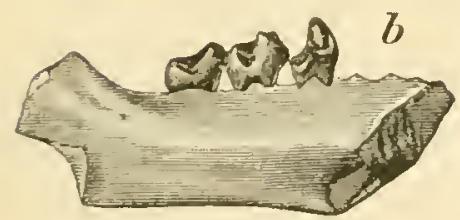

FIG, 6.

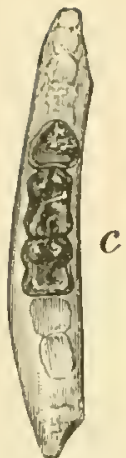

Fig. 7.

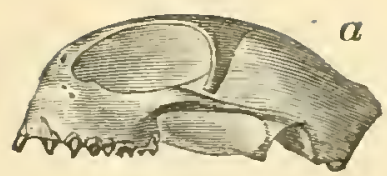

FIG. 1.

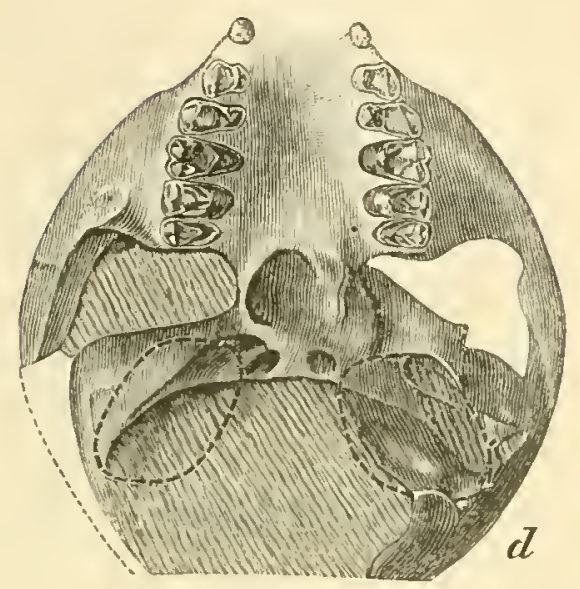

Fig. 4.

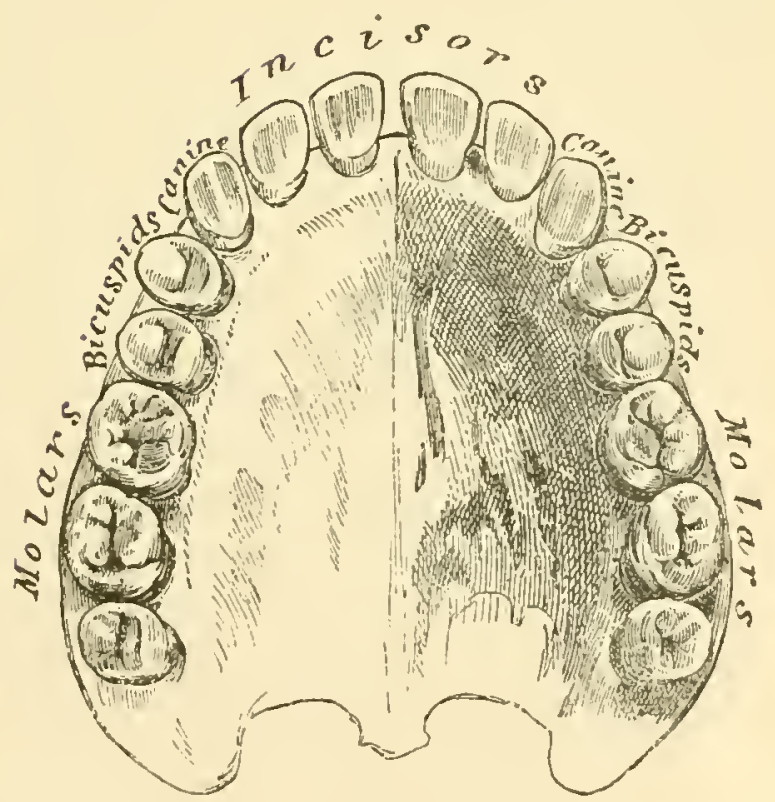

FIG. 8.

Comparison between tue Dentition of the Lemur Anaptomomplies axt Man.

Fig. 1, slull of Anaptomorphus homunculus, natural size. Fig. 2, same, oblique view, clisplaving the large cerebral hemispheres; eompare Plate IIV for velatively small size in a eontemporary (Fig. 3) or a successor in time (Fig. 2). Fig. 3, superior view of skull, natural size. Fig. 4 , inferior view, $3 / 2$ natural size. Figs. 5 , 6 , and 7 , left braneh of lower jaw of Anaptomorphus amulus, twiee natural size; 5, from left sicle; 6 , inner side; $;$, from above. Fig. 8 , superior dentition of Homo sapiens (from Allen), natural size. 
accomplished a much greater work, the evolution of the human brain and its functions.

A very important lesson is derived from these and kindred facts. The monkeys were anticipated in the greater fields of the world's aetivity by more powerful rivals; the ancestors of the ungulates held the fields and the swamps, and the Carnivora, driven by hunger, learned the arts and cruelty of the chase. The weaker ancestors of the Quadrumana possessed neither speed nor weapons of offense and defense, and nothing but an arboreal life was left them, where they developed the prehensile powers of the feet. Their digestive system unspecialized, their food various, their life the price of ceaseless vigilance, no wonder that that quality of inquisitiveness and wakefulness was stimulated and developed which is the condition of progressive intelligence. So "the race has not been to the swift nor the battle to the strong"; the "survival of the fittest" has been the survival of the most intelligent, and natural selection proves to be, in its highest animal phase, intelligent selection. 
IX.

\section{THE DEVELOPMENTAL SIGNIFICANCE OF HUMAN PHYSIOGNOMY.*}

THE ability to read character in the form of the human face and figure is a gift possessed by eomparatively fer persons, althongh most people interpret, more or less correctly, the salient points of human expression. The transient appearanees of the face reveal temporary phases of feeling which are common to all men ; but the constint qualities of the mind should be expressed, if at all, in the permanent forms of the executive instrument of the mind, the body. To detect the peeuliarities of the mind by external marks has been the aim of the physiognomist of all times; but it is only in the light of modern evolutionary science that much progress in this direction ean be made. The mind, as a function of part of the body, partakes of its perfections and its defeets, and exhibits parallel types of development. Every peenliarity of the body has probably some corresponding significance in the mind, and the causes of the former are the remoter causes of the latter. Hence, before a true physiognomy ean be attempted, the origin of the features of the face and general form must be known. Not that a perfect physiognomy will ever be possible. A mental constitution so complex as that of man can not be expected to exhibit more than its leading features in the body ; but these include, after all, most of what it is important for us to be able to read from a practical point of view.

The present essay will consider the probable origin of the structural points which constitute the permànent expression. These may be divided into three heads, viz. : (1) Those of the general form or figure; (2) those of the surface or integnment of the body with its appendages; and (3) those of the forms of the

* Abstract of a lecture delivered before the Franklin Institute of Philadelphia, January 20, 1881, in exposition of principles laid down in "The IIypothesis of Evolution," New Ilaren, 1870, p. 31. 
head and face. The prineipal points to be considered under each of these heads are the following:

\section{The General Form.}

1. The size of the head.

2. 'The squareness ol slope of the shoulders.

3. The length of the arms.

4. The constriction of the waist.

5 . The width of the hips.

6. The length of the leg, principally of the thigh.

7. The sizes of the hands and feet.

8. The relative sizes of the muscles.

\section{The Surfaces.}

9. The structure of the hair (whether curled or not).

10. The length and position of the hair.

11. The size and shape of the nails.

12. The smoothness of the skin.

13. The color of the skin, hair, and irides.

\section{The Head and Face.}

14. The relative size of the cerebral to the facial regions.

15. The prominence of the forehead.

16. The prominence of the superciliary (eyebrow) ridges.

1\%. The prominence of the alveolar borders (jaws).

18. The prominence and width of the chin.

19. The relation of length to width of skull.

20. The prominence of the malar (cheek) bones.

21. The form of the nose.

22. The relative size of the orbits and eyes.

23. 'The size of the month and lips.

The significance of these, as of the more important structural characters of man and the lower animals, must be considered from two standpoints, the paleontological and the embryological. The immediate paleontological history of man is unknown, but may be easily inferred from the characteristics displayed by his nearest relatives of the order Quadrumana. If we compare these animals with man, we find the following general differences. The numbers correspond to those of the list above given. 
I. As to General Form.-(3) In the apes the arms are longer; (8) the extensor muscles of the leg are smaller.

II. As to Surface.-(9) The body is covered with hair which is not crisp or woolly; (10) the hair of the head is short; (13) the color of the skin, etc., is dark.

III. As to Head and Face.-(14) The facial region of the skull is large as compared with the cerebral ; $(15)$ the forehead is

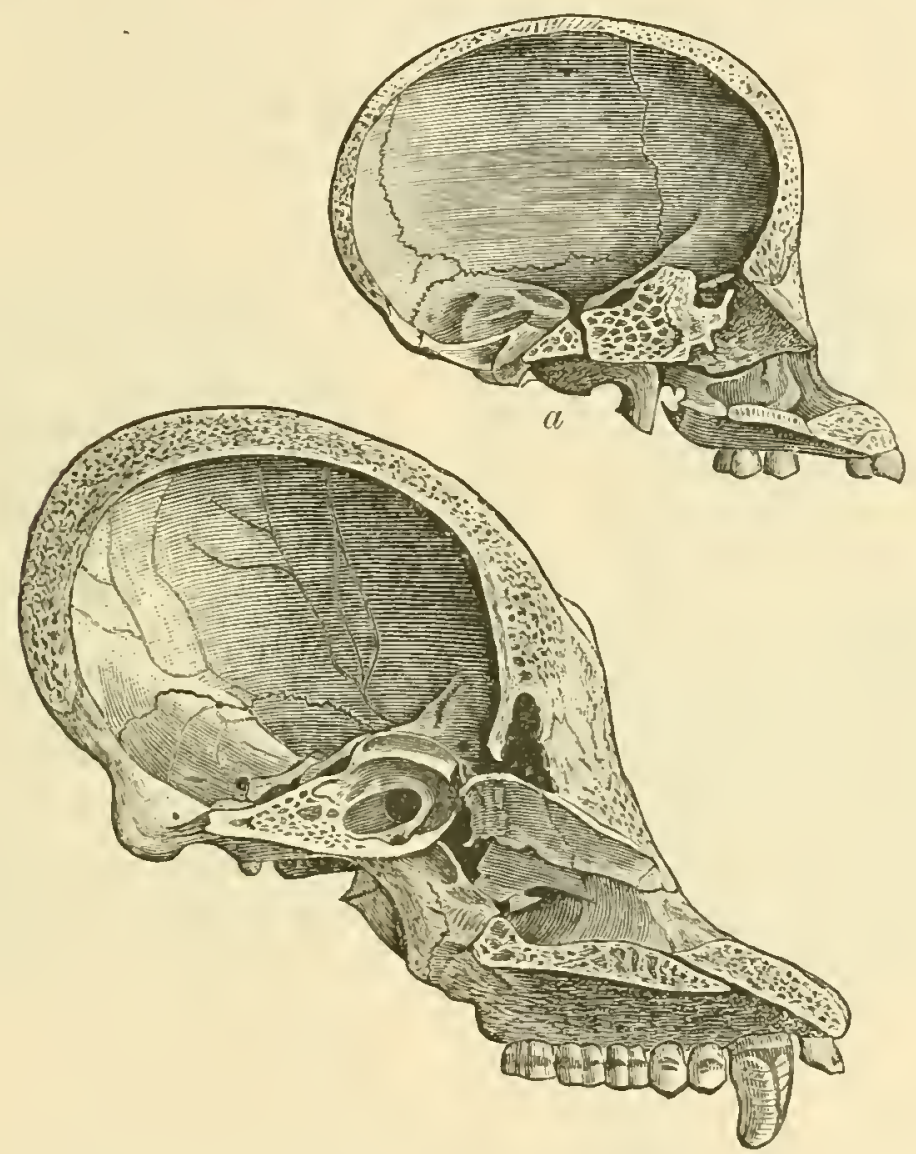

Fis. 52.-Section of sliull of adult orang-outang (Simia satyrus). a, section of skull of young orang, showing relatively shorter jaws and more prominent cerebral regrion.

not prominent, and is generally retreating; (16) the supereiliary ridges are more prominent; $(1 \%)$ the edges of the jaws are more prominent; (18) the chin is less prominent; (20) the cheek-bones are more prominent; (21) the nose is without bridge, and with short and flat cartilages; (22) the orbits and eyes are smaller (except in Nyetipithecus) ; (24) the mouth is small and the lips are thin.

It is evickent that the possession of any one of the above characteristies by a man approximates him more to the monkeys, so 
far as it goes. He retains features which have been obliterated in other persons in the process of evolution.

In considering the physiognomy of man from an embryological standpoint, we must consider the peculiarities of the infant at birth. The numbers of the following list correspond with those already used (Fig. 53).

I. As to the General Form.-(1) The head of the infant is relatively much larger than in the adult; (3) the arms are relatively

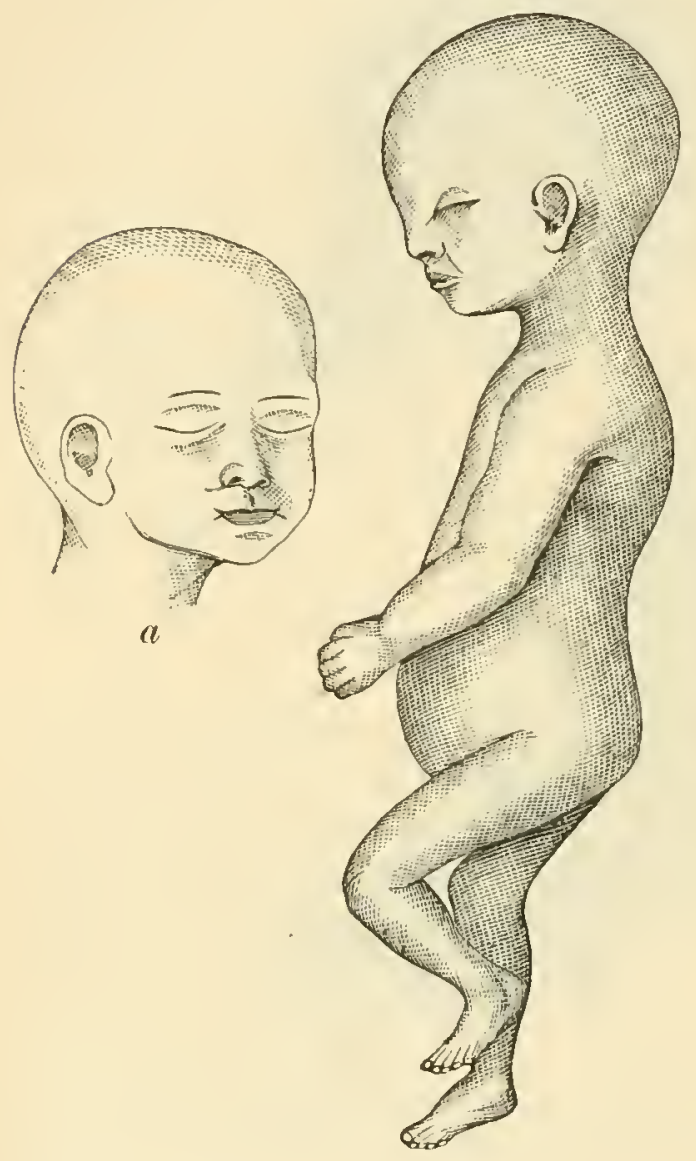

F19. 53.-Figure of infant at birth; $a$, front of face. longer ; (4) there is no waist; (6) the legs, and especially the thighs, are much shorter.

II. As to the Surfaces.(10) The body is covered with fine hair, and that of the head is short.

III. The Head and Face. -(14) The cerebral part of the skull greatly predominates over the facial; (16) the superciliary ridges are not developed; $(1 \%)$ the alveolar borders are not prominent; (20) the malar bones are not prominent; (21) the nose is without bridge and the cartilages are flat and generally short; (22) the eyes are larger.

It is evident that persons who present any of the characters cited in the above list are more infantile or embryonic in those respects than are others; and that those who lack them have left them behind in reaching maturity.

We have now two sets of characters in which men may differ from each other. In the one set the characters are those of monkeys, in the other they are those of infants. Let us see whether there be any identities in the two lists, i. e., whether there be any of the monkey-like characters which are also infantile. We find the following to be such : 
I. As to General Form.-(3) The arms are longer.

II. Surface - (10) The hair of the had is short, and the hair on the body is more distributed.

III. As to Head and Face.-(21) The nose is without bridge, and the cartilages are short and flat.

Three characters only ont of twenty-three. On the other hand, the following characters of monkey-like significance are the opposites of those included in the embryonic list : (14) The facial region of the skull is large as compared with the cerebral ; (15) the forehead is not prominent; (16) the superciliary ridges are more

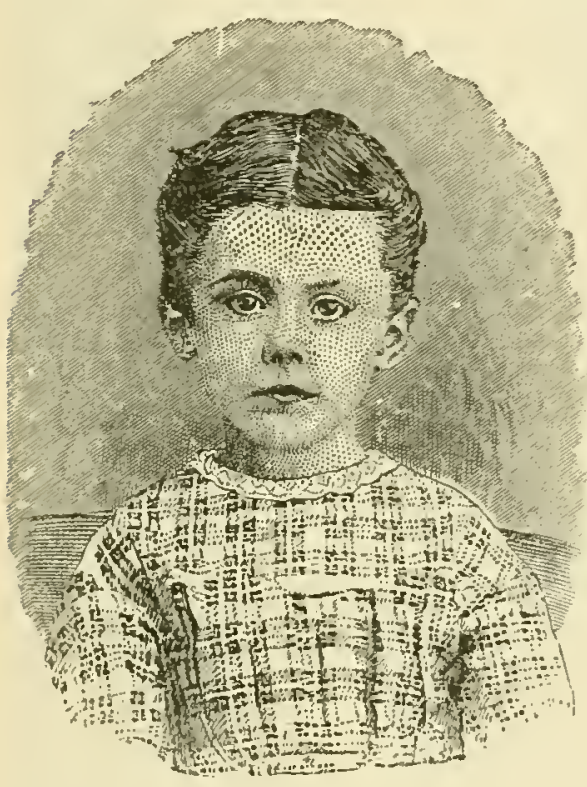

EIG. 54.

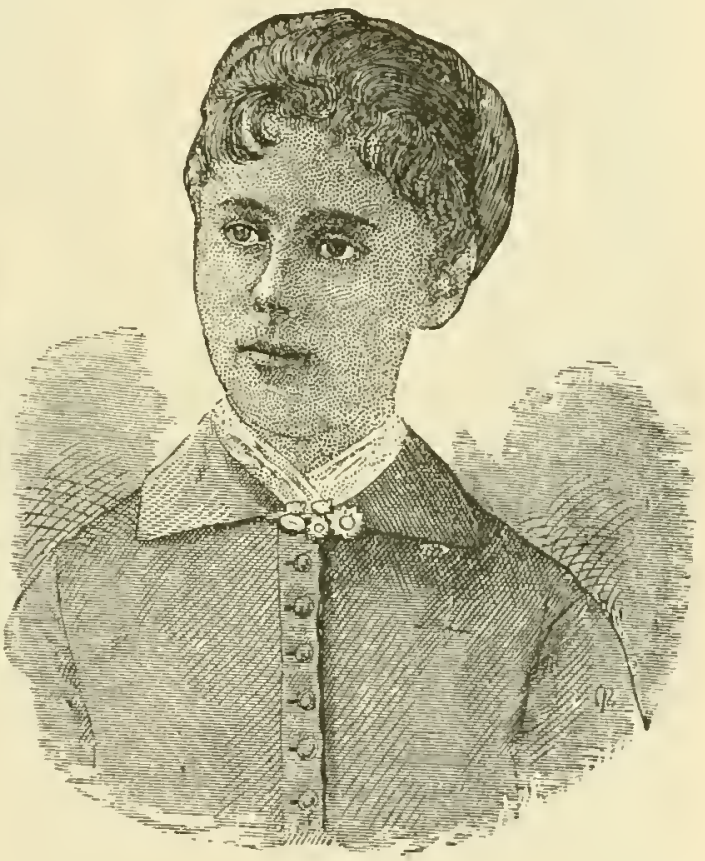

ห่เ. 5๊๊.

FIG. 54.-Portrait of a girl at five years of age. FIG. 55.-Portrait of the same at seventeen years, showing the elongation of the facial region, and less protuberance of the cerebral.

prominent ; $(17)$ the edges of the jaws are more prominent. Four characters, all of the face and head. It is thus evident that in attaining maturity man resembles more and more the apes in some important parts of his facial expression.

It must be noted here that the difference between the young and embryonic monkeys and the adults is quite the same as those just mentioned as distinguishing the young from the adult of man (Figs. 1-2). 'The change, however, in the case of the monkeys is greater than in the case of man. That is, in the monkeys the jaws and supereiliary ridges become still more prominent than in 
PLATE $X$.

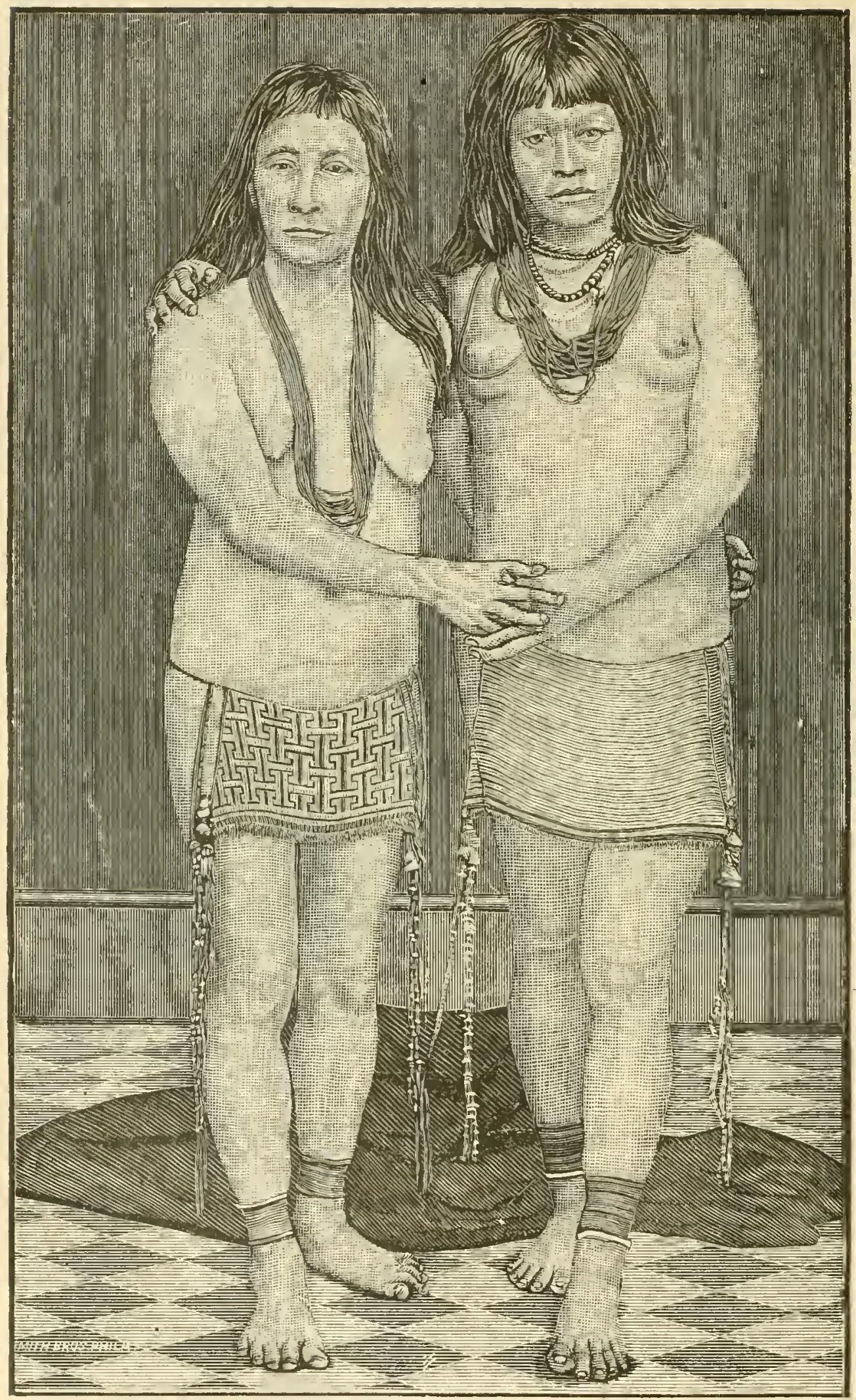

Esequibo Indian women, showing the following peculiarities: deficient bridge of nose, prognathism, no waist, and deficiency of stature through short femur. From photographs by Eudlich. 
man. As these characters result from a fuller course of growth from the infant, it is erident that in these respects the apes are more fully developed than man. Man stops short in the development of the face, and is in so far more embryonic.* The prominent forehead and reduced jaws of man are characters of "retardation." The charaeters of the prominent nose, with its elevated bridge, is a result of "acceleration," since it is a superaddition to the quadrumanous type from both the standpoints of paleontology and embryology.t The development of the bridge of the nose is no doubt directly connected with the development of the front of the cerebral part of the skull and ethmoid bone, which sooner or later carries the nasal bones with it.

If we now examine the leading characters of the physiognomy of three of the principal human sub-species, the Negro, the IIon-

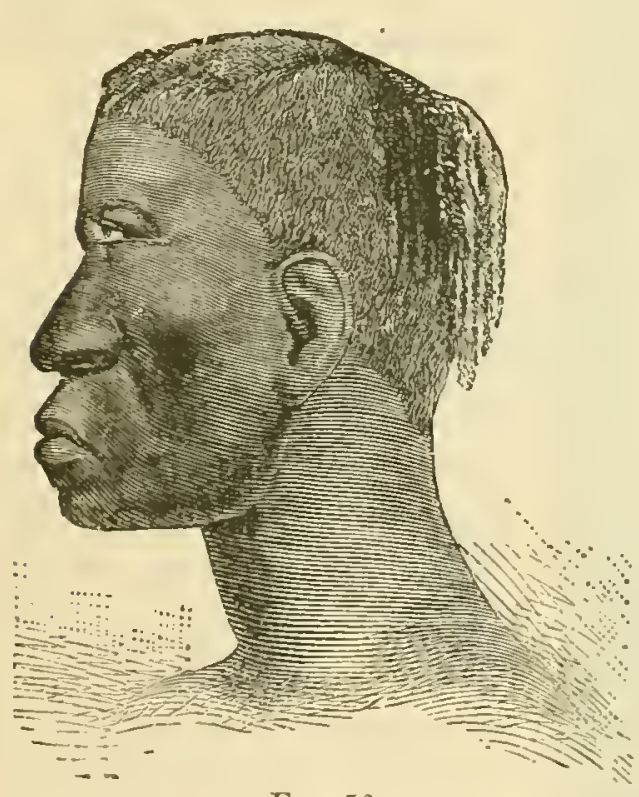

FIG. 56.

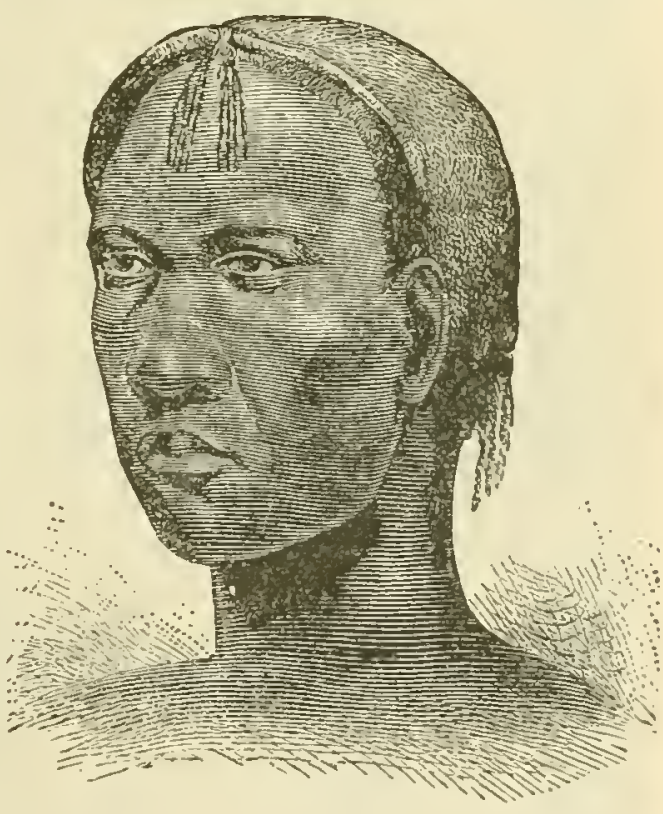

FIG. 5ว

Fia. 56.-Profile of a Lueliatze negro woman, showing defieient bridge of nose and chin, and clongate facial region and prognathism. Frg. 57.-Face of auother Luchatze, showing flat nose, less proguathism and larger cerebral region. From Serpa Pinto.

golian, and the Indo-European, we can readily observe that it is in the two first named that there is a predominance of the quadrumanous features which are retarded in man ; and that the embryonic characters which predominate, are those in which man is

* This fact has been well stated by C. S. Jinot, in the "Naturatist" for 1882, p. 511.

† Sec Cope, "The Ilypothesis of Erolution," New IIaren, 1870, p. 31. 
accelerated. In race description the prominence of the edges of the jaws is called prognathism, and its absence orthognathism. The significance of the two lower race characters, as compared with those of the Indo-European, is as follows :

Negro.-Hair crisp (a special eharaeter), short (quadrmm. accel.) ; prognathous (quadrum. accel.) ; nose flat, withont bridge (quadrum. retard.) ; * malar bones prominent (quadrum. accel.); beard short (quadrum. retard.); arms longer (quadrum. accel.); extensor muscles of legs small (quadrum. retard.).

Mongolian.-Hair straight, long (accel.) ; jaws prognathous (quadrum. accel.); nose flat or prominent, with or without bridge ;

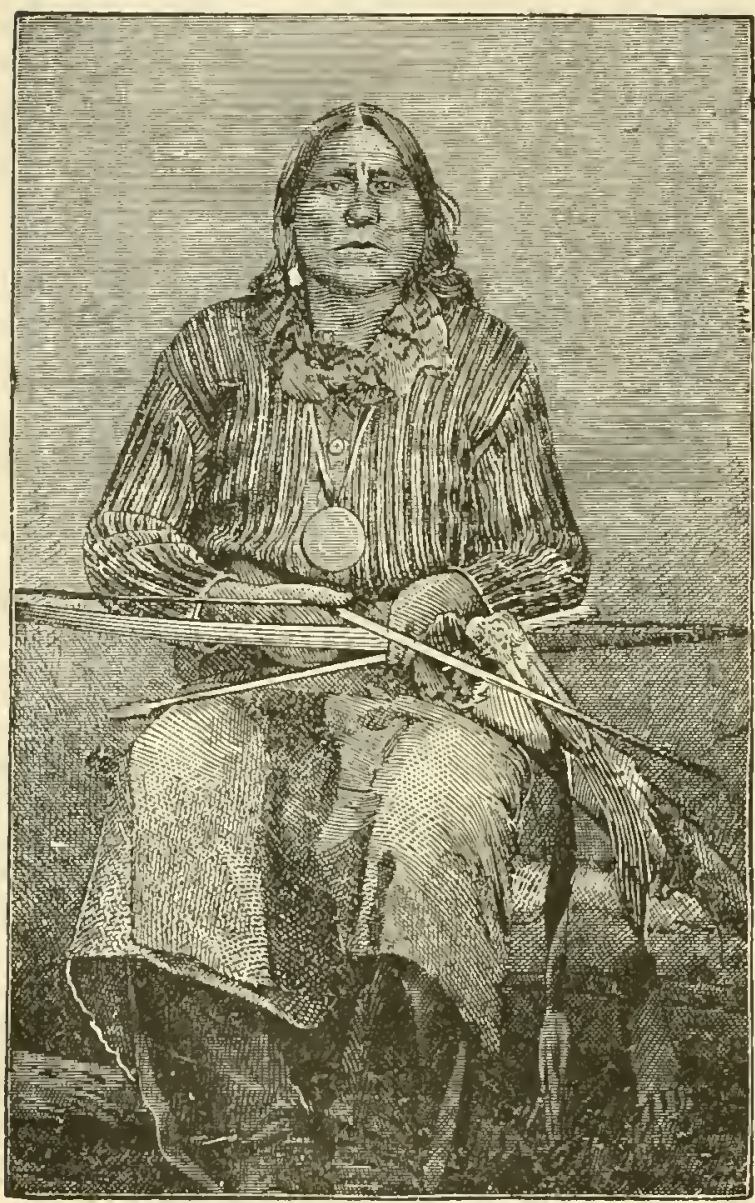

Fig. 58.-Portrait of Satanta, a late chief of the Kiowas (fiom the Red River of Texas), from a photograph. The predominance of the faeial region, and especially of the malar bones, and the absence of beard, are noteworthy. malar bones prominent (quadrum. accel.) ; beard none (embryonic); arms shorter (retard.); extensor museles of leg ("calf") smaller (quad. retard.).

Indo-European.-Hair long (accel.); jaws orthognathous (embryonic retard.); nose (generally) prominent with bridge (accel.) ; malar bones reduced (retard.); beard long (accel.); arms shorter (retard.); extensor muscles of the leg large (accel.).

The Indo-European race is then the highest by virtue of the acceleration of growth in the development of the muscles by which the body is maintained in the erect position (extensors of the leg), and in those important elements of beanty, a welldeveloped nose and beard.

* In the Boelimans, the flat nasal bones are coössified with the adjacent elements as in the apes (Tluulié). 
PLATE XI.

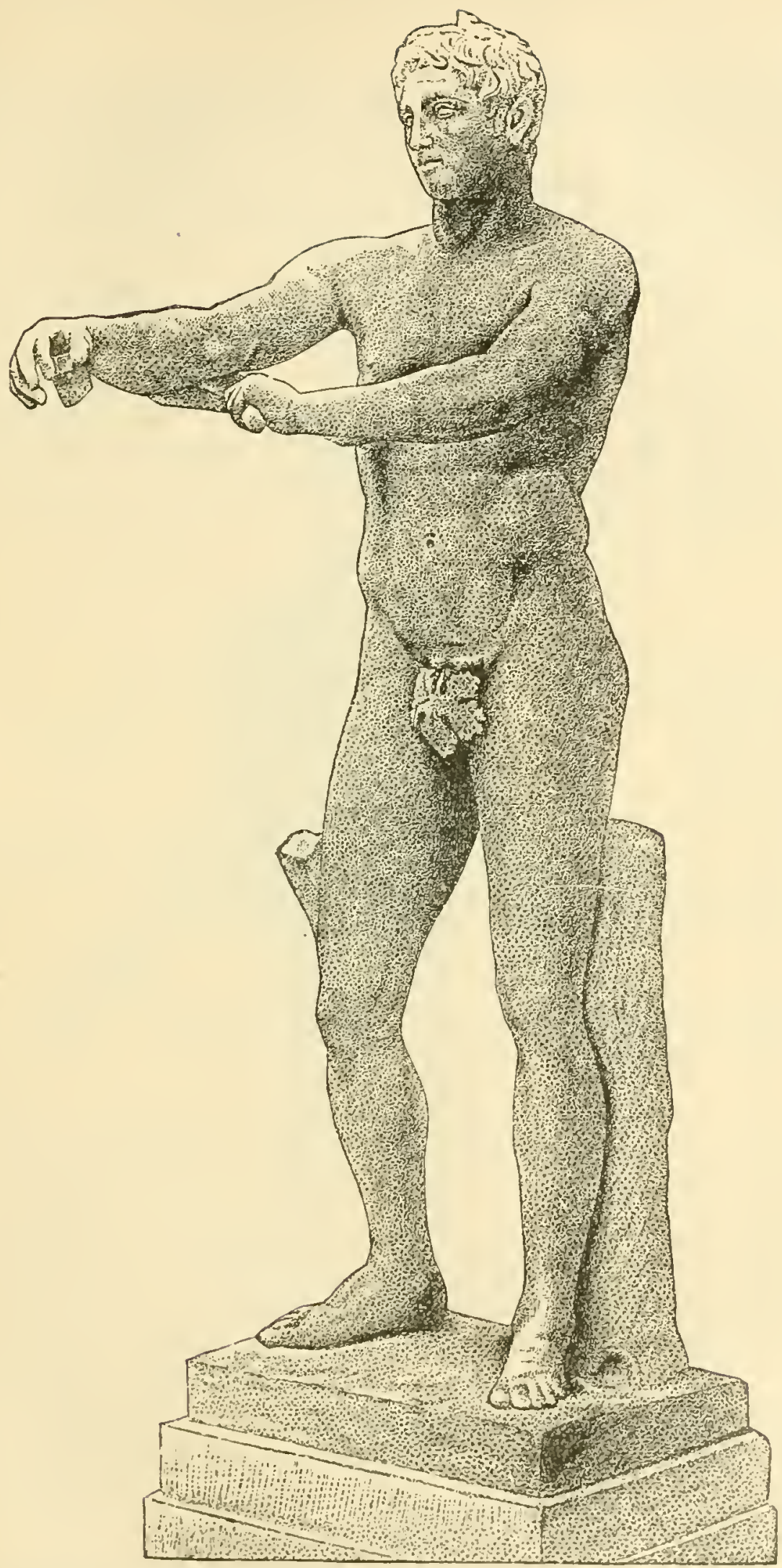

The Wrestrer; original in the Vatican. This figure displays the challacters of the male Indo-Europenn, execpt the beard. 
It is also superior in those points in which it is more embryonic than the other races, viz., the want of prominence of the jaws and cheek-bones, since these are associated with a greater predominance of the cerebral part of the skull, increased size of cerebral hemispheres, and greater intellectual power.

A comparison between the two sexes of the Indo-Europeans expresses their physical and mental relations in a definite way. I select the sexes of the most civilized races, since it is in these, according to Broca and Topinard, that the sex characters are most pronounced. They may be contrasted as follows. The numbers are those of the list on page 282, already used. I first consider those which are used in the tables of embryonic, quadrumanous, and race characters :

MALE,

\section{The General Form.}

FEMALE,

2. Shoulders square.

4. Waist less constricted.

5. Hips narrower.

6. Legs longer.

8. Muscles larger.
Shoulders sloped.

WVaist more constricted.

IIips wider.

Legs shorter (very frequently).

Muscles smaller.

\section{The Intrguments, etc.}

10. More hair on body, that of head Less hair on body, that of head longer; shorter; beard.

12. Skin rougher (generally). no beard.

- Skin smoother.

III. The Head and Face.

16. Superciliary ridges more prominent. Superciliary ridges low.

22. Eyes often smaller.

Eyes often larger.

The characters in which the male is the most like the infant are two, viz., the narrow hips and short hair. 'Those in which the female is most embryonic are five, viz., the shorter legs, smaller muscles, absence of beard, low supereiliary ridges, and frequently larger eyes. To these may be added two others not mentioned in the above lists ; these are (1) the high-pitched voice, which never falls an octave as does that of the male; 'and (2) the structure of the generative organs, which in all Mammalia more nearly resemble the embryo and the lower Vertebrata, in the female than in the male. Nevertheless, as Bischoff has pointed out, one of the most important distinctions between man and the apes is to be found in the external reproductive organs of the female.

From the preceding summary sketch the reader will be able to explain the meaning of most of the peculiarities of face and form 
which he will neet with. Many persons possess at least one quadrumanous or embryonic character. The strongly convex upper lip frequently seen among the lower classes of the Irish is a modified quadrumanous character. Many people, especially those of the Sclavic races, have more or less embryonic noses. A retreating chin is a marked monkey character. Shortuess of stature is mostly

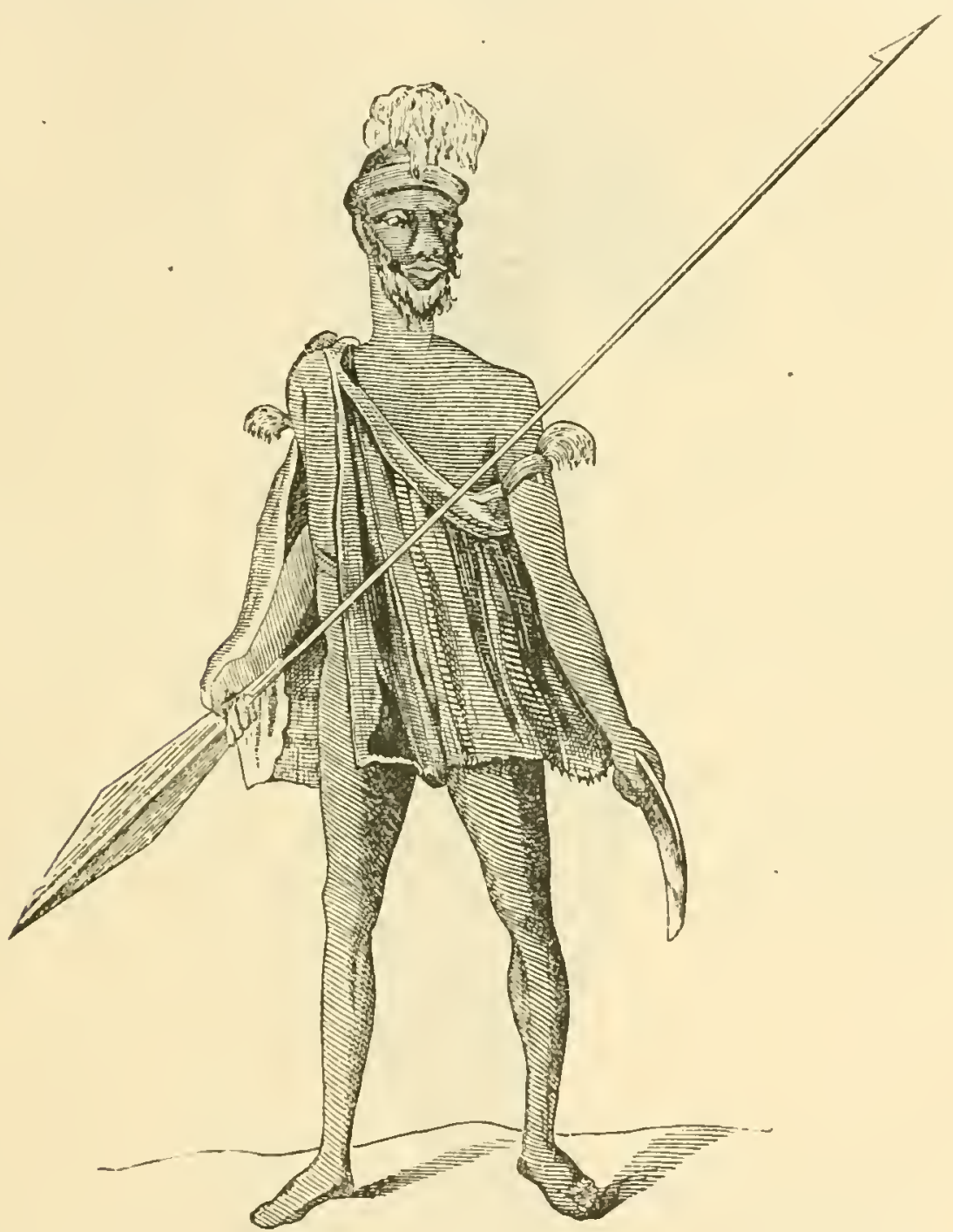

FIG. 59.-Australian native (from Brough Smyth), showing small development of muscles of lers, and prognathism.

due to shortness of the femur, or thigh ; the inequalities of people sitting are much less than those of people standing. A short femur is embryonic; so is a very large head. The faces of some people are partially embryonie, in having a short face and light lower jaw. Such faces are still more embryonie when the forehead and eyes are protuberant. Retardation of this kind is most frequently 


\section{PLATE XII.}

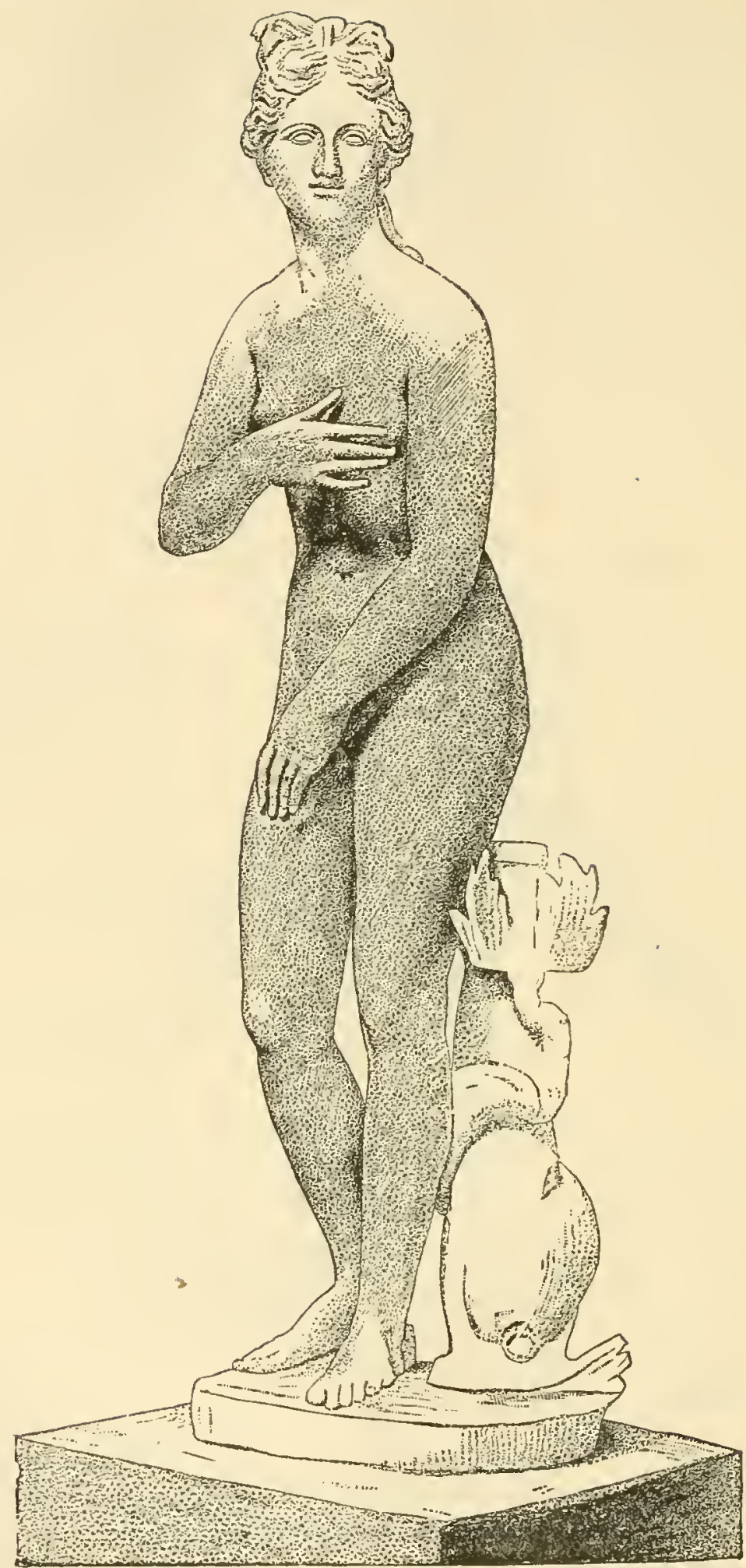

The Venus of the Capitol (Rome). The form and face present the characteristic peculiarities of the female of the Indo-European race. 
seen in children, and more frequently in women than in men. The length of the arms would appear to have grown less in comparatively recent times. Thus the humerus in most of the Greek statues, including the Apollo Belvidere, is longer than those of modern Europeans, according to a writer in the "Bulletin de la Société d'Anthropologie" of Paris, and resembles more nearly that of the modern Nubians than any other people. This is a quadrumanous approximation. The miserably developed calves of many of the savages of Australia, Africa, and America, are well known. The fine swelling gastrocnemius and soleus muscles characterize the highest races, and are most remote from the slender shanks of the monkeys. The gluteus muscles developed in the lower races as well as in the higher, distinguish them well from the monkeys with their flat posterior outline.

It must be borne in mind that the quadrumanous indications are found in the lower classes of the most developed races. The status of a race or samily is determined by the percentage of its individuals who do and do not present the features in question. Some embryonic character's may also appear in individuals of any race, as a consequence of special circumstances. Such are, however, as important to the physiognomist as the more normal variations.

Some of these features have a purely physical significance, but the majority of them are, as already remarked, intimately connected with the development of the mind, as an effect or necessary coincidence. I will examine these relations in a future article. 
$\mathrm{X}$.

\section{THE EVIDENCE FOR EVOLUTION IN THE HIS- TORY OF THE EXTINC'T MAMMALIA.*}

THE subject to which I wish to eall your attention this morning requires neither preface nor apology, as it is one with the discussion of which you are perfectly familiar. I bring it before the general session of the Association in view of the fact that you are all familiar with it in a general way, and that it probably interests the members of sections who do not pursue the special branch to which it refers, as well as those who do: also, since it has been brought before ns in various public addresses for many years, during the meetings of this Association, I thought it might be well to introduce it at this meeting, in order that we might not omit to have all the sides of it presented.

The interests which are involved in it are large: they are ehiefly, however, of a mental and metaphysical character; they do not refer so much to industrial and practical interests, nor do they involve questions of applied scienee. They involve, however, questions of opinion, questions of belief, questions which affect human happiness, I venture to say, even more than questions of applied science; certainly, which affect the happiness of the higher grades of men and women more than food or clothing, because they relate to the states of our mind, explaining as they do the reasons of our relations to our fellow beings, and to all other things by which we are surrounded, and the general system of the forces by which we are eontrolled. So it has always appeared to me: hence I have selected the department of biology for study, and liave taken a great interest in this aspect of it.

The doctrine of evolution, as tanght by the biologists of today, has several stages or parts of its presentation. First, the foundation prineiple is this: that the species of animals and of

* An address delivered before the American Association for the Advancement of Science, 1883. 
plants, the specics of organic beings, as well as the various natural divisions into which these organic beings fall, have not always been as we sce them to-day, but they have been produced by a process of change which has progressed from age to age through the influence of natural laws; that, therefore, the species which now exist are the descendants of other species which have existed heretofore, by the ordinary processes of reproduction; and that all the various structures of organic beings, which make them what they are, and which compel them to act as they now act, are the result of gradual or sudden modifications and changes during the periods of geologic time. That is the first phase or aspect which meets the naturalist or biologist.

Another phase of the question relates to the origin of that life itself which is supposed to inhabit or possess organic beings. There is an hypothesis of evolution which derives this life from no-life, which derives vitality from non-vitality. 'This is another branch of the subject, to which I can not derote much attention to-day.

There is still another department of the subject, which relates to the origin of mind, and which derives the mental organization of the higher animals, especially of man, from pre-existent types of mental organization. This gives us a gencalogy of mind, a history of the production or creation of mind, as it is now presented in its more complex aspects as a function of the human brain. This aspect of the subject is, of course, interesting; and upon it I can touch with more confidence than upon the question of the origin of life.

Coming now to the question of the origin of structures, we have by this time accumulated a vast number of facts which have been collated by laborious and faithful workers, in many countries and during many years ; so that we can speak with a good deal of confidence on this subject also. As to the phenomena which meet the student of zoölogy and botany at every turn, I would merely repeat what every one knows-and I beg pardon of my biological friends for telling them a few well-known truths, for there may be those present who are not in the biological section-the phenomena which mect the student of biology come under two leading classes. The first is the remarkable fidelity of species in reproducing their like. "Like produces like," is the old theorem, and is true in a great many cases; just as coins are struck from the die, just as castings are turned out from a common 
mold. It is one of the most wonderful phenomena of nature, that such complex organisms, consisting of so many parts, should be repeated from age to age, and from generation to generation, with such surprising fidelity and precision. This fact is the first that strikes the student of these sciences. The first impression of the ordinary person would be, that these things must continue unchanged. When I began to study zoölogy and botany, I was surprised to find there was a science of which I had no conception, and that was this remarkable reproduction of types one after another in continued succession. After a man has had this idea thoronghly assimilated by his honest and conscientious studies, he will be again struck with another class of facts. He will find, not unfrequently, that this doctrine does not apply. He will find a series of facts which show that many individuals fail to coincide with their fellows precisely, the most remarkable variations and the most remarkable half-way attitudes and double-sided aspects occmring; and he will come to the conclusion, sooner or later, that like does not produce like in some animals with the same precision and fidelity with which it is accomplished in other animals. So that we have these two classes of facts-the onc relating to, and expressing, the law of heredity; the other which expresses the law of variation. I should not like to say which class of facts is the most numerously presented to the student. In the present fauna we find many groups of species and varicties; but exactly how many species we have, how many genera and families we have, we can not definitely state. The more precise and exact a person is in his definition and in his analysis, the more definite his science becomes, and the more precise and scientific his work. Biology is a science of analysis of forms. What the scales are to the chemist and the physicist, the rule and measure are to the biologist. It is a question of dimension, a question of length and breath and thickness, a question of curves, a question of crooked shapes or simple shapes-rarely simple shapes, mostly crooked, generally bilateral. It requires that one should have a mechanical eye, and should have also something of an artistic eye, to appreciate these forms, to measure them, and to be able to compare and weigh them.

Now, when we come to arrange our shapes and our measurements, we find, as I said before, a certain number of identities, and a certain number of variations. This question of variation is so common and so remarkable, that it becomes perfectly evi- 
dent to the specialist in each department, that like does not at all times produce like. It is perfectly clear, and I will venture the assertion that nearly all the biologists in this room will bear me witness, that variability is practically unlimited in its range, and multiplied in the number of its examples. That is to say: specics vary by adding or by failing to retain certain characteristics; and generic and other characters are found to appear or disappear in accordance with some law to be discussed farther on.

I believe that this is the simplest mode of stating and cxplaining the law of variation: that some forms acquire something which their parents did not possess; and that those which acquire something additional have to pass through more numerous stages than their ancestors; and those which lose something pass through fewer stages than their ancestors; and these processes are expressed by the terms "acceleration" and "retardation."

Of course we are met with the opposite side of the case-the law of heredity. We are told that the facts there are not accounted for by any law of evolution ; that we can not pass from one class of facts to the other class of facts; that the law of the one class is not that of the other. Here is a question of rational processes, of ordinary reason. If the rules of chemistry are true in America, I imagine they are true in Australia and Africa, although I have not been there to see. If the law of gravitation is effective here, I do not need to go to Australia or New Zealand to ascertain whether it be true there. So, if we find in a group of animals a law sufficient to account for their creation, it is not necessary to know that others of their relatives have gone through a similar process. I am willing to allow the ordinary practical law of induction, the practical law of inference, to carry me over these gaps, orer these interruptions. And I state the case in this way, because it is just here that some people differ from me, and it is just here that I say the simple question of rationality comes in. I can not believe that Nature's laws are so dissimilar, so irregular, so inexact, that those which we can see and understand in one place are not true in another ; I also believe that the question of geological likelihood is similar to the question of geographical likelihood. If a given process be true in one of the geological periods, it is true in another ; if it be true in one part of the world, it is true in another ; becanse I find interruptions in the series here, it does not follow that there need be interruptions clear through from age to age. The assumption is on the 
side of the man who asserts that transitions have not taken place between forms which are now distinct.

We are told that we find no sort of evidence of that transition in past geological periods; we are assured that such changes have not taken place; we are even assured that no such sign of such transition from one species to another has ever been observed-a most astonishing assertion to make to a biologist, or by a biologist; and such persons have even the temerity to cite such a special case as that between the wolf and the dog. Many of our domestic dogs are nothing but wolves, which have been modified by the hand of man to a very slight extent indeed. Many dogs, in fact nearly all dogs, are descendants of wild species of various countries, and are variously modified.

To take the question of the definition of species. Supposing we have several species well defined, say four or five. In the process of investigation we obtain a larger number of individuals, many of which betray characters which invalidate the definitions. It becomes necessary to unite the four or five species into one. And so, then, because our system requires that we shall have accurate definitions (the whole basis of the system is definitions; you know the very comprehension of the subject requires definitions), we throw them all together, because we can not define all the various special forms as we did before, until we have but one species. And the critic of the view of evolution tells us, "I told you so! There is but one species, after all. There is no such thing as a connection between species : you never will find it." Now, how many discoveries of this kind will be necessary to convince the world that there are connections between species? How long are we to go on finding connecting links, and putting them together, as we have to do for the sake of the definition, and then be told that we have, nevertheless, no intermediate forms between species? The matter is too plain for further comment. We throw them together, simply because our definitions require it. If we knew all the known individuals which have lived, we should have no species, we should have no genera. That is all there is of it. It is simply a question of a universal accretion of material, and the collection of information. I do not believe that the welldefined groups will be found to run together, as we call it, in any one geological period, certainly in no one recent period. We recognize, however, in looking backward, that they converge to a wonderful extent: one group has diverged at one period, and 
another one has become diversified in a different period; and so each one has its history, some beginning farther back than others, some reaching far back beyond the very beginning of the time when fossils could be preserved. I call attention to this view because it is a very easy matter for us to use words for the purpose of confusing the mind; for, next to the power of language to express elear ideas, is its power of expressing no ideas at all. As we all know, we can say many things which we can not think. It is a very easy thing to say twice two are equal to six, but it is impossible to think it.

I would eite what I mean by variations of species in one of its phases : I mention a genus of snakes, Ophibolus, which is found in the United States. If we take the species of this snake-genus as found in the Northern States, we have a good many species well defined. If we go to the Gulf States, and examine our material, we see we have certain other species well defined, and they are very nicely distinguished. If, now, we go to the Pacific coast, to Arizona and New Mexico, we shall find another set of species well defined indeed. If we take all these different types of our specimens of different localities together, our species, as the Germans say, all tumble together : definitions disappear, and we have to recognize, out of the preliminary list of thirteen or fourteen, only four or five. That is simply a case of the kind of fact with which every biologist is perfectly familiar.

When we come to the history of the extinct forms of life, it is perfectly true that we ean not observe the process of descent in actual operation, because, forsooth, fossils are necessarily dead. We can not perceive any activities, because fossils have ceased to act. But, if this doctrine be true, we should get the series, if there be such a thing; and we do, as a matter of fact, find longer or shorter series of structures, series of organisms proceeding from one form into another form, which are exactly as they ought to be if this process of development by descent had taken place.

I am careful to say this; because it is literally true, as we all must admit, that species must fall into some kind of order or other. You could not collect bottles, you conld not collect old shoes, but you could make some kind of a serial order of them. There are, no doubt, characters by which such and such shoes could be distinguished from other shoes, these bottles from other bottles. But if serial order does not prove evolution, as is too often assumed, we have in recent forms of life in zoülogy and 


\section{PLATE XIII.}

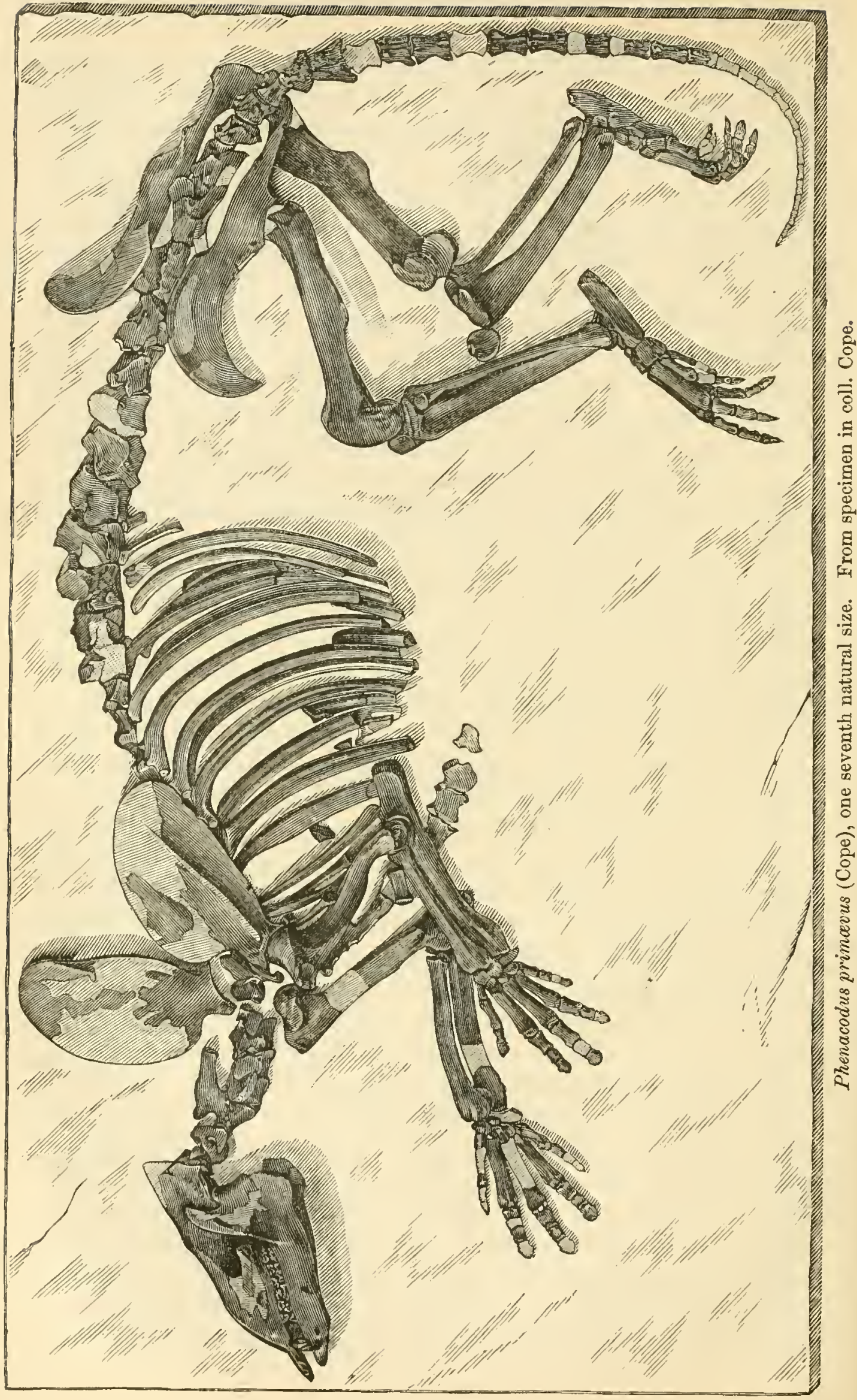


botany, irrefragable proofs of the metamorphoses, and transformations, and changes of the species, in accordance with the doctrine with which we commenced.

We now come to the second chapter of our subject. With the assumption, as I take it already satisfactorily proved, of species having changed into others, in considering this matter of geological succession or biological succession, I bring you face to face with the nature and mode of the change; and hence we may get a glance perhaps at its laws.

I have on the board a sketch or table which represents the changes which took place in certain of the Mammalia. I give you a summary of the kind of thing which we find in one of the branches of paleontology. I have here two figures, one representing a restoration, and the other an aetual picture, of two extinct species that belong to the early Eocene periods. One represents the ancestor of the horse line, Hyracotherium, which has four toes on his anterior feet, and three behind; and the other (Plate XIII) a type of animal, Phenacodus, which is antecedent to all the horse series, the elephant series, the hog, the rhinoceros, and all the other series of hoofed animals. It has five toes on all the feet. Fach presents us with the primitive position in which their series first come to our knowledge in the history of geological time.

I have also arranged here a series of some leading forms of the three principal epochs of the Mesozoic times, and six of the leading ones of the Tertiary time. I have added some dates to show you the time when the faunæ which are entombed in those beds were discovered, in the course of our studies; and you will easily sce how unsafe it is to say that any given type of life has never existed, or even to assert that such and such a form is unknown; and it is still more unsafe, I think, to assert that any given form of life properly defined, or that a specific intermediate form of life, will not be found. I think it is much safer to assert that such and such intermediate forms will be found. I have frequently had the pleasure of realizing anticipations of this kind. I have asserted that certain types would be found, and they have been found. You will sec that I attend to the matter of time beeanse there have been a great many things discovered in the last ten or fifteen years in this department. With these forms I give the date of the discovery of the fauna in which they are embraced.

Here we have the White River fauna discovered in 1856 ; then we skip a considerable period of time, and the next one was in 1869 , 
when the Cretaceous series was found. Six or seven Cretaceous faunæ have been discovered. Then we have the Bridger fauna in 18\%0, the Wasatch fauna in 18\%4. Next we have, in $18 \% \%$, the Equus beds and the fauna which they embrace, part of which was also found in 18\%8. The Permian fauna, which is one of the last, in 1879 ; and the latest, the Puerco, which gives the oldest and ancestral types of the modern forms of Mammalia, was only found in 1881. When I first commenced the study of this subject, about 1860, there were perhaps two hundred and fifty species known. There are now somewhere above 1,000, and we are angmenting them all the time. I have found many myself : if they were distributed through the days of the year, I think in some months I should have had several every day. You see then that the accessions to knowledge which are constantly being made make it unsafe to indulge in any prophecies; as, for instance, that, because such and such things have not been found, therefore they can not be ; for we find such and such things really have been and really are discovered.

The successive changes that we have in the Mammalia hare taken place in the limbs, feet, teeth, and brain, and the vertebral column. The parts which present us with the greatest numbers of variations are those in which many parts are concerned, as in the limbs and feet. In the Lower Eocene (Puerco), the toes were 5-5. In the Loup Fork fauna, some possess toes but 1-1. Prior to this period no such reduction was known, although in the Loup Fork fauna a very few species remained 5-5. Through this cntire series we have transitions steady and constant, from 5-5, to 45 , to $4-4$, to $4-3$, to $3-3$, to $2-2$, to $1-1$. In the Puerco period there was not a single mammal of any kind which had a good ankle-joint; which had an ankle-joint constructed as anklo-joints ought to be, with tongue and groove. The model ankle-joint is a tongue-andgroove arrangement. In this period they were nearly all perfectly flat. As time passes on we get them more and more grooved, until in the Loup Fork fauna and the White River fam they are nearly all grooved. The soles of the feet, in the Pnerco fanna, are all flat; but in the Loup Fork fauna the soles of the feet are in the air, and the toes only are applicd to the ground, with the exception of the line of monkeys, in which the feet have not become erect on the toes, and the elcphant, in which the feet are nearly flat also, and the line of bears, where they are also flat. As regards the angulation between the small bones of the palm and of the sole, 


\begin{tabular}{|c|c|c|c|c|c|c|c|}
\hline 莒 & 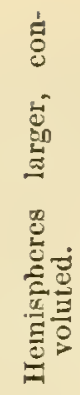 & & 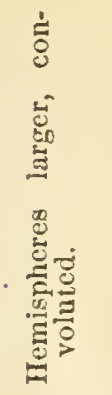 & 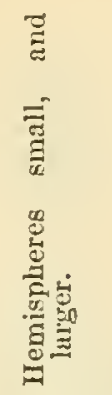 & 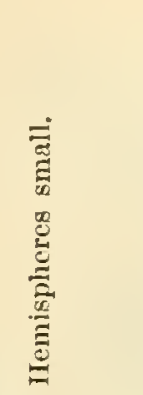 & 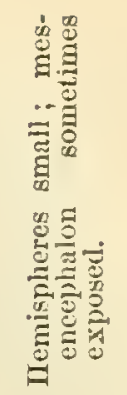 & 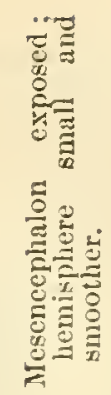 \\
\hline 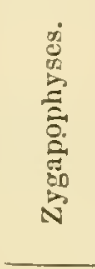 & 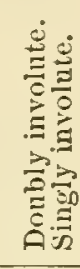 & & 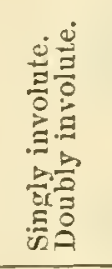 & 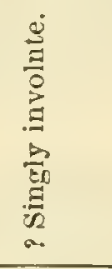 & 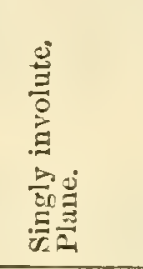 & 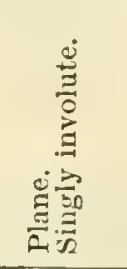 & 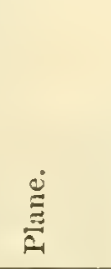 \\
\hline 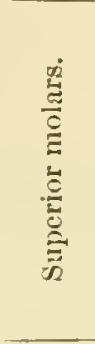 & 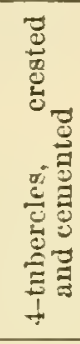 & & 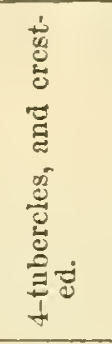 & 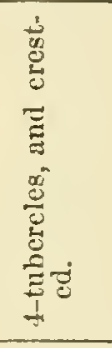 & 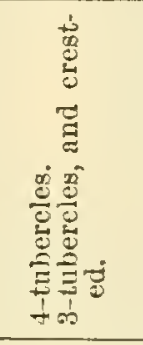 & 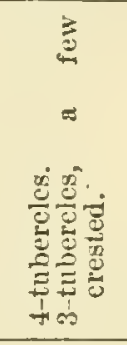 & 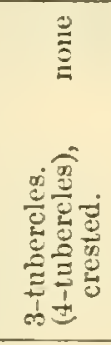 \\
\hline 寄总 & 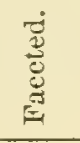 & & 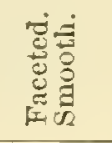 & 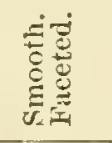 & 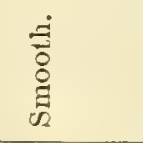 & 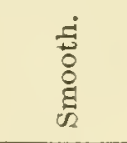 & 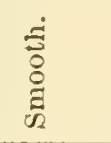 \\
\hline 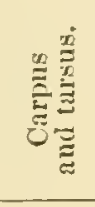 & 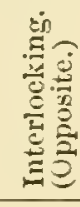 & & 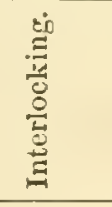 & 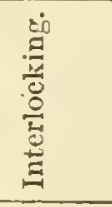 & 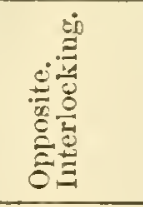 & 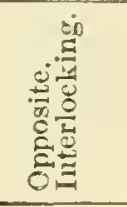 & 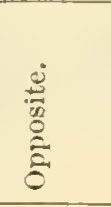 \\
\hline 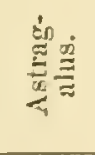 & 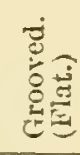 & & 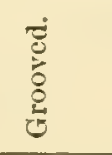 & 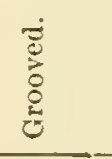 & 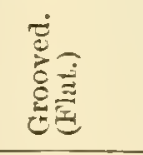 & 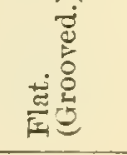 & $\dot{\vec{z}}$ \\
\hline 离 & 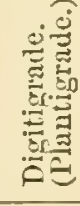 & & & 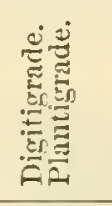 & 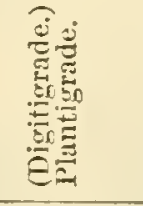 & 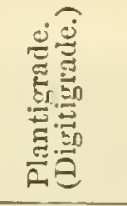 & 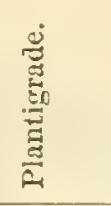 \\
\hline 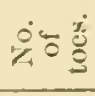 & $\begin{array}{ll}798 \\
\text { Inse }\end{array}$ & $\begin{array}{l}9+a \\
010\end{array}$ & 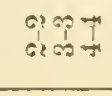 & 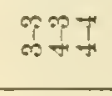 & 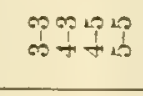 & 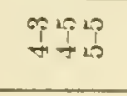 & $\begin{array}{l}3 \\
21 \\
18\end{array}$ \\
\hline 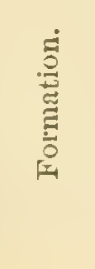 & 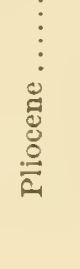 & 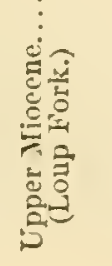 & 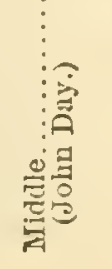 & 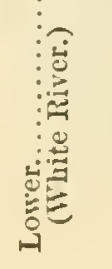 & 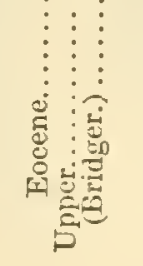 & 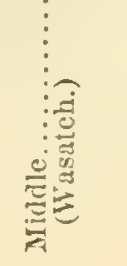 & 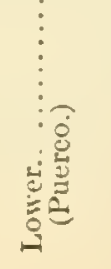 \\
\hline
\end{tabular}




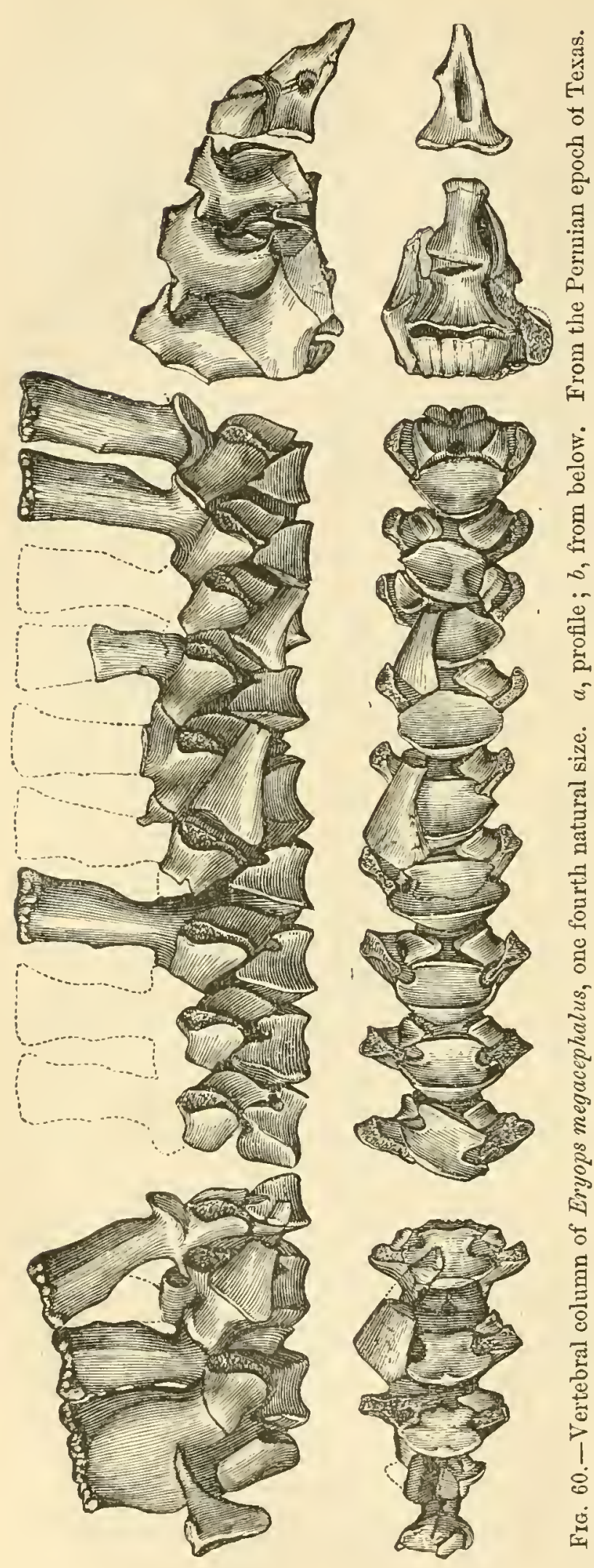

there is not a single instanee in which those bones are locked in the Lower Eocene, as they are in the later and latest 'Tertiary. So also with the artienlation of the toes with the foot.

When we come to the limbs, the species of the Puerco fauna have short legs. They have gradually lengthened out, and in the late periods they are nearly all relatively long.

Coming to the vertebræ as a part of the osseous system, I mention the zygapophyses, or anteroposteriorly directed processes, of which the posterior looks down and the anterior looks up. They move on each other, as the vertebral column bends from side to side. In the lower forms of vertebrates they are always flat, and in the hoofed mammals of the Puerco period they are all flat. In the Wasatch period we get a single group in which the articulation, instead of being perfeetly flat, be- 
comes rounded; in the later periods we get them very much rounded; and, finally, in the latest forms, we get the donble curve and the locking process in the rertebral column, which, as in the limb, secures the greatest strength with the greatest mobility.

In the first stages of the growth of the spinal column, it is a notochord, or a cylinder of cartilage or softer material. In later stages the bony deposit is made in its sheath until it is perfectly segmented. Now, all the Permian land-animals, reptiles and batrachians, retain this nctochord with the elements of osscous vertebræ, in a greater or less degree of completeness. There are some in South Africa, I believe, in which the ossification has come clear through the notochord; but they are few. In this characteristic the Permian appears almost, perhaps absolutely, peculiar as

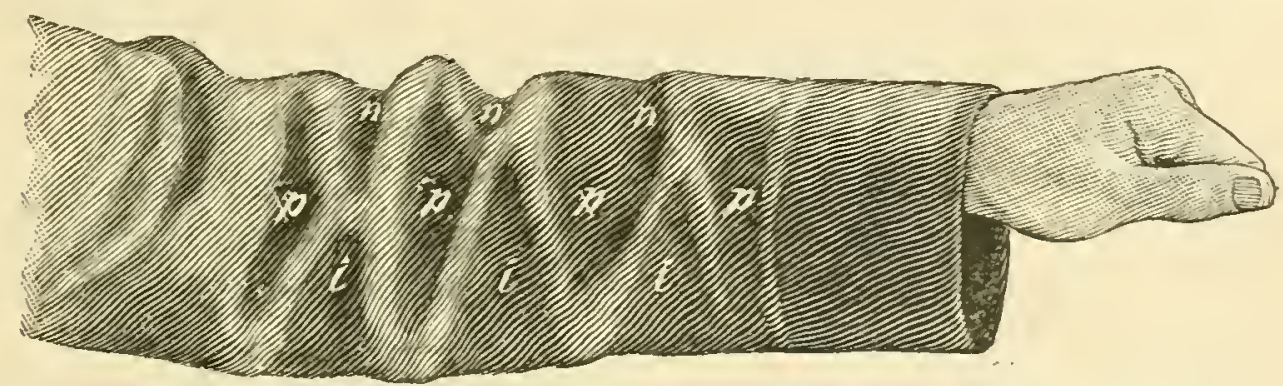

Fig. 61.--Sleeve of a coat showing folds produced by lateral flexure which leaves interspaces similar to the segments of a rhachitomous rertebra. Thus, $i$ represents ixtercentrum ; $p$, pleuro-centrum; and $n$, ncurapophssis.

regards land-animals. There is something to be said as to the condition of the column from a mechanical standpoint, and it is this: that the chorda exists, with its osseous elements disposed abont it ; and in the Permian batrachians, equally related to salamanders and frogs, these osseous elements are arranged in the sheath or skin of the chorda; and they are in the form of regular concave segments, very much like such segments as you can take from the skin of an orange-but parts of a cylinder, and having greater or less dimensions according to the group or species. Now, the point of divergenee of these segments is on the side of the column. The contacts are placed on the side of the column where the segments separate-the upper segments rising and the lower segments coming downward. 'To the upper segments are attached the arches and their articulations, and the lowersegments are like the segments of a cylinder. If you take a flexible eylinder, and cover it with a more or less inflexible skin or sheath, and bend that eylinder 
sidewise, you of course will find that the wrinkles or fractures of that part of the surface will take place along the line of the shortest curve, which is on the side; and, as a matter of fact, you have breaks of very much the character of the segments of the Permian Batrachia. It may not be so symmetrical as in the actual animal, for organic growth is symmetrical so far as not interfered with ; for, when we have two forces, the one of hereditary growth, and the other of change or alteration, and they contend, you will find in the organic being a quite symmetrical result. 'That is the universal rule. In the cylinder bending both ways, of course the shortest line of curve is right at the center of the side of that cylinder, and the longest curve is of course at the summit and base, and the shortest curve will be the point of fracture. And that is exactly what I presume has happened in the case of the construction of the segments of the sheath of the vertebral column, by the lateral mation of the animal in swimming, and which has been the actual cause of the disposition of the osscous material in its form. I have gone beyond the state of the discussion in calling attention to one of the forces which have probably produced this kind of result. That is the state of the vertebral column of many of the Vertebrata of the Permian period.*

I go back to the Mammalia and call attention to the teeth. The ordinary tooth of the higher type of the Mammalia, whether hoofed or not, with some exceptions, is complex with crests or cusps. By cutting the complex grinding surfaces, we find they have been derived by the infolding of extensions of four original cusps or tubercles. They have been flattened, have been rendered oblique, have run together, have folded up, have become acute, have descended deeply, or have lifted themselves, so that we have tecth of all sorts and kinds, sometimes very elegant, and often-

* Note (Ed. 1886).--Some further elucidation of this point is necessary, sinee the fishes have not produced this kind of segmentation by the lateral motions of the vertebral column in swimming; at least, such segmentation is not yet known among them, but rather simple diseoidal sermentation. The rluachitomous sermentation above deseribed would result from a greater flexure than that required for the propulsion of a fish through the water. This increased flexure was no doubt the coneomitant of the aequisition of a terrestrial mode of life by the early batrachians. Progression on land by an animal with weak limbs requires much greater flexure of the column than the act of swimming by the use of the caudal part of the body as in fishes. One can easily convince himself of this by comparing the morements of a fish in the water with those of a salamander on land. The snakes, where limbs are wanting, show an even stronger flexure in progression. 
times very effective in mechanism. In many primary ungulates, the primitive condition of four conical tubercles is found. In passing to older periods we find the Mammalia of the Puerco period, which never have more than three principal tubercles, with the exception of three or four species. In the succeeding periods, however, they get the fourth tubercle on the posterior side. Finally, you get a complicated series of grinding or cutting apparatus, as the case may be.

Last, but not least, we take the series of the brain. No doubt the generalization is true, that the primitive forms of Mammalia had small brains with smooth hemispheres; later ones had larger brains with complex hemispheres. In general the Carnivora hare retained a more simple form of brain, while herbivorous animals have retained a more complicated type of brain. The lowest forms of Mammalia display the additional peculiarity of having the middle brain exposed; and the hemispheres or large lobes of the brain, whish are supposed to be the seat of the mental phenomena, are so reduced in size at the back end, that you see the middle brain distinctly, though it is smaller than in reptiles and fishes. (See Plate XIV.)

It is beyond the possibility of controversy, that these series have existed, that they have originated in simplicity and have resulted in complication; and the further induction must be drawn, that the process of succession has been toward greater effectiveness of mechanical work. There are also cases of degradation, as in the growing deficiency in dentition in man. There is no doubt that a large number of people are now losing their wisdom-teeth in both jaws.

We are now brought to the question of the relations which mind bears to these principles. 'The question as to the nature of mind is not so complex as it might seem. There is a great deal of it, to be sure; but on examination it resolves itself into a few ultimate forms. An analysis reduces it to a few principal types or departments-the departments of the intelligence and of the emotions (with their primary simpler forms, likes and dislikes), and the will, if such there be. These three groups, proposed by Kant, are well known, and are adopted by many metaphysicians: and they stind the serutiny of modern science as applied to both men and the lower animals. But the question of the material of the mind, the original raw stuff ont of which mind wis malde, is one which is claiming attention now from biologists, as it always has 
$a$
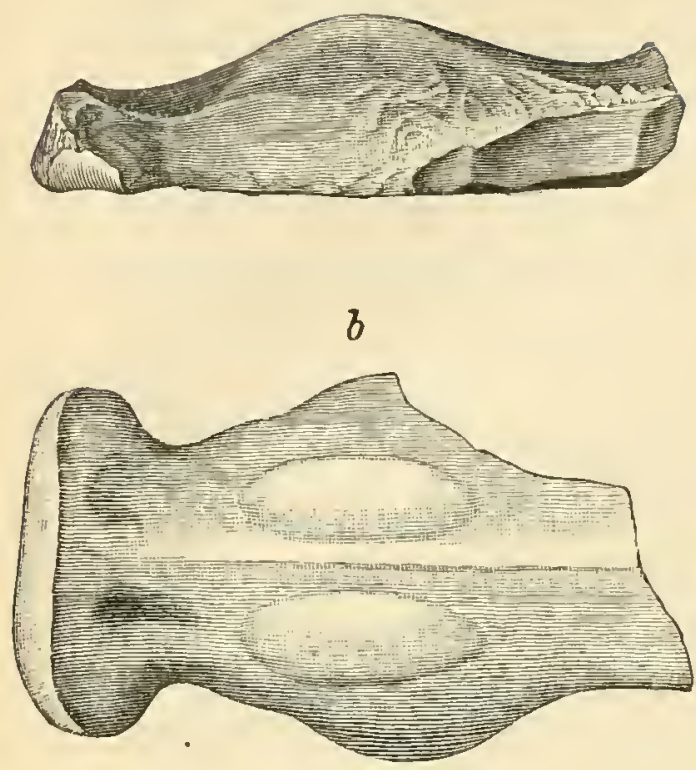

Fio. 1.

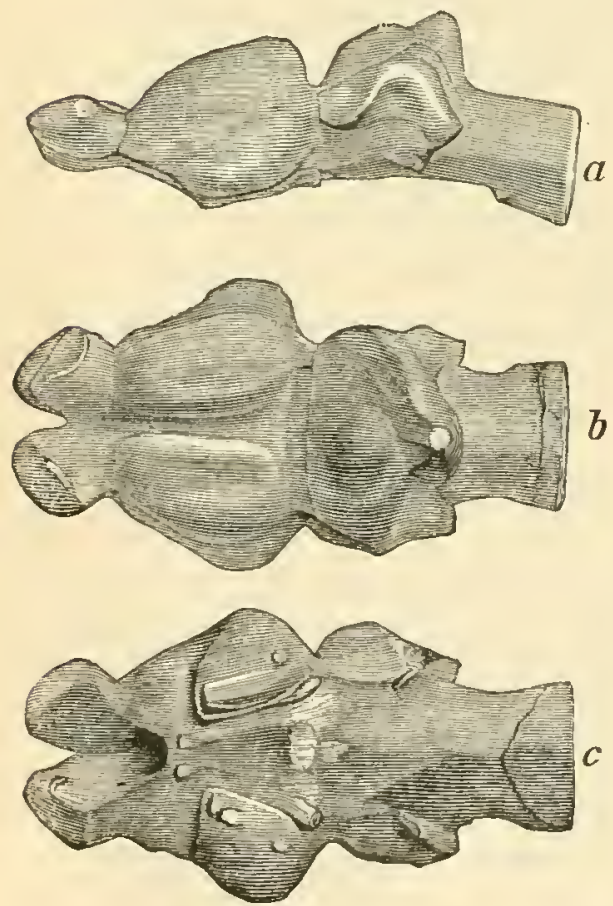

Fio. 3.

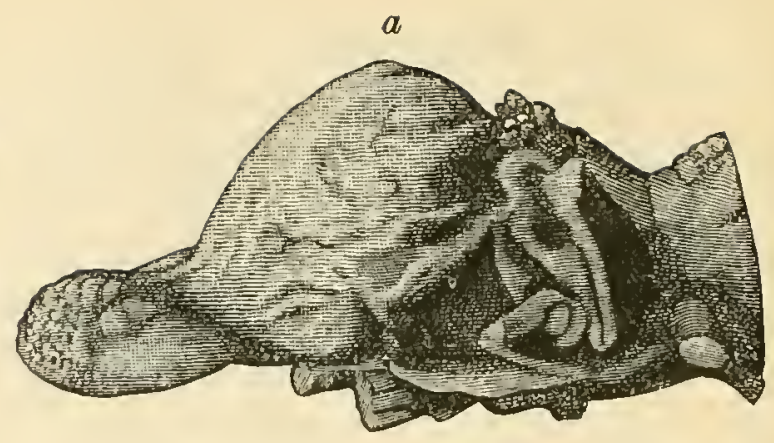

$b$

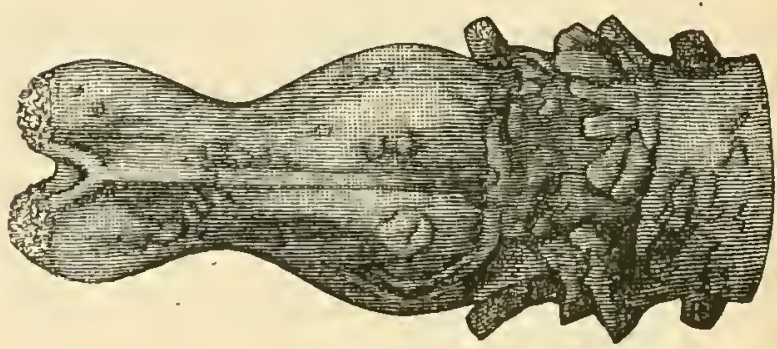

Frø. 2.
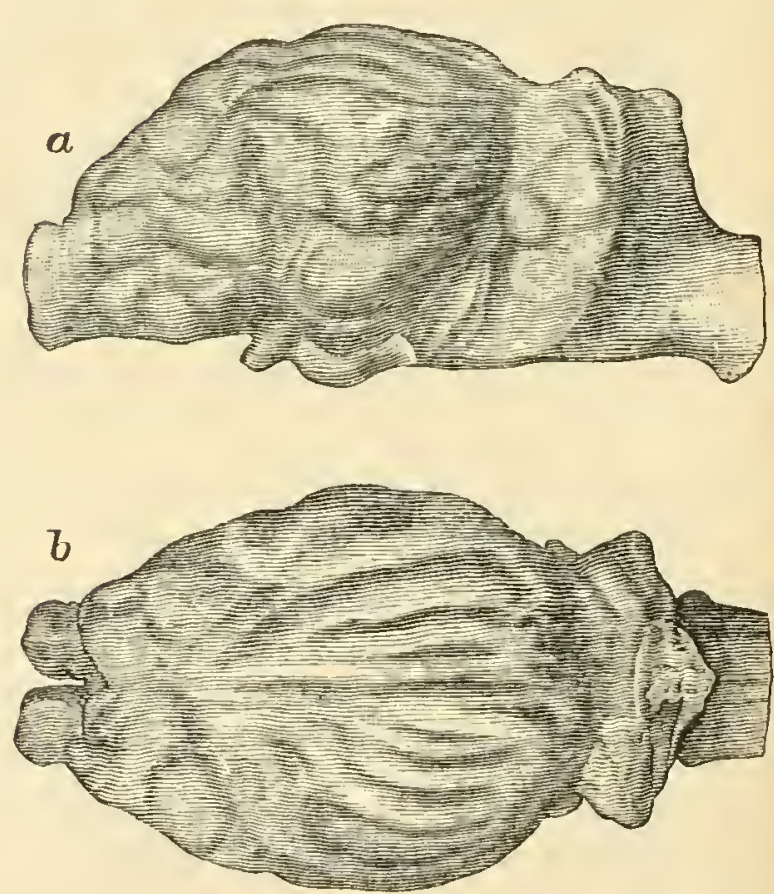

F10. 4.

Fioures of Casts of Brann-Cuambers of Extinct Manmalia.

Fig. 1, Periptychus rhabdodon, east of roof of brain case, showing middle-brain hemispheres and part of olfactory lobes, natural size. Original; from Puerco bed of New Mexico. Fig. 2, Uintatherium miratile, one third natural size, from Marsh. From Bridger bed of Wyoning. Fig. 3, Phenacodus primovus, one half natural size. Original; from Wasatch bed of Wyoming. Fig. 4, Procamelus occidentalis, one half natural size. Original; from Loup Fork bed of New Ilexico. Figs. $a$, profile; $b$, above; $c$, below. 
done from physiologists proper, and physicians. This is sensibility, mere simple sensibility, unmodified sensation, or consciousness. Sensibility, in connection with memory, is sufficient for the accomplishment of wonderful results. It is only necessary to impress the sensibility with the stimuli which this world affords, whether from the outside or the inside, to have the record made, and to have the record kept. Among wonderful things this is perhaps the most wonderful : that a given form of matter should be able to retain a record of events, a record which is made during a greater or less degree of sensibility; which is retained in a state of insensibility ; and is finally returned to the sensibility by some curious process of adhesion, as the results of impresses which are found on the material tissue concerned.

And these simple elements of mind are found in animals. No zoölogist who has perception or honesty, nor any farmer or breeder, nor any person who has charge of animals in any way, can deny sensibility to all the lower animals at times. The great stumbling-block in the way of the thinker in all this field, is the great evanescence of this sensibility; the great ease with which we dissipate it. The readiness with which we can deprive a fellow-bcing of his sense is a stumbling-block in more ways than one. While it is a question of the greatest difficulty, nevertheless, like other departments of nature, doubtless it will ultimately be explained by the researches of physiologists. I only need to call attention to conscionsness as an important factor in evolution.

We now approach the question of the origin of organic machines with fresh resources. Did the conscionsness of the animal find his structure made ready to hand, or did he, under the dire stimuli of necessity, produce through ages these modifications in his own structure? We are told by some of our friends that law implies a lawgiver, that crolution implies an evolver: the next question is, Where is the lawgiver? where is the evolver? where are they located? This question is best answered, as it appears to me, as follows. In the first place, I may say, it is distinctly proved in some directions, that the constant applications of force or motion in the form of strains, in the form of impacts and blows, upon any given part of the animal organism, do not fail to produce results in change of structure. I believe the changes in the ungulates, to which I have called your attention, are the résult of strains and impacts, precisely as I have shown you the manner of the fracture of the vertebral colunn of the primitive 
vertebrates of the Permian period. This wonld require long discussion to render clear ; nevertheless, I venture to make the assertion that this series of structures is the result of definite and distinct organic forces, directed to special ends. We have yet to get at the conflicting forces which have prodnced the results we see. Mechanical evolution will give us a good deal to do for some time to come. Of course, if motion has had any effect in modifying structure, it behooves us to investigate those conditions which give origin to motion in animals. First in order come the sensibilities of the animal, which we have traced to simple conscionsness; and stimuli, npon notice of which he immediately begins to move. The primary stimulus of all kinds of motion is necessarily tonch. If a stone falls upon the tail of some animal which has a tail, he immediately gets out of that vicinity. If a jelly-fish with a stinging apparatus runs across an eel which has no scales, the cel promptly moves. External applications of unpleasant bodies will always cause an animal to change his location. 'Then he is constantly assaulted by the dire enemy of beasts, hunger, an instinct which is evidently universal, to judge from the actions of animals. This seems to have fashioned, in large part, all forms of life from the least to the greatest, from the most unorganized to the most complex. Each exercised itself for the purpose of filling its stomach with protoplasm. Then come the stimuli which appeal to a sense allied to that of tonch, changes of temperature. No animals like to be too cold or too hot; and when the temperature is disagreeable, the tendency is to go away from that locality. Among primary instincts must be included that of reproduction. After that comes the sensation of resistance, or, carried to a high degree, of anger : when an animal's interests are interfered with, its morements restricted, the most encrgetic displays are prompted. So, you see, it is a matter of necessity that mental phenomena lie at the back of evolution, provided always that the commecting link of the argument-that motion has ever affected structure-be trne. That is a point which, of course, admits of much discussion. I have placed myself on the affirmative side of that question; and, if I live long enough, I expect to see it absolutely demonstrated.

Of course the development of mind becomes possible under snch circumstances. It is not like a man lifting himself up by his boots, which it would be were there no such thing as memory. But with that memory which accumulates, which formulates, first 
habits and then struetures, especially in the soft, delicate nervous tissue, the development of the function of the mind, as well as the machinery of the mind, becomes perfectly possible. We derelop our intellect through the accumulation of exact facts; through the collation of pure truth, no matter whether it be a humble kind of truth-as the knowledge of the changes of the seasons, which induces some animals to lay up the winter's store; whether it be knowledge of the fact that the sting of the bee is rery disagreeable; or knowledge of the fact (of which the wild ox, no doubt, is thoroughly aware) that the teeth of the wolf are not pleasant to come in contact with; or whether it be the complex knowledge of man. When the cerebral matter has become larger and more complex, it receives and retains a much greater number of impressions, and the animal becomes a more highly educated being.

As regards the department of cmotions or passions, they are also much stimulated by the environment. Animals which live in a state of constant strife, naturally have their antagonistic passions much developed; while amiable, sympathetic sentinents are better and more largely produced by peace-loving animals. Thus it is that the various departments of the mind hare the beautiful results which we now find in the human species.

There are some departments of the mind which some of our friends decline to admit having had such an origin. The moral faculty, for instance, is excepted by many from this series. But the reasons why they object to its production in this way are, to my mind, not ralid. The development of the moral faculty, which is essentially the sense of justice, appears to them not to fall within the seope of a theory of descent or of erolution. It consists of two parts. First is the sentiment of benerolence, or of sympathy with mankind, which gives us the desire to treat them as they should be treated. It is not sufficient for justice that it is unmixed merey or benevolence, which is sometimes rery injurious, and very often misplaced. It requires, in the second place, the criticism of the judgment, of the mature intellect, of the rational faculty, to enable the possessor to dispose of his sentiments in the proper manner. 'The combination of rational discrimination and judgment, with benevolence, constitutes the sense of justice, which has been derived, no doubt, as a summary of the derelopment of those two departments of the mind-the emotions and the intellect. 
It is said that a sense of justice conld not be derived from no sense of justice; that it conld not have been derived from the state of things which we find in the animals, beeause no animal is known to exhibit real justice; and that objection is valid as far as it goes. I suspeet that no animal has been observed to show a true sense of justice. That they show sympathy and kindness, there is no question; but when it comes to real justice, they do not display it. But do all men display justice? Do all men understand justice? I am very sure not. There are a good many men in eivilized commmities, and there are many tribes, who do not know what justice is. It does not exist as a part of every mental eonstitution. I never lived among the Bushmen, and do not know exactly what their mental constitution is; but in a general way the justice of savages is restrieted to the very smallest possible eirele-that of their tribe or of their own family. There is a elass of people who do not understand justice. I do not refer to people who know what right is, and do not do it; but to the primitive state of moral eharacter, in which, as in children, true justice is unknown. I call attention to the fact, because some of our friends have been very much afraid that the demonstration of the law of evolution, physical and metaphysical, would result in danger to soeiety. I suspect not. The mode in which I understand this question appears to me to be beneficial to society, rather than injurious; and I therefore take the liberty of appending this part of the subject to its more material aspect.

I refer to another topie, that is to the nature of life, and the physical basis of life. The word "life" is so eomplex that it is necessary to define it, and so to define it away that really the word "life" does not retain its usual definition. Many phenomena of life are ehemical, physical, mechanical. We have to remove all these from consideration, becanse they come within the ordinary laws of meehanical forces; but we have a few things left which are of a different character. One is the law of growth, which is displayed in the processes of embryonic suecession; seeondly, the wonderful phenomena of sensibility. Those two things we have not yet reduced to any identity with the ordinary laws of force, though we know of their dynamic equivaleney. In the phenomena of embryology the phenomena of evolution are repeated, only concentrated in the early stages through which animals have to pass. So whatever explains the general phenomena of evolution explains the phenomena of embryology. 
What is the nature of physical sensibility? In this planet, it is found residing only in one form of matter, which has a slightly varied chemical constitution, namely, protoplasm, so called from a physical standpoint. Now, this world, as you all know, has passed through many changes of temperature. Its early periods, it is probable, were so very hot that protoplasm had a very poor chance. Again, can we assume for a moment that this little speck in the great universe is the only seat of life? I suppose scarcely any scientific man will venture to do so. If, therefore, life exists in other planets, worlds, and systems, does it necessarily occupy bodies of protoplasm in those different, remote spheres? It wonld be a great assumption. It is altogether improbable. The certainty is, that in those planets which are in proximity to the sun's heat there could be no protoplasm. Protoplasm in the remote planets would be a hard mineral, and near the sun it would be dissipated into its component gases. So that, if life be found in other parts of this nuiverse, it must reside in some different kind of material. It is extremely probable that the physical conditions that reside in protoplasm might be found in other kinds of matter. It is in its chemical inertness, and in its physical constitution, that its adaptation to life resides; and the physical constitution necessary for the sustentation of life may be well supposed to exist in matter in other parts of the universe. I only say the door is open and not closed: any one who asserts that life can not exist in any other material basis than protoplasm is assuming more than the world of science will permit him to assume. And that it is confined to this single planet, among the great systems of the universe -that assumption will not for a moment be allowed. Therefore the subject is one which allows us a free field for future investigation : it is by no means closed in the most important laws which it presents to the rational thinker. I hope, also, if the evidence in favor of this hypothesis of the creation of living forms be regarded as true, that no one will find in it any ground for any very serious modification of existing ideas on the great questions of right and wrong, which have been long since known by men as a result of experience, and without any other scientific demonstration whatsoever. 


\section{ON THE EVOLUTION OF THE VERTEBRATA, PRO- GRESSIVE AND RETROGRESSIVE.}

\section{PRELIMINARY.}

IN attempting to ascertain the course of evolution of the Vertebrata, and to construct phylogenetic diagrams which shall express this history, among the difficulties arising from deficient information one is especially prominent. As is well known, there are many types in all the orders of the Vertebrata which present us with rudimentary organs, as rudimental digits, feet or limbs, rudimental fins, teeth, and wings. 'There is scarcely an organ or part which is not somewhere in a rudimental and more or less nscless condition. The difficulty which these cases present is, simply, whether they be persistent primitive conditions, to be regarded as aneestral types which have survired to the present time, or whether, on the other hand, they be results of a process of degeneration, and therefore of comparatively modern origin. The question, in brief, is, whether these creatures presenting these features be primitive ancestors or degenerate descendants.

In the first place, let us define the meaning of the word degenerate. This must be done first from a structural or anatomical standpoint. Degeneracy may be defined as a loss of parts without corresponding development of other parts. All animals are degenerate in some respect or another, as, for instance, the Mammalia in the small size of the pineal gland and of the coracoid bone; so that degeneracy, as a whole, can only be affirmed where the sum of the subtractions is greater than the sum of the additions. Function of the parts must, however, be consulted in this matter. Te naturally regard sensibility as the highest of animal functions, and mind as the highest form of sensibility. Therefore development of organs of sensibility and sense and mind, constitutes a better claim of progress than development of stomach or of skin. Since motion is under the direction of sensibility, 
organs of movement have much to do with the question. When perfection in this respect conflicts with perfection of brain, in evidence of position, we naturally give the preference to the latter in deciding. Thus the ruminating mammals are much superior to man in the structure of their feet, teeth, and stomach, yet we properly assign the higher position to the Quadrumana and to man, on account of the superior complication of their brainstructure.

Palcontology has proved, " what had been already surmised, that the development of animal organisms has been on lines of increasing specialization of parts. That is, in lines of increasingly perfect adaptations of structures to ends, or functions. In certain series of animals we witness steadily increasing perfection of mechanisms of the limbs for running; in others for digging; in others for flying. In the teeth we find increasing perfection of machines for grinding, for cutting, or for seizing. In the brain the specialization has evidently been toward increased acuteness of perception, increased energy of action, and increased intelligence. Specialization does not, however, necessarily imply progressive development. Adaptation may be to a parasitic or a sessile mode of life. Such adiptation is often displayed in a very special modification of parts, as in the anterior limbs of some of the parasitic Crustacea; in the mouth parts of some Arachnida; in the feet of the sloth, and in the jaws of the ant-eaters.

Embryology has furnished, and will furnish, many important hints and demonstrations as to the true meaning of the rudimentary condition or absence of parts, and thus indicate the phylogenetic connections of animals. Thus the origin of the Tunicata from primitive vertebrate-like forms would probably never have been suspected but for embryological studies; and the origin of the very peculiar order of Rotifera has been explained in like manner. But embryology has its limitations, for the transitional characters presented by embryos are only partially of the nature of a record of the structures which belonged to their ancestors in successive geological ages, and are frequently special adaptations to the necessities of their embryonic life. Such are the statoblists which are present in fresh-water sponges and Polyzoa, and wanting in the marine forms; and the allantois and placenta of

* Cfr. "On the Evidence for Erolution in the IIistory of the Extinct Iammalia," "Proc. Amer. Assoc. Adr. Sciences" for 1883. 
Vertebrata. In a number of groups the embryo seems to have been more susceptible to the influence of the environment than the adults.* It results that in many cases the phylogeny can only be determined by the discovery and investigation of the ancestors themselves, as they are preserved in the crust of the earth. In all cases this discovery confirms and establishes such definite conclusions as may be derived from embryology. It is also elear that on the discovery of phylogenetic series it becomes at once possible to determine the nature of defective types. It becomes possible to ascertain whether their rudimental parts represent the beginnings of organs, or whether they are the result of a process of degeneration of organs once well developed.

A great deal of light has been happily thrown on this question, as regards the Vertebrata, by the recent work done in North American paleontology. The lines of descent of many of the minor groups have been positively determined, and the plylogenetic connections of most of the primary divisions or classes have been made out. The result of these investigations has been to

* A remarkable instance of this state of things appears in the history of the evolution of the insects. It is quite impossible to understand this history without believing that the larval and pupal states of the highest insects are the results of a process of degeneracy which lias affected the middle periods of growth but not the mature results. The earliest insects are the Orthoptera, which have active aggressive larva and pupx, undergoing the least changes in their metamorphosis (Ametabola), and never getting beyond the primitive mandibulate condition at the end. The metamorphosis of the jawed Neuroptera is little more marked, and they are one of the oldest orders.

The highest orders with jaws undergo a marked metamorphosis (Coleoptera, Hymenoptera), the Hymenoptera even requiring artificial intervention in some instances to make it successful. Finally, the most specialized orders, the suetorial Diptern and Lepidoptera, especially the latter, present us with very unprotected more or less parasitic stages, both active and inactive. These animals have evidently degenerated, but not so as to prevent their completing a metamorphosis necessary for purposes of reproduction. As is well known, many imagines (Saturniidæ, Estridæ) can perform no other function, and soon die, while in some Diptera the incomplete larvie themselves reproduce, so that the metamorphosis is never completed.

This history is parallel to that proposed by Dohrn to account for the origin of the Ammocotes larval stage of the Marsipobranchii. He supposes this form to be more degenerate than its probable ancestral type in the ancestral line of the Vertebrata, as it is inferior to its own adult. An inactive life in mud is supposed by Dohrn to have been the effective cause. An inactive life on the leaves of plants, or in dead carcases, has probably been the cause of the same phenomenon in the Lepidoptera and Diptera. 
prove that the evolution of the Vertebrata has proceeded not only on lines of acceleration, but, to a much greater extent than has been heretofore suspected, on lines of retardation.* That is, that evolution has been not only progressive, but at times retrogressive. 'This is entirely in accord with the views derived by Dohrn from embryology, who, however, wrote only of the origin of the Vertebrata as a whole and not of its divisions, excepting only the Leptocardii and Marsipobranchii, that is, of the sand-lance and the lampreys and hags. The demonstration of such relations for the higher Vertebrata is now done nearly for the first time. I

Omitting from consideration the two classes above mentioned, whose remains have not yet been certainly found in a fossil state, there remain the following : the Pisces, Batrachia, Reptilia, Aves, and Mammalia.

The Mammalia have been traced to the theromorphons reptiles throngh the Monotremata. The birds, some of them at least, appear to have been derived from the Dinosaurian reptiles. 'The reptiles, in their primary representative order, the Theromorpha, have been probably derived from the rhachitomous Batrachia." The Batrachia have originated from the subelass of fishes, the Dipnoi, though not from any known form. I have shown that the true fishes or Teleostomi have descended from an order of sharks, the Ichthyotomi, which possess characters of the Dipnoi also. The origin of the sharks remains entirely obsemre, as does also that of the Pisces as a whole. Dohrn believes the Marsipo-

* See "Origin of Genera," E. D. Cope, Philadelphia, 1868, where these terms are introduced.

† See "Der Ursprung der Wirbelthiere u. d. Prineip des Functionwechsels," Leipsic, 1875.

$\neq$ "On the Pliylogeny of the Vertebrata," Cope, "Amer. Naturalist," Dec., 1884. I here remark that my researclies liave now, as I believe, disclosed the aneestry of the mammals, the birds, the reptiles, and the true fishes, or Teleostomi, including the special phylogenies of the Batrachia and Reptilia, and some of the Manmalia. See the following references: "Ameriean Naturalist," 1854, p. 1136 ; "Proceedings Academy Philalelphia," 1867, p. 234; "Procecdings American Philosoph. Society;" 1884, p. 585; "American Naturalist," 1854, p. 27; "Proceelings Ameriean Association for the Advancement of Science," xix, 1871, p. 233; "Procecdings Ameriean Philosophical Society," 1882, p. 447; "American Naturalist," 1884, pp. 261 and 1121; "Report U. S. Geol. Survey W. of 100th Her.," G. M. Wheeler, 1877, iv, ii, p. 282.

\# Through the batraehian order Embolomeri. (Ed. 1886.)

|| "Proceedings An. Pliil. Soc.," 1884, p. 585. 
branchii to have acquired its present characters by a process of degeneration. 'The origin of the Vertebrata is as yet entirely unknown, Kowalevsky deriving them from the Ascidians, and Semper from the Annelida. 'The above results I have embodied in the following phylogenetic diagram :

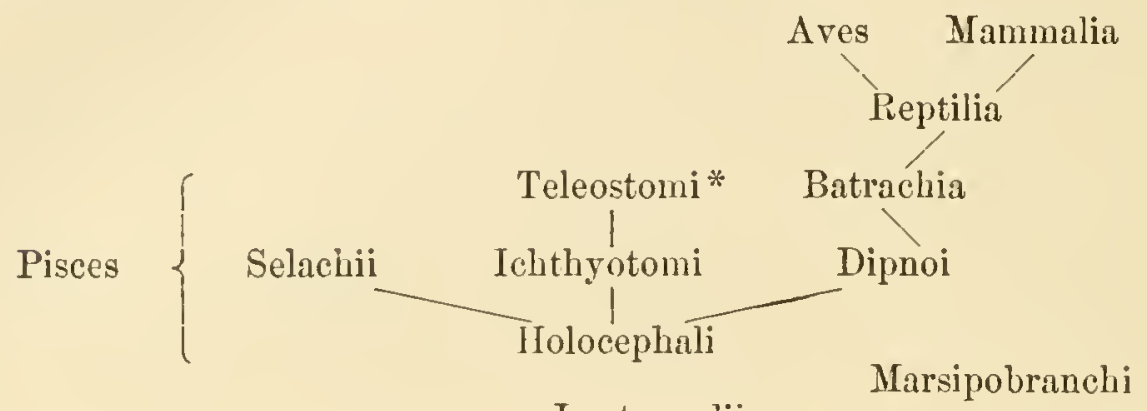

Leptocardii

Accepting this phylogeny, it becomes possible to determine the conrse of development, first, of the whole series; and, secondly, of the contents of each class taken by itself. I will first consider the direction of the evolution of the Vertebrata as a whole.

\section{THE VERTEBRATE LINE.}

The Vertebrata exhibit the most unmistakable gradation in the characters of the circulatory system. $f$ It has long been the custom to define the classes by means of these characters, taken in connection with those of the skeleton. Commencing in the Leptocardii with the simple tube, we have two chambers in the Iarsipobranchii and fishes; three in the Batrachia and Reptilia ; and four in the Ares and Mammalia. The aorta-roots commence as numerons pairs of branchial arteries in the Leptocardii; we see seven in the Marsipobranchi, five in the fishes (with number reduced in some) ; four and three in Batrachia, where they generally cease to perform branchial functions; two and one on each side in Reptilia; the right-hand one in birds, and the left-hand one in Mammalia. This order is clearly an ascending one throughont. It consists of, first, a transition from adaptation to an aquatic, to an aërial respiration; and, second, an increase in the power to aërate and distribute a circulating fluid of increased quantity,

* In the original I used the name Ifopomata for this division, but Owen's name Teleostomi is prior. (Ed. 1886.)

+See "Origin of Genera," 1868, p. 20, for a table of the characters of the circulatory system. 
and of increased calorific capacity. In other words, the circulation passes from the cold to the hot blooded type coincidentally with the changes of structure above enumerated. The accession of a capacity to maintuin a fixed temperature while that of the surrounding medium changes, is an important advance in animal economy.

The brain and nerrous system also display a general progressire ascent. Leaving the brainless Leptocardii, the Marsipobranehs and fishes present us with small hemispheres, larger optic lobes, and well-developed ccrebellum. The hemispheres are really larger than they appear to be, as Rabl Rückard has shown * that the supposed hemispheres are only corpora striata. But the superior walls are membranous, and support on their internal side only a layer of epithelial cells, as in the embryos of other Vertebrata, instead of the gray substance. So that, although we find that the cerebellum is really smaller in the Batrachia and most Reptilia than in the fishes, the better development of the hemispheres in the former gives them the preeminence. The Elasmobranehii show themselves superior to many of the fishes in the large size of their corpora restiformia and cerebellum. The Reptilia constitute an adrance on the Batrachia. In the latter the optic thalami are, with some exceptions, of greater diameter than the hemispheres, while the reverse is generally true of the reptiles. The crocodiles display much superiority over the other reptiles in the larger cercbellum, with rudimental lateral lobes. The great development of the hemispheres in birds is well known, while the general superiority of the brain of the living Mammalia over all other vertebrates is admitted.

The consideration of the snceessive relations of the skeleton in the classes of vertebrates embraces, of course, only the characters which distinguish those classes. 'These are not numerous. 'They embrace the structure of the axis of the skull; of the ear-bones; of the suspensors of the lower jaw; of the scapular arch and anterior limb, and of the pelvic arch and posterior limb. Other characters are numerous, but do not enter into consideration at this time.

The persistence of the primitive cartilage in any part of the skeleton is, embryologieally speaking, a mark of inferiority.

* "Biologisches Centralblatt," 1884, p. 449. 
From a physiological or functional stumdpoint it has the same significance, since it is far less effective both for support and for movement than is the segmented osseous skeleton. That this is a prevalent condition of the lower Vertebrata is well known. The bony fishes and Batrachia have but little of the primitive cartilage remaining, and the quantity is still more rednced in the higher classes. Systematically, then, the vertebrate series is in this respect an ascending one. The Leptocardii are membranous; the Marsipobranchii and most of the Elasmobranchii cartilaginous; the other Pisces and the Batrachia have the basicrmial axis cartilaginous, so that it is not until the Reptilia are reached that we have osseous sphenoid and presphenoid bones, such as characterize the birds and mammals. The rertebral column follows more or less inexactly the history of the base of the skull, but its characters do not define the classes.

As regards the suspensor of the lower jaw, the scale is in the main ascending. We witness a gradual change in the segmentation of the mandibular visceral arch of the skull, which clearly has for its object such a concentration of the parts as will produce the greatest effectiveness of the biting function. This is accomplished by reducing the number of the segments, so as to bring the resistance of the teeth nearer and nearer to the power, that is, the masseter and related muscles, and their base of attachment, the brain-case. This is seen in bony Vertebrates in the reduction of the segments between the lower jaw proper and the skull, from four to none. In the fishes we have the hyomandibular, the symplectic, the inferior quadrate, and the articular. In the Batrachia, reptiles and birds, we have the quadrate and articular only, while in the Mammalia these elements also are wanting.

The examination of the pectoral and pelvic arehes reveals a successive modification of the adaptation of the parts to the mechanical needs of the limbs. In this regard the air-breathing types display wide diversity from the gill-bearing types or fishes. In the latter, the lateral elements unite below withont the intervention of a median element or sternum, while in the former the sternum, or parts of it, is generally present. Either arrangement is susceptible of much mechanical strength, as witness the Siluroid fishes on the one hand, and the mole on the other. The numerous segments of the fishes' pectoral arch must, however, be an element of weakness, so that from a mechanical standpoint it must take the lowest place. The presence of sternal elements, 
with both clavicle, procoracoid, and coracoid bones on each side, gives the Reptilia the highest place for mechanical strength. The loss of the coracoid seen in the tailed Batrachia, and loss of coracoid and procoracoid in the Mammalia, constitute an element of weakness. The line is not then one of uniform ascent in this respect.

The absence of pelvis, or its extremely rudimental condition in fishes, places them at the foot of the line in this respect. The forward extension of the ilium in some Batrachia and in the Mam. malia, is to be compared with its backward direction in Reptilia, and its extension both ways in the birds. These conditions are all derived by descent from a strictly intermediate position in the Batrachia and Reptilia of the Permian epoch. 'The anterior direction must be regarded as having the mechanical advantage over the posterior direction, since it shortens the vertebral column and brings the posterior nearer to the anterior feet. The prevalence of the latter condition in the Mammalia enables them to stand clear of the ground, while the Reptilia move with the abdomen resting upon it. As regards the inferior arches of the pelvis, the Mammalia have the advantage again, in the strong bony median symphysis comnecting the ischium and pubis.* This character, universal among the land Vertebrata of the Permian epoch, has been lost by the modern Reptilia, and birds, and is retained only by the Mammalia. So the lines, excepting the mammalian, have degenerated in every direction in the characters of the pelvis.

The limbs of the Pisces are as well adapted to their environment as are those of the land Vertebrata; but, from an embryological standpoint, their structure is inferior. The primitive rays are less modified in the fin than in the limb; and limbs themselves display a constantly increasing differentiation of parts, commeneing with the Batrachia and ending with the Mammalia. The details of these modifications belong to the history of the contents of the classes, howevel, rather than to the succession of the Vertebrata as a whole.

In review, it may be said that a comparison of the characters which define the elasses of the Vertebrates shows that this branch of the animal kingdom has made with the ages suecessive steps of progress from lower to higher conditions. 'This progress has not been withont exception, since, as regards the construction of

* This is an advantage as a protection during gestation. 
the seapular arch, the Mammalia have retrograded from the reptilian standard as a whole.

In subsequent pages I shall take up the lines of the classes separately.

\section{THE LINE OF THE UROCHORDA.}

Embryological evidenee leads us to anticipate that the primitive Vertebrata possessed nothing representative of the vertebrate skeleton beyond a chorda dorsalis. Above this axis shonld lie the nervous chord, and below it the nutritive and reproductive systems and their appendages. Such a type we have in its simplest form in the Branchiostoma, the representative of the division of the Acrania. In the animals of this division the mouth and anus have the usual vertebrate position, at opposite ends of the bodycavity. The Tunieata (formerly referred to the Mollusea) are now known to present a still more primitive type of Vertebrata, to which the name of Urochorda has been given. These curious, frequently sessile creatures, have a vertebrate structure during the larval stage, which they ultimately lose. They have the necessary chorda, and nervous axis with a brain, and a cerebral eye. They have at this time a tail, and are free-swimming; a peenliarity which a few of them retain throughont life (Appendieularia).* They differ from the Acrania in the positions of the extremities of the alimentary canal. The month is on the top of the anterior end of the animal, and is supposed by some anatomists to represent an open extremity of the pineal gland of other Vertebrata; while the tract represented by this body, the third ventricle of the brain, and the pituitary body of the Craniata, are the remains of the primitive osophagus of the Urochorda. The anns in the adult tunicates is either dorsal, or it opens into the body-envity, as in the young larvæ. In Appendieularia it is ventral (Gegenbaur).

The history of the Turicata can not be traced by paleontologists as yet, owing to the absence of hard parts in their strueture. The evidence of embryology has, however, convinced phylogenists that the ancestors of this class resembled their larva, and that they have as a whole undergone a remarkable degeneracy. They have passed from an active, free life to a sessile one, and have lost the characters which pertain to the life of vertebrates generally.

It was to have been anticipated, however, that all of these an- 
cestral Tunicata did not undergo this degenerative metamorphosis, for it is to such types that we must look for the ancestors of the other Vertebrata, the Acrania and the Craniata. And here paleontology stcps in and throws new light on the question. I have pointed ont briefly, in the "Amcrican Natmralist," * that a second order must be added to the Urochorda, viz., the Antiarcha, in which the anus presents the same position as in the Acrania, at the posterior end of the body, while an orifice of the upper surface represents the mouth of the Tunicata. To this order is to be referred the family of the Pterichthyidæ, of which the typical genus,
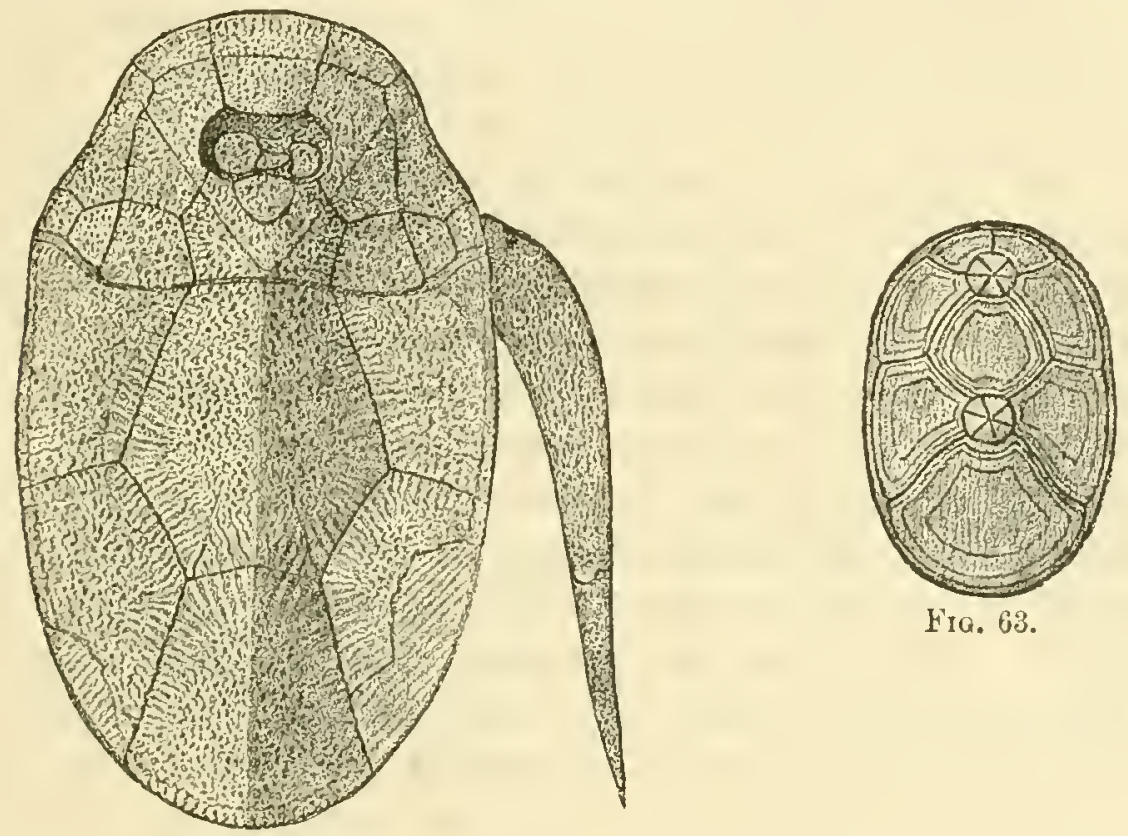

Frg. 62.

Fig. 62. Bothriolepis canadensis Whiteaves, from above, half size of a small specimen. The valve of the dorsal mouth, or notostome, is broken. Fig. 63. Chelyosoma maclovianum Brod. \& Sow., 4/3 natural size, from Point Barrow, Alaska.

Pterichthys, is a well-known form of the Devonian period. This genus retained its tail, which was the canse, in connection with the presence of lateral fin-like appendages, of its having been supposed to be a fish, by Agassiz, Hugh Miller, and others. It is possible that the American Bothriolepis canadensis lost its tail, as in the majority of Urochorda. The tunicate which approaches nearest to the Antiarcha is the Aretic Chelyosoma.

From the Antiarcha to the Acrania and Craniati, then, the line is an ascending one. 
IV. THE LINE OF THE PISCES.

The fishes form various series and subseries, and the tracing of all of them is not yet practicable, owing to the deficiency in our knowledge of the earliest or ancestral forms. Thus the origins of the four subclasses, Holocephali, Dipnoi, Elasmobranchii, and Teleostomi, are lost in the obscurity of the early Palæozoic ages.

A comparison of the four subclasses just named shows that they are related in pairs. The Holocephali and Dipnoi have no distinct suspensory segment for the lower jaw, while the Elasmobranchii and Hyopomata have such a separate element. The latter, therefore, present one step in the direction of complication beyond the former ; but whether the one type is descended from the other, or whether both came from a common ancestor or not, is unknown. If one type be derived from the other, it is not certain which is ancestor, and whether the process has been one of advance or retrogression. The famna of the Permian epoch throws some light on the relations of these subelasses in other respects. The order of the Ichthyotomi, * while belonging technically to the Elasmobranchi, presents characters of both the Dipnoi and the Teleostomi. It is so near to the Dipnoi in the characters of the skull that nothing save the presence of a free suspensor of the lower jaw prevents its entering that subelass. It indicates that the one of these divisions is descended from the other, or both from a common division which may well be the group Ichthyotomi itself. In case the Elasmobranchi have descended from the Ichthyotomi, they have undergone degeneracy, as the Ichthyotomi have a higher degree of ossification and differentiation of the bones of the skull. If they descended from a purely cartilaginous type of Dipnoi, they have advanced, in the addition of the free hyomandibular. If the Dipnoi have descended from either division, they have retrograded, in the loss of the free hyomandibular. As regards the Teleostomi, we have a clear advance over the other subclasses in the presence of the maxillary arch and the opereular apparatus.

Too little is known of the history of the subclasses, excepting the Teleostomi, for us to be able to say much of the direction of

* See "Palxontological Bulletin," No. 38, E. D. Cope, 1884, p. 572, on the genus Didymodus. 
the descent of their contained orders. On the sharks some light is shed by the discovery of the genus Chlamydoselachus Garman,** which is apparently nearly related to the Cladodonts of the Devonian seas. This genus has more numerous branchial slits than all but tro of the genera of existing sharks, and it differs from all but these two in having a more perfect articnlation between the toothbearing bones and the cranium. Of the Teleostomi a much clearer history is accessible. It has three primary divisions or tribes which differ solely in the structure of the supports of the fins. In the first division, the Crossopterygia, the anterior limbs have numerous basilar bones which are supported on a peduncle of axial bones. The posterior limbs are similar. In the second division, or Chrondrostei (the sturgeons, ete.), the posterior limb remains the same, while the anterior limbs have undergone a great abbreviation in the loss of the axial bones and the reduction of the number and length of the basilar bones. In the third group, or Actinopteri, $\nmid$ both limbs have undergone reduetion, the basilar bones in the posterior fin being almost all atrophied, while those of the fore limb are much reduced in number.

The phylogeny of these tribes is not easy to make out at present. The descent has been, no doubt, in the order named in time, but the starting-point is yet unecrtain. Thus the Chondrostei appear later in time than either of the other tribes, a history which probably only represents our ignorance. The characters of the genus Crossopholis Cope, from the American Eocene, strongly suggest that the existing forms have descended from scaled ancestors. 'The Crossopterygian fore limb, with its arm-like axis, tells of the origin of the first limbed vertebrates, the Batrachia, whose skull-structure, however, only permits their derivation. from the Dipnoi or Holocephali. As the former subclass has the Crossopterygian fin-structure, we ean safely regard them as the ancestors of the Batrachia, while the Crossopterygia are a sideline from a similar type, probably the Ichthyotomi, because these have a free suspensor of the lower jaw. But of the structure of the fins of the Ichthyotomi unfortunately we know nothing. If this position be true, then the suceessive derivation of the Chondrostei and the Teleostomi in one line is rendered probable. The modifieation of strueture has consisted in the contraction of the

* "Proceedings American Assoe. Adv. Sei.," 1884.

+ Parlly agrees with the Teleostei of Müller, but includes many of his Ganoidea. 
supporting elements of the pectoral and ventral fins by the reduction of their numbers and length. According to paleontological history, however, the tribe of 'Teleostomi with most contracted fins, Actinopteri, appeared in the Coal Measures (Paleoniscidæ), or very soon after the Crossopterygia in the Devonian.

The descent of the fishes in general has witnessed, then, a contraction of the limbs to a very small compass, and their substitution by a system of accessory radii. This has been an everwidening divergence from the type of the higher Vertebrata, and from this standpoint, and also a view of the "loss of parts without complementary addition of other parts," may be regarded as a process of degradation.

Tilking up the great division of the Actinopteri, which embraces most of the species of living fishes, we can trace the direction of descent largely by reference to their systematic relations when we have no fossils to guide ns.

The three subtribes adopted by Jordan represent three series of the true fishes which indicate lines of descent. The Holostei include the remainder of the old ganoids after the subtraction of the Crossopterygia and the Chondrostei. They resemble these forms in the muscular bulbus arteriosus of the heart and in the chiasm of the optic nerves. Both of these characters are complexities which the two other divisions do not possess, and which, as descendants coming later in time, must be regarded as inferior, and therefore to that extent degenerate. Of these divisions the Physostomi approach nearest the Holostei, and are indeed not distinctly definable without exceptions. The third division, or Physoclysti, shows a marked advance beyond the others in : (1) the obliteration of the primitive trachea, or ductus pueumaticus, which connects the swim-bladder and cesophagus; (2) the adrance of the rentral fins from the abdomen forward to the throat; (3) the separation of the parietal bones by the supraoccipital; (4) the presence of numerous spinous rays in the fins; and (5) the roughening of the edges of the scales, forming the etenoid type. There are more or less numerous exceptions to all of these characters. The changes are all further divergencies from the other vertebrate classes, or away from the general line of ascent of the vertebrate series taken as a whole. The end gained is specialization; but whether the series can be called either distinctively progressive or retrogressive, is not so clear. The development of osseous spines, rough scales, and other weapons of defense, together 
with the generally superior energy and tone which prevail among the Physoclysti, characterize them as superior to the Physostomi, but their departure from the ascending line of the Vertebrata has another appearance.

The descent of the Physoclystous fishes has probably been from Holostean ancestors, both with and without the intervention of Physostomous forms. This is indicated by increase in the number of basilar bones in the fins of families which have peetoral ventral fins, as in the extinet genus Dorypterus. *

The Physostomi display three or four distinct lines of descent. The simplest type is represented by the order Isospondyli, and paleontology indicates clearly that this order is also the oldest, as it dates from the Trias at least. In one line the anterior dorsal rertebræ have become complicated, and form an interlocking mass which is intimately connected with the sense of hearing. This series commences with the Characinide, passes through the Cyprinidx, and ends with the Silurjæ. The arrangements for audition constitute a superadded complication, and to these are added in the Siluroids defensive spines and armor. Some of this order, however, are distinetly degenerute, as the soft purblind Ageniosus, and the parasitic Stegophilus and Vandellia, which are nearly blind, without weapons, and with greatly reduced fins.

The next line (the Haplomi, pike, etc.) loses the precoracoid arch and has the parietal bones separated, both characters of the Physoclysti. This group was apparently abundant during the Cretaceous period, and it may have giren origin to many of the Physoclysti.

Another line also loses the precoracoid, but in other respects diverges totally from the Physoclysti and all other Physostomi. This is the line of the eels. 'They next lose the comnection between the scapular arch and the skull, which is followed by the loss of the pectoral fin. The ventral fin disappeared sooner. The palatine bones and teeth disappear, and the suspensor of the lower jaw grows longer and loses its symplectic element. The opercular bones grow smaller, and some of them disappear. 'The ossification of most of the hyoid clements disappears, and some of their cartilaginous bases even vanish. These forms are the marine eels or Colocephali. The most extraordinary example of speciali-

* See "Proeeds. Amer. Assoe. Adv. Science," 1S7S, 1. 29 ז. 
zation and degeneracy is seen in the abyssal cels of the family Eurypharyngidæ. Here all the degenerate features above mentioned are present in excess, and others are added, as the loss of ossification of a part of the skull, almost total obliteration of the hyoid and scapular arches, and the semi-notochordal condition of the vertebral column, etc.

The Physoclysti nearest the Physostomi have abdominal ventral fins, and belong to several orders. It is such types as these that may be supposed to have been derived directly from Holostean ancestors. 'They appear in the Cretaceous period (Dercetidæ), along with the types that connect with the Physostomi (Haplomi). Intermediate forms between these and typical Physoclysti occur in the Eocene (Trichophanes, Erismatopterus), showing several lines of descent. The Dercetidæ belong apparently to the order Hemibranchi, while the Eocene genera named belong apparently to the Aphododiridx, the immediate ancestor of the highest Physoclysti, the Percomorphi. The order Hemibranchi is a series of much interest. Its members lose the membrane of their dorsal spinous fin (Gasterosteidx), and then the fin itself (Fistularia, Pegasus). The branchial apparatus has undergone, as in the eels, successive deossification (by returdation), and this in direct relation to the degree with which the body comes to be protected by bony shields, reaching the greatest defect in the Amphisilidæ. One more downward step is seen in the next succeeding order of the Lophobranchii. The branchial hyoid apparatus is rednced to a few cartilaginous pieces, and the branchial fringes are much reduced in size. In the Hippocampidre the caudal fin disappears and the tail becomes a prehensile organ by the aid of which the species lead a sedentary life. The month is much contracted and becomes the anterior orifice of a suctorial tube. 'This is a second line of unmistakable degeneracy among true fishes.

The Physoclysti with pectoral ventral fins present us with perhaps ten important ordinal or subordinal divisions. Until the paleontology of this series is better known, we shall have difficulty in constructing phylogenies. Some of the lines may, however, be made out. The accompanying diagram will assist in understanding them.

The Anacanthini present a general weakening of the organizaltion in the less firmness of the osseons tissue and the frequent reduction in the size and character of the fins. The caudal ver- 
tebræ are of the protocereal type. As this group does not appear early in geological time, and as it is largely represented now in the abyssal oeean fauna, there is every reason to regard it as a degenerate type. * 'The scyphobranch line presents a specialization of the snperior pharyngeal bones, which is continued by the Haplodoci (Batrachidæ). 'This can not be called a degenerate line, although the fin-rays are soft. The Heterosomata (flounders) found it conrenient to lie on one side, a habit which would appear to result from a want of motive energy. 'The fins are rely inefficient organs of movement in them, and they are certainly no rivals for swift-swimming fishes in the struggle for existence, excepting as they conceal themselves. In order to see the better while mnseen, the inferior eye has turned inward, i. e., upward, and finally has penetrated to the superior surface, so that both eyes are on one side. This pe- + culiarity wonld be incredible if we did not know of its existence, and is an

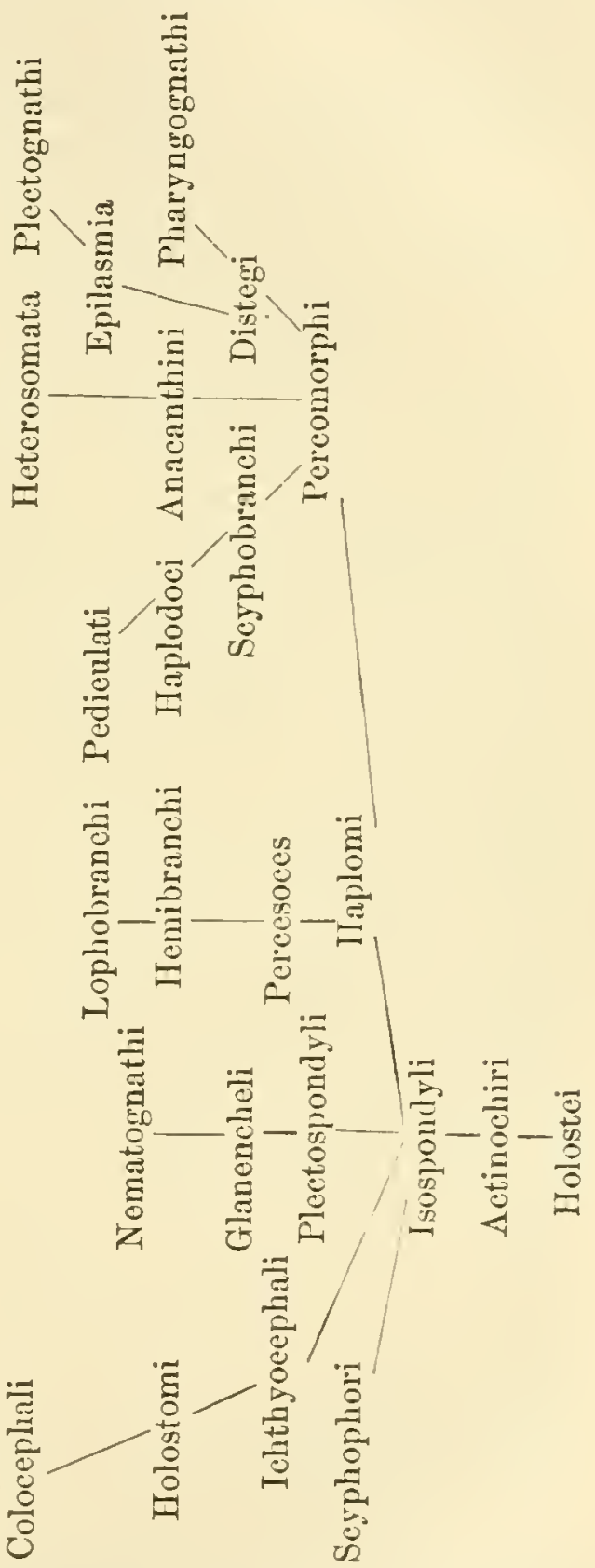
illustration of the extraordinary powers of accommodation pos(F.d. 1886.)

+ This order was proposed by Gill for the Eurypharyngidx, and is now added. (Ed. 1886.) 
sessed by nature. The Ileterosomata ean only be considered a degenerate group.

The double bony floor of the skull of the Distegous percomorph fishes is a complieation which places them at the summit of the line of true fishes. At the summit of this division must be placed the Pharyngognathi, which fill an important rôle in the economy of the tropienl seas, and the fresh waters of the Southern hemisphere. By means of their powerful grinding pharyngeal apparatus they can reduce vegetable and animal food inaccessible to other fishes. The result is seen in their multifarious speeies and innumerable individuals decked in gorgeous colors, and often reaching considerable size. This is the royal order of fishes, and there is no reason why they should not continue to increase in importance in the present fauna.

Very different is the line of the Plectognathi. The probable ancestor's of this division, the Epilasmia (Chætodontidæ, etc.), are also abundant in the tropical seas, and are among the most brilliantly colored of fishes. One of their peculiarities is seen in a shortening of the brain-ease and prolongation of the jaws downward and forward. The utility of this arrangement is probably to enable them to procure their food from the holes and cavities of the coral reefs among whieh they dwell. In some of the genera the muzzle has become tubular (Chelmo), and is aetnally used as a blow-gun by which insects are secured by shooting them with drops of water. This shortening of the basicrmial axis has produced a corresponding abbreviation of the hyoid apparatus. The smperior pharyngeal bones are so crowded as to have become a series of vertieal plates like the leaves of a book. These characters are further developed in the Plectognathi. The brain-case is very small, the face is very elongate, and the mouth is much contracted. The bones surrounding it in each jaw are co-ossified. The axial elements (femora) of the posterior fins unite together, become very elongate, and lose the natatory portion. In one group (Orthagoriscida) the posterior part of the vertebral column is lost and the caudal fin is a nearly useless rudiment. In the Ostraciontidæ (which may have had a different origin, as the pharyngeal bones are not contracted) the natatory powers are mueh reduced, and the body is inclosed in an osseous carapace so as to be capable of very little movement. 'The entire order is deficient in osseous tissue, the bones being thin and weak. It is a marked case of degeneracy. 
There are several evident instances of sporadic degeneracy in other orders. One of these is the case of the family of the Icosteidx, fishes from deep waters off the coast of California. Although members of the Percomorphi, the skeleton in the two genera Icostens and Icichthys is unossified, and is perfectly flexible. Approximations to this state of things are seen in the parasitic genus Cyclopterus, and in the ribbon-fishes, Trachypteridæ.

Thus nearly all the main lines of the Physoclysti are degenerate; the exceptions are those that terminate in the Scombridx (mackerel), Serranidæ, and Scaridæ (Pharyngognathi).

\section{Г. THE LINE OF THE BATRACHIA.}

Te know Batrachia first in the Coal Measures. They reach a great development in the Permian epoch, and are represented by large species in the Triassic period. From that time they diminish in numbers, and at the present day form an insignificant part of the vertebrate fauna of the earth. The history of their succession is told by a table of classification such as I give below :

I. Supraoccipital, intercalary and supratemporal bones present. Propodial bones distinct.

Vertebral centra, including atlas, sermented, one set of segments together support-

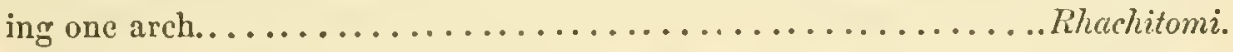
Vertebra segmented, the superior and inferiol segments each complete, forming two

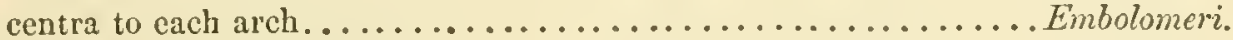

Vertebral centra, including atlas, not segmented, one to each arch.... Stegocephali.

II. Supraoccipital and supratemporal bones wanting. Frontal and propodial bones distinct.

a. An os intercalare.

A palatine arch and separate caudal vertebræ.................. Proteida. aa. No os intercalare.

A maxillary arch; palatine arch imperfect; nasals, premaxillaries and caudal rertebre distinct.........................................

No maxillary or palatine arches; nasals and prensaxillary, also caudal vertebra, dis-

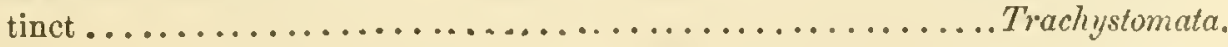

III. Supraoccipital, intercalare and supratemporal bones wanting. Frontals and parictals connate; propodial bones and caudal vertebre confluent.

Premaxillaries distinet from nasals; no palatine arch; astragalus and calcaneum elongate, forming a distinct segment of the limb............... Anura.

The probable phylogeny of these orders as imperfectly indicated by paleontology is as follows:

* Probably includes the Gymnophiona. 


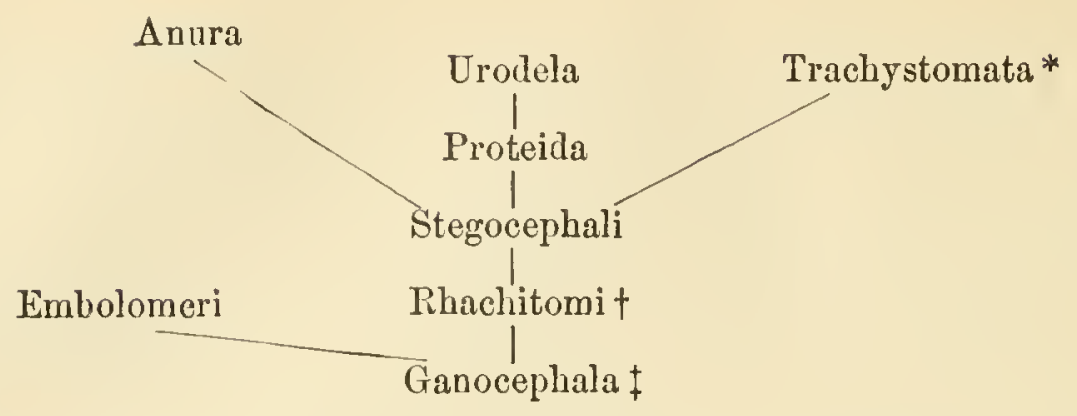

An examination of the above tables shows that there has been in the history of the Batrachian class a reduetion in the number of the elements composing the skull, both by loss and by fusion with each other. It also shows that the vertebræ have passed from a notochordal state with segmented centra, to biconcave centra, and finally to ball-and-socket centra, with a great reduction of the candal \# series. It is also the fact that the earlier forms (those of the Permian epoch) show the most Mammalian characters of the tarsus and of the pelvis. The latter forms, the salamanders, show a more generalized form of carpus and tarsus and of pelvis also. In the latest forms, the Anura, the carpus and tarsus are reduced through loss of parts, except that the astragalus and calcaneum are phenomenally elongate. We have then, in the Batrachian series, a some what mixed kind of change; but it principally consists of concentration and consolidation of parts. The question as to whether this process is one of progression or retrogression may be answered as follows: If degeneracy consists in "the loss of parts withont complementary addition of other parts," then the Batrachian line is a degenerate line. This is only partly true of the vertebral column, which presents the most primitive eharacters in the early, Permian, genera (Rhachitomi). If departure from the nearest approximation to the Mammalia is degeneraey, then the changes in this class come under that head. The carpus, tarsus, and scapular and pelvic arehes of the Rachitomi are more Mammalian than are those of any of their successors. $\|$

* The Trachystomata probably came from the Urodela by a process of degeneracy. See "American Naturalist," Dec., 1885. (Ed. 1886.)

$\uparrow$ Includes the Eryopida.

$\ddagger$ Includes Trimerorhachidx and Arehegosanridæ; and is distinguished from the Rhachitomi only by the presence of a single and cotyloid articulation of the skull with the atlas.

\# This reduction extends to the dorsal series as well. (Wd. 1886.)

\| This should read, than their latest, or anurous successors. (Ed. 1886.) 
There are several groups which show special marks of degeneracy. Such are the reduced maxillary bones and persistent gills of the Proteida; the absence of the maxillary bones and the presence of gills in the Trachystomata; the loss of a pair of legs and feebleness of the remaining pair in the sirens; and the extreme reduction of the limbs in Amphiuma. Such $I$ must also regard, with Lankester, the persistent branchix of the Siredons. I may add that in the brain of the Proteild Necturus the hemispheres are relatively larger than in the Anura, which are at the end of the line.

It must be concluded, then, that in many respects the Batrachia have undergone degeneracy with the passage of time.

\section{THE REPTILIAN LINE.}

As in the case of the Batrachia, the easiest way of obtaining a gencral view of the history of this class is by throwing their principal structural characters into a tabular form. As in the case of that class, I commence with the oldest forms and end with the latest in the order of time, which, as usual, corresponds with the order of structure. I except from this the first order, the Ichthyopterygia, which we do not know prior to the Triassic period:"

A. Extremitics not differentiated in form beyond proximal segment.

I. Os quadratum immovably articulated to squamosal, ete.

Tubcrcular and capitular rib-articulations prescnt and distinct... 1. Ichthyopterygia.

AA. Elements of extremities differentiated.

II. Os quadratum immovably articulated; capitular and tubercular rib-articulations distinct. Archosauria.

Pubis and ischium united, and with little or no obturator foramen; one posterior cranial arch; limbs ambulatory; a procoracoid...........2. Theromorpho. Ischium and pubis distinct, the latter directed forward, backward, or downward; two posterior cranial arches; limbs ambulatory; no procoracoid

3. Dinosauria.t

Iscbium and pubis united; two posteranial arches; anterior limbs volant

4. Ornithosauria.

III. Os quadratum closely united to cranial arches; but one rib-articulation. Synaptosauria.

* Generally similar to the system published by me in "Proceedings Amer. Ass. Adv. Science," xix, p. 233.

t This definition includes the Crocodilia in the Dinosauria, as it is absolutely connected with the typical Dinosaurs by the Opisthocola (Sauropoda Marsh). 
Distinct hyposternal and postabdominal bones; ribs joining each two vertebræ, and generally forming a carapace; one posterior cranial arch......5. Testudinata. Hyposternal and postabdominal bones not distinct; two posterior cranial arches; ribs attached to one vertebra; a sternum; ? no procoracoid

6. Rhynchocephalia. Hyposternal and postabdominal bones not distinet; two posterior cranial arehes; ribs attached to one centrum; no sternum; * a procoracoid. .7. Sauropterygia.

IV. Os quadratum attached only at the proximal extremity, and more or less movable; ribs with one head. Streptostylica. $\dagger$

Brain-casc membranous in front of proötic bone; trabecula not persistent

8. Lacertilia.

Brain-case with osseous walls anterior to proötic; a scapular arch and sternum

9. Pythonomorpha.

Brain-case with osseous walls anterior to proötic; no scapular arch nor sternum; trabeeular grooves of sphenoid and presphenoid bones.........10. Ophidia.

An inspection of the characters of these ten orders, and their consideration in connection with their geological history, will give a definite idea as to the character of their evolntion. The history of the class, and therefore the discussion of the question, is limited in time to the period which has elapsed since the Permian epoch inchusive, for it is then that the Reptilia enter the field of our knowledge. During this period but one order of reptiles inhabited the earth, so far as now known, that of the Theromorpha. The important character and rôle of this type may be inferred from the fact that they are structurally nearer to both the Batrachia and the Mammalia than any other, but present characters which render it probable that all the other reptiles, with possibly the exception of the Ichthyopterygia, derived their being from them. 'The phylogeny may be thus expressed :

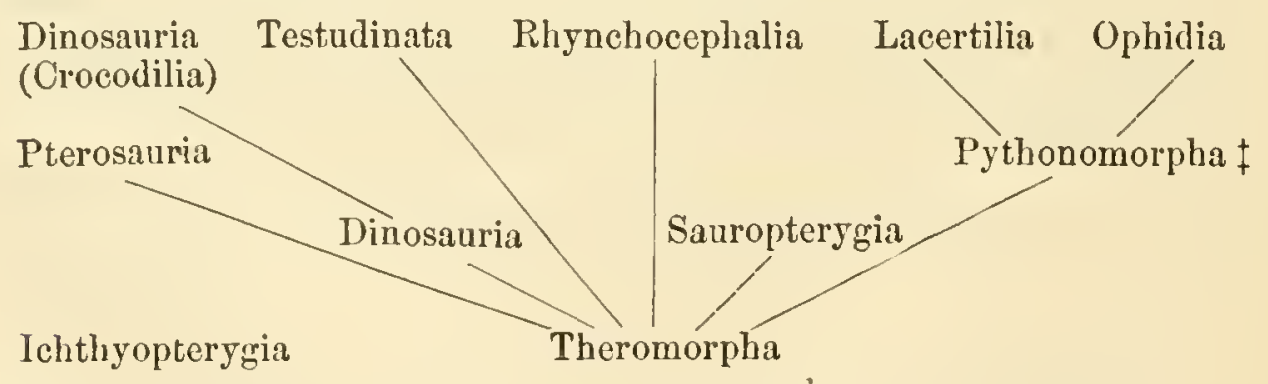

* Episternum present.

f It is quite possible that the three divisions of this head form one natural ol'der, the Streptostylica, or Squamata.

$\ddagger$ Some unknown type of this order will represent the ancestor of the Ophidia, while the Lacertilia may have come directly from the Theromorpha. (Ed. 1886.) 
In the first place, this line departs with lapse of time from the primitive and ancestral order, the Theromorpha, in two respects: First, in the loss of the capitular articulation of the ribs, and, second, in the gradual elongation and final freedom of the suspensory bone of the lower jaw (the os quadratum). In so departing from the Theromorpha, it also departs from the mammalian type. The ribs assume the less perfect kind of attachment which the mammals only exhibit in some of the whales, and the articnlation of the lower jaw loses in strength, while it gains in extensibility, as is seen in the development of the line of the eels among fishes. The end of this series, the snakes, must therefore be said to be the result of a process of creation by degeneration, and their lack of scapular arch and fore limb and usual lack of pelvic arch and hind limb, are confirmatory evidence of the trnth of this view of the case.

Secondly, as regards the ossification of the anterior part of the brain-case. This is deficient in some of the Theromorpha, the ancestral order, which resemble in this, as in many other things, the contemporary Batrachia. Some of them, howerer (Diadectidx), have the brain completely inclosed in front. The late orders mostly have the anterior walls membranous, but, in the streptostylicate series at the end, the skull in the snakes becomes entirely closed in front. In this respect, then, the latter may be said to be the highest or most perfect order.

As regards the scapular arch, including the sternum, no order possesses as many elements as thoroughly articnlated for the use of the anterior leg as the Permian Theromorpha, though the coracoid is of reduced size. In all the orders there is loss of parts, excepting only in the Ornithosauria and the Lacertilia. In the former the adaptation is to flying. The latter retain nearly the Theromorph type, enlarging the coracoid. An especial side development is the modification of abdominal bones into two peculiar clements to be united with the scapular arch into a plastron, seen in the Testndinata. In this part of the skeleton the orders are generally degenerate, the last one, the Ophidia, especially so.

The pelvic arch has a more simple history. Again, in the 'Theromorpha we have the nearest approach to the Mimmalia. The only other order which displays similar characters is the Ornithosauria (Dimorphodon, according to Seeley). In the Dinosimuria we have a side modification which is an adaptation to the erect or bipedal mode of progression, the inferior bones being 
thrown backward so as to support the viscera in a more posterior position. 'This is an obvious necessity to a bipedal animal where the vertebral column is not perpendicular, as in birds. And it is from the Dinosauria that the birds are supposed to have arisen. (Plates XV and XVI.) The main line of the Reptilia, however, departs from both the mammalian and the avian type and loses in strength as compared with the former. In the latest orders, the Phythonomorpha and Ophidia, the pelvis is rudimental or absent.

As regards the limbs, the degeneracy is well marked. No reptilian order of later ages approaches so near to the Mammalia in these parts as do the Permian Theromorpha. This approximation is seen in the internal epicondylar foramen and well-dereloped condyles of the humerus, and in the well-differentiated seven bones of the tarsus. The epicondylar foramen is only retained in later reptiles in the Rhynchocephalian Hatteria (Dollo); and the condyles of the Dinosamria and all of the other orders, excepting the Ornithosauria and some Lacertilia, are greatly wanting in the strong characterization seen in the Theromorpha. The posterior foot seems to have stamped out the greater part of the tarsus in the liuge Dinosauria, and it is reduced, thongh to a less degree, in all the other orders. In the paddled Sanropterygia, dwellers in the sea, the tarsus and carpus have lost all characterization, probably by a proeess of degeneracy, as in the mammalian whales. This is to be inferred from the comparatively late period of their appearance in time. The still more mopecialized feet and limbs of the Ichthyosaurus (Ichthyopterygia) can not yet be ascribed to degeneracy, for their history is too little known. At the end of the line, the snakes present us with another evidence of degeneracy. But few have a pelvic areh (Stenostomidæ Peters), while very few (Peropoda) have any trace of a posterior limb.

The vertebra are not introduced into the definitions of the orders, since they me not so exclusirely distinctive as many other parts of the skeleton. They nevertheless must not be overlooked. As in the Batrachia, the Permian orders show inferiority in the deficient ossification of the centrum. Many. of the Theromorpha are notochordal, a character not found in any later order of reptiles excepting in a few Lacertilia (Geconide). They thus differ from the Mammalia, whose characters are approached more nearly by some of the terrestrial Dinosauria in this respect. 
Leaving this order, we soon reach the prevalent ball-and-socket type of the majority of Reptilia. This strong kind of articulation is a need which accompanies the more elongated column which itself results at first from the posterior direction of the ilium. In the order with the longest column, the Ophidia, a second artieulation, the zygosphen, is introduced. The mechanical value of the later reptilian vertebral structure is obvions, and in this respeet the class may be said to present a higher or more perfect condition than the Mammalia.

In review it may be said of the reptilian line, that it exhibits marked degeneracy in its skeletal strueture since the Permian epoch; the execption to this statement being in the nature of the articulations of the vertebræ. And this specialization is an adaptation to one of the conditions of degeneracy, viz., the weakening and final loss of the limbs and the arches to which they are attached.

The history of the development of the brain in the Reptilia presents some interesting facts. In the Diadectid family of the Permian Theromorpha it is smaller than in a Boa constrictor, but larger than in some of the Jurassic Dinosanria. Marsh has shown that some of the latter possess brains of relatively very narrow hemispheres, so that in this organ those gigantic reptiles were degenerate, while the existing streptostylicate orders have advanced beyond their Permian ancestors.

There are many remarkable cases of what may now be safely called degradation to be seen in the contents of the orders of reptiles.* Among tortoises may be cited the loss of the ribheads and of one or two series of phalanges in the especially terrestrial family of the Testudinidx. The cases among the Lacertilia are the most remarkable. The entire families of the Pygopodidx, the Aniellidæ, the Anelytropidx, and the Dibamidx are degraded from superior forms. In the Anguidæ, 'Teïdx, and Seincidæ, we have series of forms whose stens are measured by the loss of a pair of limbs, or of from one to all the digits, and even to all the limbs. In some serics the surangular bone is lost. In others the eye climinishes in size, loses its lids, loses the folds of the epidermis which distinguishes the cornea, and finally is entirely obscured by the closure of the ophthalnie orifice in the

* Such forms in the Lacertilia have been regarded as degradational by Lankester and Joulanger. 
PLATE $X V$.

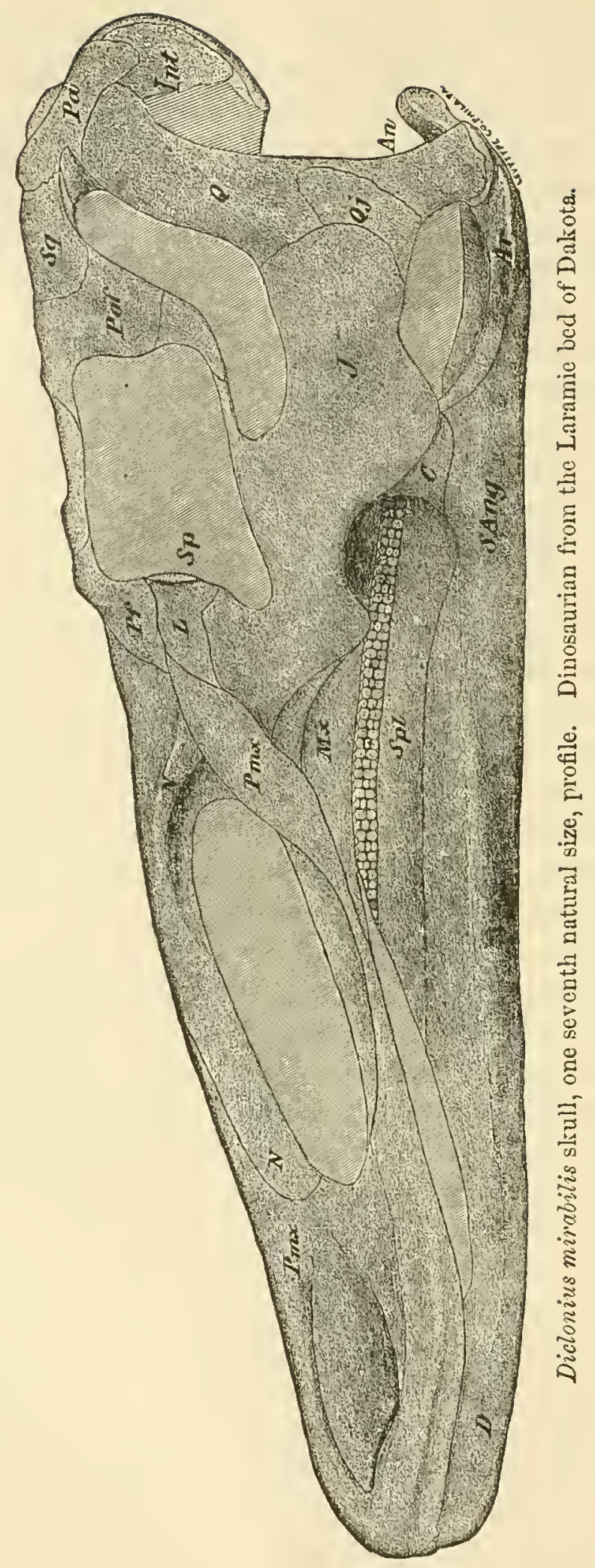


PLATE XVI.

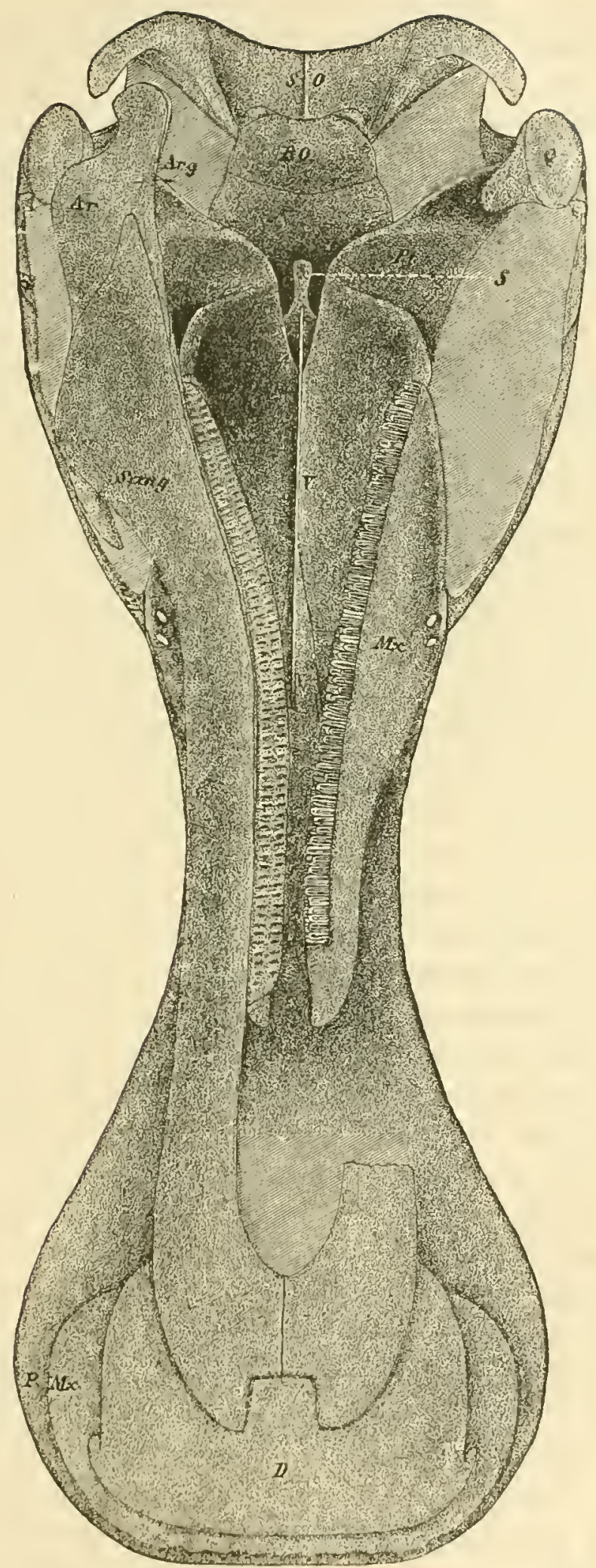

Diclonius mirabilis skull, one seventh natural size, from below. 
true skin. Among the snakes a similar degradation of the organs of sight has taken place in the order of the Scolecophidia, which live underground, and often in ants' nests. The Tortricidæe and Uropeltidæ are burrowing-snakes which display some of the earlier stages of this process. One genus of the true snakes even (according to Günther) has the eyes obscured as completely as those of the inferior types above named (genus Typhlogeophis).

\section{THE AVIAN LINE.}

The paleontology of the birds not being well known, our conclusions respecting the character of their evolution must be very incomplete. A few lines of succession are, however, quite obvious, and some of them are clearly lines of progress, and others are lines of retrogression. The first bird we know at all completely, is the celebrated Archeopteryx of the Solenhofen slates of the Jurassic period. In its elongate series of caudal vertebræ and the persistent digits of the anterior limbs we have a clear indication of the process of change which has produced the true birds, and we can see that it involves a specialization of a very pronounced sort. The later forms described by Seeley and Marsh from the Cretaceous beds of England and North America, some of which have biconcave vertebræ, and all probably, the American forms certainly, possessed teeth. This latter character was evidently speedily lost, and others more characteristic of the subclass became the field of developmental change. 'The parts which subsequently attained especial development are the wings and their appendages; the feet and their envelopes, and the vocal organs. 'Taking all things into consideration, the greatest sum of progress has been made by the perching birds, whose feet have become effective organs for grasping, whose rocal organs are most perfect, and whose flight is generally good, and often very good. In these birds also the circulatory system is most modified, in the loss of one of the carotid arteries.

The power of flight, the especially avian character, has been dereloped most irregularly, as it appears in all the orders in especiul cases. This is apparent so early as in the Cretaceous toothed birds already mentioned. According to Marsh the Hespeornithidx have rudimental wings, while these organs are well developed in the Ichthyornithidæ. They are well developed among natatorial forms in the albatrosses and frigate pelicans, and in the skuas, gulls, and terns; among rasorial types the 
sand-grouse, and, among the adjacent forms, the pigeons. Then among the lower insessores, the humming-birds exceed all birds in their powers of flight, and the swifts and some of the Caprimulgidæ are highly developed in this respect. Among the higher or true song birds, the swallows form a notable example. With these high specializations occur some remarkable deficiencies. Such are the reduction of the feet in the Caprimulgidæ, swifts, and swallows, and the foetal character of the bill in the same families. In the syndactyle families, represented by the kingfishers, the condition of the feet is evidently the result of a process of degeneration.

A great many significant points may be observed in the developmental history of the epidermic structures, especially in the feathers. The scale of change in this respect is in general a rising one, though various kinds of exceptions and variations occur. In the development of the rectrices (tail-feathers) there are genera of the wading and rasorial types, and even in the insessorial series, where those feathers are greatly reduced or absolutely wanting. 'These are cases of degeneracy.

There is no doubt that the avian series is in general an ascending one.

\section{THE MAMMALIAN LINE.}

Discoveries in paleontology have so far invalidated the accepted definitions of the orders of this class that it is difficult to give a clearly cut analysis, especially from the skeleton alone. 'The following scheme, therefore, while it expresses the natural groupings and affinities, is defective in that some of the definitions are not without exceptions:

I. A large coracoid bone articulating with the sternum.

Marsupial bones; fibula articulating with proximal end of astragalns

1. Monotremata.

II. Coracoid a small process co-ossified with the scapula.

a. Marsupial bones; palate with perforations (vagina double; placenta and corpus callosum rudimental or wanting; cerebral hemispheres small and generally smooth).

But one decidnous molar tooth. .................... Marsupialia.

aa. No marsupial bones; palate entire (one vagina; placenta and corpus callosum well developed).

B. Anterior limb reluced to more or less inflexible paddles, posterior limbs wanting (Mutilata). 
No elbow-joint; carpals discoid, and with the digits separated by eartilage; lower

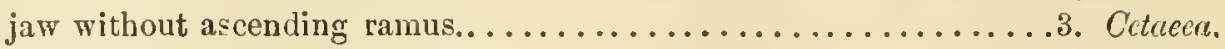

An elbow-joint; carpals and phalanges with normal articulations; lower jaw with

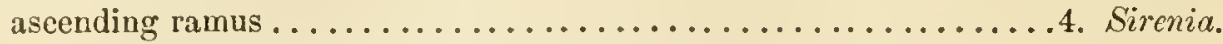

$\beta \beta$. Anterior limbs with flexible joints and distinct digits; ungual plalanges not compressed and acute at apex* (Ungulata $\dagger$ ).

$\boldsymbol{\gamma}$. Tarsal bones in linear series; carpals generally iu linear series.

Limbs ambulatory; teeth with enamel................. 'Tuxeopoda.

$\gamma \gamma$. Tarsal series alteruating; carpal series linear.

Cuboid bone partly supporting navieular, not in contact with astragalus. 6. Proboscidia.

$\gamma \gamma \gamma$. Both tarsal and earpal series more or less alternating.

Os magnum not supporting scaphoides; cuboid supporting astragalus; superio: molars tritubercular........................ Amblypoda. Os magnum supporting seaphoides; superior molars quadritubereular \#

8. Diplartira.\|

$\beta \beta \beta$. Anterior limbs with flexible joints. Ungual phalanges compressed and pointed $\Delta$ (Unguiculata).

є. Teetlı without enamel; no incisors.

Limbs not volant; hemispheres small, smooth. .

9. Edeniata.

$\epsilon є$. 'Teeth with enamel; ineisors present.

No postglenoid process; maudibular condyle round; limbs not volant; hemispheres

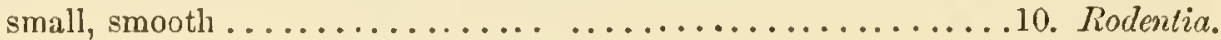

Limbs volant; hemispheres small, smooth.................. Chiroptere.

* Except the Irapalidæ. † Lamarek, "Zoölogie Plilosophique," 1809.

$\ddagger$ This order has the following suborders, whose association is now made for the first time:

Carpal series linear; no intermedium; fibula not interlocking with astragalus; no anapophyses; incisors rooted; hallux not opposable......... Condylarthe. Carpal series linear; an intermedium; fibula interlocking with astragalus; hallux

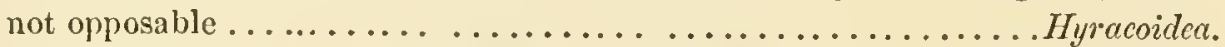

An intermedium; fibula not interlocking; anapophyses; hallıx opposable; incisors growing from persistent pulps.................. Daubentonoidea.

An intermedium; fibula not interlocking; anapophyses; hallux opposable; incisors rooted; earpus generally linear..............................

No intermedium; * nor anapophyses; carpal rows alternating; incisors rooted

Anthropoidea.

The only difference between the Taxeopoda and the Bunotheria is in the unguliform terminal phalanges of the former as compared with the clawed or unguiculate form in the latter. The marmosets among the former division are, however, furnished with typical claws.

Some may prefer to use the term Primates in place of Taxeopoda, and such may be the better course.

\# Except Pantolestes.

\| This order includes the suborders Perissodactyla and Artiodactyla. It is the Ungulata of some authors.

$\triangle$ Except Mesonyx.

* Except in Simia and Hylobates. +Includes the Anthropoid apes and man. 
A postglenoid process; mandibular condyle transrerse; limbs not rolant; no scapholunar bone; ${ }^{*}$ hemispheres small, smooth..........12. Bunotheria. $\dagger$

A postglenoid process; limbs not rolant, with a scapholunar bone; henispheres

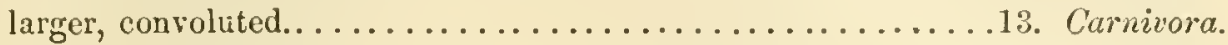

Paleontology has eleared up the phylogreny of most of these orders, but some of them remain as yet unexplained. This is the case with the Cetacea, the Sirenia, and the Taxeopoda. The last-named order and the Marsupialia can be supposed with much probability to have come off from the Monotremata, but there is as yet no paleontological evidence to sustain the hypothesis. No progress has been made in unrareling the phylogeny of the Cetacea and Sirenia. The facts and hypotheses as to the phylogeny of the Mammalia may be represented in the following diagram:

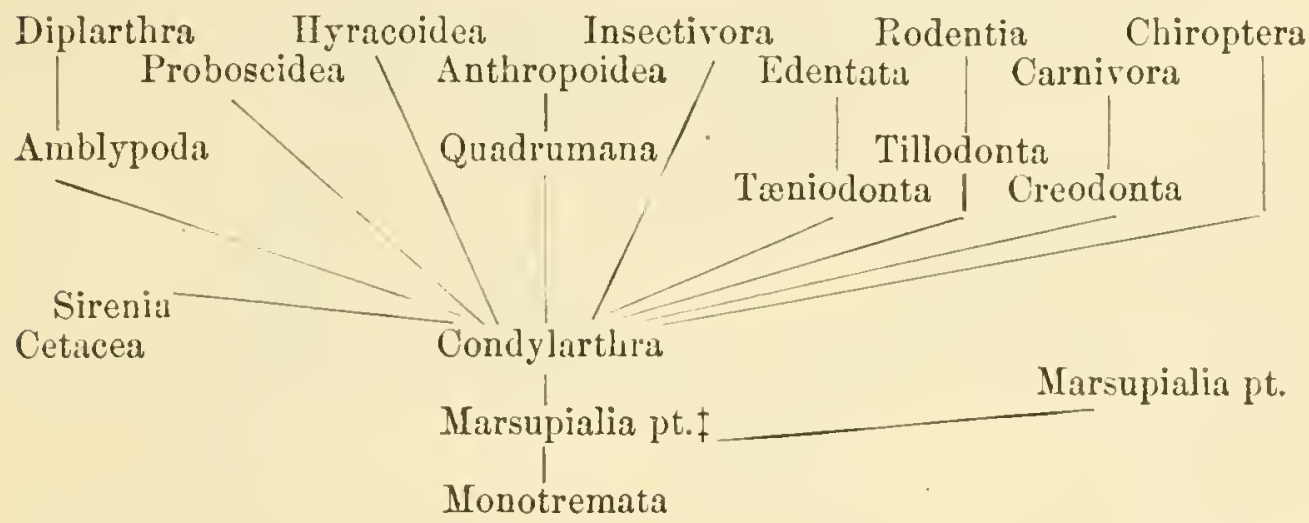

It will be readily seen from the above diagram that the discovery of the Condylarthra was an important event in the history of our knowledge of this subject. This suborder of the Lower Eocene epoch stands to the placental Mammalia in the same relation as the Theromorphous order does to the reptilian orders. It generalizes the claracteristics of them all, and is apparently the parent stock of all, excepting, perhaps, the Cetacea. The discovery of the extinct Bunotherian suborders united together insenarably the clawed orders, excepting the bats; while the extinct order Amblypoda is the ancestor of the most specialized of the Ungnlates, the odd-and even-toed Diplarthra.

The characters of the skeleton of the order Monotremata show that it is nearest of kin to the Reptilia, and many subordinate

\footnotetext{
* Except Erinaccus.

+ With the suborders Inscetivor: Creodonta, Taeniodonta, and Tillodonta.

$\ddagger$ This was inadvertently omitted in the original. (Ed. 1886.)
} 
characters point to the 'Theromorpha as its ancestral source. * In the general characters the Marsupialia naturally follow in a rising scale, as proved by the increasing perfection of the reproductive system. The Monodelphia follow with improvements in the reproductive system and the brain, as indicated in the table already given. The oldest Monodelphia were, in respect to the structure of the brain, much like the Marsupialia, and some of the existing orders resemble them in some parts of their brain-structure. Such are the Condylarthra and Amblypoda of extinct groups, and the Bunotheria, Edentati, Rodentia, and Chiroptera, recent and extinet. The characters of the brains of Amblypoda and some Creodonta are, in their superficial characters, even inferior to existing marsupials. The divided uterus of the recent forms named, also gives them the position next to the Marsupialia. In the Carnivoril, Hyracoided, and Proboscidia, a decided adrance in both brain-structure and reproductive system is evident. The hemispheres increase in size, and they become convolnted. A uterus is formed, and the testes become external, etc. In the Quadrumana the culmination in these parts of the structure is reached, excepting only that, in the lack of separation of the genital and urinary efferent, ducts, the males are inferior to those of many of the Artiodactyla. This history displays a rising seale for the Mammalia.

Looking at the skeleton, we observe the following successional modifications : $\uparrow$

First, as to the feet, and (A) the digits. The Condylarthra have five digits on both feet, and they are plantigrade. This character is retained in their descendants of the lines of Anthropoidea, Quadrumana, and Hyracoidea, also in the Bunotheria, Edentata, and most of the Rodentia. In the Amblypoda and Proboscidia the palm and heel are a little raised. In the Carnivora and Diplarthra the heel is raised, often very high, above the ground, and the number of toes is diminished, as is well known, to two in the Artiodactyla and one in the Perissodactyla. (B) The tarsus and carpus. In the Condylarthra the bones of the two series in the carpus and tarsus are opposite each other, so as to form continuous and separate longitudinal series of bones. This continues to be

* "Proceedings American Philosoph. Socicty," 1854, p. 43.

+ See the evidence for evolution in the history of the cxtinct Mammalia. "Proceeds. Amer. Assoc. Adv. Science," 1883. 
PLATE XVII.

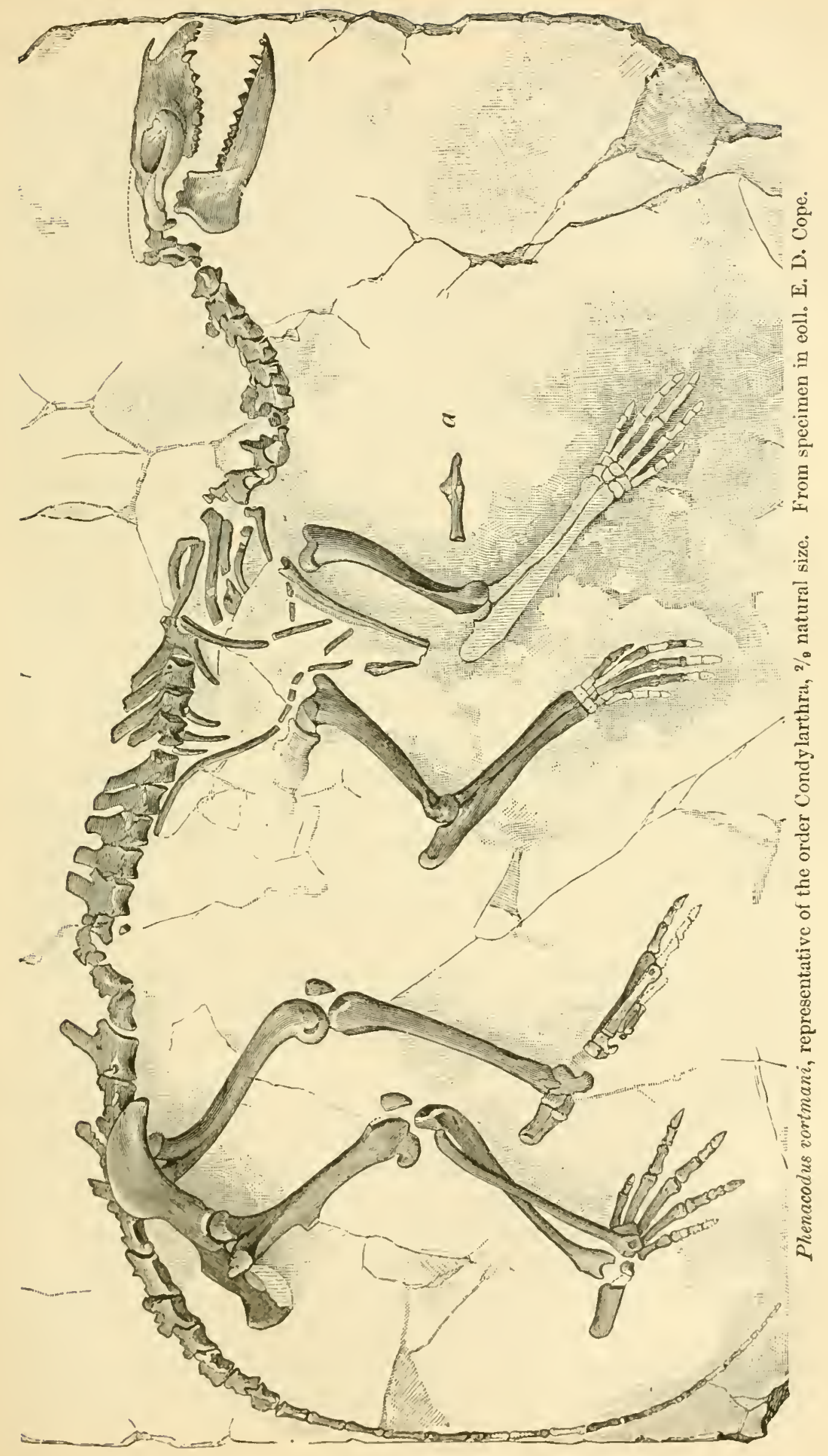


the case in the Hyracoidea and many of the Quadrumana, but in the anthropoid apes and man the second row is displaced inwards so as to alternate with the first row, thus interrupting the series in the longitudinal direction, and forming a stronger structure than that of the Condylarthra. In the Bunotherian Rodent and Edentate series, the tarsus continues to be without alternation, as in the Condylarthra, and is generally identical in the Carnivora. In the hoofed series proper it undergoes change. In the Proboscidia the carpus continues lincar, while the tarsus alternates. In the Amblypoda the tarsus alternates in another fashion, and the carpal bones are on the inner side linear, and on the outer side alterwating. The complete interlocking by universal alternation of the two carpal series is only fonnd in the Diplarthra. (C) As to the ankle-joint. In most of the Condylarthra it is a flat joint or not tongued or grooved. In most of the Carnivora, in a few Rodentia, and in all Diplarthra, it is deeply tongued and grooved, forming a more perfect and stronger joint than in the other orders, where the surfaces of the tibia and astragalus are flat. (D) In the highest forms of the Rodentia and Diplarthra the fibula and ulna become more or less co-ossified with the tibia and radius, and their middle portions become attennated or disappear.

Secondly, as regards the vertebræ. The mutual articulations (zygapophyses) in the Condylarthra have flat and nearly horizontal surfaces. In higher forms, especially of the nngulate series, they become curved, the posterior tirning npward and outward, and the anterior embracing them on the external side. In the higher Diplartha this curvature is followed by another curvature of the postzygapophysis upward and ontward. so that the vertical section of the face of this process is an S. Thus is formed a very close and secure joint, such as is nowhere seen in any other Vertebrata.

Thirdly, as regards the dentition. Of the two types of Monotremata, the Tachyglossidx and the Platypodidx, the known genera of the former possess no teeth, and the known genus of the latter possesses only a single corneons epidermic grinder in each jaw. As the Theromorphous reptiles from which these are descended have well-developed teeth, their condition is evidently one of degeneration, and we can look for well-toothed forms of Monotremata in the beds of the Triassic and Jurassic periods. Perhaps some such are already known from jaws and teeth. In the marsupial order we have a great range of dental structure, which almost 
epitomizes that of the Monodelph orders. The dentition of the carnivorous forms is creodont; that of the kangaroos is perissodactyle, and that of the wombats is rodent. Other forms repeat the Insectirora. I therefore consider the placental series especially. I have already shown that the greater number of the types of this scries have derived the characters of their molar teeth from the stages of the following succession. First, a simple cone or reptilian crown, alternating with that of the other jaw. Second, a cone with lateral denticles. Third, the denticles to the inner side of the crown forming a three-sided prism, with tritubercular apex, which alternates with that of the opposite jaw. Fourth, derelopment of a heel projecting from the posterior base of the lower jaw, which meets the crown of the superior, forming a tubercular-sectorial inferior molar. From this stage the carnivorous and sectorial dentition is derired, the tritubercular type being retained. Fifth, the development of a posterior inner cusp in the superior molar, and the elevation of the heel in the inferior molar, with the loss of the anterior inner cusp. Thus the molars become quadritubercular, and opposite. This is the type of many of the Taxeopoda, including the Quadrumana and Insectivora as well as the inferior Diplarthra. The higher Taxeopoda (Hyracoidea) and Diplarthra add various complexities. Thus the tubercles become flattened and then concare, so as to form $\mathrm{Vs}$ in the section produced by wearing; or they are joined by cross-folds, forming varions patterns. In the Proboscidia the latter become multiplied so as to produce numerous cross-crests.

The dentition of some of the Sirenia is like that of some of the Ungulata, especially of the suilline group, while in others the teeth consist of cylinders. In the Cetacea the molars of the oldest (Eocene and Miocene) types are but two-rooted and compressed, having much the form of the premolars of other Mammalia. In existing forms a few hare simple conical tecth, while in a considerable number teeth are entirely wanting.

A review of the characters of the existing Mammalia as compared with those of their extinct ancestors displays a great deal of improvement in many ways, and but few instances of retrogression. The succession in time of the Monotremata, the Marsupialia, and the Monodelphia, is a succession of adrance in all the characters of the soft parts and of the skeleton which define them (sce table of classification). As to the monotremes themselves, it is more than probable that the order has degenerated in 
some respects in producing the existing types. The history of the Marsupialia is not made ont, but the earliest forms of which we know the skeleton, Polymastodon (Cope) of the Lower Eocene, is as specialized as the most specialized recent forms. The dentition of the Jurassic forms, Plagiaulax, etc., is quite specialized also, but not more so than that of the kangaroos. The premolars are more specialized, the true molars less specialized than in those animals.

Coming to the Monodelphia, the increase in the size and complication of the brain, both of the cerebellum and the hemispheres, is a remarkable evidence of advance. But one retrogressive line in this respect is known, viz., that of the order Amblypoda, ${ }^{*}$ where the brain has become relatively smaller with the passage of time. The successive changes in the structure of the feet are all in one direction, viz., in the reduction of the number of the toes, the elevation of the heel, and the creation of tongue and groore joints where plain surfaces had previously existed. The diminution in the number of toes might be regarded as a degeneracy, but the loss is accompanied by a proportional gain in the size of the toes that remain. In every respect the progressive change in the feet is an advance. In the carpus and tarsus we have a gradual rotation of the second row of hones on the first, to the inner side. In the highest and latest orders this process is most complete, and, as it results in a more perfect mechanical arrangement, the change is clcarly an advance. The same progressive improvement is seen in the development of distinct facets in the cubito-carpal articulation, and of a tongue and groove ("intertrochlear crest") in the elbow-joint. In the vertebræ the development of the interlocking zygapophysial articulations is a clear advance.

Progress is generally noticeable in the dental structures; for, unlike the marsupial line, the earliest dentitions are the most simple, and the later the more complex. Some of the types retain the primitive tritubercular molars, as the Centetide, shrews and some lemurs, and many Carnivora, but the quadritubercular and its derivative forms are by far the most common type in the recent fanna. The forms that prodnced the complicated modifications in the Proboscidia and Diplarthra appeared latest in time, and the most complex genera, Bos and Equus, the latest of all. The extreme sectorial modifications of the tritubercular type, as

* See "Naturalist," Jan., 1885, p. 55. 
seen in the Hyænidx and the Felidæ, are the latest of their line also.

Some cases of degeneracy are, however, apparent in the monodelphous Mammalia. The loss of pelvis and posterior limbs in the two mutilate orders is clearly a degenerate character, since there can be no donbt that they have descended from forms with those parts of the skeleton present. The reduction of flexibility seen in the limbs of the Sirenia and the loss of this character in the fore limbs of the Cetacea are features of degeneracy for the same reason. 'The teeth in both orders have undergone degenerate evolution; in the later and existing forms of the Cetacea even to extinction. The Edentata appear to have undergone degeneration. 'This is chiefly apparent in the teeth, which are deprived of enamel, and which are wanting from the premaxillary bone. A suborder of the Bunotheria, the 'Tæniodonta of the Lower Eocene period, display a great reduction of enamel on the molar teeth, so that in much-worn examples it appear's to be wanting. Its place is taken by an extensive coat of cementum, as is seen in Edentata, and the roots of the teeth are often undivided as in that order. It is probable that the Edentata are the descendants of the Trniodonta by a process of degeneracy.

Local or sporadic cases of degenerate loss of parts are seen in various parts of the mammalian series, such as toothless Mammalia wherever they oecur. Such are cases where the teeth become extremely simple, as in the honey-eating marsupial Tarsipes, the carnivore Proteles, the Pteropod bats, and the aye-aye. Also where teeth are lost from the series, as in the canine genus Dysodus, and in man. The loss of the hallux and pollex without corresponding gain in rarions genera, may be regarded in the same light.

In conclusion, the progressive may be compared with the retrogressive evolution of the Vertebrata, as follows: In the earlier periods and with the lower forms, retrogressive evolution predominated. In the higher classes progressive evolution has predominated. When we consider the history of the first class of vertebrates, the Tunicati, in this respect, and compare it with that of the last class, the Mammalia, the contrast is very gleat. 


\section{PART III. \\ MECHANICAL EVOLUTION.}

XII.

\section{THE RELATION OF ANIMAL MOTION TO ANIMAL EVOLUTION.}

To explain the origin of variation in animal structure is, par excellence, the object of the doctrine of evolution. There can be little doubt that the law of natural selection includes the cause of the preservation of certain modifications of pre-existent structure, in preference to others, after they have been brought into existence. In what manner or by what process the growing tissues of young animals lave been so affected as to produce some organ or part of an organ which the parent did or does not possess, must be explained by a different set of laws. These have been termed originative, while those involved in natural selection are restrictive only.

I.

Of course we naturally look to something in the "surrounding cireumstances" in which a plant or animal is placed, or its "environment," as the most probable stimulant of change of its character, because we know that such beings are totally dependent on cosmic and terrestrial forces for their sustenance and preservation. The difficulty has been to connect these forces with change of strueture as originative; to show their operation as multiplying, restricting or destroying organisms already in existence is comparatively easy. This diffieulty is partially due to the fact that such modifientions must be realized during a limited portion of the life of an animal at least; that is, during the period of growth, when it is not at all or but little subject to the influence of external environment, but is usually protected or supported by the parent.

That the environment and changes in it affect the movements 
of plants and animals is clear enough. The potency of such changes may be read in the physical history of the earth. A long series of modifications preceded the advent of life upon it, and change, both gradual and sudden, has been exhibited in the configuration and climate of all portions of the surface of the globe since that period. Animals have again and again been called upon to face new conditions, and myriads of species have fallen victims to the inflexibility of their organization which has prevented adaptation to new surroundings. But it is evident that if change of environment has had any influence in the progress of evolution, it has not been alone destructive. It has preceded life as well as death, and has furnished the stimulus to beings capable of change, while it has destroyed those which were incapable of it. It is a truism that change of physical conditions has preceded all great famnal changes, and that the necessity for new mechanism on the part of animals has always preceded the appearance of new structure in geologic times.

The embryology and paleontology of vertebrated animals show that the primary steps in the progress of this branch of the animal kingdom are marked by the successive changes in the structure of the circulatory system. First we have the rarious mechanical methods for the aëration of blood in a watery medium; the result being a fluid whose metamorphosis in nutrition produces no heat. After the fishes followed Batractia, the earliest air-breather's, whose long tarriance to-day in early aquatic stages is an epitome of the necessarily "amphibious" character of air-breathing vertebrate life, when land and fresh water, in constantly changing areas, were rising and scparating from the universal ocean. The successive disappearances of the traces of the fish type of circulation in Batractia and reptiles, are familiar facts; and the exclusion of the unaerrated blood from the systemic circulation in the birds and mammals marks the increase of general temperature which gives those classes one of their claims to superiority.

The appearance of land of course furnished the opportunity for aquatic animals to assume a terrestrial life. Marine animals which had acquired the habit of gulping air from the surface, which some ef them now possess, perhaps becanse its ricluness in oxygen produced an agreeable exaltation or intoxication, would not find visits to the land difficnlt. And this would natmrally follow the necessity of escape from aquatic enemies, or the search for new supplies of food. 
In fine, it requires little argument to show that the environment has had in the past, as in the present, a primary influence over the movements of animals.

II.

I will now endeavor to exhibit some reasons for believing that the movements of animals affect their structure directly.

There are two alternative propositions expressive of the relations of the structures of animals to their uses. Either the use or attempt to use preceded the adaptive strueture, or else the structure preceded and gave origin to the use. The third alternative, that use and structure came into being independently of each other, is too improbable for consideration in the present article. Many facts render the first of these propositions much the more probable of the two.

A general ground for suspecting that movement affects structure is the fact well known to systematic zoölogists, that adaptive characters are the least reliable in systematic classification, i. e., are the most variable. What we call adaptive characters are those whose teleological significance we can most easily perceive; those whose uses are at the present time most obrious. Systematists habitually fall back on characters which are apparently the least related to the ordinary necessities of the life of the animal, and this not from any theoretical considerations, but because such characters are found to be the most constant. This is a very significant fact, showing as it does that it is the adaptive structures which are undergoing modification to-day. And this truth can doubtless be discerned in all past ages, for many of the structures which are not now more related to the needs of an animal than many others might be, were at one time most essential to its wellbeing, or necessarily related to its environment. Such are the structural characters of the heart and arteries already enumerated. There seems to be no reason why all Vertebrata might not exist with equal comfort and success at the present if possessed of a uniform organization in this respect. But the successive modifications which they present were, in past ages, most intimately connected with the progressive changes of the medium in which they lived, as to the volume of oxygen supplied for respiration, as compared with that of the vapor of water, carbonic acid gas, etc. But it must be here noted, in passing, that there are many structures in animals which have never been adaptive, but which 
are simply due to excess or defect of nutrition foliowing a redistribution of force. *

The most direct evidence in support of the view that motion affects structure directly is to be found in the well-known phenomenon of the increase of the size and power of all organs by use. This increase is limited in the adult animal by the general fixity of all the organs, so that one of them camnot be developed beyond a certain point withont injury to others, or withont exhansting the source of supply of nutritive material or special force derived from other organs. The syncope of the gymnast is an illustration of the natural limitation to the development of the museular system which proceeds at the expense of the digestive and circulatory. But effort and exertion may become a habit of mind, which, even if limited in its execntive means, is probably inherited by offspring like all other mental traits. Such a quality possessed by an infant or child doubtless tells on the growth of its organs during their plastic stage, and produces structure by growth which is impossible to the mature body.t And no one knows as yet how far mental bias may affect the nutrition of the parts of the infant in ntero. Certain it is, that if use modifies nutrition in the adult, it must have still greater influence in the young; and it is in the young that the changes which constitute evolution necessarily appear.

Change of strueture during growth is accomplished either by addition of parts ("acceleration") or by subtraction of parts ("retardation").

Acceleration is produced either by multiplication of parts (as cells or segments) already present ("homotopy"), or by the transfer of parts (cells) from one part of the organism to the other ("heterotopy"). Homotopy or repetition is the usual and normal mode of aeceleration ; it may proceed by an "exact repetition" of the parts already existing, as in the simplest animals and plants; or the new parts may differ from the old, as in higher animals, where the process is called "modified repetition." Where new forms traverse in their growth all the stages in which they previously existed, they neessarily present at each stage the eharaeters of those forms which have remained stationary in them, and have not changed. This relation of "exact parallelism" is the

* "Method of Creation," 1871, p. 23.

f In man these changes are chiefly produced in the brain. 
result of the simplest form of evolution or "palingenesis." When the history of growth of an advanced form does not show an identity between its stages and the varions undeveloped or lower adult types, the relation is termed "inexact parallelism," and the type of development " cœnogenesis."

Change of structure is seen to take place in accordance with the mechanical effect of three forms of motion, viz.: by friction, pressure and strain. Under the first two, epidermal tissues become both dense and thick, as is seen on the palms and soles of the hands and feet, and in corns. There is no donbt that strength of the teeth is intimately connected with the hardness of the food. Density of osseous tissue and the coössification of parts of the skeleton, are directly associated with the force and duration of museular contraction. Pathology abounds in illustrations of the determination of nutrition to new localities to meet the exigencies and demands arising from new stimuli. It is only necessary for a structure-producing supply of nutritive material to be habitually determined to a new locality by oft-recurring stimulus, for the movement to become automatic and reflex; and such a tendeney would sooner or later be inherited, and produce structure in the growing organism of the young to a degree far exceeding anything that is possible in the adult.

In view of the above considerations, we can ascribe an extensive elass of osseous projections at points of muscular insertion, to the strength and duration of muscular contractions. To the same cause may be ascribed various anchyloses, snch, for instance, as is seen in the foot of the sloth. Transverse strains or their absence may be looked upon respectively as the cause of the hingelike or immovable articulations of the segments of the limbs of vertebrate animals. It is well known that in land animals, where easy flexibility of the limbs is essential to speed, these articulations are highly developed, while in marine animals, where the limbs are only used as paddles, they are almost or quite infiexible, and the extremities of the bones are truncate. In the most highly organized land Mammalia, the tibio-tarsal and humero-cubital articulations display an interlocking or tongueand-groove character. The same thing is seen in the ulnoradial fixed articulation in the same types. These arrangements are especially adapted to prevent dislocation by side strains, and if the preceding explanations be true, this structure is a corrugation due to the lateral pressure of a more or less 
convex surface, on a concave one which embraces it, and vice versa.

In the circulatory system, pressure has doubtless played an important part. Increased oxygenation of blood, the necessary consequence of the purification of the atmosphere, would stimulate the action of all the organs, including that of the heart. Greater pressure on its walls and septa would increase their size and strength, and ultimately close such foramina as were not in the course of the blood current, as the foramen septi ventriculorum of reptiles, and the $f$. ovale. Increased force of the cmrrent would, on the other hand, soon cause the enlargement of one or other of the four or five pairs of primary aorta bows, and develop it at the expense of the others, until finally the pre-cminence of one channel be secured and the aorta be the result. This part of the subject might be prolonged to an unlimited extent, but the above illustrations must suffice to indicatc the meaning of my propositions.

III.

That movements change the environment of a plant or an animal, or parts of them, is obvious enough. If we consider only the reflex class, to which all the movements of plants and many of those of animals belong, we perceive that but for them the ordinary functions of assimilation, circulation, etc., could not be performed; there would be no change in the contents of their tubes and cells, and the environment of these would be unaltered. But when we riew the movements of the higher animals, we perceive the immense importance of the powers and organs of movement as a factor in evolution. It may be safcly assumed that, without powers of designed or adaptive movement, life would never have adranced beyond the stage presented by the regetable kingdom.

The stimuli which are effective in animal consciousness are four, viz: excessive temperature, hunger, danger from enemies, and the reproductive instinct. These prompt to the movements which we observe in animals in a wild state, and withont which it is erident that the animals themselves would soon cease to exist.

It can not be denied that organisms which are incapable of moving from place to place in search of food, or of migration to escape vicissitudes of temperature, are mucl more completely sub- 
ject to the influerces of their environment than those that are eapable of such movement. Hence animals are much more independent of the supply of food and of temperature than are plants. Hence also, other things being equal, the greater the powers of motion, the greater the independenee.

Powers of movement then enable animals to avoid extremes of elimate by migrations or by protective arts. They enable them to procure food by making journeys in search of it, and by all methods of eapturing it. They furnish the agent of active defense against enemies, and of successfully reproducing their kind.

When, through changes of level of the earth's surface, drought has overtaken a region, animals capable of the neeessary migrations have escaped. When an irruption of destructive animal enemies has threatened an animal population with death, those members of it whose strength or speed insured them safety, were the survivors. When land has been eneroached upon by water to such a degree as to bring starvation on its animal inhabitants, those which could fly or swim have sought new loealities.

Since all food-supply, as well as the ability to obtain food, is dependent on temperature, those portions of the organism which furnish means of resistanee to climatie vicissitudes have the deepest significance in the life-history of any division of animals.

The organs of circulation and motion are generally recognized as primary in the classification of Vertebrata. All situations where animal life is permitted by elimate, support vegetable life also; so each of the primary divisions of animals presents types adapted to the use of all kinds of food; herbivorons, omnivorous, and carnivorous. Aceordingly, it has been found that dental and other stmetures connected with digestion define divisions of secondary value and minor extent. Paleontology shows that the origin of such divisions is of later date than that of the great classes first mentioned; and each of the latter has in its day been modified in the subordinate directions indicated by the teeth and beak. But bere also organs of movement are of great importance; so that the herbivorons and carnivorous types at least, have ever in land animals (reptiles, birds and mammals) been characterized by the strueture of their feet also. 


\section{IV.}

It has been maintained above, that enviromment governs the movements of animals, and that the morements of animals then alter their environment. It has also been maintained that the movements of animals have modified their structure so as to render them more or less independent of their environment. The history of animal life is in fact that of a suceession of conquests over the restraints imposed by physical surroundings. Man has attained to a wonderful degree of emancipation from the iron bonds that confine the lower organisms.

It becomes then all important to examine into the elements involved in animal movements.

These are of the two classes, reflex and conscious. To the former belongs the accelerated activity of muscular aetion and circnlation, inferred to have accompanied increase in the pereentage of oxygen in the atmosphere, during the periods of geological time. To the conscionsly performed aets belong all those due to states of pain or pleasure in animals; such as are excited by the four elasses of stimuli already mentioned.

Doubtless physical changes in the surrounding medium have always produced new reflex movements in animals, and have been a first element in evolution. Such lias been the immediate canse of change of structure in plants, and in animals so fur as they are unconscious. But consciousness brings with it limitless possibilities, since it places an animal in contact with innumerable stimuli which leave unconscious beings maffected. All the causes which provoke the morements of higher animals are appeals to conseionsness, and the consequences due to morements of such beings have only been possible through eonscionsmess.

It is evident then that sensibility to impressions has been the prime essential to the aequisition of new movements, and henee of new structure, other things being equal. Another essential, not less important, has been memory; because without this faculty, experienee, and hence edueation and the acquisition of hibits of movement, are not possible.

The ascending development of the bodily structure in higher animals has thus been, in all probability, a concomitant of the erolution of mind, and the progress of the one has been dependent in an alternating way on the progress of the other. 'The development of mind has secured to animals the greatest degree of inde- 
pendence of their environment of which they are capable. The first important acquisition leading to this end was aërial respiration; the second, rapid nutrition by hot blood. And as essential to the production and preservation of these, improvements in organs of movement have been superadded to every successive type of life.

Consciousness remains as the unresolvable factor in the process; as at once the measure of, and respondent to a large class of phenomena. 


\section{XIII.}

\section{ON THE TRITUBERCULATE TYPE OF MOLAR TOOTH IN THE MAMMALIA.}

IT is now apparent that the type of superior molar tooth which predominated during the Puerco epoch was triangular or tritubercular; that is, with two external and one internal tubercles. * Thus, of sixty-seven species of placental Mammalia of which the superior molars are known, all but four have three tubercles of the crown, and of the remaining sixty-fire, all are triangular, excepting those of three species of Periptychus, and three allied forms, which have a small supplementary lobe on each side of the median principal inner tubercle. $\dagger$

This fact is importint as indicating the mode of development of the varions types of superior molar teeth, on which we have not heretofore had clear light. In the first place, this type of molar exists to-day only in the insectivorous and carnivorous Marsupialia ; in the Creadonta, and the tubercular molars of such Carnivora as possess them (excepting the plantigrades). In the Ungulates its persistence is to be found in the molars of the Coryphodontida of the Wasatch, and Dinocerata of the Bridger Eocenes. In later epochs it is occasionally seen only in the last superior molar.

It is also evident that the quadritubercular molar is derived from the tritubercular by the addition of a lobe of the inner part of a cingulum of the posterior base of the crown. Transitional states are seen in some of the Periptychidæ (Anisonchus), and in the sectorials of the Procyonidx.

The tritubercular or triangular superior molar is associated with a corresponding form of the anterior part of the inferior molar. This kind of inferior molar $\$$ I have cilled the tubereular

* See "American Naturalist," April, 1883, p. 407.

+ This type is therefore only an extension of the tritubercular. (Ed. 18S6.)

$\ddagger$ See Report G. M. Whecler, D. Chief of Engineers on Explor. Surv. W. 100th Mer., vol. iv, pt. ii; on the Creodonta. 
sectorial, and is very variable as to the degree of development of the sectorial cutting edge. The anterior triangle is formed by the connection, by angle or erest, of the median and anterior internal crests with the anterior external. Its primitive form is seen in Didelphys, Pelycodus, Pantolambda, and the Amblypoda generally; in Centetes and Talpa; and in its sectorial form, in Stypolophus and Oxyæna, etc.

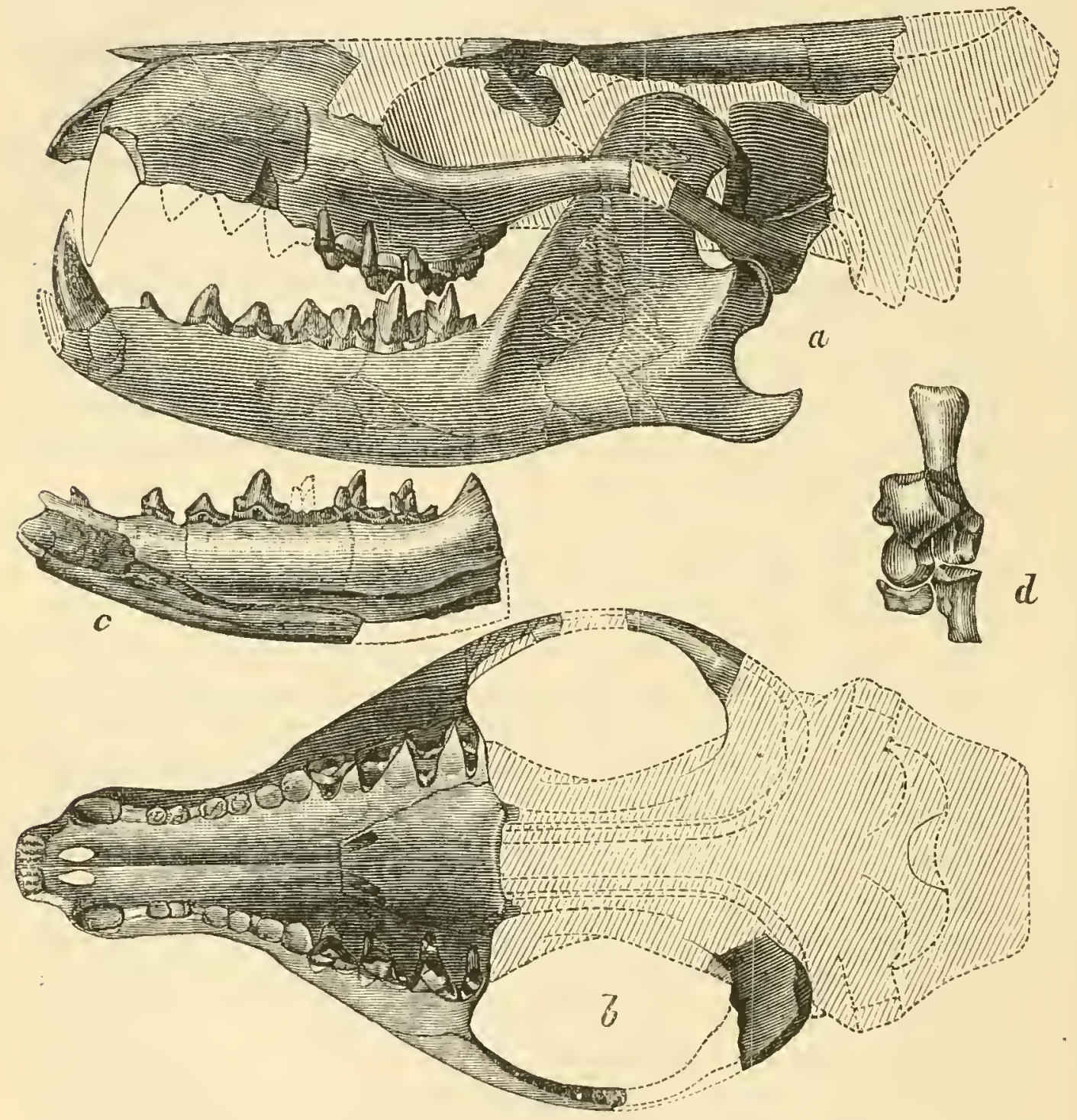

FIG. 61.-Stypolophus whitice Cope, skull two thirds natural size. A Creodont from the Wasatch Eocene, displaying well the tritubcreular superior, and the tubercular-sectorial inferior molars.

The mechanical action of such teeth is as follows: Of course, it results from the form of the superior molars that the spaces between them are wedge-shaped, the apex external, the base open- 
ing to the palate. The base of the triangular seetion of the anterior part of the inferior molar is interior, and the apex exterior, and when the jaws are elosed this triangular prism exaetly fits the space between the superior molars. The lower heel of the inferior molar receires the impact of the erown of the superior molar. Thus the oblique edges of the inferior triangle shear on the edges of two adjacent superior molars. The anterior parts of the inferior molars, and the superior molars, form an alternate dental series as distinguished from the prevalent opposed dentition of most Mammalia. In so far it resembles the reptilian dentition.

This primitive dentition has been modified in two directions, viz., to form the grinding and the sectorial dentitions. As already remarked, the superior molars gradually acquire a posterior internal lobe, which produces the quadritubereulate type. This lobe, by opposing the anterior internal lobe of the next posterior inferior molar, preeludes the entrance of the anterior triangle of the latter between the two superior molars. Hence we find in the types which possess quadritubereular superior molars, that the anterior triangle of the inferior molar is not elevated, if present, as, for instance, in Rhinocerus. It is, however, more frequently atrophied, and disappears, contributing to form the inferior quadrituberenlar molar so well known.

On the other hand, as I have pointed out,* the anterior internal ensp of the triangle of the inferior molar may be more developed antero-posteriorly, giving the antero-internal edge of the triangle much greater obliquity than the postero-internal. In correspondence with this modifieation, the superior triangular molar loses its equilateral character by the more anterior position of its internal angle, thus elongating the posterior intermal side of the erown. The latter thus fits the corresponding form of the triangle of the inferior molar, forming with it the shear of the sectorial tooth.

In a former article, "On the Homologies of the Molar Teeth," etc., I traced the modifieations of the superior and many of the inferior molars of the ungulate mammals to a parent quadrituberculate type. In a subsequent essay $f$ I traeed the origin of the

* On the origin of the sectorial tooth of the Carnivora, "American Naturalist," 1875 .

† "Journal Academy Natural Scicnecs," Philadelphia, March, 1874. 
inferior sectorial to a primitive five-tubercled, or "tubercular sectorial" type. Farther than this I did not go, and made no attempt to derive the few eases of triangular superior molars then known, nor the type of the superior sectorial. The revelations of the Puereo fauna show that the superior molins of both ungulate and unguiculate Mammalia have been derived from a tritubercular

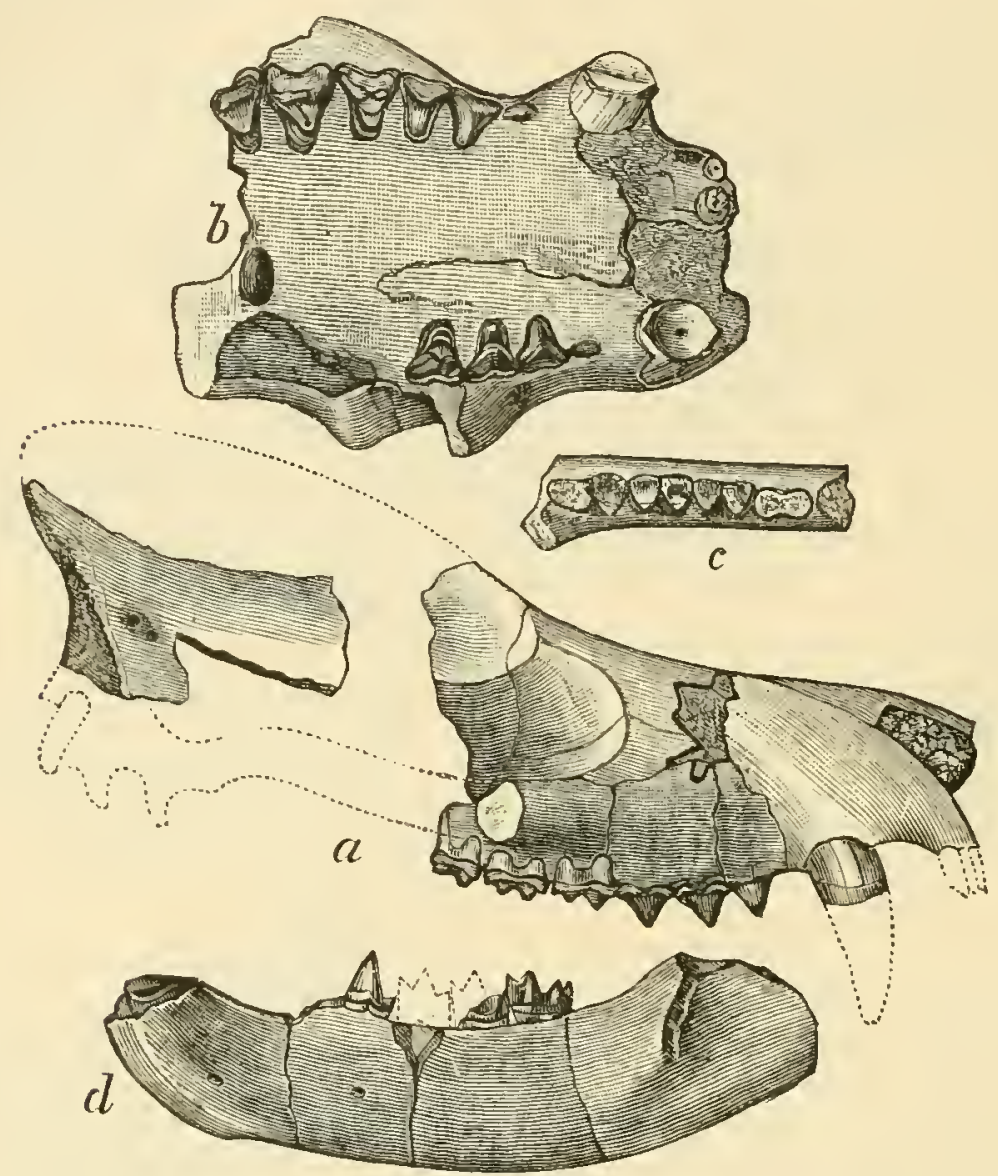

FIG. 65.-Deltatherium fundaminis Cope, skull and ramus mandibuli, two thirds natural size, from the Puerco beds of New Mexico. Figs. $a, b$, from one individual. Fig. $d$, from a second animal. Fig. $\alpha$, right side of cranium; $b$, palate from below ; $c$, mandible part, from above; $d$, left ramus, outer side. From the Report U. S. Geol. Surv. Terrs, vol. iii. Original.

type; and that the inferior true molars of both have been derived from a "tubercular sectorial" type. Shall we look for the origin of the latter in a tritubereular tooth also, i. e., tubereular sectorial withont heel; and will the crowns of the true molars of the primitive mammals alternate with, instead of oppose each other? This is a probable result of future diseovery. 


\section{XIV.}

\section{THE ORIGIN OF THE SPECIALIZED TEETH OF THE CARNIVORA.}

THE specially developed teeth of the Carnivora are the canines and sectorials. The former are large in many orders of Mammalic, and their origin is probably to be sought among the Theromorphous reptilia," as Clepsydrops and Deuterosaurus, if not in still lower types. The successire modifications of form which have resulted in the existing specialized single lower sectorial tooth of the Felidce have been already pointed out. $\nmid$ They were shown to consist in the gradual obliteration of the internal and posterior tubercles, and the enlargement of the external anterior tubercle in connection with an additional anterior tnbercle. The modification in the character of the dentition, taken as a whole, was shown to consist in the reduction in the number of teeth, until in Felis, etc., we have almost the entire function of the molar series confined to a single large sectorial in each jaw.

Observation on the movements of the jaws of Carnivora shows that they produce a shearing motion of the inferior on the superior teeth. This is quite distinct from the sub-horizontal morement of Ruminants, or the vertical motion of hogs and monkeys. Examination of the crowns of the sectorials shows that the inner side of the superior, and the external side of the inferior, are worn in the process of mastication. The attempt to cut the tongh and stringy substances found in animal bodies is best accomplished by the shearing of the outer edge of the lower molar on the inner edge of the external tubercles of the superior molar, in an animal with simple tuberenlar teeth. The width of the mandible is too great to allow the inferior teeth to shear on the inner edge of the inner tubercles of the superior scries. 'The

* "American Naturalist," 1878, p. 829.

† Cope, "Proceedings Aeademy Philada.," 1875, p. 22. 


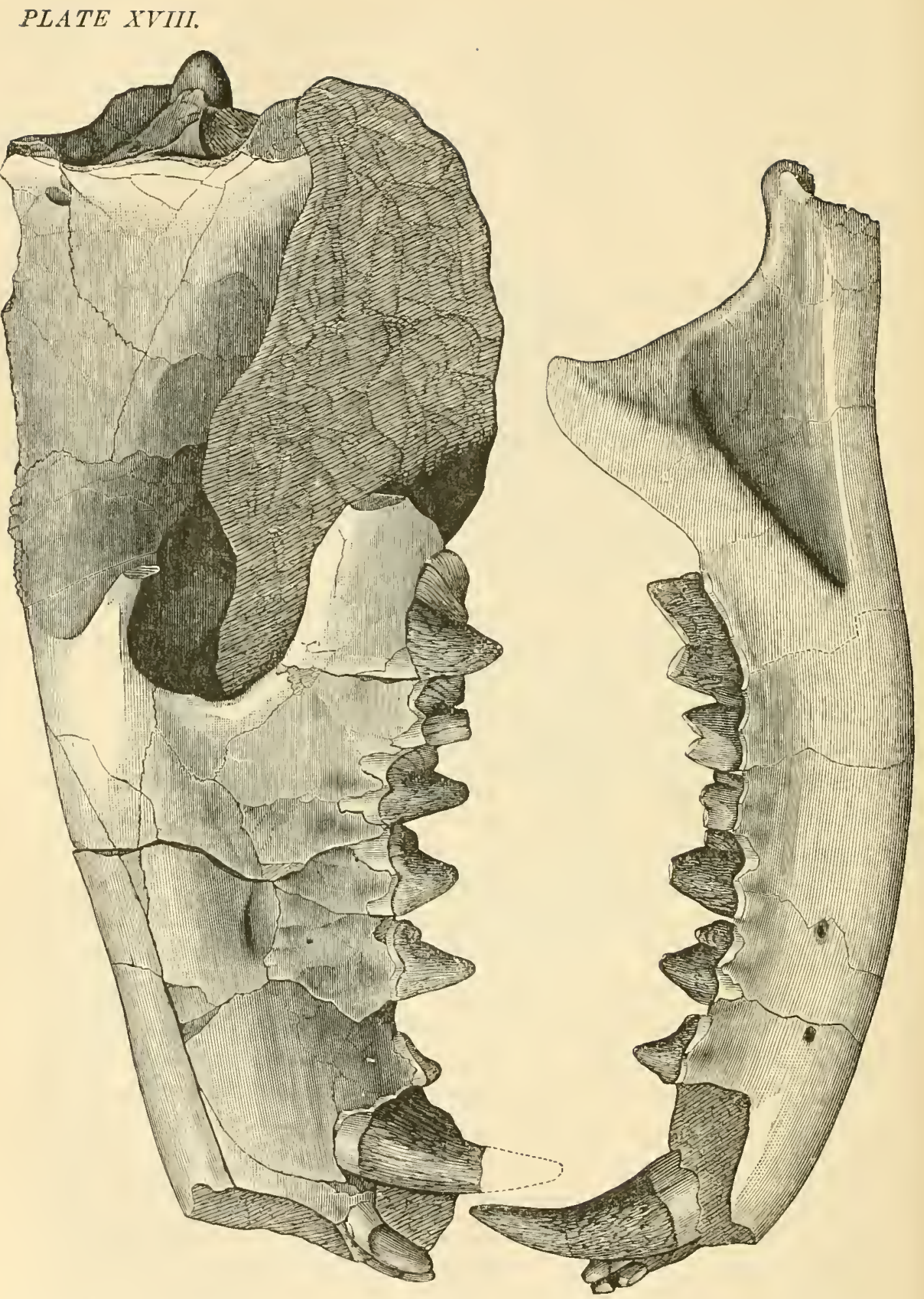

Hycenodon horridus Leidy, skull one half natural size. From the White River formation of Nebraska. From Leidy's "Extinct Mammalia of Dakota and Nebraska." 
cusps of both superior and inferior teeth engaged in this process have developed in elevation, at the expense of those not engaged in it, viz. : the internal cusps of the same teeth. The atropluy of the latter can not have been due to friction, since the internal cusps of the inferior series, which have not been subjected to it, are reduced like those of the superior sectorial, which have. Indeed, it is possible that some of the Creadonta, the carnivores of

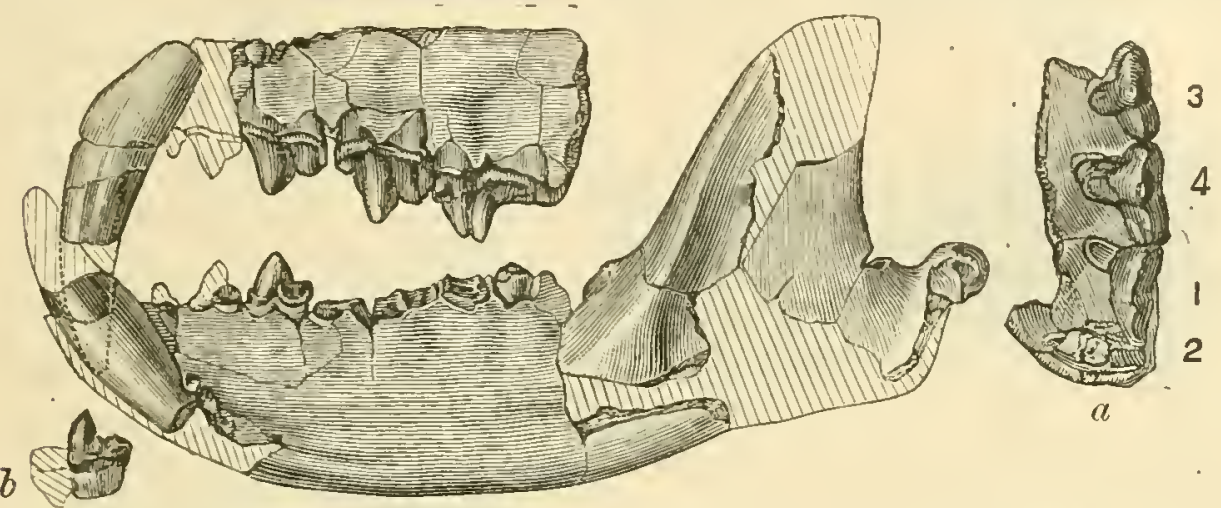

Frg. 66.- Oxycena lupina Cope, jaws, one half natural size, from the Wasatch beds of New Mexico. Fig. a, maxillary bone with teeth, from below; $b$, last superior molar, from behind. Origiual ; from the Report U. S. G. G. Survey W. of 100th Mer., G. M. Wheeler.

the Lower Eocene, may hare been derived from ancestors without or with rudimental inner cusps. In any case the effect of use in lengthening the external cusps appears to have operated in the Carnivora, as it has done to a greater degree in the Ungulate; and the lateral vertical wear would appear to have resulted in the blade-form, as transverse wear in the Ungulates has resulted in the plane grinding surface.

The specialization of one tooth to the exchusion of others as a sectorial, appears to be due to the following causes. It is to be observed, in the first place, that when a carnivore devours a carcass, it cuts off masses with its sectorials, using them as shears. In so doing it brings the part to be divided to the angle or canthus of the soft walls of the month, which is at the front of the masseter muscle. At this point, the greatest amount of force is gained, since the weight is thus brought immediately to the power, which would not be the ease were the sectorial situated much in front of the masseter. On the other hand the sectorial could not be situated farther back, since it would then be inaceessible to a carcass or mass too large to be taken into the mouth. 'The position of the sectorial tooth being thus shown to be de- 
pendent on that of the masseter muscle, it remains to ascertain a probable canse for the relation of the latter to the dental series in
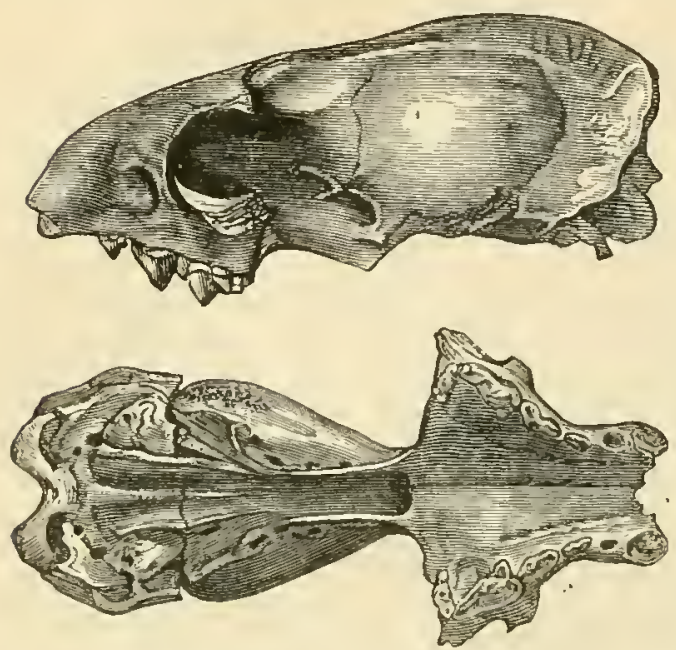

F G. 67.-Proalurus julieni Filh., two thirds natural size. From the Phosphorites of France. From Filhol. modern Carnivora. Why, for instance, were not the last molars modified into seetorial teeth in these animals, as in the extinct Hycenodon, and various Creodonta? The answer obviously is to be found in the development of the prehensile character of the canine teeth. It is probable that the gape of the mouth in the Hyænodons was very wide, since the masseter was situated relatively far posteriorly. In such an animal the anterior parts of the jaws with the canines had little prehensile power, as their form and anterior direction also indicates. They doubtless snapped rather than lacerated their enemies. The same habit is seen in the existing dogs, whose long

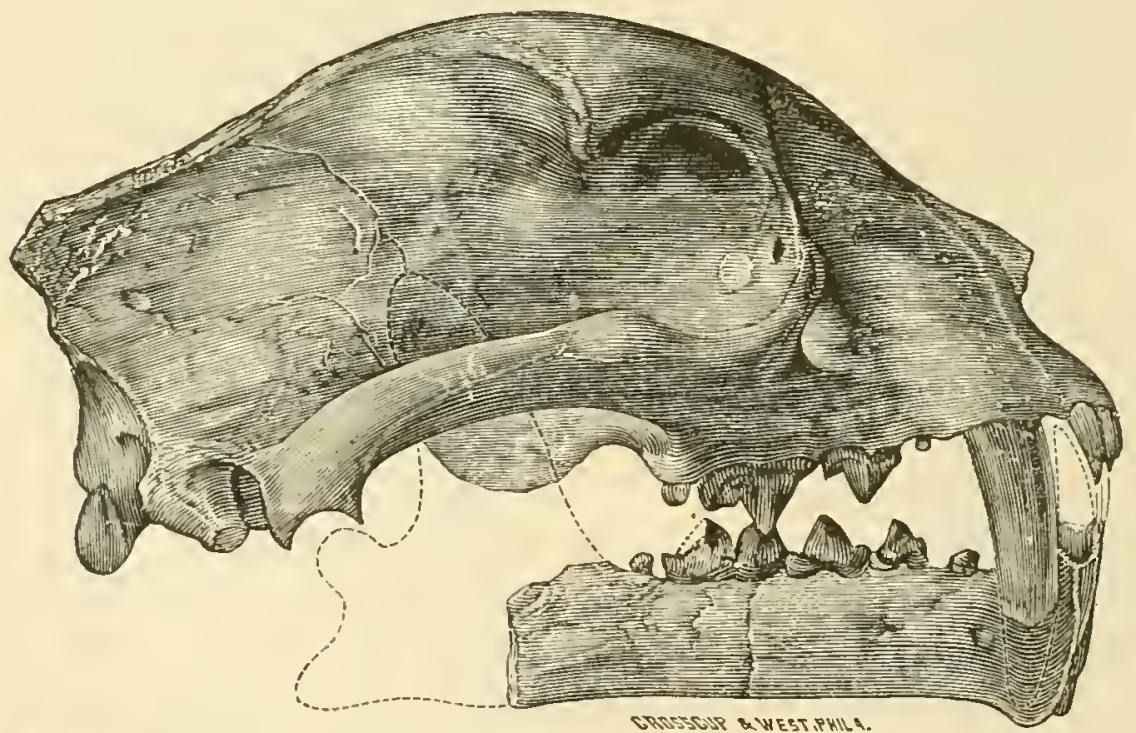

Fig. 68.-Dinictis cyclops, one half natural sizc. From John Day Miocene of Oregon. Mus. Cope. From vol, iii, U. S. Gtol. Surv. Terrs.

jaws do not permit the lacerating power of the canines of the Felida, though more effective in this respect than those of the Hycenodons. The usefulness of a lever of the third kind depends on the approximation of the power to the weight; that is, in the 
present case, the more anterior the position of the masseter muscle, the more effective the canine teeth. Hence it appears that the relation of this muscle to the inferior dental series depended originally on the nse of the canines as prehensile and lacerating organs, and that its insertion has advanced from behind forward in the history of carnivorous types. Thus it is that the only accessible molars, the fourth abore and the fifth below, hare become specialized as sectorials, while the fifth, sixth, and seventh have, firstly, remained tubercular as in the dogs, or, secondly, have been lost, as in hyenas and cats.

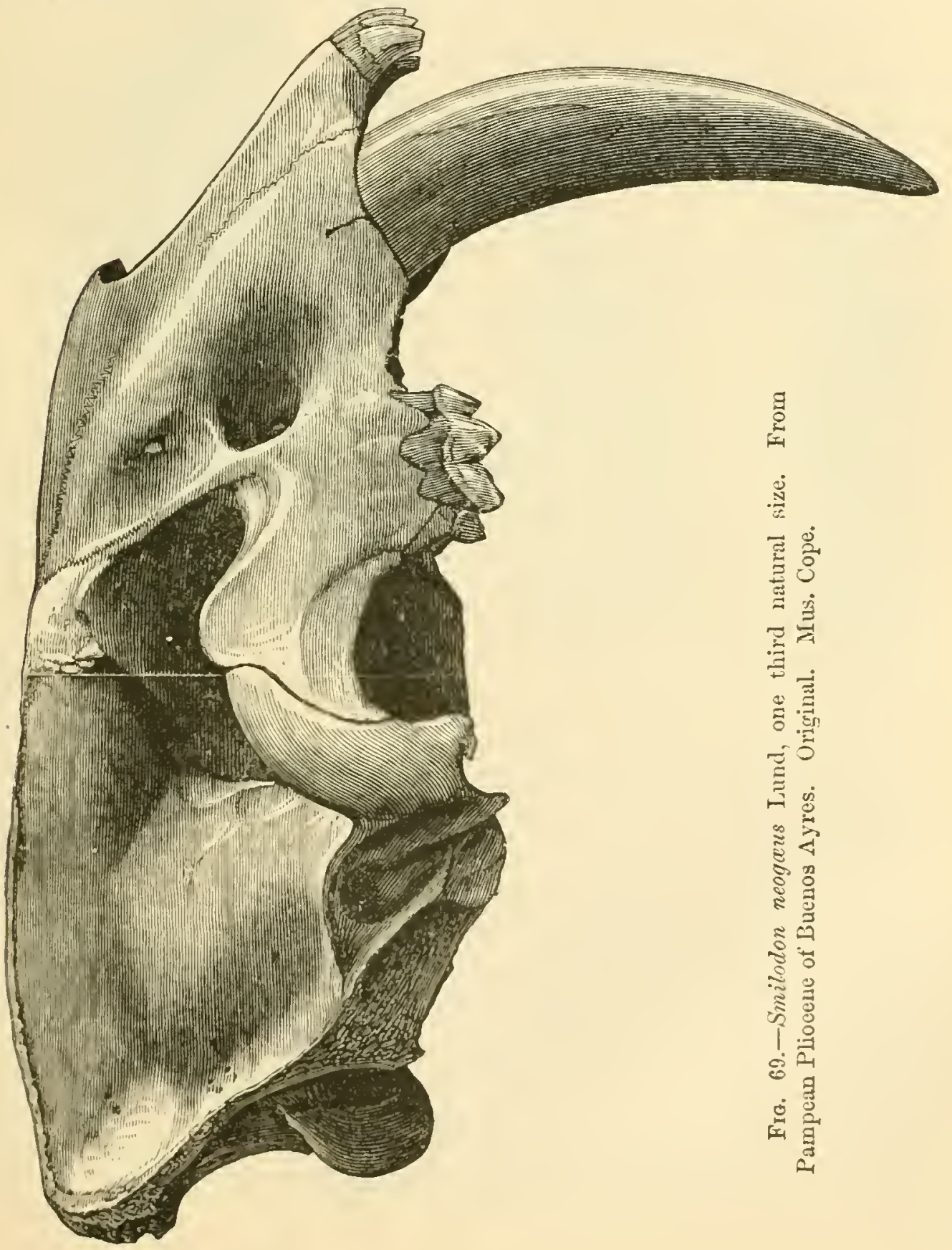


XV.

\section{ON THE ORIGIN OF THE FOOT STRUCTURES OF THE UNGULATES.}

THe following considerations have been suggested by a study of the primitive types of the odd-and even-toed ungulates. I first, in 1874, recorded the opinion that the Mammalia with a reduced number of digits were derived from pentadactyle plantigrade types. * The ungulate order which fulfills this requirement is the Amblypoda, and from them, I doubt not, both the Perissodactyla and Artiodactyla have arisen, althongh not from any of the genera now known. Both of these great orders display a regular diminution in the number of the digits; in the former, by reduction and extinction on both sides of the third digit; in the latter, by reduction and extinction on each side of the third and fourth digits. Mr. John A. Ryder $\nmid$ has pointed out that reduction in digits is probably directly related to strains and impacts. He reminds us that the anterior digits are reduced in Mammalia of unusual scansorial or fossorial powers; while in forms which display powers of rumning, the rednction is seen first in the posterior fect, which propel the body much more than the fore foet. This vicw is well illustrated in the Perissodactyle families, the majority of which have the digital formula 4-3.

No reason has ever been suggested, so far as I am aware, in explanation of the fact that one series of ungulates has retained two digits, and the other only one; that is, why there should have been two kinds of digital reduction instead of one kind. In seeking for an explanation, we will remember that the tarsus in the odd or single-toed line is bound together by fixed articulations, while in the cloven-footed line it is interrupted by the hinge between the first (astragalns) and second rows of bones. The hinge-joint, being more liable to luxation than the fixed articula-

\footnotetext{
* "Journal Academy Philadelphia," March, 1874.

† "Amcrican Naturalist," October, 1877.
} 
tion, requires a wider basis of support, sueh as would be furnished by two divergent digits, rather than by a single central one.

In the early types, where the median digits are slender, the mechanical adrantage in favor of the bidigital orer the undigital arrangement is much more obvious than in modern genera. Late in time, the horse developed the middle digit to such a width as to form ahnust as good a support as the bidigital strueture. In the Eoeene genera, the slender mediun digit could not have sustained the weight on a hinge, without great risk of dislocation.

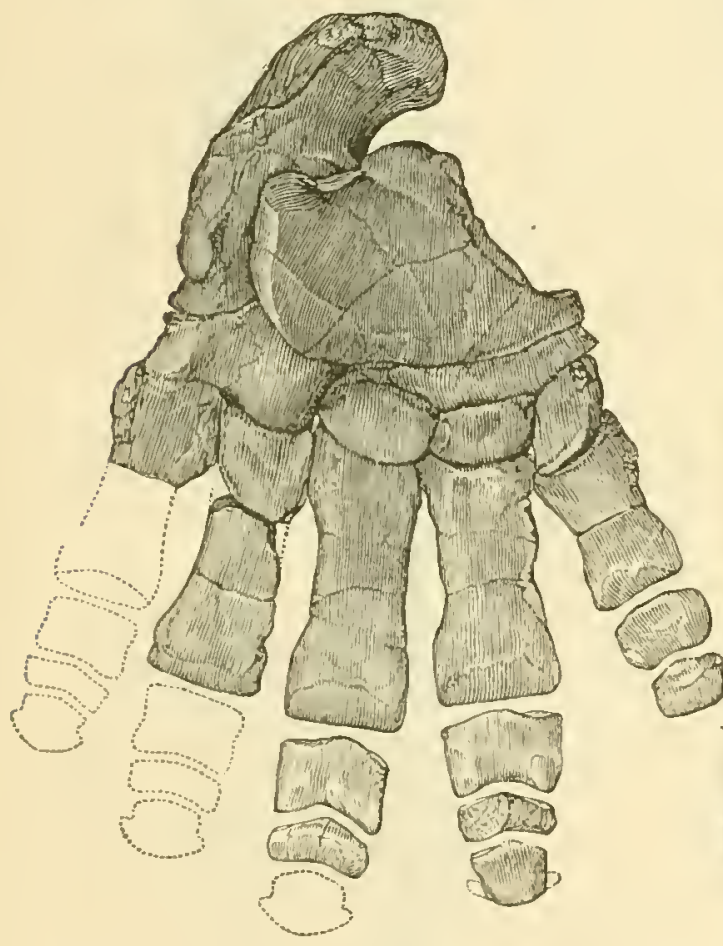

Fia. \%o.

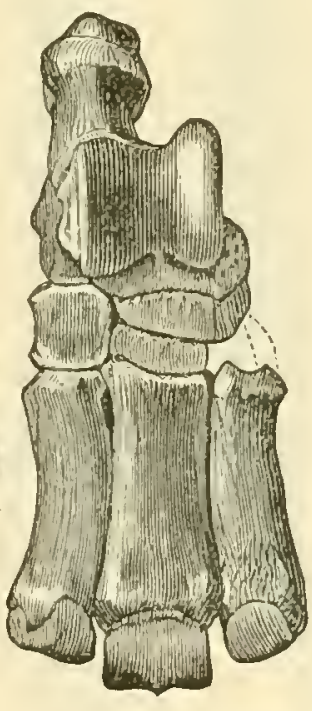

Fro. 71.

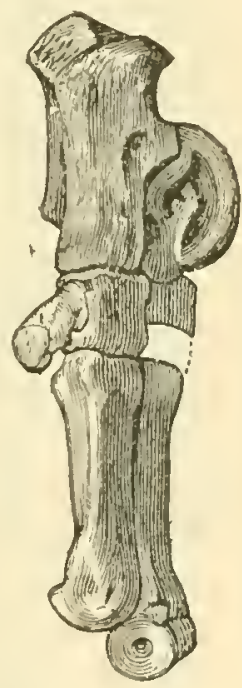

Fig. 70.- Right posterior foot of a species of Coryphodon from New Mexico, one half natural size. From Report Expl. W. of 100th Mer., G. M. Wheeler, iv, Pl. lix.

Fig. ;1.-Pight posterior foot of the rhinoceros, Aphelops megalodus Cope, from Colorido, one half nutural size. From Report U. S. Geol. Surv. Ters. F. V. Hayden, iv, Pl. exxx.

This explanation, it ean be said, applies only to the posterior foot. 'The posterior foot has, however, led the way in the evolution of Ungulata, and the fore foot may have followed in accordance with the law of antero-posterior symmetry in growth. A curiously malformed deer from Mendoeino County, Cal., throws some light on this subject. It has apparently a single functional digit on each foot. Examination shows that the posterior foot is bidigital, but that the phalanges are fused; while the anterior foot 
is perissodactyle, all the digits but the third being rudimental! Similar evidence is furnished by the genus Anoplotherium * of the French Eocene. Its posterior foot is modified artiodactyle, while the anterior is modified perissodactyle. We may assume from

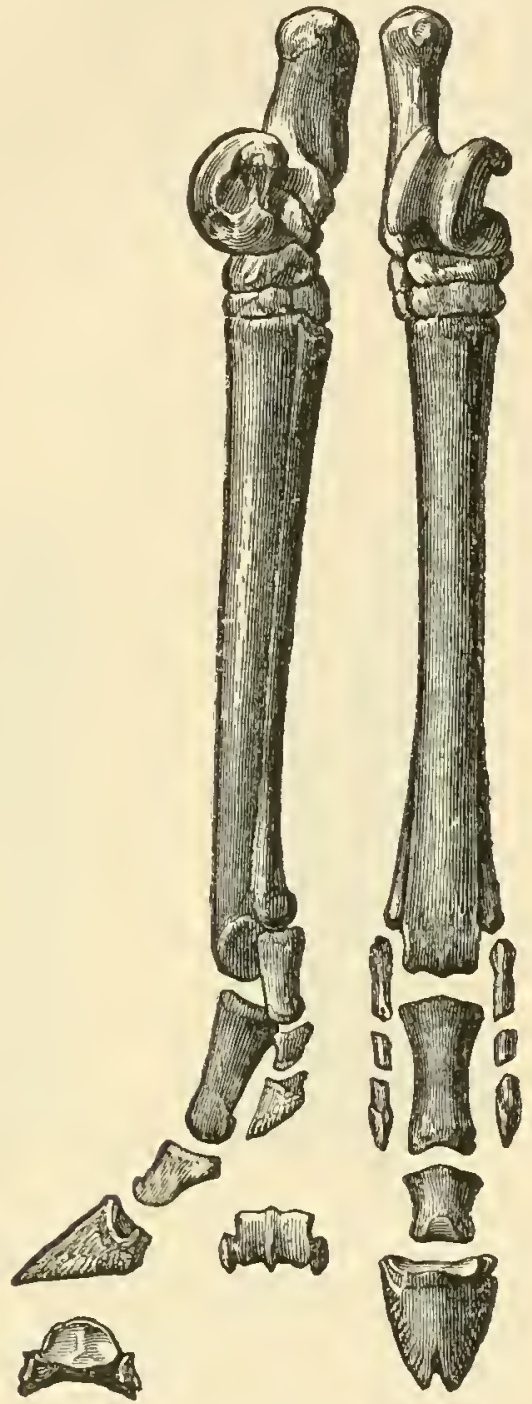

Fio. 72.

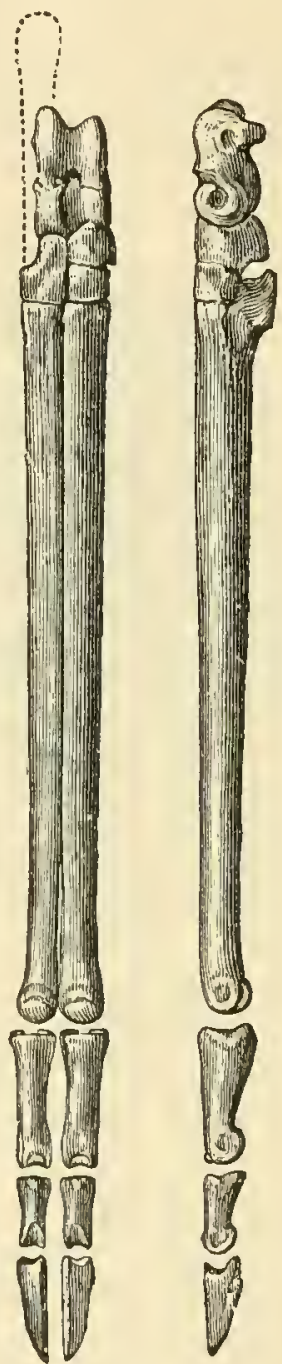

FIG. 73.

Fig. 72.-Right posterior foot of Protohippus sejunetus Cope, from Colorado, about one half natural size. From Report U. S. Geol. Surv. Terrs. F. V. Hayden, iv.

Fig. 73.-Right posterior foot of I'oëbrotherium labiatum Cope, from Colorado, three fifths natural size. From Hayden's Report, iv, Pl. exv.

these facts, that the posterior foot is more snbject to the influences which tend to produce the bidigital structure than is the anterior limb.

* Eurytherium Gerv. in the original, a name shown by Schlosser to apply to Anoplotherium. (Ed. 1886.) 
I suspect that the production of a ginglymus in the midale of the tarsus has been due to the use of the posterior limb in soft swampy ground. In the absence of this condition, as in a life on harder ground than swamp, no ginglymus would be formed. 'The action of an mngulate in walking through deep mud is very suggestive. The posterior foot is bent on the leg, and the anteroposterior strain of the weight or propulsive force is transverse to its long axis. In progression on dry land, the impact is in the direction of the length or axis of the foot. The obvious effect of a cross strain is to produce by degrees greater and greater mobility of some articnlation. The one which has yielded is that between the two tarsal rows. Another effect of walking in swampy ground is to spread the digits apart. As the first digit of both feet is always of reduced size, there are practically but four digits to be considered. The weight falling nearly medially on these, would tend to spread them equally, two on each side. Thus the same cause may have been effective in producing both the artiodactyle structures. The perissodactyle structure, so soon as the lateral digits are much reduced, ceases to be favorable for progression in soft ground, owing to the liability of the lateral digits to injury, in following the principal one into the yielding material, filled with sticks and other hard débris.

The lowest existing forms of the Artiodactyla, the Omnivora, are universally swamp lovers and livers. So, we are told, are the lower existing Perissodactyla, the tapirs and rhinoceroses. The higher types of both orders are dwellers on plains and in forests. We do not know the habits of the Eocene Perissodactyla, but I donbt their having inhabited mnddy ground to the same extent as the hogs and hippopotami, the lowest of the Artioductyla. Now,

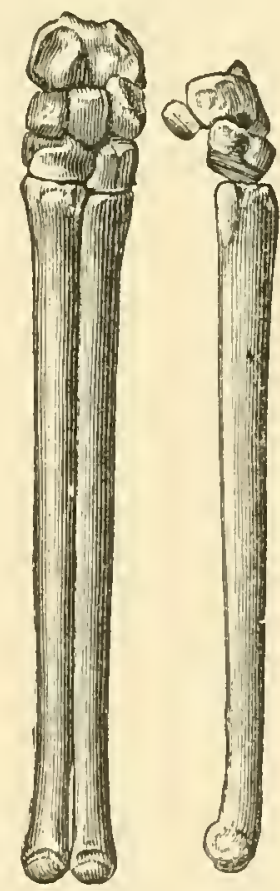

Fic. 74.-Left fore foot with part of radius of Pebrotherium. vilsoni Leidy, from Colorado, three fiftlis natural size. From IIayden's Teport, iv, I'l. crv. in progression on dry land, any pre-existent inequality in the length of the digits would tend to become exaggerated. Such an ineqnality exists in the Amblypoda, the third digit being a little the longer. In rapid movement on hard ground the longest toe receives the greatest part of the impaet, even if its exeess of 
length is but little. The harder the ground, the larger the proportion of impact it will receive.

The fact that the Perissodactyla did not develop the solid ungulate or equine foot nntil a late geological period, or, in other words, that the orders so long retained the digital formula 4-3, would indicate that it did not adopt a habitat which required great speed as a condition of safety, so early as the Artiodactyla. 


\section{XVI.}

\section{ON THE EFFECT OF IMPACTS AND STRAINS ON THE FEE'T OF MAMMALIA.*}

THE prineipal specializations in the structure of the feet of the Mammalia may be summarized as follows:

I. The reduction of the number of the toes to one in the Perissodactyla (horses, etc.), and two in the Artiodactyla (cloven feet).

II. The second hinge-joint in the tarsus of the Artiodactyla.

III. The trochlear ridges and keels at the various movable articulations of the limbs. These are as follows:

1. Looking downward-

$a$. Intertrochlear crests of the bumerus.

$\beta$. On the carpal end of the radius.

$\gamma$. Metacarnals, distal ends.

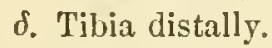

$\varepsilon$. Metatarsals distally.

2. Looking upward-

$a$. Radius distally.

$\beta$. Astragalus, edges.

$\gamma$. Astragalus distally (Artiodactyla).

$\delta$. Phalanges (very weak).

The following observations may be made respecting the structures ineluded under Dirision III : The trochlear keels which look downward are mueh the most prominent and important. Those enumerated as looking upward are weak and insignifieant, or of a different charaeter from the down-looking ones. The latter are all projections from the middles of the ends of the respective elements. The up-looking are generally projections of the edges of bones. Such are the lateral erests of the astragalus, and the adjacent edges of the euboid and navieular bones which cause the distal emargination of the astragalus in the Artiodactyla. The

* Read before the National Acallemy of Sciences, April, 1881. Abstract. Some of the points of this paper have already been discussed in the preeding artiele, but the present abstract contains additional matter. 
proximal ridges of the phalanges are very weak, and the concavities in the extremity of the radins can not be called trochlear, as they are adaptations to the carpal bones.

I. The reduction in the number of toes is supposed to be dne to the elongation of those which slightly exceeded the others in length, in consequence of the greater number of strains and impacts received by them in rapid progression, and the complementary loss of material available for the growth of the smaller ones. This is rendered probable from the fact that the types with redneed digits are dwellers on dry land in both orders, and those that have more numerous digits are inhabitants of swamps and mud. In geological history it is supposed that the Perissodactyles (Figs. 72, 73) originated from the Amblypoda, or primitive Ungulata (Figs. 69, 70), which first assumed terrestrial habits, while the Artiodactyla (Fig. 74), originating from the same order, long continued as mud dwellers; as witness the hippopotami and hogs of to-day. The mechanical effect of walking in the mud is to spread the toes equally on opposite sides of the middle line. This would encourage the equal development of the digits on each side of the middle line, as in the cloven-footed types. In progression on hard ground, the longest toe (the third) will receive the greatest amonnt of shock from contact with the earth. There is every reason to believe that shocks, if not excessire, encourage growth in the direction of the force applied. This is strongly suggested by the relations between the length of the legs and the rate of speed of animals; and the lengths of the teeth and their long-continued nse. Certain it is that the lengths of the bones of the feet of the Ungulate orders have a direct relation to the dryness of the ground they inhabit, and the possibility of speed which their habitat permits them, or necessarily imposes on them.

II. The hinge between the first and second series of tarsal bones in the Artioductyla may be accounted for by reference to the habits which are supposed to have caused the cloven-footed character. Observation on an animal of this order walking in mud, shows that there is a great strain antero-posteriorly transverse to the long axis of the foot, which wonld readily canse a gradual loosening of an articulation like that connecting the two series of tarsals in the extinct Amblypoda. Any one who has examined this part of Coryphodon will see that a little additional mobility at this point would soon resemble the second tarsal joint of the hogs. In the case of animals which progress on hard 
ground, no such cross-strain would be experienced, and the effect would be to consolidate by flattening the fixed articulation.

III. The trochlex. These prominences, which form the tongues of the tongue and groove articulations, exhibit various degrees of development in the different Mammalia. Those of different parts of the slieleton coincide in their condition in any one type of ambulatory Mammatia, and so may be all considered together. This fact suggests strongly that they are all due to a common cause.

They are all imperfect in the Rodentia and Carnivora (Figs. \%5-r\%) (except the Leporide, which are especially characterized by their great speed). Among ungulates they are very imperfeet in the Proboscidea. The orders mentioned all have elastic pads on the under sides of their feet or toes. The same is true of the lowest types of both the $A r$ liodactyla and Perissodactyla, the hippopotami and rhinoceroses. In the Ruminantia the trochleæ are well developed (Fig. 80) with one exception, and that is the distal metacarpal and metatarsal keels of the Camelide (Figs. 79, 81). These animals confirm the probability of the keels being the effect of longcontinued shocks, for

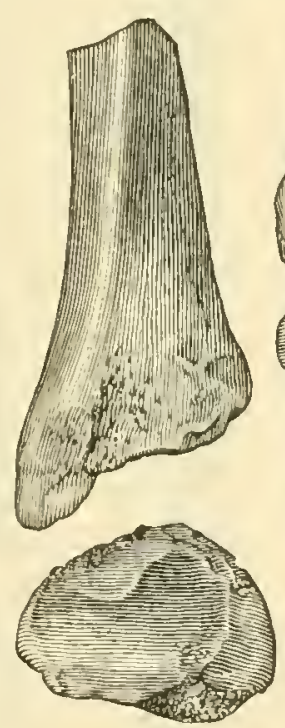

Fig. 75.
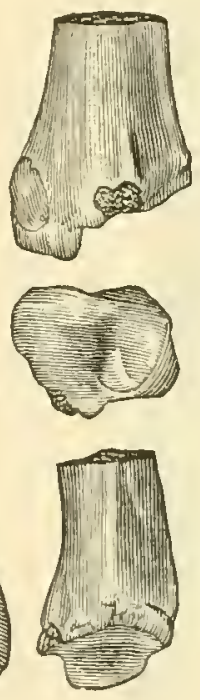

Fig. 76.

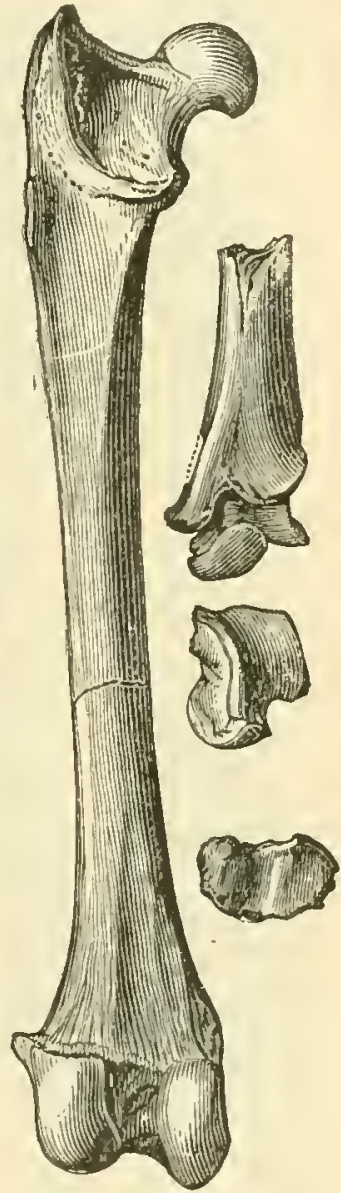

Fio. 78. F19. 77.

Fig. 75, Distal extremity of tibia of Amblyctonus sinosus Cope. Fig. 76, Distal extremity of tibia of Oxyena morsitans Cope. Both flesh-enters, and two thirds natural size. From Report Expl. and Surv. W. of 100th Mer., G. N. Wheeler, iv, Pt. ii.

Fig. 77, End of tibia and astragalus of Archolurus debilis. Fig. 78, Femur of Nimrarus gomphodus. Carnivora; one third natural size. Mlus. Cope.

they are the only Ruminants which have elastic pads on the inferior sides of their digits.

'That these processes may be displacements due to shocks long continued, is rendered probable by the structure of the bones themselres. (1) 'They project mostly in the direction of gravity. 
Constant jarring on the lower extremity of a hollow cylinder with soft (medullary) contents and flexible end walls, would tend to a decurvature of both inferior and superior adjacent end walls. If

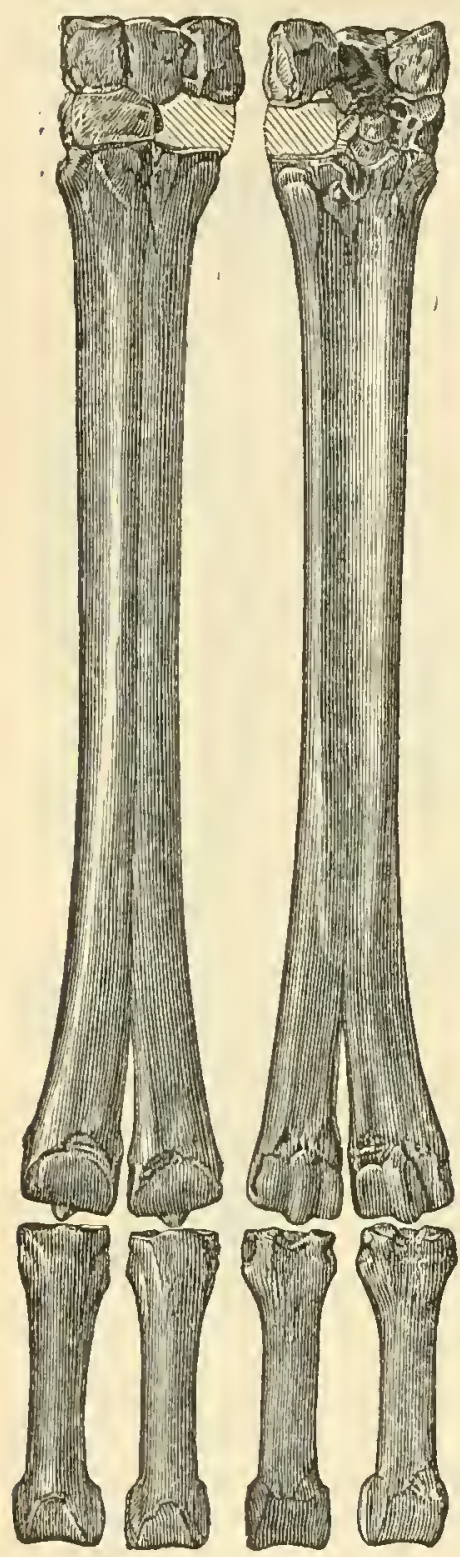

Fig. 79. the side walls are wide and resistant, the projection will be median, and will be prolonged in the direction of the flexure of the joint. The groove of the astragalus deepens coincidently with the inerease of digitigradism, showing that, while it is primarily pro-

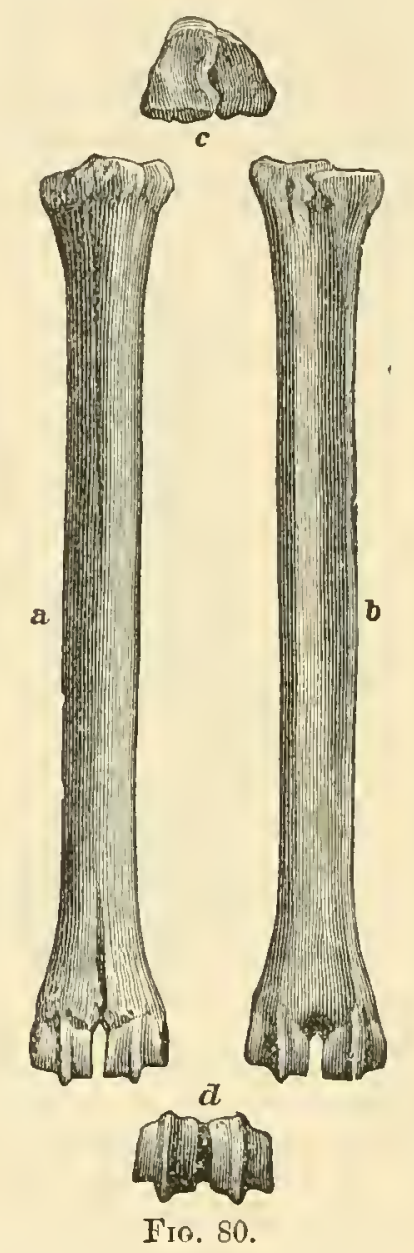
duced by shocks, it is extended fore and aft by the repeated flexure of the anklejoint. (2) They

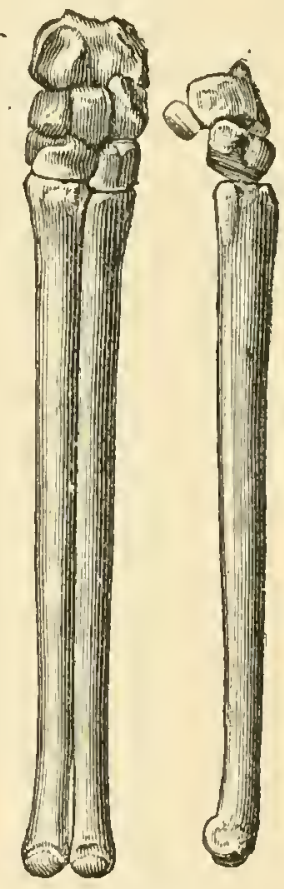

Fig. 81.

Fig. 79, Part of anterior foot of Procamelus occidentalis from New Mexico. Original from Report of Capt. G. M. Wheeler, vol. iv, Pt. ii.

Fig. S0, Metaearuals of Cosoryx furcatus from Nebraska, two thirds natural size. $a$, anterior fince ; $b$, posterior; $c$, proximal erd; $d$, distal end.

Fig. 81, Left fore foot with part of radius of Poebrotherium vilsoni Leidy, from Colorado, three fitths natural size. From Hayden's Report, iv.

fit entering grooves of the proximal ends of corresponding bones. These will be the result of the same application of force and 
displacement as the protrusion of the inferior, commencing with a concavity (Elephas); becoming more concave (Fig. 7\%), and becoming finally a groove. (3) When the dense edge of a bone, as in the case of the lateral walls of the astragalus, is presented upward, a groove is produced in the down-looking bone; e. g., the lateral grooves of the distal end of the tibia. (4) When the inferior bones are the denser, the smperior articular face yields; e. g., the distal end of the radins to the first row of carpals (Fig. 81).

(5) The metapodial keels commence in the lower types on the posterior side of the distal extremity of the bone. This is partly due to the presence there of a pair of sesamoid bones which, with the tendons in which they are dereloped, sustain and press on the lateral parts of the extremities, and leave the middle line without support (Figs. 79-81). 


\section{PART IV. \\ METAPHYSIOAL EVOLUTION.}

\section{XVII.}

\section{THE EVOLUTIONARY SIGNIFICANCE OF HUMAN CHARAC'TER.*}

'THE complicated constitution of the human mind is well impressed on the investigator as he seeks to moderstand the origin of any one of the many different types of character which come before him. The number of possible combinations of its numerons elements, each of which present developmental phases, is necessarily very great. The species of human minds, as one may properly term them, are probably as numerous as the species of animals, as defined by their physical structure. As in the case of anatomical species, however, analysis of the mind reduces its many details to a few leading departments. Althongh the classification of the elements of the mind is a classification of functions, it is, if correct, a sure index of the classification of structure also; of the grosser and more minute structure of the brain, principally of the gray matter.

The division of mental activities into three primary divisions is generally admitted. These are : the emotions, the intelleet, and the will. The emotions inclnde the likes and dislikes, or the tastes, and their strongest forms, the cmotions and the passions. The intelleet inclndes those powers which rearrange the experiences in an order different from that in which they enter the mind. This new order may have sole reference to questions of liking and disliking, and is then a product of the imagination;

* The present article is in continuation of the previous one on the Evolutionary Signifieance of Human Physiognomy, published in the "Naturalist" of June, 1883. 
or it may be a result of experience of the laws of pure necessity, without regard to questions of taste ; then it is a process of reason. 'The will, properly so called, is the spontaneous power of the mind by which the other processes are originated, directed or restrained. The range of the will, and even its existence, are questions of dispute.

Below and behind these mental activities lies sensibitity or conscionsness, in its forms of general and special sensation; that is, touch and hearing, taste, smell, sight, and the muscular sense, with many others, concomitants of both health and disease. It is well understood that these primitive mental qualities are more or less developed in animals in which the more purely mental functions are rudimental. 'The doctrine of erolution teaches that from this class the higher activities of the mind have been developed, during long ages, through the agency of memory. The nature of the present essay only permits a casual reference to the astonishing character of memory, and the remark that its phenomena demonstrate most clearly, of all others, that mind is an attribute of some kind of matter.

If we now consider these natural divisions of the mind as they present themselves in the combinations which we call human character, we shall observe a variety in the mode of their action which pervades all divisions alike. These variations fall under two heads, those of quantity and of quality.

Thus as to quantity; one human mind may present a greater amount of intellectual than emotional activity; of imaginative than rational intellection; of affectionate than irascible emotion ; of gastronomic than musical taste, ete., etc. 'The quantity here indicated is probably an index of the proportion of brain tissue devoted to the functions mentioned. The intensity or force of the action is a matter of quality.

Of qualities the variety is much larger. They are often parallel to those of inorganie force, and suggest the same kind of modifications of the material bases as those which affect the latter. 'Two prominent qualities are fineness and coarseness. Fineness observes and uses detail in both rational and emotive acts, and is essential to the precision of finish. Coarseness neglects detail, but deals with the gross of things, and is sometimes accompanied by largeness of quantity. When it is not, the result is not good. Fineness is, on the other hand, often associated with smallness. It is a more feminine attribute, while coarseness is more masculine. 
Another pair of antithetic qualities are intensity of action and the reverse. 'This probably means that a given bulk of brain tissue produces (i. e., converts) a greater amount of energy in a given time than an equal bulk of non-intense tissue.

'The speed or rate of action in time, and its opposite, slowness, are related to the last-named qualities, but are not identical with them. Thus growth of the mind always witnesses a diminution in the rate of action, but an increase in intensity.

Tenacity of mental action is a very marked character, and of great importance. It signifies the persistence of mental action, or mental endurance, and may characterize the entire mind, or only a part of it. Its opposite, seen in changeability, desultoriness or fickleness, may also characterize all or a part only of the mind. According as it characterizes the intellectual or emotional departments are its exhibitions most varied, though they probably have a common histological basis.

Impressibility and stoliclity express antitheses of character which are seen every day. The term impressibility is used as identical with irritability, and is preferred, becanse the latter has special physiological and popular meanings, some of which are only among its phases. These qualities are apt to pervade the entire mental organism, although, like others, they may characterize a part only. Impressibility is obviously a condition of tissue, since it varies greatly with physiological conditions in the same person. Its exhibitions in the department of the emotions may be confounded with strong development of the emotions themselves. A moment's thought, however, shows that easy excitation of emotion is a different thing from energy of emotion, and is often found apart from it. Impressibility of intellect shares with tenacity a leading position as an attribute of a firstclass mind, and the combination of the two forms a partnership of superior exeellence.

I may mention here a quality whose absence is pathological, and hence does not properly enter the field; this is tonicity. In its normal condition, every organ should be supplicd with sufficient nutriment or energy to insure the ocenpation of its entire mechanism. Anything short of this is followed by poor work. Debility of mental action in the emotional department is seen in abnormal irritability, such as peevishness or "spooning"; and in the intelligence, in absence of mind and blundering; and in both, in general frivolity. 
Returning to the primary elements of mind, we may examine their divisions with reference to the question of growth. To begin with the perceptions, there are great diversities in the acuteness of the general and special senses, and greater and less susceptibilities to physical pleasure and pain. In the important representative faculty, memory, the differences betwcen people are great. As perception as well as thinking involves a certain amount of structural change, it is evident that susceptibility or impressibility of the senses, which is the first stage of memory, signifies ready metamorphosis of tissue. Unimpressibility, which impedes memory, is a consequence of resistance on the part of tissue to the usual stimuli. Hence the effect of "sights, sounds, and sensations" is greatest in childhood, and the memory is most impressible, for at that time the nerrous tissue is undergoing constant change, and nutrition, being in excess of waste, constantly presents new material to be organized. And I may here refer to the general truth, that consciousness of all kinds is the especial and distinguishing attribute of life as distinguished from death or no life.* Whatever other phenomena we may be accustomed to regard as "vital," are only distinguishable from inorganic motion or force, because they primitirely took their form nnder the guidance of consciousncss, and are hence, so to speak, its children. With the perfect working of most of the mechanism of the body, consciousness no longer concerns itself, although it may speedily do so in pathological conditions. This prerogative is now restricted to the norvous system, and to certain parts of it; the one which is, histologically speaking, the most generalized of the systems. And it is quite consistent with the "doctrine of the mspecialized," that nervous tissue in.its unfinished state in childhood shonld be more impressible to stimnli than at later periods of life. But this statement requires this modification, that there is a stage of imperfection of mechanism which does not display high sensibility, as, for instance, in the earliest infancy. With age sensibility gradually diminishes.

Next in order of appearance in growth are the emotions. It is true that some of these are not fully developed until long after the appearance of many or all of the intellectnal faculties; but it is also true that their full development precedes that of the intellect, in so far as they are developed at all. The primitive condi- 
tion of the emotions is that of appetites. The first of these in the necessary physiological order, and hence in time, is the appetite of hunger. Second in order in the history of life, but not in the growth of individuals, is the instinct of reprodnetion, such as it is in animals that only multiply by fission. Very early in evolntion the emotion of fear must have arisen, and it is probably the immediate successor of hunger in the young of most animals. Anger appears as early as the mind can appreciate resistance to its first desires, and no doubt followed as third or fourth in the history of evolution. The rudiments of parental feeling would follow the origin of reproduction at a considerable interval of time. One of the latest of the instincts to appear wonld be the love of power; while later still would be the emotions of relativity (Bain), becanse they are dependent on a degree of mental appreciation of objects. Such are admiration, surprise, and wonder. These, as well as all other consequences of inherited intellect, appear earlier in infancy than they did in evolution, as may be readily understood.

Of these instincts and emotions, it is to be supposed that hunger remains mnch as it lias ever been. 'The reproduetive instinct has, on the other hand, undergone the greatest modifications. Sex instinct conld not have existed prior to the origin of the male sex, which must be regarded in evolution as a derivative from the female. Hence it is probable that the parental instinet preceded the sexual in time. These two instincts being the only ones which involve interest in individuals other than self, furnish the sources of sympathy in all its benevolent aspects. Hence it has developed in man into the powerful passion of love; into affection and charity in all their degrees and bearings. Fear being, as Bain shows, largely dependent on weakness, has varied in development in all times, but must be most pronounced in animals of high sensibility, other things being equal. Hence its power has, on the whole, increased until it probably reached its extreme in the monkeys or the lowest races of men. Increasing intelligence of the higher order diminishes the number of its occasions, so that it is the privilege of the highest types of men to possess but little of it. The earliest of the emotions of relativity to appear in time has probably been the love of beauty; how early it may have appeared it is difficult to imagine. Surprise and wonder, as distinet from fear, one can only conceive as following an advanced state of intelligence. 
Thus in psychology as in physiognomy, the palcontological crder of development is somewhat different from the embryological. I might compare the two orders as follows:

PALEONTOLOGICAL.
Hunger.
Reproduction.
Fear.
Anger.
Parcntal instinct.
Sex.
Power.
Bcauty.
Wonder.

EMrrological.
Hunger.
Fcar.
Anger.
Beauty.
Wonder.
Power.
Admiration.
Pity.
Sex.

Parental instinct.

The qualities enumerated in the first column follow each other directly in order from the simple to the complex. In the second column this order is disturbed by the earlier appearance of the derivative emotions, beauty, wonder, admiration, and pity, or benevolence, and the later appearance of the simple emotion of sex. 'Thus in psychological as in other evolution, some of the products of development appear earlier and earlier in life in accordance with the law of acceleration.

The intelligence has already been considered under the two heads of the imagination and the reason. The action of the imagination, unmixed with the exercise of reason, is chiefly to be seen in the creative fine arts, as distinguished from the imitative, the mechanic, and other arts. The musician, the painter, the sculptor, the poet, the novelist and the playwright, so far as they are not imitators, present the best illustrations of the work of the imagination. It is a faculty which must be very little developed in the animals below man. They occasionally make mistakes in the nature of objects, and suppose them to be other than what they are. 'Thus the Antilocapra supposes the Indian disguised with a skin and horns to be one of his own species, and suffers the penalty. But this is a most rudimental act of imagination, if it be not mere curiosity.

'The reason, properly so called, begins in its lowest grades with the simplest re-arrangement of the objects of sense and memory, in accordance with some principle of relation. As the principle or standard of relation varies, so does the intellectual process. If 
the process be discovery, or the enlargement of knowledge, many experienees (or hypotheses) will be successively encountered and tested, and appropriate generalizations reached (inductions). If the process be to accomplish the practical ends of life by use of well-known means, the intellect uses the customary rules of action as standards, be they moral or mechanical, financial or political, and attains its deductions and applications. 'These two types of intellect are strikingly distinet, and produce the most diverse consequences. The inductive type is the most generalized, and hence capable of the largest growth and adaptability, and the widest range of thought. The deductive is the more specialized, the more "practical," but less capable of growth or gencral thonght. Its most remarkable exhibitions are seen in the skill with which some men conduct the game of chess, and corresponding enterprises in real life. Also the ingenuity of mechanical invention, and the wonderful rapidity of calculation which some minds display. In intellectual as in many other vital phenomena, the facility once developed, the active process is often unaccompanied by conscionsness in many or even all of its stages.

Rapid and exact control of the muscles in obeying the directions of the mind is essential to the practice of many arts, especially to that of the musician. 'This accomplishment is acquired through the medium of the conseions mind, and may be regarded simply as the reflex of impressions made on the senses directed by some simple rule which has been impressed on the memory. The often surprising results involve the exercise of a very simple phase of intellection.

The appearance of the rational faculties in time, may be estimated by their relative development in the existing divisions of animals whose period of origin is known or inferred. The animal mind is capable of simple forms of induction and deduction, and sometimes acquires considerable artistic skill. Bees, ants and spiders display these in varying degrees, and their antiquity is probably co-extensive with that of the known sedimentary rocks. The supposed Aseidian ancestors of the Vertebrata, and cren the lowest vertebrate (Branchiostoma), display far less intelligence than the articulates mentioned, which are really lower in the scale of organic types. From such unpromising sources did the noble vertebrate line descend. It is probable that the inductive act preceded by a little the deductive in time, as it does in logieal order. Bnt the elaboration of these powers was doubtless long delayed; for 
untold ages they involved nothing more than the discovery and application of general principles of the simplest kind; such as the customary sequence of natural phenomena, and the anticipation of their operations, as, for instance, in the laring up of winter provisions. Occasionally deductive application of an old rule to a new case would arise, as in that of the Mygale spider which was observed by Dr. MeCook to substitute cotton for her own silk for the lining of her nest. 'The development of the rational faculty has been rather in quantity and quality, than in the nature of its constituent parts. I may remark, howerer, that the embryological order is here again different from the paleontological. Inherited aptitudes, as for music, calculation, ete., precede, in children, any considerable powers of thought, while the order of development of the race has been the reverse.

As regards the appearance of the qualities of mind already mentioned, which depend on character of tissue, it is diffienlt to present an order which shall be generally true. Our ignorance of the subject is profound; nevertheless observation of animals and men leads to the following conclusions: First, the primitive mind is negative, unimpressible, and little sensitire. In erolntion, sensibility has been developed under stimuli, and diminished by disuse and repose. The energy of high-strung sensibility has probably ever won for its possessors success in the struggle for cxistence, and more or less immunity from the pains which stimulate to ac tion.* It is true that the non-aggressive and ever-harassed Herbivora have developed the higher brain structure. The inferiority of brain type of the Carnivora is a well-known fact of present and past time. 'The early ruminants were smaller than the contempolary flesh-eaters, and therefore subject to the greatest risks. 'The best-dereloped brains, those of the Quadrumana, have been developed in still more defenseless animals, who in their arboreal life have been confronted by still more complex conditions. $f$

Inpressibility or sensitiveness has evidently been the means of acquisition of some of the other qualities mentioned. 'Thus intensity may have resulted from actire use aceompanied by vigorous nutrition, and the consequent construction of compact force-converting tissue. Rapidlity without intensity must also result from

* "The Relation of Man to the Tertiary Mammalia," "Penn Monthly," 1875.

f Mr. C. Morris very reasonably regards the social life of these animals as the source of their development of intelligenee. See "American Naturalist," June, 1886. (Fd. 1586.) 
exercise, with a less vigorous construction of tissue. Fineness and tenacity, on the other hand, can not be regarded as being so much produced by use as by very primitive conditions of tissue. Restraint under pressure might prodnce fineness. Long-continued freedom from sudden changes, under pressure, might account for the origin of tenacious tissue. As to quantity, deficiency or aiversion of nutritive energy or material must produce smallness, and the reverse condition, largeness.

These qualities impress themselves on the external as well as the internal organization, and can be more or less snccessfully discerned by the observer. I reserve the question of physiognomy to a later article, and here consider only the evolutionary bearings of character itself. As in physiognomy, we may arrange the faculties and their qualities under the two heads of ancestral and embryonic, or that of the species and that of the individual. 'The order of succession is the same in both kinds of development.

SPECIES.

Indifference.

Emotions.

Intellect.

a. Imagination.

b. Reason.
INDIVIDU AL.

Indifference.

Emotions.

Intellect.

a. Imagination.

b. Reason.

It is not practicable to go farther than this into the order of evolution of characteristics. There is probably little uniformity of sequence other than that I have already pointed out under the head of the emotions.

As a complex onteone of the emotional and rational faculties must be now mentioned the moral sense, or the sense of justice. It consists of two elements, the emotion benevolence, and the rational power of discrimination or judgment. The former furnishes the desire to do what is right to a fellow-being. Without the aid of reason, it is benevolence, not justice, and may often fail of its object. The rational element has acquired from experience a generalization, the law of right. It perceives what is most conducive to the best interest of the object of benevolence in his relation to others or to society, or whether he be a proper object of benevolence at all. By itself, this quality is absolutely useless to mankind. When it gnides the action of human sympathy, it displays itself as the most noble of human attributes. Many animals display sympathy and benevolence, but justice has not yet been observed in any of them. Hence it has been said that it can not 
be a derivative faculty, but is "intuitive" in man. The objection to this view is its great variability and oceasional entire absence in man, individually and racially. It is the last to appear in individual growth, as it has doubtless been in the order of evolution, of mind.

I now devote a little space to the discussion of the distribution of these qualities in races and sexes.

As regards the relative preponderance in action of the emotive and intellectual faculties, it is an axiom that in the great majority of mankind, apart from the necessities imposed by the simple physical instincts, it is a taste or an affection or an emotion that lies at the basis of their activities. Perhaps the most universal is the affection of sex. Given two types of rational beings who are objects of admiration and of pleasure to each other, each of whom desires to possess the other, and who therefore employs many devices to please and attract the other, and we have an effective agent of general development. Then the parental, and especially the maternal, affections arouse and direct many labors. Fear of suffering and death is at the basis of many others. The love of power or of possession, including ambition, is a well-known stimulus. The love of beauty is a strong motice in many persons. The pleasure derived from the exereise of the intelligence is a sufficient motive for a life-work in a comparatively small number of persons. 'These are the artists and the scientists; but it is far from being an uumixed motive in many of them.

Intellectual motives, however, enter into association with the affectional in many instanees, as, for example, in the profession of teaching. But it is as guide and agent in the accomplishment of the main ends of life that the intellect, especially the reason, has its great field, and displays itself in an endless variety of ways.

If we now survey men as we find them, it is a general truth that it is in the male sex that the greatest proportion of rational method is to be found, and in the female the greatest proportion of the affectional and emotional. As we descend the seale of humanity, the energy and amount of the rational element grows less and less, while the affectional elements change their proportions. The benevolent and sex elements diminish in force more rapidly than the other sentiments, but it is probable that all the emotions are less active in savages, excepting those of power and of fear. In the lowest races there is a general deficiency of the emotional qualities, excepting fear, a condition which rosembles 
one of the stages of childhood of the most perfect humanity. To this must be added revenge, where hatred may be re-enforced by several other sentiments, with a feeble perception of equivalent suffering or punishment, which may or may not be just. 'The pleasnre of muscular exercise is greatly developed in people of ontdoor habits.

The order of the appearance of the intelligence is nearly dependent on the development of the powers of observation. In most savages these are very acute, and vary according to the nilture of the environment which impresses them. The eharacter of most eivilizations tends to dimiuish the power of the perceptive, while the higher departments of imagination and reason are enlarged. The imagination reached a high development before reason had attained much strength. With the exception of a few families, the intelligence of mankind has, up to within two or three centuries, expressed itself in works of the imagination. When exact knowledge first began to be cultivated, it was in the department of astronomy, where the least precision was attainable, and where the greatest scope for the imagination is to be found.* Next in time metaphysics was the throne of learning, a field in which much may be said with the least possible reference to the facts of observation. With the modern cultivation of the natural and physical sciences, the perceptive faculties will be restored, it is to be hoped, to their true place, and thus many avennes opened up for the higher thought-power of a developed race. Thus it is that in the order of human development there is to be a return to the primitive powers of observation, without loss of the later acquired and more noble capacities of the intellect.

The relation of the qualities of impressibility, fineness, intensity, speed and tenacity, to our development in time, may have been as follows: Impressibility of mind is no donbt an embryonic character of "retardation," parallel to, and probably a consequence of, the retardation which is also expressed in the human skull and face. The preponderance of the osseous and nutritive elements over the nervous is the usual accompaniment of non-impressibility, and vice versa. IIence this quality is of late origin in the

* The governments of antiquity required the knowledge of the Chaldean astronomers as important to the success of their undertakings, and the governments of Furope and America were, for a long period, more liberal in their support of astronomy than any other science. At present, however, geology shares in this aid, and to a less degree botany and zoülogy. 
history of the Vertebrata and of man, and is most developed in the young, and better developed in women than in men.

'Tenacity has an opposite signifieance, being an especial characteristic of maturity in the human mind. Hence it may have been more general in early ages than at present, but could have little value so long as the mind remained small in quantity. Curiously, it is a quality which may co-exist with a good deal of impressibility.

Fineness can only be a quality of full development, and is totally independent of the other qualities. It is unknown among sarages, and is developed apparently in a few animals. Of intensity it is diffieult to say much definitely. The nervous operations of animals often display the highest degree of this quality, and it is not unlikely that its appearances differ as much in savages as in civilized people. Its importance in mental action depends of course on the kind and amount of mental fumetion which exhibits it. The same may be said of speed. 'The faculties which exist are more or less affected by it. In the well-formed reason it is an important characteristic, and a special form of development.

Having gone as far into the origin and developmental relation of mental functions and qualities as the nature of this sketeh permits, I refer briefly to the stimulus to their growth; always remembering that the percentage of inherited qualities is much larger in a given character than that of aequired ones. On this head one word expresses a good deal, and that word is use. No truth is bettel known than this one, that mental faculties develop with use more rapidly than those of any other organ of the human body. Brain and nerve are apparently the most plastic of all tissues; the one which retains the properties of the primitive protoplasm, multiplied and intensified a thousand fold. It has always been the seat of ereation, throwing off its "formed matter" in useful directions. It is still doing so; and in the human brain, ever ereating itself, is in addition the seat of a new creation, which it exeentes through its instruments, the other organs of the body. Hence the greatest sin against the brain is idleness, or' disuse. 'The brain aetivity of to-day is an indication of health and happiness beyond what the world has seen hitherto.

'I'he greatest stimulus to excreise of the brain is human society. Hence the greatest developments of mind have always been in the centers of population. Whatever may be the passice rirtues of country life, it is the cities that furnish both the stimulus and the field for the triumphs of mind. 


\section{XVIII.}

\section{CONSCIOUSNESS IN EVOLUTION.*}

\section{PRELIMINARY.}

THE evidence of what is termed "design" in the structure of beings exhibiting life, is often appealed to by one class of thinkers, as proving the intervention of a personal Deity in the creation of such; and the same feature exhibited in the morements of living creatures is regarded by metaphysicians of a similar class as an indication of their possession of a power of choice, or "free agency," at least in the case of man. The opposing school, of whom Professor Bain may be selected as an example, believes that designed acts are without an element of freedom, bnt are simply performed in obedience to stimuli of various kinds, motion following stimulus as inevitably as effect succeeds cause in the nonliving world. 'The evolntionists attempt to explain design in structure through the operation of the Darwinian law of the "survival of the fittest," showing that only those beings whose organization displays that adaptation to use in relation to its surroundings, which is termed "design," could possibly continue to exist. It is justly urged against this reasoning that it attempts no explanation of the origin of such struetures. Another school of evolutionists have therefore maintained that such structures are due to the effect of effort, i. e., stimulus or use, exerted by the living being on its own body, and that the design thus displayed is an expression of the intelligence at some time possessed by itself.

So long as there is any probability of the last explanation proving valid, it will be important to examine in to the questions of metaphysics which it necessarily involves. The investigation is indeed but the neeessary projection of those which have resulted in satisfying the great majority of biologists of the reality of evolution, or of the fact of the descent of existing living beings,

* $\Lambda$ lecture delivered before the Franklin Institute, Philadelphia, February, 1874. 
species by species, order by order, and class by class, from others which have preceded them in time. Clearly, then, we enter the question by considering the nature of movements of plants and animals in relation to the stimuli which are supposed to call them forth.

\section{THE CNCONSCIOUS.}

A true study of metaphysics necessarily has for its objects plants, animals, idiots, and infants, as well as healthy men ; nevertheless, necessity compels us, in discussing the question, to dwell on our own experiences as a sine qua non. Now experience, in a general sense, includes not only the memory of our conscious acts, but a knowledge of our unconscions ones, and to the latter especial attention must be directed, since they are most readily overlooked. The marrelous character of memory can not be too much considered. Of the millions of impressions which the mind has received and registered, in the course of a lifetime, but one can be clearly present in conscionsness at one time. The remaining millions are not lost ; they are stored, each in its appropriate place, to be sprung into consciousness when the appropriate suggestion presents. How much more vast, from this point of view, is the unconscious mind than the conscious! But the phenomenon is not confined to memory. Who that has erer attempted the digestion of a subject which includes a mass of details, is not acquainted with the unconscious activity of the mind in classification? How frequently a question involving many parts, is, on the first reception of the constituent facts, all confusion; but in time displays its symmetry clearly to the consciousness, every part in its proper place, and that with little or no further attention having been devoted to it. It is indeed probable that the every-day process of inductive reasoning is conducted in unconsciousness on the part of the subject. Induction consists in the generalization of some quality as common to a great number of objects of memory ; a greater or smaller number of other qualities being neglected in the process. When this act is performed roluntarily, one or many qualities are successively passed in review before the mind-cach one being in its turn impressed on the pereeptive center's-so long as it is the object of inquiry, the others being excluded from conscionsness for the time being. It is simply a process of elassification, and when performed in consciousness, constitutes "experiment." But when 
no generality is anticipated, and its existence is unknown, it often happens that such generalization becomes known or rises into consciousness, without the bestowal of effort in elassification of the objeets to which it refers. The impressions conscionsly received have been arranged ont of conscionsness, and when revived into conscionsness display an order which was not previously known to exist. It is in the latter way that the "practical man" "finds out" the rules by which, as by an instinct, he reguilates his intercourse with the world. He often can not explain the reasons of their truth, nor does he know how he eame by them, being generally content to call them the results of "experience." In some persons they are so feebly expressed in consciousuess as to be called "feelings"; and many experiences or repetitions are sometimes necessary to impress on us the importance of these mental prodnets before we are willing to follow them in action. "Strength of mind" is an expression applied to a high degree of this unconscious reasoning; expressing the extent of ground the process covers continuously, as well as the exactitnde of its results. The experimental investigator, on the other hand, performs this work deliberately, and is acquainted with the processes; he is, therefore, at first more confident of his results. And we observe here, in passing, that a rule once discovered is as readily retained in the cells of the uneonscious as is the memory of a simple object or event.

Another form of uneonseions cerebration is seen in deduetive reasoning, which employs rules already discovered in application to new cases. Calenlating prodigies are a case in point. It is well known that those persons who have from time to time appeared possessed of the power of ealeulating with enormons nnmbers with marvelons rapidity, have never been able to explain the process by which they reach their conclusion, nor are they conscions of going through the steps involved in the calculation they perform; and it has been said that great calculators have rarely been great mathematicians.

The explanation of these phenomena is not far to seek. In simpler forms it is presented to us every day. Thus it is an easy matter to read with but little conscionsness of the proeess, and no recollection of the subject-matter of what is read. Most manual operations can be performed while the consciousness is ocenpied with other objects.

If these be facts of human experience, how much more likely 
are they to be true of animals? If man be unconscious of the process during the performance of some of his most complex acts, how much more probable is it that animals are so while pursuing the narrower circle of their simpler ones? Yet animals are not devoid of consciousness; indeed, it is scarcely credible that any one should deny to them consciousness, after experience in their education.

But let these automatic acts be ever so simple or complex, it is here claimed that they could not have originated ont of conscionsness. Whatever we call voluntary acts in ourselres undoubtedly have to be learned. The acquisition of the primary act of walking is accomplished by a slow and painful education; whilc knitting and other manual exercises necessarily require preliminary training, some of shorter, others of longer, duration. This is true of such voluntary acts as we perform most readily automatically, and such as might be supposed to be most probably acquired by hereditary transmission, as for instance speaking. The case is the same with animals. All those scrvices which are useful to us, or tricks which amuse us, are acquired at the expense of training, which involves a system of stimuli, consisting of rewards and punishments, as in our own species. Is there any reason to suppose that those habits which we observe them to possess in a state of nature have had a different origin?

It is incontrovertible that a regular succession of muscular movements may be committed to memory as certainly as a color or a shape, and that a change of brain substance, such as causes the retention of the simple impression, is also involved in the retention of the complex. When this machinery is completed, through the repetition of conscious stimulus, it works thenceforth withont necessary intervention of consciousness. The consciousness may then be engaged in fresh acquisitions, accomplishing $1 \mathrm{ew}$ organizations, thus accumulating a store of powers. Once organized, these powers are at the disposal of their possessor, yet the organized machine will at some time undergo change, if not more or less frequently used. Without use it may indeed finally disappear, showing that the eapacity for organization is identical with a facility of disorganization.

\section{THE ORIGIN OF AUTOMATIC MOVEMENTS.}

Is any liabit originated in unconsciousness? Those who affirm this proposition point to the novements of plants in the extension 
of their tendrils, and the closing of some sensitive leaves; the timely expansion of the down of the Asclepias seed, and the insect-catching habits of Drosera and Dionced. No one surely attributes conscionsmess to these. And there are many similar movements in animals which are as thoroughly unconscionsly performed as are those of plants, from the first moment of the animal's birth : as, for instance, the involuntary activities of the circulatory and digestive systems, etc. Did these originate in consciousness or unconsciousness? The answer to this question constitutes the key to the mysteries of evolution, and around it the battle of the evolutionists of the coming years will be fought.

It may be asserted at the outset that those habits whose origin we have had the opportunity of observing in ourselves and in other anjmals were certainly acquired in conscionsness, and that we do not believe that they could have originated out of it. 'The stimuli to action are divided into the two general classes of pleasures and pains, and each stimulus is potent in proportion to the intensity with which it is conseiously apprehended. If many and complex acts may be performed antomatically, througln the organization of special machinery in the gray matter of the brain, it is altogether reasonable that similar powers should be found to be conferred on gray nervous tissnes in parts of the body which are no longer seats of conscionsness. It is well known that the spinal corch of the headless frog responds to stimnli, in the vigorous muscular contractions of the limbs which follow the application of acid to the skin. So the ganglionic centers of organic life respond to their appropriate excitants; the various glands of the digestive system discharging their contents into the ingesta at the proper moment, conscionsness having no share in the proceeding. These phenomena are more readily explained on the theory of endowment than on that of physical movements ; since by means of the former the evident design in the movements is accounted for, while the latter gives us no clew to this characteristic feature of these and all other vital processes.

The lowest form of consciousness is common sensibility ; and, judging by the resemblance between our own experience and that of the higher animals, the lowest of animals also are not deroid of this quality. The structureless jelly of Rhizopods, such as Amobas, Gromias, ete., evidently selects its food with regard to its nutritions qualities, in most instances preferring diatoms and desmids to sand and other innutritious substances. Its acquisi- 
tions in knowledge of articles of food can only be accounted for on the hypothesis of original, pleasurable or painful, consciousness of the effects of external and internal contact with these substances, and retention of the impression in unconsciousness. The impression reviving on the recurring of a similar contact, the substance is accepted or rejected as the former sensations were pleasurable or painful. And this is not incredible, if, as the researches indicate, the structure of the protoplasm of these creatures is of the same type as that of the bioplastic bodies of the gray tissue of the brain.

In accordance with this view, the automatic "involuntary" movements of the heart, intestines, reproductive systems, etc., were organized in successive states of conscionsness, which conferred rhythmic movements, whose results raried with the machinery already cxisting and the material at hand for use. It is not inconceivable that circulation may hare been established by the suffering produced by an overloaded stomach demanding distribution of its contents. The structure of the Colenterata offers the structural conditions of such a process. A want of propulsion in a stomach or body sack occupied with its own functions would lead to a painful clogging of the flow of its products, and the "voluntary" contractility of the body or tube-wall being thus stimulated, would at some point originate the pulsation necessary to relieve the tension. Thus might have originated the "contractile vesicle" of some protozoa, or contractile tube of some higher animals; its ultimate product being the mammalian heart. So with reproduction. Perhaps an excess of assimilation in wellfed individuals of the first animals led to the discovery that selfdivision constituted a relicf from the oppression of too great bulk. With the increasing specialization of form, this process would become necessarily localized in the body, and growth would repeat such resulting structure in descent, as readily as any of the other structural peculiarities. No function bears the mark of conscious origin more than this one, as conscionsness is still one of the conditions of its performance. While less completely "voluntary" than muscular action, it is more dependent on stimulus for its initial movements, and does not in these display the unconscious antomatism characteristic of the muscular acts of many other functions.

Bearing in mind the property of protoplasm to organize machinery which shall work automatically in the abscnee of con- 
sciousness, we can glance at the succession of vegetable forms. The active movements of the primary stages of the Algæe are well known. After swimming actively through the water, they settle down, take root, and assume the role of plants. The Aethalium, swimming with the movements of a Rhizopod, has been known to take food before establishing itself on the damp piles of the tanbark, where it speedily becomes a low form of fungus. The approximation of the lower forms of plants to animals is notorious. The fungi, it is said, are the only terrestrial plants which live like animals on organic matter, appropriating the humus of their rich nidus in a state of solution. Now the paleontology of animals has absolutely established the fact that the predecessors of all characteristic or specialized types have been unspeeialized or generalized types, "neither one thing nor another." It may then be regarded as almost certain that the ancestors of the present higher types of plants were more animal-like than they; that the forms displaying automatic movements were more numerous, and the difficulty of deciding on the regetable or animal nature of a living organism greater than it is now. Henee it may be concluded that "animal" conscionsness has from time to time organizerl its machinery and then disappeared forever, leaving as result the permanent form of life which we call vegetable. But it is not to be supposed that all changes of strueture cease witl the departure of consciousness. Given spontaneous movement (i. e., growth), and surrounding conditions, and the resultant product must be structures adapted to their surroundings, just as the plastic clay is fitted to its mold. And this is essentially the distinguishing charaeter of vegetable teleology as compared with animal. In the average plant we see adaptation to the eonditions of unconscious nutrition ; in the animal, adaptation to conditions of conscious contact with the world under a great variety of conditions.

\section{GROTTH-FORCE.}

The active processes of living beings are examples of conversion of physical forces, only differing from the conversions observed to take place in inorganic bodies, in the nature of the machinery which exhibits them. The construction of this machinery, as in its use when finished, involves a conversion of force, the resultant consisting of the attraction of nutritious material in definite new directions. This determinate attraction has been regarded as a distinct foree, to which the name of bathmic or growth force has 
been applied. It differs from all the physical forces in this, that while they are only exerted inversely as the square of the distance, this one is in addition most excessive where pleasure has been experienced, and weakest where pain has left its deepest traces. In other words, its movements express design, the essential condition of which is conseiousness. It is thus evident that it differs utterly from all other forces, although a retrograde metamorihosis of matter is as necessary for its production as for that of any of the other forces. Now, although the evidences that stimulated consciousness, or if you choose, mind, can modify structure, are, as matter of observation, not very satisfactory; yet, since the essential peculiarity of growth-force is its instant attendance on the needs of consciousness, it is a permissible lyypothesis that its activity is immediately due to consciousness. This activity is located in bioplasts which do not exhibit conscionsness; whether it co-exists with consciuusness in brain bioplasts is mknown. The successive exhibitions of this force, from the lowest to the lighest of living beings, have ever been additions to the executive machinery of a more and more specialized conscionsness. Thus it is that its results in structure have ever become more and more complex, that is, composed of an ever-increasing number of parts in some region of the organism. Hence another point of distinction from other forees exists, which las been pointed out in a previous paper. It is quite evident that the higher forms of life are the result of continued superaddition of one result of growth-force on another, some examples of subtraction or simplification of parts being generally accompanied by a great preponderance of additions. This is evidence of the accumulation of the property of producing this kind of force, since each successive addition imposes on the growing animals a great number of successive stages before the process reaches its termination, maturity. This involves the belief that the property of exhibiting frequent "repetitions" of growth-activity exists in a ligher degree in the reproductive bioplasm of the more complex animal than in that of the lower ones. 'This is in accordance with the fact of the regnlar increase in relative complexity and bulk of the nervous system, which accompanies complexity of structure in other respects in the ascending scale of animals. 'Thus this force differs from all others, as remarked by Prof. Hartshorne, in that its expenditure ultimately increases the amonnt of its production, because it constructs machinery which feeds its especial organs more and more successfully. Althongh expended 
by becoming energetic, its energy produces the means of its own increase. Unlike the physical forces whose expenditure renders matter ever more inert, growth-force when expended adds material which, as a profitable addition, increases the power of the central machine from which the force emanates, by furnishing an increased supply of food.*

'Thus it is erident that growth-force is not concentric nor polar in its activity, as are the physical forces, and that its determinations are antagonistic to these. Its existence in the earth has been a succession of conquests over polar force, and, if preceding assumptions be true, the gradual progress presented by animals in abandoning the symmetrical forms exhibited by the lower types has donbtless been due to the constantly increasing amount of conscionsness.

V. THE DOCTRINE OF THE UNSPECIALIZED.

It is, howerer, evident that the directing power of consciousness is limited by the nature of the matter with which it has to deal. There are certain fundamental necessities to which it must conform. No one supposes that any degree of power can make twice two equal to six, canse two solid substances to oceupy the same space at the same time, or make an absolutely solid substance out of incompressible atoms of different forms. These involve the absurdity that something can be made out of nothing, or nothing ont of somothing. From the present conduct of the inorganic world, it would appear to possess properties which render conscionsness impossible to it. This is doubtless due to the relations existing between the atoms or molecules of which its various species consist. The morements it displays are polar. The colloid molecular state is, so far as this planet is concerned, the only one which we know to be capable of couscionsness, and then only while in a state of active transformation. As we have seen, when protoplasm is once organized and working antomatically, conscionsness need not be present; and when this is absent, the rate of transformation, that is, the amount of food consumed, is greatly lossened. The excess of expenditure during conscions

* It is incorrect to say that growth-force is "potential" in highly organized types, as it is undoubtedly expended in the movement of nutritive pabulum to a given locality. The maintenance of it in that locality is due to ordinary molecular cohesion, which can only be set free by greater molecular consolidation. 
activity over that necessary to unconscious activity is well known. It is thus evident that organization renders consciousness unnecessary, so long as external conditions are unchanger, and most probably a degree of fixity may be attained which renders consciousness impossible. The history of the evolution of animal types is apparently an illustration of this truth. 'The relations of the divisions of the animal kingdom are those of the limbs, branches, and trunk of a tree. Althongh the termini of the branches are successively nearer the root or starting-point as we proceed from the apex downward or backward, yet the connection is not from end to end of these. To find this we pass down the limb to its junction with the trunk, and trace the branches from the axis outward. Thus with the branches of the animal kingdom. Although the divisions Vertebrata, Mollusca, Echinodermata, etc., stand in an undoubted relation of succession to each other, there is no connection between the highest representative of one and the lowest of another. It is the lower or less specialized forms of each which exhibit the relationship. Thus, among the articulates, the low group of the worms gives us connection with the Mollusca above by Brachiopoda, and the echinoderms connect themselves with the Vermes by the less specialized Holothuride. It seems highly probable also that the point of contact of the Vertebrata with these is by one of the lowest divisions, formerly regarded as molluscan, viz.: the Ascidia. The same principle holds good within the great divisions. The most specialized orders of Mammalia are the Artiodactyla, higher Perissodactyla, the Carnivora, Quadrumana, and perhaps Cetacea; but the higher of these have not been derived from the lower. Modern inrestigations show that several of them have been derived from a common type of mammals of the Eocene period, which is intimately connected with their lower forms, while wanting in the features which give them their special characters. These two illustrations serve to explain the universal law of zoölogical affinity, and therefore of evolution.

The conclusion derived from a survey of this field is, that structure, like habit, when once established, is closely adhered to, and that the movement of growth-force once determined or organized becomes antomatic, i. e., independent of consciousness. Therefore a type which reproduces itself automatically becomes after a time so established as to be incapable of radical change, in consequence of a molecular fixity which precludes it. Nererthe- 
less susceptibility to influences of conscious stimuli may remain in some portions of the organism, and thus subordinate modifications of structure have their origin. When conditions of life change, as they often have done during geologic time, those changes of structure which are possible take place under the stimulus of roused conscionsness. But if the changes be radical, affecting the foundation processes of vital economy, the specialized forms must undoubtedly perish, and the life of the succeeding time be derived from forms of less pronounced character. 'The adaptability of generalized types, as to habits, and the absence of mechanical peculiarities in their structure, explain fully the cause of their standing in ancestral relation to all the typical fauns of the earth.

Nowhere is this truth more remarkably.illustrated than in the case of man, the predominant mammal of the present period. From the generalized mammalian fauna of the Eocene, the Carnivora developed a highly organized apparatus for the destruction of life and appropriation of living beings as food. The clovenfooted and odd-toed hoofed orders * are the result of constantly inereasing growth of the mechanical appliances for rapid motion over the ground; the former superadding exceptional powers of assimilation of innutritions food. The proboscidians developed huge bulk and an extraordinary prehensile organ. The Quadrumana produced none of these things. In respect to speed of limb and power's of digestion, both in function and strueture, they remain nearly in the generalized condition from which the other orders of mammals have risen. The limbs and teeth of man retain the characters of the primitive type. Yet but two species of proboscidians remain; the Perissodactyle multitudes are represented by but a few vanishing species. The day of the Carnivora has passed forever, and the remaining Artiodactyle herds exist but by the permission of their master, man. But past geologic time reveals no such abundance of true Quadrumana as the present period displays. These animals were evidertly unable to compete with those of other types in seizing on the opportunities of living. They were excluded from the chase by the more sanguinary ancestors of the Carnivora, and from the field by the multiplying herds of the swifter or more resistant hoofed animals. They possessed neither bulk, nor speed, nor cruelty to serve them

* Represented by the ox and the horse. 
in the struggle for existence. So they were doubtless eompelled to assume an arborcal life, which required little or no modifieation of the limbs for its maintenance, althongh the ultimate production of the grasping thumb from their primitive squirrel-like feet may be traced to this mode of life. The acquisition of a hand must be regarded as the first step in that marvelous aceession of experienees which is the condition of mental development. And this latter growth has taken the place of all other means of conquering a position in the world of life, so that man has even retrograded in the efficieney of bodily powers. He has lost the prehensile quality of the hind fect, and the speeial usefulness of his eanine teeth. But the competition among men continues to be such as to render it in the highest degree improbable that he will, as a species, lose the position gained, or suffer any.prolonged diminution of the power of intelligence.

Now it is obvious that the more restricted the conditions of the life of a given animal type, the more sensitive it will be to changes. Hence it is that the risks to the existenee of Carnivora, Artiodactyla, Proboscitia, ete., are much greater than to the omnivorous, all-adaptive order of Quadrumana. The same is true of mind. 'The greater the proportion of uneonseious antomatism of habits, the less the power of adaptation; and this must be the condition of all animals whose structure is so specialized as to place them beyond reach of competition, or to ent them off from a wide range of experiences. The greater the degree of conseionsness of stimulns, the greater will be the degree of adaptability to new relations, and to such constant ronsing the unspecialized mind is always open. If, without strong natural weapons, vigilanee is the price of existence ; if not confined by organization to a peculiar kind of food, ccaseless investigation is stimulated. And these are the mental peculiarities which distinguish the monlieys among all the Mammalia.

The reverse of this pieture may now be described, as has been done by Prof. Vogt. It is well known that the young of many parasitic animals are free and aetive, and discover during migration the localities to which they afterward attach themselves for life. During the early stages they present the characteristic marks of their order and class, and in some instances the males, remaining free, eontinue to do so. Such are the Entoconcha mirabilis, the Sacculine and the Trematoda; the first a mollusk, the second a cirrliped crustacean, the third a worm. On their beeoming at- 
tached to their host a successive obliteration of their distinctive characters takes place, so that they become so simplified as to be no longer referable to their proper class, but susceptible, as Prof. Vogt remarks, of being united in a single division. A similar process is observed in the structural degeneration of the Lernean parasites, which are at first free, but afterward become parasitic on fishes. There is in this instance a coincidence between degeneracy of structure and loss of compulsory activity : not only is every function of their sluggish lives antomatically performed, but consciousness itself must experience little stimulus.

From what has preceded, it is evident that automatism is at once the product and the antagonist of evolution, and that it is represented in structure by specialization. It appears also that conscionsness is the condition of the inauguration of new habits, and this is only possible to structures which are not already too far specialized. 'This is doubtless true, whether' osseons and muscular tissue be concerned in evolution, or whether it be nervous and brain tissue. Hence in the highest form of development, that of brain mechanism, automatism is the enemy, and conscionsuess the condition of progress. As a product of development, antomatism is the condition of stationary existence, and constitutes its effective machinery, but every additional step requires the presence of consciousness. This may be expressed in the every-day language of human affairs, by saying that routine and progress are the opposite poles of social cconomy.

\section{THE ORIGIN OF CONSCIOUSNESS.}

This question has not yet been touched upon, nor is it necessury to give it prolonged attention at present. Conscionsness is in itself inserutable to us, and the contrast which it presents to physical and vital forces is the great fact of life. It is obvious enough that certain molecular conditions are essential to its appearance; drugs intensify or obscure it; concussions and lesions destroy it. It will doubtless become possible to exhibit a parallel scale of relations between stimuli on the one hand, and the degrees of consciousness on the other. Yet for all this it will be impossible to express self-knowledge in terms of force. 'The question as to whether the product of the force conversion involved is the consciousness itself, or only a condition of conscionsness, may receive light from the following consideration.

Nowhere does "the doctrine of the unspecialized" receive 
greater warrant than in the constitution of protoplasm. Modern chemistry refers compound substances to four classes, each of which is characterized by a special formula of combination. These are called the hydrochloric-acid type, the water-gas type, the ammonia type, and the marsh-gas type. These series are defined by the volumetric relations of thcir component simple substances : thus, in the first, a single volume unites with an equal volume of hydrogen ; in the second, two volumes of hydrogen unite with a single volume of another element; in the third, three, and in the fourth, four volumes of hydrogen unite with the single volume of other elements. Hence the composition of these compounds is expressed by the following formulas-chlorine, oxygen, nitrogen, and carbon being selected as typical of their respective classes: $\mathrm{HCl}, \mathrm{H}_{2} \mathrm{O}, \mathrm{H}_{3} \mathrm{~N}$, and $\mathrm{H}_{4} \mathrm{C}$. Now it is an interesting fact that protoplasm is composed of definite proportions of four simple substances, each one representing one of the classes above named, or, in other words, the capacity for proportional molecular combination which characterizes them. The formula $\mathrm{C}_{24} \mathrm{~N}_{8} \mathrm{OH}_{17}$ expresses the constitution of this remarkable substance. Now, although the significance of these combining numbers is unknown, there is a conceivable connection between the characteristic peculiarities of protoplasm and the nature of the substances which compose it. It is probable that these, when in combination with each other, exert a mutually antagonistic control over each other's especial and powerful tendencies to form stable, and hence dead, compounds. It is therefore reasonable that the terms " mnspecialized" or "undecided" should be applicable to the molecular condition of protoplasm, and in so far it is a suitable nidus for higher molecular organization, and a capacity for higher forms of force-conversion than any other known substance. If also in inorganic types, as in the organic, the generalized have preceded the specialized in the order of evolution, we are directed to a primitive condition of matter which presented the essentially unspecialized condition of protoplasm, without some of its physical features. We are not necessarily bound to the hypothesis that protoplasm is the only substance capable of supporting consciousness, but to the opposite view, that the probabilities are in favor of other and mnspecialized, at present $\mathrm{nn}$ known, forms of matter possessing this capacity.

Conscionsness constitutes then the only apparently initial point of motion with which we are acquainted. If so, we are at liberty to search for the origin of the physical forces in consciousness, as 
well as the vital ; their present unconscious condition being possibly due, as in the case of the vital, to automatism : the automatism being the expression of the atomic type of the substance exhibiting it. And, doubtless, the simple quantitative relations of the lowest types of forces are related to correspondingly simple geometrical conditions of matter, both representing the simplest grade of antomatic action and machinery. We may also suppose that all of these primary conditions were necessary to the production of protoplasm, the only form of matter known to us in which consciousucss can persist.

In conclusion, it is obvious that the metastatic condition of protoplasm necessary to the persistence of consciousness could not be supported without a constant source of supply by assimilation. Hence it would appear that the preliminary creation of dead and unconscious substances and organisms were a necessary antecedent to the accomplishment of this end; at least under circumstances of temperature under which living beings or protoplasm exist on this planet. Without the unconscious inorganic and organic products of nature, consciousness could not exist on the earth for a day. No animal can maintain conscionsness without food; and that food must be, in the main, protoplasm. Protoplasm is manufactured from inorganic matter by the (supposed) unconscious protoplasm of the plant. What form of matter originally gave origin to protoplasm is yet unkuown, but it is obvious that the ordinary physical forces must have existed as conditions of its creation, since now they are absolutely necessary to its persistence. Hence we may view the succession of antomatic activities somewhat in the light of the fagots used by the elephant to lift itself from the well into which it liad fallen. One placed upon another finally raised the footing to an elevation which enabled the animal to obtain its freedon.

Consciousness is the essential condition of personality; so that in this view of the case we are led to a primitive personality, although not to what we call life. And the reason why this personality is to us so obscure a conception is probably to be found in the fact that it, as well as ourselves, is conditioned in its relations to matter by necessary laws of "mathematical" truth. 


\section{XIX. \\ ON AROH ÆSTHETISM.}

\section{THE HYPOTHESIS OF USE AND EFFORT.}

THE claims of the theory of Lamarek, that use modifies strueture in the animal kingdom, are being more carefully considered than heretofore, and are being admitted in quarters where they have been hitherto neglected or ignored. Eleven years ago I restated the question as follows: *

"The influenees and forces which have operated to produce the type-structures of the animal kingdom have been plainly of two kinds: 1. Originative; 2. Directive. The prime importance of the former is obvious; that the latter is only secondary in the order of time or suecession, is evident from the fact that it controls the preservation or destruetion of the results or creations of the first.

"Wallace and Darwin hare propounded as the cause of modifieation in deseent their law of natural selection. This law has been epitomized by Spencer as the 'survival of the fittest.' 'This neat expression no doubt covers the case, but it leaves the origin of the fittest entirely untonehed. Darwin assumes a 'tendency to variation' in nature, and it is plainly necessary to do this, in order that materials for the exercise of a selection should exist. Darwin and Wallace's law is, then, only restrictive, directire, conservative, or destruetive of something already created. I propose then to seek for the originative laws by which these subjects are furnished-in other words, for the canses of the origin of the fittest.

"It has seemed to the author so clear from the first as to require no demonstration, that natural selection includes no actively progressive principle whatever; that it must first wait for the de-

* "The Method of Creation," 1871, pp. 2 and 18, Walker Prize Essay, Proceeds. Amer. Pliilos. Soe., pp. 230-246. 
velopment of variation, and then, after securing the survival of the best, wait again for the best to project its own variations for selection. In the question as to whether the latter are any better or worse than the eharacters of the parent, natural selection in no wise conecrns itself."

In seeking for the causes of the origin of variation, the following hypothesis was proposed :

"What are the influences locating growth-force? The only efficient ones with which we are acquainted are, first, physical and chemical causes; second, use ; and I would add a third, viz. : effort. I leave the first as not especially prominent in the economy of type-growth among animals, and confine mysclf to the two following. The effects of use are well known. We ean not use a muscle without increasing it's bulk; we can not long use the teeth in mastication without inducing a renewed deposit of dentine within the pulp-cavity to meet the encroachments of attrition. The hands of a race of laborers are always larger than those of men of other pursuits. Pathology furnishes us with a host of hypertrophies, exostoses, etc., produced by excessive use, or necessity for increased means of performing excessive work. 'The tendency, then, induced by use in the parent, is to add segments or cells to the organ used. Use thus determines the locality of new repetitions of parts already existing, and determines an increase of growth-force at the same time, by the increase of food always accompanying increase of work done, in every animal.

"But supposing there be no part or organ to use. Such must have been the condition of every animal prior to the appearance of an additional digit or limb or other useful clement. It appears to me that the cause of the determination of growth-force is not merely the irritation of the part or organ used by contact with the objects of its use. This would seem to be the remote canse of the deposit of dentine in the used tooth; in the thickening epidermis of the hand of the laborer; in the wandering of the lymph-cells to the scarified cornea of the frog in Cohnheim's experiment. You can not rub the selerotica of the eye without producing an expansion of the eapillary arteries and corresponding increase in the amount of nutritive fluid. But the case may be different in the muscles and other organs (as the pigment cells of reptiles and fishes) which are under the control of the volition of the animal. Here, and in many other instances which might 
be cited, it can not be asserted that the nutrition of use is not under the direct control of the will through the mediation of nerve-force. 'Therefore I am disposed to believe that growthforce may be, through the motire force of the animal, as readily determined to a locality where an executive organ does not exist, as to the first segment or cell of such an organ already commenced, and that therefore effort is, in the order of time, the first factor in acceleration."

A difficulty in the way of this hypothesis is the frequently unyielding character of the structures of adult animals, and the difficulty of bringing sufficient pressure to bear on them without destroying life. But in fact the modifications must, in most instances, take place during the period of growth. It is well known that the mental characteristics of the father are transmitted through the spermatozoöid, and that therefore the molecular movements which produce the mechanism of such mental characters must exist in the spermatozoöid. But the material of the spermatozoöid is combined with that of the ovum, and the embryo is composed of the united contents of both bodies. In a wonderful way the embryo develops into a being which resembles one or both parents in minute details. This result is evidently determined by the molecular and dynamic character of the original reproductive cells, which necessarily communicate their properties to the embryo, which is produced by their subdivision. Rud. Hering has identified this property of the original cells with the faculty of memory. This is a brilliant thought, and, under restriction, probably correct. The sensations of persons who have suffered amputation shows that their sensorium retains a picture or map of the body so far as regards the location of all its sensitive regions. 'This simulacrum is invaded by conscionsness whenever' the proper stimulus is applied, and the locality of the stimulus is fixed by it. This picture probably resides in many of the cells, both sensory and motor, and it doubtless does so in the few cells of simple and low forms of life. The spermatozoöid is such a cell, and, how or why we know not, also contains such an arrangement of its contents, and contains and communicates such a type of force. It is probable that in the brain-cell this is the condition of memory of locality. If now an intense and longcontinued pressure of stimulus produces an unconscions picture of some organ of the body in the mind, there is reason to suppose that the energies communicated to the cmbryo by the spermato- 
zoöid and ovum will partake of the character of the memory thus created. The only reason why the oft-repeated stories of birthmarks are so often untrue is because the effect of temporary impressions on the mother is not strong enough to counterbalance the molecular structure established by impressions oftener repeated throughout much longer periods of time.

The demonstration of the truth or falsity of this position, so as to constitute it the true doctrine of evolution, could only be rerified from the prosecution of the science of paleontology. It is only in this field that the consecntive series of structures can be obtained which show the directions in which modification has taken place, and thus furnish evidence as to the canses of change. The most complete result of these investigations, up to the present time, has been the obtaining of sufficiently full series of the Mammalia of the Tertiary period to show their lines of descent. In this way the series of modifications of their teeth and feet has been discorered, and the homologies of their parts been ascertained.* Perhaps the most important result of these investigations is the following: The variations from which natural selection has derived the persistent types of life have not been general or even very extensive. They have been in a limited number of directions, $\nmid$ and the most of these have been toward the increase in perfection of some machine. They bear the impress of the presence of an adequate originating canse, directed to a special end. Some of the lines struck out have been apparently inadequate to cope with their environment, and have been discontinued. Others have been more successful, and have remained, and attained further modification.

The reader can estimate the chance of the production of an especially adaptive mechanism in the absence of any pressure of force directing growth to that end. It appears to me that the probability of such variation appearing under such circumstances is very slight indeed, and its continuance through many geologic ages directed to the perfecting of one and the same machine still smaller. For this reason, attempts have been made to demonstrate a mechanical cause for the modifications of structure ob-

* "Homologies and Orimin of the Molar Teeth of the Mammalia educabilia." Journal Academy Nat. Sciences, Philadelphia, March, 1874. Procedings Academy Nat. Sci., 1865, p. 22.

+ See Hyatt on this point, "Tertiary Planorbis of Steinheim." Anniv. Mem. Bost. Soc. Nat. Hist., 1880, p. 20. 
served. For these I refer to papers by Messrs. Alphens Hyatt, J. A. Ryder and myself : by Prof. Hyatt ... "Upon the Effects of Gravity on the Forms of Shells and Animals;" * Mr. Ryder" "On the Mechanieal Genesis of Tooth Forms;" $f$ and "On the Laws of Digital Reduction ;" $\ddagger$ by myself "On the Origin of the Specialized T'eeth of the Carnivora;" " "On the Origin of the Foot Structures of the Ungulates ;" " "On the Effect of Impacts and Strains on the Fect of Mammalia." $\Delta$ Now demonstration of the mechanical effects of the application of force to matter can only be obtained by observation of the process, and this can not be seen, of course, by the observation of fossils. The relation of the observed facts to the hypothesis is, however, shown by the above papers to be so precise that it only needs observation on the production of similar changes by similar causes in living types to give us a demonstration by induction, which will satisfy most minds. That such facts have been observed among the lower animals is well known. The change of form of animals withont hard parts, in adaptation to their environment, is an every-day occurrence.

That these views are now shared by many naturalists is becoming every day more evident. Prof. E. Dubois-Raymond $\diamond$ has recently delivered a lecture before the physicians of the German army, on exercise or use, in which he makes some important admissions. We give the following extract: "We should be, therefore, free to admit, with some appearance of reason, that the vigor of the muscles of wings and of digging feet; the thick epidermis of the palm of the hand and of the sole of the foot; the callosities of the tail and of the ischia of some monkeys ; the processcs of bones for the insertion of museles; are the consequences of nutritive and formative excitation, transmitted by heredity." In this position Prof. Raymond is in strict accord with the Lamarekian school of evolutionists. But Prof. Raymond still clings to the obscurities of the Darwinians, though Darwin himself is not responsible for them, in the following sentences: "It is necessary to admit, along with development by use, develop-

* "Procecls. Amer. Assoc. Adv. Science," 1880, p. 527.

† "Proceedings Academy Philadelphia," 1878, p. 45; $1879,47$.

† Loc. cil., 1877, October.

\# "American Naturalist," March, 1879, p. 171.

|| Loc. cit., April, 1881, p. 269.

$\triangle$ Loc. cit., July, 1881, p. 542.

$\checkmark$ "Revue Scientifique," Paris, Jan. 28, 1882. 
ment by natural selection, and that for three reasons. First, there are innumerable adaptations-I cite only those known as mimetic coloration-which appear to be only explicable by natural selection and not by use. Second, plants which are, in their way, as well adapted to their environment as animals, are of course incapable of activity. 'Thirdly, we need the doctrine of natural selection to explain the origin of the eapacity for exercise itself. Unless we admit that which it is impossible to do from a scientific stand-point, that designed structures have a mechanical origin, it is necessary to conclnde that in the struggle for existence the victory has been secured by those living beings who in exereising their vatural functions have increased by chance (' par hasard') their capacity for these functions more than others, and that the beings thus favored have transmitted their fortunate gifts to be still further developed by their descendants."

To take up first the second and third of these propositions, Prof. Raymond does not for the moment remember that movement (or use) is an attribute of all life in its simplest forms, and that the sessile types of life, both regetable and animal, must, in view of the facts, be regarded as a condition of degeneration. It is scarcely to be doubted that the primordial types of regetation were all free swimmers, and that their habit of building cellulose and stareh is responsible for their early-assumed stationary condition. Their protoplasm is still in motion in the limited confines of their walls of cellulose. The movements of primitive plants have donbtless modified their strueture to the extent of their duration and scope, and probably laid slightly varied foundations, on which antomatic nntrition has built widely diverse results. We may attribute the origin of the forms of the vegetable kingdom to three kinds of motion which have acted in conjunction with the physical environment ; first, their primordial free movements ; second, the intracellular movements of protoplasm; third, the movements of insects, which have donbtless modified the structure of the floral organs. Of the forms thus produced, the fit have survived and the unfit have been lost, and that is what natural selection has had to do with it.

The origin of mimetic coloration, like many other things, is yet unknown. An orthodox Darwinian attributes it to "natural selection," which turns ont, on analysis, to be "hasard." The survival of useful coloration is no doubt the result of natural selection. But this can not be confounded with the question of origin. On 
this point the Darwinian is on the same footing as the old-time Creationist. The latter says God made the variations, and the Darwinian says that they eame by chance. Between these positions science can pereeive nothing to choose.

I have attempted to explain the relation which non-adaptive struetures bear to the theory of use and effort, in the following language : *

"The complementary diminution of growth-nutrition follows the excess of the same in a new locality or organ, of necessity, if the whole amount of which an animal is capable be, as I beliere [for the time being], fixed. In this way are explained the cases of retardation of character seen in most higher types. The discovery of truly complementary parts is a matter of nice observation and experiment. Perhaps the following cases may be correctly explained.

"A complementary loss of growth-force may be seen in the absence of superior incisor teeth and digits in ruminating Mammalia, where excessive force is evidently expended in the development of horns, and complication of stomach and digestive organs. The excess devoted to the latter region may account for the lack of teeth at its anterior orifice, the mouth; otherwise, there appears to be no reason why the ruminating animals should not have the superior incisors as well developed as in the odd-toed (Perissodactyl) Ungulates, many of which graze and browse. The loss to the osseous system in the subtraction of digits may be made up in the development of horns and horn-cores, the horn sheath being perhaps the complement of the lost hoofs. It is not proposed to assert that similar parts or orguns are necessarily and in all groups complementary to each other. The horse has the bones of the feet still further reduced than the ox, and is nevertheless without horns. The expenditure of the complementary growth-force may be sought elsewhere in this animal. The lateral digits of the Equide are successively retarded in their growtl, their reduction being marked in Hippotherium, the last of the three-toed horses; it is accompanied by an almost coincident acceleration in the growth-nutrition of the middle toe, which thus appears to be complementary to them."

* "Method of Creation," p. 23, 1871.

$$
\begin{aligned}
& \text { COPE, E, D. } 1887 \text {. Origin of the Fittert. D. Ap } \\
& \text { a Co. New youk }
\end{aligned}
$$




\section{THE OFFICE OF CONSCIOUSNESS.}

If the law of modification of structure by use and effort be true, it is evident that consciousness or sensibility must play an important part in evolution. This is because movements of animals are plainly in part controlled by their conscions states. The question as to how many of the actions of animals are due to conscious states at once arises. It is well known that most of the more strictly vital functions are unconsciously performed. Not only these, but many acts which have to be learned come to be performed in unconsciousness. Further, movements appropriate to needs which arise at the moment, and which are ordinarily termed roluntary, becanse they require the introduction of more or less of the rational faculty, are readily performed by vertebrated animals deprived of a brain, through the agency of the spinal cord alone.* The history of the origin of these movements must then be traced.

The movements of living beings generally possess the peculiarity of design, in which they differ from the movements of nonliving bodies. That is, their actions have some definite reference to their well-being or pleasure, or their preservation from injury or pain, and are varied with circumstances as they arise. This is not the case with non-living bodies, which move regardless of their integrity or of that of objects near them. This characteristic at once suggests that some element enters into them which is wanting to the movements of non-living masses. It has been suggested that the attraction of animals for their food and their repulsion from pain are derivatives from the attractions and repulsions of inorganic bodies, supposed to be the exhibitions of the force called chemism. But this supposition does not explain the wide difference between the two classes of acts. The adaptation to the environment seen in organic acts is unknown to the inorganic world, while the invariable character of the motions of inorganic force is greatly modified in beings possessed of life. Whether conscionsly performed or not, the acts of organic beings resemble those of conscions beings actuated by instincts of hunger, reproduction, and defense.

An explanation of these facts seems to be offered by a well-

* Such expressions as "uneonscious sensibility" and "unconscious will" are not used here, as being self-contradictory in terus aud without meaning. 
known phenomenon. We know that it is true of ourselves and of many other animals, that while all new movements have to be learned by repeated attempts, with each succeding movement the aet becomes easier, and that finally it can be performed without requiring any attention whatever. If continued, the morement becomes automatic, so that it may be or is performed in a state of unconsciousuess. In the words of Spencer, nervous currents move most readily along accustomed channels. Thus the "habits" of animals may be looked on as movements acquired in consciousness, and become antomatic through frequent repetition. Not only this, but the organization thus produced in the parent is transmitted to the suceeeding generation, so that the movements of the latter are automatically and often unconsciously performed. This view may be eren extended to the purely vital functions, with every probability of its being the true explanation of their origin and development. On a former occasion * I wrote:

"In accordance with this view, the automatic 'involuntary" movements of the heart, intestines, reproductive systems, ete., were organized in successive states of consciousness, which conferred rhythmic movements whose results varied with the machinery already existing and the material at hand for use. It is not inconceivable that circulation may have been established by the suffering produced by an overloaded stomach demanding distribution of its contents. The structure of the Colenterata offers the structural conditions of such a process. A want of propulsire power in a stomach or body sac occupied with its own functions, would lead to a painful clogging of the flow of its products, and the 'voluntary' contractility of the body or tube wall being thus stimulated, would at some point originate the pulsation necessary to relieve the tension, 'Thus might have originated the 'contractile vesicle' of some protozoa, or contractile tube of some higher animals; its ultimate product being the mammalian heart. So with reproduction. Perhaps an excess of assimilation in wellfed individuals of the first animals led to the discovery that selfdivision constituted a relief from the oppression of too great bulk. With the increasing specialization of form, this process would become necessarily localized in the body, and growth would repeat such resulting structure in descent as readily as any of the other structural peculiarities. No function bears the mark

* "Conseiousness in Erolution." "Penn Monthly," August, 1875, p. 565. 
of conscious origin more than this one, as consciousness is still one of the conditions of its performance. While less completely 'volmutary' than muscular action, it is more dependent on stimnlus for its initial movements, and does not in these display the unconscious automatism characteristic of the muscular acts of many other functions."

It was not proposed in the preceding paragraph that the contractility of living protoplasm should be regarded as due to consciousness, but that the location in a particular place of a contractility already existing might be due to that cause.

The preceding hypotheses bring us to a general theory of the evolution of organic structures or species. It is that they are the result of morements long continued and inherited, and that the character of these movements was originally determined by consciousness or sensibility. It remains then to consider the nature of consciousness.

It may be mentioned that it is here left open whether there be any form of force which may be especially designated as "vital." Many of the animal functions are known to be physical and chemical, and if there be any one which appears to be less explicable by reference to these forces than the others, it is that of nutrition. Probably in this instance force has been so metamorphosed, through the influence of the originative or conscious force in evolution, that it is a distinct species in the category of forces. Assuming it to be such, I have given it the name of Bathmism ("Method of Creation," 18\%1, p. 26). Perhaps the contractility generally regarded as an attribute of living protoplasm may be a mechanical phenomenon dependent of course on nutrition; or it may be the exhibition of a force peculiar to living beings; and hence one of the 'vital' group.

\section{ARCH ESTHETISM.}

The doctrine of evolution derives the organs of special sense from those of simple sensibility or tonch. In other words, their history has been that of other organs; the complex have been derived from the general and simple. There are then generalized consciousness and specialized consciousness. A number of forms of consciousness multiplies its vividness, the one kind reënforcing the other by a slightly different appreciation of the same thing. In the case of persons deprived of the sense of touch, the sense of sight is not sufficient to convince them of their own existence, 
as a matter of intellectual reflection. When there is no nervous system we must suppose sensibility to be generally distributed throughont the protoplasmic substance of the animal. The localization of consciousness must depend on a localization of the kind and condition of protoplasm which sustains it; while in other parts of the body the protoplasm is modified in other directions and for other purposes. If this be true, the nervous tissue of the higher animals should retain the characters of the lowest simple organisms. In point of fact this is the case, the nucleated cell being the essentially active element in the functions of brain and nerve, and being more numerous in that tissue than in any other.

The remarkable evanescence of consciousness is one of its most marked characteristics. It is this peculiarity which has led many thinkers to deny its existence in the lower animals, and to induce other's to believe that it can have had but little place among the causes of evolution. Partly for the same reason many biologists attempt to derive it by metamorphosis from some form of force.

But the nature of conscionsness is such that it can not be derived from unconsciousness, any more than matter can be derived from no matter, or force from no force. 'The "unthinkable dogma of creation" (Haeckel) can not be applied to consciousness more than to matter or force. It is a thing by itself, and with matter and force forms a trio of primitive things which have to be accepted as ultimate facts. This is perfectly consistent with the position that consciousness is an attribute of matter, and neither more nor less difficult to comprehend than the fact that force is an attribute of matter. This view is maintained in a fashion of his own by G. H. Lewes. Prof. Raymond* says in support of the same position :

"Morc temperate heads betrayed the weakness of their dialectics in that they conld not grasp the difference between the view which I opposed, that conscionsness can be explained upon a mechanical basis, and the vicw which I did not question, but supported with new arguments, that consciousness is bound to material antecedents." This position has been maintained by various writers, among them Prof. Allman $\nmid$ and the writer. But Prof.

* Address on the celebration of the Birthday of Leibnitz. "Pop. Science Month1y," Feb., 18S2.

+ Address delivered before the British Association for the Adrancement of Science. 
Raymond has not found it to be acceptable to his nearest contemporaries. He says: "The opposition which has been offered to my asscrtion of the incomprehensibility of consciousness on a mechanical theory, shows how mistaken is the idea of the later philosophy, that that incomprehensibility is self-evident. It appears, rather, that all philosophizing upon the mind must begin with the statement of this point." In stating this point some years ago we used the following language: * "It will doubtless become possible to exhibit a parallel scale of relations between stimuli on the one hand and the degrees of consciousness on the other. Yet for all this it will be impossible to express self-knowledge in terms of force." And again : $\nmid{ }^{*}$ An unprejudiced scrutiny of the nature of consciousness, no matter how limited that scrutiny necessarily is, shows that it is qualitatively comparable to nothing else. . . From this stand-point it is looked upon as a state of matter which is coëternal with it, but not coëxtensive."

It is probable then that consciousness is a condition of matter in some peculiar state, and that wherever that condition of matter exists consciousness will be found, and that the absence of that state implies the absence of consciousness. What is that state?

It would be a monstrous assumption to suppose that consciousness and life are confined to the planet on which we dwell. I presume that no one would be willing to maintain such an hypothesis. Yet it is obvious that if there be beings possessed of these attributes in the planets Mereury and Saturn, they can not be composed of protoplasm, nor of any identical substance in the two. In the one planct protoplasm would be utterly disorganized and represented by its component gases; in the other it would be a solid, suitable for the manufacture of sharp-edged tools. $\ddagger$ But as it is probable that protoplasm is adapted for the phenomena of consciousness by a certain peculiarity of its constitution, it seems evident that other substances having a similar peculiarity may also be able to sustain it. I have elsewhere attempted to discover what this is, in the following language: \#

"Nowherc does 'the doctrine of the unspecialized' receive greater warant than in the constitution of protoplasm. Modern chemistry refers compound substances to four classes, each of

* "Consciousness in Evolution." "Penn Monthly," July, 1875.

† "The Origin of the Will." "Penn Monthly," 1877, p, 439.

‡Frazer in "American Naturalist," 1879, p. 420.

" “Consciousness in Evolution," 1 1575, p. 573. 
which is characterized by a special formula of combination. These are called the hydrochloric-acid type, the water-gas type, the ammonia type, and the marsh-gas type. These series are defined by the volumetric relations of their component simple substanees: thus in the first, a single volume unites with an equal volume of hydrogen; in the second, two volumes of hydrogen unite with a single volume of another element; in the third, three, and in the fourth, four volumes of hydrogen unite with the single volume of other elements. Hence the composition of these compounds is expressed by the following formulas-chlorine, oxygen, nitrogen, and carbon being selected as typical of their respective classes: $\mathrm{HCl}, \mathrm{H}_{2} \mathrm{O}, \mathrm{I}_{3} \mathrm{~N}$, and $\mathrm{H}_{4} \mathrm{C}$. Now it is an interesting fact that protoplasm is composed of definite proportions of four simple substances, each one representing one of the classes above named, or, in other words, the eapacity for proportional molecular combination which characterizes them. The formula $\mathrm{C}_{24} \mathrm{~N}_{8} \mathrm{OH}_{19}$ expresses the constitution of this remarkable substance. Now, although the significance of these combining numbers is nuknown, there is a conceivable connection between the characteristic peenliarities of protoplasm and the nature of the substances which compose it. It is probable that these, when in combination with each other, exert a mutually antagonistic control over each other's especial and powerful tendencies to form stable, and hence dead, compounds. It is therefore reasonable that the terms ' unspecialized' or ' undecided' should be applicable to the molecular condition of protoplasm, and in so far it is a suitable nidus for higher molecular organization, and a capacity for higher forms of forceconversion than any other known substance. If also in inorganic types, as in the organic, the generalized have preceded the specialized in the order of evolution, we are directed to a primitive condition of matter which presented the essentially unspecialized condition of protoplasm, without some of its physical features. We are not necessarily bound to the hypothesis that protoplasm is the only substance capable of supporting consciousness, but to the opposite view, that the probabilities are in favor of other and $\mathrm{mn}$ specialized, but unknown, forms of matter possessing this capacity."

The condition of living protoplasm was also referred to in the following language in a later publication : *

* "The Origin of the Will." "Penn Montlı!y," June, 1877, p. 439. 
"The cause of the difference between conscions and unconscious foree must be secondarily due to different conditions of matter as to its atomic constitution; conscionsness being only possible, so far as we can ascertain, to matter which has not fallen into fixed and automatic relations of its atoms."

Protoplasm in the form of food is not conscious; and tissue formed of protoplasm is not conscious, excepting certain cells where the forming process is in action. Nor is consciousness present in all cells where nutrition is active. From the increased consumption of energy, and the increased expenditure of energy (heat, Lombard) which takes place during conscions processes, we may well believe that the decomposition of protoplasm is more considerable in such processes than in other forms of nervous activity. We can imagine simple nutrition to be a condition of the clements of this substance in which the chemical force is simultaneously combining and dissolving its combination, and that during the process there is a condition in which the chemism is for the time being unsatisfied, though present. The direction which this mutrition or metastasis takes, is due to the arrangement of the molecules already existing in the tissue, the new molecules taking the form of the old ones in replacement, so long as no extraneous force interferes. That they are rearranged under the influence of consciousness is apparent in the origin of variations of strueture in accordance with the views of evolution already cntertained. It is the arrangement of the molecules which constitutes the automatic machinery of nutrition as well as of other activities, so that conseiousness necessarily only appears in that stage of nutrition while the matter is in a transition state, and unformed. Whether chemism must be regarded as suspended, or only unsatisfied, at this stage, can only be imagined. As non-satisfaction is probably the temporary condition in all nutrition, it is not unlikely that suspension may be the condition of consciousness.

Perhaps the character of the components of protoplasm is sueh that the movements of their atoms, i. e., their chemism, mutually interfere and destroy each other, as in the cases of the interference of the waves of light and sound.

The colloid form of protoplasm is especially favorable to internal movements which shall not destroy the integrity of the mass, perhaps more so than a gaseous state in a compound of similar constitution. It is, morcover, more favorable to the preservation of molarity than a gas could be, on account of the ease with which 
it adheres to solid substances, and transports and locates them as part of its external and internal supports. But it is not inconccivable that under other conditions of temperature, etc., the gascons condition of matter might answer the same purpose. It must be borne in mind, however, that this is a subordinate question, and that the real characteristic of the "physical basis of life" is to be found rather in its generalized dynamic condition.

We must then believe that wherever this generalized condition exists, consciousness will be present. As soon as mechamical or chemical force appears in the molecules of the sustaining substance, consciousness disappears. The organism has taken the first step toward death, but is not dead, but is ancesthetized. Constant nutrition is essential to the performance of all life fnnctions, including consciousness, and it is evident that this is neccssary to the maintenance of the unspecialized condition in which the latter appears.

Is the appearance of sensibility on the development of its sustaining condition, evidence that the latter stands to the former in the relation of canse and effect? If the view of the pre-existence of consciousness be true, there is no more relation of cause and effect than in the case of the opening of a door which admits a wind. The foree expended in opening the door is not converted into the energy exerted by the wind as it enters the room. It simply releases it, or admits it to a now field. It is, howerer, true, that consciousness having once entered, a larger conversion of force is necessary to its persistence than is expended during its absence. Like combustion, which is only communicable under suitable conditions, consciousness having once been transmitted to a new cesthetophore, , lives on it, and requires constant supplies of material for its sustenance.

The hypothesis of the primitive and creative function of consciousness may be called Archresthetism.

\section{PAN TSTHETISM.}

It has been the custom of men from the dawn of thought to attempt to construct for themselves cosmogonies and theologies. Seience is yet far from smpplying the facts necessary to the construction of a true system of the universe, and philosophy can only stretch out a little further in to the unknown by the use of neces-

* Esthetophore, a substance which sustains consciousness. 
sary inference. In spite, however, of the insufficiency of the data, men still suggest new views or cling to old ones, and an occasional flight into this region of thought at least brings the thinker into sympathy with the thoughts of his fellow-men.

The admission of the possibility of the existence of consciousness in other forms of matter than protoplasm, and in other regions than the Earth, lends countenance to a rational belief in the socalled "supernatural" (better called the supersensuous) so prevalent among men in irrational forms. The question naturally arises, Is there any generalized form of matter distributed through the universe which could sustain conscionsness? The presumption is that such a form of matter may well exist. Evolution or specialization has only worked up part of its raw material in the organic world. Wherever primitive conditions remain, there primitive organisms abound. Protozoa are yet numerous on land, and the Protobathybius inhabits the depths of the sea. Highly specialized forms of life are in fact numerically a minority of living beings. May not this be true also of inorganic beings? It is thought that various celestial bodies represent unfinished worlds. Is it not probable that the grand sources of matter not yet specialized into the sixty odd substances linown to us, may still sustain the primitive force not yet modified into its species, and that this combination of states may be the condition of persistent consciousness from which all lesser lights derive their brilliancy? There is much to warrant such a vicw in the observed facts of life, taken in connection with the general course of evolntion. Moreorer, that some form of matter connects the intersteilar spaces, is thought to be proved by the transmission of light in some cases, and light and heat in others. That such a form of matter pervades all spaces whatever, is the theory of some physicists. If it be so generalized as to be capable of sustaining conscionsness, it becomes the source from which other substances derive it, so soon as they, through the encrgy of nutrition, which resists death, maintain the same primitive and unformed constitution capable of exhibiting it.

Of course there is no evidence in our own memory of the existence of our personality prior to our human experience. No one on awaking from unconscionsness remembers having been anywhere in particular during the interval. These facts may be harmonized with the theory here presented, on the supposition that memory is lost on a transfer of conscionsuess from one physi- 
cal basis to another. The arguments in favor of a transfer of consciousness do not sustain the idea of a transfer of memory. Nemory requires an arrangement of molecules or atoms which when finished no longer exhibits consciousness. With proper stimulus, when the proper kind of force conversion is set up in them, consciousness extends into them, and, taking their form, produces reminiscence or conseions memory. The molecular arrangement would be probably lost on a transfer of conscionsness to a new material basis. It might then be supposed that with every such transfer a new personality is established. Though the correct definition of personality includes memory as well as consciousness, when viewed as an objective concept, it may be questioned whether memory is necessary to the subjective belief in one's own personality. Those insane persons who believe that they have lost their personality, and think that they are some one else, nevertheless recognize the fact that what they now are has a continuity of existence with what they once were. The material limitations of conscionsness are the anthor's of the kind of personality it presents. A limitation or an expansion of its range would not destroy the idea of personality, but would simply restrict or extend it. The possible confluence of many personalities would not destroy them, but each one would regard the others as additions to himself, and himself, thereiore, as so much the greater being.

As a summary of the preceding conclusions, the following analysis of metaphysical systems may be given. It defines the place of the doctrine of archæsthetism, above proposed, as distinguished from the opposing view of metrsthetism, which is held by many monists :

I. Consciousness ("spirit") is independent of matter............. Dualisu.

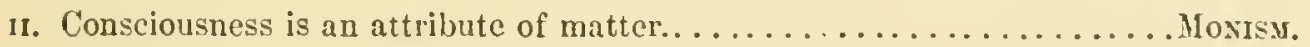

$\alpha$. Consciousness is primitive and a cause of erolution...........chesthetism.

$\beta$. Consciousness is a product of the erolution of matter and force.

Mctosthctism. 


\section{XX.}

\section{ON CATAGENESIS.*}

\section{THE EVOLUTION OF ORGANISHS.}

THE general proposition that life has preceded organization in the order of time, may be regarded as established. It follows necessarily from the fact which has been derived from paleontological investigation, that the simple forms have, with few sporadic exceptions, preceded the complex in the order of appearance on the earth. The history of the lowest and simplest animals will never be known, on account of their perishability ; but it is a safe inference from what is known, that the earliest forms of life were the rhizopods, whose organization is not even cellular, and includes no organs whatever. Yet these creatures are alive, and authors familiar with them agree that they display, among their vital qualities, evidences of some degree of sensibility.

The following propositions were laid down by Lamarck, as established by facts known to him, in $1809: \dagger$

I. "In every animal which has not passed the term of its development, the frequent and sustained employment of an organ, gradually strengthening it, develops and enlarges it, and gives. it power proportional to the duration of its use ; whilst the constant disuse of a like organ insensibly weakens it, deteriorates it, progressively reduces its functions, and finally causes it to disappear.

II. "All that nature aequires or loses in individuals, through the influence of circumstances to which the race has been exposed for a long time, either by the predominant use of an organ or by the disuse of such part, she preserves by generation among new

* An address delivered before the Biologieal Section of the American Asrociation for the Advancement of Seience, at Philadelphia, September 4, 1884, by E. D. Cope, vice-president.

+ "Philosophie Zoülogique," Pt. I, p. 235 (Edit. 1830). 
individuals which spring from it, provided the acquired changes be common to both sexes or to those which produce new individuals."

'The same proposition was previously enunciated by Lamarck in the following condensed form ("Recherches sur les Corps vivans," p. 50) :

"It is not the organ, that is, the nature and form of the parts of the body, which have given origin to its habits and peculiar functions, but it is, on the contrary, its habits, its manner of life, and the circumstances in which individuals from which it came found themselves, which have, after a time, constituted the form of the body, the number and character of its organs, and the functions which it possesses."

Several years ago, not haring read Lamarck, I characterized the above hypothesis as the "law of use and effort," * and I have subsequently formulated the modus operandi of this law into two propositions. The first of these is, that animal structures have been produced, directly or indirectly, by animal morements, or the doctrine of kinetogenesis; the second is, that as animal movements are primitively determined by sensibility, or conscionsness, consciousness has been and is one of the primary factors in the erolution of animal forms. This is the doctrine of archesthet$i s m$. The doctrine of kinetogenesis is implied in the speculations of Lamarck in the following language ("Philosophie Zoölogique," ed. 1830, p. 239): "With regard to the circumstances which [Nature] uses every day to vary that which she produces, one can say that they are inexhanstible. The principal arise from the influence of climates; from diverse temperature of the atmosphere and of the environment generally; from dirersity of location ; from habits, the most ordinary movements, and most frequent actions," etc. The influence of motion on development is involred in Spencer's theory of the origin of vertebra by strains; $\uparrow$ and $I$ have maintained the view that the varions agencies in producing change mentioned by Lamarek are, in the case of animals, simply stimuli to motion. $\downarrow$ The immediate mechanical effect of motion on animal structure has been discussed in papers by Ryder,

* "Icthod of Creation," "Proceedings American Philosophical Socicty," 1871, p. 247.

† "Principles of Biology," II, p. 195.

f "On the Relation of Animal Jlotion to Animal Evolution," "Ameriean Naturalist," Jan., 1878. 
Hyatt, Clevenger, and myself, and I have cited the evidence of vertebrate paleontology as conclusively proving such an effect." *

The object of the present paper is to pursue the question of the relation of sensibility to evolution, and to consider some of the consequences which it involves. It is searcely necessary to observe that, in the early stage which the subject presents at the present time, I can only point out the logical conelusions derivable from facts well established rather than any experimental discoveries not already known. And I will say here to those who object to the introduction of metaphysics into biology, that they can not logically exelude the subject. As in one sense a funetion of nervous tissue, mind is one of the furctions of the body. Its phenomena are everywhere present in the animal kingdom. Moreover, when studied in the inductive, a posteriori method, metaphysies is an exact science. As Bain observes, it is a good deal easier to foretell the actions of a man than those of the woather. It is only want of familiarity with the subject which ean induce a biologist to exclude the science of mind from the field.

For the benefit of those who are not familiar with the doctrine of arehæsthetism, $\uparrow I$ give an ontline of its implieations. In the first place, the hypothesis that conscionsness had played a leading part in evolution would seem to be negatived by the well-known facts of reflex action, automatism, ete., where acts are often w11consciously performed, and often performed in direet opposition to present stimuli. But while it is well understood that these phenomena are funetions of organized structure, it is believed that the habits which they represent were inaugurated through the immediate ageney of conseiousness. It is not believed that a designed act ean have been performed for the first time \$ withont conseionsness on the part of the animal of the want which the act was designed to relieve or supply. This opinion aceords with our knowledge of ourselves, and, by irresistible inference, with our belief regarding other animals. From such familiar observation we also know that so soon as a movement of body or mind has been acquired by repetition, conscionsness need no longer aceompany the act. The act is said to be automatic when performed

* "The Evidence for Erolution in the History of the Extinct Mammalia," Am. Ass. Adv. Sci., 1883, p. 32.

$\nmid$ "American Naturalist," 1882, p. 454.

$\ddagger$ The same view is expressed by Ribot, "Diseases of the Will," p. 38 (Humboldt Libr.). 
without exertion, either conscionsly or unconscionsly, and in those functions now remored from the influence of the unconscions mind such acts are called reflex. The origin of the acts is, however, believed to have been in consciousness, not only for the reatsons above stated, but also from facts of still wider application. The hypothesis of archasthetism then maintains that conscionsness as well as life preceded organism, and has been the primum mobile in the creation of organic structure. This conclusion also flows from a due consideration of the nature of life. I think it possible to show that the true definition of life is, energy directed by sensibitity, or by a mechanism which has originated under the direction of sensibility. If this be true, the two statements that life has preceded organism, and that conscionsness has preeeded organism, are co-equal expressions.

\section{CONSCIOLSNESS, ENERGY, AND MATTER.}

Regarding for the time being the phenomena of life as energy primitively determined by conscionsness, let us look more closely into the characteristies of this remarkable attribute. 'That conscionsness, and therefore mind, is a property of matter, is a necessary truth which to some minds scems difficult of acceptance. That it is not an attribute of all kinds of matter is clear enough, but to say that it is not an attribute of any kind of matter is to utter an unthinkable proposition. To my mind the absence of tridimensional matter is synonymous with nothingness or absolute racuity. To say that phenomena have a material basis, is for me only another way of saying that they exist. It being granted then that consciousness is an attribute of matter, or a certain behavior of matter, it remains to trace its relation to energy, which is here used in the sense of motion. Cousciousness is clearly not one of the kuown so-called inorganic forces. Objects which are hot, or luminons, or sonorous, are not, as is well known, on that account conscious. Consciousness is not then a necessary condition of energy. On the other hand, in order to be conscions, bodies must possess a suitable temperature, and must be suitably nourished. So energy is a necessary condition of conscionsness. For this reason some thinkers regard consciousness as a form or species of energy. For my own part, in classification, I prefer to keep very different things apart. 'To classify consciousness with heat, light, somnd, etc., does violence to my sense of fitness and to all proper definitions. 'This is well shown by Prof. Clifford in 
the following passage: "It will be found excellent practice, in the mental operations required by this doctrine, to imagine a train the fore part of which is an engine and three earriages linked with iron couplings, and the hind part three other carriages linked with iron conplings; the bond between the two parts being made out of the sentiments of amity subsisting between the stoker and the guard." * This satire, whether intentionally or not on the part of its learned author, expresses at once the distinctive character of consciousness in esse and the impossibility of dissociating it from energy in posse. For it is sufficiently clear that while the conscious feelings of the stoker and the guard could by themselves do nothing for the train, such a state is essential to the energy displayed by them when they are at work for its benefit. We all understand the absurdity of such expressions as the equivalency of force and matter, or the conversion of matter into force. 'They are not, however, more absurd than the corresponding proposition more frequently heard, that consciousness can be converted into energy, and vice versa.

The energetic side of conscionsness, however, may be readily perceived by a little attention to its operations. Acts performed in conscionsness involve a greater expenditure of energy than the same acts unconscionsly performed. The difficulty of a given piece of labor is in direct proportion to its norelty; that is, is in direct proportion to the amount of endeavor we use in its performance. This is another way of saying that the labor is directly as the consciousness involved. Another evidence of the dynamic character of consciousness is its exclusive and therefore complementary character. Two opposite emotions can not ocenpy the mind at the same moment of time. An emotion exchudes all high intellectual work, and vice versa.

But there is no fact with which we are more familiar than that conscionsness in some way determines the direction of the energy which it characterizes. The stimuli which affect the movements of animals at first only produce their results by transmission through the intermediation of consciousness. Withont conscionsness, education, habits, and designed movements would be impossible. So far as we know, the instinct of hunger, which is at the foundation of animal being, is a state of consciousness in all animals. This incontestable fact is orerlooked by the materialists properly so called.

* "Scientific Basis of Morals," Iumboldt Library Ed., 1. 21. 
On the other hand, as consciousness is an attribute of matter, it is of course subject to the laws of necessity to which matter and energy conform. For instance, it can not cause two solid bodies to occupy the same space at the same time, nor can it add one body to one body and thus make three bodies. No more can it make ten foot-pounds of energy out of fire foot-ponnds of energy, and it can not abolish time more than it can annihilate space. These are fundamental truths which are overlooked by a majority of mankind. Moreover, nothing is more common than to hear life or mind spoken of as though it of itself is a "substance," and not, as it should be, as an attribute or condition of substance or matter.

What is, then, the immediate action of conscionsuess in directing energy into one channel rather than another? To take an illustration: Why, from a purely mechanical point of riew, is the adductor muscle of the right side of the horse's tail contracted to brush away the stinging fly from the right side of the horse's body rather than the left addnetor muscle? Why was the contraction-provoking energy deflected into the right interspinal motor nerres rather than into those of the left side? Why is the ear of the horse turned forward to catels the sound in front of him and backward to gather the sound coming from behind? The first crude thought is, that consciousness supplies another energy which turns aside the course of the energy required to produce the muscular contraction; either as the man with the rein in his hand turns aside the horse's head, or as the shield he holds deflects a moving body. But consciousness per se, that is, regarding it in its proper and distinctive definition, is not itself a force (= energy). How, then, can it exercise energy? Certainly no more than the bare good-will of the train hands can pull the train. Such an explanation is to admit the possibility of maling something out of nothing.

\section{THE RETROGRADE IETAMORPHOSIS OF ENERGY.}

The key to many weighty and mysterions phenomena lies in the explanation of the so-called voluntary movements of animals. I say "so-called," because true will is not at all inrolved in the question. I mean the acts directed by consciousness, the acts which would not take place at all if the animal were mnconscions. 'That there are many such acts you well know. The explanation can only be found in a simple acceptance of the fact as it is, in 
the thesis, that energy can be conscious. If true, this is an ultimate fact, neither more nor less difficult to comprehend than the nature of energy or matter in their ultimate analyses. But how is such a hypothesis to be reconciled with the firets of nature, where consciousness plays a part so infinitesimally small? The explanation lies elose at hand, and has already been referred to. Energy become automatic is no longer conscious, or is about to become unconscious. That this is the ease is matter of every-day observation on ourselves and on other animals. What the molecular conditions of consciousness are, is one of the problems of the future, and for us a very interesting one. One thing is certain, the organization of the mechanism of habits is its enemy. It is clear that in animals, energy, on the loss of consciousness, undergoes a retrograde metamorphosis, as it does later in the history of organized beings on their death. This loss of conscionsness is first succeeded by the so-called in roluntary and antomatic functions of animals. According to the law of catagenesis, the vegetative and other vital functions of animals and plants are a later product of the retrograde metamorphosis of energy. With death, energy falls to the level of the polar tensions of ehemism, and the regular and symmetrical movements of molecules in the crystallization of its inorganic products. Let us now trace in more detail the energies displayed by animals and plants.

It has been already advanced (see page 425 ) that the phenomena of growth-foree, which are especially characteristic of living things, originated in the direction given to nntrition by eonscionsness and by the automatic movements derived from it. There remain, however, some other phenomena which do not yield so readily to this analysis. These are : first, the eonversion by animals of dead into living protoplasm; second, the conversion of inorganic substances into protoplasm by plants; and third, the mannfacture of the so-called organic compounds from the inorganic by plants. To these points we may return again. It is also well known that living animal organisms aet as producers, by conversion, of varions kinds of inorganic eneregy, as heat, light, sound, electricity, motion, ete. It is the uses to which these forces are put by the animal organism, the evident design in the occasion of their production, that gives them the stamp of organic life. We recognize the specific nltility of the secretions of the glands, the appropriate distribution of the products of digestion, and adaptation of muscular motion to many uses. The increase 
of heat to protect against depression of temperature; the light to direct the sexes to each other ; the electricity as a defense against enemies-display unmistakably the same utility. We must not only believe that these functions of animals were originally used by them under stimulus, for their benefit, but, if life preceded organism, that the molar mechanism which does the work has developed as the result of the animal's exertions under stimuli. This will especially apply to the mechanism for the production of motion and sound. Heat, light, chemism, and electricity doubtless result from molecular aptitudes inherent in the constitution of protoplasm. But the first and last production of even these. phenomena is dependent on the motions of the animal in obtaining and assimilating nutrition. For withont nutrition all energy would speedily cease. Now the motion required for the obtaining of nutrition has its origin in the sensation of hunger. So, eren for the first steps necessary to the production of inorganic forces in animals, we are brought back to a primitive conscious. ness.

To regard consciousness as the primitive condition of energy, contemplates an order of erolution in large degree the reverse of the one which is ordinarily entertained. The usual view is, that life is a derivative from inorganic energies as a result of high or complex molecular organization, and that consciousness (= sensibility) is the ultimate outcome of the nervous or equivalent energy possessed by living bodies. The failure of the attempts to demonstrate spontaneous generation will prore, if continued, fatal to this theory. Nevertheless the order can not be absolutely reversed. Such a proceeding is negatived by the facts of the necessary dependence of the animal kingdom on the vegetable, and the regetable on the inorganic, for nutrition, and consequently for existence. So the animal organism could not have existed prior to the regetable, nor the vegetable prior to the mineral. 'The explanation is found in the wide application of the "doctrine of the inspecialized," * so clearly demonstrated by paleontology. From this point of view creation consists in specialization, an expression which describes the specific action of the general principle described by Spencer as the conrersion of the homogeneous into the heterogeneous. 'To be more explicit, it consists of the

* The term specialized, introduced into biology by Prof. Dana, has been used in connection with energy in creation by the author, "Penn Monthly," 1875, p. 569. 
production of mechanism out of no mechanism, of different kinds of energy out of one kind of encrgy. The material basis of consciousness must then be a generalized substance which does not display the more automatic and the polar forms of energy. From a physical standpoint protoplasm is such a substance. Its instability indicates weakness of chemical energy also, which suggests that the complexity of its molecule may be dne to some form of energy not properly chemical. The readiness with which it undergoes retrograde metamorphosis shows that it is not self-sustaining, and furnishes a good illustration of creation of specialized substances by a running down in the scale of being. Loew and Bokorny * suggest that "the cause of the living movements in protoplasm is to be sought for in the intense atomic movements, and therefore easy metamorphosis of its aldehyde groups of components"; the molecnlar movements becoming molar, to use the language of Lester Ward. The position which I now present requires the reversal of the relations of these phenomena. Generalized matter must be supposed to be capable of more varied molecular movements than specialized matter, and it is believed that the most intense of all such movements are those of brain tissue in mental action, which are furthest removed of all from molar movements. From this point of view, when molar morements are derived from molecular movements, it is by a process of running down of energy, not of elevation; by an increase of the distance from mental energy, not an approximation to it.

The fact that the physical basis of consciousness is composed of four substances, which are respectively a monad, a dyad, a triad, and a tetrad, doubtless has something to do, as I have suggested, $\uparrow$ with its exhibition of this remarkable attribute. It might be supposed that the presence of carbon had the effect of restraining the chemical and physical molecular tendencies of the three other substances. From this standing-ground we may imagine that other substances besides protoplasm might support conscionsness and life. In other parts of the miverse, other substances they would have to be, if consciousness exist there.

The manner in which protoplasm is made at the present time is highly suggestive. It is manufactured by living plants ont of

* "Die chemische Kraftquelle in lcbenden Protoplasma:" ron 0. Loew u. T. Bokorny, Munich, 1882, I.

† "Penn Monthly," 1875, p. 5 †4. 
inorganie matter, the hydrogen, carbon, nitrogen, and oxygen contained in the atmosphere and in the earth. As dead plants will not perform this function, this action is regarded as in some way due to the presence of life. The energy peculiar to living protoplasm, and derived primarily in part only from the sun's rays, directs energy so that the complex molecular aggregation protoplasm is the result. This is the only known method of manufacture from inorganic matter of this substance. The first piece of protoplasm had, however, no paternal protoplasm from which to derive its being. 'The protoplasm-produeing energy must, therefore, have previously existed in some form of matter not protoplasm. This is also suggested by the fact that it really antagonizes the chemical forces, and might be called, from this faet, antichemism. The protoplasm-sustaining energy of animal protoplasm may be a less encrgetic derivative, or vice versa. In terms of the theory of catagenesis, the plant life is a derivative of the primitive life, and it has retained enough of the primitive quality of self-maintenance to prevent it from rumning down into forms of energy which are below the life level; that is, such as are of the inorganic chemical type, or the crystalline physical type. A part of the energy does so run down, as can be seen in the few automatic movements of plants, and the phospliorescence of some. Also symmetrical crystals are made by some. But M. Pasteur has shown * that whenerer the crystals are of the organic type, i. e., contain carbon, they are not symmetrical but are milateral, or, as he terms tliem, dissymmetrieal. This indicates that the presence of earbon has restrained a little the absolute symmetrical automatism of the formative force.

\section{ORIGIN OF LIFE ON THE EARTH.}

If, then, some form of matter other than protoplasm has been capable of sustaining the essential energy of life, it remains for future research to detect it, and to ascertain whether it has long existed as part of the carth's material substance or not. 'The heat of the earlier stages of our planet may lare forbidden its presence, or it may not. If it were excluded from the earth in its first stages we may recognize the ralidity of Sir William Thomson's suggestion that the physical basis of life may luave reached ns from some other region of the cosmos by transporta- 
tion on a meteorite. If protoplasm in any form were essential to the introduction of life on our planet, this hypothesis becomes a necessary truth. Here let me refer to the fact that hydrocarbonaceous substances have been discovered in meteorites. Here also the remarkable discovery of Huggins claims attention. * This veteran spectroscopist has detected the lines of some hydrocarbon vapor in the spectra of interplanetary spaces. The significance of this discovery is at once perceived if we believe that hydrocarbons are only prodneed under the direction of life. $\dagger$

Granting the existence of living protoplasm on the earth, there is little doubt that we have some of its earliest forms still with us. From these simplest of living beings both regetable and animal kingdoms have been derived. But how was the distinction between the two lines of derelopment, now so widely divergent, originally produced? The process is not difficult to imagine. The original plastid dissolved the salts of the earth and appropriated the gases of the atmosphere and built for itself more protoplasm. Its energy was sufficient to overcome the chemism that binds the molecules of nitrogen and hydrogen in ammonia, and of carbon and oxygen in carbonic dioxide. It apparently communicated to these molecules its own method of being, and raised the type of energy from the polar non-vital to the adaptive vital by the process. Thus it transformed the dead mineral world, perhaps by a process of inrasion, as when a fire communicates itself from burning to not burning combustible material. Thus it has been doing ever since, but it has redeposited some of its gathered stores in various non-vital forms. Some of these are in organic forms, as cellulose; others are crystals imprisoned in its cells: while others are amorphous, as waxes, resins, and oils. But consciousness apparently early abandoned the regetable line. Donbt-

* See address of C. W. Siemens, Prest. British Ass. Adv. Seience, 1882 ; "Nature," 1882 , p. 400 .

† Says Mr. S. F. Peckham ("American Joumal of Seience and Arts," 1884, p. 105), on the origin of bitumens: "These chemical theories [of the origin of bitumen] are supported by great names, and are based upon very elaborate researehes, but they require the assumption of operations nowhere witnessed in nature or known to technology. ... In the chemical processes of nature complex organic compounds pass to simpler forms, of which operation marsh gas, like asphaltum, is a resultant, and never the crude material upon which decomposing forces aet."

The fact that many organic compounds are now produced in the laboratory, does not prove that such substances can be produced without the exercise of a species of energy different from the inorganic types with which we are acquainted. 
less all the energies of vegetable protoplasm soon became automatic. The plants in general, in the persons of their protist ancestors, soon left a free-swimming life and became sessile. 'Their lives thus became parasitic, more automatic, and in one sense degenerate.

'The animal line may have originated in this wise. Some individual protists, perhaps aceidentally, devoured some of their fellows. 'The easy nutrition which ensued was probably pleasurable, and once enjoyed was repeated, and soon became a habit. The excess of energy thus saved from the laborious process of making protoplasm was available as the vehicle of an extended consciousness. From that day to this, consciousness has abandoned few if any members of the animal kingdom. In many of them it has specialized into more or less mind. Organization to subserve its needs has achieved a multifarious derelopment. There is abundant evidence to show that the permanent and the successful forms have erer been those in which motion and sensibility have been preserved, and most highly dereloped.

This review of the history of living organisms has been epitomized in the following language: "Evolution of living types is then a succession of elevation of platforms, on which succeeding ones have built. The listory of one horizon of life is that its own completion but prepares the way for a higher one, furnishing the latter with conditions of a still further derelopment. Thus the regetable kingdom died, so to speak, that the animal kingdom might live, having descended from an animal stage to subserve the function of food for animals. The successive types of animals first stimulated the development of the most susceptible to the conflict, in the struggle for existence, and afterward furnished them with food."

\section{CATAGENESIS OF IYORGANIC ENERGY.}

If the prineiples adopted in the preceding pages be true, it is highly probable that all forms of energy have originated in the process of ruming down or specialization from the primitive energy.

In the department of physics I am not at home, and tonch upon it merely to carry out to a necessary conclusion the bypothesis presented in the preceding pages. It may be that physieists and chemists may find value in the suggestions which come from the side of biology. A cursory perusil of the general hy- 
potheses current in these departments shows that the door is wide open to receive light from this quarter. What can be offered here is of the vaguest, yet it may suggest thought and research in some minds.

In the first place, it is highly probable that one of the problems to be solved by the physicists of the present and future is that of a true genealogy of the different kinds of energy. In this connection a leading question will be the determination of the essential differences between the different forms of energy and the material conditions which cause the metamorphosis of one kind of energy into another.

In constructing a genealogy of energies, it must be observed that we will probably obtain not a single line of succession, but several lines of varying lengths. It must also be remembered that, as in the forms of the material world, which are their expression, a greater or less extensive exhibition of all the types remains to the present day.

That the tendency of purely inorganic energy is to "run down," in all except possibly some electric operations, is well known. Inorganic chemical activity constantly tends to make simpler compounds ont of the more complex, and to end in a satisfaction of affinities which can not be further disturbed except by access of additional energy. In chemical reaction the prefercnce of energy is to create solid precipitates. In the ficld of the physical forces we are met by the same phenomenon of running down. All inorganic energies or modes of motion tend to be ultimatcly converted into heat, and heat is being steadily dissipated into space. Therefore the result has been and will be the creation of the mineral kingdom ; of the rocks and fluids that constitute the masses of the worlds.

The process of creation by the retrograde metamorphosis of energy, or, what is the same thing, by the specialization of energy, may be called catagenesis. It may be denied, however, that this process results in a specialization of energy. The vital cnergies are often regarded as the most special, and the inorganic as the most simple. If we regard them, however, solely in the light of the essential nature of energy, i. e., power, we must see that the chemical and physical forces are most specialized. The range of each species is absolutely limited to one kind of effect, and their diversity from each other is total. How different this from the versatility of the vital energy! It seems to dominate all forms of 
conversion of energy, by the mechanisms which it has, by evolution, constructed. Thus, if the inorganic forces are the products of a primitive condition of energy which had the essential characteristies of vital energy, it has been by a process of specialization. As we have seen, it is this specialization which is everywhere inconsistent with life.

With these preliminary remarks we may now consider very tentatively the relations of the different kinds of energy to each other and to consciousness. In practice it is sometimes difficult to draw the line between conscious and unconscious states of energy. One reason is that, although a given form of energy may be unconscions, conscionsness may apprehend the action by perceiving its results. The distinction is rendered clearer by the reflection that we can perceive by sight or touch any action of the body of whatever character The energy of the conscions type is therefore altogether mental. The relations may be expressed as follows :

A. Designed (always molecular).

Examples.

I. Conscious.

1. Inrolving effort.................... Voluntary" acts.

2. Not involving effort................

II. Unconscious.

3. Involving mental process................ Unconscious automatic.

4. Not involving mental process............... Reflex.

B. Not designed.

I. Molecular.

5. Electric,

6. Chemical,

7. Physical, $\}$ Crystallific and non-crystallific.

II. Molar.

8. Cosmic.

The only strietly molar energies of the above list are the cosmical movements of the heavenly bodies. 'The others are molecular, although they give rise to molar movements, as those of the muscles, of magnetism, ete. Some molar movements of orgauic beings are not, in their last phases, designed; as those prodnced by nerrous diseases.

'The transition between the organic and the inorginic energies may be possibly found in the electric group. Its influence on life, its production of contractions in protoplasm, and its resemblance to nerve force, are well known. It also compels chemical unions 
otherwise impracticable, thus resembling the energy of the protoplasm of plants, whose energy in actively resisting the disintegrating inorganic forees of nature is so well known. Perhaps this type of foree is an early-born of the primitive energy, one which lias not descended so far in the scale as the chemism which holds so large a part of nature in the embrace of death.

Vibration is inseparable from our ideas of motion or energy, not exchuding conscious energy. There are reasons for supposing that in the latter type of activity the vibrations are the most rapid of all those characteristic of the forees. A center of such vibrations in generalized matter would radiate them in all directions. With radiant divergence the wave lengths would become longer, and their rate of movement slower. In the differing rates of vibrations we may trace not only the different forms of energy, but diverse results in material aggregations. Such may have been the origin of the specialization of energy and of matter which we behold in nature.

Such thoughts arise unbidden as a remote but still a legitimate induction from a study of the wonderful phenomenon of animal. motion; a phenomenon everywhere present, yet one which retreats, as we pursue it, into the dimness of the origin of things. And when we follow it to its fountain head, we seem to have reached the origin of all energy, and it turns npon us, the king and master of the worlds. 


\section{XXI. \\ THE ORIGIN OF THE WILL.}

\section{THE DEFINITION OF THE WILL.}

Definitions of the term "Will," as we find them in metaphysical writers, are not identical ; and much apparent difference of opinion depends, as usual, on this diversity of statement. Locke regards the concepts "will" and "freedom" as entirely distinct in their nature, and not cssentially related to each other. He says: "Freedom belongs as little to the will, as swiftness to sleep, or squareness to virtue. Freedom to do is one power, will to do is another: will, a power of the mind exerting dominion over some part of a man by employing it in or withholding it from any particular action ; freedom, again, a power which a man has to do or to forbear doing any particular action." It appears that what Locke here denominates will is that common activity of the mind which expresses itsclf in action, which may be readily considered apart from the question of choice. This doubtless expressed something to the metaphysicians of that time, but merely significs to the physiologist of the present day the movement derived from the metamorphosis of nutritive material in the arterioles of the brain, which when consciously performed are called thoughts and feelings, and are the necessary precursors of a class of muscular acts. The question of will properly so called is not yet entered on at this point. Dr. Willis * elaborates Locke's position in the following langnage: "But there is, in fact, no one particular primitive faculty that wills in the human mind; will is a general term, and belongs to and is expressive of the activity of each of the primitive faculties of on nature; the benevolent faculty being active, causes us to will to do good and charitable offices; the reverential faculty being active, to will to fecl respectfully or rererently; the musical faculty active, to will to sing or hear music,

* "Benedict de Spinoza : his Life, Correspondence, and Ethics," 1870, p. 145. 
etc.; and the willing here is necessary ; but whether we yield to the impulse of the benevolent, reverential, or musical faculty, and indulge therein their various willings, is not so ; here we are free, and can yield or abstain as we list." This passage renders it the more clear that the latter part of Locke's statement, in which he defines freedom, is that in which he really refers to the will as generally understood; and Dr. Willis's assertion of the existence of our ability "to yield or abstain as we list," grants all that the advocate of "the freedom of the will" conld desire.

The modern antomatic school only aroid discarding the term will altogether by using it in the sense of Locke's definition. 'They make it merely the conscious mental activity that precedes the act; the direction of that activity being necessary in its character; i. e., the result of impinging stimuli. In other words, on the antomatic theory, the spontaneous activity of the body is directed or deflected by stimuli, whose ultimate form depends on the existing mental machinery through which they pass. There is avowedly no room for a self-determination in such a process, and its existence is therefore denied by this school. Inasmuch as a faculty of self-determination is what is here understood by the term will, and the question in the present article is whether there be or be not such a faculty, the inquiry to which we address oursalves is whether a human will exist or not. Says Dr. Carpenter :* "The psychologist may throw himself into the deepest waters of speculative inquiry in regard to the relation between his mind and its bodily instrument, provided that he trusts to the inherent buoyancy of that great fact of conscionsness that we have within us a self-determining power which we call will." The existence of such a faculty is in these words assumed by Dr. Carpenter, but I have looked in vain in his writings for a demonstration of the truth of this position. The same is true of the works of many other metaphysicians.

Will may be considered in two aspects : first, as a control over the origin of mental or bodily movements; and second, as a control over the direction which those movements take. The latter case is the one chiefly considered here, as the one involved in customary definitions of human will.

It need scarcely be added that the concept will is an abstraction from supposed special exhibitions of it, and represents a supposed mental property. 


\section{THE NATURE OF ACTIONS.}

The discussion between the advocates of the freedom of the will on the one hand, and those of the doetrine of necessity on the other, has often been obstructed by a petitio principii, which yields the case to the latter side' at the outset. This is the dictum which has often passed unchallenged by both parties, that "human action is the product of the strongest inducement," or, otherwise stated, that "the will is the result of a balaneing of opposing motives," or that "the will obeys the strongest motive." This is simply the statement, in reversed order, of what we might suppose without examination to be a general truth, viz. : that the motives which precede the acts which we observe are stronger than all others at the time. If this proposition be true without qualification, there is no further need of diseussion, since it involves the negation of freedom, or of a power of choosing. But as such, it is an assumption in advance of a conclusion in the case under consideration; a begging of the question in a clear sense. Such a position ean only be adopted as a result of the fullest investigation into the phenomena; it ean not be accorded before examination into the facts.

But the statement may be admitted with this important qualification, by which the argument is transferred to another stage of the subject, viz.: that we do not thereby explain why the inducements to act thus and so, do, in many obvious eases, overbalance all others in a given human mind. 'This inquiry is not fruitless, so long as we have before us every day examples of men aeting differently under identical cireumstances. If there be any "liberty," it is exereised at the point of permitting inducements or motives of one kind to oceupy the mind to the exclusion of those of another kind ; and secondly, such oceupation being granted, freedom might be exereised in removing restraint from the pressure of the present motive, so that the act ean take place. If there be no inherent power of eontrolling the attention, and none of restraining the pressure of motive, then there is 110 will in any proper sense of the word, and man is an irresponsible automaton. 'The proof or disproof of this proposition must, however', be the end, not the beginning, of the discussion.

An inquiry into the origin of actions must be preecded by an examination into the nature of the acts themselves. The following classification is offered, as expressing as nearly as possible their 
relations to the general developmental position of ative beings, without any pre-suppositions as to their antomatic or voluntary character. It is necessarily assumed that all acts are performed with reference to the acquisition of pleasure or the avoidance of pain ; in other words, that all acts are due to motive, and are the expression of design on the part of the actor. This is as true of the simplest as of the most complex aetions of animals, whether consciously or unconscionsly performed. The movement of the Amoba in ingulfing a Diatom in its jelly, is as much designed as the diplomacy of the statesman, or the investigations of the student. And the motive may be the same in all thrce cases; viz.: hunger. But as the unconscious acts have been probably derived from conscious ones by organization, a fundamental classification must first recognize their relations to the two necessary terms of consciousness, the subject and the object. All actions may then be divided into two classes; those which are performed with the design of sceuring the pleasure of the subject, and those whose motive is to secure pleasure for the object as distinct from, i. e., opposed to, that of the subject. The tendencies thus defined have been named, in other connections, the appetent and the altruistic, and these names may be preserved as equally appropriate for the present purpose. Actions of the appetent class differ according to the developmental grade of the animal displaying them, or the grade of the organ of the body to which they are proper. In their simplest form they are mechanical movements, following a stimulus without the intervention of any rational process ; the end being attained by movements, whose directions are determined by mochanical or physical laws only. Such acts belong to the lowest type of animals, and are also seen in the organic functions of all animals; they may be called the ancesthetic division. They may be performed consciously or meonscioasly. Aets of another order are those which, while dne to stimuli, are direeted by a process of ratiocination. 'They are higher than those of the previons order, becanse they successfully aceomplish their object under changing circumstances, to which they adapt themselves as the others can not. Like them they may be performed in conscionsness or in unconscionsness, or in a still higher state of the mind, that of selfconsciousness. The last condition is only possible to animals of a high order of intelligence, sinec it not only demands an exercise of the rational faculty, with reference to objects, but also with reference to itself-the subject. These three groups form the 
rational order. The unconscions actions of both the anæsthetic and rational kinds are ealled "reflex;" and all of them are "automatic," in so far as they are performed without will ; terms more fully defined in the following pages. The process of intellection in unconsciousness is called unconscious cerebration.

Actions of the second great class, the altruistic, demand for their performance the attributes necessary for the highest of the appetent class. They require intelligence enongh for the perception of what is the pleasure of the object, and self-consciousness, to know that that pleasure is inconsistent with its own, or subjective pleasure.

The arrangement may be summarized as follows:

I. Appetent class.

1. Anæsthetic. $\left\{\begin{array}{l}\text { Unconscious (reflex). } \\ \text { Conscions. }\end{array}\right.$
2. Rational. $\left\{\begin{array}{l}\text { Unconscious (reflex). } \\ \text { Conscious. } \\ \text { Self-conscious. }\end{array}\right.$

II. Altruistic class; rational and self-conscious.

Under the definition of will above given, it can not be present in unconscious or reflex actions, and the inquiry is limited to the conscious groups exclusively. It may then be well to add a few words on the nature of conscionsness.

This faculty is here understood in its broadest sense, namely, subjective perception. The term conscionsness expresses the kuowledge by the subject of the effects of stimuli on itself, which ranges all the way from the mere sense of contact to the sense of an idea. An unprejudiced scrutiny of the nature of conseionsness, no matter how limited that scrutiny necessarily is, shows that it is qualitatively comparable to nothing else. The attempts to correlate it with the physical forces have so far been utter failures, although the vital forees, to which it gives direction, are evidently not excluded from the laws of quality and quantity. 'The common hypothesis that consciousness is the product of evolution appears to the writer, in view of this primary fact, to be irrational; while the converse, that evolution is a product of conscionsness, is far more likely to receive nltimate demonstration. From this stand-point it is looked upon as a state of matter which is co-cternal with it, but not co-extensive. Itself in its totality a reservoil of force, it is the somree of all physical and vital forces, with which it has therefore an equivalency of quanti- 
ties, but not of qualities. The canse of the difference between conscious and unconscious force must be secondarily due to different conditions of matter as to its atomic constitution ; conscionsness being only possible, so far as we can ascertain, to matter which has not fallen into fixed and automatic relations of its atoms. 'The condition appears to be one of tension, in which the automatic (crystalline) tendencies antagonize each other, the material being all the while in the metastatic condition of mutrition. This idea is parallel to that of Heraclitus, who held that the essence of all things lay in perpetual modification, a universal becoming, an eternal emergence and disappearance.

In accordance with the preceding views, the relations between consciousmess and matter are thus depicted as of a mutually necessary character, the movements of conscious force involving consequences to itself from which the properties of matter wecessarily preclude its escape.

If we trace the consciousmess of amimals to such an origin, it may be asked, Why have not such beings the powars and perfections of their source, in quality if not in quantity? 'The answer to this query, in view of the fact that they lave not such qualities, is only to be found in an investigation of the nature of memory. The absence of memory of the past would be equivalent to ignorance; while a new material vehicle might render memory possible for the future, and thus education, under new surroundings, create diverse beings from a primal common source.

We must include in our estimation of the distributions of consciousness and forces not our planet alone, nor our system only, but the universe. Hence Sir William Thompson's idea, that consciousness ("life") was originally exotic to our earth, is an altogether permissible hypothesis.

If there be such a state of consciousness as will, it must have appeared in course of the evolution of animals, at some point in the series of the stages of progress through which their mind has passed. Yet it is maintained by some thinker's that the doctrine of evolution necessarily excludes the idea of freedom from the nature of the minds thus produced. The case is, howerer, involved in that of consciousness, and the investigation of it must proceed in the same manner. If it has been shown that will does exist in connection with evolution, we must proceed to discover, if possible, the relation between the two facts.

The proof of the existence of a freedom, power of choice, or 
will, is found in the origin of the altruistic class of acts, which are probably only possible to the human species. 'These have been above defined as those in which the pleasure of the object, as distinet from, and therefore opposed to, that of the subject, is the design of the act. 'This definition excludes acts for the bencfit of others in which the actor is also gratified, since the motive may be in that case the pleasure of the subject. No doubt, many generous acts are of this character, but they were not such the first time they were performed, since experience of their pleasurable character had not then been acquired, and the evidence of all past experience was of a diametrically opposite character. In other words, the motives already organized in the mind of the subject were all in favor of the subject. The laws of evolution render the introduction of a new element of character at this point absolutely necessary. It is well known that the development of mind, and through it of all the acts of the first or appetent class, has been due to the pursuit of pleasure and avoidance of pain on the part of the subject. The pursuit of an opposite conrse, by animals whose pleasures and pains are those of the successful fulfillment of the necessary functions of life, or the reverse, would insure their speedy extinction. Their survival has been dne to their prompt discrimination of favorable and unfarorable conditions through their sensibilities, and the human species, as the product of evolution, displays these sensibilities in their highest form. Under these circumstances it is obvious, since none but the inherited motives, with refinements due to more complex circumstances, can be found in his mind, that without the interrention of will, an altruistic act is impossible.

It has also been pointed ont that such ean only be performed by a being capable of the highest state of consciousness, i. e., selfconsciousness; in other words, by a being capable of recognizing its own mental states. Under such circumstance only can it distinguish the mental states of a being apart from itself, toward whom the altruistic act is directed.

It being then conceded that will is exhibited in certinin human actions, it becomes important to determine, if possible, the conditions under which it appeared in the course of the evolntion of man.

III. TIIE ELEMENTS OF MIND.

Prior to considering the origin of states of mind, it is necessary to go over the well-trodden field of its original constitution. 
There are three primary conditions of conscionsness, which naturally grade into each other, viz.: pain, indifference, and pleasure. Conseiousness is of one or the other of these types in all animals. The constant flow of activity, either in movements of the whole body or of particular parts of the body, has brought animals from their beginning into contact with other bodies, either at rest, or animated by active forces, as light and heat, which have varied their sensations, rendering them more positive in each of the three directions named. These sensations soon cease, leaving consciousness where it was, but not without marks of their former presence in the organism. They are recorded, and continue in unconsciousness so long as the organism remains unchanged. This is the first part of memory, i. e., retention. Under the influence of what is called cohesion, the impressions may be returned to consciousness in a less distinet form by the occurrence of new impressions which have some near relation with them as to time, place, or qualities of other kinds. This is the second part of memory, or reminiscence. The sum of the impressions which are necessary to memory constitutes experience. It is evident that reminiscence is pleasurable or painful, as the experiences recalled were pleasurable or painful. Another quality is rendered possible by the two faculties of retention and cohesion, viz.: classification. This consists of a re-arrangement of retained impressions in accordance with different kinds of cohesions, i. e., different kinds of likenesses. The prodnets of classification may be brought into consciousness just as sensible impressions are revived; but unlike these, they constitute in their totality a new experience of internal origin. When a cohesion between two eireumstances is due to a repeated experience of the one as following the other, men entertain the idea that one is necessary to the other. From memory of the neeessary results of our own activity, we have come to regard necessary sequences as the result of activity somewhere. If activity be discerned in the first of two coherent events, we regard it as a cause of the second : if the first be passive, the idea of cause does not arise in connection with it, but in some other active agent. Finally, all processes involving reminiscences are less distinct than the original impressions. Spencer calls the former faint, the latter distinct; the faint order are the processes of reason ; the distinet, of perception.

Whether these processes are pleasurable, painful, or indifferent, 
depends on the characteristics of the reminiscences which are their subjects. As the reminiscence is less distinct than the original impression, so there comes to be, as pointed out by Spencer, a firint order of pleasures and pains, which, with the indifferent class, form the material of the processes of reason. These mental states of pleasurable and painful consciousness constitute that primary division of the mind, the feelings or affections, as distinguished from the intellect.

The feelings co-exist with intellectual operations of all grades of complication, since pleasures and pains are states which follow all kinds of activities, and therefore also reminiscences. To seek pleasure and to avoid pain constitutes the business of the lives of all conscious organisms; and hence the feelings, as derived from experiences, are the directive and often originative conditions of movements or actions. In animals with higher intellectual powers, the general classification of experiences of given objects or actions results in a higher order of the mental feelings, which are called likes and dislikes. When these forms of consciousness assume an intense condition due to stimuli, they become emotions or passions.

These details are entered into in order to show that the feelings in their various grades are the motives of action in all animals, from the Ameba to man. In the former they are mere reminiscences; in the latter they are so generalized as to become enduring principles of action, which put the intellect to cvery conceivable labor. And it is evident, from this foundation fact, how the intellect itself has been constructed. 'The activity stimulated by the feclings has resulted in new experiences, and the accumulation and elaboration of these into new combinations of the faint type of consciousness, has been the law of their development. This we can observe in the education of one generation of living animals, and it has doubtless been the law of the generations of the past as well. We maly then review the probable method of development of mind through the ages of past time.

\section{THE DEVELOPMENT OF MIND.}

In the first place, it is evident that the evolution of mind has been due to the activity of animal life. Although not asserted, it is sometimes inplied that "circumstances," in which the animal is passive, hare been the efficient cause of mental development. That this could have been the case is inherently impossible, and 
since animals of the lowest types possess powers of movement, their activity has necessarily been an immediate cause, while surrounding circumstances have exercised a controlling influence.

Animal activity must be traced to the generation of force or motion by a protoplasmic body which is constantly supplied with nutriment. This production of force is the basis of the acts of animals, up to and including man; often, as remarked by Prof. Bain, displaying itself in aimless discharges or playful movements, as in lambs and boys.

But we observe even in very simple organisms, as the Amceba, ete., that many movements are not aimless, nor without design. We observe that these mere specks of jelly devour nutritious substances, and reject the innutritions; that they even distinguish between the Diatom which contains protoplasm within its shell, and the empty shell. Many facts of this kind lead us to believe in the conscionsness of these pioneers of life, and seem to show that they have experiences of the pleasures of nutrition, and of the pains of retaining insoluble substances in the seats of assimilation. It would also appear that they remember these sensations, so as to seek the pleasures and reject the pains, when in the course of their wanderings they again come into contact with the material objects which have caused them. Given these two terms, sensibility (consciousnsess) and memory, and we have the conditions by means of which the entire complex superstructure of the affectional and the intelligent acts has been elaborated out of mere morements.

This has been accomplished by the well-known laws of organization of habits, and heredity. The performance of an act under stimulus so modifies the structure of the bioplasts of the brain as to facilitate its repetition. With further repetition the organization is soon complete, and action follows the stimnlus without direction, so long as no adrerse influence affects the consciousness. Whether the act be one of the Rational or Anæsthetic orders, from this habitual stage it becomes antomatic in the true sonse, between which and the reflex act no line can be drawn. It is evident that the degree of consciousness present in animals will depend on the number of changes appearing in their surroundings, whether due to modifications of the external world, or movements of their own bodies. Inasmuch as the habits of the lower animals are few and simple, most of them must be antomatically performed, the consciousness being only present at the commencements of the several 
processes. It is probable that the organization of mental functions was at the first identical with the so-called organic functions, ${ }^{*}$ so fir as they consist of mechanical movements; and that the latter early became reflex and deroid of consciousness, developing subsequent forms through mechanical causes. The organization of mental functions, on the other hand, was by continued education, which requires the presence of consciousness at every step.

The well-known fact of the inheritance of mental qualities shows that the evolution of mind has advanced by a continued process of acenmulation as the product of animal experiences. The new generation has inherited the organization of the old, and all the reflex and automatic activities entailed by it, and has proceeded in proportion to its activity to acquire new experiences, habits, and organization.

\section{THE BEGINNINGS OF DEVELOPMENT.}

\section{(a) The Feelings.}

'The intellectual faculties of every animal thus belong to two classes: first, those which have been inherited; and second, those which it has acquired by its own experienees. Of eourse progress consists in accessions to the latter class, since inheritance without addition is mere repetition. If no aequisitions were made, or to be made, the mental, i. e., the cerebral organization inherited by animals would continually repeat the form of their actions as unerringly as the nature of a machine gives the character to the movements propagated through its wheels and cranks. 'That much the larger proportion of animal acts are of this class, that is, are automatic, there can be no room to doubt. With an impetus to movement given, the strongest liking or disliking selects the object or direction, and the reason furnishes the mode of acquisition ol avoidance. The known past teaches of the unknown futnre, and the established circle of the functions of life is fulfilled. But without aequisitions, development is impossible.

Aequisitions to experience are gained by morements of the body, and hence by the mental activity to which the latter are due. But it is erident that the primary morement lias precedence in the order of time over the feeling which deflects it, or the experience which directs later actions. In the lowest animal

* See "On Consciousness in Evolution, " "Penn Monthly", 1875, Aug., where this view is held. 
the first movement was doubtless a mere discharge of force; but the first designed action, the appropriation of food, was due to a sense of want or hmuger, which is a form of pain. 'This was followed by gratification, a pleasure, the memory of which constituted a motive for a more evidently designed act, viz.: pursuit.

These two mental states, the one painful, the other pleasurable, form the basis in the feelings of all appetent acts. 'The painful sense of want is the motive to the performance of the primary class of actions, and the experience of pleasurable gratification furnishes the motive for a class which must be regarded as secondary.

The primary organized feelings of animals are not numerous.

In man, the most highly developed, Prof. Bain enumerates * only eleven types, and some of these he states may be further resolved. From the stand-point of the evolutionist this is evidently necessary, and a corresponding reduction in number can be made. The development of the feelings has proceeded from the early beginnings above described, in subsequent ages, pari passu with that of the intellect. It is necessary in the mature of things that it should be so, since the finer and fuller the sensibility to pleasures and pains in all directions, the greater will be the complexity of experience, and hence of intelligence. It is not practicable to trice the history of the feelings here, but I allude briefly to one class of them-the social affections-as they have been treated by Herbert Spencer, whose contributions to this department of knowledge have been very important.

This author main tains that the social affections are the product, in the department of mind, of the function of reproduction. They are the organized products of experiences of pleasures derived from fellow beings, just as other kinds of likes and dislikes are derived from experiences of the qualities of various objects. It is sufficiently evident that this faculty must survive, and the social instincts become more and more refined or specialized. It is a remarkable fact in the successional relations, and hence evolution, of the vertebrata, that the only system that has accompanied the nervous in its progress from generalization to specialization and perfection, is the reproductive. Man, standing at the head of the series by his developed brain, possesses also the most specialized reproductive system. He is inferior to many other Mammatic in his osseons and muscular type, and in his digestive 
organs, including dentition, etc:, but the orders which are his superiors in these respects yield to him the supremacy in the two systems mentioned.

Functionally the two systems oppose each other, and that exercise of the one is at the expense of the other is a physiological law. Health of the individual, and persistence of the species, depend on the maintenance of the equilibrium between them. This is because success in obtaining food on the one hand depends on intelligence, and undue power can not be expended in other directions without starvation. Thus the law of evolution lends full support to the doctrine first formulated by Kant, of the dual nature of the human mind, in its division into the intellect and the affections.

\section{(b) In the Intelligence.}

The intellect includes a record of experiences of resemblances and differences, of causes and effects, arranged in orders of place, time, and of qualities of all kinds. The importance of an intellect depends on the number of experiences it contains ; on the clearness with which qualities can be brought into consciousness; on the correctness with which the clissification expresses the qualities; on the relation which the qualities preferred bear to an object of pursuit; and on the rapidity with which any or all of these functions may be performed. The triumph of reason is foresight or predication, in which it brings into consciousness the unknown, by reproducing its experiences of the known. This is the service rendered by education, by the acquisition either of experiences themselves, or of the experiences of others.

Acquisitions then do not imply a predication of the unknown from the known, but an actual addition to the stock of the known. The antomatic life above described includes no such process, but is a rontine varying only in unimportant details, and changing in no great feature. Progress evidently depends on something besides knowledge, for in proportion to the degree of progress is the departure from the known, and in proportion to the novelty of a situation is experience worthless as a guide.

Designed actions which are performed withont a basis of knowledge which is sufficient for predication are not antomatic. 'That is, while the activity may be physically spontaneous and compulsory, the direction it takes and the mode of its execution ean not be automatic, nnless the machinery which must give the direction, and which creates the mode, be already in existence. 
The field of the known is very limited, as compared with that of the unknown, in the experience of the Amoba. In its first movements, it has absolutely no basis on which to establish an anticipation of the future. Such is also the situation of the young of every animal. But the cases of the inferior and superior species present the important difference that in the former there exist few or no mental powers derived by inheritance, while in the latter snch are present in proportion to the position of the species in the scale of intelligence.

The facts of evolution teach that the habits of animals have been modified during past geological ages, under the influence of changes in their physical surroundings. While these changes may, perhaps, have furnished the stimuli to the adoption of new habits, the conditions have not often been so rigid as to define exactly what those habits should be, in some or all of their details. The animal has neeessarily proceeded blindly in many instances; in others, his mental darkness has been illumined by a low grade of imagination. This may be believed in view of the many attempts which animals often make before succeeding in attaining a desired end. Imagination plays an important part in the origin of motives and of actions, and is related to predication. It is defined as the presentation or construction of images or representations from items of experience, which representations so far differ in the connection of their details from actual experience, or so far lack the qualities of experiences, as not to constitute a predication of future events. Predication may be defined as the certain knowledge of the unexperieneed from the experienced; while imagination includes the grades of probable, possible, and impossible concepts, construeted from the same material as predication. Whether this faculty exists in the animals which can not speak, is not readily ascertained; but, inasmuch as many of them predicate, it is probable that they possess some degree of imagination also. But it is obviously a quality of the highest types of mind, since its development depends primarily on the furniture of memory, derived from a long period of experience, whose amount depends on receptivity and retentiveness.

\section{THE ORIGIN OF MOTIVES.}

It lias been said that the operation ordinarily called choosing, in which the will is popularly supposed to be free, consists merely of a sum in addition and subtraction, where various inducements 
are balanced, the resultant preponderance being expressed in the act. It will be easily seen that while this statement is true in regard to cases where the elements of the calculation are known, it is not true where any or all of them are unknown. The difference in the two cases is rery great. All likes and dislities are based upon experience or knowledge; and when there is no knowledge, likes and dislikes can not be said to exist. Since likes and dislikes constitute motives, where the former are wanting the latter are also wanting. Whatever indncements are presented from beyond the ficld of knowledge are derived from the imagination, and are in self-conscious minds relatively weak as motires, or absolutely without weight. They might be regarded as motires in embryo, ready to become such on the acquisition of a corresponding experience. 'The imagination can prefigure one alternatire as well as another, in a direction where experience is wanting, and might indeed be said under such circumstances to have no cxistence, and the expression, "I can't imagine," be thought to have fomdation in fact. The influence of such a guide is not imperative, and raises no obstacle to the origin of a new feature of conscionsness by an act of choosing, when the pressure to act at all is sufficiently great.

There is, perhaps, but one situation of the mind where the pressure of feeling is strong enough, and predication and imagination sufficiently excluded, to develop a will which shall create motives rather than obey them. This is in the cases where selfinterest is weighed in the balance against the interest or good of other people: Here the feclings are most severely pressed, and the future results to self most uncertain. Self-sacrifice may be beneficial to self, or it may not: one may be the gainer by the general prosperity, or he may be the loser. Morality may promise future good to the community, but why sacrifice self for the community? Gratitude for services rendered is an uncertain anticipation. Man's most limited knowledge and greatest inability in predication is in the ficld of human motives and actions, and chiefly in respect to those which belong to his moral feclings. As already remarked, the complication in this direction is so great as to produce the effect of novelty : so that man, come into possession of an intellect which is the product of ages of derelopment, finds before him a new field of his own making, where his inherited powers fail.

'This is the field where the most momentous decisions possibie 
in human life are made. Since questions of right and wrong relate to the happiness of men in their relations to each other, the social affections are the stronghold of the motives that bear on this result. It is evident that a thonsand subordinate motives take their direction from the primary decisions between these two original alternatives of feeling.

It is true that the predication of hmman actions, necessitated by bodily functions alone, is easy, even when they come to be of a highly complex character, as in the mercantile transaction of a populous business center. But so soon as the ethical element enters into the calculation the diffieulty is greatly increased, and with the majority of men predication ceases, and faith begins. This is illustrated in the many credit transactions, without which it is well known that trade on any but the most limited scale is impossible. So it must be admitted that many men practice faith in many affairs, and that this faith is chiefly reposed in the moral excellence of other men. Under these circumstances, that state of the affections alises in most men which is termed faith, and which is only present in the highest form of progressive action, whether the results of that action be beneficial or not. It is a condition of the affections, as imagination is a condition of the intellect. The lowest animal, when attempting a novel act in obedience to imperative stimnli, doubtless moves blindly, and adopts one of two or more alternatives throngh pure accident. In mimals of a higher grade of intelligence, new situations are known to be such, and fear or suspicion is the usual result. Generally, animals of the higher orders do not adopt new habits excepting under severe pressnre, and the majority of them have perished, in past geologie ages, on account of their inability to assume new modes of life. Nevertheless, in so fir as an animal or a man rentures into an mnknown field of action, where he is withont the guidance of a past experience, he or it performs an act of trust in the broad meaning of the word. So far as this state of mind is known to the subject, the act is one of trae faith in the restricted or proper sense of the word. Imaginations may and do assume to men the importance of truths, and in so far they are such to them. But in proportion as this is the case, faith in its proper sense is wanting, and the action following is antomatic. The highest form of intellect is necessary to the highest form of faith, since it is only by a knowledge of the absence of knowledge that an act of faith is possible. In proportion to this knowledge of self is faith enlarged; in pro- 
portion to certainty, or supposed certainty, in affairs, is faith diminished in its scope.

It is erident then that, abstractly speaking, occasions must arise in human experience where a decision between two altematives is dependent on choice alone. That these occasions have arisen, and the choice been made, is shown by the existence of the altruistic class of actions. The number of these occasions mat not be very great, but the consequences are very inportant. In whatever direction these decisions are made, long series of antomatic actions are organized.

Althongh the existence of the altruistic class of acts affords the clearest proof of the origin of will, it is not denied that corresponding situations may not oceur in other directions. It is also probable that will, once organized as a facnlty of conscionness, can be exercised in many acts in opposition to habits, differing in accordance with the constitution of the indiridual; and that it can be inberited like any other quality of mind. But I will show later, that the organization of altruistic habits has narrower limits than that of those of the appetent class, becanse self-preservation depends on the latter, and not on the former, so that the appetent qualities are more certain to be inherițed and survive.

The conchsion of this portion of the subject is, that that department of mind called the feelings * is the primury source of action; that they act antomatically, with or withont the aid of the reasoning powers, when dealing with the known; but when dealing with the unknown may derelop, in self-conscions beings, the state of faith and acts of will; that this freedom is born of tension of the affections and of inability of the intellect.

Thus hare the irregular and fortuitous decisions of animals been replaced by volition, as the highest quality of the mind, and therefore the crown of erolution. No new "physical" force is here called into requisition. The determination of the direction of such forces already existing in or passing throngh the brim in execntive action need not add to nor substract from them. Will is, under these circumstances, looked npon as dereloped conscionsuess.

All this is, of course, opposed by the doctrine of the origin of moral excellence by development, on the basis of the utilitarian theory of morals. I therefore proeeed to a brief eximination of its claims in this direction.

* Which appears to be identical witb what Schopenhauer calls the will. 
Good is well defined as the greatest happiness of the greatest number ; and by a natural transfer, the term is applied to whatever is conducive to that object. It therefore includes not only present pleasures, but also the influences which conduce to future pleasures, and which may be sown in the mind long before they bring forth fruit. As present pleasures are not always consistent with greater ones in the future, so present pleasure is not always good. Evil being the reverse or negation of good, or happiness, is avoided by all beings to whom it is consciously known; but what they regard as evil will of course depend on their intelligence in determining or predicating the future effects of actions. But no matter what the degree of intelligence, no responsibility, as usnally understood, can be expected of beings which have no power of choosing, or will.

The utilitarian theory of the evolution of morals asserts that the development of goodness is simply due to the discovery and enforcement of the law of self-protection and preservation. The selfish interests require the protection of person and property, without which a community is an impossibility. Law being thus established and enforced, moral habits are imposed upon men, which become incorporated into character and transmitted to succeeding generations. This is all donbtless true, but whether it is a fundamental or secondiry truth is the point requiring attention.

The fundamental objection to this hypothesis is, that the altruistic affections are not inherited or transmitted. This is becanse the pains and penalties of wrong-doing as inflicted by law, can not (and ought not to) overcome the inherent instinct of selfpreservation in man. It is true that moral character is inherited, and that changes in this department for better or worse are transmitted to offspring. The mental organization of a race may be improved by the weakening of the emotional or the strengthening of the rational faculties. But since the affections are at the forndation of all activity whatsoever, of right-doing as well as of wrong-doing, it is obvious that no amount of legal restraint can render them innocuous. Their existence is necessary for selfpreservation, and law only restrains their activities to certain directions. 'That intelligence tends to restrain wrong-doing is true; but although intellect is inherited, the manner in which its teachings are applied in practice is not. Each man must learn the merits of different courses of action in regard to morals for himself; his intelligence places before him the facts, and shows him 
how to execute his wishes, but the state of his affections determines the direction of his acts. Moral amelioration has attended the progress of intelligence on the one hand, and moral abasement on the other. Intelligence is the condition of the perception of moral truth; in other words, intelligence, as applied to moral questions, is the conscience. Consequences of acts are understood, and their relations to the pleasures and pains of men are weighed. Thus, no donbt, the world has advanced in the knowledge of good and evil, and of right and wrong. That it has improved in the practice of right has not been due to the inheritance of respect for law, but to the self-destructive nature of wrong. That continued wrong sooner or later ends in the destruction of the wrongdoer, either from within or without, must be generally admitted. Thus is the truth of the doctrine of "the survival of the fittest" vindicated in moral as in natural law. But it is also true that this law is restrictive only, and that the school of Hume and Bentham has overlooked the deeper originative law in moral philosophy, as the school of Darwin has done in biological philosophy.

It may still be urged that, if it be granted that experience of the pains of eril-doing be not transmitted as an intellectual acquisition from generation to generation, nevertheless such experience is sufficient to educate each separate generation as it passes, without any other than automatic action on their part. It may be replied to this that the results thus obtained are not due to will, but simply follow compulsion, the motive thus created only varying in strength with the characters of the individuals. Its success is restricted to circumstances where the penalties are sufficiently certain to constitute counter-inducements to effect the necessary restraint. 'This can only be the case with the reaker' nembers of society. Wherever there is sufficient power to escape penalties, wrong-doing has no restraint. Under such a system might and right are identical ; for the strongest needs no protection of law. It is true that society can combine against a single malefactor, but it is also true that malefactors can combine. In fact, it is one of the nsual phenomena of human society to find men becoming malefactors as soon as they attain to power; or to find society governed by a few malefactors who have an army to enforce their pleasure.

While then inheritance does not secure the performance of altruistic acts, appetent affections may be so increased by aceumulation in descent as to become uncontrollable, so that will either 
does not come into existence, or is extinguished, so far as regards those affections. In such a situation there is no such equivalency between opposing motives as gives opportunity for the will, the experience of appetent pleasure being too strong to allow of hesitaney in the face of vague representations of imaginary consequences on the other side. Even in highly intelligent men, to whom consequences are best known, knowledge may be thrust from consciousness, by strong feeling in favor of one alternative at the moment of action.

\section{CONSEQUENCES.}

It is now well to consider how far an autonatic mind has any claim to personality or individuality, as generally inderstood. From the usual stand-point, a being without "liberty," or will properly so ealled, is without character, and is in so far a nonentity. Even the character of the Deity can not escape this destruetive analysis; for aceording to Spinoza, if He is good, but a single line of action, without alternatives, lies open to God, if He be at the same time omniscient. All this is changed if the element of spontaneity in character be presupposed. The existence of such a quality in man renders foresight of its decisions in some cases no more than a calculation of chances, and in other cases impossible; thus offering the only conceivable limit to omniscience, and hence to omnipotence. And as we regard the goodness of God as the anchor of the miverse, if that goodness be in some respect inconsistent with omnipotence, we are strengthened if we discover that there is ground for correcting our traditional suppositions in regard to the latter. Can we not find this ground in a liberty or freedom which is the condition of what we suppose, in the absence of knowledge, to be the characteristic of the highest class of conscions existences?

NOTE.-Another explanation of this conclusion of Spinoza's, quite apart from the question of human freclom, is to be found in some of the nccessary properties of matter. The old theologians expressed this point obseurely in their phrase, "the intraetability of matter." (Ed. 18s6.)

Seconn Note. (E.l. 1856.)-The preceding essay was written sereral years priol' to that on Catagenesis. In the latter article a mental quality was referred to as present in all animals, which constitutes "the will " of various writers, although it is not free. It is described in the following passage: "Why, from a purely mechanical point of view, is the adduetor muscle of the right side of the horse's tail contracted to brush away the stinging fly from the riglit sile of the horse's body, rather than the left adductor muscle? Why was the contraction-provoling energy deflected 
into the right interspinal motor nerves rather than into those of the left side?" The conclusion was that this phenornenon can not be explained on purely mechanical principles; but that it required the assumption of the thesis that "energy can be conscious." (Supra, p. 4:7.)

Further thought on this subject shows elearly that this conscious state of energy is solf-directive in accordance with the lessons of experience, but without being necessarily free in the sense referred to in the preceding essay. In Mammalia the current of euergy derived from stimulus, after reaching the cortical cells of the anterior cerebral lobes, issues from them in a direction appropriate to the needs of the animal, haring undergone a deflection or determination within them. This capacity for "design" is peculiar to beings which can be conscious, and constitutes the most important proof in evidence of a degree of control of miud orer matter. The eridence strongly suggests that this control is greatest when the environment is simple or generalized, since motires are then relatirely simple.

Note to Catagexesis dy the Acthor, 18S6. On p. 434 reference is made to the fact that "in chemical reaction the preference of energy is to create solid precipitates." This fact is but one illustration of the law of thermo-chemistry that "in any reaction, those bodies, the formation of which gires rise to the greatest derelopment of heat, are formed in preference to others." This is a retrograde metamorphosis of energy, or catagenesis. 



\section{N D E X.}

Acceleration, ri, 142, $182,287,383$.

Acceleration and retardation, 2, 11, 125 , $127,297$.

Aerania, 322, 323.

Actinia, 33.

Actinophrys, 27, 187, 192.

Actinopteri, 325, 326.

Asthetophore, 419.

Aethalium, 396.

Agassiz, vii, $8,45,58,60,61,62, \$ 3,91$, $92,103,121,124$.

Ageniosus, 327.

Allen's "Anatomy," 272, 279.

Allen, II., 115, 242.

Allen, Keen, and Pepper on "Unirersal Irperostosis," 183.

Allman, Prof., 415.

Altruisin, xi, 237, 441, 453.

Amblyetonus sinosus, 375 .

Amblyopsis, 196.

Amblypoda, 278, 342, 343, 344, 346, 348, $360,368,371,374$.

Amblystoma, 4.

Amblystoma marortiun, $\mathrm{ss}$.

tigrinum, 89.

Ameiva plcii, 87.

American Association for the Advancement of Science, $x, x i$, xii, xiii.

"American Naturalist," ix, xi, xii, xiii, $244,277,859,36 ?, 383$.

Ametabola, 316 .

Aniturus, 4 .

Amiurus allidus, 85.

lynx, 85.

Ammocoetes, 316 .

Anmonites, 18.
Amœba, 440, 445, 446, 450 .

Amcobodonts, 247, 248, 257.

Amplioxus, 182.

Amphiuma, 333.

Anaptomorphus cemulus, 279.

homunculus, 279.

Ancestral types of mammalia educabilia, 266.

Anchitherium aurelianense, 275 .

Aneistrodon contortix, 197.

piscivorus, 197.

Anelytropidæ, 337.

Anguidæ, 337.

Anicllidæ, 337.

Anisonchus, $245,359$.

Anolis, 4.

Anoplotherium, 247, 265, 370 .

Anthracotherium, $x$.

Anthropoidea, 842, 343.

Antiarcha, 328.

Antilocapra, 383.

Antiodonts, 247.

Anura, 331, 332, 333.

Aphelops megalodus, 369.

Aphodoảiridæe, 328.

Appendicularia, 322.

Archelurus delilis, 375.

Archasthetism, xii, 405, 414, 419, 421.

Arclixopteryx, 340.

Areiferous anura, 95, 218.

Artiodactyla, 344, 368, 371-374, 375, $399,401$.

omnivora, 199.

Ascertained cases of transition, 87.

Ascidia, 399.

Atroply, 13, 127. 
Aturia, 17.

Australian native, 291.

Avian line, the, 340 .

Bain, Prof., 446, 448.

Baird, S. F., 55, 85, 87.

Barnard, 205.

Bascanium cmstrictor, 197.

Bathmism, 26, 205, 226, 414.

Batlimodonts, 248, 259.

Batraclia, 351.

Batrachia anura, 46, 216, 332.

Bexinnings of development, the, 447 .

Bennett, Alfred, 199, 214.

Bentham, 455.

Bokorny, 430 .

Borborocetes, 4 .

Bos, 348.

Bothriolepis canadensis, 323.

Boulanger, 337.

Bibroll, 95.

Bidens frondose, 86.

Bischoff, 290 .

Brachiopoda, 399.

Branchiostoma, 322, 384.

Bridger fauna, 302.

Broca, 290.

Bronn, Prof., 45, 51, 102.

Bufoniformia, 217.

Bunodont type, 243.

Bunotleria, 343, 346, 349 .

Buteo, 4.

\section{Calcmodon, 278.}

California Academy of Sciences, xi.

Camelida, 375.

Canidæe, 246.

Canis familiaris, 224.

Caprimulgidæ, 341.

Cariaenes virginiareus, 50, 177-178. maerotis, 178.

Carnassial bunodonts, the, 251.

Carnivora, 261, 275, 344-346, 348, 399401.

Carpenter, Dr., viii, 191, 206, 438.

Casts of brain-chambers of extinet mammalia, fignres of, 308.

Catagenesis, xiii, 422, 428, 434.
Caudisona, 4.

Causes of evolution, 14.

Cebide, 180.

Cebus apella, 12.

capucinus, 12, $3 \mathrm{~S}$.

Celestus phoxinus, 84.

Cell-repetition, on, 185.

Centetes, 360.

Centetidre, 348 .

Centrotelma geographicum, 85 .

Cephalization, 39.

Cervidæ, 177.

Cetacea, 26, 342, 343, 347, 349, 399.

Chaenobryttus viridis, 213.

Chatodontidæ, 330.

Chamcesaura anguina, 84.

Change in amount of growth-forec, 200.

Characinidx, 327.

Character of higher groups, of the, 132.

Chelyosoma maclovianum, 323 .

Chiromys, 180, 202.

Chiroptera, 342, 343, 844 .

Chorophilus, 4.

Chrondrostei, 325, 326.

Cinclidium maximum, 85.

Cladodonts, 525 .

Clark, H. J., 167.

Clepsydrops, 363.

Clevenger, 424.

Clifford, Prof., 425.

Coelenterata, 182, 413.

Conogenesis, 126.

Cohnhein, 195, 406.

Coleoptera, 316.

Colocephali, 327.

Comparison of the opposing series, 250 .

Complementary diminution of growth force, viii.

Condylartbra, xiii, 342-6.

Consciousness, energr, and matter, 425.

Consciousness in crolution, $\mathrm{x}, \mathrm{xi}, 390$.

Coranus subapterus, 89.

Coreopsis discoidca, $\mathbf{8 6 .}$

Correlation of physical and rital forees, 191.

Corrus, 4.

Corsphodon, 270, 272, 275, 274, 276, 369, 374. 
Coryphodon elephantopues, 209.

Corypbodontida, 359.

Cosoryx, 224, 271, 376.

Crania of anura, 22.2.

Craniata, 322, 323.

Creodonta, 359, 365 .

Cretaccous fauna, 302 .

Crossopterygia, $325,326$.

Crotalus confluentus, 212.

Cuvier, 8, 88, 124, 129, 146, 176

Cyclopterus, $3: 1$.

Cyprinidx, 327.

Dana, J. D., 39, 429.

Darwin, Charles, 2, 3, 11, 13, 15, 42, 106 , $124,174,405,409,455$.

Daubentonioidea, 342 .

Deltatherizem fundaminis, 362.

De Serres, Prof., 74, 7 .

Desmognathus jusca, 87.

nigra, 87.

Deuterosaurus, 363.

Derelopment of the fine arts, 153. of intelligence, 149.

of inind, the, 445 .

Developmental relation of generic to specific characters, 82.

Derelopmental significance of luman pluysiognomy, 281.

Diadectida, 335.

Dibamila, 337.

Diclonius mirabilis, 338, 339.

Didelplys, 360.

Dirlymictis protemes, 245.

Dimorpliodon, 335.

Dinictis cyelops, $: 36$.

Dinocerata, 3.)9.

Dinosauria, $333,335,336,398$.

Dinotherium, 248.

Diplarthra, 342, 343, 346, 347.

Diploylosses monotropis, 81.

Dipnoi, 184, 324.

Diptera, 316.

Dircetion of repetition, on the, 192.

Doctrine of the unspecialized, the, 398.

Doln'n, 316, 317 .

D'Orbigny, 101.

Dolypterus, 327.
Dualism, 421.

Dubois-Raymond, Prof. E., 409.

Duméril, 88, 89, 91, 95.

Dyer, 213.

Dysodus, 349.

Edentata, 342, 343, 344, 349.

Effect of impacts and strains on the feet of mammalia, on the, xii, 373.

Effort, 195, 206-7, 426.

Elaps, 4.

Elasmobranchii, 319, 320, 324.

Flectric energy, 435.

Elements of mind, the, 443 .

Elephas, 377.

africanus, 110.

antiquus, 110.

meridionalis, 110.

planifions, 110.

primigenius, 110.

Embolomeri, 331, 332.

Embryologs, 383.

Emotions, 158, 163, 381, 447.

Empidonax, 4.

"Encyclopadia of Dentistry," 104.

Endlich, 286.

Entoconcha mirabilis, 401.

"Entwickelungsgeschichte der Natter," 94.

Eobasileus, 250.

Epochal relations, 112.

Epilasmia, 330.

Equida, 411.

Equus, $276,348$.

Evyops megacepha'us, 304.

Esequibo Indian women, 286.

Eucnemis bicolor, 114.

Eurypharyngide, 328, 329.

Eurytherium, 370.

Futania, 4.

Fridence from archeology, 150 .

Fvidences of derivation, 130, 215.

Evidence for erolution in the lisitory of extinct mammalia, xii, 294.

Fvolution and its conscquences, ix, 1.

Frolution of organisms, the, 422 .

Fvolution of the vertelnata, progressive and retrorressive, xiii, 314 . 
Evolntionary significance of human character, xii, 378.

Exact parallelism, vi, 46, 76, 189.

Extent of parallelism, 74.

Extinction of evil, the, 169.

"Extinet Mrammalia of Daliota and Nebraska," 364.

Falco, 4.

Falconer, 55, 109.

Feelings, the, 447.

Felidæe, 349, 363, 366.

Felis, 363.

"Final Reports of the U. S. Geological Surveys," v.

Flower, W. If., 104.

Ganocephala, 332.

Garman, 325.

Gastræa theory, 219.

Gaudry, A., 275.

Gecconidx, 336.

Gegenbaur, 322.

General evolution, 1.

"Geological Survey of Montana," 258, 267.

Geothlypis tephrocotis, 85.

Gill, T., 329.

Goethe, 7.

Goniatites, 18.

Grade cliaracteristics, viii.

Gralle influence, viii, 203-6.

Gratiolet, 104.

Gray, 86, 176.

Gray, Asa, 208.

Greatest resistance, 30.

Gronias nigrilabris, 84 .

Growth-force, 18, 190, 396.

Günther, 58, 86, 340.

Gymnophiona, 331.

Glyptostrobus curopreus, S6.

Ilacckel, ix, x, xiii, $75,125,190,219$, $229,415$.

Halobates amerieanus, 90.

Haplodont type, 243.

Hartshorne, Prof., 397.

Hayden, F. V., v, 246, 269, 369-71, 376.
Hemibranchi, 328.

Henry, Prof. Joseph, 19, 191.

Hesperoruithidæ, 340.

Heterodon nasicus, 212.

Heterology, 96.

Heterosomata, 328.

Hippocampidæ, 328.

Hippodonts, 249.

Hippopotamus, 272.

Hippotherium, 202, 411.

Hippotherium gracile, 275.

History of creation, xiii.

Hogg, 89.

Holocephali, 324.

Holothurida, 193, 399.

Hominidæe, 180.

Homo sapiens, 272, 279.

Homologies and origin of the types of molar teeth of the mammalia educabilia, 241.

IIomologous groups, vi, 26, 95.

IIomology, 6 .

Humboldt, 425.

Hunie, 455.

Huxley, 15, 136, 146, 265.

Hyænidæ, 246, 349.

Uyænodon, 366.

Hycenodon hovidus, 364.

Hyænodontidæ, 246.

IIyatt, A., 2, 8, 11, 51, 91, 125, 408-9, 424.

Hyla, 4.

Hylorana erythroca, 114.

Hyopomata, 318, 324.

IIypothesis of evolution, physical and metaplyssical, vii, xii, 128, 167, 287.

Hypothesis of use and effort, the, 405.

Hypsilepis analostanus, 213.

Hymenoptera, 316.

Hyrachyus, 247.

Hyracoidea, 342, 843, 344, 346, 347.

Hyracodonts, 249.

Hyracotherium, 301.

Hyracotherium venticolum, 271.

Hyrax, 233.

Ielithyopterygia, 184, 333, 336.

Ichtlyyornithidæ, 340 . 
Ichthyosaurus, 184, 336.

Icichthys, 331.

Icosteus, 331.

Improvement in arehitecture, 151.

Improrement in the use of materials, 150.

Increase of growth-force, 200-1.

Indo-European, $2 s 8$.

Induction, 6, 14.

Inexact parallelism, 52, 139.

Influence of physical causes, 196.

Insectivor'a, 347 .

Intelligence, 449.

Intelligent selection, viii, ix, 35, 208.

Isospondyli, 327 .

Jena, 8.

John Day river epoch, 366.

Jones, Rupert, 86.

Jordan, D. S., æ̈26.

Kant, 307, 449.

Kiowa Indian, 288.

Kner, R., 113.

Kölliker, 15, 103.

Kowalevsky, x, 318.

Lacertilia, 334, 335, 336.

Lamarck, viii, 124, 342, 422, 405, 422423.

Lambdotherium popoagicum, 275.

Lartet, 104, 254.

Lankester, 96, 322, 333, 337.

Laws of evolution, the, 225.

Least resistance, 30 .

Leeonte, 115 .

Lcibnitz, 415.

Leidy, 50, 85, 258, 364, 3九1, 376 .

Lepidoptera, 316.

Leporidx, 375.

Leptocardii, 317, 318, 319, 320.

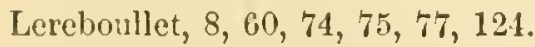

Lespes, 57.

Lewes, G. II., 415.

Line of the Batrachia, the, 331.

Line of the Pisces, the, 324.

Location of growth-force, on the, 24, $195,205$.

Iocke, 488.
Loew, O., 430 .

Lombard, 418.

Lophiodon, 247.

Lophodont type, 243.

Loss of growth-force, 201.

Loup Fork fauna, 302.

Loxolophodonts, 248, 250, 259.

Luchatze negro woman, 287.

Lund, 367.

Lycodon, 4.

Mammalia, 278.

Mammalia educakilia, ix, 241.

Nammalian line, the, 341.

Man, development of, 123, 146, 155, 267, 278.

Mancus macrolepis, 84.

Mandibular teeth, the, 245, 249.

Manner of evolution, the, $6,11$.

Marsh, O. C., x, 258, 277, 308, 333, 840.

Marsipobranchii, 316, 817, 318, 319, 320.

Marsupialia, 341-344. 347-348, 359.

Mastodon ohioticus, 56.

Maternal impressions, viii, 213.

Maxillary tecth, the, 244, 246.

MeCook, Dr., 385 .

Meehan, T., 160, 161.

Mechanical erolution, 350.

Meleagris, 24.

"Memoirs Boston Society Natural His. tory," 51.

Menodus, 272.

"Jental Plissiology," 438.

Mesodon albolabris, 178.

Mesonyx, 246, 278.

Metachrosis, 211.

Metresthetism, 421.

Metaphysical evolution, ix, 148, 378.

Metaphysical species, on, 111.

Metaphysies of evolution, 229.

Method of creation of organic types, rii, $11,173,229,241,353$.

Mimetic analogy, viii, 10.1, 212.

Mind, derelopment of, 214, 385, 445 .

Minot, C. S., 287.

Mioclacnus corrugatus, 275.

llivart, 15, 28. 
Jodifications of animals under domestication, 110 .

IIonas, 27.

Jongolian, 288.

Monism, 421.

Monodelphia, 344, 347, 348 .

lionotremata, 341, 346, 347 .

Norals of erolution, the, 236,311 .

Morris, C., 385.

Müller, 8, 325 .

Murphy, 194.

Mustelidæ, 246.

Mutilla, 212.

Mycelium, 30.

Myiodinctes cancedcrsis, 85.

Naja, 4.

Natural selection, 2, 14, 43, 78, 106, 107, 174,175 .

Nature of actions, the, 439.

Nautilus, 18.

Necturus, 333.

Necturus maculatres, 49.

Negro, 288.

Neurism, 20, 205.

Numida, 24.

Neuroptera, 316.

Newton, 14.

Nimravus gomploodus, 375.

Wistridæ, 316.

Office of consciousness, 412.

Oken, 7.

Omnivola, 371.

Oncocephalus griscus, 00.

Ophibolus, 299.

triangulus, 197.

Ophidia, 334, 335.

Oporornis agilis, 85.

formosus, Sö.

Orconcctes pollucidus, 13.

Origin of automatic movements, the, 395.

Origin of consciousness, 402.

"Origin of the Fittest," xiii, 175, 225.

Origin of the foot-structure of the unsgulates, xi, 368 .

"Origin of Genera," ri, vii, 11, 41, 1:-, 256.
Origin of inexact parallelism, 92.

Origin of intclligence, 31 .

Origin of the modern types of bunodont and lophodont dentition, 251 .

Origin of motives, 450 .

Origin of the specialized teeth of the carnivora, $x i, 363$.

Origin of species, 2, 7, 42, 107.

Origin of the will, $x, 437$.

Ornithorhynchus, 184.

Ornitlosauria, 335, 336.

Orthagoriscidæ, 330 .

Orthoceras, 18.

Osborn, H., 277.

Ossemens fossiles, 49, 176 .

Osteocephalus, 46, 221.

Ostraciontidæ, 330 .

Owen, Sir R., 85, 91, 103, 318.

Oxyæna, $246,360$.

Oxycena lupina, 365. morsitans, 375.

Oxyrrhopus, 4.

Packard, A. S., 2, 13.

Palreosyops, 247.

Palæothcriodont, 258.

Palæotherium, 247, 248.

Paleontological bulletins, xii.

Paleontological evidence, 383.

Palingenesis, 126.

Panasthetism, 419.

Pantolambda, 360.

Pantolumbdr bathmodon, 275.

Parallelism, 7.

Parallelism in higher groups, 58.

Parker, 86.

Pasteur, 431.

Paro, 24.

Pelyeodus, 360.

Perca, 4.

Percomorphi, 328, 331.

Perigenesis, ix.

Periptychus, 359.

Pcriptychus rleablodon, 268, 308.

Perissodactyla, 250, 265, 3:8, 371-373, $375,399$.

Permian famna, 302.

Peters, 33t. 
Pharyngognathi, 330, 331.

Phenacodus, 301.

Phenacodus primcevus, 270, 273, 275, 300, 308. vortmani, 345.

"Philosophic Zoologique," viii, 423.

Phrenism, 205.

Physical evolution, 128.

Physical origin of man, the, 146.

Physiophilosophs, 7.

Physoclysti, 328.

Pliysostomi, 32S.

Patyophis sayi, 197.

Plagiaulax, 348.

Platypodidæ, 346.

Plecostomus, 4.

Plectognathi, 330.

Plesiosaurus, 26, 185.

Pleuronectidæ, 196.

Pliauchenia, 223.

Poëbrotherium, 223.

Pö̈brotherium labiatum, 271, 370. vilsoni, 3个1, 376.

Polyeystina, 27.

Polyphyletic descent, rii.

Porter, Noah, xi.

Pressure, effect of, 228.

"Primitire Types of Mammalia Edueabilia," 216.

"Principles of Biologr!," ix, xi, 423.

"Principles of Psychologr," is.

Procelurus julicni, 366.

Probable cases of transition, 83 .

Proboscidia, 233, 265, 342-1, 346-8, 375, 401.

Procamclus occidcntalis, 308,376 .

Trocyonidæ, 359.

Prostemma gutiula, 89.

I'rotamœba, 190.

Proteida, 331-3.

I'roteles, 349.

Protobathybius, 420.

Protohippies sejunctus, 271, 370.

I'rotolabis, 223.

Protozoa, 33, 420.

Ptychodont type, 243.

Ptychostomus, 4.

I'tychostonus pidicnsis, 213.
Puereo fauna, 302.

Pygopodidæ, 337.

Pythonomorpha, 26, 334.

Quadrumana, 179, 278, 280, 342-4, 317, $385,899,400,401$.

Radeliffe, 20.

Radiata, 27.

Rana, 4.

Rana agilis, 222. affinis, 47,84 .

ar'colata, 48.

caícshciana, $4 \mathrm{~S}$.

clamata, 222.

corregata, 48.

cyanophlyctis, 48.

delalandii, 47.

chrenbergii, 48.

fasciata, 47.

fresigula, 48.

gracilis, 48 .

grayi, 47.

grumicus, 48.

hexadactyla, 45, 222.

mascariensis, 47 .

occipitalis, 48.

oxyrhyzechus, 47, 222.

prolmipes, 47.

porosissima, 47 .

temporaria, St.

tigrina, 48 .

vittiger $\alpha, 48$.

Raniformia, 217.

Ranula chrysoprasina, 222.

Rathke, 57, 61, 76, 93.

Iiationale of moral derelopment, 166.

Rattle of the rattlesnalie, the, 197.

Rayınond, Dubois, 21, 409, 415.

Relation of animal motion to animal erolution, xi, 266, 350 .

Rationale of the derelopment of intelligence, 154.

Relation of man to the tertiary niammalia, $x, 268$.

Relations of nearly aliied genera, on the, 44 .

Relations of physical and moral nature, 158. 
Relations of the types of dentition to types of foot, 260.

Repetitive addition, 180.

"Report on Geological Survey of Mlontana, Wyoming, etc.," 246.

"Report United States Exploring Survey W. 100th Meridian," 224.

Reptilian line, the, 333 .

Respiratory and cireulatory system of vertebrates. 196.

Retardation, vi, 13, 142, 182, 287, 385 .

Retardation and acceleration, $11,43,75$, $175,226$.

Retrograde metamorphosis of encrgy, 427.

"Reriew of Birds of North America," 55.

Review of modern doctrine of evolution, $x i, 215$.

Rhachitomi, $331,332$.

Rhinocerus, 247.

Rhynchocephalia, 334, 336.

Riickhard, Rabl, 319.

Roceus lincatus, 213.

Rodentia, 180, 342-4, 346, 375.

Rotifera, 315.

Ruminantia, 223, 247, 375 .

Ryder, J. A., ix, 368, 409, 423.

Sacculina, 401.

Salamandra atra, 87.

maculosa, 87.

Salmo, 4.

Salticus, 212.

Saturniidæ, 316.

Sauropterygia, 334, 336.

Searide, 331.

Schlosser, 370.

Schopenhaner, 453.

Schöpfungsgeschichte, xiii.

Schreiber, 87.

Scincidæ, 337.

Sclater and Salvin, 118.

Scolecophidia, 340 .

Scombridæ, 331.

Scops asio, 4.

Seeley, 11. G., 335, 340.

Segment-repetition, 182.

Selenodonts, 247.
Serranidæ, 331.

Siluridæ, 327.

Simic satyrus, 283.

Simiidæ, 180.

Siredon, 333.

Sirenia, 342, 347, 349.

Smilodon nengeeus, 267 .

Smith, Aubrey, 86.

Smyth, Brough, 291.

Spelerpes, 4.

Spencer, Herbert, viii, ix, xi, 2, 15, 413, $444,445,448$.

Spinoza, 90, 456.

Spiritual or moral development, $15 \%$.

Spizella pusilla, 16.

socialis, 16.

Stegocephali, 331, 332.

Stegophilus, 327.

Steindachner, 86.

St.-Hilaire, 91, 146.

Streptostylica, 334.

Structural evidence of evolution, the, 241.

Stypolophus, 246. whitice, 360 .

Subordinate types of bunodonts, the, 244.

Subordinate types of lophodonts, the, 246.

Successional relation, 7 .

Survival of the fittest, 15.

Swainson, 96.

Symborodonts, 248, 250, 257.

Synopsis of the vertebrata of the eocene of New Mexico, 245.

Synthesis of repctition, 187 .

Trenia, 184.

Taniodonta, 343, 349.

Tachyglossida, 346.

Talpa, 360.

Tapirodonts, 247, 255.

Tapirus, 247.

Taxeopoda, 342, 347.

Taxodium disticluem, 86.

Teïdæ, 337.

Teleolog $5,7,16$.

Teleostomi, 318, 324-326. 
"Tertiary Planorbis of Steinheim," 408.

Testudinata, 334.

Testudinidæ, 337.

Theory of evolution, $x, 124$.

Theromorpha, 333, 335, 38\%.

Thomson, Sir William, 431, 442.

Thulié, 288.

Tillodonta, 343 .

Tillotherium, 248.

Topinard, 290.

Tortricidæe, 340.

Trachystomata, 331, 332, 333.

Trematoda, 401.

Trichechodonts, 248, 255.

Trichodiscus, 27.

7 rodopsis tridentata, 178.

Tritubercular type of molar teeth in the mammalia, xii, 3 פ9.

Tropidonotus sipcdon, 197.

Tryon, G. W., 177.

Types of mammalian molars, the, 241.

Typhlichthys subterraners, 13.

Typhlogeophis, 340 .

Uhler, P. R., 90.

Uintatherium, 248, 274, 278.

Uintatherium cornutum, 277. mirabile, 277, 308.

Unconscious, the, 391 .

Unconscious cerebration, 32.

Ungulata, 347, 359, 365, 369, 3个4.

Unity in variety, 7 .

Urochorda, 322, 323.
Urodela, 331, 332.

Use and effort, ix, 6, 194.

Vegretable growth, force of, 31.

Velia, 90.

Venus of the Capitol, 292.

Vermes, 399.

Vertebrata, 352, 356.

Vertebrate line, the, 318.

Vibrio, 188, 192.

Viverridre, 245.

Vogt, C., 12, 401, 402.

Von Baer, vi, 8, 45, 60, 62, 74, 77, 92.

Von Siebold, 86.

Wagler, 88, 95.

Walker prize, viii.

Waliace, 13, 14, 15, 106, 174, 405.

Wallace and Bates, 212.

Wrard, Lester, 430.

Wasatch fauna, 302.

Wheeler, G. M., v, 224, 317, 359, 365$369,375,376$.

Westwood, 89.

Whiteares, 323.

White river fauna, 301,302 .

Wiegmann, 95, 100.

Will, 208, 210, 434, 456 .

Willis, Dr., 438.

Wrestler, the, 289.

Wortman, J. L., 104, 275.

Wyman, 87.

"Zoologie Philosophique," 342, 423. 



\section{SCIENTIFIC PUBLICATIONS.}

\section{The Human Species.}

By A. De Qcatrefages, Professor of Anthropology in the Museum of Natu. ral History, Paris. 12mo. Cloth, $\$ 2.00$.

The work treats of the unity, origin, antiquity, and original localization of the human species, peopling of the globe, acclimatization, primitive num, formation of the human races, fossil human races, present human races, and the physical and psychological characters ot mankind.

\section{Students' Text-book of Color; or, Modern Chromatics.}

With Applications to Art and Industry. With one hundred and thirty Original 1llustrations, and Frontispiece in Colors. By OGDEx X. ROod, Professor of Phrsies in Columbia College. 12mo. Cloth, \$2.00.

"In this interesting book Professor Rood, who, as a distinguished Professor of Physics in Columbia College, Lnited States, must he accepted as a competent authority on the branch of science ot which he treats, deals bricfly and suecinetly with what may be termed the scientific rationale of his subject. But the chiet value of his work is to be attributed to the fact that he is himself" an accomplished artist as well as an authoritative expounder of science."-Edinburgh liccieu, October, 18i9, in an article on "The Philosophy of Color."

\section{Education as a Science.}

By Alexayner Bary, LL. D. I2mo. Cloth, \$1.75.

"This work must be pronnunced the most remarkable discussion of educational problems which has been published in our day. We do not hesitate to bespeak tor it the widcst eirculation and the most camest attention. It should be in the hands of every school-teacher and friend of education throughout the land." - New Iork sun.

\section{A History of the Growth of the Steam-Engine.}

By Ronert П. Therstox, A. M., C. E., Professor of Mechanical Engineering in the Sterens Institute of Technology, Hoboken, X. J., ctc. With one hundred and sixty-three Illustrations, including fifteen Portraits. 12 mo. Cloth, s.:.50.

"Professnr Thurston almost exiausts his suhject; details of mechanism are followed by interesting bingraphies ot the more important inventors. If. as is contended, the stean-cngine is the most inportant plyrsical agent in eivilizing the world, its history is a desideratum, and the readers of the present work will agree that it could have a no more amusing and intelligent historian than our author." Boston Gaztti.

\section{Studies in Spectrum Analysis.}

By J. Normax Ionkyer, F. R. S., Corespondent of the Institute of Framee, etc. With sixty 1l!ustrations. $12 m 0$. Clotlı, š.50.

"The study of spectrum analysis is one franght witl a peculiar fascination, and some of the author's experiments are excedingly picturesque in their results. They are sn lucidly described, ton. that the reader keeps on, from latge to page, never flagging in intere-t in the matter betore him, nor putting clown the book until the list page is reached." - lewe York Evening Lirpress.

New York: D. APRLETON \& CO., 1, 3, \& 5 Bond Street. 


\section{SCIENTIFIC PUBLICATIONS.}

\section{General Physiology of Muscles and Nerves.}

By Dr. I. Rosential, Professor of Physiology at the University of Erlangen. With seventy-five Woodeuts. ("International Scientific Series.") 12 mo. Cloth, $\$ 1.50$.

"The attempt at a connected aecount of the gencral physiology of museles and nerves is, as far as I know, the first of its kind. The general data for this branch of scienee have been gained only within the past thirty years." - Extract from Preface.

\section{Sight:}

An Exposition of the Principles of Monocular and Binocular Vision. By Joseril LE CoNTE, LL. D., author of "Elements of Geology"; "Rcligion and Science"; and Professor of Geology and Natural Ilistory in the University of California. With numerous Illustrations. $12 \mathrm{mo}$. Cloth, $\$ 1.50$.

"It is pleasant to find an Ameriean book which can rank with the very best of foreign works on this subject. Professor Le Conte has long been linown as an original iuvestigator in this department; all that he gives us is treated with a masterhaad." - The Nation.

\section{Animal Life,}

As affected by the Natural Conditions of Existence. By KarL Samper, Professor of the University of Würzburg. With two Haps and one hundred and six Woodeuts, and Index. 12mo. Cloth, \$2.00.

"This is in many respects one of the most interesting contributions to zoölogienl licerature which has appeared for some time."-Nature.

\section{The Atomic Theory.}

By AD. Wurtz, Memore de l'Institut; Doyen IIonoraire de la Faculté de Hédecine; Professeur à la Faculté des Sciences de Paris. Translated by E. Cleminshaw, M. A., F. C. S., F. I. C., Assistant Master at Sherborne School. 12mo. Cloth, $\$ 1.50$.

"There was need for a book like this, which discusses the atomie theory both in its historie evolution and in its present form. And perhaps no man of this age could have been selected so able to perform the task in a masterly way as the illustrious French chemist, Adolph Wurtz. It is impossible to eonvey to the reader, in a notiee like this, any adequate idea of the scope, lucid instructiveness, and scientitic interest of Professor W Wrtz's book. The modern problems of ehemistry, whieh are eommonly so obseure from inperfect exposition, are here made wonderfilly clear and attractive."-The Iopular Science Nonthly.

\section{The Crayfish.}

An Introduction to the Study of Zoölogy. By Professor T. H. IIvxury,

F.R.S. With eighty-two Illustrations. 12mo. Cloth, \$1.75.

"Whoever will follow these pages, erayfish in hand, and will try to verify for himself the statements which they eontain, will find himself brought faee to face with all the great zoölogical questions which excite so lively an interest at the present day."

"The reader of this valuable monograph will lay it down with a fceling of wonder at the amount and variety of matter which has been got out of so seemingly slight and unpretending a subjeet." -Saturday Review.

New York: D, APPLETON \& CO., 1, 3, \& 5 Bond Street. 


\section{SCIENTIFIC PUBLICATIONS.}

\section{SUICIDE:}

AN ESSAY IN COMPARATIVE MORAL STATISTICS. By Hexry Monseler, Professor of Psyehological II dicine in the Royal University, Turin. 12mo, cloth. Price, $\$ 1.75$.

"Suicide" is a scientific inquiry, on the basis of the statistical method, into the lawy of suicidil phenomena. Dealiug with the subject as a branch of social science, it consiclers the increase of suicides in different conntries, and the couparison of nations, races, aut periods in its manifestation. 'The iufluences of age, sex, constitution, climate, sea fon, nccupation, religion, prevailing ideas, the elements of character, the tendencieg of civilization, are comprehensivelv analyzed in their bearing upon the propensity to self-destruct'on. Professor Morselli is an eminent Eurobeau autherity on this snbject. It is accompanied by colore 1 maps illustrating pictorially the results of statistical inquiries.

\section{VOLCANOES:}

WIAT THEY ARE AND WHAT THEY TEACH. By J. W. JUnD, Professor of Geology in the Royal Sehool of Diines (London). With Ninety-six Illustrations. $12 \mathrm{mo}$, cloth. $\$ 2.00$.

"In no field has modern research been more fruitful than in that of which Profescor Jurd gives a popular account in the present volnme. The great lines of dynamical, geological, and meteorological inquiry converge upon the grand problem of the interior constitution of the earth, and the vast influence of subteriatean agencies. . . His book is very far from being a mere dry description of volcanoes and their elnptions; it is raller a presentation of the terrestrial facts and laws with which volcanic phenomeua are associated."-Popular Science Monthly.

"The volume before us is one of the pleasantest science manuals we have rcad for sorae time."-Athencum.

"Mr. Judd's summary is so full and so concise, that it is almost impossible to give a fail idea in a short review." - Fall Mall Gazette.

\section{THE SUN.}

By C. A. Yodng, Ph. D., LL. D., Professor of Astronomy in the College of New Jersey. With numerous Illustrations. 12mo, cloth. $\$ 2.00$.

"Professor Young is an anthority on 'The sun,' and writes from intimate knowledge. He has studied that great luminary all his life, invented and improved instruments for observing it, gone to all quarters of the world in search of the best places and opporlunities to watch it, and has contributed important discoreries that have extended our knowledge of $\mathrm{jt}$.

"It would take a cyclopadia to represent all that has been done toward elearing up the solar mysteries. Professor Young luas summarized the information, and presented it in a form completely available for general readers. There is no rhetoric in his book: lie trusts the grandeur of his theme to kindle interest and impress the feelinge. llis statements are plain. direct, clear, and condensed. though ample enough for his jurpose, and the substance of what is generally wanted will be found accurately given in his pages." Popular Science Monthly.

\section{ILLUSIONS :}

A PSYCHOLOGICAL STUDY. By JAMES SUlLT, author of "Sensation and Intuition," etc. $12 \mathrm{mo}$, cloth. \$1.50.

"An interesting contribution by Mr. James Sully to the study of mental patholomy. The anthor's field of inquiry covers all the phenomena of illusion observed in sense-jerception, in the introspection of the mind's own feelings, in the reading of others' feelings, in memory, and in belief. The antluor's conclnsions are often illustrated by concrete example or aneclote, and his gencral treatment of the subject, while essentially scientific, is eaffciently clcar and animated to attract the general reader." - New York Sun.

New York: D. APPLETON \& C0., 1, 3, \& 5 Bond Street. 


\title{
SCIENTIFIC PUBLICATIONS.
}

\section{The Brain and its Functions.}

\author{
By J. Lurs, Physician to the Hospice de la Salpêtrière. Trith Illustra.
} tions. 12mo. Cloth, $\$ 1.50$.

"No liviug phssiologist is hetter entitled to speak with anthority apon the structnre and functions of the brain than Dr. Luys. His studies on the anatomy of the nervolis system are aclinowledged to be the tullest and most systematic ever undertaken. Dr. Lnys snpports his conclusions not only by his own anatomical researches, hut also by many functional ohservations of varions other physiologists, including of course Professor Ferrier's now classical experiments."-St. James's Gazelte.

"Dr. Lnys, at the head of the great French Insane Asylum, is one of the most eminent and ancessin! iuvestigators of cerebral science now living; and he has given unquestionably the cltarest and most interestiug brief acconnt yet made of the surmcture aud operations of the brain. We have been fascinated by this volume more than by any other treatise we have yet seen on the machinery of sersibility and thought; and we have been instructed not anly by mucil that is new, but by many saqacious practical hints such as it is well tor everybody to understand." - i'he Popular Science Monthly.

\section{The Concepts and Theories of Modern Physics.}

\author{
By J. B. Stallo. 12mo. Cloth, \$1.75.
}

"Judge Stallo"s work is an inquiry into the ralidity of those mechanical conceptions of the universe which are now held as fundamental in physical science. He takes up the leading modern dectrines which are based upon this mechanical conception, wheh as the atomic coristitution of matter, the kinetic theory of gascs, the conservation of energy, the nebuin hypothesis, and other views, to find how mach stauds apon solid empirical yround, and how unch rests uvon metaphysical speculation. Since the appearance of Dr. Draper" $\$$ - Religion and science, no book has been published in the conntry calculated to make so deep an impression ou thonghtful and edncated readers as this volume. . . The range anl minnteness of the authol"s learning, the acnteness of his reasoning, and the singulas precision nud cleamess of his style, ar qualities vbich very seldom have been jointly tribited in a scientific treatise." - Iew Jork S'un.

\section{The Formation of Vegetable Mould,}

\author{
THROEGIF TIIF ACTION OF WORMS, WITH OBSERVATIOSS ON \\ THEIR HaBITS. By Charles Dariwix, LL. D., F. R. S., anthor of "On \\ the Origin of Speciss," etc., etc. With Illustrations. 12mo, cloth. Price, \\ $\$ 1.50$.
}

or vTr. Darrin's litte rolume on the hahits and instincts of earth-worms is no less marlsed than the earlier or more elaborate efforts of his genias by freshness of observation, nufuiling power of interpreting and conrelating fact, and logical vigor in generalizing mpon then. The main purpose of the work is to point ont the share which worms have taken in the formation of the layer of vegetable monld which covers the whole surface of the fond in every moderately humid conntry. All lovers of mature will nnite in thanking Mr. Darwin for the new and interesting liohe tre lras thrown upon a subject so long ovellooker, yet so full of interest and instruction, as the strmctnre and the labors of the earthworm."-Saturday Reviero.

"Respecting worms as amour the most usefol portions of animate natnre. Dr. Darwin relates, in this nemarkable book, their'strncture and labits, the part they have played in the burial of ancient bundings and the cleundation ot the land, in the disintegration of rocks, the preparation of soil for the growth of plants, and in the natural history of the world." -Boston Advertiser.

New York: D. APPLETON \& CO., 1, 3, \& 5 Bond Street. 


\section{SCIENTIFIC PUBLICATIONS.}

\section{Ants, Bees, arid Wasps.}

A Fecord of Observations on the Habits of the Social Hymenoptera. By Sir Jorx Lubbock, Bart., M. P., F. R.S., ete., author of "Orịin of Civilization, and the Prinitive Condition of Man," etc., ete. With Colored Plates. $12 \mathrm{mo}$, cloth, $\$ 2.00$.

"This rolume contains the record of variousexperiments marle with ants. bees. and masps c.uring the last ten years. with a view to test their mental condition and powers of :ense. The prineipal point in which sir John's mode of experiment differs from those of Iluber, Forel. Mecook. and others, is that he has carefully watched and marked particular insects, and has had their nests nud $r$ ubservation for long periouls-ove of his ants' yests having been under constant inspection ever since 1sit. His observations are made principally upon ants because they show more power and flexibility of mind; and the vulue of bis studies is that they belong to the deIartment of original researeb."

-. We have no hesitation in saying that the author has presented us witl the most raluahie series of observations on a special subject tha: has ever been produced, charmingly writ ten, full of Iorical deductions. and, when we consided his multitudinous engagements, a remarkab!e illustration of economy of time. Is a contribution to insect psyebolegy. it will be long before this book finds a parallel." - London Athenceum.

\section{Diseases of Memory:}

An Essay in the Positive Psyehologr. By. Tr. Rinot, aullor of "Heredity,"

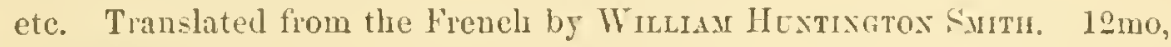
cioth, $\$ 1.50$.

"M. Ribot rednees diseases of memory to law, and his treatise is of extraordinary interest." - Philudelphia Press.

"Not merely to seientific, but to all thinking unen, this rolume will prove intenscly interusting."-Tew Fonk ubserver.

"Il. Ribot has bestowed the most pains taking attention upon his theme. and numerous examples of the conditions considered greatly increase the value and interest of the velume." I'helade'phia Yorth Americun.

"I'n the general reader the work is made entertaining by many illustratiors connected with Ench nann" as Lingiens, Newtun, sir Walter seott, Horace Verbet, Gustare Doré, and uany others."- Cirisburg Telegraph.

"Th: whule subject is presented with a Frenchman's viracity of style."-Proridence Journa'.

"It is not ton much to say that in no single work have so many curious cases bechl brought together and interpreted in a scientitic manner."-Boslon Evening Travel'ter.

\section{Myth and Science.}

B. Trto Ticisol. I.mo, eloth, price, $\$ 1.50$.

"His book is ingenious; . . . his theory of how science gradually differentiated from and conquered myth is extremely well wronght ont, and is probably in essentials correct." - Saturday seview.

"The book is a strong one. and fal more interesting to the general rearles than its title would indicate. "The learning, the acutcnuss, the strong reasoning power, and the seientitic spirit of the

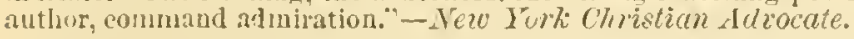

"An attempt male. with much ability and no small measure of suecess, to traee the origin and develipment of the myth. The athor has pursurd his inquiry with much patience and ingemuity, and has produced a rery readable and luminous treatise." - Philadelphia liorth tmericun.

-It is a curious if not starling contribution both to psychology and to the carly history of man's levelopment." - Terv York World.

Sold by all booksellcrs; or sent by mail, post-paid, on recint of price.

New York: D. APPLETON \& CO., 1, 3, \& 5 Bond Strect. 


\section{SCIENTIFIC PUBLICATIONS.}

\section{Man before Metals.}

By N. JoLy, Professor at the Science Fraculty of Toulouse; Correspondent of the Institute. With 148 Illustrations. 12mo. Cloth, $\$ 1.75$.

"The diseussion of man's origin and early history, by Professor De Quatrefages, formed one of the most useful yolumes in the "International Fcientific series,' and the same collection is now further enriched by a popular treatise on paleontology, by M. N. Joly, Professor in the University of 'Toulouse. The title of the book, 'Man before IIetals,' indieates the limitations of the writer's theme. His object is to bring together the unmerous proots, collected by modern resear $\mathrm{h}$, of the great age of the human race, and to show us what man was. in respect of customs, industries, and moral or religious ideas, before the use of" inetals was known to him." New York Sun.

"An interesting, not to say fascinating volume."-Nezv Fork Churchman.

"M. Joly's book sums up the discoveries of modern science bearing on the primeral history of mall, on the antiquity of the human race, and on the circumstances attencing its slow and partial ascent to the modern level of eivilization. It also presents with brevity but thoroughness the generally accepted theories relating to the habits and environment of primitive man. Its usefulness and interest are much increased by numerous and excellent illustrations." - Philadelphia North American.

"This is a book worth owning."-New Iork Chrislian Advocate.

\section{Animal Intelligence.}

By Geonge J. Rouranes, F. R. S., Zoölogical Secretary of the Linnæan Society, etc. $12 \mathrm{mo}$. Cloth, $\$ 1.75$.

"My objeet in the work as a whole is twofold: First, I have thought it desirable that there should be something resembling a text-book of the fuets of Comparative Psychology, to which men of science, and also metaphysicians, may turn whenever they bave oecasion to nequaint themselves with the partienlar level of intelligenee to which this $\mathrm{cr}$ that species of animal attains. My seeond and mneh more important object is that of considering the faets of animal intelligence in their relation to the theory of descent." - From the Preface.

". Unless we are greatly inistaken, Mr. Romanes's work will take its place as one of the most attraetive volumes of the 'International Scientific Selies.' Some persuns may, indeed, be disposed to say that it is too attractive, that it feeds the popular taste for the curious and marvelcus withont supplying any commensurate diseipline in exact scientifie refiection: but the author has, we think, fully justified himself in his modest preface. 'T'he result is the appenance of a collection of facts which will be a real boon to the student of Comparative Psvchology, for this is the first attempt to present systematically well-assured observations on the wental life of animals. - Saturday Reriewo.

"The anthor believes bimself, not without ample eause, to have completely bridged the supposed gap between instinet and reason by the authentic proots here marshaled of remarkable intelligence in some of the higher animals. It is the seemingly conclusive evidence of reasoning powers furnished by the adaptation of means to ends in eases whieh cau not be explaiued on the theory of inberitel aptitude or habit."-New Tork Sun.

\section{The Science of Politics.}

By Sireldon Amos, M. A., author of "The Seience of Law," ete. $12 \mathrm{mo}$. Cloth, \$1.75.

"It is an able and exhmustive treatise, within a reasonable compass. Some of its conclusions will be disputed, although stering common sense is a ebaracteristie of the book. To the political student and the practieal statesman it onght to be of great value." - New York Herald.

"The anthor traces the subject from Plato and Aristotle in Greece, and Cicero in Rome, to the modern seliools in the Encrlish field, not slighting the teaehings of the American Revolution or the lessons of the French Revolution of 1793. Forms of government, politieal terms, tho relation of law, written and unwritten, to the sulject, a corlification from Justinian to Napoleon in France and Field in Ameriea, are treated as parts of the subjeet in hand. Necessarly the subjects of excentive and legislative anthority, police, liquor, and land laws are considered, and the question ever growing in importanee in all countries, the relations of corporations to the state."-New Iork ubserver.

New York: D. APPLETON \& CO., 1, 3, \& 5 Bond Street. 


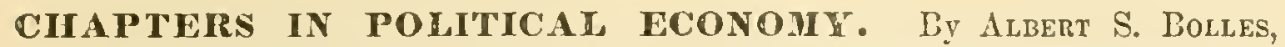
Lecturer on Political Economy in the Boston University. Square 12 mo. Cloth, $\$ 1.50$.

CONTENTS.-The Field and Importance of Political Economy; The Payment of Labor; On the Increase ol Wages; Effect of Machinery on Labor; Un the Meaning and Canses of Value; A Measure of Value; Monev and its Uses: Decline in the Value of Gold and Silver: The Money of the Future; 'The Good and Evil ol' Banking; The Financial Panic of 1873; Relation of Banks to speculators; Inflnence of Credit on Prices; un Legal Interference with the Loan of Money, Payment of Labor, and Cuntracts of Corporatious; Advantages of Exchange; Taxation.

FINANCIAL HISTORY OF THE UNITED STATES FROM 1774 TO 1789, EHBRACING THE PERIOD OF THE AMERICAN REVOLUtion. By Aleert S. Bolles. Sro. Cloth, $\$ 2.50$.

"It fills a place and meets a want which. so far as my observation extends, is not supplied by any one publication." -Darid $A$. Wells.

FINANCIAT HISTORY OF THE CNITED STATES FFOII 1789 TO 1860. By Albert S. Bolles. 8ro. Cloth, \$3.50.

FINANCIAL HISTORY OF THE UNITED STATES FROTI 1861 TO 1885. By Albert S. Bolles. 8vo. Cloth, $\$ 3.50$.

NOMISIA ; OR, "LEGAL TENDER." By Hexr Cernuschi, author of "BiMetallic Money." 12mo. Cloth, \$1.25.

The prineipal part of the information contained in this volume was given by the author, before a commission appointed by Congress. for the purpose of ascertaining whether it was feasible for the C'nited states to introduce a bi-metallic standard of gold and silver.

The author is an authority ou tinance in France.

ON THE PROBABLE FATL IN THE VALUE OF GOLD. By Micher Chevalier. Translated by Ricilard Coboen. Sro. Cloth, \$1.25.

WEIGHTS, MEASURES, AND MONEY OF ALI NATIONS. Compiled by F. W. Charke, S. B., Professor of Physics and Chemistry in the University of Cincinnati. 12mo. Half bound, $\$ 1.50$.

HAND-BOOK OF SOCIAL ECONOHY; OR, THE WORKER'S A B C. By Endox About. $12 \mathrm{mo}$. Cloth, $\$ 2.00$.

CONTENTS,-Man's Wants; Useful Things: Production; Parasites; Exchange; Liferty: Money: Wages: Savings and Capital; Strikes; Co-operation; Assurauce, and some otber Desirable Novelties.

Political LConomy. By W. Stanley Jerons, Professor of Logic and Political Economy in Owens College, Manchester. ISmo. Flexible cloth, 45 cents.

MONEY AND THE MECIANESI OF EXCHANGE. BY W. STAN. LEY JEFONS. 12 mo. Cloth, $\$ 1.75$.

New York: D. APPLETON \& CO., Publishers, 1, 3, \& 5 Bond Street. 


\section{APPLETON \& CO'S PUBLICATIONS.}

\section{PRINCIPILS OF POLITICAL ECONOMY, WITH SOME OF 'THEIR APLIOATIONS TO SOCIAL PHIEOSOPIIY. By}

John Stuart MiLl. 2 rols. Sro. Cloth, $\$ 4.00$; half calf, extra, $\$ 8.00$.

In the whole range of extant anthorship on political economy, there is no writer except Alam Smith with whom John Stuart Mill can, without Injustice, be compared. in originality, Adam Smith, as being the acknowledged rather of the science, takes the precedence, as be does also in exuberance of apt illustration. But in rectitude of understanding, clearness, and saqacity, Mill is fully his peer: in precision of method, range of topics, and adaptation to the present state of society, be is altogether his superior. The "Wealth of Nations" now belongs, indeed, rather to the history of the science than to its exposition. Bnt the "Principles of Political Economy" is an orderly, symmetrical, and lucid exposition of the science in its present advanced state. In extent of information, breadth of treatment, pertinence of fresh illustration, and accommodation to the present wans of the statesman, the merchant, and the social philosopher, this work is anrivaled. It is written in a lnminous and smooth, yet elear-cnt style: and there is diffused over it a solt atmosphere of feeling. flerived from the author's ncaffected humanity and enlightened interest in the welfare of the masses.

MILL'S PRINCIPLFS OF POLITICAL ECONOKY: ABRIDGED, WITII CRITICAL, BIBLIOGRAPIICAL, AND EAPLANATORY NOTES, AND A SKETCH OF THE HISTORI OF POLITICAL ECONOMY. By J. Laurence Ladghlin, Ph. D., Assistant Professor of Political Economy in Harvard University. With Twenty-four Japs and Charts. A Text-Book for Colleges. 8ro. 658 pages. Cloth, $\$ 3.50$.

"An experience of five years with Mr. Mill's trealise in the class-room convinced me, not only of the great usefulness of what still remains nne of the most hucid and svstematic booke yet published which cover the whole range of the stndy, bnt I have also been convineed of the need of such additions as shonll give the results of later thinlizg, witlout militating against the general tenor of Mr. Mill's system; of such illnstrations as shonld fit it better for American students, by farning their attention to the application of principles in the fucts aromurl us: of a bibliography which should make it ensier to get at the wrilers of other schools who off r opposing viewe on controverted questions ; and of some attempts to lighten those parts of bis work in which Mr. Mill Irightened awar the reader by an appcarance of too great abstractness, and to render them, if possible, more easy of comprehension to the studeut who first approaches Political Economy through this author."-From Prefiace.

THE STUDY OF POLITCAL ECONOHY. HINS TO STU. DENTS AND TEACHERS. By J. LAvrexce Laughis, Ph. D, Assistant Professor of Political Economy in Harrard University. 16mo. Cloth, $\$ 1.00$.

"The existence of this little book is due to an attempt to convey, by lectures to students, an $n$ nderstancing of the position which political economy holds in regard, not merely to lts actual usefulness for erery citizen, but to its disciplinaly power. . . The interest which the public now manifests in economic studies led me to pat the material of my lectures into a general form, in order that they might assist inquiress in any part of the country."-From Preface.

THE HISTORY OF BIMETALISM IN TIE UNTTED STATES. By J. Laurence Lacghis, Ph. D., Assistant Professor of Political Economy in Harrard University. 12 mo. Cloth.

MONEY. By Charles Joran. 12mo. Cloth, \$1.25.

New York: D. APPLETON \& CO., Publishers, 1, 3, \& 5 Bond Street. 


\section{APPLETON \& CO:'S PUBLICATIONS.}

THE MAY TERSUS THE STATE: containing "The New Toryism," "The Coming Slavery," "The Sins of Legislators," and "The Great Politi. cal Superstition." By Herbert Spexcer. With a Postscript. Small Sro. Paper, 30 cents.

"Though written by an Englishman, with primal rezence to abuses in his own land, erery rord of them is just as applicable to mischievous tendencies or results in the Lnited States. No tmerican has yet attacked our hesetting sins of over-legislution with the vigor ot Mr. Spencer. Men of ali parlies should read his ealnest warniugs against the perilous dritt of that spirit oi interference and medding witl private coucerns of which every year re see many evidences at Washiugton and all the state capitals." - Few Iork Jour. nal of Commerce.

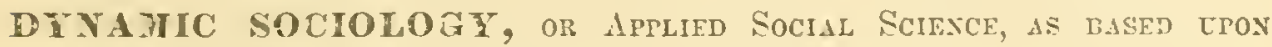
Statical sociologr ayn the Less Conplex Sciesces. By Lester F. WaRd, A. M. Two rolumes, 12 mo. Cloth, \$s.0ij.

"In his two volumes, containing npward of 1,300 pages, Mr. Ward lakes us from the primordial atom. througl, the three stages of atomic agrregaliun indicated by 'Cosmogeny," 'Biozeny, and 'Sociogeny.' to the consideration of some of the most comples problems presented to the student of lite mind morals, and societs. Especially interesting are Atr. Ward's reflections upon the $R$ eproductive Forces, which he very sensibly and successfully vindicates from the opprobrium with which superficial prejodice has surrounded them, and we would particularly recomment to all those who take interest in socia] questions, and who are capable of free and unbiased thought, his remarks upon Marriage Institutions.

"We are glad to find that Mr. Ward strongly dissents from the views expressed with such curious Pmphasis by Mr. Herbert Spencer upon the subject of compulsory state education. A consideration of the matter, mears. and method of education brings to its conclusion a work from which all readers, whether or not they agree with the doctrines therein expounded, can not fail to derive henefit, more especiuly if they are capable of briuging to its consideration a mind divested of prejudice, and only cesirous of the truth." - Ihe Westminster Review.

CONFLICT IN NATURE AND LIFE: A STEDF OF ANTAGONisy iN tinf Cosstitctios of Tinsgs. Fol the Elucidation of the Problem of Good and Eril, and the Reconciliation of Optimism and Pessimism. 12mo, cloth, $\$ 2.00$.

"It is a thonghtful and philosophical consideration of a creat many important subjects, from the natıril and pliysical environments of mankind on earth. to the sccial. industrial, sanitary, and moral questions that are now more and more everywhere thrusting themfelves into prominence. If the reconciliation of the two great forces of Good and Evil is not here made complete to the understanding of every reader, the autlor can at least feel that he has conte as near the mork as any one-and he has certainls presented a mass of very interesting fucls $t 0$ the reader, the result of what must bave been a lifetime of actire Etucly and thoughtul observation." - Hartford Times.

"A semi-religions work corering one of the most interestiug fields of thought and observation." - iew Iork Chisican Union.

\section{IEFORMS: TII:IR DIFFICULTIES AND POSSIBILITIES.}

By the author of "Conflict in Nature and Life." 1:mo. Cloth, $\$ 1.00$.

Thls work is in a sense a sequel to "Conflict in Nature and Life," and reaclers of that work who recognized its penetraling and judicial spirit will welcome the present volnme, which diseu 2 es current projects fur reform in an impartial and searching manner, and in a style to enlist the interest of all iutellectual readers.

New York: D. APPLETON \& CO., 1, 3, \& 5 Bond Street. 


\section{APPLETON \& CO.'S PUBLICATIONS.}

THE ELEMENTS OF WCONOMICS. By Henry Dunning Macleod, M. A., of Trinity College, Cambridge; Lecturer on Political Economy in the Cniversity of Cambridge. Volumes I and II. 12mo. Cloth, \$1.75 each.

"The author attempts to establish an exact science of economics on a mathematical basis - to establish 'a new inductive science'; and he presents what he calls ' a new body of phenomena brought under tle dominion of mathematics.' "New York World.

PROGRESS AND POVERTY. An Inquiry into the Cause of Industrial Depressions, and of Increase of Want with Increase of Wealth: The Remedy. By Henry George. Cheap edition. 12mo. Cloth, \$1.00.

" 'Progress and Porerty' is not merely the most original, the most striking and important contribution which political economy has jet receirel from America, but it is not too much to say that in these respects it has had no equal since the publication of 'The Wealth of Nations,' by Adam Smith, a century ago, or, at least, since Malthus formulated his theory of population and Ricardo his theory of rent. A more aggressive, not to say audacious, book was nover written." - lew York Herald.

"His book must be accounted the first adequate presentation in the English language of that new economy which has found powerful champions in the German universities, and which aims at a radical transformation of the science forunulated by Adam Smith, Ricardo, and J. S. Mill. Few books hare, in recent years, proceeded from any American pen which have more plainly borne the marks of wide learning and strenuous thought, or which have brought to the cxpounding of a serious theme a happier faculty of elucidation." $-N_{c w}$ York Sun.

TIIE PRINCIPLES OF TEE LAW. An Examination of the Law of Personal Rights, to Discover the Principles of the Law, as ascertained from the Practical liules of the Law, and harmonized with the Nature of Social Relations. By A. J. Willard. Sro. Cloth, \$2.50.

"This is a philosophical and logical book, peculiarly appealing to scholars or lawyers who love to linger rather with legal cainse and worldly effect than reported cases or legal principles applied to erents. The author was formerly a member of the New York bar, and lately Chief-Justice of South Carolina."-New York World.

"The author takes the practical rules as they exist; he concerns himself only with their motive and harmony. Ilc aims at treating jurisprudence somewhat as Emerson, Darwin, Spencer have written on ethics, nature, socicty." -Now Fork Times.

CAPITA I AND POPULATION. A Study of the Economic Effects of their Relations to Each Other. By Frederick B. Hawler. 12mo. Cloth, \$1.50.

"It would be false modesty in me to seem nnaware that the cconomic law I hare attempted to establish equals in its influenee upon economic conclusions any hitherto ascertained. Granted its truth, it throws new and decisive light on nearly all the unsolved problems of the sciance."-Extract from Pregece.

HERBERT SPENCER ON TIIF AMERICANS, AND THE AMERICANS OY HERBERT SPENCER. Being a full Report of his Interview, and of the Procecdings at the Farewell Banquet (November :, 1882), with the Spjeches of Erarts, Spencer, Sumner, Schurz, Marsh, Fiske, and Bcecher, carefully rerised by their authors. 12mo. Thick paper, 25 cents ; paper, 10 cents.

Now York: D. APPLETON \& CO., 1, 3, \& 5 Bond Street. 
ROSCOE'S CIIEMISTRY-Part II of Volume III.

A Treatise on Chemistry. Hy II. E. Roscoe, F. R. S., and C. Schorlemare, F.R.S., Professors of Chemistry in the Tietoria Unirersity, Owens College, Manchester. Volume III-Part II. The CueMistry of min II rnocarboss and thim Derifatites, or Organic Chemistry. 8vo, cloth, $\$ 5.00$.

* The previous volumes are:

Inorganic Chemistry. Vols. I and II. Vol. I. Nox-Mietallic Elevexts. 8ro. \$5.00; Vol. II. Part I. Metals. 8vo. $\$ 3.00$; Vol. II. Part II. Metals. Sro. $\$ 3.00$.

Organic Chemistry. Vol. III. Part I. The Chemistry of tine MrdroCarbons ayd their Derivatives, or Organic Chemistry. Sro. \$5.00.

"It is difficult to praise too highly the selection of materials and their arrangement, or the wealth of illustrations which explain and adorn the text." - London Acaderny.

ELEUENTS OF CHEMISTRY. By Professol F. W. Clarke, Chemist of the United States Geological Surrey. (Appletons' Science Text-Beoks.) $12 \mathrm{mo}$, cloth, $\$ 1.50$.

"The author in this text-book presents the difficulties of chemical science to elementary students progressively, and has so arranged the helps in the text and notes that those who have to stuly without a teacher can readily make certain progress. To those who study the science as a part of thcir general education, and apply it merely to the erery-day applications of life, this book will be found amply complets. To such as seck an adranced course of technical chemical training, this work will serve as a sound, seientific basis for higher study. The experiments cited are simple, and can be readily performed by the student himself with apparatus and materials easily secured. The questions and exercises at the end of the book are not exhaustive, but silggestive and stimulating to further investigation. The book is divided into two parts, Inorganic and Organic Chemistry. In appendix gives a comparative table of English and metric tables, ctc."-Bostore Journal of Education.

'EXT'BOOK OF SYSTEMATIC MINERALOGY. Dy MILARY Baterman, F.G.S., Associate of the Royal School of Hines. 16mo, cloth, $\$ 2.25$.

TEXT-BOOK OF DESCRIPTIVE MINERALOGY。 Ry HILARY Baversan, F.G.S., Associate of the Royal Scliool of Mines. 16mo, clotl, $\$ 2.25$.

New York: D. APPLETON \& CO., 1, 3, \& 5 Bond Street. 


\section{APPLETON \& CO.'S PUBLICATIONS.}

A PIYSICAI, TREATISE ON EIECTRICITY AND MAGNER-

IsI. By J. E. H. Gordon, B. A. Camb., Member of the International Congress of Electricians, Paris, 1881; Manager of the Electric Light Department of the Telegraph Construction and Maintenance Company. SEcoxd EDrtiox, revised, rearinged, and enlarged. Two rolnmes, Sro, with abont 312 full-page and other Illustratious. Cloth, $\$ 10.00$.

"There is certainly no book in English-we think there is none in any other language-which corer's quite the same ground. It records the most recent advances in the experimental treatment of electrical problems, it describes with mimute carefulness the instruments and methods in use in physical laboratories and is prodigal of beatifully exccuted diagrams and drawings made to scale." London Times.

"The fundamental point in the whole work is its perfect reflection of all that is best in the modern modas of regarding electric and magnetic forces, and in the modern uethods of constructing electrical instruments."-Engincoring.

A PRACTICAL TREATISE ON ERETRIC LHGHTNG. By J. E. II. Golvon, autbor of "A Physical Treatise on Electricity and Magnetism"; Member of the Paris Congress of Electricians. With Twenty-three full-page Plates, and numcrous lllustritions in the Text. 8ro. Cloth, $\$ 4.50$.

"This work has been in preparation for seme two years, and has been modified again and again as the science of which it treats has progressed, in order that it might indicate the state of that science very vearly up to the present date." From Pieface.

THE TODERN APPLICATIONS OF ELECHRICHTE. By E. Hospltalier. New edition, revised, with many Additions. Translated by Julius MaIER, Ph. D.

Vol. I. Electrio Gener:tors, Electrio Ligirt.

Vol. II. Terephone: Tarions Applications, Electrical Transmission of Energy. Two volumes, 8ro. With numerous Illustrations. $\$ 8.00$.

"M. Mospitalier aistingnishes three sources of electricity, namely, the decomposition of metals or other decomposable bodies in acil or alkaline solutions, the transformation of heat into electrical energy, and listly the conversion of worie into current-giving rise to the three specific modes of force styled respectively galvanism, thermo-electricity, and dynamic electricity. He gives a history of the progress of each, from the first crude constructions of the pioneer to the latest and most perfect form of battery, thus fumishing the student of science with a sufficiently copious text-book of the subject, while at the same time affording to the electrical engincer a valuable encyclopæedia of his profession. The work presents a most uscful and thorough compendium of the principles and practice of electrical engineering, written as only an expert can write, to whom the abstruse by lonm study has become simple. The translator has acted the part of an editor also, and has added considerable material of value to the original text."-New Iork Times.

New York: D. APPLETON \& CO., 1, 3, \& 5 Bond Street. 


\section{APPLETON \& CO.'S PUBLICATIONS.}

THE ELECTRIC IIGHT: ITS HISTOPY, PRODUCTION, AND APPLICATIONS. By Er. Alghare and J. Boulard. Translated from the French by T. O'Conor Sloane. Edited, with Notes and Additions, by C. ir. Lungren. With 250 Illustrations. 8vo. Cloth, \$ัง.00.

"Not one of the recent scientific publications was more needed or is more likely to be eagerly wclcomed than a clear, exhaustive, and authoritative account of the application of electricity to the production of light. We are indebted to Messrs. Appleton for issuing, in a large rolume of 450 pages, illustrated with seceral hundred woodeuts, an English translation of the well-known treatise by MII. Alglave and Boulard."-Nev York Sun.

ELECTRICITY AND MAgNeisu. By Flenirg Jenkin, Professor of Engineering in the University of Eainburgh. Illustrated, and Index. With $\Lambda$ ppendix on the Telephone and Microphone. 121110. Cloth, $\$ 1.50$.

"The plan followed in this book is as follows: First, a general s.nthetical view of the scienee has been given, in which the main phenomena are deseribed and the terms employed explained. If this portion of the work can be mastered, the student will then be readily able to understand what follows, viz., the description of the apparatus used to measure clectrical magnitudes and to produce electricity under rarious conditions. The reneral theory of electrieity is permanent, depending on no hypothesis, and it luas been the anthor's aim to state this general theory in a connected manner, and in such simple form that it might be readily understood by practical men." - Firom the Introduction.

\section{ELEMENTARY TREATISE ON NATURAL PHILOSOPHY.}

By A. Privat Descinaner, formerly Professor of Physies in the Lycée Louis-le-Grand, Inspector of the Academy of Paris. Translated and edited, with Extensive Modifications, by J. D. Everett, Professor of Natural Philosophy in the Queen's College, Belfast. Sixth edition, revised, complete in Four Parts. Illustrated by 783 Engravings on Wood, and Three Colored Plates.

Part I. Mecmaxics, Irorostatics, axp Pxetmatics. Cloth, $\$ 1.50$.

Part II. IIEAT. Cloth, $\$ 1.50$.

Part III. Electricity ayd Míignetism. Cloth, \$1.50.

Part 1V. Souvd axd Ligirt. Cloth, $\$ 1.50$.

Complete in one volume, 8ro, with Problems and Inder. Cloth, \$.).ro.

"Systematically arranged, clearly written, and admirably illustrated, showing no less than $T 8$, engrarings on wool and three colored plates, it forms a model work for a class of experimental physics. Far from losing in its Englisl tress any of the qualities of matter or style which distinguished it in its original form, it may he said to hare gained in the able lands of Professor Ererett, hotl by way of arrangement and of incorporation of fresh matter, without partines in the trans. lation with any of the fieshess or foree of the author's text." - Saturday Reviov.

New York: D. APPLETON \& CO., 1, 3, \& 5 Bond Street. 


\section{APPLETON \& CO'S PUBLICATIONS.}

BRAIN EXIIAUSTION, WITH SOME PRELIMINARY CONSID. ERATIONS ON CEREBRAL DYNAMICS. By J. Leonard CoraING, M. D., formerly Resident Physician to the Hudson River State Hospital for the Insane. Crown 8vo, cloth, $\$ 2.00$.

"The author begins by laying a broad foundation for his deductions in con. sidering the law of the convertibility of forces to the dynamics of the brain. This parallelism between inanimate physies and cerebral action is closely followed by our author, and with excellent resilts. Dr. Coming proceeds to classify his facts, which appear to be drawn from wide experience and study, and to marshal them with the skill of a trained scientist. He first considers the rarious existing canses which conduce to brain exhaustion in the plysical sense, such as alcolıol-drinling, tobacco, excessive sexualism, irregular hours, ete. ; in the mental sense, overwork, whether in study and business, fret and worry, false educational methods, etc. He concludes with a summary of the principles of brain hygienics, and indicatcs very clearly how brain exluaustion may be remedied before the final and inevitable result comes. In these latter chapters the author discusses the relation of blood to muscle and brain, the relation of food to mental phenomena, rest, special medication, etc. The book is admirably written. The style is simple, direct, lucid, with as much avoidance as possible of technical terms and purely professional logic. It is a timely work, which every thinking man can read witl interest without being a physician. Brain-workers everywhere can study this able digest with both profit and pleasure."-Eclectic Magazine.

OUTLINES OF PSYCHOLOGY, WITI SPECIAL REFERENCE TO THE TIEURY OF EDUCATION. A Text-Book for Colleges. By JAmes Sully, A. M., Examiner for the Moral Sciences Tripos in the University of Cambridge, ete., etc. Crown 8 ro, cloth, $\$ 3.00$.

"A book that has been long wanted by all who are engaged in the business of teaching and desire to master its principles. In the first place, it is an elaborate treatise on the human mind, of independent merit as representing the latest and best work of all schools of psychological inquiry. But of equal importance, and what will be prized as a new and most desirable feature of a work on mental science, is the educational applications that are made throughout in separate text and type, so that, with the explication of mental phenomena, there comes at onee the application to the art of education."

\section{BODY A ND WILT: BEING AN ESSAY CONCERNING WILL IN} ITS METAPHYSICAL, PHYSIOLOGICAL, AND PATHOLOGICAL ASPECTS. By Henry MAudser, M. D. 8vo, cloth, $\$ 2.50$.

"Dr. Maudsley's powers of logic have never been more keenly exercised than in 'Body and Will,' his latest rolume. Ite takes the ultra-materialistic riew of the luuman mind, and regards will as the result of definite material causes, so that, were synthetical science a little further adranced, it would be possible, having given physical conditions, to declare the inevitable result. The slill and erudition displayed in 'Body and Will' are only equaled by the keenness of its criticisms upon what, from the writer's point of view, are empirical dogmas. No fairer or more able exposition on the latest scientific teaching upon the subject of man as a free agent is to be found than in this volume."-Boston Courier.

New York: D. APPLETON \& CO., 1, 3, \& 5 Bond Street. 
DARWINISH STATED BY DARWIN HIMSELF : CIIARACTERISTIU PASSAGES FROM THE WRI'INGS OF CHARLES DARWIN. Selected and arranged by Professor NathaN SHeppard. $12 \mathrm{mo}$, clotb, 360 pages, $\$ 1.50$.

"A compact and clear statement of the doctrines collectively linown as Darwinism. By consulting this single rolume it is now possible to know exaetly what Darwin taught without sifting the contents of a dozen bools. Mr. Nathan Sheppard has edited the work with good judgment." - New York Joumal of Commerce.

"Mr. Sheppard must be credited with exemplifying the spirit of impartial truth-seeking which inspired Dalwin himself. From these condensed results of the hard labor of seleetion, excision, and alrangement applied to more than a dozen volnmes, it is impossible to draw any inference respecting the philosophical opinions of the compiler. With the exception of a bricf preface there is not a word of comment, nor is there the faintest indication of an attempt to infuse into Darwin's text a meaning not patent there, by unwarranted sub-titles or head-lines, by shrewd omission, unfair emphasis, or artful collocation. Mr. Sheppard has nowhere swerred from his purpose of showing in a clear, connected, and very compendious form, not what Darwin may lave meant or has been charged with meaning, but what he actually said." - The Sun.

MENTAL EVOLUTION IN ANIMALS. By George J. RoNANes, author of "Animal Intelligence." With a Posthumous Essay on Instinct, by Charles Darwix. $12 \mathrm{mo}$, cloth, $\$ 2.00$.

"Mr. Romanes has followed up his careful enumeration of the facts of 'Animal Intelligence,' contributed to the 'International Scientific Selies,' with a work dealing with the successive stages at which the various mental phenomena appear in the scale of life. The present installment displays the same evidence of industry in collecting facts and cantion in co-ordinating them by theory as the former." The Alhenceum.

"The author confines himself to the psychology of the subject. Not only are his own views Darwinian, but he has incorporated in his work considerable citations from Darwin's unpublished manuscripts, and he has appended a posthumous essay on Instinct by Mr. Darwin."-Boston Journal.

"A curious but richly suggestive rolume."-Ncro York Iterald.

PrACTICAL ESSA Ys. By Alexander Bain, LT. D., author of "Mind and Body," "Education as a Science," etc. 12mo, cloth, $\$ 1.50$.

"The present volume is in part a reprint of artieles contributed to reviews. The principal bond of union among then is their practical character. . . That there is a certain amount of norelty in the rarious suggestions here embodied, will be admitted on the most eursory per"usal."-From the Preface.

\section{TIE LSSENTILS OF ANATOMY, PHYSIOLOGY, AND FY-}

GIFNE. By Roger S. Traor, M. D., Health Inspector of the New Tork Board of Health; author of "Hand-Book of Sanitary Information for Iouscholders," etc. (Forming a volume of Appletons' Science Text-Books.) 12mo, cloth, $\$ 1.25$.

"Dr. Tracy states in his prefaee that his aim has been 'to compress within the narrowest space such a clear and intelligible account of the structures, activities, and care of the human system as is essential for the purposes of general education.' And he has so far succecded as to make his manual one of the most popularly interesting and useful text-books of its kind. . . The book is excellently arranged, the illustrations are adnrirable."-Boston Daily Advertiser.

$$
\text { New York: D. } \triangle \text { PPLETON \& CO., 1, 3, \& } 5 \text { Bond Street. }
$$




\section{POPULAR SCIENCE MONTHLY.}

CONDUCTED BY E. L. AND W. J. YOUMANS.

The Popdlar Scuexce Monthur will continne, as heretofore, to supply its readers with the results of the latest investigation and the most valuable thonght in the various departments of scientific inquiry.

Leaving the dry and technical details of science, which are of chief concern to specialists, to the journals devoted to them, the Mostricy deals with those more general and practical subjects which are of the greatest interest and importance to the public at large. In this work it has achieved a foremost position, and is now the acknowledged organ of progressive scientific ideas in this country.

The wide range of its discussions includes, among other topies:

The bearing of science upon education;

Qnestions relating to the prevention of disease and the improrement of sanitary conditions;

Subjects of domestic and social economy, including the introdnction of better ways of living, and improved applications in the arts of every kind;

The phenomena and laws of the larger social organizations, with the new standard of ethics, based on scientific principles;

The subjects of personal and honsehold hygiene, medicine, and arclitecture, as exemplified in the adaptation of public buildings and private houses to the wants of those who use them;

Agriculture and the improvement of food products;

The study of man, with what appears from time to time in the departments of anthropology and archaology that may throw light upon the derelopment of the race from its primitive conditions.

Whatever of real advance is made in chemistry, geography, astronomy, physiology, psychology, botany, zoölogy, paleontology, geology, or such other department as may have been the field of research, is recorded montbly.

Special attention is also called to the biographies, with portraits, of representative scientific men, in which are recorded their most marked achierements in scienee, and the general bearing of their work indicated and its value estimated.

Terus: \$5.00 per Annum, in advance.

The New York Medical Jommal and The Popular Scienee Monthly to the same address, $\$ 9.00$ per Anmum (full price, $\$ 10.00$ ).

New York: D. APPLETON \& CO., 1, 3, \& 5 Bond Street. 






\title{
BINDING SECT. JAN 261976
}

\author{
PLEASE DO NOT REMOVE \\ CARDS OR SLIPS FROM THIS POCKET
}

\section{UNIVERSITY OF TORONTO LIBRARY}

QH Cope, Edward Drinker
367
C6

BioMed 
